Pragmatic Approaches to Drama 


\title{
The Language of Classical Literature
}

\author{
Series Editors \\ Irene J.F. de Jong \\ Caroline H.M. Kroon
}

\section{Editorial Board}

Rutger J. Allan

Mark A.J. Heerink

VOLUME 32

The titles published in this series are listed at brill.com/tlcl 


\title{
Pragmatic Approaches to Drama
}

\author{
Studies in Communication \\ on the Ancient Stage
}

\author{
Edited by \\ Gunther Martin \\ Federica Iurescia \\ Severin Hof \\ Giada Sorrentino
}

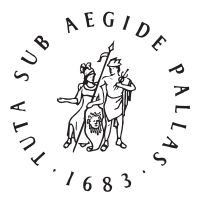

B R I L L

LEIDEN | BOSTON 
This is an open access title distributed under the terms of the CC BY-NC-ND 4.o license, which permits any non-commercial use, distribution, and reproduction in any medium, provided no alterations are made and the original author(s) and source are credited. Further information and the complete license text can be found at https://creativecommons.org/licenses/by-nc-nd/4.o/

The terms of the cc license apply only to the original material. The use of material from other sources (indicated by a reference) such as diagrams, illustrations, photos and text samples may require further permission from the respective copyright holder.

This publication was financially supported by the SNSF (Swiss National Science Foundation).

The Library of Congress Cataloging-in-Publication Data is available online at http://catalog.loc.gov LC record available at http://lccn.loc.gov/2020035021

Typeface for the Latin, Greek, and Cyrillic scripts: "Brill”. See and download: brill.com/brill-typeface.

ISSN 2590-2709

IS BN 978-90-04-44019-7 (hardback)

ISBN 978-90-04-44026-5 (e-book)

Copyright 2021 by the Editors and Authors. Published by Koninklijke Brill NV, Leiden, The Netherlands. Koninklijke Brill NV incorporates the imprints Brill, Brill Hes \& De Graaf, Brill Nijhoff, Brill Rodopi, Brill Sense, Hotei Publishing, mentis Verlag, Verlag Ferdinand Schöningh and Wilhelm Fink Verlag. Koninklijke Brill NV reserves the right to protect this publication against unauthorized use.

This book is printed on acid-free paper and produced in a sustainable manner. 


\section{Contents}

Notes on Contributors IX

Introduction 1

Gunther Martin, Federica Iurescia, Severin Hof, and Giada Sorrentino

\section{PART 1}

Verbal Communication I: Doing Things with Words

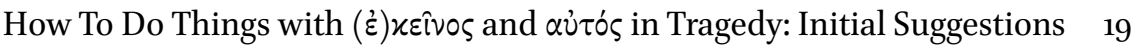
Anna Bonifazi

Pointing to Common Ground in Dramatic Dialogue: The Case of $\delta \dot{\eta}$ and

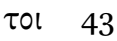

Rutger J. Allan

Terms of Address on Right Periphery in Greek Tragedy $\quad 70$

Sandra Rodríguez-Piedrabuena

The Linguistic Characterisation of Oedipus in oT: A Pragmatics-Based Approach to 'Mind Style' 96

Evert van Emde Boas

Resonance in the Prologue of Sophocles' Ajax $\quad 121$

Severin Hof

Pentheus und Dionysos in den Bakchen: Die Grenzen des klaren Dialogs Camille Semenzato

Iphigenie und ihre Mutter: Pragmatische Bemerkungen zur Iphigenie in Aulis $\quad 160$

Giada Sorrentino 


\section{PART 2}

Verbal Communication II: Being More or Less Kind with Words

Oedipus and Tiresias: Im/politeness Theory and the Interpretation of Sophocles' Oedipus Tyrannus 187

Luigi Battezzato

Politeness and Impoliteness in Aristophanes 213

Michael Lloyd

Developments in Politeness from Aristophanes to Menander and

Beyond 234

Peter Barrios-Lech

Advice-Giving in Roman Comedy: Speech-Act Formulation and $\mathrm{Im} /$ politeness 264

Łukasz Berger

The Politics of Manipulation: Politeness and Insincerity in the Language of Parasites and Courtesans in Plautus' Comedies 291

Luis Unceta Gómez

PART 3

Verbal and Non-verbal Communication: Doing Things Not Just with Words

Silence and the Failure of Persuasion in Tragic Discourse $\quad 319$

Vanessa Zetzmann

Doing Things with Words ... and Gestures on Stage 338 Matteo Capponi

Reflections on Gestures and Words in Terence's Comedies 364 Licinia Ricottilli

The Kiss in Plautus' Stichus: Notes on Gestures and Words in View of a Pragmatics of Comic Communication 382

Renata Raccanelli 
Lacrimae and uultus: Pragmatic Considerations on Gestures in Seneca's Tragedies 403

Evita Calabrese

Pragmatics of fraus: Encoding and Decoding of Deceit in Seneca's Troades and Thyestes 421

Lavinia Scolari

\section{EPILOGUE}

Euripides: Von der Rhetorik zur Pragmatik 447

Carlo Scardino

Index Rerum 473

Index Locorum $\quad 478$ 
-978-90-04-44026-5

Downloaded from Brill. com $04 / 26 / 2023$ 11:30:38AM via free access 


\title{
Notes on Contributors
}

\author{
RutgerJ. Allan
}

is a Lecturer in Ancient Greek at the Free University Amsterdam. He has published on a variety of topics in Ancient Greek linguistics relating to verbal semantics, discourse analysis, and pragmatics. He has a special interest in cognitive linguistic and narratological approaches to Greek narrative texts.

\section{Peter Barrios-Lech}

is Associate Professor of Classics at University of Massachusetts Boston. In his current research, he explores the syntax of Greek and Latin, as well as these languages' pragmatic and sociolinguistic dimensions.

\section{Luigi Battezzato}

is Professor of Greek Literature at the Università del Piemonte Orientale, Vercelli (Italy). He is the author of a commentary on Euripides' Hecuba (Cambridge University Press, 2018), three monographs on Greek poetry (Leggere la mente degli eroi: Ettore, Achille e Zeus nell'Iliade, Pisa 2019, Linguistica e retorica della tragedia greca, Rome 20182; Il monologo nel teatro di Euripide, Pisa 1995), and many papers on ancient Greek literature. He has been visiting professor at the Scuola Normale Superiore, Pisa, at the Istituto Universitario di Studi Superiori, Pavia, at the École Normale Supérieure, Lyon, and Visiting Fellow at All Souls College, Oxford.

\section{Łukasz Berger}

is an Assistant Professor in the Institute of Classical Philology at the Adam Mickiewicz University in Poznan (Poland). His PhD dissertation defended in 2015 examines various pragmatic aspects of the conversation openings in the comedies by Plautus. Currently, he is developing investigation on the language of Roman comedy, applying insights from im/politeness research, speech act theory, and methods of Conversation Analysis. Among his main interest, there are the organisation of talk, phatic routines, and the use of terms of address.

\section{Anna Bonifazi}

is Professor at the University of Cologne, Institute of Linguistics, HistoricalComparative Linguistics. She applies frameworks from pragmatics, discourse analysis, and cognitive linguistics to ancient Greek literature. The monographs that she published so far discuss deixis and other pragmatic phenomena in Pindar (Mescolare un cratere di canti, 2001), the discourse functions of a few pro- 
nouns, particles, adverbs, and a few incongruous utterances in Homer (Homer's Versicolored Fabric: The Evocative Power of Ancient Greek Epic Word-Making, 2012), and the pragmatics of several particles in Herodotus and Thucydides (Particle Use in Herodotus and Thucydides, 2016). Her current research encompasses anaphoric expressions, discourse segmentation, and multimodality beyond ancient Greek.

\section{Evita Calabrese}

holds a PhD in Literature and Philology and attained the Italian National Scientific Qualification 2016 for functions as associate professor. She is currently an adjunct professor at the Department of Cultures and Civilisations of the University of Verona. Her research focuses on the application of the pragmatics of human communication to Latin literature She has dedicated two books to Senecan tragedies: Il sistema della comunicazione nella Fedra di Seneca (Palumbo 2009) and Aspetti dellidentità relazionale nelle tragedie di Seneca (Pàtron 2017). She specifically dealt with gestures in a third book, Prospettive relazionali della gestualità nel Satyricon (Pàtron 2019).

\section{Matteo Capponi}

teaches Ancient Greek at the University of Lausanne. He also provides an initiation to classical texts and mythology at the École polytechnique fédérale de Lausanne (EPFL). He devoted his Ph.D. to Greek tragedy, addressing issues related to anthropology, pragmatics, and kinesics. Today his research focus on the relationship between words and gestures. He is also involved in translating ancient texts to staging, acting, and exploring new ways of teaching classics. In parallel to his academic work, he directs the company sтоA, which specialises in the staging of ancient texts (www.projet-stoa.ch).

\section{Evert van Emde Boas}

is Associate Professor in Classical Philology at the University of Aarhus. He previously held posts at the University of Oxford and at various universities in the Netherlands. His research focuses on the application of modern linguistic and cognitive approaches to Greek literature. He is the lead author of The Cambridge Grammar of Classical Greek (CUP 2019), author of Language and Character in Euripides' Electra (OUP 2017), and co-editor of Characterization in Ancient Greek Literature (Brill 2018).

\section{Severin Hof}

holds an MA from the University of Zurich (2016). He is a member of the research group on the pragmatics of the dialogue in ancient tragedy that organ- 
ised the conference from which this volume has originated and is currently finishing his $\mathrm{PhD}$ thesis on multiperspectivity in Sophoclean dialogue. His research interests include Greek drama, papyrology, and Medieval Latin, and he has previously published on Sophocles' Ajax (2019) and on Pindar (2014), as well as edited a documentary papyrus (2017).

\section{Federica Iurescia}

is SNSF scientific collaborator in the Department of Classics at the University of Zurich. After her studies in Classics at the Universities of Siena and Pisa, she obtained her PhD in 2017 with a dissertation on quarrels in Latin literary texts. Her research interests deal with issue of pragmatics in Latin Literature; she is now working on conversational coherence in tragic dialogues. Her main publication is Credo iam ut solet iurgabit. Pragmatica della lite a Roma (Göttingen, 2019).

\section{Michael Lloyd}

is Professor of Greek Language and Literature at University College Dublin, Ireland. He is the author of The Agon in Euripides (1992), Euripides' Andromache: with Introduction, Translation, and Commentary ( ${ }^{2} 2005$ [1994]), and Sophocles: Electra (2005). He is also the editor of Aeschylus in the Oxford Readings in Classical Studies series (2007), and of articles on Homer, Herodotus, Plato, and Greek tragedy. He has a particular interest in politeness theory.

\section{Gunther Martin}

has been leading, as an SNSF-Professor, the research group on the pragmatics of the dialogue in ancient tragedy at the University of Zurich that organised the conference from which this volume has originated. He has published an edition and commentary on Euripides' Ion (Berlin 2018) and books on religion in the Attic orators (Oxford 2009) and the historian Dexippus (Tübingen 2006).

\section{Sandra Rodríguez-Piedrabuena}

holds an MA from the University of Salamanca (2015) and a PhD on linguistic characterisation in Euripides from the University of Seville (2019), where she has also lectured. Her research interests are Greek Drama and the pragmatics of Greek language. She has previously published contributions on Euripides' Heraclidae (2019), Plutarch and progymnasmata (2017) as well as on Corinna and Boeotian dialect (2015). 


\section{Renata Raccanelli}

is an associate professor in Latin Language and Literature (University of Verona). Her research interests include archaic theatre (Plautus) and ethicopolitical thought (Cicero, Seneca, Lucretius), with special focus on the study of relationships (e.g. kinship, amicitia, citizenship) and their symbolic representations in ancient Roman culture. Within such a field, she adopts the lens of the pragmatics of communication in order to examine ancient theories and practices of social exchange and interaction, and in particular the intersection between verbal and non-verbal language (esp. gesture, rhythm of interaction on stage).

\section{Licinia Ricottilli}

is full professor of Latin language and literature at the University of Verona. She must be credited for her application of pragmatics of communication (a new methodological framework of psychiatric and cybernetic origins) to classical texts starting from 1982. Since the mid-199o's, she has further developed this method in collaboration with Renata Raccanelli, and later also with Evita Calabrese. Her research areas include the works of Menander, Plautus, Terence, Virgil and Seneca the Younger, as well as fields such as colloquial Latin, gestures, silence and aposiopesis.

\section{Carlo Scardino}

completed at the University of Basel in 2006 his $\mathrm{PhD}$ with a thesis on the speeches in Herodotus and Thucydides (Gestaltung und Funktion der Reden bei Herodot und Thukydides). He also participated in the research Project 'Iulius Africanus, Kestoi' (2007-2012). In 2012 he earned his Habilitation at the Philipps-Universität Marburg with an interdisciplinary Graeco-Arabic thesis on the transmission of ancient agricultural writers in Arabic ('Edition antiker landwirtschaftlicher Werke in arabischer Sprache,' 2015). Currently, he is working as senior researcher at the University of Düsseldorf in the long-term project 'Minor and Fragmentary Historians of Late Antiquity' (KFHist).

\section{Lavinia Scolari}

holds an MA from the university of Palermo (2009), and a PhD on benefit and revenge in Seneca's corpus from the University of Siena (2013). Her main research interests are reciprocity and gift-giving in Latin literature and Roman Mythology. On this issue, she has published two books: Doni funesti. Miti di scambi pericolosi nella letteratura latina (Pisa 2018) and Beneficium $e$ iniuria. Rappresentazioni del dono e dell'offesa nel De beneficiis di Seneca (Palermo 2018). Since 2018 she collaborates with the Department of Humanities of the University of Palermo. 


\section{Camille Semenzato}

is a post-doctoral researcher and lecturer at the Universities of Zurich and Neuchâtel (Switzerland). After a PhD on the Muses in Archaic Greece (De Gruyter 2017), she is currently completing a habilitation on Euripides' Bacchae. Her research focuses on the various forms of inspiration, wisdom and mysteries, in connection with the relation between humans and gods throughout Ancient Greece.

\section{Giada Sorrentino}

has completed her post-doc research project "Kommunikation, Handlung und Figuren in Euripides' Tragödie”, supported by the Fritz Thyssen Foundation, at the Albert-Ludwigs-Universität in Freiburg (Germany). She is author of Comunicazione e relazioni interpersonali nelle commedie di Menandro (Göttingen 202O) and of various articles on Middle and New Comedy.

\section{Luis Unceta Gómez}

is Associate Professor of Latin at the Autonomous University of Madrid, Spain. His main research interests are Latin semantics and pragmatics, specially speech act theory, pragmatic markers, and linguistic politeness, topics about which he has published a book, La petición verbal en latín. Estudio léxico, semántico y pragmático (2009), and several articles, such as "Congratulations in Latin Comedy: Types and functions" (Journal of Politeness Research, 2016), or "Conceptualizations of Linguistic Politeness in Latin: the Emic Perspective" (Journal of Historical Pragmatics, 2019), among others.

\section{Vanessa Zetzmann}

studied Greek and Latin at the University of Würzburg and at Corpus Christi College, Oxford. In her Würzburg dissertation, she focused on the portrayal of failing rhetoric in Attic tragedy and spent research stays in Zurich, Pisa and Vandœuvres. Her other research interests include ancient rhetoric and progymnasmata, communication and pragmatics as well as myth and mythopoiesis in Greek literature. 
-978-90-04-44026-5

Downloaded from Brill. com $04 / 26 / 2023$ 11:30:38AM via free access 


\section{Introduction}

Gunther Martin, Federica Iurescia, Severin Hof, and Giada Sorrentino

This book assembles selected papers from a conference entitled Doing things with words on stage. Pragmatics and its use in ancient drama, which was held at the University of Zurich from 4 th to 7 th July 2018.* The conference brought together scholars who, in their work, use the heuristic potential of interpersonal pragmatics, i.e. the systematic and theoretically informed study of communicative interaction. ${ }^{1}$ Rather than following a single approach or creating a uniform picture of the objects and objectives of pragmatic analysis, however, their contributions illustrate the breadth of the discipline and show the many different forms that engagement with the pragmatic dimension of literary texts can take: from the force that a single word can have in referring to its intra- and extratextual context to the back and forth in conversations; from the purely linguistic resources of communication to the interplay of verbal and non-verbal forms of interaction and to the grounding of communicative acts in social structures and norms of conduct. In other words, this volume offers a panoramic view that illustrates the continuum of pragmatic phenomena by which meaning is constructed: from lingual to non-lingual forms of interaction, or as it were, from 'doing things with words' to 'making statements without words'. As each author contributes their unique perspective, this volume demonstrates the different opportunities that pragmatic work on interaction in literature affords, and it aims to stimulate the exchange between the different branches of pragmatics to create synergies and thereby further advance the study of the field.

While the pragmatic approaches that the authors take may be diverse, they all tackle the same literary medium: drama. In that way the papers deal with a

* The Swiss National Science Foundation provided generous funding for the conference and the research projects in the course of which this volume was prepared (PPooP1_157444 and PPooP1_183707). For help with the preparation of the manuscript the editors are indebted to Alexander Herren.

1 Since its inception in the first half of the 2oth century, the exact nature and definition of pragmatics has been much discussed. The two branches this volume is mainly concerned with are pragmalinguistics, which received its first major impulse by Austin $\left({ }^{2} 1975\right)$, and the pragmatics of communication, as founded by Watzlawick et al. (1967). The lack of mutual recognisance between these two approaches has often been lamented, e.g. by Mey ( $\left.{ }^{2} 2001: 69\right)$.

(C) GUNTHER MARTIN, FEDERICA IURESCIA, SEVERIN HOF, AND GIADA SORRENTINO,

2021 | DOI:10.1163/9789004440265_002

This is an open access chapter distributed under the terms of the CC BY-NC-ND 4.o license. 
comparable set of parameters and similar characteristics of the representation of communication. The choice of ancient comedies and tragedies as the corpus of pragmatic studies is a natural one. For drama is a mimetic and performative art form, and as such it endows interaction with a privileged position. At least among the poetic genres, there is no other in which it is represented in the same concentrated und unfiltered way: not only do dramatic texts consist to a large extent of interaction, both verbal and physical; they are, moreover, characterised by the absence of an intermediary voice. For example, narrators in epic can explain situations and actions of their characters. They can even report and assess the characters' thoughts and motives from a privileged vantage point. In so doing they guide the readers' perception and interpretation. In drama, these options do not exist: the information that the spectators or readers need in order to make sense of the plot is conveyed almost exclusively on the intradramatic level or 'internal system of communication.'2 The burden of giving a sufficient amount of clues about the characters' dispositions, thoughts, and manner of execution of (speech-)acts rests entirely on their shoulders. What the characters say, and in equal measure how they say it and how they interact with each other, becomes the source of all our knowledge about the dramatic world. What is more, since we do not have stage directions or other external information about the performative side of the plays, the characters' speech is all we can rely on: even their own gestures and movements as well as their meaning can only be gauged from the indications the characters give verbally about what they do and what it signifies.

What the characters convey about the world of each drama and the people that populate it is still plenty. Far from letting us know only about their identity, they also provide rich insight into who they are, i.e. which character type they belong to and also what makes them unique as individuals. ${ }^{3}$ On the one hand, they act as representatives of groups: old vs young, male vs female, dominant vs powerless, hero vs villain, etc., and both their behaviour as such and their conduct towards others helps, in its pragmatic aspects, to reaffirm their belonging to these types. We see, moreover, how interaction enacts typical patterns of communication. These can be types of 'scripts', i.e. standard situations that

2 For the concept see Pfister (1988: 3, 40-41). The exception are some prologue speakers in comedy, who as $\pi \rho \delta \delta \omega \pi \alpha \pi \rho \sigma \tau \alpha \tau i x \alpha$ or 'real-life' characters breach the fourth wall. Messengers can also engage in some limited mind-reading, but they do so strictly as intra-dramatic characters (see de Jong 1991).

3 The degree to which individualisation is achieved or even attempted has of course been the matter of an old debate: on the Greek side cf. e.g. Gould (1978); Easterling (1990); Gill (1990); Budelmann and Easterling (2010); see the substantial volume by De Temmerman and van Emde Boas (2018a) and the recent dissertation by Rodríguez-Piedrabuena (2019). For Roman drama cf. Dupont (1998) and Faure-Ribreau (2012). 
recur in very similar fashion and follow an identifiable (though often informal) protocol, such as introductions and recognitions; they can also concern the typical conduct in certain kinds of rapport, e.g. subordination or confrontation. The dialogue thus contributes to the establishing, shaping, and changing of the relationships between the speakers, wherein each interaction has the potential to foster, destroy, or alter the nature of such relationships.

On the other hand, the text of the plays also gives the dramatic situation and the interaction of the various personae an individual touch. The way in which the latter act with words, gestures, movements, and so forth distinguishes the individual instance from a ritualised staple scene: it can, for example, illustrate the specific frictions and struggles of the characters in an agon scene-beyond the issues of the disputed matter; in a scene of counsel, it can cast light on the relationship of the characters and their attitudes to the advice and each other: whether, for instance, the advisor/advisee relationship resembles that between father and son, teacher and disciple, or warner and recalcitrant tyrant.

On account of the specific way in which information is distributed in drama, pragmatic approaches have proven immensely fertile for the study of tragedy and comedy. Elements of pragmatic analysis avant (or sans) la lettre have long been floating around. ${ }^{4}$ Early ventures into pragmatic theory were first combined with rhetorical elements (see Battezzato 2000). In a volume on Sophocles and the Greek Language (de Jong and Rijksbaron 2006) pragmatics features as part of a triad of linguistic aspects, together with diction and syntax. The last few years have seen a flourish of studies on drama that were firmly rooted in pragmatic theory. ${ }^{5}$ The innovative approaches that pragmatics has brought to the field have thus led to considerable progress in our understanding of drama as such and of individual plays. The system by which they explain behaviour in communication has laid the foundations for a more pervasive and strongly conceptualised description of what 'happens' or 'is done' in and through a text.

The result - from a literary point of view - is a more solid footing of interpretation and an approach to a methodology to test earlier descriptions of interaction. Moreover, new criteria emerge by which we can describe and measure interactional behaviour and compare particular characters within a play or even the same or similar characters across plays. Pragmatic approaches

4 E.g. Schwinge (1968); Ireland (1974); Mastronarde (1979); Turner (1980); Pfeiffer-Petersen (1996); Rutherford (2012) essentially still does not use the pragmatic framework. For a synopsis of works on Latin literature, see Ricottilli (2009).

5 Sorrentino (2013); Schuren (2015); Barrios-Lech (2016); Unceta Gómez (2016); van Emde Boas (2017); Ricottilli (2018); Iurescia (2019). 
demonstrate by means of clear criteria and on the basis of a consistent modelrather than by nit-picking scattered details-how speakers exhibit uncooperative or impolite behaviour and how they search to find common ground with their addressee or employ techniques of dominating the discussion with their partner. In essence, pragmatics permits us to detect and describe dramatic techniques and how they are employed - and thereby to extend the concept that Fraenkel has called the 'grammar of dramatic technique' (1950: II 305).

The interpretations that pragmatic studies have produced do, however, come with two important caveats:

Firstly, they treat dramatic characters as agents that are not just black boxes but endowed with a character and mental abilities that manifest themselves in the characters' (inter-)actions. The characters react-or are interpreted as reacting - to each other and adapt to what they assume to be the other's thoughts and intentions. Thus, there is a layered process of 'theory of mind' going on: on the one hand, we as recipients try to explore what is going on in the characters' minds and ascribe feelings and other cognitive processes to them that we extrapolate from words (both content and pragmatics) and gestures (see in particular Easterling 1990); we construct 'realistic', i.e. understandable and believable, personalities out of what we hear and see from the personae. On the other hand, we ascribe to the characters the same mental processes with regard to their interactants - we read their minds reading each other's minds. This is not a case of the number of Lady Macbeth's children; instead, it has a fundamental impact on the 'sense' we make of a piece of literature: whether we construct such a sense by forming a coherent picture from all the actions and utterances of a character or whether we take every play scene by scene or even sentence by sentence, without looking behind the actor's mask and trying to draw conclusions for the character (see most recently De Temmerman and van Emde Boas 2018b: 11-19).

Perhaps even more pressing is another caveat concerning pragmatic analysis of literature: that it presupposes-with varying degrees of strictness and awareness - that principles of the 'real life' can be transferred to the study of literary texts. In order to address this problem, pragmatics-based work on drama has fostered theoretical and methodological reflection. One of the main branches of the 'pragmatics of fiction' (see Locher and Jucker 2017) deals very generally with the applicability of pragmatics to fictional and scripted representation of speech. There is a general willingness to accept the validity of pragmatic phenomena in literary texts (e.g. Pilkington 1991, 2000; Sperber and Wilson 1995: 231-237; Wilson 2011), including dramatic texts (Hess-Lüttich 1981; Petrey 1990; Herman 1995; Leech and Short ${ }^{2} 2007$ ). For ancient drama specific- 
ally, this question has not been discussed extensively. However, Ricottilli (2010) emphasises that drama goes far into imitating the practices of real-life interaction, and Schuren (2015: 11-49) offers a differentiated view of the naturalism of one of the most formalised elements of tragedy: stichomythia. She argues that, while that format may be reductionist in some aspects, in others it concurs with real dialogues. We may add that, as a consequence, the latter can still be analysed by means of pragmatic parameters: we can look for turn-allocating mechanisms and interpret the degree of co-operation, or we can rearrange lines from the order in which they have been transmitted on the basis that this leads to greater coherence. Ultimately, this procedure means little more than taking the mimetic character of ancient drama seriously. In that sense, the instruments of pragmatics can be legitimately and profitably applied to dramatic dialogue. At the same time, it has never been contentious that dramatic language has an artificial, literary character, be it the penchant for the grotesque and coarse in Aristophanes and Plautus, be it the 'high style' in tragedy, which is distinctive enough for comedy to parody. This artificiality of literary language, specifically tragic language, and its distance from the registers of 'regular' language pose specific difficulties for the analysis of pragmatic phenomena. Literature in general, and individual genres in particular, carry their own frame of reference, their specific audience expectations, something that may be explained, for example, as shifting the scale of relevance (Uchida 1998; Giltrow 2017; for Greek tragedy now Willi 2019). Hence, it is crucial to identify the degree to which 'principles, norms and conventions of use which underlie spontaneous communication in everyday life are precisely those which are exploited and manipulated by dramatists in their constructions of speech types and forms in plays' (Herman 1995: 6). In other words, we must try to find out where literature starts developing its own conventions that are recognised and understood by the audience and that can be exploited. This is especially the case in genres such as tragedy and comedy, which show a high degree of formalisation of both language and gestures, such as the already mentioned stichomythia or the rather strict rules that apply to characters' weeping (see e.g. Telò 2002).

Once we undertake to reflect on the particular frame in which dramatic interaction articulates itself, we can start to reassess the potential scope of use of pragmatics. We may then hope to distinguish between, on the one hand, universals (be it the theoretical background of philosophical linguistics à la Grice or the ethnomethodological approach of conversational analysis) that can be applied to a set of literary texts and, on the other hand, factors that manifest themselves in a deviant way in literature. For example, while the mechanisms of im/politeness (Brown and Levinson ${ }^{2} 1987$ as well as more recent approaches: Watts 2003; Terkourafi 2005; Culpeper 2011) are still in place (see Lloyd 2006; 
van Emde Boas 2017: 31-39; Berger 2017), what counts as im/politeness or overpoliteness must be inferred or even negotiated anew when we approach drama. For, the cosmos of tragedy and that of comedy demonstrate very different standards in the formality or coarseness of their language. The problem may be even more acute when generic conventions clash with pragmatic indicators: is an interruption of the interlocutor's turn in stichomythia to be read pragmatically or is it merely a consequence (void of meaning) of the dramatic form, which constrains a speaker's turn to one line-or can it be both at the same time? What distinguishes an interruption from an aposiopesis, and what does that distinction mean for the understanding of the ongoing interaction? With answers to questions like these, we may ultimately not only define the applicability of pragmatic principles but simultaneously make a judgement about the interpretability of a feature of the text. The judgements on pragmatic principles and those on the defining elements of genre condition each other and demarcate each other's realms. In order to use the full potential of a pragmatic approach to ancient drama, we need to remind ourselves constantly about these two realms and the fact that the line between them is often arguable and potentially subjective.

\section{Outline of the Volume}

The papers in this volume address the issues raised above, each in its own way and with its own focus. However, focal points of interest do emerge, which are mirrored in the structure of this book: the force of language in communication; more specifically, questions of politeness; and the fringes of language and its interplay with non-verbal means of communication. Several contributions also address the points of contact of pragmatics with other fields and the potential of synergies, and they form the core of the last paper, on the old question of the relationship between pragmatics and rhetoric.

\subsection{Part 1: Verbal Communication I-Doing Things with Words}

The first part illustrates different levels on which and different ways in which the pragmatic potential of language transcends its semantic or syntactic value. The first contributions deal with the micro-level of language, namely structural words and addresses. In themselves, these elements of language do not seem to carry much weight; in specific contexts, however, they assume qualities or connotations that create an added layer of meaning or position the message in the wider communicative situation, making a point about the utterance itself, the wider conversation, or the relationship between the speakers. 
Regarding the contemplation of the macro-level, Conversation Analysis (CA) takes a prominent role borne out in several contributions: the organisation of dialogue is viewed as a sequence of turns forming larger units. Through the construction of adjacency pairs of related utterances (e.g. question-answer), interlocutors become partners whose co-operation, or lack thereof, is analysable und helps grasp conversational behaviour.

The tools of pragmatic analysis that are introduced in this part all bear an obvious relationship to aspects such as characterisation and motivation of action. As such, they have a direct impact on our understanding of the literary meaning of the texts. This potential of pragmatics is explored with greater focus on literary interpretation in the second half of this part.

Anna Bonifazi demonstrates by the example of au่tós and $(\dot{\varepsilon}) x \varepsilon \hat{\imath} \nu \circ \varsigma$ how even inconspicuous deictics can be connected with cognitive operations and then charged with implied meaning that makes them more than just anaphoric markers. The aspects thus signposted include the connection to the visual or corporeal, distance, or identity; when clustered, deictics may even create a resonance effect. The conclusion she offers is that structural words are not chosen out of metrical convenience but must be considered with their full range of context-specific connotations.

The interaction between characters comes more into view in Rutger Allan's study of the particles $\delta \dot{\eta}$ and $\tau o$ in tragedy. By drawing on the concept of common ground, he accomplishes a more comprehensive account of their function and effect, which reconciles earlier competing explanations of their use: both particles serve as grounding devices, i.e. they put the information in relation with knowledge, notions, or attitudes that are shared, or presumed to be shared, between the interlocutors. They differ in the degree to which the speaker assumes the hearer is aware of this information being inside the common ground.

While forms of address have long been established as a fruitful area of research, the position of addresses within a sentence is shown by Sandra Rodríguez-Piedrabuena to be an underestimated carrier of pragmatic significance in Greek drama. She focuses on the right periphery, i.e. addresses at the end of sentences, and carves out the specific patterns and effects this placement of the address has by correlating their frequency with parameters such as speech acts, type of term of address, and social status. As a result of the analysis, the position of a term of address emerges as an important pragmatic factor along with the lexis and the frequency or omission of addresses.

The particular contribution of pragmatics to the analysis of dramatic characters and their minds is discussed by Evert van Emde Boas. He argues that through the study of 'mind style', the distinctive linguistic representation of a 
mental self, it becomes possible to extrapolate that self and thereby to assess its individuality as projected by the author. Van Emde Boas exemplifies the methods and the potential of this approach by reference to the protagonist of Sophocles' Oedipus Tyrannus. From the analysis of pragmatic aspects of his linguistic behaviour Oedipus emerges as a character distinguished by a particular style that highlights his inquisitiveness, which in turn mirrors his mental qualities of intelligence and distrust.

Severin Hof draws on resonance theory in order to explore what the dialogic character of the prologue of Sophocles' Ajax contributes to the play. He studies how each utterance is interwoven into the tissue of dialogue and how it has its meaning enriched by the echoes and resumptions of the other speaker's turns. By reading Athena's and Odysseus' parts against each other, we can gauge the differences in their predispositions and mindsets, which create a friction of different perspectives that will continue in different constellations throughout the play.

The development of the confrontation between Pentheus and Dionysus in Euripides' Bacchae is traced by Camille Semenzato. With reference to CA concepts, she diagnoses the different misunderstandings that occur (or are deliberately produced) between the two characters. Patterns of coherence manifest, on a linguistic level, the shifting relationship and the distribution of control. Differences of knowledge thus turn into differences of linguistic competence, and Pentheus' limitations in this regard contribute to his downfall.

Finally, Giada Sorrentino draws a contrastive characterisation of Iphigenia and Clytaemestra in Euripides' Iphigenia in Aulis, using speech acts, im/politeness theory, floor management, and other CA tools. She shows how the two dramatic figures are consistently opposed in their conversational behaviour, even transcending the change in their personal characters as a result of the major plot turn. In this way, not only does that opposition define them against each other, but it also makes tangible the antithetical shift in control over the course of events that the revelation of Iphigenia's fate brings. The characters' linguistic conduct in dialogue and the emphasis on the difference between them becomes both a window into the inner self of the two women and a means to elaborate Iphigenia's self-empowerment.

\section{2}

\section{Part 2: Verbal Communication II-Being More or Less Kind with Words}

Part 2 deals specifically with im/politeness, an aspect of pragmalinguistics that has received a great amount of attention in Classical Studies over the last decade. The phenomenon had originally been couched in terms of Face 
Threatening Acts (FTAs) that could either infringe on someone's self-image (positive face) or their freedom of action (negative face). Politeness then consists, according to this approach, in the avoidance of face-threats through, for example, expressions of respect or mitigating devices. The papers in this volume partly expand on this theoretical framework and partly look at more recent developments. Extensive use is made of the seminal work by Watts (2003) that moves away (in the so-called discursive approach) from the analyst's perspective, which considers abstract mechanisms and assigns to them the character of im/politeness. Watts proposes to complement this approach (which he terms second-order politeness) with the consideration of how the interactants qualify utterances as im/polite (first-order politeness). The focus shifts to the relativity of what is perceived as polite and to the importance of contextual factors. This combination of two dimensions of politeness opens new alleys of investigation: it brings to the fore both the specificities of the culture and the language as well as the principles of operation that are shared across language communities. One aim of recent studies in im/politeness has accordingly been to give historical depth to the study of politeness phenomena, and to highlight the difficulties of polite behaviour in different cultures and in cross-cultural communication (cf. Watts 2010; Maha 2014). The contributions in this part that deal with Greek and Roman comedy similarly expand the analysis of their corpus by exploring the advances that can be made by the recent developments in politeness studies.

First, however, Luigi Battezzato explores the compatibility of politeness in the sense of Brown and Levinson with cognitive approaches (theory of mind and theory of possible worlds). He uses as a test case a paradoxical comment Tiresias makes in Sophocles' Oedipus Tyrannus: by stating that he had said what he had come to say, the seer seems to contradict the content of the preceding conversation. As Battezzato argues, the three approaches unite to open up new readings and create a sense in Tiresias' quizzical remark: politeness is a mechanism active on the local level of the text, while the cognitive approaches help to understand the general mindset with which the seer approaches the scene. If read in this sense, the dialogue between Oedipus and Tiresias as well as the latter's behaviour in it offer an important contribution to Tiresias' characterisation.

Positive face-threats and their avoidance are discussed by Michael Lloyd, who demonstrates the limits of the traditional model: a model that ascribes an absolute effect to certain types of expressions, such as Brown and Levinson's, strongly correlates semantic value and impact on politeness. Lloyd questions this connection by reference to terms of endearment in Aristophanes. He shows how these terms, which would traditionally be considered positive face- 
work, can be bereft of any such effect and, in fact, even turn into over-politeness and thus FTAs. By demonstrating how the two conceptions and levels of politeness jar he makes the advantages of adopting Watts' approach in the interpretation of the text clear. He brings into play the parameters of distance and power, which influence the perception of terms of endearment - and he raises 'the question whether there is more to politeness than hypocrisy' (this volume, p. 231).

Relativity of politeness, this time from a diachronic perspective, is also the subject of Peter Barrios-Lech's contribution, which investigates aspects of the politeness system between the fifth and the third centuries BCE. In so doing he advances work on Greek politeness by adopting a diachronic approach, as is frequently practised with modern languages (for English cf. e.g. Jucker and Taavitsainen 2008). He traces the use of directives and softening devices in dialogue-centred genres and highlights the continuities and differences that exist in comedy, prose dialogue, and mime: both the ratio of softened to unsoftened directives and the relative frequency of individual softeners are largely stable across the texts of the corpus, independent of the social and political environment. Only mime exhibits deviant patterns. The result is even more significant when compared to Roman comedy, where the figures differ and thus indicate the cultural specificity of the Greek politeness system.

Łukasz Berger looks at the pragmatics of offering advice in Roman comedy and proposes a new framework of analysis. Going beyond the analysis of single speech acts and turns, he treats advice as a multi-act move in which different factors have to be equilibrated to ensure the acceptability of the move and avoid intrusiveness: the choice of the sub-type of directive speech-act and politeness devices must be dovetailed with contextual (social) factors to form a complex but effective operation. In addition, Berger demonstrates that the sequence in which the elements are arranged also has an impact on whether advice is welcome, and how redressive action can be taken into the middle of the exchange to accommodate the advisees' face wants.

Over-politeness employed by characters of low social rank in Roman comedy is the subject of Luis Unceta-Gómez' paper. As he demonstrates, the communicative strategies of parasites and meretrices entail heavy use of devices to enhance the positive face of the people they depend on. Their use is interpreted as both conscious and insincere: they are means employed to gain a certain personal advantage, but at the same time they appear to be accepted norm for the respective classes. These observations make a strong case for the social determination of felicitousness in Roman comedy of forms of facework. 


\subsection{Part 3: Verbal and Non-verbal Communication-Doing Things Not Just with Words}

While our knowledge of individual plays does not go far beyond their text, the communicative interaction between the characters does not stop at their use of language. On the contrary, even the decision not to speak can convey information and create meaning in a pragmatic way. Moreover, the deployment of gestures adds a vital layer to our understanding of relationships and social operations, especially in the performative genres of drama. However, much of the characters' non-verbal behaviour-certainly the part authors wanted to have preserved for future performances-is captured and can be inferred from the text, as gestures and other physical actions are regularly verbalised, i.e. redeployed in the medium of language. The gestures are not simply the extension of language but equivalent as a means of expression and communication; or rather, they can be read in analogy to speech acts, serving the same function, albeit in a different medium. As such, they follow their own pragmatic playbook and can interplay with the verbal forms of communication.

Silence is a special case of linguistic action and takes us to the borderline between verbal and non-verbal behaviour. Vanessa Zetzmann deals with cases in which a character in Greek tragedy stays silent. She distinguishes between different types of infelicity in conversation that such a silence can signal. Some cases can be read as speech acts through denial to speak and hence as a dispreferred response. The subsequent prompts to answer (i.e. questions of the type $\tau i$ $\sigma i \gamma \hat{\alpha} \iota \zeta ;)$ are interpreted as relational markers: they are pragmaticalised signs that indicate a mental operation - the formation of a theory of mindinitiating a new attempt at persuasion. These attempts, however, regularly fail.

The interplay of language and gesture and their respective function in communication is conceptualised by Matteo Capponi. He emphasises the parallelism and the equivalence of words and gestures and the need for a 'unitary' analysis: gestures and verbal dialogue unite to spell out the meaning of the action. The expressive force and the pragmatic importance of this combination is then exemplified with reference to the recognition scenes of Sophocles' and Euripides' Electrae: these plays show very different patterns of gesticulation, which results in a shift of the expressive dynamics in the symbolic 'language' of the physical performance.

The boundaries between words and gestures are the subject also of the contribution by Licinia Ricottilli, who deals with the question how gestures may be interpreted in terms of Pragmatics of Communication. Drawing on her previous work on gestures in the Aeneid, she provides a definition of gesture as bodily or facial behaviour that takes on communicative, informative, or interactive value. In her paper, she applies this definition in order to study gestures, 
especially movements of the head, in Terence's comedies. Her analysis underscores the importance of gestures in the communication between Terence and his audience and retrieves the emic specificities of certain gestures in Roman culture. Ultimately, we see how this shared knowledge is harnessed to create comic effects and adds further details to the relationships between characters.

Ricottilli's definition of gestures also provides the methodological framework of Renata Raccanelli's and Evita Calabrese's papers, who each focus on a specific kind of gesture: kisses and tears respectively. More specifically, Raccanelli offers a reading of Plautus' Stichus as a case-study to demonstrate the culture-specific significance of the kiss. She argues that the kiss between father and daughter can only be thoroughly understood when placed in its proper Roman context: not only does a kiss between relatives serve as a ritual of greeting, but it is embedded in the practice of male social control over the pudicitia of female relatives.

Calabrese's contribution discusses gestures that have an impact on human interactions, focussing on Seneca's tragedies. Gestures related to countenance enable interactants to manage their personal relations on a one-to-one level. More specifically, Calabrese shows how one type of gesture, namely female tears, is used to negotiate and calibrate the relationship between an individual and the community or to deceive.

Strategies of deception in tragic dialogues are also explored by Lavinia Scolari, who is interested in how gestures and words concur in attempts to deceive an interlocutor. In a bottom-up approach, she provides a definition of fraus, tracking the vocabulary and the emic representation of deception in Seneca's tragic dialogues. Through a combination of pragmatic, dramaturgical, and anthropological approaches, she identifies the main features of successful deception in Seneca's Troades and Thyestes.

\subsection{Epilogue}

The last contribution looks at the notoriously difficult relationship between pragmatics and rhetoric. Almost from its inception on, pragmatics as a discipline has had to defend its position against the claim that it was as a mere subset of the ancient art of speaking. Looking back at the long discussion about the distinction between the two fields, Carlo Scardino instead makes the case that these two approaches are in fact complementary. The mutual fostering of the disciplines is exemplified by the Fourth Epeisodion of Euripides' Orestes. United, they allow a more thorough exploration of the ideas and emotions that are conveyed, Scardino argues, especially under the performative conditions of the stage: for tragedy moves between the poles of conformance with natural 
language and the demands of a Kunstsprache, both of which are harnessed by the poets to shape our understanding of the fictional world.

\section{References}

Austin, J.L., ( ${ }^{2} 1975$ [1962]), How to Do Things with Words, Oxford.

Barrios-Lech, P., (2016), Linguistic Interaction in Roman Comedy, Cambridge.

Battezzato, L., (2000), 'Pragmatica e retorica delle frasi interrogative in Euripide. Note ai fr. 125 e 255 Nauck e ad Andr. 366 s. (con una parentesi sul fr. 172 Nauck)', Materiali e discussioni per l'analisi dei testi classici 44, 141-173.

Berger, Ł., (2017), 'The Old Man and Linguistic Politeness in the Comedies of Plautus', Symbolae Philologorum Posnaniensium Graecae et Latinae 27, 249-273.

Brown, P. \& Levinson, S.C., ( ${ }^{2} 1987$ [1978]), Politeness: some Universals in Language Usage, Cambridge.

Budelmann, F. \& Easterling, P.E., (2010), 'Reading Minds in Greek Tragedy', Greece \& Rome 57, 289-303.

Culpeper, J., (2011), Impoliteness: Using Language to Cause Offence, Cambridge.

De Temmerman, K. \& Emde Boas, E. van (eds.), (2018a), Characterization in Ancient Greek Literature, Leiden.

De Temmerman, K. \& Emde Boas, E. van, (2018b), 'An Introduction', in De Temmerman and van Emde Boas 2018a, 1-26.

Dupont, F., (1998), 'Le masque tragique à Rome', Pallas 49, 353-363.

Easterling, P.E., (1990), 'Constructing Character in Greek Tragedy', in C.B.R. Pelling (ed.), Characterization and Individuality in Greek Literature, Oxford, 83-99.

Emde Boas, E. van, (2017), Language and Character in Euripides' Electra, Oxford.

Faure-Ribreau, M., (2012), Pour la beauté du jeu, Paris.

Fraenkel, E., (1950), Agamemnon, 3 vols., Oxford.

Gill, C., (1990), 'The Character-personality Distinction', in: C.B.R. Pelling (ed.), Characterization and Individuality in Greek Literature, Oxford, 1-31.

Giltrow, J., (2017), 'The Pragmatics of the Genres of Fiction', in Locher and Jucker 2017, $55^{-92 .}$

Gould, J., (1978), 'Dramatic Character and "Human Intelligibility” in Greek Tragedy', Proceedings of the Cambridge Philological Society 24, 43-67.

Herman, V., (1995), Dramatic Discourse: Dialogue as Interaction in Plays, London/New York.

Hess-Lüttich, E.W.B., (1981), Soziale Interaktion und literarischer Dialog, Berlin.

Ireland, S., (1974), 'Stichomythia in Aeschylus: the Dramatic Role of Syntax and Connecting Particles', Hermes 102, 509-524.

Iurescia, F., (2019), Credo iam ut solet iurgabit: pragmatica della lite a Roma, Göttingen. 
Jong, I.J.F. de, (1991), Narrative in Drama: the Art of the Euripidean Messenger-speech, Amsterdam.

Jong, I.J.F. de \& Rijksbaron, A. (eds.), (2006), Sophocles and the Greek Language: Aspects of Diction, Syntax and Pragmatics, Leiden/Boston.

Jucker, A.H. \& Taavitsainen, I. (eds.), (2008) Speech Acts in the History of English, Amsterdam/Philadelphia.

Leech, G.N. \& Short, M., $\left({ }_{2}^{2} 2007\right.$ [1981]), Style in Fiction: a Linguistic Introduction to English Fictional Prose, Harlow.

Lloyd, M., (2006), 'Sophocles in the Light of Face-threat Politeness Theory', in de Jong and Rijksbaron, 225-240.

Locher, M.A. \& Jucker, A.H. (eds.), (2017), Pragmatics of Fiction, Berlin/Boston.

Maha, L., (2014), 'Cross-Cultural Perspectives on Linguistic Politeness', Cross-Cultural Communication 10, 56-6o.

Mastronarde, D., (1979), Contact and Discontinuity: some Conventions of Speech and Action on the Greek Tragic Stage, Berkeley.

Mey, J., (22001 [1993]), Pragmatics: an Introduction, Oxford.

Petrey, S., (1990), Speech Acts and Literary Theory, London/New York.

Pfeiffer-Petersen, S., (1996), Konfliktstichomythien bei Sophokles: Form und Gestaltung, Wiesbaden.

Pfister, M., (1988), The Theory and Analysis of Drama, Cambridge (Engl. transl. of Das Drama: Theorie und Analyse, Munich 1977).

Pilkington, A., (1991), 'Poetic Effects', in R.D. Sell (ed.), Literary Pragmatics, London, 4461.

Pilkington, A., (2000), Poetic Effects: a Relevance Theory Perspective, Amsterdam/Philadelphia.

Ricottilli, L., (2009), 'Appunti sulla pragmatica della comunicazione e della letteratura latina', in A. Barchiesi \& G. Guidorizzi (eds.), La stella sta compiendo il suo giro. Atti del convegno internazionale di Siracusa, 21-23 maggio 2007, Florence, 121-170.

Ricottilli, L., (2010), 'Teatro latino e pragmatica della comunicazione', Dionysus ex machina $1,360-379$.

Ricottilli, L. (ed.), (2018), Modalità della comunicazione in Roma antica, Bologna.

Rodríguez-Piedrabuena, S., (2019), La lengua de los personajes. Caracterización lingüística en la obra de Eurípides a partir de Los Herclidas, $\mathrm{PhD}$ thesis (University of Seville).

Rutherford, R.B., (2012), Greek Tragic Style: Form, Language, and Interpretation, Oxford. Schuren, L., (2015), Shared Storytelling in Euripidean Stichomythia, Leiden/Boston.

Schwinge, E.-R., (1968), Die Verwendung der Stichomythie in den Dramen des Euripides, Heidelberg.

Sorrentino, G., (2013), Comunicazione e relazioni interpersonali nelle commedie di Menandro: un'indagine sul Dyscolos e sulla Samia, PhD thesis (University of Frei- 
burg). https://freidok.uni-freiburg.de/fedora/objects/freidok:9582/datastreams/

FILE1/content (18/o6/2019).

Sperber, D. \& Wilson, D., ( ${ }^{2} 1995$ [1986]), Relevance: Communication and Cognition, Oxford/Cambridge, Mass.

Telò, M., (2002), 'Per una grammatica dei gesti nella tragedia greca', Materiali e discussioni per l'analisi dei testi classici 48, 9-75 and 49, 9-51.

Terkourafi, M., (2005), 'Beyond the Micro-level in Politeness Research', Journal of Politeness 1, 237-262.

Turner, E.G., (1980), 'The Rhetoric of Question and Answer in Menander', in J. Redmond (ed.), Drama and Mimesis, Cambridge, 1-23.

Uchida, S., (1998), 'Text and Relevance', in R. Carston \& S. Uchida (eds.), Relevance Theory: Applications and Implications, Amsterdam/Philadelphia, 161-178.

Unceta Gómez, L., (2016), 'La respuesta al agradecimiento en la comedia de Plauto y Terencio', Pallas 102, 229-236.

Watts, R.J., (2003), Politeness, Cambridge.

Watts, R.J., (2010), 'Linguistic Politeness Theory and its Aftermath: Recent Research Trails', in M.A. Locher \& S.L. Graham (eds.), Interpersonal Pragmatics, Berlin/Boston 2010, 43-70.

Watzlawick, P., Helmick Beavin, J., \& Jackson, D.D., (1967), Pragmatics of Human Communication: a Study of Interactional Patterns, Pathologies, and Paradoxes, New York.

Willi. A., (2019), 'Der Sprachraum der Tragödie', in id. (ed.), Formes et fonctions des langues littéraires en Grèce ancienne, Vandœuvres, 97-142.

Wilson, D., (2011), 'Relevance and the Interpretation of Literary Works', UCL Working Papers in Linguistics 23, 69-80. 
-978-90-04-44026-5

Downloaded from Brill. com $04 / 26 / 2023$ 11:30:38AM via free access 
PART 1

\section{Verbal Communication I:}

Doing Things with Words 
-978-90-04-44026-5

Downloaded from Brill. com $04 / 26 / 2023$ 11:30:38AM via free access 


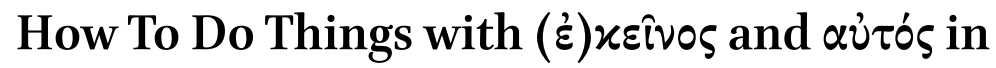 Tragedy: Initial Suggestions
}

\author{
Anna Bonifazi
}

\section{$1 \quad$ Aim and Origin of the Present Contribution}

This chapter offers an input on the pragmatics of $(\dot{\varepsilon})$ xદivo when they are used as anaphoric markers and, in a few cases, as deictic markers. ${ }^{1}$ The target corpus is formed by Classical tragedies, where anaphoric references are third-person references, that is to say, other characters than the 'I'-'you' present on stage, i.e. people who are absent at a given moment staged in the performance: people who have disappeared, who are going to appear later, or even dead people.

This paper selects investigation materials and pursues selected results: on

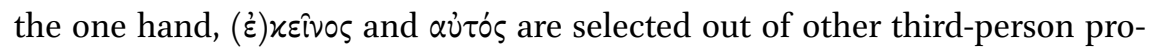
nouns used in Classical Greek (e.g. o $\tau \leftarrow \varsigma,, \sigma \varphi$ - forms) because their grammar (in terms of language use) still needs additional considerations; on the other hand, the readings that I am about to offer cannot claim any general conclusions as they apply to very few passages. In other words, this contribution presents preliminary analyses, and the thoughts being put forward invite expansion through future research and more systematic investigations.

However limited the evidence may be, the theoretical back-up relies on considerable work in linguistics from the second half of the 1970s. Moreover, parallels in modern literary texts as well as in other Ancient Greek genres do not fail to provide significant cases. The present argument does not start from classical Greek drama language or from ancient Greek grammars but aims at importing concepts and ideas from outside ancient Greek, in line with other chapters in this volume. The overarching goal is to view the skilful usages of these words by Aeschylus, Sophocles, and Euripides as part of a bigger set of usages, that is, what literary genres offer also in modern times; most of all, they will be observed in the light of general linguistic studies on how we process anaphoric markers in order to understand each other.

1 In view of upcoming analyses and for the sake of coherence, I shall focus on aủ tó accom-

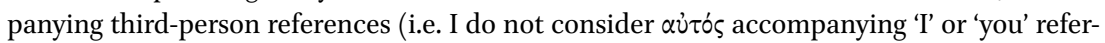
ences). 
Section 2 singles out central concepts in relevant pragmatic and cognitive accounts of anaphora, including studies on pronouns in narrative texts. Section 3 proposes instances from modern literary texts confirming but also expanding on general contemporary assumptions, and it draws conclusions about the methodology of textual analyses. Section 4 recaps points from my previous

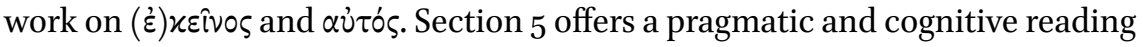
of $(\dot{\varepsilon}) \chi \varepsilon i v o \varsigma$ and aủrós in several tragic passages. Section 6 closes the investigation with a summary and future research directions.

\section{Anaphora Processing: Current Understanding}

Since the end of the 1970s, researchers from Linguistics, Psychology, and Artificial Intelligence have questioned the idea that the interpretation of a pronoun involves the search for earlier words (see e.g. Grosz 1977, Clancy 1980, Brown and Yule 1983). Nowadays, most theories of anaphora processing highlight the cognitive operations and the psychological factors influencing our comprehension of anaphoric markers. Concepts that are crucial in this respect regard how accessible a referent is (e.g. Ariel 199o, Fretheim and Gundel 1996), or how active an entity is in one's consciousness (Chafe 1996). For example, we may prefer to use 'light' recalls for entities that are already active or 'in focus' in the recipient's mind, e.g. 'she', and heavy recalls for entities that are inactive and are about to be activated again, e.g. 'this girl' (cf. Cornish 1999). A further relevant term is anadeixis (see e.g. Fossard et al. 2012): instead of a clearcut distinction between anaphora and deixis, we may think of a continuum from retrieving referents in our mind out of the extralinguistic context (deictic pole) to retrieving referents in our mind out of previous discourse (anaphoric pole).

Equally profitable are studies on the interface between reference management and people's perspective, starting from investigations on logophoricity (i.e. dealing with reflected or reported points of view) and free reflexive/indirect markers (reflexives whose verbal antecedent resides outside of the host clause), e.g. Hagège (1974), König and Siemund (2000). A seminal work on positive and negative attitudes of speakers towards referents recalled by means of demonstratives is Lakoff (1974), although the author calls the phenomenon 'emotional deixis'. More recently, Hinterwimmer and Bosch (2016) discusses German demonstratives and perspective taking, and Dancygier (2008) reads pronouns as part of viewpoint configurations: a phenomenon that may encompass the personal viewpoint of characters as well as authorial design about large portions of texts. 
Finally, relevant research has been focusing on the role of anaphoric markers in elaborated texts or narratives: Fox (1987) discusses anaphora in popular English narratives, Daneš (1990) the stylistic relevance of anaphoric choices, Baker (1995) locally free reflexives in Jane Austen, Conte (1996) anaphoric 'encapsulation' (recapping 'this' and the like), and Emmott (1997) participant tracking and contextual frames. Clancy (1980) and Hofmann (1989), among others, stress the relationship between discourse structure and anaphoric choices. Illuminating contributions on anaphora processing and participant tracking in Latin literature encompass Bolkestein and van de Grift (1994) and Kroon (2007).

All these works address the pragmatic and cognitive relevance of anaphoric markers, which I summarise in terms of their illocutionary force, their 'doing things', in Austin's terms: what speakers convey by uttering them, and how they signal what is going on in the discourse. Instances of illocutionary force include what characters or authors may imply, such as 'by uttering this marker I signal that this person is already active in my mind', 'as I utter this marker let me express what I think of/how I see that person', or what the position in the ongoing discourse may imply, such as 'a new episode is starting' or 'a turning point in the story is about to involve the referent'.

\section{Hints from Modern Literary Texts}

Actual instances of anaphoric markers representing choices rather than mechanical coherence tools can be found everywhere; for the present purposes, I shall draw the reader's attention towards a sample of passages from German and English literary texts. ${ }^{2}$ The first passage is relevant to ancient Greek tragedy because it is from a play written in meter.

[1] G.E. Lessing Nathan der Weise (1779), Act 1, Scene 1 (ed. Bark [1954: 12] $]^{3}$ )

Daja $\quad$... Ihre ganze Seele war / Die Zeit her nur bei Euch—und ihm.

Nathan Bei ihm? / Bei welchem Ihm?

2 The following analysis is part of my research that I have presented in recent papers (University of Stuttgart, Linguistics department, December 2017; University of Padua, Conference on qualitative and quantitative methods for the study of modern literatures, June 2018; University of Birmingham, Poetics and Linguistics Association Conference, July 2018; University of Poznań, Cognitive Linguistics Conference, October 2018). I am grateful to the respective (and very diverse) audiences for their fruitful feedback.

3 Tr. Taylor (http://www.fullbooks.com/Nathan-the-Wise1.html.). 
Daja $\quad .$. Her thoughts [Reha's] have only been with you—and him.

Nathan And HIM? What him?

The referent of German 'ihm' is the young Templar who rescued Recha (Nathan's daughter and a close friend of Daja) from a terrible fire. In Daja's mind, he is a fully active entity, whereas Nathan does not know him yet, which is why he raises an anaphora-resolution question: 'Bei welchem Ihm?'/ 'With which "he"?' This discrepancy of knowledge at the onset of the play triggers curiosity about the person that looks so dear to the protagonist's daughter and enhances everyone's attention to a character that is still absent from the scene.

The second passage features a supposedly ungrammatical use of an anaphoric reflexive marker:

[2] J. Austen Sense and Sensibility (ed. Copeland [2006:16o])

Could he [E.F.] ever be tolerably happy with Lucy Steele; could he, were his affection for herself [Elinor] out of the question, with his integrity, his delicacy, and well-informed mind, be satisfied with a wife like herilliterate, artful, and selfish?

Austen's use of indirect reflexive markers (see 'herself' in this passage with reference to Elinor) can be fully understood only in the light of large discourse domains, such as the chapters of Sense and Sensibility hosting [2], where Elinor's perspective is predominant.

The final passage shows a case of blurred distinction between anaphora and what Bühler calls 'Deixis am Phantasma' (1934: 121-140).

[3] Agatha Christie, The Bloodstained Pavement (2008: 340)

'If anyone sees those bloodstains-'

I submit that, in this short crime story, Christie's use of the adjective 'those' to recall some stains of blood that have been mentioned earlier in the discourse, may suggest a momentary visualisation of the stains (almost deictically) invited by the speaker — an old fisherman - to keep everyone's attention on them. Not by chance do they represent a decisive detail in the development of the story.

From the analysis of anaphoric markers encompassing not just third-person pronouns but all types of nouns phrases used to recall somebody/something in large discourse domains such as a crime story or an entire novel a few methodological points emerge: 
a) The individual form may have a local function-justified by the host clause or small discourse unit—and a global function-inviting the processing of referents as they evolve throughout complex narrations, or as they are mentioned at different points of the articulation of discourse.

b) Local functions never rely exclusively on the anaphoric form; they emerge from the understanding of the co-text as well, along with its syntactic, semantic, and pragmatic features; by the latter, I mean the illocutionary force of a whole clause together with the illocutionary force of the single anaphoric marker.

c) Like particles and tenses, anaphoric markers are particularly discourse sensitive and multifunctional.

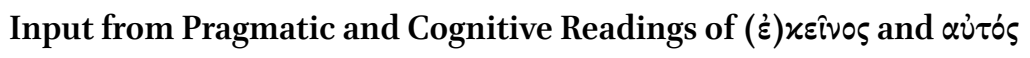
in Pindar and in Homer

In previous work of mine ${ }^{4}$ I challenge a few canonical assumptions about

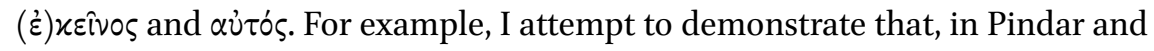
in Homer, not only the nominative cases but also non-nominative cases of both markers may convey emphasis. This emphasis comes from a range of implied meanings inferable from local and global context. I also offer counterexamples

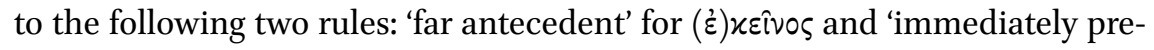
ceding' referent for aù tós (esp. Bonifazi 2009, 2010, 2012). I also explore the strongly visual potential of $(\dot{\varepsilon})$ $)$ iv $v$ (Bonifazi 2004, 2012: 40-68) and the image schema - a cognitive notion referring to skeletal structure - that possibly overarches all the meanings and syntactic functions of aùrós (Bonifazi 2019). The first three chapters of Bonifazi (2012: 13-183) combine the analysis of local as well as global contexts by the means of the analysis of the distribution, position,

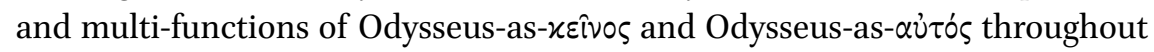
the Odyssey. ${ }^{5}$

As a way of recapping my readings, I shall list the range of implications that I see up to now behind the use of the two markers in lyric as well as in epic. Along with the surrounding co-text, $(\hat{\varepsilon}) \varkappa \varepsilon \hat{\imath} v o s$ pronoun and $(\hat{\varepsilon}) \varkappa \varepsilon i v o s$ adjective

4 Bonifazi (2004, 2009, 2010, 2012, and 2019).

5 On pages 19-40 of the same monograph, I preface the analysis with a section inspired by current linguistic accounts of third-person pronouns, titled 'Alternative readings of third-person pronouns: accessibility of the referent, narrative functions, and pragmatic impact'. Then, I test the main ideas on the proem of the Odyssey, and I make a case for an anaphoric reading of $\ddot{\alpha} v \delta \rho \alpha($ Odyssey 1.1). 
in noun phrases can suggest physical distance, intersubjective distance, emotional distance (to the degree of stigmatisation in the negative sense and of veneration in the positive sense); it can invite visualisation (possibly in relation to PIE ${ }^{*} k e$ ) and/or a connection between the mind's eye and the sight (appearance) of someone.

Along with the surrounding co-text, aùtós adjective (in attributive or predicative position), pronoun, and indirect reflexive suggests a centre evoking (implicitly or explicitly) periphery: one vs. many; chiefs vs. subordinates (see Latin ipse); gods vs. humans; persons vs. animals; body vs. body adornments/ weapons; ${ }^{6}$ aloneness; one's inner part; one's true self; one's identity (deictically); discourse prominence; cognitive sameness ('still in focus').

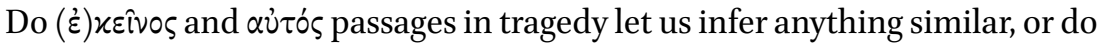
they mean something different? Reverence

The following passage from Alcestis features a double anaphoric choice $(\dot{\varepsilon}) \chi \varepsilon \hat{\imath}-$ vos with reference to the dead (in 866 as a pronoun, in 867 as an adjective connoting the dwelling of the dead).

[4] Euripides Alcestis $861-867^{7}$

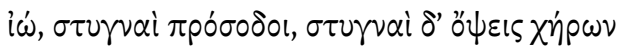

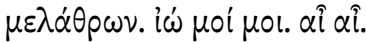

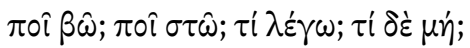

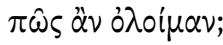

$\hat{\eta} \beta \alpha \rho \nu \delta \alpha i \mu o v \alpha \mu \eta^{\prime} \tau \eta \mu^{\prime}$ हैं $\varepsilon \chi \varepsilon v$.

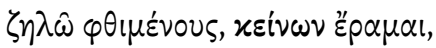

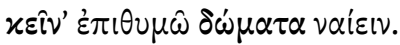

Oh, how gloomy

are the entrances, how gloomy the sight

of this bereaved dwelling. Oh! Alas, alas!

6 These contrasts already appear in Wagnon 188 o (with no reference to cognitive linguistics).

7 The Greek texts of Euripides follow Diggle (1981-1994); those of Sophocles Lloyd-Jones and Wilson (1990); those of Aeschylus Page (1972). 
Where should I go? Where should I stay? What should I say? What should I not say?

How I wish I would perish!

Really, my mother bore me luckless.

I admire the dead, I long for those ones, those dwellings are the ones I love to stay in. ${ }^{8}$

As his beloved wife dies in his place, Admetus falls into a state of desperation and laments his own misery at the funeral procession. By stating that he longs for 'those ones' and 'those dwellings', he not only expresses physical and intersubjective distance towards entities that are no longer part of 'this' world, but also reverence, just as in Odyssey 1-4, where the most frequent pronoun used for Odysseus (uttered exclusively by characters) is $(\hat{\varepsilon}) \varkappa \varepsilon i v 0 \varsigma$, which recalls the absent and perhaps already dead hero. ${ }^{9}$ In this passage certain general grammatical characteristics of $(\dot{\varepsilon}) x \varepsilon \hat{\imath}$ os turn out to be disregarded or even irrelevant: the emphasis provided by the repetition of the form does not relate just to the nominative but also to the genitive and the accusative case ( $\chi \varepsilon^{i} \nu \omega \nu, 866$, and $\varkappa \varepsilon \hat{i} \nu \alpha, 867$ ). Moreover, in line 866 , the verbal antecedent immediately precedes the anaphoric marker, which, conventionally, is not supposed to be the case.

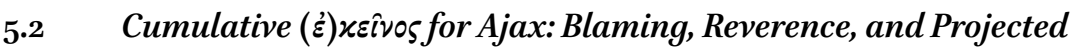 Lament}

Within the range of implied meanings of $(\xi) x \varepsilon i v o s$ in tragedy, blaming (derived from a negative sense of distance) is well represented in Ajax, although commentaries hardly pay attention to this lexical choice and its recurrence. Ajax has to be reproached for what he has done, and yet his heroic figure is predominant in his life and afterlife. I suggest that the twelve occurrences of $(\dot{\varepsilon}) \varkappa \varepsilon i v \circ \varsigma$ for Ajax in the homonymous play reflect a mix of implied meanings that match his controversial figure and the mixed feelings of people towards him. These meanings include blame, the reconnection of the characters' and the audience's mind's eyes with his presence, and reverence. Moreover, in the

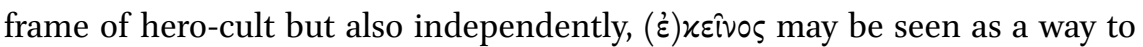
avoid pronouncing someone's name, while the referent is clear in everybody's mind..$^{10}$

8 The translations of [4] and [9] are mine.

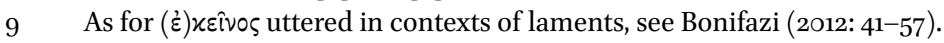

10 For an overview of scholarship pro and contra hero-cult reflected in Ajax, see Finglass (2011: 47-51). 


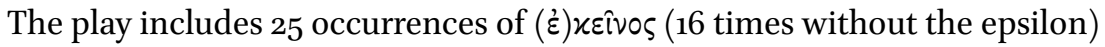
in masculine singular forms. ${ }^{11}$ Ajax takes the lion's share with twelve of them (see the following table). The other referents are his father Telamon $(437,472$, 1303), Teucer (567, 798), Odysseus (113), Hector (1032), Eurysaces (513), someone who thinks differently from Teucer (1039), xpóvos (933), and three times in almost contiguous lines 'the inventor of war and weaponry' (1195, 1198, 1199).

Here is a synopsis of the instances with Ajax as the referent throughout the play:

\begin{tabular}{|c|c|c|c|}
\hline Line & Form & Speaker & Local co-text \\
\hline 6 & xEívov & Athena & scanning his fresh tracks \\
\hline 20 & xEîvov & Odysseus & tracking that one \\
\hline 28 & 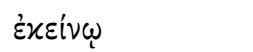 & Odysseus & all lay responsibility to that one \\
\hline 220 & 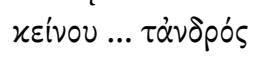 & Tecmessa & victims as sacrifices made by that man \\
\hline 271 & 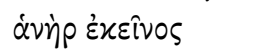 & Tecmessa & that man, frenzied, ... \\
\hline 275 & 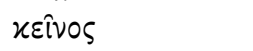 & Tecmessa & that one is subjected to anguish \\
\hline 285 & 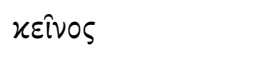 & Tecmessa & that one, in the dead of night ... \\
\hline 755 & 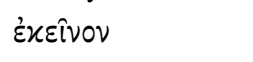 & Messenger & to see that one alive \\
\hline 762 & xદivos & Messenger & that one was foolish also earlier \\
\hline 783 & 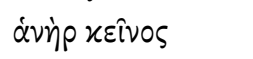 & Messenger & that man does not exist any longer \\
\hline 795 & દ̇xદivov & Messenger & to keep that one in his tent \\
\hline 991 & 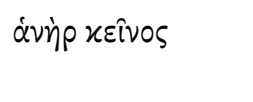 & Chorus & $\begin{array}{l}\text { that man had asked for the care of his } \\
\text { child }\end{array}$ \\
\hline
\end{tabular}

I shall solely comment on these occurrences that illustrate, along with their cotext, the inferable speakers' attitudes or show how different anaphoric markers in the same passage are meaningful choices rather than metrical alternatives.

11 An additional occurrence, $\chi \dot{\alpha} \varkappa \varepsilon i v 0 v$ in 1035, refers to the girdle that Ajax had once given to Hector; Achilles later used it to drag Hector's corpse around Troy. Finglass (2011: 430), in line with other scholars, considers lines 1028-1039 spurious; interestingly, one reason is the apparently awkward anaphora resolution of the pronoun: ' $\chi \dot{\alpha} x \varepsilon i v$ ov looks back five lines for its referent, a fault not eased by the syntactic compression and interposed nouns'. Independently of whether those lines are spurious or not, I submit that the relatively remote verbal antecedent of $x \dot{\alpha} x \varepsilon \hat{\imath} v o v$ is not necessarily a problem: anyone would easily retrieve 'that girdle' in connection to Hector's story rather than in connection to previous textual referents; in other words, the referent may be activated through the memory of another known discourse separate from the present one. 
[5] Sophocles Ajax 25-31 (Odysseus speaking)

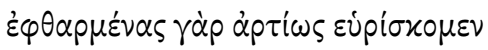

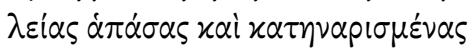

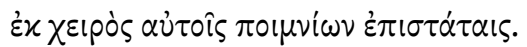

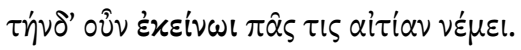

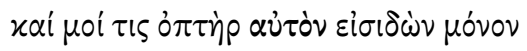

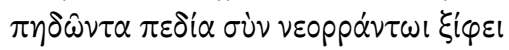

$\varphi p \dot{\alpha} \zeta \varepsilon l \tau \varepsilon \varkappa \dot{\alpha} \delta \dot{\gamma} \lambda \omega \sigma \varepsilon v \cdot \ldots$

For we recently found all the cattle, our plunder, dead—yes, slaughtered by human hand - and with them the guardians of the flocks. Now, all men lay responsibility for this crime to him. And further, a scout who had seen him bounding alone over the plain with a newly-wet sword reported to me and declared what he saw. ${ }^{12}$

In line 28, Odysseus stresses the guilt of Ajax as collectively attributed to him ('that one'). Odysseus is also a good candidate for indirectly conveying his own personal hatred, or at least emotional distance towards Ajax. A further element of this passage that lends support to the non-neutral choice of the anaphoric marker is the occurrence of avं tóv in the following line (29). A 'plain third-person pronoun' reading thereof would miss the pragmatic implication

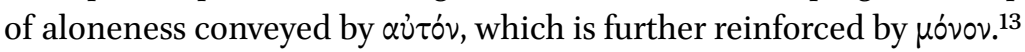

The next passage confirms that the discourse strategies behind using both

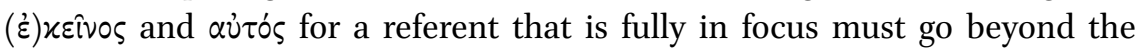
'simple' necessity of recalling Ajax.

[6] Sophocles Ajax 271-276 (Tecmessa speaking)

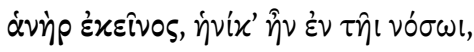

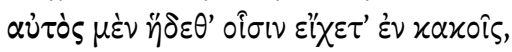

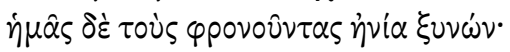

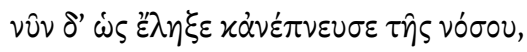

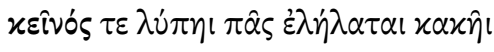

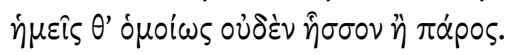

12 Translations of the Ajax are from Jebb ( $\left.{ }^{3} 1907\right)$.

13 See section 4 and Taillardat (1987) about isolation and unity as components of the semantic nucleus of aủ tós. 
That man, while afflicted, found joy for himself in the dire fantasies that held him, though his presence distressed us who were sane. But now, since he has had pause and rest from the plague, he has been utterly subjected to lowly anguish, and we similarly grieve no less than before.

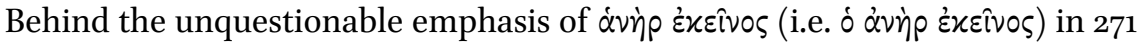
(see also 783 and 991, where the same anaphoric expression is uttered by the messenger and the chorus respectively), I see Tecmessa's tragic despair and torment adding to the negative evaluation of Ajax' sickness. The additional

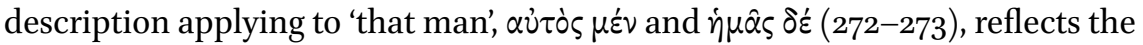
cognitive image schema centre-periphery: the basic relation is between Ajax-

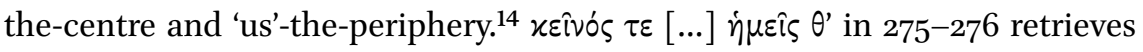
the juxtaposition of 'he' and 'us', this time, however, to lament what is common to both, namely sorrow and grief (see the $\tau \varepsilon$... $\tau \varepsilon$ construction).

Example [7] shows that the implications of uttering $x \varepsilon i v o \varsigma$ may additionally concern the discourse function of the hosting unit.

[7] Sophocles Ajax 282-287 (Chorus and Tecmessa)

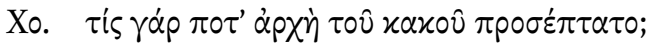

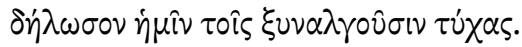

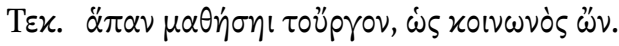

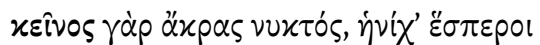

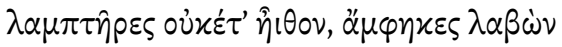

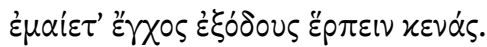

Ch. In what way did the plague first swoop down on him? Tell us who share your pain how it happened.

Tek. You will hear all that took place, since you are involved. In the dead of night when the evening lamps were no longer aflame, he seized a two-edged sword and wanted to leave on an aimless foray.

By means of $\gamma \dot{\alpha} \rho$, Tecmessa starts the narrative of Ajax' mad actions. ${ }^{15}$ The use of $x \varepsilon i v \circ \varsigma$ cannot be explained due to the far antecedent, be it in the text or in the mind: the hero is in fact the focus of the chorus' and Tecmessa's attention

\footnotetext{
14 See section 4 and Bonifazi (2019).

15 In its discourse function, this $\gamma \alpha \dot{\alpha}$ resembles $\gamma \alpha \dot{\alpha} \rho$ that starts embedded narratives in Homer (on which see de Jong 1997 and recently Bonifazi et al. 2016: II.3 §§ 20-32) and in Herodotus and Thucydides (see Bonifazi et al. 2016: IV.3 §§109-110).
} 
and discourse at least since the entrance of Tecmessa at line 201. Rather, I see two co-existing functions of $x \varepsilon i v o s$ : one is the mental visualisation of Ajax in the setting of the report (Deixis am Phantasma), the other is a strong recall of the referent at the onset of a new discourse units (we would call this the beginning of a new paragraph). ${ }^{16}$

The last passage features Al $\alpha \nu \theta^{\prime}, \dot{\varepsilon} \varkappa \varepsilon \hat{\imath} \nu 0 v$ and $\alpha$ żóv: all referring to Ajax in three contiguous lines.

[8] Sophocles Ajax 752-762 (the messenger speaking)

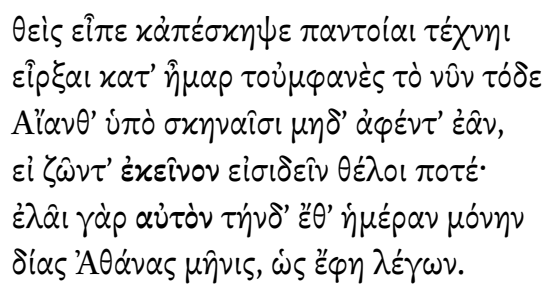

The prophet [= Calchas] then addressed him [= Teucer $]$ and strictly commanded him to use every possible resource to keep Ajax inside his tent for the duration of this day that now shines on us, and to prevent him from moving about if he wished ever to look on him alive. For this day alone will the anger of divine Athena lash at him.

Teucer is the implied grammatical subject of the हi clause in 755; nevertheless, the participle $\zeta \hat{\omega} \nu \tau \alpha$ suffices to recall Ajax in the object position (see Al' $\alpha \nu \theta^{\prime}$ at

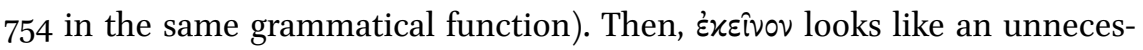

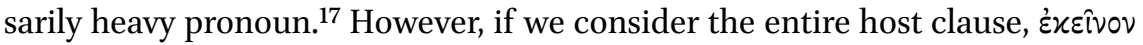

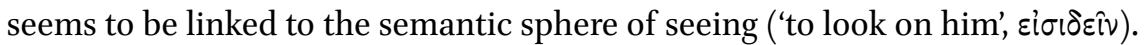
I advocate the reading of the following a ¿ióv as keeping Ajax as the centre of everyone's attention and possibly hinting at the corporeal side of his persona as Athena lashes at him (more below on aĩós and one's body). 'Lashing' is to be understood metaphorically, but it is as if avं óv keeps the physicality of the action; in other words, it matches the frame of the source. ${ }^{18}$

\footnotetext{
16 See section 2 and Hofmann (1989).

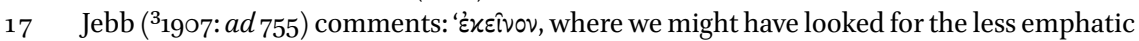

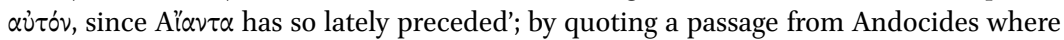

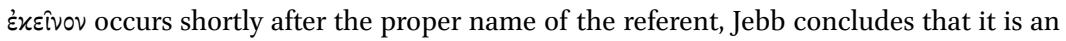
Attic idiom.

18 I am grateful to Douglas Cairns (personal communication) for drawing my attention to
} 


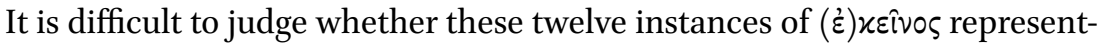
ing Ajax are enough to produce a resonance effect for the actors on stage and the audience. ${ }^{19}$ My point is that at least they share two pragmatic, cognitive, and poetic aspects: a. all of them mentally (if not visually) reconnect everyone to Ajax' presence when he is not on stage, with the exception of 991, as

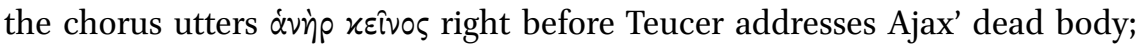
b. on the whole, they compress a network of references to what he has done: they recall his isolation/distance and his death; furthermore, they project, from the very beginning (in a proper tragic style), the dimension of lament that will accompany the performance until his burial. Perhaps there is a link between this anaphoric strategy and the thematic (and visual?) centrality of a dead Ajax. ${ }^{20}$

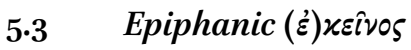

As the chorus of elderly citizens of Colonus enters the stage and sings (Soph. $O C$ 118-137), Antigone and a blind Oedipus hide in the sacred grove of the Eumenides, but afterwards they come forward, and at that point Oedipus talks:

[9] Sophocles Oedipus at Colonus 137-140

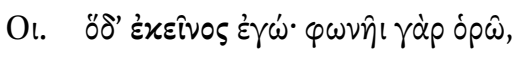

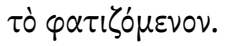

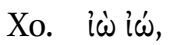

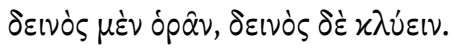

Oe. Here I am; I can see with the sound, as they say.

Ch. Oh! Oh!

Fearful to see, fearful to hear! ${ }^{21}$

the general possibility that metaphorical expressions 'attract' to the source frame other linguistic features than themselves.

19 The name 'Ajax' appears 39 times in the play; however, it is a vocative case twelve times, which reduces the references to him in third person to 27 occurrences. On a side note, nothing prevents us from hypothesising that uttering the proper name of a hero may in turn hint at a series of implied meanings, not so different from what happens with anaphoric markers.

20 On the interpretive problems about the visibility of Ajax on the ekkyklèma, see in particular Meineck (2006); on ambiguities regarding the scene settings of the play, see Finglass (2011: 11-20).

21 The translation is from Jebb $\left({ }^{3} 1900\right)$. 


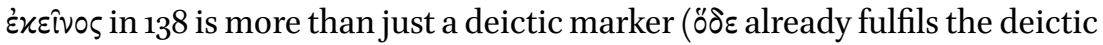
role of pointing to the referent). Ruijgh (2006:160) sees in this combination of

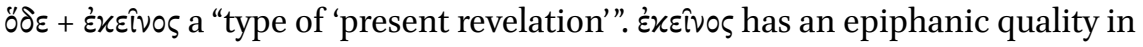
itself, which results from the combination of co-occurring cognitive operations dealing with vision and memory: someone/something appears to the speaker, and the speaker, visually (re-)connects this someone/something to a referent that is in her mind. The visual component is essential. ${ }^{22}$

\section{4 avizósfor Corpses}

It is well known that on the onset of the Iliad, aviroús refers to the corpses of heroes that are fed to the dogs (Il. 1.4). Homeric poetry features other instances where aủ tós implies 'body' (i.e. someone's body without weapons or anything else) and 'alone' (i.e. without anything else around), which makes Taillardat (1987: 77-79) argue for separation and distinction as its basic semantic components. The following utterance by Orestes in Libation Bearers seems to keep the epic implication of 'dead body':

[10] Aeschylus Libation Bearers 903-904

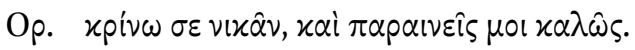

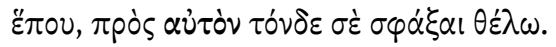

Or. (to Pylades) I judge you the winner; you have advised me well. (to Clytaemestra) Follow me. I want to slay you right next to that man. ${ }^{23}$

I let the reader notice that Sommerstein's translation 'right next to that man' fails to translate both the allusion to Aegisthus' corpse and the deixis. I interpret this phrase to mean 'next to this corpse'.

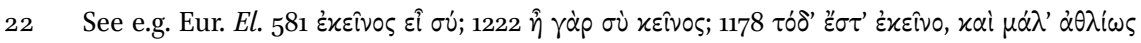
हैxov with reference to Electra's visual perception of Orestes (in line 1178, the object is

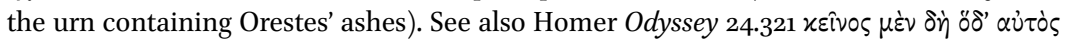

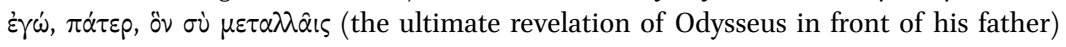

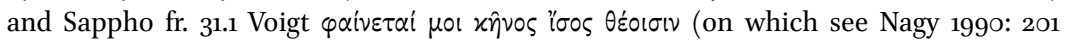
n. 110).

23 The translation is from Sommerstein (2008). 


\section{5 avizós Implying 'Someone's Body' as well as Discourse Prominence}

Let us go back for a moment to Ajax. Ajax wants to take his leave of his son after giving him his shield (529-577). Example [11] shows different ways in which Eurysaces is referred to over the stichomythia in lines 529-545 when the child is unquestionably the topic of the conversation (presumably a fully active referent in Tecmessa's and Ajax' mind). In order to refer to Eurysaces, Sophocles

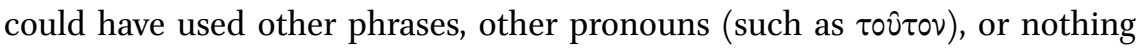
(null anaphora, given that direct objects are part of the pro-drop characterist-

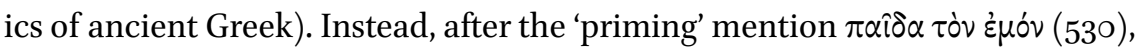

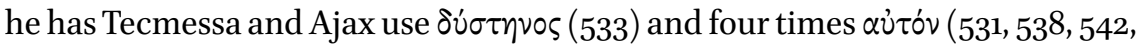
$545)^{24}$

[11] Sophocles Ajax 530-545

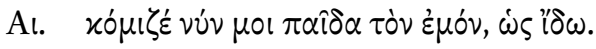

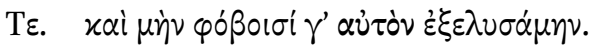

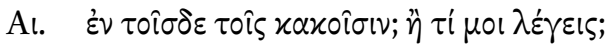

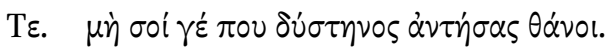

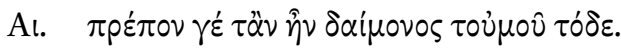

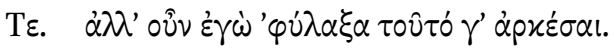

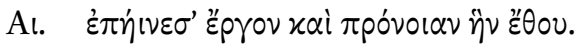

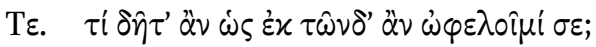

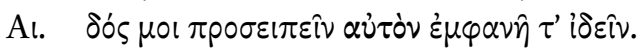

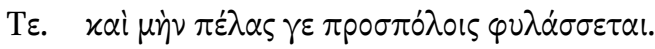

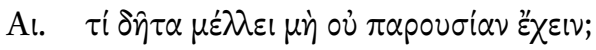

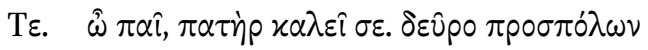

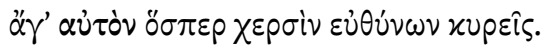

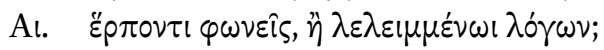

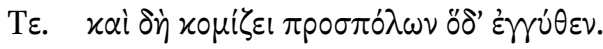

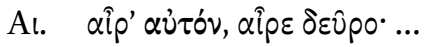

Aj. Then bring me my son, so that I may see him.

Tek. But in my fear I released him from my keeping.

Aj. Because of these troubles of mine? Or what do you mean?

Tek. Yes, for fear that somehow the poor child would get in your way, and die.

24 I shall not discuss the vocative $\hat{\omega} \pi \alpha \hat{\imath}$ and the second-person pronoun $\sigma \varepsilon$ (541), even though they refer to the child as well; as deictic markers they interrupt the focus on him in third person. 
Aj. Yes, that would have been truly worthy of my destiny.

Tek. Well, at least I took care to avert that disaster.

Aj. I approve of your action and of your foresight.

Tek. How, then, can I serve you, as things stand now?

Aj. Let me speak to him and see him face to face.

Tek. Oh, yes-he is close by, watched by our servants.

Aj. Then why is his presence delayed?

Tek. My child, your father calls you. Bring him here, servant, whichever of you is guiding his steps.

Aj. Is the man coming? Or has he missed your call?

Tek. Here now one of the servants approaches with him.

Aj. Lift him; lift him up here.

I interpret this exceptional concentration of à̃ tós for the same referent as a pragmatic signpost for two implications: a. the discourse prominence of the child (centre opposed to the periphery made of other people); b. the focus on Eurysaces' body, as the respective co-texts indicate: 'releasing him from keeping' (531), 'speaking and seeing him' (538), 'bringing him' (542), and 'lifting him' (545).

\subsection{Cumulative aùtós for Hippolytus: Centrality and Relevance of the Body}

The combination of discourse prominence, centre-and-periphery, and the relevance of the body is what characterises the use of aivós with Hippolytus as the referent in Euripides' homonymous tragedy. Out of twelve masculine singular forms of aùtós used in third-person (two extra times, the marker is used in first or second person, 'I' av่tós and 'you' aùtós), nine occurrences have the protagonist as the referent. Here is a synopsis of the occurrences throughout the play:

\section{Line Form Speaker Local co-text}

\begin{tabular}{|c|c|c|c|}
\hline 54 & $\ddot{\alpha} \mu^{\prime} \alpha \nu \tau \omega \hat{\omega} t$ & Aphrodite & The $x \hat{\omega} \mu \circ \varsigma$ following him \\
\hline 895 & 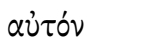 & Theseus & Poseidon will send him to Hades \\
\hline 899 & aủtós & Chorus & He ipse is here \\
\hline 1084 & aủtóv & Theseus & Drag him away \\
\hline 1166 & 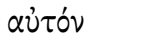 & Messenger & His own chariot destroyed him \\
\hline 1172 & 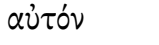 & Theseus & The cudgel of Justice struck him \\
\hline 1187 & $\pi \alpha \rho^{\prime} \alpha u \dot{\tau} \tau \dot{v}$ & Messenger & We set the horses beside him \\
\hline
\end{tabular}


(cont.)

\begin{tabular}{|c|c|c|c|}
\hline Line & Form & Speaker & Localco-text \\
\hline 1236 & $\alpha$ $\tau o ́ s$ & Messenger & He, entangled ... \\
\hline 1265 & $\alpha$ น่นóv & Theseus & Bring him \\
\hline
\end{tabular}

Each of these occurrences is meaningful if we take only the local co-text into

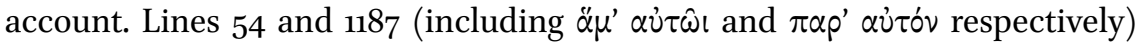
feature a centre-periphery construction: in 54 the $x \hat{\omega} \mu \circ \varsigma$ of the servants (periphery) is following him (centre) as soon as he returns from the hunt; in 1187 the servants (again, the periphery) prepare the chariot with the horses (periphery) beside the master (the centre). In 1084, 1166, 1172 (metaphoric action), 1236, and 1265, the semantic relevance of Hippolytus' body simply emerges from the semantics of the host clause ('drag him away', 'the chariot destroyed him', 'the cudgel struck him', 'he, entangled ...', and 'bring him' respectively). I link these occurrences to the thematic relevance of the male body in pain: ${ }^{25}$ just as the visualisation of dying bodies comes to the fore with gripping details in other plays, the tragedy of Hippolytus cannot prescind from the reported spectacle of his disfigured body. Perhaps the most striking of these passages is 1169-1172 where Theseus is eager to learn from Poseidon how he wrecked Hippolytus:

[12] Euripides Hippolytus 1169-1172

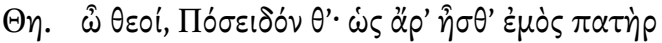

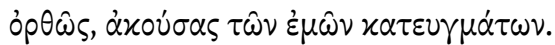

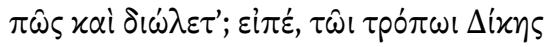

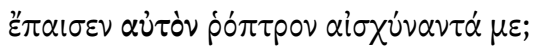

Th. (stretching out his arms, palms upward, in prayer) Merciful gods! So after all you are truly my father, Poseidon, since you heard my prayer! How did he perish? Tell me, how did the cudgel of Justice strike him for dishonoring me? ${ }^{26}$

25 See in particular Hawley (1998).

26 The translations of the Hippolytus are from Kovacs (1995). 
The question $\pi \hat{\omega} \varsigma$ xai $\delta \omega^{\prime} \lambda \varepsilon \tau \tau^{\prime}$ (1171) shows no encoding of the grammatical subject, which tells us that Hippolytus is fully in focus in Theseus' mind. This

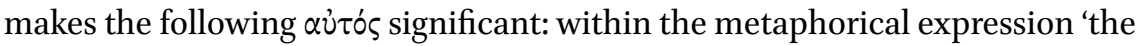
cudgel of Justice stroke him' aùrós is almost required if the intended referent is Hippolytus' body. ${ }^{27}$

The remaining instances occur in the following passage:

[13] Euripides Hippolytus 887-900

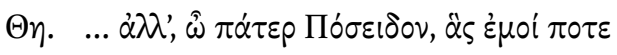

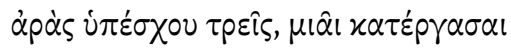

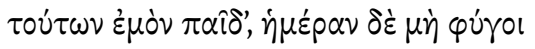

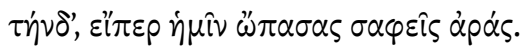

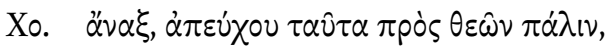

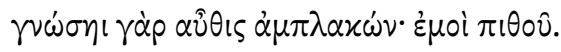

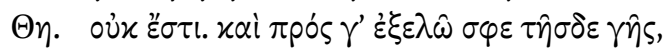

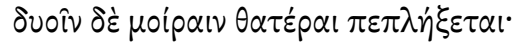

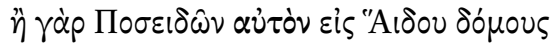

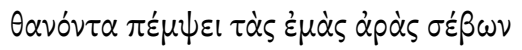

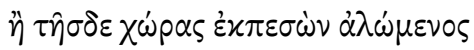

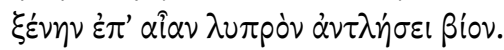

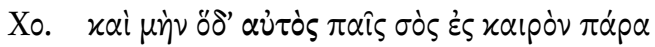

'I $\pi \pi \dot{\lambda} \lambda v \tau \circ \varsigma^{\prime} . .$.

Th. ... But, father Poseidon, those three curses you once promised mewith one of them kill my son, and may he not live out this day, if indeed you have granted me curses I may rely on.

Ch. My lord, I beg you by the gods, take back your prayer! For you will learn in time that you have made a mistake. Take my advice!

Th. It cannot be. And what is more, I shall banish him from this land, and of two fates one shall strike him: either Poseidon, honoring my curses, will send him dead to the house of Hades or being banished from here he will wander over foreign soil and drain to the dregs a life of misery. [Enter Hippolytus by Eisodos B.]

Ch. Look! Your son Hippolytus is here himself, a timely arrival! 
In this excerpt, Hippolytus is primed in 889 ( $\xi \mu o \dot{\nu} \tau \alpha \hat{\imath} \delta \alpha$ ) and recalled in 893 by the means of $\sigma \varphi \varepsilon$. Then, Theseus formulates two alternatives for ruining his son's life. In the first, we find $\alpha \dot{v} \tau o$ v, whereas in the alternative there is no marker for Hippolytus (null anaphora; see the finite verb $\alpha \nu \tau \lambda \dot{\eta} \sigma \varepsilon l, 898$, and the two participles $\dot{\varepsilon} \chi \pi \varepsilon \sigma \dot{\omega} \nu \dot{\alpha} \lambda \dot{\omega} \mu \varepsilon v \circ \varsigma, 897$ ). The full accessibility of Hippolytus as the referent from 889 through 900 makes av่tóv in 895 useless unless something else is implied by its use. The semantics of the host clause disambiguates the sense: what Theseus wishes is that Poseidon sends his dead body to Hades.

The later aviós (899) is, conversely, a deictic marker of identity: the chorus

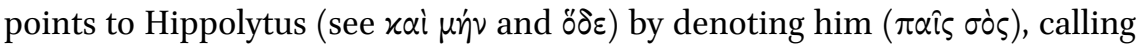

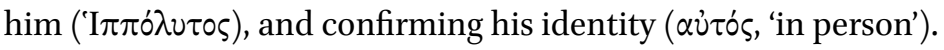

\section{7 avizós as a Reflexive Marker}

Towards the end of the Cassandra's long scene in Agamemnon (1172-1330), the prophetess announces her own imminent death by setting forth a contradiction that is in line with further shocking predictions about Agamemnon and about Orestes. $^{28}$

[14] Aeschylus Agamemnon 1322-1323

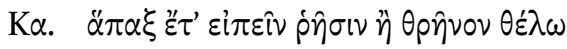

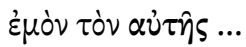

Ca. I would make one speech more, or it may be a dirge - my own. ${ }^{29}$

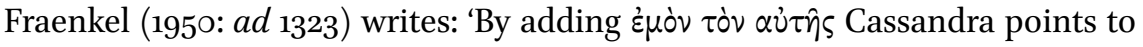
the peculiarity of her situation, for it is in itself contrary to the nature of things that anyone should sing or speak his own dirge.' Indeed, his translation captures

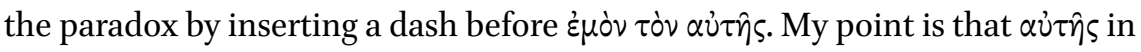
this peculiar construction emphatically refers to Cassandra's own self ('mine, of myself'). ${ }^{30}$ The cognitive and pragmatic implication of aùtós in this case resides

28 On this as a 'mad-scene', see especially Schein (1982).

29 The translation is from Fraenkel (1950).

30 Pearson (1910: ad loc.) provides further Euripidean examples of what he calls a loosely added genitive' after żuóv. While the Loeb edition (by Smyth; see Sommerstein 2008) has

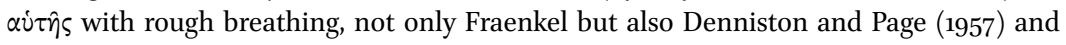
West (1990) have $\alpha \dot{\tau} \tau \hat{\jmath} \varsigma$ with smooth breathing, thus indirectly acknowledging the form as being in line with archaic reflexive usages of aìós with smooth breathing (e.g. Odyssey 4.247), and at the same time as distinct from the more common żuavтóv. 
in the reference to the centre (Cassandra herself) as indirectly opposed to others for whom the dirge may be sung (periphery).

\section{8 avंtós for Someone's (Actual) Identity, and the Incorporation of Multiple Perspectives}

The final cognitive and pragmatic illocutionary force of aùtós that I consider draws from the subtle interplay between Odysseus-in-disguise to the eyes of many and Odysseus-the-actual-one through aĩós in the second part of the Odyssey. ${ }^{31}$ There, uttering aùtós as an anaphoric marker can be associated with different referents-in-the-mind, such as the hero in disguise or the hero recognised; this reveals the following co-existing cognitive and pragmatic possibilities: aù tós can imply the reference to the person just mentioned in the discourse; it can convey someone's specific perspective adopted about the referent (for example, ' $\mathrm{X}$ the real one'); finally, it can retrieve the deictic value of avंós to point to someone's identity (ipse, as in Hippolytus 899, in [13]) or sameness between speaker and the referent of aìós. All these possibilities are alluded to, for example, in the following exchange between Electra and Orestes in Euripides' Electra:

[15] Euripides Electra 274, 276, 278-28o, 282

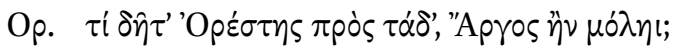

$[\ldots]$

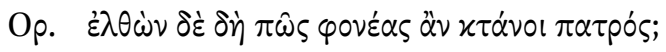

$[\ldots]$

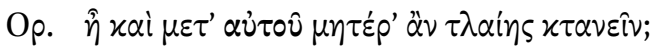

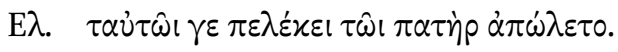

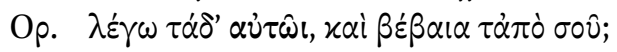

$[\ldots]$

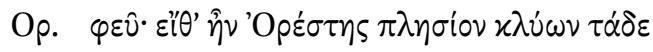

Or. Then what should Orestes do about this, if he comes to Argos? $[\ldots]$

Or. But if he does come, how might he kill his father's murderers? [...]

Or. And would you dare, with him, to kill your mother?

El. Yes, with that same axe by which my father died. 
Or. Am I to tell him this, and that your purpose is steadfast? $[\ldots]$

Or. Ah! Would that Orestes were nearby, to hear that $!^{32}$

Into the mouth of Orestes-in-disguise, Euripides puts an explicit reference to Orestes-the-real-one as the former envisions the latter's hypothetical arrival

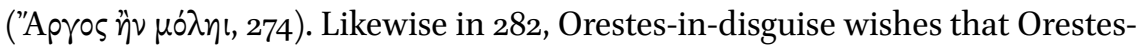
the-real-one is near and is able to hear the current exchange. However, in two lines that occur in between, Euripides lets Orestes-in-disguise use aìtós ambiguously: in Electra's perspective the anaphoric marker means 'Orestes, the referent I just mentioned'; in the audience's perspective it means 'the real Orestes, who is currently talking to her; they are the same persons'; in Orestes' perspective, it means 'Hey, I am exactly him, I am Orestes myself'.

Overall, this passage shows that àं tós can be uttered to do several things at once such as connecting referents at the level of discourse coherence and suggesting sameness as well as someone's identity to different people, therefore implying the adoption (and the revelation) of multiple perspectives at once.

\section{$6 \quad$ Conclusion}

By taking contemporary accounts of how we process anaphoric markers into account as well as pragmatic and cognitive readings of third-person pronouns in modern literary texts as well as in ancient Greek lyric and epic, it is possible to see what $(\hat{\varepsilon}) \varkappa \varepsilon i v$ vo and aủ tós do in tragedies, at least in some passages. The similarities in language use that I see across ancient Greek lyric, epic, and drama reinforce the idea that these key words are the result of meaningful choices rather than metrically convenient solutions. Objections regarding the value of interpreting what words do not say explicitly are answered by stating that everything we understand from words (more so from poetic words) comes from our inferences (however well-read) about what they meant, individually and in context.

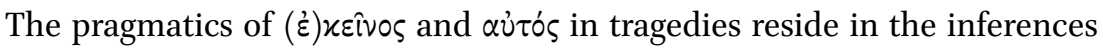
that they invite on multiple levels: about the status of referents in the mind of the speaker(s), about personal or intersubjective attitudes towards them, and about how the discourse unfolds (transitions/no transitions; global narrative

The translation is from Kovacs (1998). 
trajectories). They may carry their own illocutionary force (e.g. aủ tós meaning 'someone's body') and/or participate in the broader illocutionary force of the host unit (e.g. 'I long for $x \varepsilon i v o l$ ' conveying a positively-oriented distance between mortals and special persons). Their force may reside in multiple functions carried out at once. This is not different from the multiple functions that individual deictic markers may fulfil (let us think of the multiple co-working readings of the referents of 'we' in the Queen's 'We are the champions'). Finally, individual occurrences of $(\hat{\varepsilon}) x \varepsilon \hat{\imath} v \circ \varsigma$ and ai่tós can remind the audience of overarching implicatures (conventional as well as conversational) concerning the same character through different scenes or moments of the play, allowing us to appreciate different facets or, conversely, invariant thoughts associated with a specific character. ${ }^{33}$

As I close this paper, I would like to raise a few questions for further (muchneeded) research. How many times is Ajax recalled as oivos in the Sophoclean

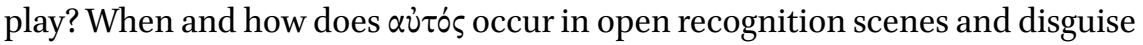
situations? What is the frequency of $(\dot{\varepsilon})$ xeivos in laments and in choral songs? Are the discussed as well as other anaphoric markers in drama connected to someone's perspective or some intersubjective (traditional) perspective in par-

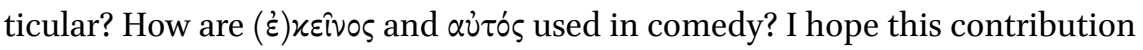
will stimulate more work on such questions or at least foster awareness of the

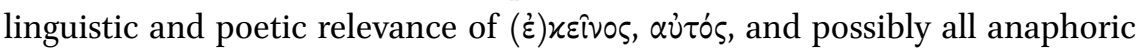
expressions in Greek drama.

\section{Acknowledgements}

The author warmly thanks Gunther Martin and all the organisers of a highly stimulating conference.

\section{References}

Ariel, M., (1990), Accessing Noun-phrase Antecedents, London/New York.

Baker, C.L., (1995), 'Contrast, Discourse Prominence, and Intensification, with Special Reference to Locally Free Reflexives in British English', Language 71, 63-101.

Bark, J., (1954), G.E. Lessing, Nathan der Weise, Munich.

33 The consideration of all these aspects could correspond to more attention to the occur-

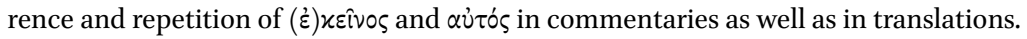


Bolkestein, A.M. \& Grift, M. van de, (1994), 'Participant Tracking in Latin Discourse', in J. Herman (ed.), Linguistic Studies on Latin, Amsterdam/Philadelphia, 283-302.

Bonifazi, A., (2004), ' 'єîvos in Pindar: between Grammar and Poetic Intention', Classical Philology 99, 283-299.

Bonifazi, A., (2009), 'Discourse Cohesion through Third Person Pronouns: the Case of

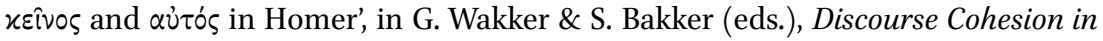
Ancient Greek, Leiden/Boston, 1-19.

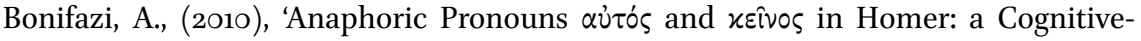
pragmatic approach', in I. Putzu, G. Paulis, G. Nieddu, \& P. Cuzzolin (eds.), La morfologia del greco tra tipologia e diacronia. Atti del VII Incontro internazionale di linguistica greca, Cagliari 13-15 settembre 2007, Milan, 97-114.

Bonifazi, A., (2012), Homer's Versicolored Fabric: the Evocative Power of Ancient Greek Epic Word-making, Washington, D.C./Cambridge, Mass.

Bonifazi, A., (2019), 'Autos and the Center-Periphery Image Schema', in W.M. Short \& E. Mocciaro (eds.), The Embodied Basis of Constructions in Greek and Latin, Berlin, 126-148.

Bonifazi, A., Drummen, A., \& Kreij, M. de, (2016), Particles in Ancient Greek Discourse. Five Volumes Exploring Particle Use Across Genres, Washington, D.C. http://chs.harva rd.edu/CHS/article/display/6391 (31/o3/2020).

Brown, G. \& Yule, G., (1983), Discourse Analysis, Cambridge.

Bühler, K., (1934), Sprachtheorie. Die Darstellungsfunktion der Sprache, Jena.

Chafe, W., (1996), 'Inferring Identifiability and Accessibility', in Fretheim and Gundel, $37-46$.

Christie, A., (2008), Miss Marple and Mystery. The Complete Short Stories, London.

Clancy, P.M., (1980), 'Referential Choice in English and Japanese Narrative Discourse', in W.L. Chafe (ed.), The Pear Stories: Cognitive, Cultural, and Linguistic Aspects of Narrative Production, Norwood, 127-202.

Conte, M.-E., (1996), 'Anaphoric Encapsulation', in W. de Mulder and L. Tasmowski (eds.), Coherence and Anaphora, Amsterdam/Philadelphia, 1-10.

Copeland, E., (2006), Jane Austen, Sense and Sensibility, Cambridge.

Cornish, F., (1999), Anaphora, Discourse, and Understanding, Oxford.

Dancygier, B., (2008), 'Personal Pronouns, Blending, and Narrative Viewpoint', in A. Tyler, Y. Kim, \& M. Takada (eds.), Language in the Context of Use: Discourse and Cognitive Approaches to Language, Berlin, 167-182.

Daneš, F., (1990), 'On the Stylistic Relevance of the Choice of Anaphoric Expressions', Rivista di Linguistica 2, 121-139.

Denniston, J.D. \& Page, D.L., (1957), Aeschylus, Agamemnon, Oxford.

Diggle, J., (1981-1994), Euripidis fabulae, 3 vols., Oxford.

Emmott, C., (1997), Narrative Comprehension, Oxford/New York.

Finglass, P.J., (2011), Sophocles, Ajax, Cambridge. 
Fossard, M., Garnham, A., \& Wind Cowles, H., (2012), 'Between Anaphora and Deixis ... The Resolution of the Demonstrative Noun Phrase "that N"', Language and Cognitive Processes 27, 1385-1404.

Fox, B., (1987), 'Anaphora in Popular Written English Narratives', in: R.S. Tomlin (ed.), Coherence and Grounding in Discourse: Outcome of a Symposium, Eugene, Oregon, June 1984, Amsterdam/Philadelphia, 157-174.

Fraenkel, E., (1950), Agamemnon, vol. 3, Oxford.

Fretheim, T. \& Gundel, J.K. (eds.), (1996), Reference and Referent Accessibility, Amsterdam/Philadelphia.

Grosz, B., (1977), The Representation and Use of Focus in Dialogue Understanding. Technical Report 151, SR I International, Menlo Park.

Hagège C., (1974), 'Les pronoms logophoriques', Bulletin de la Société de Linguistique de Paris 69, 287-310.

Hawley, R., (1998), 'The Male Body as Spectacle in Attic Drama', in L. Foxhall \& J. Salmon (eds.), Thinking Men:Masculinity and its Self-representation in the Classical Tradition, London/New York, 83-99.

Hinterwimmer, S. \& Bosch, P., (2016), 'Demonstrative Pronouns and Perspective', in P. Grosz \& P. Patel-Grosz (eds.), The Impact of Pronominal Form on Interpretation, Berlin/New York, 189-220.

Hofmann, T.R., (1989), 'Paragraphs \& Anaphora', Journal of Pragmatics 13, 239-250. Jebb, R.C., ( ${ }^{3} 1907$ [1868]), Sophocles, Ajax, Cambridge.

Jebb, R.C., ( ${ }^{3} 1900$ [1885]), Sophocles, Oedipus Coloneus, Cambridge.

Jong, I.J.F. de, (1997), 'Гáp Introducing Embedded Narratives', in A. Rijksbaron(ed.), New Approaches to Greek Particles, Amsterdam, 175-186.

König, E. \& Siemund, P., (2000), 'Locally Free Self-forms, Logophoricity, and Intensification in English', English Language and Linguistics 4, 183-204.

Kovacs, D., (1995), Euripides, vol. 2, Cambridge, Mass./London.

Kovacs, D., (1998), Euripides, vol. 3, Cambridge, Mass./London.

Kroon, C., (2007), 'Anaphoric Reference in Latin Epic. Discourse functions of Referential Choices in Ovid's Metamorphoses', paper given at the XIV Colloquium on Latin Linguistics, Erfurt.

Lakoff, R., (1974), 'Remarks on This and That', Chicago Linguistic Society 10, 345-356.

Lloyd-Jones, H. \& Wilson, N.G., (1990), Sophoclis fabulae, Oxford.

Meineck, P.W., (2006), 'Ancient Drama Illuminated by Contemporary Stagecraft: some Thoughts on the Use of Masks and Ekkyklèma in Ariane Mnouchkine's Le Dernier Caravansérail and Sophocles' Ajax', American Journal of Philology 127, 453-46o.

Nagy, G., (1990), Pindar's Homer: The Lyric Possession of an Epic Past, Baltimore.

Page, D.L., (1972), Aeschyli septem quae supersunt tragoediae, Oxford.

Pearson, A.C., (1910), The Agamemnon of Aeschylus, translated by W. Headlam. Cambridge. 


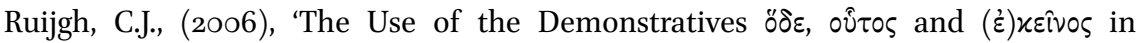
Sophocles', in I.J.F. de Jong \& A. Rijksbaron (eds.), Sophocles and the Greek Language: Aspects of Diction, Syntax and Pragmatics, Leiden/Boston, 151-162.

Schein, S.L., (1982), 'The Cassandra Scene in Aeschylus' Agamemnon', Greece \& Rome $29,11-16$.

Sommerstein, A.H., (2008), Aeschylus, vol. 2, Cambridge Mass./London.

Taillardat, J., (1987), 'A propos de grec av่ ós: ipséité, identité, anaphore', Lalies 5, 75-86.

Wagnon, A., (1880), Le pronom d'identité et la formule du réfléchi dans Homère, dans les poètes tragiques et chez les Doriens, Geneva.

West, M.L., (1990), Aeschyli Tragoediae, Stuttgart. 


\title{
Pointing to Common Ground in Dramatic Dialogue: The Case of $\delta \dot{\eta}$ and $\tau 0 เ$
}

\author{
RutgerJ. Allan
}

$1 \quad$ Introduction

Every word we speak, every speech act we perform, is only intelligible to our interlocutor against the backdrop of a body of shared knowledge and beliefs. When we are engaged in a conversation, we assume that our interlocutor knows such things as the vocabulary and rules of the language in which we hold the conversation. We naturally assume that our conversation partner is talking about the same topic, and has not forgotten the preceding part of the conversation. We take a certain amount of general world knowledge for granted and we often also presuppose knowledge of our personal lives. People engaged in conversation do not only share a considerable amount of information, but they are also mutually aware that they share this information. This presumed background information, often left implicit, but no less vital to successful communication, is usually referred to as common ground.

Common ground as a theoretical concept has been developed in the field of language philosophy in the 1970s by philosophers such as Robert Stalnaker, who defines common ground as follows:

[1] Stalnaker (2002: 701)

To presuppose something is to take it for granted, or at least to act as if one takes it for granted, as background information - as common ground among the participants in the conversation.

The psycholinguist Herbert Clark, a prominent figure in the study of common ground in conversation, describes common ground in a similar way as: '[...] the sum of [two people's] mutual, common, or joint knowledge, beliefs, and suppositions' (Clark 1996: 93). Fundamental to Clark's view on communication is that communication is a form of joint action:

[2] Clark (1996: 92)

Everything we do is rooted in information we have about our surroundings, activities, perceptions, emotions, plans, interests. Everything we do 
jointly with others is also rooted in this information, but only in that part we think they share with us. The notion needed here is common ground. [...] When my son and I enter a conversation, we presuppose certain common ground, and with each joint action-each utterance, for example - we try to add to it. To do that, we need to keep track of our common ground as it accumulates increment by increment.

Common ground typically plays a dual role in communication. First, speakers will normally tailor their utterances in order to bring them in alignment with the common ground; that is, to relate them to what they presume their interlocutors know or believe. The most obvious way to adapt your utterance to the common ground is by simply leaving out information you suppose your interlocutor already possesses. However, also many choices regarding vocabulary and grammatical constructions are dependent on the common ground. For example, speakers will use a definite article if they presume that the entity at issue will already be known and identifiable to the addressee.

In a similar way, common ground management is relevant to Greek word order. It is by now commonly accepted that the crucial factor determining the position of a constituent in a Greek clause is its information status: does the constituent at issue refer to given information (i.e. is it a Topic) or does it provide new or otherwise salient information (i.e. is it Focus)? The distinction between topicality and focality, which is at the heart of the grammar of Greek word order, can readily be described in terms of common ground management. Topical referents are referents that are already (presumed to be) part of the common ground, while focal information is not yet part of the common ground but is mentioned in order to add information to the common ground. This brings us to the second aspect of common ground.

The second key aspect of common ground in communication relates to the fact that the common ground is not a static entity: it changes in the course of the conversation through a process referred to as grounding (Clark and Brennan 1991). During a conversation, common ground is being negotiated by the interlocutors. Utterances can be seen as proposals to add to the common ground, or to correct an element in the common ground. By accepting the proposal-sometimes implicitly - the interlocutor effects an update of the common ground. The updated common ground then serves as a basis for further communication.

In order to add to their common ground, interlocutors will have to engage in a process of aligning their, possibly different, perspectives on the world. In Arie Verhagen's cognitive linguistic approach to common ground negotiation, speakers are seen as subjects of conceptualisation co-operating in order to co- 
ordinate their perspectives with respect to some object of conceptualisation to which their joint attention is directed, a process called intersubjective coordination by Verhagen:

\section{[3] Verhagen (2005: 7)}

[The] subjects of conceptualization engage in cognitive coordination by means of the utterance, with respect to some object of coordination. [...] The point of a linguistic utterance, in broad terms, is that the first conceptualizer invites the second to jointly attend to an object of conceptualization in some specific way, and to update the common ground by doing so.

According to Verhagen, the interlocutors' cognitive coordination is a crucial function of many linguistic (lexical as well as grammatical) phenomena:

\section{[4] Verhagen (2005: 4)}

For a range of linguistic phenomena which are arguably quite basic (negation and negation-related constructions, complementation, discourse connectives) it can be demonstrated that connecting, differentiating, and 'tailoring' the contents of points of view with respect to each other (rather than organizing a connection to the world) is essential for understanding their semantics and, perhaps surprisingly, their syntax. ${ }^{1}$

A cognitively-oriented approach to discourse, very similar to Verhagen's, is that of Ronald Langacker, who defines the common ground-which he refers to as Current Discourse Space-as: 'the mental space comprising those elements and relations construed as being shared by the speaker and hearer as a basis for communication at a given moment in the flow of discourse' (Langacker 2001: 144). In Langacker's insightful model, the Current Discourse Space, i.e. common ground, is structured as represented by Figure 1.

Langacker distinguishes a number of elements that, together, constitute the Current Discourse Space, i.e. common ground. Central to the common ground are the speaker $(\mathrm{S})$ and the hearer $(\mathrm{H})$ as the subjects of conceptualisation, and the time and space of the speech event. ${ }^{2}$

1 A helpful introduction to the cognitive linguistics approach to joint cognition and common ground is Verhagen (2015).

2 Langacker calls the ensemble of speaker, hearer, time and space of the speech event the 


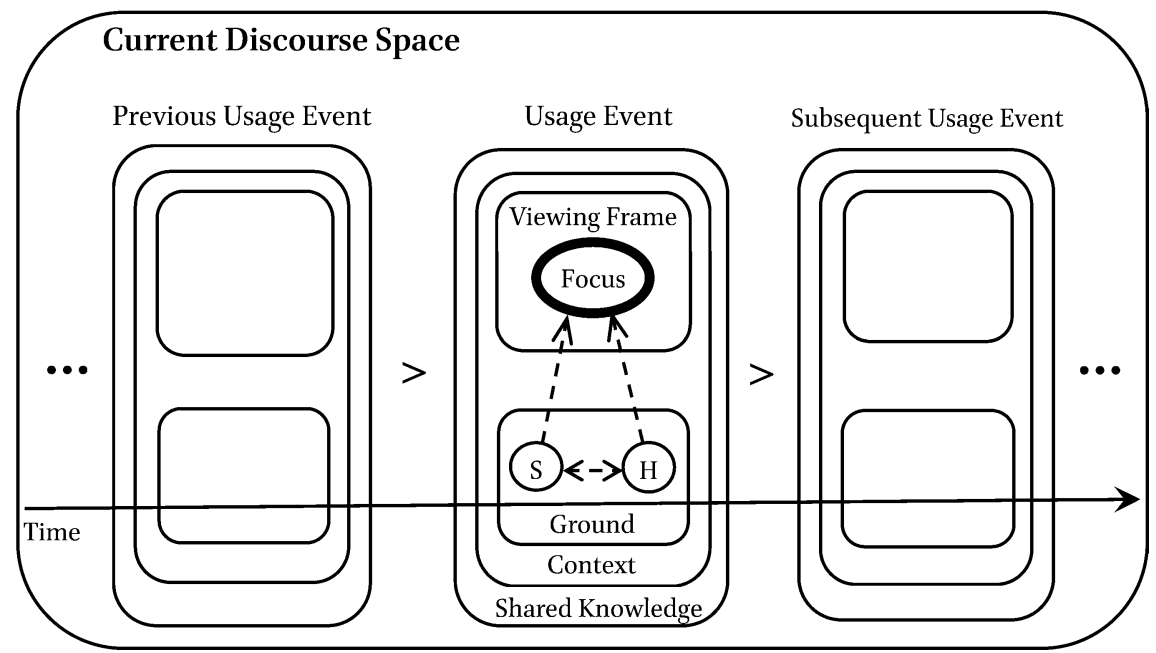

FIGURE 1 Common ground/Current Discourse Space in Cognitive Grammar Usage Event $=$ utterance, actual instance of language use (typically a clause) LANGACKER 2001: 145

The second element of the common ground is the speaker's and hearer's joint attention (indicated in Figure 1 by the dashed arrows) directed at some real or imagined entity or situation, i.e. the object of conceptualisation. This entity or situation is in the focus of their attention. ${ }^{3}$ This focused entity is located within a viewing frame, a window (or, to use a theatre metaphor, an 'on stage' region) through which we are viewing the world. The speech act participants are also mutually aware of one another's knowledge and perspectives (see the double-headed dashed arrow between S and H in Figure 1). The third element of the common ground is the immediate context of the speech event: the various physical, mental, social, and cultural circumstances of the conversation. The fourth element is the body of knowledge shared by the interlocutors. Shared knowledge can have roughly two sources: it is either general knowledge, which is often based on a shared community, or culture. Shared cultural knowledge includes knowledge of social practices, cultural norms, ste-

Ground. In Langacker's terminology, in other words, the Ground is only a part of the common ground, i.e., in his terms, Current Discourse Space.

3 It should be noted that the term focus, as it is used here, is not equal to the informationstructural notion of Focus, i.e. new information. In this context, it is used in a broader sense, as the conceptual content referred to by an utterance, typically a clause or an intonation unit, which is fully active in the consciousness (that is, in the focus of attention) of the interlocutors at some point in time. 
reotypes, topoi, genre conventions, etc. Shared knowledge can also be based on shared personal experiences. The fifth element relates to the discourse context of the utterance. A speaker can presuppose that the information conveyed by their previous utterances is known to the addressee, and the speaker may also presume that the addressee entertains specific expectations about how the conversation will further develop.

Elements of the Current Discourse Space/Common Ground:

(1) Speaker $(\mathrm{S})$, Hearer $(\mathrm{H})$, speech time and space (Ground)

(2) Joint directing of attention on a focal entity (Focus)

(3) Context of speech: immediate perceivable physical, mental, social, and cultural circumstances (+ simple inferences based on them)

(4) Shared knowledge:

- general world knowledge, typically based on shared culture (social/ religious practices, cultural norms and values, stereotypes, topoi, genre conventions etc.)

- shared personal experience

(+ simple inferences based on shared knowledge)

(5) Discourse context: shared knowledge of preceding discourse, shared expectations about subsequent discourse (+ simple inferences based on discourse context)

Let us now move away from the theory and turn to particles. What I would like to show is that the notion of common ground can also be helpful in understanding what the function of Greek particles in discourse is. More specifically, what I will argue is that particles play an important role in what you might call common ground management. Particles can be seen as instructions from the speaker to the addressee on how to cognitively anchor the utterance at issue to the common ground. ${ }^{4}$ As an illustration of this aspect of particle meaning, I will examine two particles more closely, namely $\delta \dot{\eta}$ and $\tau 0$, particles that are usually classified as modal or interactional particles but whose precise meaning is not easy to pinpoint. ${ }^{5}$ What I would like to show is that it is helpful to analyse

4 In Allan and van Gils (2015) and Allan (2017a), I argued that Greek adversative particles such as $\dot{\alpha} \lambda \dot{\alpha}, x \alpha i \tau o l, \mu \varepsilon \dot{v} \tau \circ$, and $\mu \eta^{\prime} \nu$ can also be insightfully analysed as devices used to anchor their host utterance in the common ground. There is also an increasing number of studies approaching particles in modern languages in terms of common ground management, e.g. Karagjosova (2003), Verhagen (2005), Fetzer and Fischer (2007), Simon-Vandenbergen and Aijmer (2007).

5 For this classification, see e.g. Wakker (1997: 211), van Emde Boas et al. (2018: 686-688). 
$\delta \dot{\eta}$ and $\tau o \mathrm{l}$ as grounding devices, that is, as a signal from speaker to addressee specifying the relationship between the utterance and the common ground. More specifically, I will argue that $\delta \dot{\eta}$ and $\tau 0 \mathrm{l}$ are used to communicate that the proposition or the speech act is supposed to be cognitively accessible to the addressee as part of the common ground, or otherwise easily inferrable on the basis of the common ground.

A convenient starting point for our discussion is the particle $\delta \dot{\eta}$, since it is probably the particle that relates to the common ground in the most direct and obvious way. There has been, and still is, considerable discussion on the exact function of $\delta \dot{\eta}$. Since space prevents me from rehearsing the extensive scholarly discussion on the particle, I will here only present the two most prominent approaches to the particle. ${ }^{6}$

One approach stresses the particle's function as a marker of evidentiality, that is, the particle as a marker of information that is visible, evident, or otherwise known to the addressee. An influential proponent of this view is Kühner's and Gerth's grammar:

[5] Kühner and Gerth (1898: II 123)

[...] aus dieser [temporalen Bedeutung, RJA] entwickelte sich die bildliche, in der es auf bereits (iam) Bekanntes, Offenbares, Augenscheinliches hinweist, so dass es sich oft durch gewiss, offenbar erklären lässt.

More recently, this view has also been advocated by Sicking and van Ophuijsen, who characterise the particle's function as:

[6] Sicking and van Ophuijsen (1993: 52, 141)

[I]t is possible to describe $\delta \dot{\eta}$ as a primarily 'evidential' sentence particle which presents a statement as immediately evident to the senses or the understanding or as common knowledge. It thus implies that the speaker and hearer are in the same position with respect to this statement.

6 For a very helpful overview of the discussion, see now the Online Repository of Particle Studies (Volume 5 of Bonifazi et al. 2016). 
[...] the basic value of the particle relates to what is visible to the mind's eye as well as to the organ of sight $[\ldots]$

Sicking and van Ophuijsen's characterisation of $\delta \dot{\eta}$ as a marker of what is evident and common knowledge, of course, comes very close to viewing the particle as a marker of common ground. ${ }^{7}$

Beside the 'evidential' view on $\delta \dot{\eta}$, there is an approach to $\delta \dot{\eta}$ which states that the particle serves to draw attention to the proposition in which it occurs and to point out to the addressee that it is of special importance. This is the approach proposed by linguists such as Ruijgh and Wakker who describe the particle's function respectively as:

$$
\text { [7a] Ruijgh (1971: 646-647) }
$$

En effet, $\delta \dot{\eta}$ semble souligner l'importance du fait nouveau qui est le contenu de la phrase. En exagérant beaucoup, on pourrait rendre ớ par 'voici un fait important'.

\section{[7b] Wakker (1994: 351)}

an attitudinal particle which demands the addressee's special attention for the (important and interesting) proposition presented by the speaker.

How to overcome this deadlock of opposing views? My answer would not be to accept one in favour of the other, but to acknowledge that both approaches capture important aspects of the particle's meaning. In other words, it is more attractive to come to a synthesis between the two approaches, recognising that $\delta$ ' combines two functions: it is both a common ground marker (its 'evidential' function) and an attention-focuser. ${ }^{8}$ A characterisation of $\delta$ '’ function along these lines would run as follows:

7 The new Cambridge Grammar of Classical Greek (CGCG), which has an excellent chapter on particles, also seems to side with the 'evidential' view (van Emde Boas et al. 2018: 686688). The term 'evidential', in the sense of 'marking what is evident', is somewhat unfortunate because it is potentially confusing: the term is more often used in a different sense, namely referring to the grammatical system found in many languages which indicates the source of knowledge.

8 In their monumental study of Greek particles, Bonifazi et al. (2016) also acknowledge these two central, i.e. 'intensifying' and 'evidential', functions of $\delta \dot{\eta}$. However, they do not seem to 
[8] The particle $\delta \dot{\eta}$ focuses the joint attention on an entity (i.e. a person, object, property, proposition, or speech act) which is (construed as being) part of the common ground. ${ }^{9}$

The fact that $\delta \dot{\eta}$ may focus on the attention on different types of entities, e.g. properties, persons, objects, states of affairs, propositions, and even speech acts, has consequences for the syntactical scope of $\delta \eta \dot{\eta}$ : the particle may scope over adjectives, (pro)nouns, verbs, and whole clauses. According to Wackernagel's Law, $\delta \dot{\eta}$ is normally placed in the second position in the syntactic unit it has scope over, i.e. a word, phrase, or clause. ${ }^{10}$

To fully understand the use of $\delta \dot{\eta}$, it is not sufficient to solely consider its inherent semantic features, but it is also important to take a number of itscontextually evoked - pragmatic features into account. More specifically, $\delta \eta^{\prime} s$ attention-focusing property tend to be associated with a number of additional pragmatic side-effects (implicatures).

A natural side-effect of the attention-focusing function of $\delta \eta \dot{~ i s ~ t h a t ~ t h e ~}$ speaker wishes to point out to the addressee that an entity is noteworthy for some reason. Depending on the context, this sense of noteworthiness may be accompanied by more specific mental attitudes or emotions such as contempt, indignation, irony, sarcasm, or scepticism. ${ }^{11}$ Another occasional side-effect of the focusing function of $\delta \dot{\eta}$ is exclusivity. In some contexts, $\delta \dot{\eta}$ emphasises that a proposition is true only for the entity in its scope, in contrast to a set or scale of (implicit) potential alternatives. ${ }^{12}$

assume that these two functions operate simultaneously. Kees Thijs is preparing a doctoral disseration on $\delta \dot{\eta}$ (and other particles) in which $\delta \dot{\eta}$ is also analyzed in terms of Common Ground and focus of attention.

9 The combination of focaliser and common ground marker should not come as a surprise. Cross-linguistically, discourse markers and adverbs, e.g. English indeed, often combine functions such as common ground marking, expectation marking, emphasis, and focalisation (see e.g. Simon-Vandenbergen and Aijmer 2007).

10 Occasionally, however, $\delta \dot{\eta}$ may also be separated from the item in its scope by one or more words or it may be placed before the item in its scope (Denniston $\left.{ }^{2} 1954: 228-229\right)$. For its scope, see also Bonifazi et al. (2016: IV.4 §100).

11 Irony may also be a side-effect of the common-ground-marking function of $\delta \dot{\eta}$ : crosslinguistically, irony is frequently associated with common ground markers, cf. English no doubt (Simon-Vandenbergen and Aijmer 2007). For the use of $\delta \dot{\eta}$ with an ironic undertone, see also Bonifazi et al. (2016: IV.4.5.5, 4.6.4).

12 As a marker of exclusivity (or restrictiveness), $\delta \dot{\eta}$ shows some similarity to more typical focus (or scope) particles such as $\gamma \varepsilon,-\pi \varepsilon \rho$ and $\chi \alpha$ i 'also, even'. 


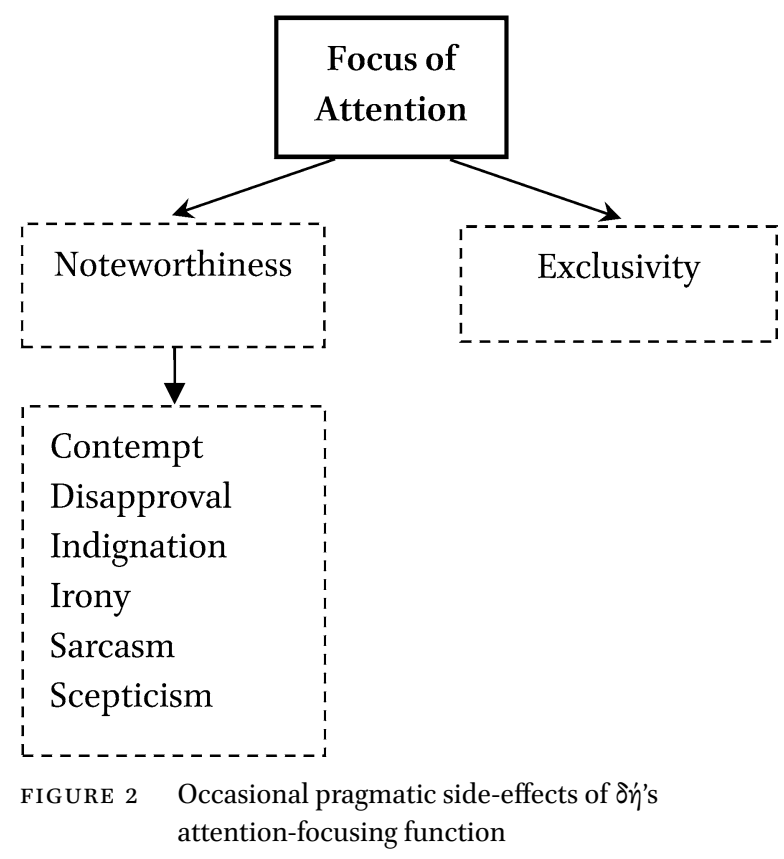

3 $\delta \eta \dot{~ i n ~ D r a m a ~}$

The dual function of $\delta \dot{\eta}$ as an attention-focusing device and a common ground marker can also be observed in its use in drama. ${ }^{13} \delta \dot{\eta}$ seems to be capable of invoking all possible components of the common ground, such as (i) the immediate physical context, (ii) shared personal and communal knowledge (and inferences based thereon), and (iii) shared knowledge of, and expectations about, the discourse. In other words, $\delta \dot{\eta}$ may mark out an entity that is supposed to be perceptually or cognitively accessible to the addressee, e.g. 'as you can see/hear', 'as you know', 'as expected', 'evidently', 'obviously', 'clearly', 'of course', 'indeed'.

\subsection{Immediate Context: Focus on a Visible Entity or State of Affairs}

The first category concerns cases in which $\delta \eta^{\prime}$ is used to direct the addressee's attention to a person or an event in the immediate physical context of the speaker and addressee. In the following example, $\delta \dot{\eta}$ is used 'marking the

13 The corpus examined consists of Aeschylus' Agamemnon and Persae, Sophocles' Ajax and Antigone, and Euripides' Bacchae and Medea (96 instances of $\delta \dot{\eta}$ in total). I will, at times, also cite examples from other plays in case a particular type of particle use did not occur in the corpus of these six plays. 
appearance of a new character on stage' (Denniston $\left.{ }^{2} 1954: 103\right)$ : the chorus interrupt their song to announce the arrival of Creon on the scene.

[9] Sophocles Antigone ${ }^{155^{-1}} 5^{8}$

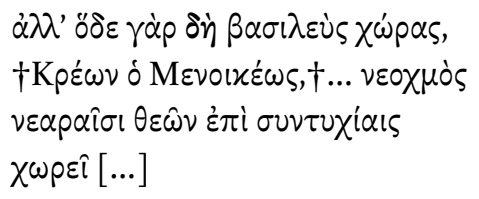

But here comes the new king of the land, ... Creon, under the new conditions given by the gods $[\ldots]^{14}$

The function of $\delta \eta^{\prime}$ in [9] is related to the function of the combination $x \alpha i \delta \dot{y}$ as a marker of entries. According to van Erp Taalman Kip, xai $\delta \dot{\eta}$ 'is used to mark an entry that has been prepared for by the words that precede it. ${ }^{15}$ The use of $x \alpha \mathrm{i}$ $\delta$ ' can be contrasted with the use of xai $\mu$ ' $\nu$ which 'marks an entry that is not prepared for by the words that immediately precede it [...]' (van Erp Taalman Kip 2009:128). $\delta \eta$ in the context of entries seems to evoke two different aspects of common ground: not only does it draw the attention to a person that is visible in the direct physical context (note the presence of the deictic pronoun ö $\delta \varepsilon$ in [9]), it also points out to the addressee that the entry is somehow expected on the basis of (or prepared for by) the preceding discourse. In [9], the chorus of elders already expect Creon's arrival since he has summoned the elders in order to address them. The function of $\alpha \lambda \lambda$, incidentally, can also be described in terms of common ground management. What we have here is $\alpha \lambda \lambda \dot{\alpha}$ in its function as a marker of discourse boundaries: it signals that the speaker interrupts the expected flow of discourse and shifts the interlocutors' joint focus of attention to another discourse topic. ${ }^{16}$

[10] Sophocles Antigone 441-442

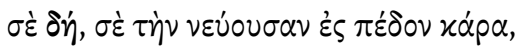

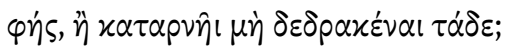

14 The Greek texts are taken from the ост editions of Aeschylus (Page 1972), Sophocles (Lloyd-Jones and Wilson 1990) and Euripides (Diggle 1981-1994). The translations are taken, sometimes with minor adaptations, from the editions of Fraenkel (1950) (Aesch. Ag.), Lloyd-Jones (1994-1996) (Sophocles) and Kovacs (1994-2003) (Euripides), unless otherwise indicated.

15 E.g. Soph. Aj. 544, Eur. Med. 1118.

16 For this function of $\delta \dot{\eta}$ in drama, see Drummen (2009: 151-152), Allan (2017a: 287). 
You there, you that are bowing down your head towards the ground, do you admit, or do you deny, that you have done this?

Creon is calling Antigone's attention in a rather harsh way by means of an accusative (suggesting an ellipse of a verb like $x \alpha \lambda \hat{\omega}$ ). The use of $\delta \dot{\eta}$ can again be interpreted in terms of its two functional aspects: it focuses the attention on Antigone ('you there!'), who is as the addressee by definition part of the common ground. As often, $\delta \dot{\eta}$ in combination with a personal pronoun conveys an additional sense of the speaker's contempt for the addressee. ${ }^{17}$

[11] Sophocles Antigone 937-939

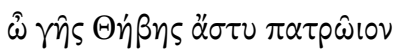

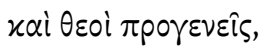

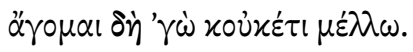

O city of my fathers, land of Thebes, and you gods, our ancestors! I am led away now; there is no more delay!

In a final emotional appeal to the Thebans, Antigone draws attention to the outrageous fact, visible to the Thebans, that she is being led away. $\delta \dot{\eta}$ seems to convey an additional sense of indignation. ${ }^{18}$

\subsection{Shared Communal Knowledge: Common Knowledge, Gnomic Knowledge}

With $\delta \dot{\eta}$, a speaker may also invoke general knowledge that is shared among members of a particular community. For example,

[12] Sophocles Antigone 162-163

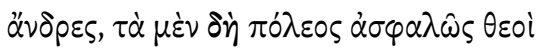

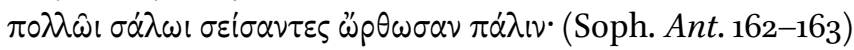

17 More examples in Denniston ( $\left.{ }^{2} 1954: 208\right)$.

18 Other examples of $\delta \dot{\eta}$ drawing attention to observable entities or events in the immediate context are: A. Pers. 1071 (sounds of wailing), A. Ag. 887 (dried up eyes), Soph. Aj. 877 (Ajax

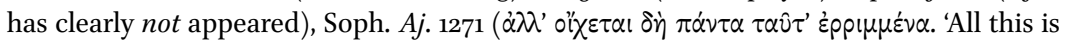
clearly cast and gone!' [indignant tone also present?]). 
Sirs, the gods have shaken the city's fortunes with a heavy shaking, but now they have set them right in safety.

As a strategical starting-point of his maiden speech as a ruler of Thebes, in which he is to proclaim a number of rather controversial issues, Creon refers to what is undoubtedly the most salient element in the common ground between him and the elders: their shared experience of the recent civil war ('Sirs, we all know the gods have shaken ...').

$\delta$ ' also occurs in gnomic expressions, emphatically pointing out that the content of the utterance is supposed to be well-known to the addressee. In [13], ràp $\delta$ ' ('for, after all') stresses that it is an obvious fact that hope brings profit as well as deceptions:

[13] Sophocles Antigone 613-617

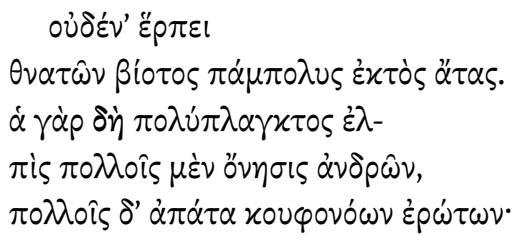

To none among mortals shall great wealth come without disaster. For, after all, widely wandering hope brings profit to many men, but to many the deception of thoughtless longings.

In the following example, in Euripides' Bacchae, $\delta \dot{y}$ once again marks out a fact that is common knowledge: we all know what kind of schemes the gods are inclined to devise.

[14] Euripides Bacchae 29o-291

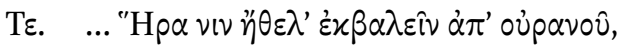

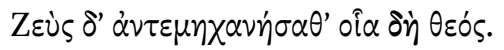

Ti. Hera wanted to hurl him it out of heaven. But Zeus in return devised a scheme such as a god indeed devises. ${ }^{19}$

19 The translation is from Seaford (2001). 
However, as is often the case when $\delta \eta$ is used in a relative clause, additional pragmatic effects come into play. ${ }^{20}$ In this case, $\delta \dot{\eta}$ might have a disapproving, or even sarcastic, undertone vis-à-vis the notorious wiliness of the gods. Another pragmatic effect which is also frequently found with $\delta \dot{\eta}$ in relative clauses is that $\delta \dot{\eta}$ marks exclusivity, contrasting the referent with possible alternatives: 'precisely such a scheme as a god devises' ('a scheme typical of a god'). A comparable effect can be observed in the following example:

[15] Sophocles Ajax 1045

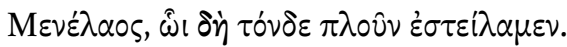

Menelaos, for whom we launched this expedition.

Again, the speaker, namely the chorus of Salaminian sailors, who are friends of Ajax, refer to the well-known fact that the Trojan expedition was launched for the sake of Menelaos. Again, one may also sense an additional notion of exclusivity ('precisely for whom', 'for whom alone', 'the very man for whom'), accompanied by a sense of contempt.

\subsection{Shared Knowledge of Preceding Discourse and Shared Expectations about Subsequent Discourse}

$\delta$ may also refer to common ground which is based on the discourse in which the speaker and addressee are currently engaged. For example, in [16], Antigone and Ismene are coming to the end of their heated discussion whether or not they should bury Polyneices:

[16] Sophocles Antigone 78-81

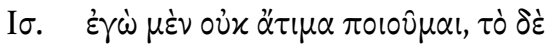

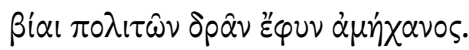

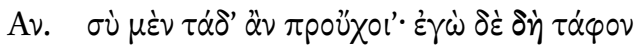

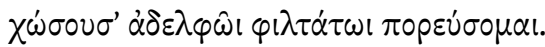

Is. I am not dishonouring them, but I do not have it in me to act against the will of the people of the city.

$20 \quad$ See also Denniston $\left({ }^{2} 1954: 218-220\right)$. For the meaning of oi $\alpha$ in this line, see Rijksbaron (1991: ad loc.). 
An. You may offer that excuse; but I go to heap up a tomb for my dearest brother!

To put an end to their discussion, Antigone emphatically repeats her firm intention to bury their brother, thus hammering home to Ismene, once and for all, that she will bury Polyneices ('As should be clear to you by now, I will go to bury my brother').

The particle is also used in reference to words that have been spoken at an earlier stage of the conversation and are, therefore, presumed to be familiar to the addressee. ${ }^{21}$

[17] Aeschylus Agamemnon 539, $55^{\circ}$

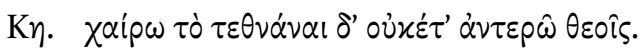

$[\ldots]$

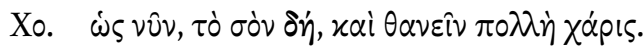

Her. Joy I have; and I no longer object to being dead.

$[\ldots]$

Ch. [I had to fear] So much that now, in your own words, even death is a great joy.

In [17], $\delta \eta \dot{~ i s ~ u s e d ~ b y ~ t h e ~ c h o r u s ~ t o ~ r e m i n d ~ t h e ~ H e r a l d ~ o f ~ h i s ~ o w n ~ w o r d s, ~ s p o k e n ~}$ a dozen lines earlier (539).

A very frequent discourse-oriented use of $\delta \eta \dot{~ r e l a t e s ~ t o ~ i t s ~ o c c u r r e n c e ~ i n ~ c o m-~}$ mands and questions. In such contexts, too, $\delta \dot{\eta}$ shows its dual function as an attention-getter and a common ground marker.

[18] Sophocles Antigone 531-535

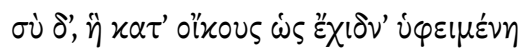

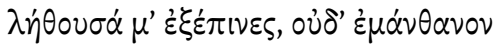

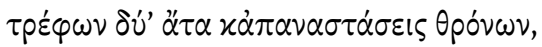

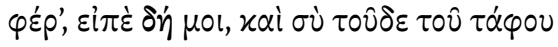

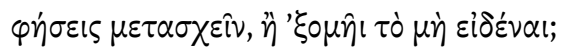

21 For $\delta \eta^{\prime}$ 's quoting function, see also Denniston ( ${ }^{2}$ 1954: 235), Sicking and van Ophuijsen (1993: 142) and Bonifazi et al. (2016: III.2 § 76). 
You, whom I never noticed as like a viper hiding in the house you sucked my blood - nor did I know that I was rearing up two plagues and two subverters of the throne-come, tell me, do you admit being a party to this burial, or will you swear that you know nothing?

$\delta \dot{n}$ combined with an imperative shows two functions: (1) it reinforces the imperative by urging the addressee to pay attention to it, and (2) it construes the command as a part of the common ground. More specifically, it presents the discourse act to the addressee as expected and understandable, and as a logical consequence prepared by the preceding discourse ('then', 'therefore'). ${ }^{22}$ Thus $\delta \dot{\eta}$ often implies that the addressee is supposed to comply with the order without any hesitation.

In [18], Creon expresses his suspicion against Ismene. He presents his request to Ismene - to tell him whether or not she has been an accomplice-as a discourse act following logically from the preceding discourse ('tell me, therefore, ...').

In questions, as well, $\delta \dot{\eta}$ invokes the common ground: its function might be compared to its function in directives, expressing that the speech act at issue, be it a command or a question, should be seen as an expected continuation of the preceding discourse. ${ }^{23}$

[19] Euripides Bacchae 821-822

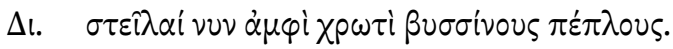

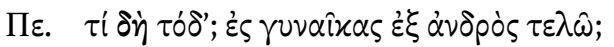

Di. Then dress yourself in a long linen robe.

Pe. Why that? Shall I become a woman instead of a man?

22 See also Kühner and Gerth (1898: II 127), Denniston (21954: 216).

23 See also Bonifazi et al. (2016: III.2 $\$ 78)$. In commands and questions, $\delta \dot{\eta}$ functions, in terms of the layered model of Functional Discourse Grammar (Hengeveld and Mackenzie 2008), on a different linguistic layer from the uses mentioned earlier. While, in the uses mentioned earlier, the particle functions as an operator on the level of the Communicated Content (as it marks that the Communicated Content or some part of it is known information), in commands and questions the particle can be analysed as an operator on the level of the Discourse Act: it reinforces the illocution and signals that the speech act is an expected consequence of the previous discourse. In the FDG model, both the layer of the Communicated Content and the layer of the Discourse Act are part of the Interpersonal Level. It is incorrect to interpret $\delta \dot{\eta}$ as only having scope over (and thus emphasising) the interrogative pronoun since the particle also occurs in yes/no-questions, with an identical function. 
Dionysus orders Pentheus to put on a linen robe. With $\delta \dot{\eta}$, Pentheus signals that his question ('Why that then?') is an understandable reaction to the order, given by Dionysus, to put on a linen robe. The use of $\delta \dot{\eta}$ in questions is often also associated with emotions such as indignation or impatience (Denniston ${ }^{2}$ 1954: 236), a contextual side-effect of its attention-getting function.

Another frequent context in which $\delta \dot{\eta}$ appears in drama is in the combination xai $\delta \dot{\eta}$. As we have seen earlier, xai $\delta$ ' can be 'used to mark an entry that has been prepared for by the words that precede it' (van Erp Taalman Kip 20og: 128). The particle combination $x \alpha i$ o $\eta^{\prime}$ is also used in other contexts, such as in responses to requests. In this context, too, we may recognise $\delta \eta^{\prime}$ 's twofold function as a common ground marker and attention-focuser.

[20] Sophocles Antigone 244-245

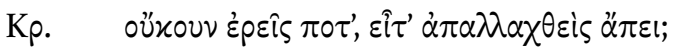

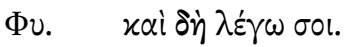

Cr. Will you not speak out, and leave after having been discharged? ${ }^{24}$ Guard I am already telling you. ${ }^{25}$

xai $\delta$, in reactions to a request, is used to express that-or at least to pretend as if - the order has already been carried out, or is in the course of being carried out: in most cases, the tense used is either a present (cf. $\lambda \dot{\varepsilon} \gamma \omega$ in 245) or a perfect indicative. ${ }^{26}$ With $x$ ai $\delta \dot{\eta}$, the speaker suggests to the person giving the order not to insist any longer, as the speaker has no intention to hesitate to comply with the order. In [20], Creon commands the guard finally to speak out as to why he has come (ov plus future indicative is often used to express an emphatic command; see Rijksbaron $\left.{ }^{3} 2006: 34\right)$. $\delta \dot{\eta}$, on the one hand, signals to the addressee to pay attention ('Look!'); on the other hand, $\delta \dot{\eta}$ suggests that the addressee should be able to observe ('as you can see') that the action ordered is already being performed (or has been performed).

There may be a further element relating to common ground management that is relevant in such contexts - that the speaker's compliance to the order should come as expected to the addressee ('of course'). That the element of expectation does indeed play a role in this use of $(x \alpha i) \delta \dot{\eta}$ may be gathered

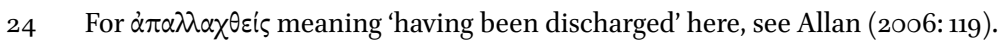

25 My translation.

26 See also Denniston ( $\left.{ }^{2} 1954: 251\right)$, Wakker (1997: 216-217). 
from the contrasting use of $x \alpha i$ $\mu$ in in reactions to orders, which expresses that the speaker somehow counters an expectation entertained by the person giving the order: speakers use $x \alpha i$ inv to indicate that their compliance ${ }^{27}$ or their non-compliance ${ }^{28}$ with the command may come as unexpected to the person ordering. In short, $x \alpha i \mu \eta^{\prime} v$ and $x \alpha i$ ó show complementary pragmatic functions: while the former signals that the speaker's reaction is somehow contrary to expectation, the latter suggests that the compliance should not come as a surprise to the addressee. ${ }^{29}$

There is still one other intriguing use of xai on worth discussing in more detail. We have seen that xai $\delta \dot{\eta}$ usually points out that some entity or event is perceivable (and often also according to expectation) to the addressee, and, thus, part of the common ground. Building on the notions of perceivability and joint attention, the combination $x \alpha i$ $\delta$ is also used to invite the addressee to vividly imagine ('before the inner eye'), for the sake of the argument or by way of thought experiment, that a particular situation has indeed (already) been realised. For example,

$$
\begin{aligned}
& \text { [21] Euripides Medea 1107-1111 }
\end{aligned}
$$

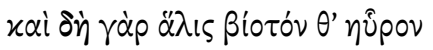

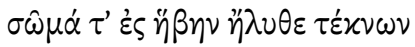

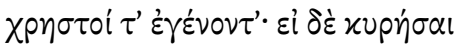

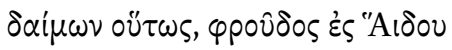

$$
\begin{aligned}
& \theta \dot{\alpha} \nu \alpha \tau 0 \varsigma \pi \rho \circ \varphi \dot{\varepsilon} \rho \omega \nu \sigma \omega^{\prime} \mu \alpha \tau \alpha \tau \varepsilon \dot{\varepsilon} \kappa \nu \omega \nu \text {. }
\end{aligned}
$$

Suppose they have found a sufficient livelihood, suppose the children's bodies have arrived at young manhood and their character is good: yet if their destiny so chances, off goes death carrying the children's bodies to Hades.

27 Denniston cites a considerable number of instances of $x \alpha i$ $\mu$ ' v 'expressing, directly or by implication, agreement or consent' (Denniston ${ }^{2}$ 1954: 353). As Wakker (1997: 216) has shown, however, $x \alpha i \mu \eta \dot{v}$ in consenting reactions does not express the consent itself, but the fact that the consent is (presumably) not expected by the addressee (the person commanding).

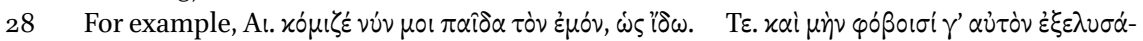
$\mu \eta \nu$. ('Ajax: Then bring me my son so that I can see him. Tecmessa: Why, I was afraid and sent him away', Soph. Aj. 530-531).

29 Note that solitary $\delta \dot{\eta}$, without $\chi \alpha$ í, can also be used in assentient reactions (Denniston 21954: 227). 
In such contexts, xai $\delta$ in introduces a presupposition ('let us assume that ...', 'suppose that ...'), functioning as common ground between the interlocutors and serving as a starting point for further reasoning. ${ }^{30}$

Let us move away from the combination xai $\delta \dot{\eta}$ and examine yet another combination in which $\delta \dot{\eta}$ tends to occur: with anaphoric pronouns and adverbs.

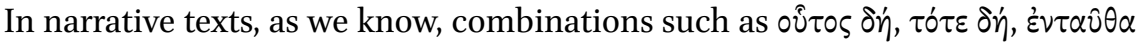
$\delta \dot{\eta}$ abound. Although in drama occurrences of this combination are few and far between, it is not difficult to recognise the double function of $\delta \dot{\eta}$. On the one hand, $\delta \dot{\eta}$ marks that the element in its scope is part of the common ground. In the case of an anaphoric pronoun, this is not very surprising since an anaphoric pronoun by definition refers to an entity which has already been mentioned, and which is therefore necessarily part of the common ground. ${ }^{31}$

On the other hand, the attention-focusing function of $\delta \dot{\eta}$ serves to single out the referent of the anaphoric pronoun while excluding potential alternative candidates. ${ }^{32}$ Thus, a combination such as $\tau \alpha \hat{\tau} \tau \alpha$ $\delta$ ' can be paraphrased by 'that alone', 'precisely that', or 'that and nothing else'.

\section{[22] Aeschylus Persians 159}

[Chorus: Queen, you were wife and are mother of a god, unless ancient fortune has abandoned our army.]

$30 \quad$ More examples can be found in Denniston $\left({ }^{2} 1954: 252\right)$.

31 I do not see the necessity to distinguish an additional function of $\delta \dot{\eta}$ as a marker of larger narrative steps (Bonifazi et al. 2016: II.3.3.1, IV.4.5.1). In my view, $\delta \eta \dot{~ i n ~ c o m b i n a t i o n s ~ s u c h ~}$ as $\dot{\alpha} \lambda \lambda^{\prime}$ ö $\tau \varepsilon \delta \dot{\eta}$ or $\delta \dot{\eta} \tau o ́ \tau \varepsilon / \tau o ́ \tau \varepsilon \delta \dot{~ c a n ~ b e ~ e x p l a i n e d ~ w e l l ~ o n ~ t h e ~ b a s i s ~ o f ~ i t s ~ f o c u s i n g ~ f u n c-~}$ tion, excluding alternative (earlier or later) moments on the time line ('once', 'as soon as',

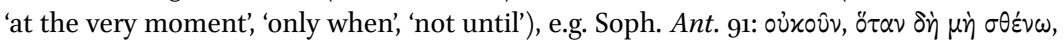
$\pi \varepsilon \pi \alpha \dot{\sigma} \sigma 0 \mu \alpha$ ' 'Then, not until my strength fails, will I be at rest' (my translation). The fact that, in narrative, there is often a discourse boundary should be ascribed to contextual elements rather than to the function of $\delta \dot{\eta}$ : e.g., the boundary marking should be ascribed to the presence of $\alpha \lambda \lambda \dot{\alpha}$, or to $\delta \eta \dot{\prime}$ 's occurrence in preposed temporal clauses, which typically mark transitions to a new narrative episode/move/paragraph (see Buijs 2005). In the same vein, frequent combinations such as $\pi$ piv $\delta \dot{\eta}$ ('until the very moment', 'until at last'), $\delta \dot{\eta} \pi \circ \tau \varepsilon$ and $\tau \dot{\tau} \tau \varepsilon \delta$ ' ('only then', 'at that very moment', 'not until then', 'then at last') can be explained well on the basis of the exclusive function of $\delta \dot{\eta}$ - it is, again, unnecessary to invoke an additional function of $\delta \dot{\eta}$ as a marker of narrative steps.

32 Depending on the context, the set of alternative referents may be ordered on an implicit scale, e.g. a temporal scale, as in the case of $\tau \dot{o} \tau \varepsilon \delta \dot{\eta}^{\prime}$ 'at that very moment', 'only then' (i.e. neither at an earlier, nor at a later moment in time). 


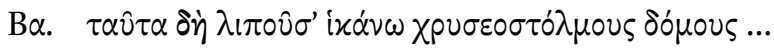

$\mathrm{Qu}$. For this very reason I have left the gold-decked palace and come here .$^{33}$

In some contexts, the combination of $\delta \dot{\eta}+$ anaphoric demonstrative seems to be associated with an indignant undertone ('that — of all things!'):

\section{[23] Sophocles Electra 385}

[Chrysothemis tells Electra that they plan to lock her up in a dungeon.]

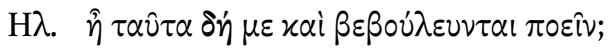

El. Is that really what they have decided to do with me?

The particle $\hat{\eta}$ in questions usually expresses a sense of unbelief ('really?').

That $\delta \eta$ is indeed also a common ground marker and not only an attentionfocusing device, as is sometimes claimed, can be concluded from the fact that $\delta \dot{y}$ only combines with anaphoric (backwards-referring) pronouns- that is, referring to entities already known from the preceding discourse-, and not with cataphoric (forwards-referring) pronouns. If $\delta \dot{\eta}$ would merely be an attention-focusing device, there would be no reason why it would not also be combined with cataphoric pronouns. However, the striking asymmetry between its distribution with anaphoric and cataphoric pronouns shows that $\delta \eta$ is indeed also a common ground marker.

The last context of use to be addressed here is $\delta \eta \eta^{\prime} s$ combination with lexical

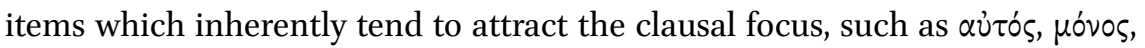
$\pi \hat{\alpha} \varsigma, \pi \circ \lambda v$ s, and superlatives. An example from drama of $\delta \dot{\eta}$ with a superlative is:

[24] Aeschylus Persians $33^{1}$

$\alpha \hat{i} \alpha \hat{\imath}, x \alpha \kappa \hat{\omega} \nu \ddot{u} \psi 1 \sigma \tau \alpha \delta \dot{\eta} x \lambda \nu \dot{\omega} \tau \tau \dot{\alpha} \delta \varepsilon$.

Aiai, what I hear is the worst disaster indeed. ${ }^{34}$ 
The fact that $\delta \eta$ is so often combined with these inherently focus-oriented words should not be surprising, given its function as an attention-focuser: $\delta \dot{\eta}$ reinforces the focality of the item in its scope. As often, the attention-focusing aspect of $\delta \dot{n}$ is also accompanied by additional senses, such as exclusivity (i.e. 'only', 'the very ...' + superlative) and noteworthiness (or, more specifically, mental attitudes such as indignation, contempt or amazement).

However, when combined with such focus-attracting items, not only $\delta \eta^{\prime} s$ focusing function is relevant, but I would argue that $\delta \dot{\eta}$ also invokes the interlocutors' common ground. For example, in [24], $\delta$ ' not only focuses the attention to $ن \psi \psi(\sigma \tau \alpha$ ('the very worst', 'absolutely the worst'), but it also used by the Queen to signal that it should be obvious to the messenger (i.e. common ground) that the catastrophic lost battle at Salamis is indeed the worst disaster she has ever experienced.

It is not easy to pinpoint what $\tau$ o exactly does in the interaction between the speaker and the addressee. There is a general consensus that its function is strongly interactive: it serves to make an urgent appeal to the addressee. In this interpretation, the particle's origin as an ethic dative of the second person pronoun ('to you', 'for you') undoubtedly plays an important role. ${ }^{35} \mathrm{~A}$ helpful characterisation of the particle's function, reflecting the common opinion, is given by Annemieke Drummen:

[25] Drummen in Bonifazi et al. (2016: III.4 §58); Drummen (2017: 258)

The particle $\tau 0$ เ $[. .$.$] works to further a speaker's persuasive ends. The$ particle's function is to signal an appeal to the addressee, who is strongly encouraged to take note of, and believe, the statement being uttered.

Drummen rightly stresses strong persuasive force of $\tau 0$ as a device to appeal to the addressee to take note and to believe the truth of the statement. ${ }^{36}$ Although this characterisation of $\tau$ o is correct, I would like to argue that it is possible to arrive at a more precise definition if one takes into account its function in com-

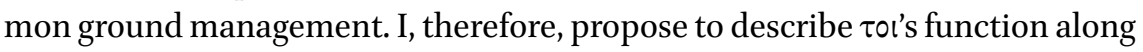
the following lines:

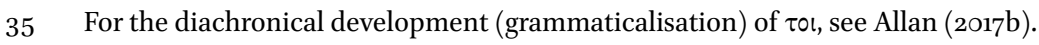

36 A similar characterisation of $\tau$ or is given by the $c G c G$ (van Emde Boas et al. 2018: 691). 
[26] The particle $\tau 0$ is used by a speaker to emphatically appeal to the addressee to pay attention to the speech act, typically serving to remind the addressees of common ground information which the addressee seems to ignore or to have forgotten.

What $\tau 0$ shares with $\delta \dot{\eta}$ is its function to point out an element in the common ground to the addressee. The main difference, however, is that $\delta \dot{\eta}$ typically refers to an element in the common ground that is already relatively active in the addressee's consciousness or, at least, (supposed to be) easily accessible to the addressee's mind or perception. $\tau 0$, on the other hand, is used to bring information to the addressee's attention that, for some reason or another, has been lying dormant in the addressee's memory, or information which the addressee might even be unwilling to recall to mind. ${ }^{37}$ In other words, $\tau 01$, unlike $\delta \dot{\eta}$, implies that the speaker confronts, or expects to confront, a certain degree of resistance on the part of the addressee to acknowledge a piece of information in the common ground.

A typical context for the use of $\tau 0$ in Greek drama is a speaker's attempt to persuade an addressee to perform a particular action; that is, to is not so much employed for the purpose of conveying information as it is part of a rhetorical strategy to bring the addressee to change his or her behaviour: it points out to the addressee that there is some sort of conflict between the addressee's present behaviour or beliefs on the one hand, and an element in the common ground on the other. ${ }^{38}$

\subsection{Shared Communal Knowledge: Common Knowledge, Gnomic Knowledge}

In drama, $\tau$ o frequently appears in gnomic statements. As general truths express shared communal knowledge, they are by definition presumed to be known to the addressee and as such part of the common ground. In gnomic expressions, $\tau$, is ised to remind the addressee of some conventional wisdom as the addressee seems to be behaving or thinking contrary to the content of the gnomic statement at issue. For example,

37 Compare also Denniston's formulation: 'Its primary function is to bring home to the comprehension of the person addressed a truth of which he is ignorant, or temporarily oblivious' (Denniston ${ }^{2}$ 1954: 537).

38 The corpus examined, again, consists of Aeschylus' Agamemnon and Persae, Sophocles' Ajax and Antigone, and Euripides' Bacchae and Medea (59 instances of $\tau 0$ in total). 
[27] Sophocles Antigone 241-243

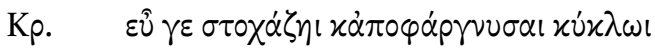

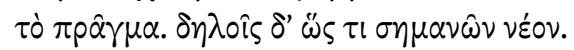

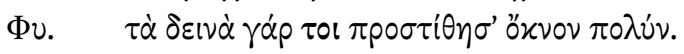

Cr. You are skilfully setting fences and palisades around the matter, and it is clear that you have some news to tell us.

Guard Yes, serious matters make one very nervous.

Creon is annoyed by the guard's circuitous approach to the matter at hand and urges him to get to the point. The guard defends himself by reminding Creon of a gnomic truth which states that terrible things normally bring about a strong hesitation.

The particle also occurs in other expressions of common knowledge:

[28] Sophocles Antigone 834-835

[Antigone: Like Niobe, I will die the saddest death.]

Xo. $\alpha \lambda \lambda \dot{\alpha} \theta \varepsilon o ́ s ~ \tau o l ~ x \alpha i ̀ ~ \theta \varepsilon o \gamma \varepsilon v v \eta ́ s$,

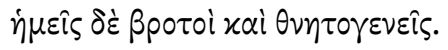

Ch. But she was a goddess and the child of gods, and we are mortal and the children of mortals.

Antigone tells the story of Niobe, who died a terrible death, while comparing herself to Niobe, since the gods also bring death upon her. The chorus reject Antigone's identification with Niobe by reminding Antigone of Niobe's divinity ('But don't forget she was a goddess and the child of gods etc.'). ${ }^{39}$

In the following instance from Aeschylus' Agamemnon, Agamemnon emphatically reminds Clytaemestra of the fact that the tokens with which she wishes to honour him are only fitting to the gods:

39 Other examples from my corpus of $\tau$ or in gnomic expressions and other statements of common communal knowledge: A. Ag. 974, 1014, 1040, 1304, Pers. 287, 706; Soph. Aj. 520, 58o, 988, 1119, 1350, Ant. 473, 522, 580, 1028. See also Denniston ( ${ }^{2} 1954: 4^{2-}$ 543). 
[29] Aeschylus Agamemnon 922

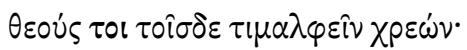

The gods we must honour in this way.

\subsection{Immediate Context}

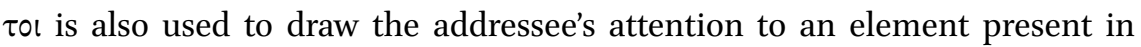
the immediate physical environment which is ignored by the addressee, even though it is (supposed to be) perceivable and obvious. An illustrative example of this use of $\tau 0$ is from a messenger speech in Euripides Bacchae.

[30] Euripides Bacchae 1118-1119

[Messenger, quoting Pentheus' words:]

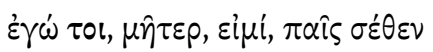

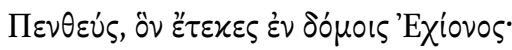

'It's me, mother, Pentheus, the son you bore in Echion's house!'

The messenger is describing the events leading to Pentheus' death, citing Pentheus' last words. Failing to recognise his true identity, Agaue hurls herself upon Pentheus, who tries to stop her by reminding her that he is, in fact, her son. Again, $\tau 0$ is used in an appeal to alert the addressee to an obvious fact which the addressee fails to acknowledge. A similar example is seen in the Ajax:

[31] Sophocles Ajax 356-36o

i⿳亠口冋

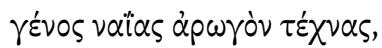

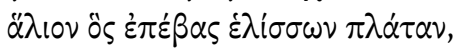

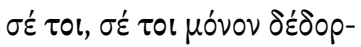

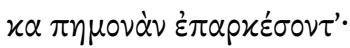

Hail, race helpful with the seaman's skill, you who came on board to ply the oar at sea, you, you are the only guardians I see who will help me!

Ajax is inside the hut in which he killed the cattle which he took for the Greek commanders. Tecmessa opens the door of the hut and Ajax is revealed sitting 
motionless among the slaughtered cattle. Ajax catches sight of his friends, the sailors from Salamis, who are with Tecmessa, and he calls upon them to help him. The sailors ignore Ajax's call for help and, instead, say to Tecmessa that Ajax is still beside himself. Ajax, then, for a second time attempts to appeal to the sailors. With the use of $\tau 0$ Ajax desperately tries to finally establish contact

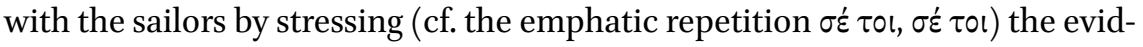
ent fact, ignored by the sailors, that they are indeed the only ones to be seen ( $\delta \varepsilon \delta \delta p x \alpha)$ in the immediate environment who are able to help him.

\subsection{Shared Knowledge of Preceding Discourse: Reminding the Addressee of What Has Been Said Earlier}

$\tau$ o can also relate to the discourse context, serving to remind the addressee of what has been said earlier. In [32], from the Ajax, the messenger asks the chorus where Ajax is. The chorus reply that Ajax is not in his hut but has just left. The messenger tells that Teucer has said that they should not allow Ajax to leave until Teucer himself would be present. In line 734, the chorus ignore the messenger's words (note the particle $\alpha \lambda \lambda \dot{\alpha}$ at the beginning of their turn, forcefully redirecting the discourse) and emphatically remind the messenger that they had already mentioned that Ajax had left.

[32] Soph. Ajax 735-736, 743-744

[Messenger: Teucer is here from Mysia. Where is Ajax?]

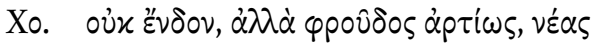

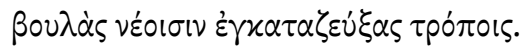

[Messenger: Teucer said that you should not allow him to go out until Teucer himself would be there.]

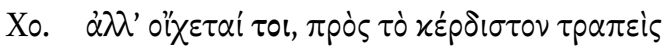

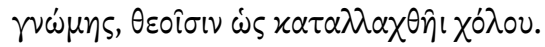

Ch. He is not in, but departed lately, with fresh counsels harnessed to a fresh mood.

$[\ldots]$

Ch. Well, as I said, he has gone. He had turned his thoughts in a more profitable direction, to be reconciled with the gods with whom he had been angry. 
A similar example is:

[33] Euripides Bacchae 489-49o, 515-517

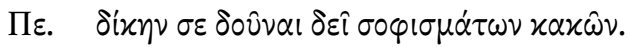

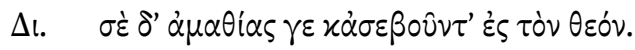

[...]

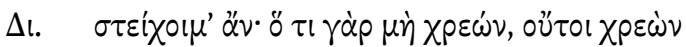

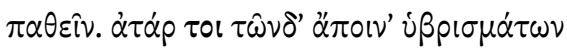

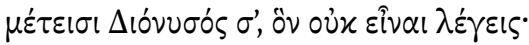

Pe. You'll pay for your knavish cleverness.

Di. And you for your obtuseness and impiety against the god.

$[\ldots]$

Di. I'm ready to go: I shall not suffer anything I am not meant to suffer. But Dionysus, you know, will punish you for this highhandedness.

Pentheus has just ordered to lock Dionysus up. Dionysus has the last word before he is led away and he reminds Pentheus one last time that he will not escape punishment for his impiety.

\section{Conclusion}

It is certainly no overstatement that Greek particle research has been flourishing over the last two decades. Thanks to a number of significant studies, we are slowly getting to grips with these 'intangible and elusive words' - as Denniston called them in his preface to the first edition of The Greek Particles. What I have tried to show here is that the notion of common ground may be a helpful addition to the existing theoretical apparatus that has been brought to bear on the Greek particles. It seems worthwhile to analyse Greek particles as grounding devices, that is, as the speaker's instructions to the addressee how to relate the utterance to the common ground. In the case of $\delta \dot{\eta}$ and $\tau 01$, for example, a common ground approach helps to distinguish the two particles more clearly from one another and from other attitudinal or interactional particles such as $\hat{\eta}$ or $\mu$ ív. An additional advantage of a common ground approach as a general framework for discourse analysis is provided by Occam's razor: common ground management is a crucial factor in many different discourse-pragmatic phenomena, including such basic linguistic phenomena as the use of negation, 
the article, deictic pronouns, conjunctions, clausal complementation, tenseaspect, modality, and word order.

\section{References}

Allan, R.J. \& Gils, L. van, (2015) 'Anchoring New Ideas in Common Ground: a Linguistic Approach', Proceedings International Conference Anchoring in Antiquity. https://ww w.ru.nl/oikos/anchoring-innovation/anchoring-scholarship/anchoring-antiquity-i nternational-conference/ (o3/o6/2019).

Allan, R.J., (2006), 'Sophocles' Voice: Active, Middle, and Passive in the Plays of Sophocles', in I.J.F. de Jong \& A. Rijksbaron (eds.), Sophocles and the Greek Language: Aspects of Diction, Syntax and Pragmatics, Leiden/Boston, 111-126.

Allan, R.J., (2017a), 'Ancient Greek Adversative Particles in Contrast', in C. Denizot \& O. Spevak (eds.), Pragmatic Approaches to Latin and Ancient Greek, Amsterdam/Philadelphia, $273^{-} 301$.

Allan, R.J., (2017b), 'The Grammaticalization of Greek Particles: a Functional Discourse Grammar Approach', in F. Logozzo \& P. Poccetti (eds.), Ancient Greek Linguistics: New Approaches, Insights, Perspectives, Berlin/Boston, 103-118.

Bonifazi, A., Drummen, A., \& Kreij, M. de, (2016), Particles in Ancient Greek Discourse: Five Volumes Exploring Particle Use across Genres, Washington, D.C. https://chs.harva rd.edu/CHS/article/display/6391.particles-in-ancient-greek-discourse (o3/o6/2019).

Buijs, M., (2005), Clause Combining in Ancient Greek Narrative Discourse. The Distribution of Subclauses and Participial Clauses in Xenophon's Hellenica and Anabasis, Leiden/Boston.

Clark, H.H. \& Brennan, S.A., (1991), 'Grounding in Communication', in L.B. Resnick, J.M. Levine, \& S.D. Teasley (eds.), Perspectives on Socially Shared Cognition, Washington, D.C., 127-149.

Clark, H.H., (1996), Using Language, Cambridge.

Denniston, J.D., (21954 [1934]), The Greek Particles, Oxford.

Diggle, J., (1981-1994), Euripidis fabulae, 3 vols., Oxford.

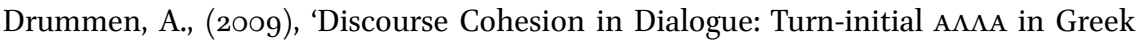
Drama', in S.J. Bakker \& G.C. Wakker (eds.), Discourse Cohesion in Ancient Greek, Leiden/Boston, 135-169.

Drummen, A., (2017), Language on Stage. Particles in Ancient Greek Drama, $\mathrm{PhD}$ thesis (University of Heidelberg). http://www.ub.uni-heidelberg.de/archiv/23002 (14/o6/ 2019).

Emde Boas, E. van, Rijksbaron, A., Huitink, L., \& Bakker, Mathieu de, (2018), The Cambridge Grammar of Classical Greek, Cambridge.

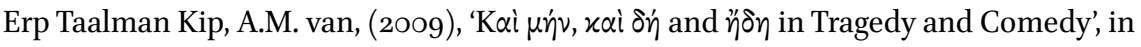


S.J. Bakker \& G.C. Wakker (eds.), Discourse Cohesion in Ancient Greek, Leiden/Boston, 111-133.

Fetzer, A. \& Fischer, K. (eds.), (2007), Lexical Markers of Common Ground, Amsterdam. Fraenkel, E., (1950), Aeschylus, Agamemnon, 3 vols., Oxford.

Hengeveld, K. \& Mackenzie, J.L., (2008), Functional Discourse Grammar. A Typologically-based Theory of Language Structure, Oxford.

Karagjosova, E., (2003), 'Modal Particles and the Common Ground: Meaning and Functions of German ja, doch, eben/halt and auch', in P. Kühnlein, H. Rieser, \& H. Zeevat (eds.), Perspectives on Dialogue in the New Millennium, Amsterdam, 335-349.

Kovacs, D., (1994-2003), Euripides, Cambridge, Mass./London.

Kühner, R. \& Gerth, B., (1898), Ausführliche Grammatik der griechischen Sprache, Zweiter Teil: Satzlehre, 2 vols., Hanover.

Langacker, R.W., (2001), 'Discourse in Cognitive Grammar', Cognitive Linguistics 12, 143188.

Lloyd-Jones, H., (1994-1996), Sophocles, Cambridge, Mass./London.

Lloyd-Jones, H. \& Wilson, N.G., (1990), Sophoclis fabulae, Oxford.

Page, D.L., (1972), Aeschyli septem quae supersunt tragoediae, Oxford.

Rijksbaron, A., (1991), Grammatical Observations on Euripides' Bacchae, Amsterdam.

Rijksbaron, A., ( ${ }^{3} 2006$ [1984]), The Syntax and Semantics of the Verb in Classical Greek. An Introduction, Chicago/London.

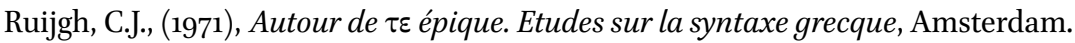

Seaford, R., (2001), Euripides, Bacchae, Warminster.

Sicking, C.M.J. \& Ophuijsen, J.M. van, (1993), Two Studies in Attic Particle Usage, Leiden/ New York/Copenhagen/Cologne.

Simon-Vandenbergen, A.-M. \& Aijmer, K., (2007), The Semantic Field of Modal Certainty: a Corpus-Based Study of English Adverbs, Berlin/New York.

Stalnaker, R.C., (2002), 'Common Ground', Linguistics and Philosophy 25, 701-721.

Verhagen, A., (2005), Constructions of Intersubjectivity:Discourse, Syntax, and Cognition, Oxford.

Verhagen, A., (2015), 'Grammar and Cooperative Communication', in E. Dąbrowska \& D. Divjak (eds.), Handbook of Cognitive Linguistics, Berlin, 232-252.

Wakker, G.C., (1994), Conditions and Conditionals: an Investigation of Ancient Greek, Amsterdam.

Wakker, G.C., (1997), 'Emphasis and Affirmation: some Aspects of $\mu$ 'v in Tragedy', in A. Rijksbaron (ed.), New Approaches to Greek Particles. Proceedings of the Colloquium held in Amsterdam, 4-6 January 1996, to Honour C.J. Ruijgh on the Occasion of his Retirement, Amsterdam. 


\title{
Terms of Address on Right Periphery in Greek Tragedy
}

\author{
Sandra Rodríguez-Piedrabuena
}

\section{1 \\ Introduction}

The purpose of this paper is to analyse whether the position of a given term of address (TAd) bears any meaning for the understanding of the utterance and the context to which it relates (Dik 2007: 253). ${ }^{1}$ The idea that the placement of TAds can be meaningful has been considered under the framework of Conversation Analysis (Sidnell 2010: 261-264). As will be seen, CA has provided many clues as to how this research on Greek drama is to be conducted. There are obvious limitations. For instance, stand-alone items are rarely found due to formal constraints, ${ }^{2}$ such as the metre (Shalev 2003: 359 n. 12). Accordingly, the focus of this paper will be on TAds at the end of a clause, i.e. on the right periphery (RP). RP-TAds are rare compared to the frequency with which TAds appear at the start of a clause (left periphery [LP]) or in the middle (M). LP-TAds (266) are, in fact, more than twice as frequent as RP-TAds (125) in the sample (see Section 2.1). The question arises as to whether there are differences concerning the distribution of RP-TAds and that of the other positions, and what implications this may have. The distribution of LP-, M- and RP-TAds from a selected sample of Greek drama will be examined in accordance with the same range of parameters.

Few studies on TAds have been conducted and research on the placement of TAds in Ancient Greek remains scarce. Bassett (1934: 140 n. 1) expresses an interest in whether the vocative appears at the start, in the middle, or at the end of a clause. No research on this issue, however, has come to fruition. Fraenkel (1965) focuses on M-TAds. The way in which he describes the position of TAds mainly relies on syntactic categories. Donati (2013: 74) only considers LP-TAds. Dickey (1996: 195) includes a section on the 'position of addresses within the

1 The following abbreviations are used in this paper: TAd = term of address, $\mathrm{LP}=$ left periphery, $\mathrm{M}=$ term of address in the middle, $\mathrm{RP}=$ right periphery, $\mathrm{IC}=$ independent clause-TAd, $\mathrm{DP}=$ doubtful position, $2 \mathrm{PP}=$ second pair part of an adjacency pair, ECC = extra-clausal constituent, FTA = Face Threatening Act.

2 See Parkinson $(1985: 37)$ and Haverkate $(1984: 69)$ on the use of TAds as stand-alone items. 
sentence' (197). By 'postpositive vocatives', she means only those vocatives that do not head a sentence, but which are immediately preceded by another word or phrase. ${ }^{3}$

I subscribe to the approach by Dik (2007:253-254), which is opposed to taking only the line and not the clause as a unit when analysing word order in Greek drama, thereby leading to the worn-out metri causa argument. I speak of left and right periphery because only free and not bound TAds are considered in this paper (following Dickey [1996: 5-6, 23], Parkinson [1985: 36], and Kleinknecht and Souza [2017: 26o]). TAds are not bound if they are extraclausal constituents ${ }^{4}$ that relate to the corresponding clause while being syntactically independent. From a formal standpoint, these TAds are prototypically in the vocative, including the usage that is traditionally known as nominativus pro vocativo. Note that vocatives can hardly be considered as cases under the framework of traditional case grammar since they perform no syntactical function within the clause nor within any noun phrase of the proposition. ${ }^{5}$ The following are examples of TAds on LP and RP:

[1] LP: Euripides Alcestis 476-477 (Heracles to the chorus)

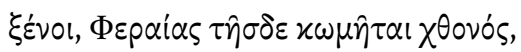

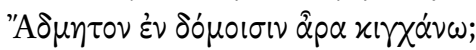

Strangers, dwellers in this land of Pherae, will I find Admetus at home? ${ }^{6}$

3 In a later work, Dickey (2010: 330-331) speaks of 'expressive addresses', but only from a semantical standpoint. Wendel (1929) is mainly a compilatory work. Scott $(1903,1904,1905)$ explains the use and omission of $\hat{\omega}$. Brioso-Sánchez (1971) questioned many of Scott's findings. Bassett (1934) focuses especially on omission. Donati (2013: 116-136) analyses $\hat{\omega}$ diachronically and considers it a case of grammaticalisation. McClure (1995:50-56) attempts to establish female speech in Euripides by considering TAds, among other features. Dickey's seminal work (1996: 20) generally leaves out tragedy. Rutherford (2012: 101-109) addresses the issue briefly but acutely. See Dickey (2002) on Latin forms of address and Brioso-Sánchez (1971: 35) for prior bibliography on the vocative. Berger (forth.) has recently devoted a study on a similar topic regarding TAds in Latin. According to this work, TAds are important elements of turn design and they function on three different levels: dialogical (turn-taking), interpersonal (stance-taking and politeness) and textual (discourse organisation).

4 ECCs as coined in Functional Grammar (Dik 1997: 379-407). See also Haverkate (1984: 67): '[...] vocatives typically fill the peripheral slots at the beginning or the end of the sentence'.

5 Haverkate (1984: 68). The matter remains controversial: see Donati (2013: 19-74, 95-96).

6 Unless stated otherwise, translations for Eur. Alc. are taken from Conacher (1988), for Eur. Andr. from Lloyd (1994), for Soph. Trach. from Jebb $\left({ }^{2} 1908\right)$. The remaining translations are my own. 
[2] RP: Euripides Andromache 234-237

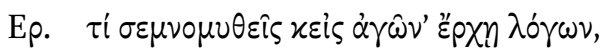

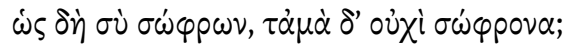

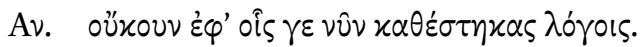

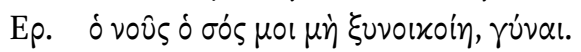

He. Why do you preach and enter into a contest of words, alleging that you are virtuous and I am not virtuous?

An. You are certainly not on the evidence of your recent words.

He. May your 'sense' never be mine, Andromache.

Combined with TAds in the middle of a clause, a further category should be added, labelled here as 'Independent-Clause-TAd' (IC-TAd). A typical example is given by what Lee (1997: 212) calls 'extended apostrophe', e.g. Eur. Ion 492506 , which generally consists of a vocative in combination with a relative clause. ${ }^{7}$ Lastly, the position of a small number of cases is hard to establish, mainly due to the various possibilities of punctuation or due to asyndeta, i.e. when no particle or postpositive makes a clear split between utterances (Dik 2007: 11). This often happens when a TAd lies between two interrogatives, since it can be difficult to decide whether the TAd should be ascribed to the previous or to the following question. The position can also be difficult to establish when subordination is loose, as in the case of certain correlatives, and whenever there is no conjunction clearly establishing the ties between clauses. ${ }^{8}$ These TAds could correspond to 'pivotal turn extensions' according to Clayman (2012), where they simultaneously complete the prior syntactic unit and initiate the subsequent unit as a resource for extending turns at talk.

Unmarked cases seem to be in LP since they often appear just as part of the mechanics of conversation, in that they are used 'to get the attention of the addressee or to single him out of a group'. ${ }^{9}$ From the standpoint of Conversation Analysis (CA), this implies establishing contact or selecting the next addressee, respectively. As will be seen, this is not the case when it comes to R P-TAds. In principle, characters who use TAds are deferential or at least considerate towards their addressee, excluding, obviously, overt insults. Bassett (1934: 142) speaks of the 'vocative of courtesy', i.e. the vocative addressed in

7 See Kannicht (1969: ad 1451-1464).

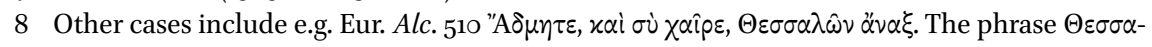
$\lambda \hat{\omega} \nu \alpha \ddot{\alpha} \alpha \xi$ seems to be an apposition to "A $\delta \mu \eta \tau \varepsilon$ rather than an independent RP-TAd.

9 Dickey (1996: 198-199); Parkinson (1985: 37). 
the first speech of one character to another, which can be omitted in further turns. Other reasons for omission include that of the addressee being greatly inferior to the speaker in status, the urgency of the situation, and the identity of the addressee remaining unknown (Bassett 1934: 144-146; Dickey 1996: 193, 247). Consequently, the omission of TAds could be felt as being rude, abrupt, or unfriendly. ${ }^{10}$ Eustathius (806.27) describes Hector as rude when compared to Nestor because the latter begins a similar call for volunteers with $\hat{\omega} \varphi$ i $\lambda$ or (Il. 20.204), whereas Hector (Il. 20.303) uses no TAd.

I have looked into whether RP-TAds fulfil conversational functions, such as contact establishment, next addressee selection, and turn allocation, and compared them with LP- and M-TAds. I have also examined which types of TAds are more frequently employed in RP, which kinds of characters utter these TAds, and in connection with which speech acts they do so. These and other parameters could eventually shed light on whether RP-TAds behave in the same way as do LP- and M-TAds.

\section{$2 \quad$ Method}

\subsection{Corpus}

I have selected the following plays for my research: Aesch. Supp.; Soph. El., Trach.; Eur. Alc., Heracl., Andr., Ion; Ar. Nub. The base texts are drawn from TLG online, although later editions and commentaries have been checked in every case. ${ }^{11}$ My preference is for the manuscript reading, unless it is impracticable.

The following sample of TAds, classified in terms of position, emerges from this corpus: LP-TAds (266), M-TAds (272), RP-TAds (125), IC-TAds (51), uncertain (51), total (765).

\subsection{Parameters}

The distribution of every TAd has been analysed in accordance with the following parameters: CA-functions (i.e. turn allocation and contact establishment),

10 Rutherford (2012: 101, 103-109, esp. 105); Dickey (1996: 193). The same applies to other languages, such as Egyptian Arabic (Parkinson 1985: 39). See also Venegas-Lagüéns (1991: 135). From a broader perspective, this could be analysed under the framework of the impoliteness strategy 'withhold politeness', consisting on 'the absence of politeness work where it would be expected' (Culpeper 1996: 357, 2016: 425).

11 The main editions and commentaries followed are: Johansen and Whittle (1980); Jebb ( $\left.{ }^{3} 1894\right)$, Finglass (2007); Jebb (21908), Davies (1991); Dale (1954), Conacher (1988), Parker (2007); Wilkins (1993); Stevens (1971), Lloyd (1994); Lee (1997), Martin (2018); Starkie (1966), Dover (1968), Wilson (2007) respectively. 
TAd types, speech act types, and non-redressive action. I consider as 'nonredressive action' every case where a TAd is uttered in the context of an FTA (Face Threatening Act) that is performed explicitly and as a direct speech act (bald-on-record FTAs).

Three more parameters deserve to be mentioned, namely distance (D factor), i.e. the degree of familiarity between participants (Brown and Levinson ${ }^{2} 1987$ : 15-16, 74-82, 249-253), text type, and TAd-variation. Distance has turned out not to be a relevant parameter. Out of 765 TAds, there are 402 examples with a negative D factor (i.e. characters are close to each other), compared to 146 where the $\mathrm{D}$ factor is positive (i.e. characters are not familiar with each other). ${ }^{12}$ This is, perhaps, due to the fact that characters in tragedy are often acquaintances or relatives. ${ }^{13}$

Similarly, TAds in any position are more common in dialogue than in long speeches (exceeding 10 lines), odes, and distichs by the chorus. Nonetheless, RP-TAds belong, more significantly $(72.8 \%, 91)$, in dialogue than the TAds in the other positions do, since this figure exceeds both the percentage of TAds in dialogue of the whole sample $(55.69 \%, 426)$, as well as the corresponding percentage of LP-TAds (53.01\%, 141) and M-TAds $(49.26 \%$, 134).

Finally, the variation of TAds within a speech or play raises an interesting question (Haverkate 1984: 71-76), but this, unfortunately, lies beyond the scope of this research. The use of $\hat{\omega}$ also falls outside the scope, especially since the sample is too limited for the purpose. The matter is, moreover, truly controversial (Dickey 1996: 205).

\subsubsection{TAd Types}

My TAd typology roughly follows that of Dickey (1996), ${ }^{14}$ although it is simplified in accordance with what was actually found in the sample. Wendel's labelling is added in brackets and followed by an example:

A. Names:
a. Anthroponym (Eigenname).
b. Patronymic, origin (Patronymika, Völkername). Patronymics convey

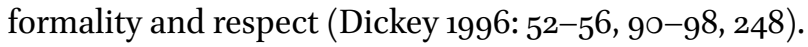

B. Age (Lebensalter) and kinship terms (e.g. $\pi \dot{\sigma} \sigma l)$. When $\pi \alpha \hat{\imath}$ is addressed to slaves it is probably derived from an age term and not from a kinship

\footnotetext{
12 The remaining 217 cases are 'non-applicable' since the degree of closeness of the participants is difficult to ascertain.

13 Dramatic plots seem to work more effectively when focused on family relationships: see Rutherford (2012: 103) and Aristotle (Poet. 1453b19-22).

14 See also Rutherford (2012: 101).
} 
term (i.e. the address to one's own child) (Dickey 1996: 258). In any case, $\pi \alpha \hat{\text {, }}$ both when addressed to slaves and to one's own offspring, is in this paper classified as an 'age' term (Rutherford 2012: 105 n. 107) in contrast to $\tau \varepsilon ́ x v o v$, which is clearly a kinship term, and possibly more emotional.

C. Indefinite addresses and $\xi \dot{\varepsilon} v \varepsilon$. The standard TAd was the anthroponym, to which Dickey (1996: 46, 2010: 329) refers as the first name, 'unless the addressee was a woman, a child, a slave, a foreigner, or a close relative of the speaker'. Deviations thereof were accordingly salient except for róval when a male addressed a female who was not his wife. Thus, rúvaı was the standard TAd for respectable women in these contexts (Dickey 1996: 243-248; Wendel 1929: 60).

D. Doubtful TAds (Beinamen). ${ }^{15}$ Among others, I include $\hat{\omega} \mu \varepsilon \dot{\varepsilon} \lambda \varepsilon$, $\hat{\omega} \tau \hat{\alpha} \nu$ (see

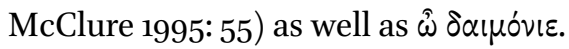

E. Invocations, e.g. $\hat{\omega} \lambda \dot{\varepsilon} x \tau$ pov. Dickey (1996: 24) only includes exclamations when they are actual addresses or prayers to the gods. For a more accurate comparison, all the examples of free TAds are considered in this paper, including TAds to offstage characters, self-addressed TAds, and oaths.

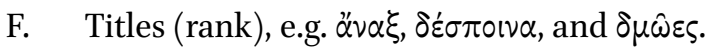

G. Endearment terms, e.g. $\hat{\omega} \varphi\left(\lambda \tau \alpha \alpha \theta^{\prime}\right.$ "Exтор. The endearment term in the

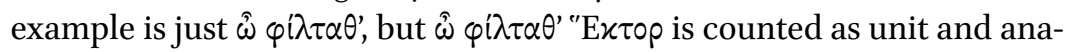
lysed as an endearment term. The same is true in $\mathrm{H}$.

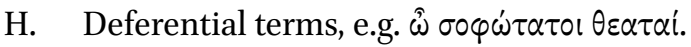

I. Derogatory terms, e.g. $\grave{\omega} \mu \hat{\imath} \sigma \circ \varsigma$.

\subsubsection{Speech Act Types}

Busse (2006: 112) claims that 'speech act theory is of particular importance' in her study on the vocative constructions in Shakespeare. I have implemented a typology of speech acts based on Risselada (1993: 32-49). Speech acts are classified in accordance with two dimensions: orientation towards the speaker or towards the addressee, ${ }^{16}$ and whether 'the content [...] primarily refers to action, information or emotions' (Risselada 1993: 35). The following diagram displays these two criteria, combined in the form of intersecting horizontal and vertical axes respectively, and should be taken as a continuum since no clear-

15 Beiname ('epithet') is something different than 'doubtful TAd', but the content denoted by these two terms is roughly the same.

16 I have not considered orientation towards a definite or indefinite third person (Risselada 1993: 36 ), since this can be subsumed by the declarative type and, depending on the context, can be understood as an impersonalisation strategy under the framework of Politeness Theory (Brown and Levinson ${ }^{2}$ 1987: 191; House and Kasper 1981: 168). 
Orientation:

Speech acts about:

FACTS

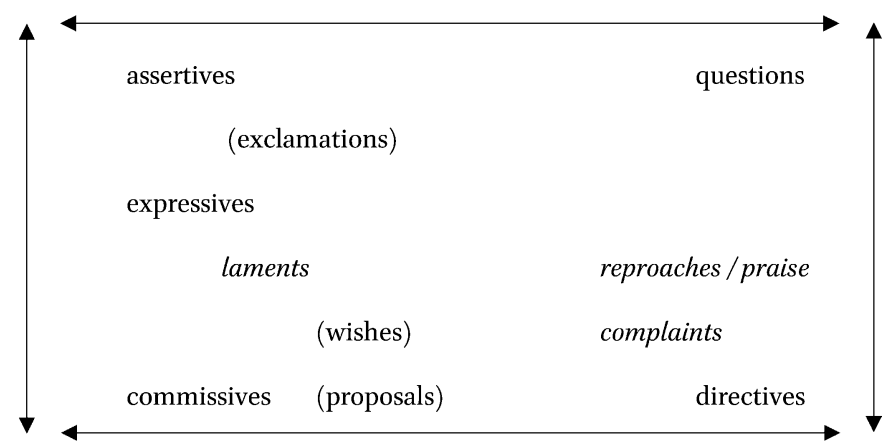

FIGURE 1 Typology of speech acts

MODIFIED FROM RISSELADA 1993: 37

cut categorisation is intended. Accordingly, a number of borderline speech acts are represented in brackets (Figure 1 ).

I have included several modifications (in italics), especially by further elaborating on the speech acts about emotions. ${ }^{17}$

Risselada (1993) focused on the subtype of directive speech acts, which are in turn classified in accordance with the scheme below. ${ }^{18}$ There are two criteria: the degree to which the speech act is presented as compulsory, ${ }^{19}$ and whether the benefit is addressed towards the speaker or the addressee. Again, it is a continuum (Figure 2).

I have also elaborated on the commissive speech acts by distinguishing between promises, threats, and warnings in accordance with two criteria, namely whether the speaker is the agent and whether a benefit or detriment is addressed more or less directly towards the recipient, i.e. the eventual perlocutionary effect. Thus, in promises, the speaker is the agent and there can be a benefit directly towards the addressee. In turn, the agent does not explicitly identify with the speaker in warnings and the damage is not explicitly oriented towards the addressee. In contrast, threats are detrimental for the addressee

17 While reproaches and laments relate to the past and the state of affairs is not likely to change (Risselada 1993: 78), speech acts about emotions which belong in a more non-factual dimension, e.g. wishes and complaints, lie between expressive and directive speech acts.

18 Hindelang (1978: 19, 119, 131, 141) also distinguishes between bindende and nicht-bindende Aufforderungen, which, in turn, are subclassified; see also Haverkate (1984: 19).

19 Thus, in requests 'the decision whether or not to realize the content is left to the addressee' (Risselada 1993: 47; see also Berger on bindingness in this volume). 
Bindingness:

Benefit:

BINDING

OPTIONAL

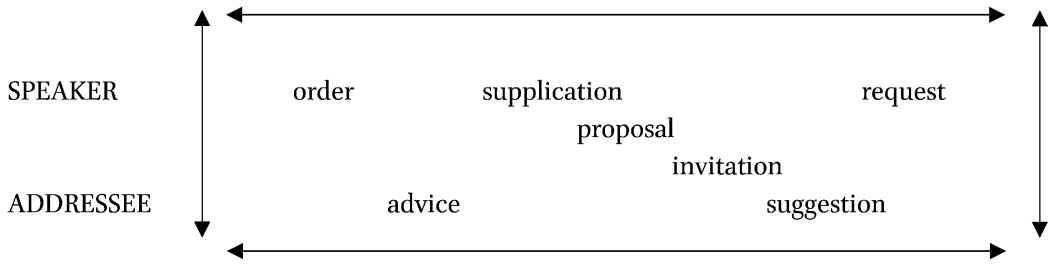

FIGURE 2 Typology of directive speech acts

RISSELADA 1993: 48

and the speaker is the agent. Finally, the concept of 'metadirectivity' should be considered for a better account of the speech act types:

[...] there is [...] a metadirective element in every speech act type. This metadirective element results from the systematic perlocutionary effects $[\ldots]$ this concept $[\ldots]$ is needed for an adequate description of utterances which contain the imperative of a 'perlocutionary' verb (e.g. crede mihi 'believe me' or dic mihi 'tell me'). These metadirective utterances [...] are often misinterpreted as ordinary directives. They constitute, in fact, the functional counterparts of performative expressions like I tell you that or I ask you whether [...]. Just as I promise that I will be here is not an assertive speech act, but an emphatically expressed commissive, believe me that Inever saw him do that before is not a directive but an emphatically expressed assertion. ${ }^{20}$

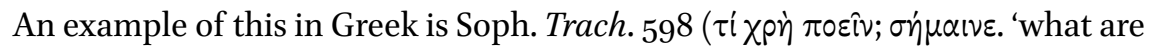
thy commands? Give me my charge.'). $\sigma \dot{\eta} \mu \alpha$ เve is not an order but a metadirective relating to the previous question.

\subsubsection{CA-Functions (Turn Allocation and Contact Establishment)}

Here, I consider functions that are normally studied under the framework of Conversation Analysis (see Sacks et al. 1974: 701), to which Parkinson referred $(1985: 36)$ in the following way: TAds 'play an important role in some speech acts, and also an important part in the "mechanics" of conversation'. From a broader perspective, Geluykens (1987: 121) similarly considered two major functional domains (informational and interactional) when analysing 'tails' (right-dislocations) under the framework of Functional Grammar. He does in

20 Risselada (1993: 44-45; her emphases). 
fact point out that 'tails are an interactional process rather than a mere word order variation' and that 'tails are interactional patterns, and they have to be studied in relation to the turn-taking process' (Geluykens 1987: 122, 127). In line with this proposal, the distribution of TAds in terms of position is analysed according to whether or not LP-, M- and RP-TAds fulfil a CA-function. A TAd performs a CA-function whenever it is used for the establishment of contact (see Mastronarde 1979), for turn assignment (when the speaker selects the next addressee or allocates the next turn in trilogues), and in second pair parts of an adjacency pair (2PP). On the other hand, TAds do not always perform one of these CA-functions, since they can be used even when the speaker has already established contact and/or has already selected the next addressee. These cases are labelled as interactive. Finally, TAds that do not perform CAfunctions can also be non-interactive, whenever there is no direct interaction, e.g. invocations, TAds to offstage characters, and self-references. Thus, TAds performing a non-CA-function are labelled as either interactive or not interactive.

Data

The following data lead to results in the form of tendencies, since no TAd distribution is absolutely neat. However, there are trends that are well supported by the data which point to differences, particularly between LP- and RP-TAds, and which support the idea that TAd position is not random but can convey a variety of nuances. For several parameters some subtypes are badly attested in the sample. For instance, there are only eight examples of suggestions and warnings; in all, there are four threats (Table 4). The low percentages of these cases probably have less to do with the TAd position than with the fact that the sample is small. For this reason, results in Section 4 are drawn only from those parameters that are sufficiently attested.

\subsection{TAd Position and the Mechanics of Conversation}

There are significant differences in how the TAd position relates to the mechanics of conversation. LP-TAds are employed to establish contact between the characters $(30.83 \%)$. If they are not uttered to fulfil turn-allocation functions, then they are not used in direct interactions (39.1\%) but in invocations to the gods, to offstage characters, or in self-references. M-TAds are more or less evenly distributed across the various categories. Conversely, RP-TAds are rarely used to establish contact and are uttered mostly when they are not strictly needed for turn allocation, since contact is already established and/or the next addressee 
TABLE 1 Distribution of TAd position by CA-functions. Row percentages by the number of coded references

\begin{tabular}{|l|l|l|l|l|l|}
\hline \multicolumn{2}{|l}{} & \multicolumn{3}{c|}{ CA-functions } \\
\hline & Interactive & Not interactive & 2 PP & $\begin{array}{l}\text { Next addressee } \\
\text { selection }\end{array}$ & $\begin{array}{l}\text { Contact, Turn } \\
\text { assignment }\end{array}$ \\
\hline LP & $7.14 \%(19)$ & $39.1 \%(104)$ & $7.89 \%(21)$ & $15.04 \%(40)$ & $30.83 \%(82)$ \\
\hline M & $25.74 \%(70)$ & $19.12 \%(52)$ & $17.65 \%(48)$ & $22.06 \%(60)$ & $15.44 \%(42)$ \\
\hline RP & $49.6 \%(62)$ & $8.8 \%(11)$ & $20 \%(25)$ & $14.4 \%(18)$ & $7.2 \%(9)$ \\
\hline IC & $9.8 \%(5)$ & $70.59 \%(36)$ & $3.92 \%(2)$ & $1.96 \%(1)$ & $13.73 \%(7)$ \\
\hline DP & $27.45 \%(14)$ & $23.53 \%(12)$ & $9.8 \%(5)$ & $23.53 \%(12)$ & $15.69 \%(8)$ \\
\hline To & $22.22 \%(170)$ & $28.1 \%(215)$ & $13.2 \%(101)$ & $17.12 \%(131)$ & $19.35 \%(148)$ \\
\hline
\end{tabular}

is already selected (49.6\%). Unlike LP-TAds, they are rare when there is no direct interaction (e.g. invocations or self-references), see Table 1.

These results match those of Zwicky (1974), whereby he proposes a correlation between the function of the vocative and its position in comparable terms, namely that vocatives in the form of calls are limited to the first position, whereas the M- and RP-positions are for vocatives as addresses. Similarly, Slocum (2016:18-20) claims that 'calls must occur sentence initially' in English, whereas 'addresses may appear in a wide variety of positions'. Further similar typologies have been proposed, in which the TAd position appears to be a relevant factor in the determination of its function. ${ }^{21}$

\subsection{Distribution of TAd Position by TAd Type}

There are several differences, particularly between LP and RP, in terms of the distribution of TAd types. Invocations to gods (27.07\%) and endearment terms $(18.8 \%)$ score the highest in LP. In turn, RP-TAds are most frequently kinship $(23.20 \%)$ or indefinite $(21.60 \%)$ forms, where they have the highest proportion.

21 See Kleinknecht and Souza (2017: 26o-261). 
TABLE 2 Distribution of TAd position by TAd type. Row percentages by the number of coded references. Inv.: invocations; Dear.: endearment terms; IA: indefinite; Der.; derogatory; Def.: Deferential; Kin.: kinship; FN: first name; Patr.: patronymic ${ }^{\mathbf{a}}$

\begin{tabular}{|l|l|l|l|l|l|l|l|l|l|l|}
\hline & Inv. & Dear. & IA & Rank & Der. & Def. & Age & Kin. & FN & Patr. \\
\hline LP & $\begin{array}{l}27.07 \\
(72)\end{array}$ & $\begin{array}{l}18.8 \\
(50)\end{array}$ & $\begin{array}{l}7.14 \\
(19)\end{array}$ & $\begin{array}{l}6.77 \\
(18)\end{array}$ & $\begin{array}{l}6.02 \\
(16)\end{array}$ & $\begin{array}{l}4.89 \\
(13)\end{array}$ & $\begin{array}{l}7.89 \\
(21)\end{array}$ & $\begin{array}{l}10.53 \\
(28)\end{array}$ & $\begin{array}{l}3.76 \\
(10)\end{array}$ & $\begin{array}{l}5.64 \\
(15)\end{array}$ \\
\hline M & $\begin{array}{l}10.29 \\
(28)\end{array}$ & $\begin{array}{l}15.07 \\
(41)\end{array}$ & $\begin{array}{l}11.76 \\
(32)\end{array}$ & $\begin{array}{l}5.88 \\
(16)\end{array}$ & $\begin{array}{l}6.25 \\
(17)\end{array}$ & $\begin{array}{l}2.57 \\
(7)\end{array}$ & $\begin{array}{l}(6.54 \\
(45)\end{array}$ & $\begin{array}{l}18.01 \\
(49)\end{array}$ & $\begin{array}{l}9.19 \\
(25)\end{array}$ & $1.1(3)$ \\
\hline RP & $4(5)$ & $8(10)$ & 21.6 & $\begin{array}{l}10.4 \\
(27)\end{array}$ & $\begin{array}{l}(13) \\
8(10)\end{array}$ & $0.8(1)$ & $\begin{array}{l}10.4 \\
(13)\end{array}$ & $\begin{array}{l}23.2 \\
(29)\end{array}$ & $8(10)$ & $3.2(4)$ \\
\hline IC & $\begin{array}{l}41.18 \\
(21)\end{array}$ & $\begin{array}{l}33.33 \\
(17)\end{array}$ & 0 & 0 & $\begin{array}{l}3.92 \\
(2)\end{array}$ & $\begin{array}{l}7.84 \\
(4)\end{array}$ & $\begin{array}{l}3.92 \\
(2)\end{array}$ & $\begin{array}{l}3.92 \\
(2)\end{array}$ & $\begin{array}{l}5.88 \\
(3)\end{array}$ & 0 \\
\hline DP & $\begin{array}{l}11.76 \\
(6)\end{array}$ & $\begin{array}{l}23.53 \\
(12)\end{array}$ & $9.8(5)$ & $\begin{array}{l}7.84 \\
(4)\end{array}$ & $\begin{array}{l}5.88 \\
(3)\end{array}$ & $\begin{array}{l}3.92 \\
(2)\end{array}$ & $\begin{array}{l}(19.61 \\
(10)\end{array}$ & $\begin{array}{l}11.76 \\
(6)\end{array}$ & $\begin{array}{l}3.92 \\
(2)\end{array}$ & $\begin{array}{l}1.96 \\
(1)\end{array}$ \\
\hline To. & $\begin{array}{l}17.25 \\
(132)\end{array}$ & $\begin{array}{l}16.99 \\
(130)\end{array}$ & $\begin{array}{l}10.85 \\
(83)\end{array}$ & $\begin{array}{l}(5.67 \\
(51)\end{array}$ & $\begin{array}{l}6.27 \\
(48)\end{array}$ & $\begin{array}{l}3.53 \\
(27)\end{array}$ & $\begin{array}{l}(91.9 \\
(91)\end{array}$ & $\begin{array}{l}14.9 \\
(114)\end{array}$ & $\begin{array}{l}6.54 \\
(50)\end{array}$ & $\begin{array}{l}3.01 \\
(23)\end{array}$ \\
\hline
\end{tabular}

a The remaining 16 TAds are doubtful.

On the other hand, other trends which could be revealing can be at risk of being neglected, since TAd types are many and the figures associated with them remain low. For this reason, it is particularly instructive not only to consider the raw percentages but also to account for them in relation to the average percentages across the whole sample (see the last row in Table 2). For instance, although RP-TAds present the highest rate of derogatory forms, this makes up only $8 \%$. However, insults are not as common in tragedy as the other types: only $6.27 \%$ of the TAds from the sample are insults, and hence $8 \%$ is already a higher rate regarding the overall sample. The same over-representation applies to rank, actually the highest percentage (10.40\% of RP-TAds), and first names ( $8 \%$ of RP-TAds): these percentages are proportionally higher in RP-TAds if we consider the average scores of rank TAds and first names $(6.67 \%$ and $6.54 \%$ respectively). Conversely, deferential TAds on the RP are very rare and present the lowest proportion $(0.8 \%)$. In this regard, it is also worth noting the over- 
TABLE 3 Distribution of TAd position by speech act type. Row percentages by the number of coded references

\begin{tabular}{|l|l|l|l|l|}
\hline & Facts & Actions & Emotions & Metadirectives \\
\hline LP & $27.44 \%(73)$ & $17.67 \%(47)$ & $53.76 \%(143)$ & $1.13 \%(3)$ \\
\hline M & $34.93 \%(95)$ & $28.31 \%(77)$ & $31.62 \%(86)$ & $5.15 \%(14)$ \\
\hline RP & $27.2 \%(34)$ & $46.4 \%(58)$ & $24 \%(30)$ & $2.4 \%(3)$ \\
\hline IC & $1.96 \%(1)$ & $0 \%(0)$ & $98.04 \%(50)$ & O\%(o) \\
\hline DP & $27.45 \%(14)$ & $25.49 \%(13)$ & $43.14 \%(22)$ & $3.92 \%(2)$ \\
\hline Total & $28.37 \%(217)$ & $25.49 \%(195)$ & $43.27 \%(331)$ & $2.88 \%(22)$ \\
\hline
\end{tabular}

all sample (3.53\%), the LP-TAds ( $4.89 \%)$, and especially the IC-TAds, namely wordy apostrophes, where deferential TAds rate the highest $(7.84 \%)$.

\subsection{Distribution of TAd Position by Speech Act Type}

The position of TAds also depends on the kind of speech act type (Table 3). While LP-TAds are found significantly more often in speech acts about emotions or facts ( $53.76 \%$ and $27.44 \%$ respectively), RP-TAds mainly appear in the context of speech acts about actions $(46.4 \%)$. Indeed, this is the highest percentage, followed by those about facts $(27.2 \%)$ and emotions $(24 \%)$. In turn, M-TAds are more evenly distributed.

The distribution of the subtypes is presented below (Section 3.3.1-3.3.2) with the exception of speech acts about facts, since there are no significant differences regarding the distribution of the corresponding subtypes (i.e. declaratives and interrogatives).

\subsubsection{Distribution of TAd Position by Directive Speech Acts}

More than half of the RP-TAds in the context of directive speech acts appear in orders $(53.45 \%)$, which is well above the average rate $(34.36 \%)$. This is a property shared with stand-alone TAds. ${ }^{22}$ In contrast, LP-TAds in the context

22 Haverkate (1984: 70): ‘[...] impositive speech acts in particular [...] are performed by the 
TABLE 4 Distribution of TAd position by directive speech act type. Row percentages by the number of coded references. IC-TAds are not attested. Sugg.: suggestions; Adv.: advice; Prop.: proposals; Req.: requests; Warn.: warnings; Prom.: Promises

\begin{tabular}{|l|l|l|l|l|l|l|l|l|}
\hline & Sugg. & Adv. & Prop. & Req. & Orders & Threats & Warn. & Prom. \\
\hline $\begin{array}{l}\text { LP } \\
(47)\end{array}$ & $2.13(1)$ & $6.38(3)$ & $\begin{array}{l}17.02 \\
(8)\end{array}$ & $\begin{array}{l}34.04 \\
(16)\end{array}$ & $\begin{array}{l}23.4 \\
(11)\end{array}$ & $2.13(1)$ & $2.13(1)$ & $\begin{array}{l}12.77 \\
(6)\end{array}$ \\
\hline $\begin{array}{l}\text { M } \\
(77)\end{array}$ & $3.9(3)$ & $\begin{array}{l}11.69 \\
(9)\end{array}$ & $\begin{array}{l}11.69 \\
(9)\end{array}$ & $\begin{array}{l}27.27 \\
(21)\end{array}$ & $\begin{array}{l}27.27 \\
(21)\end{array}$ & $2.6(2)$ & $2.6(2)$ & $\begin{array}{l}12.99 \\
(10)\end{array}$ \\
\hline $\begin{array}{l}\text { RP } \\
(58)\end{array}$ & 0 & $6.9(4)$ & $6.9(4)$ & $\begin{array}{l}17.24 \\
(10)\end{array}$ & $\begin{array}{l}53.45 \\
(31)\end{array}$ & $1.72(1)$ & $6.9(4)$ & $6.9(4)$ \\
\hline $\begin{array}{l}\text { DP } \\
(13)\end{array}$ & $7.69(1)$ & $\begin{array}{l}15.38 \\
(2)\end{array}$ & $7.69(1)$ & $\begin{array}{l}15 \cdot 38 \\
(2)\end{array}$ & $\begin{array}{l}30.77 \\
(4)\end{array}$ & 0 & $7.69(1)$ & $\begin{array}{l}15.38 \\
(2)\end{array}$ \\
\hline $\begin{array}{l}\text { To. } \\
(195)\end{array}$ & $2.56(5)$ & $\begin{array}{l}9.23 \\
(18)\end{array}$ & $\begin{array}{l}(22) \\
(1.28\end{array}$ & $\begin{array}{l}25.13 \\
(49)\end{array}$ & $\begin{array}{l}34.36 \\
(67)\end{array}$ & $2.05(4)$ & $4.10(8)$ & $\begin{array}{l}11.28 \\
(22)\end{array}$ \\
\hline
\end{tabular}

of directive speech acts are more common in non-binding speech acts, such as in requests $(34.04 \%)$ and proposals ( $17.02 \%)$, especially if we take into account the overall score for the sample $(25.13 \%$ and $11.28 \%$ respectively), see Table 4 .

\subsubsection{Distribution of TAd Position by Speech Acts about Emotions}

The distribution of speech acts concerning emotions also points to the different nuances between LP- and RP-TAds. RP-TAds are more often uttered in reproaches $(30 \%)$ whereas LP-TAds are more common in laments $(38.46 \%)$. Since laments are self-addressed or addressed to offstage characters, normally gods, this distribution corresponds to that previously discussed about LP-TAds, namely that they are often non-interactive (invocations, self-addresses, and addresses to offstage characters) in most of the remaining cases, in which they are not mechanically used to fulfil CA-functions (particularly that of establishing contact).

utterance of a vocative alone. [I] f someone is ringing at the door, [...] a vocative like $\mathrm{i}$ Juanita! perfectly serves the purpose of requesting or ordering the person addressed [...] to open the door.' 
TABLE 5 Distribution of TAd position by speech acts concerning emotions. Row percentages by the number of coded references. Compl.: complaints; Repr.: reproaches; Greet.: greetings

\begin{tabular}{|l|l|l|l|l|l|l|l|}
\hline & Praises & Wishes & Compl. & Repr. & Greet. & Prayers & Laments \\
\hline $\begin{array}{l}\text { LP } \\
(143)\end{array}$ & $\begin{array}{l}9.79 \% \\
(14)\end{array}$ & $\begin{array}{l}8.39 \% \\
(12)\end{array}$ & $\begin{array}{l}7.69 \% \\
(11)\end{array}$ & $\begin{array}{l}9.09 \% \\
(13)\end{array}$ & $\begin{array}{l}9.79 \% \\
(14)\end{array}$ & $\begin{array}{l}16.78 \% \\
(24)\end{array}$ & $\begin{array}{l}38.46 \% \\
(55)\end{array}$ \\
\hline $\begin{array}{l}\text { M } \\
(86)\end{array}$ & $\begin{array}{l}4.65 \% \\
(4)\end{array}$ & $\begin{array}{l}10.47 \% \\
(9)\end{array}$ & $\begin{array}{l}12.79 \% \\
(11)\end{array}$ & $\begin{array}{l}11.63 \% \\
(10)\end{array}$ & $\begin{array}{l}11.63 \% \\
(10)\end{array}$ & $\begin{array}{l}17.44 \% \\
(15)\end{array}$ & $\begin{array}{l}31.4 \% \\
(27)\end{array}$ \\
\hline $\begin{array}{l}\text { RP } \\
(30)\end{array}$ & $\begin{array}{l}3.33 \% \\
(1)\end{array}$ & $\begin{array}{l}16.67 \% \\
(5)\end{array}$ & $\begin{array}{l}23.33 \% \\
(7)\end{array}$ & $30 \%(9)$ & $\begin{array}{l}6.67 \% \\
(2)\end{array}$ & $\begin{array}{l}6.67 \% \\
(2)\end{array}$ & $\begin{array}{l}13.33 \% \\
(4)\end{array}$ \\
\hline $\begin{array}{l}\text { IC } \\
(50)\end{array}$ & $\begin{array}{l}8 \%(4) \\
40\end{array}$ & $42)$ & $4 \%(2)$ & $4 \%(2)$ & $\begin{array}{l}20 \% \\
(10)\end{array}$ & $\left.\begin{array}{l}6 \% \\
6 \%\end{array}\right)$ & $\begin{array}{l}54 \% \\
(27)\end{array}$ \\
\hline $\begin{array}{l}\text { DP } \\
(22)\end{array}$ & $\begin{array}{l}4.55 \% \\
(1)\end{array}$ & 0 & $\begin{array}{l}4.55 \% \\
(1)\end{array}$ & $\begin{array}{l}(3.64 \% \\
(3)\end{array}$ & $\begin{array}{l}31.82 \% \\
(7)\end{array}$ & $\begin{array}{l}9.09 \% \\
(2)\end{array}$ & $\begin{array}{l}36.36 \% \\
(8)\end{array}$ \\
\hline $\begin{array}{l}\text { To. } \\
(331)\end{array}$ & $\begin{array}{l}7.25 \% \\
(24)\end{array}$ & $\begin{array}{l}8.46 \% \\
(28)\end{array}$ & $\begin{array}{l}9.67 \% \\
(32)\end{array}$ & $\begin{array}{l}11.18 \% \\
(37)\end{array}$ & $\begin{array}{l}12.99 \% \\
(43)\end{array}$ & $\begin{array}{l}13.9 \% \\
(46)\end{array}$ & $\begin{array}{l}36.56 \% \\
(121)\end{array}$ \\
\hline
\end{tabular}

RP-TAds rate the highest in non-factual speech acts about emotions, namely wishes $(16.67 \%)$ and particularly complaints $(23.33 \%)$, both in comparison with the other positions and with the average percentage. Note that wishes and complaints are borderline speech acts which are closer to directives. On the other hand, R P-TAds barely occur in prayers $(6.67 \%)$ or praise $(3.33 \%)$, with a score below the general rating $(13.9 \%$ and $7.25 \%$ respectively), see Table 5 .

\subsection{TAd Position and Non-redressive Action (Bald-on-Record FTAs)}

There are significant differences between RP-, M- and LP-TAds if we look into how these speech acts are performed. RP-TAds stand out for being used in the context of FTAs with non-redressive action, i.e. bald on record. Over half of the RP-TAds (55.2\%, 69 occurrences) are performed in explicit FTAs with no hedging strategies, and they even score the highest percentage (35.75\%) of the overall sample (193 occurrences) despite being much fewer in number (125) than LP- (266) and M-TAds (272). In contrast, only $16.92 \%$ (45) of LP-TAds 
TABLE 6 Distribution of TAds by age. Row percentages by the number of coded references

\begin{tabular}{|l|l|l|l|l|l|}
\hline & NA (4) & Old age (14) & Deity (6) & $\begin{array}{l}\text { Youth-child } \\
(14)\end{array}$ & $\begin{array}{l}\text { Adulthood } \\
(31)\end{array}$ \\
\hline $\begin{array}{l}\text { LP } \\
(266)\end{array}$ & $0.38 \%(1)$ & $27.07 \%(72)$ & $3.38 \%(9)$ & $24.44 \%(65)$ & $\begin{array}{l}44.74 \% \\
(119)\end{array}$ \\
\hline $\begin{array}{l}\text { M } \\
(272)\end{array}$ & $1.47 \%(4)$ & $24.63 \%(67)$ & $3.31 \%(9)$ & $27.57 \%(75)$ & $\begin{array}{l}43.01 \% \\
(117)\end{array}$ \\
\hline $\begin{array}{l}\text { RP } \\
(125)\end{array}$ & $1.6 \%(2)$ & $29.6 \%(37)$ & $2.4 \%(3)$ & $32 \%(40)$ & $34.4 \%(43)$ \\
\hline $\begin{array}{l}\text { IC } \\
(51)\end{array}$ & 0 & $25.49 \%(13)$ & 0 & $49.02 \%(25)$ & $25.49 \%(13)$ \\
\hline $\begin{array}{l}\text { DP } \\
(51)\end{array}$ & $3.92 \%(2)$ & $25.49 \%(13)$ & $1.96 \%(1)$ & $25.49 \%(13)$ & $43.14 \%(22)$ \\
\hline $\begin{array}{l}\text { Total } \\
1.18 \%(9)\end{array}$ & $\begin{array}{l}26.41 \% \\
(202)\end{array}$ & $2.88 \%(22)$ & $28.5 \%(218)$ & $\begin{array}{l}41.05 \% \\
(314)\end{array}$ \\
\hline
\end{tabular}

are employed in overt FTAs and they amount for only $23.32 \%$ of the sample, although the number of LP-TAds stands at over twice as many as the number of RP-TAds.

\subsection{TAd Position and Socio-Demographics}

According to Bassett (1934: 148-149), the omission of TAds characterises Odysseus and Diomedes in their speeches in the Iliad, i.e. a mature vs. a younger character respectively. The latter omits TAds in his speech and is 'youthful, high-spirited and impetuous', whereas the former uses TAds and speaks with 'caution, deliberateness and tact'. Regarding the position of TAds, the opposite age groups seem to share a tendency for RP-TAds. The young and the old score $32 \%$ and $29.6 \%$ of the total of RP-TAds respectively, even though there are only 14 young characters (15,187 words) and 14 elders (14,110 words), whereas 31 adult characters utter 25,850 words. These percentages are higher than the average number of TAds uttered by these age groups regardless of the position of the TAds ( $28.5 \%$ and $26.41 \%$, for the young and the old respectively), which makes these figures all the more significant, see Table 6 . 
I have deliberately excluded the distribution of TAd position by gender and status: tests of the type run in this paper can lead to misleading results in these categories, since they fail to account for the differences regarding whether female characters interact with other female characters or, e.g., with male servants, whether the women are older than their interlocutors, etc. Even more difficulties arise regarding status, as this can be a shifting attribute not only in each interaction but also throughout a play (e.g. E. Ion, Ar. Nub.).

\section{$4 \quad$ Results}

The most significant findings are summarised in Figure 3.

There is a hierarchy concerning the analysed parameters as well as correlations between said parameters. CA-functions are the defining parameter, as they constrain the use or omission of a given TAd in the first place. ${ }^{23}$ Unlike RP-TAds, LP-TAds can be unmarked in that they are often required simply for the establishment of contact or the allocation of the next turn. In turn, RPTAds seldom play such a part in the mechanics of conversation. In this sense, RP-TAds tend to be marked since they are of a more expletive nature.$^{24}$ Second, if we rule out the cases when LP- and RP-TAds are 'mechanical' and just compare the remaining examples where LP- and RP-TAds are both unconstrained by the mechanics of conversation, then we find that LP-TAds are mainly used for invocations, self-addresses, or addresses to off-stage characters, i.e. they are no longer directly interactive. In contrast, unconstrained RP-TAds are still directly interactive and convey nuances which range from self-initiated repair strategies to reinforcement of the previous clause. ${ }^{25}$ Self-initiated repair is linked to the choice of respectful or rank TAds, such as $\alpha^{2} v \alpha \xi$ (see [5]); it takes place when the urgency of the situation pushes the content into the first position. Nevertheless, these cases remain rare.

The other parameters also correlate: for instance, orders are more common with non-constrained RP-TAds and this in turn is related to more RP-TAds in the context of bald-on-record actions. TAd-types also correlate, as not many RP-TAds are deferential.

23 See Haverkate (1984: 69): '[...] the attention-getting function of the vocative needs to be set apart from its other functions, since it is not related to the internal structure of the speech act.'

24 This is regardless of the fact that, from a traditional syntactical and semantic standpoint, any vocative is optional, see Haverkate (1984: 68).

25 See Haverkate (1984: 71-72), precisely with RP-TAds examples. 
LP

RP

\section{CA-Functions}

CONTACT. Omission is salient since abruptness is intended or the situation is urgent.

NON-INTERACTIVE:

invocations, offstage, and self-addresses
INTERACTIVE, although contact is already established and the turn allocated. Consequently, omission is not salient.

TAd type

INVOCATIONS

ENDEARMENT terms

\section{KINSHIP terms \\ INDEFINITE ADDRESSES}

*Deferential terms are remarkably rare, whereas derogatory terms are well represented.

Speech act type

Directive speech acts

REQUESTS (NON-BINDING) ORDERS (BINDING)

\section{Emotions}

LAMENTS, PRAYERS

REPROACHES, COMPLAINTS, WISHES

FIGURE 3 Distribution patterns of LP- and RP-TAds 


\section{$5 \quad$ Discussion}

As seen, there are distribution patterns that argue for differences between LPand RP-TAds. However, it is difficult to pin down a single function of RP-TAds as opposed to LP-TAds, especially since the context has a significant bearing on each specific case. ${ }^{26}$ Thus far, RP-TAds relate to bald-on-record orders, reproaches, and complaints; they are uttered especially by the young and the old. Most importantly, they are employed when there is no longer any need either for the establishment of contact or for the selection of the addressee. In this regard, while the omission of LP-TAds can be salient, that which is salient concerning the use of RP-TAds is precisely the fact that they are used (see Kleinknecht and Souza 2017: 261). Accordingly, there should be an input of some sort, even in the deviant cases where RP-TAds do not follow the abovementioned trends, e.g. the fewer cases of RP-TAds in the context of interrogatives, factual statements, prayers, and generic reflections. The observed distribution patterns (see Figure 3) can shed light on the input of RP-TAds in these non-prototypical cases, as will be presently seen.

In view of the majority of the examples, it seems that RP-TAds, probably uttered with distinctive intonation, add a note of insistence, impatience, worry, or unease with a varying degree of im/politeness depending on each case. ${ }^{27}$ This can be made explicit by the lexical items - a fact that is not very revealing as to the nuance of the RP-TAd itself, since the semantic elements already convey the character's discomfort, e.g. Ar. Nub. 790, 854-858. More revealing are the cases in which querulousness, insistence, or unease can be hinted at by the context in which the RP-TAd plays a part, regardless of the lexical elements:

[3] Aristophanes Clouds 80

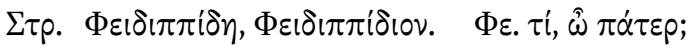

Str. Pheidippides! Pheidippides, my little one!

Ph. What, o father?

26 See Dik (1997: 383); Sonnenhauser and Noel Aziz Hanna (2013: 14); Kleinknecht and Souza (2017: 262).

27 NB: in natural conversation there are other situations that can account for RP-TAds which are probably not found in dramatic texts, at least not in this sample. For instance, a teacher could pose a question in a classroom and then select the next speaker, especially if there are no volunteers for the answer or because the speaker was not actually thinking about any specific addressee when uttering the question. Cf. Parkinson (1985: 37). 
Strepsiades is insisting on calling his son and waking him up. Pheidippides wants to continue sleeping, and he already asked his father to let him do so (Ar. Nub. 38). Consequently, he is annoyed and the way he replies, together with a certain intonation in antilabe, could convey his querulous attitude. ${ }^{28}$

LP- and M-TAds can also convey unease, insistence, querulousness, or reproach but the context needs to be semantically overt in this respect. On the other hand, when a character utters an insult in the form of a TAd, needs to establish contact as well, or to allocate a turn, said TAd moves mechanically into the first position (i.e. LP). In the absence of such constraints, M- or RP-TAds are preferred. This is because CA-functions prevail in the case of LP-TAds unlike RP-TAds. In contrast, RP-TAds can, as it were, 'modalise' the meaning of speech acts that are initially neutral, even in the absence of explicit lexical items or a clearer given context, as in the following examples, which are precisely nonprototypical considering the distribution patterns of RP-TAds:

a. Generic reference. The RP-TAd in [4] makes it explicit that what Heracles is expressing is not just a general reflection but a reproach to Admetus for his deceitful behaviour:

[4] Euripides Alcestis 1007-1008

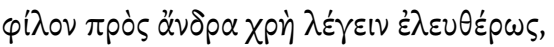

"Аठ $\mu \eta \tau \varepsilon$.

A man should speak frankly to his friends, Admetus.

The entire clause is not as neutral as it would be without the RP-TAd, which is not needed for the selection of the addressee. ${ }^{29}$

b. Statements ${ }^{30}$. There are other instances in which there is no bald-on-record action but where the characters insist upon something. Admetus insists on hosting Heracles:

28 See also Ar. Nub. 86-93, 731-736, 776-784; Eur. Ion 999, 1211; Soph. El. 673-675.

29 See also Aesch. Supp. 99-102.

30 See Eur. Alc. 516-517, where there is a prima facie indifferent declarative sentence with an RP-TAd, which, if uttered with a certain intonation at the end, would probably increase Admetus' discomfort with the situation later disclosed (Eur. Alc. 629). See also Ar. Nub. 1325; Eur. Alc. 529, 536-539; Andr. 1073-1074; Supp. 403; Ion 309, 645; Soph. El. 924-925 (ఓ $\tau \dot{\alpha} \lambda \alpha \iota v \alpha), 1179-1182$. 
[5] Euripides Alcestis 536-539

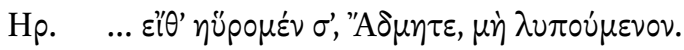

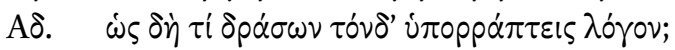

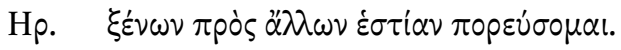

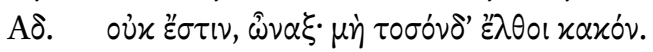

Her. ... I wish, Admetus, that I had not found you in mourning.

Ad. What action do you hint at by these words?

Her. I'll travel to the hearth of other hosts.

Ad. My lord, that cannot be! May such a dreadful thing not come to pass.

In view of examples like these, it is possible to distinguish between two types of contexts that would account for the placement of TAds at RP:

(a) Contexts, often of urgency, in which the content pushes itself into first position and an RP-TAd is added as self-initiated repair. This would be a property shared with tail material from the standpoint of Functional

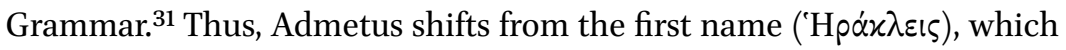
he had been previously using (Eur. Alc. 517, 529), to a rank term ( $\left.\alpha \alpha^{\prime} \alpha \xi\right)$ in [5] in order to balance out and avoid a possible note of disrespect after his hasty reaction ( $0 \dot{\varkappa}$ है $\sigma \tau \imath$ ). Example [3] could also be interpreted along these lines.

(b) Contexts in which the RP-TAd is added as a modifier of tone, generally as reinforcement of the previous utterance.

In example [5], (a) would be possible: Admetus is self-repairing a potential FTA. This, however, does not seem to be exactly an FTA but instead a way of insisting that there is no problem if Heracles wants to stay at home. Alternatively, another interpretation is possible, which relates to a usage found in modern Spanish and which would be closer to (b). We can distinguish between two expressions with different punctuation and inflection:

[6] No, señor, 'no sir'

$[7]^{* * *}$ Noseñor / Noseñora

$31 \quad$ Geluykens (1987: 122); Dik (1997: 403). 
I purposely misspelled [7] in order to represent the difference in intonation and punctuation. No. [6] corresponds to 'no sir'; it is respectful and formal, and it normally appears in the second term of an adjacency pair. However, [7] is far from respectful. It appears in contexts where there is familiarity between the speakers and the speaker feels close enough to overtly disagree with the addressee. Otherwise, it is impolite. With noseñor the speaker seems to reinforce his stance by distancing himself from the addressee. In abstract terms, expressions ending in noseñor would result in 'closeness + reinforcement of one's own stance by generating distance'.32 This seems to match that which Admetus does in [5]: he had been addressing his friend by his first name (Eur. Alc. 517, 529), and now he insists on his invitation and disagrees with him,

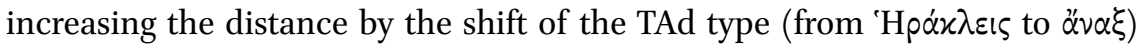
in RP. Note that noseñor seems to have been pragmaticalised, if not already grammaticalised, in Spanish, as can be found in its invariable form (only masculine $^{33}$ ) and in contexts other than direct dialogues, becoming an emphatic stance-taking expression:

[8] J. Sámano, "Con lo que tenía, debía haber firmado a Karpin" (El País).

Mi meta no es salir en EL PAís o en la primera del As o el Marca, no busco eso, no quiero notoriedad. Mucha gente piensa que como técnico de Primera mi ambición es ir al Madrid, al Barça, al Athletic ... ¡Pues no señor! No es mi caso, no tengo ninguna necesidad.

My goal is not to be in EL PAís nor in the front page of the AS or Marca. I'm not looking for that, I don't seek fame. Many people think that my aspiration as a Premier League manager is to become the head coach of Madrid, Barça, Athletic ... Not at all, mister! It is not the case for me, I don't need it.

Another example in which an RP-TAd appears in the context of a declarat-

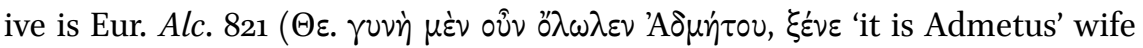
who is dead, stranger' [my translation]). However, the utterance is not so much informative as tense. Thus, Dale states that 'the Servant might intend 821 as a reproachful correction ( $\mu \dot{\varepsilon} v \circ \mathrm{u} v){ }^{\prime} .{ }^{34}$ The indefinite RP-TAd in the last line of the

32 In this regard, see also Haverkate (1984: 77-78) on the ironic use of señorito and of usted as 'typical of conflictive forms of verbal interaction' by generating distance through the code-switching.

33 Cf. Kleinknecht and Souza (2017: 257, 259, 261, 280-281).

34 Dale (1954: 111). See also Parker (2007: 214). 
stichomythia can also contribute towards conveying the servant's uneasy attitude and his insistence on the fact that Heracles should leave now. This is comparable to an example by Haverkate (1984: 75-76), in which an RP-TAd appears in a similar context of a declarative from which an inference can be drawn: Está lloviendo a cántaros, Adela ('It's pouring with rain, Adela'). Haverkate relates this example to the implication 'You cannot play tennis now' and concludes:

In the performance of indirect speech acts vocatives [...] serve as a signal for the hearer to infer that a multiple speech act is performed by the speaker.

c. Prayers. In Aesch. Supp. 811-816, there is an RP-TAd in the context of a prayer

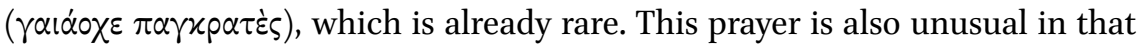
a present imperative is used instead of an expected aorist imperative. Note Johansen and Whittle's comment (1980: ad 814-815):

The shift from an aor. (811 $\tilde{\varepsilon} \pi(\delta \varepsilon)$ to a pres. imperat. [...] would indicate an emotional crescendo - an interpretation which is not improbable here but cannot be supported by other indications in the context.

It seems that the need of 'other indications' is provided by the RP-TAd and that this prayer could be considered especially urgent and emotional not just because of the present imperative but also because of the position of the invocation. Further, note that $\gamma \alpha \alpha_{\alpha} \alpha \chi \varepsilon \pi \alpha \gamma \varkappa p \alpha \tau \dot{\varepsilon} \varsigma$ in RP is a strong epithet which, added to the prayer, can work as a way of reinforcement. All these examples allow us to conclude that RP-TAds are less often employed to fulfil cA-functions than to reinforce or change the illocutionary force of (indirect) speech acts (Busse 2006: 114-115).

Both Bassett (1934: 146) and Dickey (1996) consider TAds as devices for characterisation. TAds can be a source for characterisation not only through semantic variation ${ }^{35}$ or omission (Bassett 1934: 145-146) but also through position, especially since RP-TAds are rare. Thus, there are (clusters of) RP-TAds instead of the expected LP- or M-TAds in the first words ${ }^{36}$ of troubled, hos-

35 Already at the very beginning of her monograph, Dickey (1996) considers TAd-variation as a device for characterisation, e.g. Hdt. 1.35.3, 41.1, 42.1, 45.2; Pl. Phd. 8ob-81c, and Socrates in Pl. Ap. (Dickey 1996: 179). See, likewise, Wendel (1929: 62-63) and Rutherford (2012: 102109).

36 See Rutherford (2012: 101) on the relevance of the first words addressed to a character and of the use of TAds. 
tile, and unsympathetic characters: Thanatos (Eur. Alc. 30), Alcmene (Heracl. 646-647[?], 648, 1050-1051), Peleus (Andr. 59o, 631), Pheres (Alc. 614, 620), Hermione (Andr. 170, 234-237), Menelaus (Andr. 309-313), and Ion (Ion 237-240, 244, 255, 289, 309, 333, 339, 372, 379). These characters are either young or old and/or unsympathetic. In light of these examples, the correlation between RPTAds and age seems to be of a secondary nature, in that RP-TAds do not depend on age in the way that, for instance, the use of the term $\pi \alpha \hat{\imath}$ does (which is used predominantly by significantly older characters). RP-TAds seem to occur particularly frequently with eagerness or excitement in behaviour. This in turn appears to be linked to a tendency to portray impetuous characters either as old or young.

\section{Conclusion}

TAds are mostly uttered in upward interactions, i.e. from lower-status characters to higher-status characters. In this regard, their omission can be salient from the standpoint of politeness. Regardless of their position, TAds were generally considered as devices for the establishment of contact and turn allocation. These considerations are still valid with regard to LP- and M-TAds. In contrast, RP-TAds are generally uttered when contact has already been established or when the next addressee has already been selected. Thus, the omission is not salient, and this leads to the question as to why they are used at all. On the other hand, RP-TAds are commonly uttered by impetuous characters, e.g. characters who are hostile and/or young/old.

In sum, LP- and RP-TAds are not randomly distributed. This leads us to the conclusion that not only the lexical meaning or the omission allow us to recognise the input of a specific TAd but also its position. LP-TAds relate to politeness, to CA functions, or to both. In either case, omissions are salient, in that they are either rude or urgent. RP-TAds are a way of conveying nuances that range from insistence, impatience, uneasiness, or worry to even greater feelings of hostility that challenge the addressee. A few instances could be interpreted as self-initiated repair: generally, when the content pushes itself into the first position and the RP-TAd is a respectful term. Thus, depending on the TAd type and the context, the degree of im/politeness varies. ${ }^{37}$ From a wider perspective, this is yet another example of how meaningful word order is, especially in

37 Similar conclusions were reached by Hill (1994: 325) on the familiariser dude in American English. 
Ancient Greek, where word order is syntactically less constrained than in other languages, such as English.

\section{Acknowledgements}

I am most thankful to the reviewers, to Emilia Ruiz Yamuza, and to Professor Mastronarde for improving my work. I would like to thank Severin Spring and Mevina Puorger. Above all, I feel deeply grateful to Gunther Martin for his invaluable help and comments on previous versions of this draft. I am responsible for every remaining infelicity.

\section{References}

Bassett, S., (1934), 'The Omission of the Vocative in Homeric Speeches', American Journal of Philology 55, 140-152.

Berger, Ł., (forthcoming), 'Position and Function of Nominal Address in Roman Comedy', in 2oth International Colloquium on Latin Linguistics (Universidad de las Palmas de Gran Canaria, 17th-21st June 2019).

Brioso-Sánchez, M., (1971), 'El vocativo y la interjección ڤ̂', Habis 2, 35-48.

Brown, P. \& Levinson, S.C., ( ${ }^{2} 1987$ [1978]), Politeness: some Universals in Language Usage, Cambridge.

Busse, B., (2006), Vocative Constructions in the Language of Shakespeare, Amsterdam.

Clayman, S.E., (2012), 'Pivotal Address Terms', Journal of Pragmatics 44, 1853-1867.

Conacher, D.J., (1988), Euripides, Alcestis, Warminster.

Culpeper, J., (1996), 'Towards an Anatomy of Impoliteness', Journal of Pragmatics 25, 349-367.

Culpeper, J., (2016), 'Impoliteness Strategies', in A. Capone \& J.L. Mey (eds.), Interdisciplinary Studies in Pragmatics, Culture and Society, Cham, 421-445.

Dale, A.M., (1954), Euripides, Alcestis, Oxford.

Davies, M., (1991), Sophocles, Trachiniae, Oxford.

Dickey, E., (1996), Greek Forms of Address: from Herodotus to Lucian, Oxford.

Dickey, E., (2002), Latin Forms of Address: from Plautus to Apuleius, Oxford/New York.

Dickey, E., (2010), 'Forms of Address and Markers of Status', in E.J. Bakker (ed.), A Companion to the Ancient Greek Language, Malden/Oxford/Chichester, 327-337.

Dik, H., (2007), Word Order in Greek Tragic Dialogue, Oxford.

Dik, S.C., (1997), The Theory of Functional Grammar, vol. 2, Berlin/New York.

Donati, M., (2013), Il vocativo nel processo identitario dell'interazione linguistica: prospettive dalle lingue classiche, Munich. 
Dover, K.J., (1968), Aristophanes, Clouds, Oxford.

Finglass, P.J., (2007), Sophocles, Electra, Cambridge.

Fraenkel, E., (1965), Noch einmal Kolon und Satz, Munich.

Geluykens, R., (1987), 'Tails (Right-dislocations) as a Repair Mechanism in English Conversation', in J. Nuyts \& G. de Schutter (eds.), Getting One's Words into Line: on Word Order and Functional Grammar, Dordrecht, 119-129.

Haverkate, H., (1984), Speech Acts, Speakers and Hearers: Reference and Referential Strategies in Spanish, Amsterdam.

Hill, R.A., (1994), 'You've Come a Long Way, Dude: a History', American Speech 69, 321327 .

Hindelang, G., (1978), Auffordern: Die Untertypen des Aufforderns und ihre sprachlichen Realisierungsformen, Göppingen.

House, J. \& Kasper, G., (1981), 'Politeness Markers in English and German', in F. Coulmas (ed.), Conversational Routine: Explorations in Standardized Communication Situations and Prepatterned Speech, The Hague/Paris, 157-185.

Jebb, R.C., ( ${ }^{3} 1894$ [1867]), Sophocles, The Electra, Cambridge.

Jebb, R.C., ( ${ }^{2} 1908$ [1892]), Sophocles, The Trachiniae, Cambridge.

Johansen, H.F. \& Whittle, E., (1980), Aeschylus, The Suppliants, 3 vols., Copenhagen.

Kannicht, R., (1969), Euripides, Helena, Heidelberg.

Kleinknecht, F. \& Souza, M., (2017), 'Vocatives as a Source Category for Pragmatic Markers', in C. Fedriani \& A. Sansò (eds.), Pragmatic Markers, Discourse Markers and Modal Particles. New perspectives, Amsterdam, 257-287.

Lee, K.H., (1997), Euripides, Ion, Warminster.

Lloyd, M., (1994), Euripides, Andromache, Warminster.

Martin, G., (2018), Euripides, Ion, Berlin/Boston.

Mastronarde, D., (1979), Contact and Discontinuity: some Conventions of Speech and Action on the Greek Tragic Stage, Berkeley.

McClure, L., (1995), 'Female Speech and Characterization in Euripides', in F. De Martino \& A.H. Sommerstein (eds.), Lo spettacolo delle voci, Part 2, Bari, 35-6o.

Parker, L.P.E., (2007), Euripides, Alcestis, Oxford.

Parkinson, D., (1985), Constructing the Social Context of Communication: Terms of Address in Egyptian Arabic, Berlin/New York.

Risselada, R., (1993), Imperatives and Other Directive Expressions in Latin: a Study in the Pragmatics of a Dead Language, Amsterdam.

Rutherford, R., (2012), Greek Tragic Style: Form, Language, and Interpretation, Cambridge.

Sacks, H., Schegloff, E.A., \& Jefferson, G., (1974), 'A Simplest Systematics for the Organization of Turn-taking for Conversation', Language 50, 696-735.

Sámano, J., 'Con lo que tenía, debía haber firmado a Karpin', El País, retrieved from https://elpais.com/diario/2002/12/o2/deportes/1038783614_850215.html [14/05/ 2019]. 
Scott, J.A., (1903), 'The Vocative in Homer and Hesiod', American Journal of Philology 24, $192-196$.

Scott, J.A., (1904), 'The Vocative in Aeschylus and Sophocles', American Journal of Philology $25,81-84$.

Scott, J.A., (1905), 'Additional Notes on the Vocative', American Journal of Philology 26, $32-43$.

Shalev, D., (2003), 'Yes (and No) in Ancient Literary Greek', in M. Bondi \& S. Stati (eds.), Dialogue Analysis 2000, Tübingen, 351-36o.

Sidnell, J., (2010), Conversation Analysis: an Introduction, Chichester.

Slocum, P.M., (2016), The Syntax of Address, Stony Brook.

Sonnenhauser, B., \& Noel Aziz Hanna, P. (eds.), (2013), Vocative! Addressing between System and Performance, Berlin/Boston.

Starkie, W.J.M., (1966), The Clouds of Aristophanes, Amsterdam.

Stevens, P.T., (1971), Euripides, Andromache, Oxford.

Venegas-Lagüéns, M., (1991), Elizabeth C. Gaskell: Characterization through Language, Sevilla.

Wendel, T., (1929), Die Gesprächsanrede im griechischen Epos und Drama der Blütezeit, Stuttgart.

Wilkins, J., (1993), Euripides, Heraclidae, Oxford.

Wilson, N.G., (2007), Aristophanis Fabulae, vol. 1, Oxford.

Zwicky, A.M., (1974), 'Hey, whatsyourname', in M.W. La Galy, R.A. Fox, \& A. Bruck (eds.), Papers from the 1oth Regional Meeting, Chicago Linguistic Society, Chicago, 787-801. 


\title{
The Linguistic Characterisation of Oedipus in $O T$ : A Pragmatics-Based Approach to 'Mind Style'
}

\author{
Evert van Emde Boas
}

\author{
Introduction: Mind Style and Linguistic Characterisation in Greek \\ Tragedy
}

[I]f a character talks with the power of the Deception Speech in Ajax or Electra's opening anapaests [...] we are forced to recognize the reality of the person portrayed. I am not of course suggesting that Sophocles consistently gives each character a style of his own. There are habits of style that any character will use in certain circumstances [...] in response to what Miss Dale called 'the rhetoric of the situation' [...] However, one can detect some degree of characterization by style, for example in contrasts between noble and lower characters ... ${ }^{1}$

So writes Easterling, in a characteristically lucid and insightful discussion of Sophoclean characterisation. The 'of course' in 'I am not of course suggesting' is revealing of an entrenched view, relevant not just to Sophocles but to all Greek tragedy, which appears to have gone largely unchallenged in the 40plus years since Easterling's article. The consensus remains that while some stylistic variation occurs, mostly on the margins and mostly used to delineate relatively minor characters, the language of the characters of Greek tragedy is still for the most part evened out by the weight of tragedy's all-levelling stylisation (of dialect, register, tone, and indeed situational rhetoric). In the words of another scholar, 'the conventional tragic Kunstsprache serves to disguise individual mannerism.'2 What remains difficult to see, however, is how this notion of linguistic uniformity can coexist with the 'power' of characters' language which forces us 'to recognize the reality of the person portrayed'. What kind of 'reality' could there be if every character speaks the same way, if no one is lifted out somehow from the homogeneous mass of tragic style?

1 Easterling (1977: 127-128); my italics.

2 Griffith (1977: 170). Griffith himself, to be fair, has since offered nuanced discussions of difference between the linguistic habits of some tragic figures, particularly those of Antigone (1999: 36-37, 2001). 
I have argued in previous publications (van Emde Boas 2017b, 2018) that a great deal more stylistic variation may be detected in the language of different characters in Greek tragedy, so long as one allows for a suitably broad conception of what falls under the header 'style.' ${ }^{3}$ It is true, of course, that tragic diction is circumscribed in various respects - a character will not stand out for his or her use of obscenities or foreign-language words and constructions, as such things simply do not occur in tragedy—but within these constraints the range with which tragic playwrights could operate was still significant. Modern linguistic approaches, not least pragmatics, furnish a wealth of methodological techniques that can help us to isolate and identify such stylistic variations, in ways that more traditional approaches to style do not always permit. $^{4}$

A broad conception of style, informed by modern linguistics, is in fact entirely in line with the overall approach of stylistics (a well-established field of research, conspicuously underused on the whole by classicists). ${ }^{5}$ My aim in this chapter is to bring to bear on Greek tragic characterisation the methodology and findings of a particular subfield of that discipline, namely work concerned with so-called 'mind style'. This is in itself a fairly broad field, at least in terms of methodological inclusiveness (as we shall see), but my main focus, in line with that of the volume, will be on its use of different areas of linguistic pragmatics as a key to getting at the distinguishing features of any individual character's style, and through that style, at the workings of the underlying represented mind. ${ }^{6}$ The particular mind I have in mind is that of Oedipus in Sophocles' Oed-

3 For an excellent recent book-length approach to Greek tragic style, see Rutherford (2012). It is noticeable that after a good discussion of definitional issues and previous approaches to style (2012: 4-27), the word 'style' is in fact not much used throughout the rest of that book, which includes chapters on such not obviously stylistic topics as 'The characters of Greek tragedy', 'The irony of Greek tragedy', and 'The wisdom of Greek tragedy'. This demonstrates a suitably loose and inclusive (if perhaps slightly undertheorised) approach as to what counts as tragic style.

4 For an example of such a 'traditional' approach to style, see Earp (1944) (still a useful book, even if not for my present purposes).

5 For good introductions and general overviews of the field, see e.g. Toolan (1998); Simpson (2004); Leech and Short ( $\left.{ }^{2} 2007\right)$; Nørgaard et al. (2010); Sotirova (2016).

6 This presupposes, as do notions such as Easterling's 'reality', that audiences approach characters on stage as if endowed with minds that can be read. For this presupposition as a necessary corollary of pragmatic approaches, see the Introduction to this volume; for mindreading in Greek tragedy see also Budelmann and Easterling (2010). I have discussed the notions of realism and mind-reading in tragic characterisation myself at greater length in van Emde Boas (2018, forthcoming b). A recent general treatment of characterisation in Sophocles (with further references, and including some discussion of characterisation by style) is Lloyd (2018). 
ipus Tyrannus, a character that, as we will see, has long challenged notions of tragic stylistic uniformity.

Although the tradition appears to be entirely untapped by classicists, 'mind style' as a term and concept has had considerable currency within stylistics since the late 1970s, and particularly since Leech and Short devoted a chapter to it in their Style in Fiction - a key text in the field. ${ }^{7}$ The term was originally coined by Fowler in his work Linguistics and the Novel (1977), as follows:

Cumulatively, consistent structural options, agreeing in cutting the presented world to one pattern or another, give rise to an impression of a world-view, what I shall call a 'mind style'.

We may coin the term 'mind style' to refer to any distinctive linguistic representation of an individual mental self. 8

As these definitions make clear, mind style refers to the way that linguistic patterns can reveal the mind of a writer or speaker (mind style research has investigated, variously, such patterns of authors, narrators, and characters). At the heart of mind style research lies a two-pronged methodological approach, neatly summarised by Semino:

The application of the notion of mind style requires two interrelated analytical steps, namely, the identification in a text (or part of a text) of linguistic patterns that are distinctive and systematic, and the interpretation of these patterns as the reflection of the characteristic, often idiosyncratic, workings of an individual's mind. ${ }^{9}$

Neither of these steps is straightforward. The identification of linguistic patterns is a difficult proposition for at least two reasons: first - and this is where the broad conception of style comes in - there is no obvious limit to the number of aspects of language use that might be relevant. Indeed, mind style research has focused on a great variety of linguistic phenomena, including not merely pragmatic aspects (such as adherence or non-adherence to Gricean

7 Leech and Short (1981, second edition 2007). For general discussions of mind style and overviews of the relevant literature, see Semino (2006, 2007); Shen (2010); Hoover (2016). The latter piece by Hoover argues for a restrictive application of mind style research which focuses mainly on 'narrators or characters with relatively abnormal minds' (2016: 338). This has, indeed, been the main focus of mind style research; to be clear, I do not mean to suggest anything about the (ab)normality of the mind of any individual Greek character.

8 Fowler (1977: 76 and 103 respectively).

9 Semino (2006: 143). 
maxims, marked use of deixis, marked conversational patterns), ${ }^{10}$ but also grammatical structure (sentence length and complexity, transitivity patterns, etc.), ${ }^{11}$ lexis ('key words' and semantic fields, over- and underlexicalisation, etc.), ${ }^{12}$ 'cognitive stylistic' approaches (blending theory, conceptual metaphor theory, schema theory, cognitive grammar, etc.), ${ }^{13}$ and other aspects such as formal logic, narrative focalisation, and second-language use and codeswitching. ${ }^{14}$

The second challenge on the identification side is getting the label 'distinctive and systematic' to stick to any individual pattern: quantitative analysis serves a key function here (as it will in my discussion below), but is not the whole story, particularly as it cannot be used for all of the areas of interest just listed.

As for the interpretation of linguistic patterns as reflective of an individual mind, this is no less tricky an enterprise, and necessarily dependent on a critic's subjective take-particularly, of course, when dealing with works from a culturally and historically remote society..$^{15}$ As my own analysis of Oedipus' language may demonstrate, such interpretations have a greater chance at being plausible if several features point in the same direction - and, of course, if the interpretation arrived at is compatible with interpretations previously derived otherwise.

$10 \quad$ E.g. Culpeper (2001); Semino (2002, 2014).

11 E.g. Halliday (1971); Bockting (1994); Hoover (1999); Leech and Short (2007: ch. 6); McIntyre and Archer (2010); Glotova (2014); MacMahon (2014).

12 E.g. Fowler (1986); Black (1993); Bockting (1994); Culpeper (2001, 2009a); Semino (2002); Leech and Short (2007: ch. 6); McIntyre and Archer (2010).

13 The advent of cognitive stylistics has been the most significant recent driver of mind style research. Under this (itself very broad) header fall such approaches which 'combin[e] the kind of explicit, rigorous and detailed linguistic analysis of literary texts that is typical of the stylistics tradition with a systematic and theoretically informed consideration of the cognitive structures and processes that underlie the production and reception of language' (Semino and Culpeper 2002: ix). Relevant publications include Semino and Swindlehurst (1996); Culpeper (2002, 2009b); Semino (2002, 2014); Glotova (2014); Nuttall (2018). Given this volume's focus on pragmatics, my own will not lie narrowly on cognitive approaches, although one of the branches of pragmatics with which I will deal briefly, Relevance Theory, could easily be ranged under that header. For a cognitive perspective on pragmatics more generally see e.g. Bara (2017), with references.

14 E.g. Nischik (1993); McIntyre (2005); Lugea (2016).

15 In the case of present-day speakers, a more 'objective' method is becoming a possibility, as a speaker's language can be compared to large databases that correlate linguistic features with independently measured personality traits (cf. e.g. the tool developed by The Psychometrics Centre at the University of Cambridge, https://applymagicsauce.com/ [accessed 1/o7/2019]). 
When it comes to previous interpretations of Oedipus (in $O T$ ), a memorable and hugely influential one is that of Bernard Knox, expounded first in his Oedipus at Thebes (1957) ${ }^{16}$ and later in the broader context of his The Heroic Temper (1964). Knox sums up his version of Oedipus, who he thinks was modelled by Sophocles on 'Athens itself, its heroic energy', ${ }^{17}$ by way of the following character vignette:

Such is the character of Oedipus: he is a great man, a man of experience and swift courageous action, who yet acts only after careful deliberation, illuminated by an analytic and demanding intelligence. His action by its consistent success generates a great self-confidence, but it is always directed to the common good. He is an absolute ruler who loves and is loved by his people, but is conscious of the jealousy his success arouses and suspicious of conspiracy in high places. He is capable of terrible, apparently ungovernable anger, but only under great provocation, and he can, though grudgingly and with difficulty, subdue his anger when he sees himself isolated from his people. ${ }^{18}$

Individual scholars and critics will agree or disagree to a greater or lesser extent with the terms of this sketch (and/or the very nature of it, depending on one's views about tragic characterisation): I myself am highly sympathetic to it. ${ }^{19}$ What I am more interested in, however, is the particular way in which Knox arrives at his description: his approach is relatively unusual in that it involves, in fact, a good amount of stylistic research. In a demonstration of what modern stylisticians might call 'key words' analysis, ${ }^{20}$ Knox runs through a number of specific Greek terms and semantic fields which, he thinks, are used especially by Oedipus or about him, and are revealing of his character: ${ }^{21}$

16 The book was republished, with a new preface by Knox, in 1998.

17 Knox (1964: 60); the full argument for this reading is presented in Knox (21998: ch. 2).

18 Knox ( $\left.{ }^{2} 1998: 29\right)$.

19 It may be worth noting that Knox's sketch is not dissimilar from how Oedipus is described

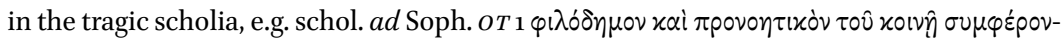

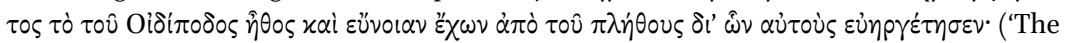
êthos of Oedipus is patriotic and shows forethought for the public good, and the people favour him on account of the good he has done for them.')

20 For key words analysis as an approach to characterisation in drama, see Culpeper (2001, 20oga).

21 Such an approach is inexplicably infrequent in tragic scholarship, even if not in Knox's 
- 'The words which express action (dran, prassein) are typical of his own speech and of the opinions of him expressed by others.' (Knox $\left.{ }^{2} 1998: 14\right)$

- '"Swift", tachys, is his word.' (Knox ${ }^{2}$ 1998: 15)

- "'I" (egô) is a word that is often on his lips: in the first 15o lines Oedipus speaks there are fourteen lines ending with some form of "I" or "my", and fifteen beginning in the same way.' (Knox $\left.{ }^{2} 1998: 21\right)$

Such features of Oedipus' diction could be taken, then, as the 'distinctive and systematic' indicators of a particular mind style, one geared towards swift action and self-confidence. But how distinctive are these features, really? In other words, how likely is it that such terms as caught Knox's eye and ear would have also jumped out at a fifth-century audience member sitting in the theatre?

We have, of course, no hope of deriving any conclusive proof about such questions, but some (rudimentary) statistics may at least help us get a sense. ${ }^{22}$ A good place to start may be to compare the features that Knox identifieswords relating to action, relating to speed, and first-person pronouns-in the language of Oedipus himself and that of the other characters of Oedipus Tyrannus. ${ }^{23}$ The relevant figures are given in Table 1 (the percentages indicate frequencies relative to the total number of words uttered by each speaker).

What these figures seem to suggest, at first glance, is that Oedipus does not use the relevant terms much more frequently than the other characters in the play, with the possible exception of first-person pronominal forms. ${ }^{24}$ There is, of course, more to Knox's claims, and such statistics in themselves cannot capture their full extent: thus Knox is interested not just in things 'typical of [Oed-

own further work (not merely in The Heroic Temper [ch. 1], but also e.g. in his analysis of Medea in Euripides' play [Knox 1977]).

22 Almost all the figures presented below are based on searches using Perseus under PhiloLogic (http://perseus.uchicago.edu/ [1/o7/2019]), maintained at the University of Chicago. This search tool permits, at least for the Greek tragic and comic corpus, searches by speaker (as well as by word class, morphological features, lemma, etc.). One minor drawback is that searches are necessarily based on Perseus' somewhat antiquated text editions, in the case of Sophocles those of Jebb. Variations between editions of Sophocles are largely insignificant, however, for the data presented below; for $о$ T, I have checked relevant passages against the edition of Finglass (superior, in my view, to those of Dawe and LloydJones and Wilson).

23 I have excluded the chorus from these figures, on the grounds that they do not offer a fully suitable comparison to any individual character, and that their lyric passages (which are not easily excluded from automatic searches) would unhelpfully skew any data about them.

24 This should be seen against the backdrop, however, of the very high frequency of first-

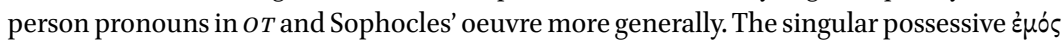
is, in fact, the most frequent lemma both in $о т$ and in all of Sophocles (see e.g. Rigo 1996, or the new 'Statistics' feature of the online TLG). 
TABLE 1 Word counts and frequencies in OT

\begin{tabular}{|c|c|c|c|c|c|c|c|c|}
\hline & Oedipus & Priest & Creon & Tiresias & Iocasta & Corinthian & Servant & Messenger \\
\hline Total number of words & 4208 & 318 & 879 & 520 & 793 & 379 & 189 & 432 \\
\hline \multicolumn{9}{|l|}{ Action words } \\
\hline $\begin{array}{l}\pi \rho \alpha \gamma-((\dot{\varepsilon} x) \pi \rho \alpha \dot{\alpha} \sigma \sigma \omega, \pi \rho \hat{\alpha} \gamma \mu \alpha, \\
\text { etc. })\end{array}$ & $\begin{array}{l}10 \\
0.2 \%\end{array}$ & $\begin{array}{l}0 \\
0.0 \%\end{array}$ & $\begin{array}{l}1 \\
0.1 \%\end{array}$ & 1 & $\begin{array}{l}2 \\
0.3 \%\end{array}$ & $\begin{array}{l}2 \\
0.5 \%\end{array}$ & $0.0 \%$ & $\begin{array}{l}1 \\
0.2 \%\end{array}$ \\
\hline$\delta \rho \alpha-(\delta \rho \alpha \omega$, etc. $)$ & 12 & $0.0 \%$ & $\begin{array}{l}9 \\
1.0 \%\end{array}$ & $0.0 \%$ & $\begin{array}{l}1 \\
0.1 \%\end{array}$ & 1 & $\begin{array}{l}1 \\
0.5 \%\end{array}$ & $\begin{array}{l}1 \\
0.2 \%\end{array}$ \\
\hline 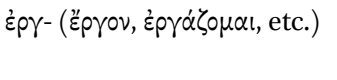 & 12 & $0.0 \%$ & $\begin{array}{l}2 \\
0.2 \%\end{array}$ & $0.0 \%$ & $\begin{array}{l}0 \\
0.0 \%\end{array}$ & $\begin{array}{l}0 \\
0.0 \%\end{array}$ & $0.0 \%$ & $\begin{array}{l}1 \\
0.2 \%\end{array}$ \\
\hline total & $\begin{array}{l}34 \\
0.8 \%\end{array}$ & $\begin{array}{l}\text { O } \\
0.0 \%\end{array}$ & 12 & 1 & $\begin{array}{l}3 \\
0.4 \%\end{array}$ & $\begin{array}{l}3 \\
0.8 \%\end{array}$ & $\begin{array}{l}1 \\
0.5 \%\end{array}$ & $\begin{array}{l}3 \\
0.7 \%\end{array}$ \\
\hline \multicolumn{9}{|l|}{ Speed words } \\
\hline 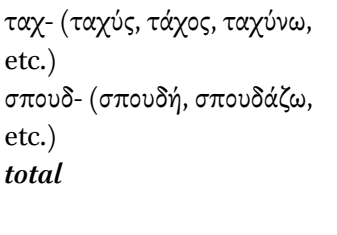 & $\begin{array}{l}12 \\
0.3 \% \\
1 \\
0.0 \% \\
13 \\
0.3 \%\end{array}$ & $\begin{array}{l}0 \\
0.0 \% \\
0 \\
0.0 \% \\
0 \\
0.0 \%\end{array}$ & $\begin{array}{l}2 \\
0.2 \% \\
0 \\
0.0 \% \\
2 \\
0.2 \%\end{array}$ & $\begin{array}{l}2 \\
0.4 \% \\
0 \\
0.0 \% \\
2 \\
0.4 \%\end{array}$ & $\begin{array}{l}2 \\
0.3 \% \\
0 \\
0.0 \% \\
2 \\
0.3 \%\end{array}$ & $\begin{array}{l}1 \\
0.3 \% \\
0 \\
0.0 \% \\
1 \\
0.3 \%\end{array}$ & $\begin{array}{l}1 \\
0.5 \% \\
0 \\
0.0 \% \\
1 \\
0.5 \%\end{array}$ & $\begin{array}{l}2 \\
0.5 \% \\
0 \\
0.0 \% \\
2 \\
0.5 \%\end{array}$ \\
\hline \multicolumn{9}{|l|}{ First-person pronouns } \\
\hline 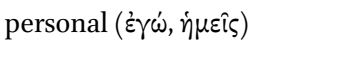 & $\begin{array}{l}165 \\
3.9 \%\end{array}$ & $\begin{array}{l}8 \\
2.5 \%\end{array}$ & $\begin{array}{l}30 \\
3.4 \%\end{array}$ & $\begin{array}{l}20 \\
3.8 \%\end{array}$ & $\begin{array}{l}15 \\
1.9 \%\end{array}$ & $\begin{array}{l}10 \\
2.6 \%\end{array}$ & $\begin{array}{l}3 \\
1.6 \%\end{array}$ & $\begin{array}{l}3 \\
0.7 \%\end{array}$ \\
\hline 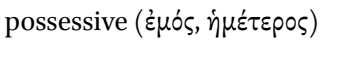 & $\begin{array}{l}42 \\
1.0 \%\end{array}$ & $\begin{array}{l}1 \\
0.3 \%\end{array}$ & $\begin{array}{l}4 \\
0.5 \%\end{array}$ & $\begin{array}{l}3 \\
0.6 \%\end{array}$ & $\begin{array}{l}1 \\
0.1 \%\end{array}$ & $\begin{array}{l}2 \\
0.5 \%\end{array}$ & $\begin{array}{l}1 \\
0.5 \%\end{array}$ & $\begin{array}{l}0 \\
0.0 \%\end{array}$ \\
\hline reflexive ( $(\dot{\mu} \mu \alpha \tau \tau \diamond \hat{\nu})$ & $\begin{array}{l}12 \\
0.3 \%\end{array}$ & $\begin{array}{l}0 \\
0.0 \%\end{array}$ & $\begin{array}{l}0 \\
0.0 \%\end{array}$ & $\begin{array}{l}1 \\
0.2 \%\end{array}$ & $\begin{array}{l}0 \\
0.0 \%\end{array}$ & $\begin{array}{l}1 \\
0.3 \%\end{array}$ & $\begin{array}{l}0 \\
0.0 \%\end{array}$ & $\begin{array}{l}0 \\
0.0 \%\end{array}$ \\
\hline total & $\begin{array}{l}219 \\
5.2 \%\end{array}$ & $\begin{array}{l}9 \\
2.8 \%\end{array}$ & $\begin{array}{l}34 \\
3.9 \%\end{array}$ & $\begin{array}{l}24 \\
4.6 \%\end{array}$ & $\begin{array}{l}16 \\
2.0 \%\end{array}$ & $\begin{array}{l}13 \\
3.4 \%\end{array}$ & $\begin{array}{l}4 \\
2.1 \%\end{array}$ & $\begin{array}{l}3 \\
0.7 \%\end{array}$ \\
\hline
\end{tabular}

ipus'] own speech' but also of 'the opinions of him expressed by others'; and his discussion of first-person pronouns is attentive to local clustering (in the first 15 o lines) and to word placement, ${ }^{25}$ not just to raw frequencies. Even such amendments leave a mixed picture, however: for instance, none of the twelve

25 But for helpful correctives to the notion that line-initial or line-final placement in itself means very much in Greek tragedy in general (and Sophocles in particular), see Dik (2007). 
action words uttered by the most frequent user of such vocabulary, Creon (we may wonder how applicable the label 'man of swift courageous action' is to him), refers unambiguously to action by Oedipus alone. Similarly, while there are numerous stretches of Oedipus' language that contain interesting clustering of first-person pronouns, none of them approaches the density of Tiresias' first few turns, where the priest uses such forms at a rate of once per line. ${ }^{26}$

I do not wish to minimise the relevance of the semantic fields identified by Knox, all of which are indeed of some significance in the play. It is more difficult to maintain, however, that these areas of the lexicon are specifically characteristic of the language of any individual speaker, Oedipus or anyone else. Nor, as it turns out, does Oedipus stand out in this respect in a very noticeable way from speakers in other Sophoclean plays. We may compare him, for instance, to all other Sophoclean males with major speaking roles: see Table $2 .{ }^{27}$

Again, Oedipus scores high on the use of first-person pronouns, but again he is not exceptional even on this front (and indeed outperformed by Heracles and Philoctetes). Even if, then, these lexical items are thought to be significant, that significance is not easily mapped onto the distinctive nature of the language of an individual speaker or, by extension, the underlying working of his mind.

It may be in part for this reason that many of the traits and characteristics that Knox originally (in Oedipus at Thebes, 1957) presented as peculiar to Oedipus became, by the time of his Sather lectures (The Heroic Temper, 1964), features more generally of the 'Sophoclean hero' (male or female, incidentally). To be clear, I am not arguing that all Sophoclean heroes are exactly alike in their language - in fact over-generalisation is one of the criticisms sometimes levelled at Knox's work: rather, I argue that meaningful variation is best sought elsewhere - and this is precisely where pragmatics can come in. ${ }^{28}$

26 Possibly significant clusters of first-person pronouns in Oedipus' language may be found (in addition to the first 15 o lines identified by Knox) at 774-834, 964-972, 1076-1085, 13691415, 1446-1475. Tiresias uses 14 of his 24 first-person pronouns in his first 14 lines (107 words, with a frequency of $13.1 \%$, i.e. roughly once every eight words).

27 I have set the benchmark for 'major role', entirely arbitrarily, at 1000 spoken words or more (in the complete plays only).

28 As regards key words and semantic fields, some other aspects identified by Knox as relevant for the Sophoclean hero in general do show unusual distributions in $O T$, if not always weighted towards Oedipus himself. Knox observes: 'The use of the verbal adjective, a form expressing necessity, of the future tenses, above all of the tone which brooks no argument - all this is characteristic of the hero's resolve to act' (1964: 10). In $O T$, forms of $\chi \rho \eta$ are used only by Oedipus (10x) and, once, by Jocasta (the verbal adjective and $\delta \varepsilon \hat{\imath}$ are somewhat more regularly distributed). Tiresias is a significant outlier with respect to the future stem (using it roughly twice as often as other speakers in the play). For other semantic fields, see Knox (1964: 11-26). 
TABLE 2 Word counts and frequencies for male speakers in Sophocles

\begin{tabular}{|c|c|c|c|c|c|c|c|c|c|c|c|c|}
\hline & 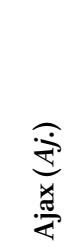 & 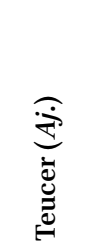 & 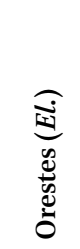 & 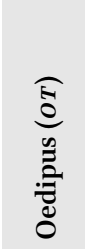 & 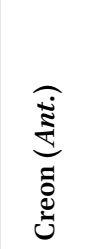 & 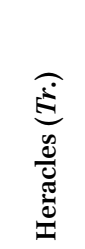 & 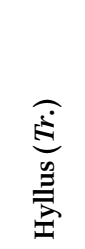 & 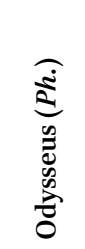 & 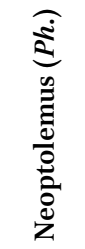 & 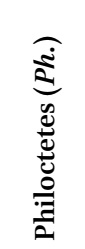 & 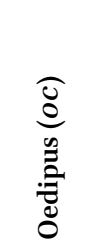 & 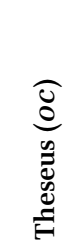 \\
\hline $\begin{array}{l}\text { Total number } \\
\text { of words }\end{array}$ & 1625 & 1317 & 1006 & 4208 & 2088 & 1182 & 1063 & 1058 & 2423 & 3769 & 3849 & 1218 \\
\hline
\end{tabular}

\section{Action words}

\begin{tabular}{|c|c|c|c|c|c|c|c|c|c|c|c|c|}
\hline \multirow[t]{2}{*}{$\pi \rho \alpha \gamma^{-}$} & 2 & 1 & 1 & 10 & 4 & 1 & 4 & 2 & 4 & 4 & 6 & 6 \\
\hline & $0.7 \%$ & $0.1 \%$ & $0.1 \%$ & $0.2 \%$ & $0.2 \%$ & $0.1 \%$ & $0.4 \%$ & $0.2 \%$ & $0.2 \%$ & $0.1 \%$ & $0.2 \%$ & $0.5 \%$ \\
\hline \multirow[t]{2}{*}{$\delta \rho \alpha-$} & 3 & 4 & 2 & 12 & 8 & 5 & 4 & 5 & 14 & 12 & 7 & 6 \\
\hline & $0.2 \%$ & $0.3 \%$ & $0.2 \%$ & $0.3 \%$ & $0.4 \%$ & $0.4 \%$ & $0.4 \%$ & $0.5 \%$ & $0.6 \%$ & $0.3 \%$ & $0.2 \%$ & $0.5 \%$ \\
\hline \multirow[t]{2}{*}{ 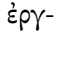 } & 5 & 4 & 4 & 12 & 4 & 4 & 4 & 4 & 3 & 6 & 7 & O \\
\hline & $0.3 \%$ & $0.3 \%$ & $0.4 \%$ & $0.3 \%$ & $0.2 \%$ & $0.3 \%$ & $0.4 \%$ & $0.4 \%$ & $0.1 \%$ & $0.2 \%$ & $0.2 \%$ & $0.0 \%$ \\
\hline \multirow[t]{2}{*}{ total } & 10 & 9 & 7 & 34 & 16 & 10 & 12 & 11 & 21 & 22 & 20 & 12 \\
\hline & $0.6 \%$ & $0.7 \%$ & $0.7 \%$ & $0.8 \%$ & $0.8 \%$ & $0.8 \%$ & $1.1 \%$ & $1.0 \%$ & $0.9 \%$ & $0.6 \%$ & $0.5 \%$ & $1.0 \%$ \\
\hline
\end{tabular}

\section{Speed words}

\begin{tabular}{|c|c|c|c|c|c|c|c|c|c|c|c|c|}
\hline$\tau \alpha \chi^{-}$ & $\begin{array}{l}9 \\
0.6 \%\end{array}$ & $\begin{array}{l}3 \\
0.2 \%\end{array}$ & $\begin{array}{l}3 \\
0.3 \%\end{array}$ & $\begin{array}{l}12 \\
0.3 \%\end{array}$ & $\begin{array}{l}3 \\
0.1 \%\end{array}$ & $\begin{array}{l}2 \\
0.2 \%\end{array}$ & $\begin{array}{l}2 \\
0.2 \%\end{array}$ & $\begin{array}{l}3 \\
0.3 \%\end{array}$ & $\begin{array}{l}4 \\
0.2 \%\end{array}$ & $\begin{array}{l}5 \\
0.1 \%\end{array}$ & $\begin{array}{l}6 \\
0.2 \%\end{array}$ & $\begin{array}{l}3 \\
0.2 \%\end{array}$ \\
\hline טठ- & O & O & O & 1 & O & O & O & 1 & O & 1 & 1 & 1 \\
\hline & $0.0 \%$ & $0.0 \%$ & $0.0 \%$ & $0.0 \%$ & $0.0 \%$ & $0.0 \%$ & $0.0 \%$ & $0.7 \%$ & $0.0 \%$ & $0.0 \%$ & $0.0 \%$ & $0.7 \%$ \\
\hline tal & $\begin{array}{l}9 \\
0.6 \%\end{array}$ & $\begin{array}{l}3 \\
0.2 \%\end{array}$ & $\begin{array}{l}3 \\
0.3 \%\end{array}$ & $\begin{array}{l}13 \\
0.3 \%\end{array}$ & $\begin{array}{l}3 \\
0.1 \%\end{array}$ & $\begin{array}{l}2 \\
0.2 \%\end{array}$ & $\begin{array}{l}2 \\
0.2 \%\end{array}$ & $\begin{array}{l}4 \\
0.4 \%\end{array}$ & $\begin{array}{l}4 \\
0.2 \%\end{array}$ & $\begin{array}{l}6 \\
0.2 \%\end{array}$ & $\begin{array}{l}7 \\
0.2 \%\end{array}$ & $\begin{array}{l}4 \\
0.3 \%\end{array}$ \\
\hline
\end{tabular}

\section{First-person pronouns}

\begin{tabular}{lllllllllllll}
\hline personal & 55 & 32 & 28 & 165 & 52 & 53 & 28 & 38 & 74 & 183 & 164 & 44 \\
& $3.4 \%$ & $2.4 \%$ & $2.8 \%$ & $3.9 \%$ & $2.5 \%$ & $4.5 \%$ & $2.6 \%$ & $3.6 \%$ & $3.1 \%$ & $4.9 \%$ & $4.3 \%$ & $3.6 \%$ \\
possessive & 22 & 6 & 5 & 42 & 10 & 14 & 7 & 2 & 12 & 19 & 21 & 8 \\
& $1.4 \%$ & $0.5 \%$ & $0.5 \%$ & $1.0 \%$ & $0.5 \%$ & $1.2 \%$ & $0.7 \%$ & $0.2 \%$ & $0.5 \%$ & $0.2 \%$ & $0.5 \%$ & $0.7 \%$ \\
reflexive & 0 & 0 & 0 & $\mathbf{1 2}$ & 2 & 0 & 0 & 0 & 0 & 0 & 3 & 0 \\
& $0.0 \%$ & $0.0 \%$ & $0.0 \%$ & $0.3 \%$ & $0.1 \%$ & $0.0 \%$ & $0.0 \%$ & $0.0 \%$ & $0.0 \%$ & $0.0 \%$ & $0.1 \%$ & $0.0 \%$ \\
total & $\mathbf{7}$ & $\mathbf{3 8}$ & $\mathbf{3 3}$ & $\mathbf{2 1 9}$ & $\mathbf{6 4}$ & $\mathbf{6 7}$ & $\mathbf{3 5}$ & $\mathbf{4} \%$ & $\mathbf{8 6}$ & $\mathbf{2 0 2}$ & $\mathbf{1 8 8}$ & $\mathbf{5 2}$ \\
& $\mathbf{4 . 7} \%$ & $\mathbf{2 . 9} \%$ & $\mathbf{3 . 3} \%$ & $\mathbf{5 . 2} \%$ & $\mathbf{3 . 1} \%$ & $\mathbf{5 . 7} \%$ & $\mathbf{3 . 3} \%$ & $\mathbf{3 . 8} \%$ & $\mathbf{3 . 5} \%$ & $\mathbf{5 . 4} \%$ & $\mathbf{4 . 9} \%$ & $\mathbf{4 . 3} \%$
\end{tabular}


TABLE 3 Sentence-ending punctuation in OT

\begin{tabular}{|c|c|c|c|c|c|c|c|c|}
\hline & Oedipus & Priest & Creon & Tiresias & Iocasta & Corinthian & Servant & Messenger \\
\hline $\begin{array}{l}\text { Sentence-ending } \\
\text { punctuation }\end{array}$ & 430 & 22 & 97 & 57 & 86 & 49 & 31 & 32 \\
\hline $\begin{array}{l}\text { frequency } \\
\text { (every \# words) }\end{array}$ & 9.8 & 14.5 & $9 \cdot 1$ & 9.1 & 9.2 & $7 \cdot 7$ & 6.1 & $13 \cdot 5$ \\
\hline Full stop & 200 & 10 & 64 & 33 & 44 & 32 & 20 & 25 \\
\hline $\begin{array}{l}\text { proportion } \\
\text { (of all sentence-enders) }\end{array}$ & $46.5 \%$ & $45.5 \%$ & $66.0 \%$ & $57.9 \%$ & $51.2 \%$ & $65.3 \%$ & $64.5 \%$ & $78.1 \%$ \\
\hline frequency & 21.0 & 31.8 & 13.7 & 15.8 & 18.0 & 11.8 & $9 \cdot 5$ & $17 \cdot 3$ \\
\hline High dot & 101 & 12 & 16 & 16 & 19 & 6 & 2 & 7 \\
\hline $\begin{array}{l}\text { proportion } \\
\text { (of all sentence-enders) }\end{array}$ & $23.5 \%$ & $54.5 \%$ & $16.5 \%$ & $28.1 \%$ & $22.1 \%$ & $12.2 \%$ & $6.5 \%$ & $21.9 \%$ \\
\hline frequency & 41.7 & 26.5 & $54 \cdot 9$ & 32.5 & 41.7 & 63.2 & $9 \cdot 5$ & 61.7 \\
\hline Question mark & 129 & o & 17 & 8 & 23 & 11 & 9 & o \\
\hline $\begin{array}{l}\text { proportion } \\
\text { (of all sentence-enders) }\end{array}$ & $30.0 \%$ & $0.0 \%$ & $17.5 \%$ & $14.0 \%$ & $26.7 \%$ & $22.4 \%$ & $29.0 \%$ & $0.0 \%$ \\
\hline frequency & 32.6 & $\mathrm{n} / \mathrm{a}$ & $5^{1.7}$ & 65.0 & 34.5 & 34.5 & $94 \cdot 5$ & $\mathrm{n} / \mathrm{a}$ \\
\hline
\end{tabular}

Bare statistics may still serve as a useful starting point for isolating distinctive aspects, however. In Table 3 and Table 4, I have done no more than count every instance of sentence-ending punctuation-i.e. full stops, high dots, and question marks - in digitally available editions. Here, Oedipus does stand out, both with respect to the other characters of Oedipus Tyrannus and those of Sophocles' work more widely.

Some of the more notable figures in these tables are in fact fully expected: that the messenger of Oedipus Tyrannus, for instance, does not use questions (and overwhelmingly favours full stops) is fully in line with his role: he is on stage to relate a series of narrative facts. ${ }^{29}$ But the finding that I am interested in here, of course, pertains to Oedipus' use of questions. No other character, either in his play or in the rest of the Sophoclean oeuvre, can match the frequency with which he utters them. There are, of course, plot reasons for this:

29 It is significant here that the messenger's speech does not include quoted direct speech. 
TABLE 4 Sentence-ending punctuation of male speakers in Sophocles

\begin{tabular}{|c|c|c|c|c|c|c|c|c|c|c|c|c|}
\hline & 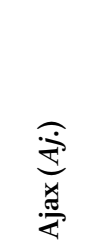 & 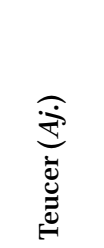 & 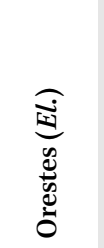 & 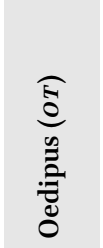 & 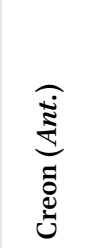 & 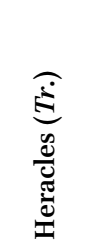 & 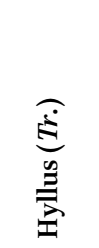 & 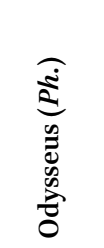 & 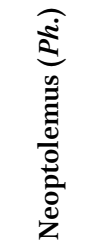 & 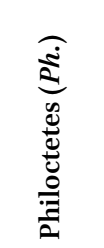 & 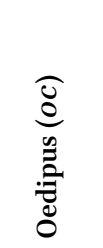 & 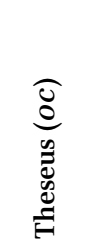 \\
\hline $\begin{array}{l}\text { Sentence- } \\
\text { enders }\end{array}$ & $15^{2}$ & 157 & 128 & 430 & 207 & 111 & 110 & 116 & 286 & 386 & 372 & 115 \\
\hline frequency & 10.7 & 8.4 & $7 \cdot 9$ & 9.8 & 10.1 & 10.6 & $9 \cdot 7$ & 9.1 & 8.5 & 9.8 & 10.3 & 10.6 \\
\hline Full stop & 85 & 94 & 72 & 200 & 121 & 67 & 61 & 61 & 153 & 194 & 194 & $6 o$ \\
\hline proportion & $55.9 \%$ & $59.9 \%$ & $56.3 \%$ & $46.5 \%$ & $58.5 \%$ & $60.4 \%$ & $55.5 \%$ & $52.6 \%$ & $53.5 \%$ & $50.3 \%$ & $52.2 \%$ & $52.2 \%$ \\
\hline frequency & 19.1 & 14.0 & 14.0 & 21.0 & $17 \cdot 3$ & 17.6 & 17.4 & $17 \cdot 3$ & 15.8 & 19.4 & 19.8 & 20.3 \\
\hline High dot & 43 & 30 & 31 & 101 & 36 & 27 & 32 & 31 & 75 & 96 & 76 & 26 \\
\hline proportion & $28.3 \%$ & $19.1 \%$ & $24.2 \%$ & $23.5 \%$ & $17.4 \%$ & $24.3 \%$ & $29.7 \%$ & $26.7 \%$ & $26.2 \%$ & $24.9 \%$ & $20.4 \%$ & $22.6 \%$ \\
\hline frequency & 37.8 & 43.9 & 32.5 & 41.7 & 58.0 & 43.8 & 33.2 & 34.1 & $32 \cdot 3$ & $39 \cdot 3$ & $5^{\circ} .6$ & 46.8 \\
\hline $\begin{array}{l}\text { Question } \\
\text { mark }\end{array}$ & 24 & 33 & 25 & 129 & $5^{\circ}$ & 17 & 17 & 24 & 58 & 96 & 102 & 29 \\
\hline
\end{tabular}

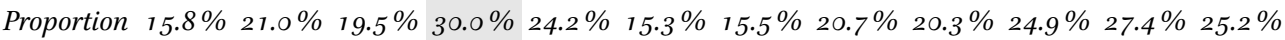

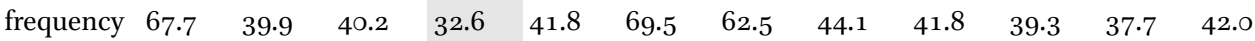

the Oedipus Tyrannus is in many ways a detective story, with Oedipus as the lead investigator asking the questions. But it is difficult not to broaden such interpretations to include notions of characterisation: what Knox described as Oedipus' 'analytic and demanding intelligence' makes him into a particularly persistent asker of questions. His investigative performance stands out, not merely within his own play but within Sophocles' oeuvre. This becomes all the more clear when we examine (in the next section) his style of questioning in more detail, as a pragmatics-based approach will allow us to do. 


\section{$3 \quad$ Pragmatics and Oedipus' Mind Style}

\section{1 'Oh Really?': Oedipus the King of Post-expansions}

Looking at Oedipus' questions more closely reveals some interesting and pertinent pragmatic aspects of his language. First, it is notable how few of Oedipus' interrogatives are not genuine information-seeking questions: overwhelmingly, Oedipus asks questions in order to get answers. ${ }^{30}$ More striking still, though, is Oedipus' use of a particular kind of follow-up question, one that we see very frequently repeated in his investigations.

This questioning technique may well be captured in the terms of Conversation Analysis (CA), particularly insofar as that field (a subdiscipline of pragmatics, on some accounts) is concerned with 'sequence organisation'. ${ }^{31} \mathrm{CA}$ has well established that the most basic organisational resource of naturally occurring talk-in-interaction is the 'adjacency pair', a sequence of two related turns by two speakers, with a 'first pair part' (FPP) which projects its own completion by a particular kind of 'second pair part' (SPP). Common action sequences performed by adjacency pairs include greeting-greeting, requestacceptance/refusal, assessment-agreement/disagreement, and indeed question-answer. A further crucial notion is that of 'expansion': adjacency pairs may be preceded, interrupted, or followed by expansion sequences (themselves typically adjacency pairs), which are oriented to the most efficient resolution of the 'base pair' to which they belong. The basic schema is set out in Figure 1.

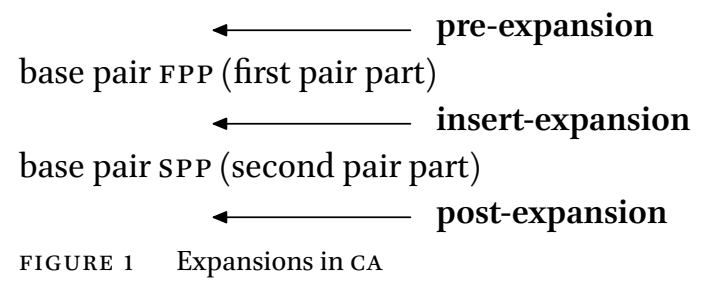

The following (fictional) English example contains each of the three kinds of expansion, organised around a question-answer base pair:

30 For different uses of questions in tragedy, see Mastronarde (1979: ch. 1); for a linguistic account of non-information-seeking questions more generally see Ilie (1994). Exceptions among Oedipus' questions include 334-336, 339-340, 429-431, 1489-149o.

31 For CA as applied to Greek tragedy, see Schuren (2015); Drummen in Bonifazi et al. (2016); van Emde Boas (2017a, 2017b, forthcoming a). Of these, Drummen and van Emde Boas (2017a) have fuller introductions to the discipline. Good surveys of the field are Sidnell (2010); Sidnell and Stivers (2012). The best work specifically on sequence organisation is Schegloff (2007). 

A: Could you help me?
$F P P 1$
(pre-expansion)
B: Of course.
SPP1
A: How much does that phone cost?
FPP2 (base pair first part)
B: Pounds or euros?
$F P P 3$
(insert-expansion)
A: Pounds, please.
$\triangle P P 3$
B: It's three-nine-nine, then.
$S P P 2$ (base pair second part)
A: Sorry, how much?
FPP4
(post-expansion;
other-initiated repair)

B: Three-nine-nine.

SPP4

This passage also exemplifies another significant notion in CA, that of 'repair'. This term refers to 'overt efforts to deal with trouble sources or repairables', that is, with any troubles or problems 'in speaking, hearing, or understanding' (Schegloff 2007: 100-101). The primary locus of repair, particularly 'other-initiated repair', tends to be in insert- or (as in the example above) post-expansions specifically initiated for the purpose.

Something quite like this kind of post-expansion is a noticeable staple of Oedipus' language in Oedipus Tyrannus. A first highly pertinent example will set the stage here:

\section{[1] Sophocles Oedipus the King $35^{6-362^{32}}$}

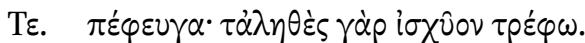

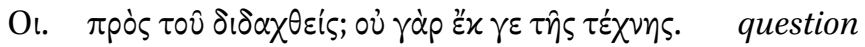

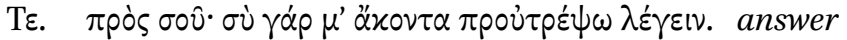

Oı. $\pi 0 \hat{i o v ~ \lambda o ́ \gamma o v ; ~} \lambda \varepsilon^{\prime} \gamma^{\prime} \alpha \hat{\theta}$

question

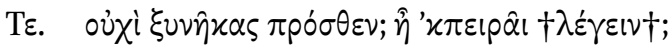

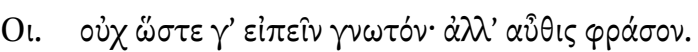
question -insert-exp.

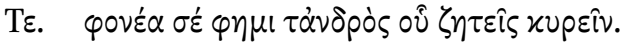
answer answer

Ti. I have escaped it; for I nourish the strength of truth.

Oe. Taught by whom? Not by your art, at any rate.

Ti. By you. For you made me speak although I was unwilling.

Oe. Speak what? Tell me again, so I can learn once more.

Ti. Did you not understand before? Or are you trying ...? 
Oe. Not so that I could say that I knew; come, say it again.

Ti. I say that you are the killer of the man whose killer you are seeking.

In the context of the (at this point very angry) conversation between Oedipus and Tiresias, and more generally given the conventions of tragic dialogue, it seems unlikely that we are dealing here with a genuine mishearing, nor is this, presumably, a 'normal' kind of misunderstanding: Oedipus (mis)understood Tiresias full well the first time (350-353), in the same way that he will (mis)understand him throughout the rest of scene. ${ }^{33}$ Rather, Oedipus here uses the resources of repair-sequences (particularly marked as such by his $\lambda \bar{\varepsilon}^{\prime} \gamma^{\prime} \alpha \hat{\theta} \theta ı$, $\dot{\omega} \varsigma \mu \hat{\alpha} \lambda$ ㅇ $\mu \dot{\alpha} \theta \omega)$ to initiate a further sequence of questioning. ${ }^{34}$ This particular type of post-expansion, which looks like a repair-sequence but is in fact geared towards eliciting further talk on a topic mentioned in the second pair part of the base pair, has been well investigated within CA under the header of 'topicalisation':

Several of the turn types which can be used for other-initiation of repair can also be used to mark some utterance or utterance part as of special interest, and worthy of further on-topic talk. [... This] type of postexpansion [...] is the topicalization of something done or mentioned in the base second pair part. Such expansions then become subject to the organizational contingencies of topic-talk. ${ }^{35}$

In English such topicalisation sequences are regularly marked by (partial) repeats or 'pro-repeats' ('he is?') or by '(oh) really'.6 In Greek tragedy, an apparently fairly conventional marker of this kind of sequence is the use of the interrogative adjective $\pi 0 \hat{0}$ ऽ 'what kind of ...?', as in [1] above. ${ }^{37}$ Oedipus, I contend, is a uniquely fervent user of this type of post-expansion, especially with $\pi$ oîos. He repeatedly puts it in to play to pick up a particular point of information from a preceding second pair part as a topic for more precise

33 See Battezzato in this volume.

34 Cf. Dawe ( ${ }^{2} 2007$ : $a d$ 359): 'More than once in tragedy one character asks another to repeat what he has said, so that the audience may fully grasp some important point ... Here Sophocles puts new life into an old convention by making the very request for repetition the material for generating further ill-will between the two parties.' On this passage, see also Battezzato's paper in this volume.

35 Schegloff (2007:155-158).

36 See Heritage (1984: 339-344); Schegloff (2007: 155).

37 The device is also frequently used in post-expansions in comedy, but there is no need to assume a coarse or colloquial tone: see Bond (1981) on Eur. Her. 518, Collard (2018: 87-89). 
questioning. He is, I should add, not the only character to use the technique in the play, but he uses it much more frequently than anyone else, and the device could easily be described as a 'distinctive and systematic' Oedipodeanism. ${ }^{38}$

Most of the relevant examples, like [1], are 'follow-ups', in which Oedipus attaches a post-expansion to a question-answer sequence which he himself has initiated, when he is not satisfied that the answer provided has told him all he needs to know:

[2] Sophocles Oedipus the King 116-121

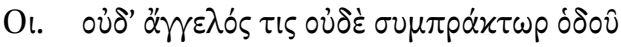

question

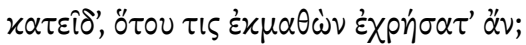

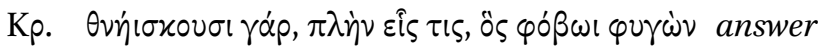

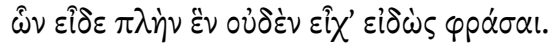

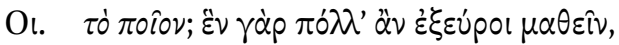

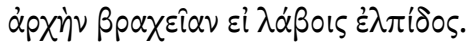

question-post-exp.

Oe. Didn't either some messenger or fellow-traveller see anything, from whom one would have learned something, putting him to use?

Cr. No, because they are dead - apart from one, who fled in fear and was not able to state anything reliably about what he had seen, except for one thing.

Oe. What is that? One thing might lead to the discovery of many for us to learn, if we could grasp some brief beginning of hope.

38 Oedipus' examples with $\pi$ oî́ are $89,99,120,291,359,437,1176$; he also has similar postexpansions without $\pi 0 \hat{10 \varsigma, ~ e . g . ~ a t ~} 1017,1041$. He uses $\pi$ oî also in new sequences that are not obviously post-expansions, at 102, 128, 1124, 1164 (the distinction between new sequences and post-expansions in extended talk-in-interaction is often slight). Different again are 1489 and 149 , rhetorical $\pi 0 \hat{0}$ - $-q u e s t i o n s$ addressed to his children (1371, lastly, is similar, but in an indirect question). Other characters use $\pi 0$ îs-post-expansions at 935 (Jocasta), 989 (Corinthian) and 1129 (Servant). Creon's two instances of $\pi$ oî ent: at 559 and 571 he uses $\pi$ oî́ questions in interruptions, anticipating (syntactically as well as in terms of content) Oedipus' own questions. As this survey shows, raw frequencies of $\pi$ oî́-usage are only partly indicative: Oedipus scores high on this front $(14 \times)$, but is matched or outstripped by Tiresias ( 2 instances, not post-expansions), Jocasta ( $2 \times$, including the case at 935 mentioned above), and the Servant (1×, 1129). Elsewhere in Sophocles only Theseus in $O C$ approaches Oedipus' level of usage $(5 \times \pi 0 i 0 \varsigma$, three of which are comparable post-expansions). 
This restive style of questioning is, of course, dramatically important, in that it causes Oedipus to pick at all the threads which, for his own sake, he had better left unpicked. In this way, as so often in tragedy, characterisation and plot design are inextricably intertwined: as Oedipus is relentless in his pursuit of every last detail of fact, so the plot drives relentlessly, through every new revelation, towards the final discovery of the truth. Example [2] indeed thematises this point explicitly early on in the play: one discovery will lead to many. ${ }^{39}$

We see the same impulse to pick at threads, at similar points of dramatic significance, demonstrated in a few other cases where Oedipus attaches a postexpansion to second parts which do not form part of an ongoing questionanswer sequence. Oedipus' interlocutors in these cases seem to want to close off an ongoing sequence, but Oedipus refuses to let things lie and immediately 'reactivates' the sequence with a post-expansion to further interrogate an element that has come up in his interlocutor's turn:

[3] Sophocles Oedipus the King 284-291

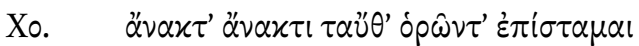

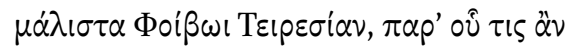

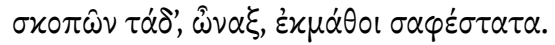

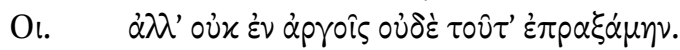

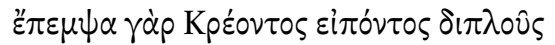

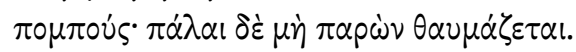

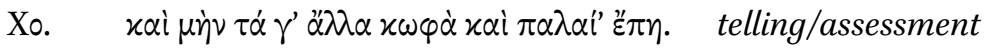

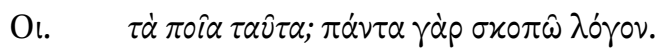
(sequence-closer?) question-post-exp.

Cho. I know that lord Tiresias sees the same things as does lord Phoebus, and from him, my lord, one might learn these things most truly in the course of investigation.

Oe. Well, I saw to it that not even this act should be among things neglected. For at Creon's request, I have sent two messengers, and for some time it has been a source of wonder that he is not here.

Cho. Yes, and as for the rest, they are mute, ancient tales.

Oe. What is that rumour? I am examining the whole question. ${ }^{40}$

39 As Finglass points out (2018: ad loc.), “' $\mathrm{t}$ ] he sententious remark is more relevant than Oedipus realises, since the information provided by the witness is centred on the distinction between singular and plural' (i.e. the question of how many robbers there were).

The translation of the last line is mine. 
[4] Sophocles Oedipus the King 432-437

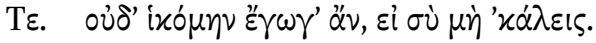

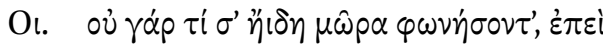

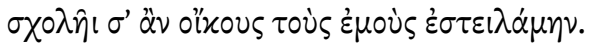

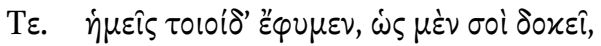
$\mu \omega \hat{\omega} \rho \mathrm{l}, \gamma$,

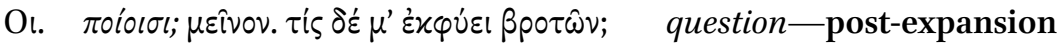

Te. I would not have come, if you had not called me.

Oe. Yes, because I had no idea that you would speak words of foolishness, since otherwise I would scarcely have had you summoned to my house.

Te. That is what I am, as it seems to you-foolish; but to your parents, who begot you, I seemed wise.

Oe. What parents? Stay! Who among mortals was my parent?

Commentators' observations on these moments are revealing: on [4], Finglass (2018: ad loc.) notes that 'for the first time in nearly a hundred lines, Oedipus suddenly becomes desperately eager to hear what the prophet has to say [...] the staccato language expresses agitation'; on [3], Dawe ( ${ }^{2} 2007$ : ad loc.) notes that the chorus' 'casual throwaway remark instantly excites Oedipus' detective instincts'. Such remarks show how natural it is to interpret Oedipus' style of questioning in terms of his frame of mind, and indeed (as Dawe does) as an indication of his more permanent 'instincts'.

Dawe is more reluctant, however, to adopt a similar explanation for a further instance in the final sleuthing scene of the play, in which Oedipus at last discovers the truth:

[5] Sophocles Oedipus the King 1173-1176

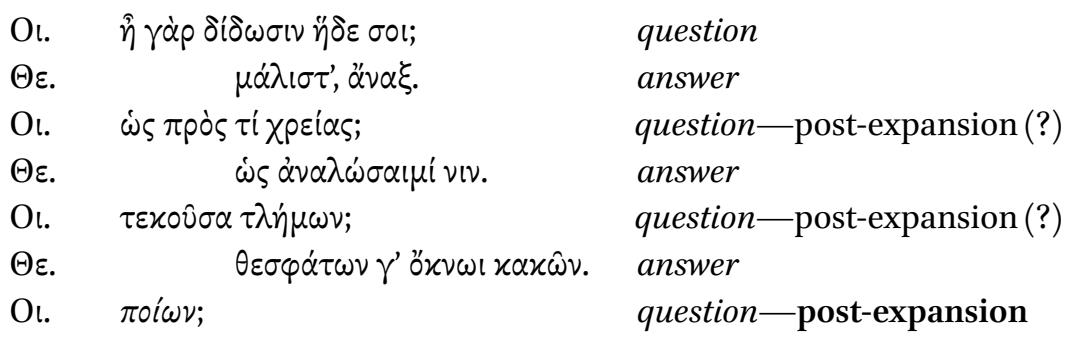

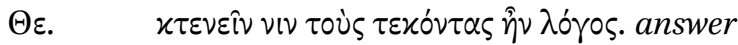


Oe. So it was she who gave it to you?

Shep. Yes, my lord.

Oe. For what purpose?

Shep. So that I would kill it.

Oe. She brought herself to do that, after giving birth to the child?

Shep. Yes, through fear of dire prophecies.

Oe. What prophecies?

Shep. The story was that it would kill its parents.

Dawe comments:

In real life no one would ever ask these supplementary questions after facts of incomparably greater importance had been revealed, not even a man as remorseless in the pursuit of the truth as Oedipus. It is for the audience's benefit that Sophocles is giving the final clarification here. ${ }^{41}$

Yet given what we have seen from Oedipus 'remorseless [...] pursuit of the truth' previously in the play, I would argue that Oedipus' style of questioning in this scene is entirely in character. It is, in fact, in the build-up to this scene that we have had the most explicit statement by Oedipus of his own investigative approach, a self-assertion which may well be taken as emblematic for his behaviour throughout the play:

[6] Sophocles Oedipus the King 1064-1065 ${ }^{42}$

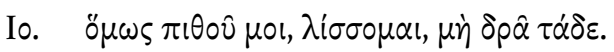

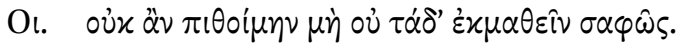

Jo. All the same do as I wish, I beg you! Do not do this!

Oe. You will never persuade me not to find out the truth!

\subsection{Maximising Relevance: Oedipus the King of Implicatures}

Oedipus in Oedipus the King is the conscientious ruler of a city gripped by plague, confident in his ability to solve problems through energy and

41 Dawe (2007: $\left.a d{ }^{2} 176\right)$.

42 The translation in this case is taken from Lloyd-Jones (1994). 
intelligence. [...] As the play continues, this energy turns out to have a darker side. Oedipus is impatient, hot-tempered, prone to jump to conclusions. ${ }^{43}$

Scodel's character sketch, which of course shares many features with Knox's (cited above) and those of others, ${ }^{44}$ explicitly draws the link between on the one hand the 'energy and intelligence' that we have seen come through in Oedipus' uncompromising style of questioning, and on the other his overly suspicious nature, which he demonstrates particularly in the scene with Tiresias and in the subsequent exchange with Creon.

A pragmatics-based reading, too, invites us to see these two traits-intelligence and distrust verging on paranoia — as two sides of the same coin. What appears to drive Oedipus, in all parts of the play, is primarily an overdeveloped desire for 'relevance', meant in the technical sense that that term has in Relevance Theory. In Relevance Theory, Sperber and Wilson's cognitively inflected update of Grice's foundational model of conversational maxims and conversational implicatures ${ }^{45}$ communication operates as a constant balancing exercise. On the one hand an individual confronted with any given input will attempt to extract as much useful information as possible from that input, but on the other hand he or she will attempt to exert as little cognitive processing effort as possible in order to do so. In the formal terms used by Wilson and Sperber, these two competing 'principles of relevance' are formulated as follows:

Other things being equal, the greater the positive cognitive effects achieved by processing an input, the greater the relevance of the input to the individual at that time.

Other things being equal, the greater the processing effort expended, the lower the relevance of the input to the individual at that time. ${ }^{46}$

43 Scodel (2005: 240-241).

44 So, Gould (2002 [1988]: 257) writes of the 'quickness of rationality' of Oedipus' mind, and of the 'swiftness with which one inference follows on another': 'it is [...] the habit of his mind to leap ahead in making connections, in picking on the link in the chain of reasoning that must be tested.'

45 Agood introduction to Relevance Theory (RT) is Wilson and Sperber (2004) (but it is worth going straight for the fuller discussions in Sperber and Wilson $\left.{ }^{2} 1995\right)$. For RT and mind style see Semino (2014). Some rudimentary attempts to apply RT to tragedy may be found in van Emde Boas (2017b).

$46 \quad$ Wilson and Sperber (2004: § 2). 
Grice's notion of conversational implicature-that is, meaning that is implied and inferred rather than 'literal'-is recast on this model as the continued processing of an input (beyond a literal surface reading) until sufficient relevance is extracted: we keep deriving implicatures until (but only until) the information we have derived is worth the effort.

What we may observe in Oedipus is that the balance of this calculation is off: the 'positive cognitive effects' that Oedipus achieves in his interactions are never enough for him. As we have seen in his style of questioning, he is always hungry for more inputs, always probing his interlocutors for any bit of information that can still his hunger for relevance. The other direction that he can swing in, however, is to extract unreasonable amounts of relevance from minimal (and as such deficient) inputs: where 'normal' people might stop deriving implicatures from such deficient information, Oedipus just never stops processing, and jumps to entirely unfounded conclusions about what it means when (particularly) Tiresias and Creon tell him (or do not tell him) things. Again, we are given, fairly early on in the play, an almost programmatic statement of this feature of Oedipus' behaviour, in his own words:

[7] Sophocles Oedipus the King 342-349

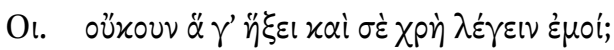

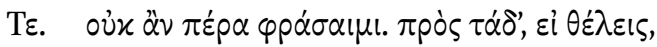

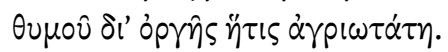

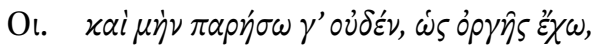

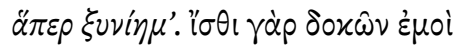

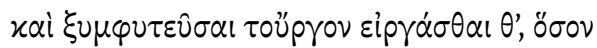

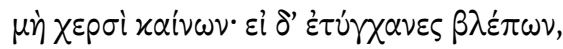

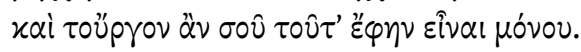

Oe. Ought you not actually to tell me what is going to come?

Ti. I will speak no further. In the face of that, if you want to, rage with the anger that is fiercest.

Oe. Well, I will leave out nothing — such is my anger — of what I understand. Know that you seem to me to have actually plotted the deed and carried it out, except that you did not commit the actual murder; and if you happened to have sight, I would have said that this deed too was yours alone.

'I will leave out nothing [...] of what I understand', indeed: Oedipus understands much. In some cases, though, what he understands is far too much, and 
horribly misguided. This, then, is the 'darker side' of Oedipus' probing intelligence and his relentless commitment to uncovering the truth, the same traits which propel him to ask ever more searching questions and to never be satisfied with the answers.

It is hugely telling that Oedipus himself would connect, in [7], his communicative behaviour to his own mental and emotional state-his óprý (344). In a play in which, as Lloyd has well noted, 'there is relatively little direct characterisation of Oedipus [...] either by himself or by others, ${ }^{47}$ there is added significance to such moments, in which the characters themselves draw connections between certain kinds of behaviour and certain mental and emotional frames.

The particular contribution that pragmatics can make to the analysis of such moments is first of all to bring into clearer focus that the 'kinds of behaviour' that we may be interested in go well beyond the outward and physical (such as striking down a driver in an altercation on crossroads: $\pi \alpha^{\prime} \omega \delta^{\prime} \iota^{\prime}$ op $\left.ү \hat{\eta} \varsigma, 807\right)$ but include verbal and communicative behaviour: it is in the ways in which Oedipus engages conversationally with everyone with whom he shares the stage that we see the workings of his mind most clearly. Those interactions vary in tone-as can only be expected, seeing that the king is confronted variously with a co-operative interviewee, an enigmatic priest, an aggrieved brother-inlaw(/uncle), a concerned wife(/mother), and an unforthcoming servant. For all their variety, however, there is remarkable consistency in what Oedipus' interactions reveal about him.

What pragmatics can offer us above all is the detailed tools to make sense of the precise nuances of communicative behaviour. It is through some of these details, as we have seen, that playwrights are able to draw fine-grained distinctions between individual characters. As long as we are happy to class these aspects of language use under the header 'style', it turns out that it is precisely in them that we can find the kinds of stylistic variation that the Greek tragedians used, even within the superficially homogeneous tragic Kunstsprache, to achieve remarkably subtle characterisation.

47 Lloyd (2018:344). 'Direct characterisation' refers to the explicit and direct verbal ascription of (relatively stable) traits to a character (in drama always by the character him/herself or another character, in narrative also by the narrator). 


\section{References}

Bara, B.G., (2017), 'Cognitive Pragmatics', in Y. Huang (ed.), The Oxford Handbook of Pragmatics, Oxford, 279-299.

Black, E., (1993), 'Metaphor, Simile and Cognition in Golding's The Inheritors', Language and Literature 2, 37-48.

Bockting, I., (1994), 'Mind Style as an Interdisciplinary Approach to Characterisation in Faulkner', Language and Literature 3, 157-174.

Bond, G.W., (1981), Euripides, Heracles, Oxford.

Bonifazi, A., Kreij, M. de, \& Drummen, A., (2016), Particles in Ancient Greek Discourse: Five Volumes Exploring Particle Use Across Genres, Washington, D.C. https://chs.harv ard.edu/CHS/article/display/6391.particles-in-ancient-greek-discourse [05/o7/ 2019].

Budelmann, F. \& Easterling, P.E., (2010), 'Reading Minds in Greek Tragedy', Greece \& Rome 57, 289-303.

Collard, C., (2018), Colloquial Expressions in Greek Tragedy, Stuttgart.

Culpeper, J., (2001), Language and Characterisation: People in Plays and Other Texts, Harlow.

Culpeper, J., (2002), 'A Cognitive Stylistic Approach to Characterisation', in E. Semino \& J. Culpeper (eds.), Cognitive Stylistics: Language and Cognition in Text Analysis, Amsterdam, 251-278.

Culpeper, J., (2009a), 'Keyness: Words, Parts-of-Speech and Semantic Categories in the Character-Talk of Shakespeare's Romeo and Juliet', International Journal of Corpus Linguistics 14, 29-59.

Culpeper, J., (2009b), 'Reflections on a Cognitive Stylistic Approach to Characterisation', in J. Vandaele \& G. Brône (eds.), Cognitive Poetics: Goals, Gains and Gaps, Berlin, 125159 .

Dawe, R.D., ( 2007 [1982]), Sophocles, Oedipus Rex, Cambridge.

Dik, H.J.M., (2007), Word Order in Greek Tragic Dialogue, Oxford.

Earp, F.R., (1944), The Style of Sophocles, Cambridge.

Easterling, P.E., (1977), 'Character in Sophocles', Greece \& Rome 24, 121-129.

Emde Boas, E. van, (2017a), 'Analyzing Agamemnon: Conversation Analysis and Particles in Greek Tragic Dialogue', Classical Philology 112, 411-434.

Emde Boas, E. van, (2017b), Language and Character in Euripides' Electra, Oxford.

Emde Boas, E. van, (2018), 'Aeschylus', in K. De Temmerman \& E. van Emde Boas (eds.), Characterization in Ancient Greek Literature, Leiden, 317-336.

Emde Boas, E. van, (forthcoming a), '(Im)politeness and Conversation Analysis in Greek Tragedy: The Case of Theseus and the Herald in Euripides' Supplices', in L. Unceta Gómez \& Ł. Berger (eds.), Im/politeness in Greek and Roman Literature, Cambridge. 
Emde Boas, E. van, (forthcoming b), 'Mindreading, Character, and Realism: The Case of Medea', in F. Budelmann \& I. Sluiter (eds.), Minds on Stage: Cognitive Approaches to Greek Tragedy, Leiden.

Finglass, P.J., (2018), Sophocles, Oedipus the King, Cambridge.

Fowler, R., (1977), Linguistics and the Novel, London.

Fowler, R., (1986), Linguistic Criticism, Oxford.

Glotova, E., (2014), 'The Suffering Minds: Cognitive Stylistic Approach to Characterization in The Child-Who-Was-Tired by Katherine Mansfield and Sleepy by Anton Chekhov', Theory and Practice in Language Studies 4, 2445-2454.

Gould, J., (2002 [1988]), 'The Language of Oedipus', in Myth, Ritual, Memory, and Exchange: Essays in Greek Literature and Culture, Oxford, 244-262 [repr. of H. Bloom (ed.), (1988), Sophocles, Oedipus Rex, New Haven, 143-16o].

Griffith, M., (1977), The Authenticity of 'Prometheus Bound', Cambridge.

Griffith, M., (1999), Sophocles, Antigone, Cambridge.

Griffith, M., (2001), 'Antigone and her Sister(s): Embodying Women in Greek Tragedy', in A. Lardinois \& L. McClure (eds.), Making Silence Speak: Women's Voices in Greek Literature and Society, Princeton, 117-136.

Halliday, M.A.K., (1971), 'Linguistic Function and Literary Style: An Inquiry into the Language of William Golding's The Inheritors', in S. Chatman (ed.), Literary Style: a Symposium, New York, 330-368.

Heritage, J.C., (1984), 'A Change-of-State Token and Aspects of Its Sequential Placement', in J.M. Atkinson \& J.C. Heritage (eds.), Structures of Social Action, Cambridge, 299-345.

Hoover, D.L., (1999), Language and Style in The Inheritors, Lanham.

Hoover, D.L., (2016), 'Mind-Style', in Sotirova 2016, 325-340.

Ilie, C., (1994), What Else Can I Tell You? A Pragmatic Study of English Rhetorical Questions as Discursive and Argumentative Acts, Stockholm.

Knox, B., ( ${ }^{2} 1998$ [1957]), Oedipus at Thebes: Sophocles' Tragic Hero and his Time, New Haven.

Knox, B.M.W., (1964), The Heroic Temper: Studies in Sophoclean Tragedy, Berkeley.

Knox, B.M.W., (1977), 'The Medea of Euripides', Yale Classical Studies 25, 193-225.

Leech, G.N. \& Short, M., ( ${ }_{2}^{2007}$ [1981]), Style in Fiction: A Linguistic Introduction to English Fictional Prose, Harlow.

Lloyd-Jones, H., (1994), Sophocles, vol. 1, Cambridge, Mass./London.

Lloyd, M.A., (2018), 'Sophocles', in K. De Temmerman \& E. van Emde Boas (eds.), Characterization in Ancient Greek Literature, Leiden, 337-354.

Lugea, J., (2016), 'Spanglish Dialogue in You and Me: An Absurd World and Senile Mind Style', in J. Gavins \& E. Lahey (eds.), World Building: Discourse in the Mind, London, 221-240.

MacMahon, B., (2014), 'Relevance Theory, Syntax and Literary Narrative', in S. Chapman \& B. Clark (eds.), Pragmatic Literary Stylistics, Basingstoke, 90-110. 
Mastronarde, D.J., (1979), Contact and Discontinuity: some Conventions of Speech and Action on the Greek Tragic Stage, Berkeley.

McIntyre, D., (2005), 'Logic, Reality and Mind Style in Alan Bennett's The Lady in the Van', Journal of Literary Semantics 34, 21-40.

McIntyre, D. \& Archer, D., (2010), 'A Corpus-Based Approach to Mind Style', Journal of Literary Semantics 39, 167-182.

Nischik, R., (1993), 'Mind Style Analysis and the Narrative Modes for the Presentation of Consciousness', in H. Foltinek, W. Riehle, \& W. Zacharasiewicz (eds.), Tales and 'Their Telling Difference': Zur Theorie und Geschichte der Narrativik. Festschrift zum 70. Geburtstag von Franz K. Stanzel, Heidelberg, 93-107.

Nørgaard, N., Busse, B., \& Montoro, R., (2010), Key Terms in Stylistics, London.

Nuttall, L., (2018), Mind Style and Cognitive Grammar: Language and Worldview in Speculative Fiction, London.

Rigo, G., (1996), Sophocle, Opera et fragmenta omnia: index verborum, listes de fréquence, Liège.

Rutherford, R., (2012), Greek Tragic Style: Form, Language, and Interpretation, Cambridge.

Schegloff, E.A., (2007), Sequence Organization in Interaction, Cambridge.

Schuren, L., (2015), Shared Storytelling in Euripidean Stichomythia, Leiden.

Scodel, R., (2005), 'Sophoclean Tragedy', in J. Gregory (ed.), A Companion to Greek Tragedy, Malden/Oxford/Chicester, 233-250.

Semino, E., (2002), 'A Cognitive Stylistic Approach to Mind Style in Narrative Fiction', in E. Semino \& J. Culpeper (eds.), Cognitive Stylistics: Language and Cognition in Text Analysis, Amsterdam, 95-122.

Semino, E., (2006), 'Mind Style', in E.K. Brown \& A. Anderson (eds.), Encyclopedia of Language \& Linguistics, Amsterdam, 142-148.

Semino, E., (2007), 'Mind Style Twenty-Five Years On', Style 41, 153-173.

Semino, E., (2014), 'Pragmatic Failure, Mind Style and Characterisation in Fiction about Autism', Language and Literature 23, 141-158.

Semino, E. \& Culpeper, J., (2002), 'Foreword', in E. Semino \& J. Culpeper (eds.), Cognitive Stylistics: Language and Cognition in Text Analysis, Amsterdam, ix-xvi.

Semino, E. \& Swindlehurst, K., (1996), 'Metaphor and Mind Style in Ken Kesey's One Flew Over the Cuckoo's Nest', Style 30, 143-166.

Shen, D., (2010), 'Mind-Style', in D. Herman, M. Jahn, \& M.-L. Ryan (eds.), Routledge Encyclopedia of Narrative Theory, London.

Sidnell, J., (2010), Conversation Analysis: An Introduction, Malden/Oxford/Chicester.

Sidnell, J. \& T. Stivers (eds.), (2012), The Handbook of Conversation Analysis, Malden/ Oxford/Chichester.

Simpson, P., (2004), Stylistics: A Resource Bookfor Students, London.

Sotirova, V. (ed.), (2016), The Bloomsbury Companion to Stylistics, London. 
Sperber, D. \& Wilson, D., ( ${ }^{2} 1995$ [1986]), Relevance: Communication and Cognition, Oxford.

Toolan, M.J., (1998), Language in Literature: An Introduction to Stylistics, London.

Wilson, D. \& Sperber, D., (2004), 'Relevance Theory', in L.R. Horn \& G. Ward (eds.), The Handbook of Pragmatics, Malden, 607-632. 


\title{
Resonance in the Prologue of Sophocles' Ajax
}

\author{
Severin Hof
}

\section{Doing Things with Words Together}

In the mid-twentieth century, the American classicist G.M. Kirkwood wrote about the functioning of Sophoclean drama that it depended, more than in the cases of Aeschylus and Euripides, on 'character interaction.' ${ }^{1}$ While I am not going to probe the claim concerning Aeschylus and Euripides, I will undertake a reading of a scene of a Sophoclean drama, the prologue of the Ajax (1-133), where I will pay close attention to the way the characters interact, utterance for utterance, and show how intimately the communicative mechanisms that are displayed in the characters' dialogue are tied up with the functioning of the prologue as a dramatic text. ${ }^{2}$

Looking at interaction means, first and foremost, being aware of the fact that dialogue is a joint product of the interlocutors involved, hence something they do together. Doing things together with words is where pragmatics — or, for the sake of this paper, the concept of resonance-enters the picture. Central to this concept, developed by the American linguist J.W. du Bois within his theory of dialogic syntax, is the insight that not only is a dialogue as a whole a joint product, but so is, to a certain extent, also every single contribution by the interactants. ${ }^{3}$ For, to understand the meaning of a single turn-at-talk, it is not sufficient to look at it by itself, but it needs to be considered in the light of what has been said before, i.e. of the material already present in the 'his-

1 Kirkwood (1958: 99-101).

2 In doing so, my paper is firmly anchored within the domain of pragmatics, since both communicative systems, the external and the internal one in the terms of Pfister (1988: $3-4)$, are, for the fact of being communicative, open to a pragmatic analysis (cf. Jucker and Locher 2017: in particular 1-2; an analysis of the external system inevitably shows overlaps with domains such as narratology and reception theory). This is even more the case since the paper does not analyse these two systems alongside each other (if such a thing is possible) but shows how understanding the external communicative system depends on a precise understanding of the internal one.

3 Du Bois (2014), especially 372-375. The genesis of the theory of dialogic syntax is influenced by the concept of dialogism famously developed by Bakhtin (1986: 87-100; see also 1981: 275294) and Vološinov (1973: 83-98); see Clark (1996) on language use as a 'joint action' and Linell (1998: 86-87, 127-154) on dialogue as a 'joint construction'; see also Drummen (2016b: §§ 1-7) and cf. the concept of 'common ground' (Allan in this volume). 
tory' of the dialogue (the 'co-text') with which the speaker makes it 'resound':4 how does an interactant embed his or her contribution in the dialogue? How does he or she, at the different levels of syntax, semantics, and pragmatics, take up and make use of what has been said before and expand on it, thus adding new elements to the 'history' of the conversation?5 I shall explain this by means of an example from the play under discussion. In the second half of the Ajax, Teucer and Menelaus argue about the latter's denial of burial to Ajax. In their dispute, the following exchange occurs: ${ }^{6}$

[1a] Sophocles Ajax 1139-1141

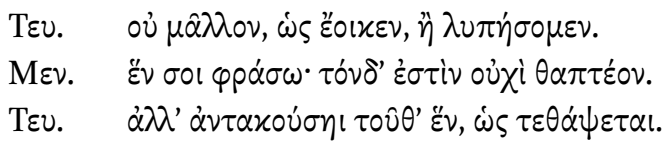

Teu. To no more pain, I think, for me than for you.

Men. I will say one word to you; this man must not be buried!

Teu. But you shall hear one word in reply, that he shall be buried!

The pragmatic value of Menelaus' affirmation consists not only of his denial of Ajax's burial, but also of claiming unconditional authority by virtue of his word, as is shown by his breaking off the preceding discussion. Instead of continuing the discussion, he affirms without further argument, but with the metalinguistic expression 'I will say one word to you', that Ajax will not be buried (note the verbal adjective $\theta \alpha \pi \tau \varepsilon$ ' 0 1140, 'must [not] be buried').

Teucer's riposte also dispenses with any supporting argument but states as a fact that Ajax will be buried. Thus, not only does he affirm his determination to bring about the burial, but he also challenges Menelaus' claim to authority by virtue of his word that he has made before. (Note that Teucer, as well, prefaces his affirmation with a metalinguistic utterance, viz. 'But you shall hear one word in reply', thus echoing — also syntactically—Menelaus' 'I will say one word to you'.) Teucer's contestation of Menelaus' claim to authority by vir-

4 Resonance is a concept particularly helpful to investigate Greek particles, which function as 'contextualisation cues' (Cook-Gumperz and Gumperz 1976), i.e. as means by which interlocutors express the particular pragmatic intention of their taking up elements of preceding utterances. For the importance of particles to this paper's argument cf. n. 21, 22, and 30 below.

5 Du Bois (2014: 36o-365).

6 Texts are from Lloyd-Jones and Wilson (1990); translations are adapted from Lloyd-Jones (1994). 
tue of his word is central to the entire exchange of the two men, ${ }^{7}$ and, in the excerpt just discussed, this contestation can be grasped by looking at resonance.

In order to visualise the relationships between single turns-at-talk, I will make use of typographic means. I will italicise elements taken up and print in bold new elements with which the interlocutors expand on the preceding dialogue (e.g. 1140 being bold means that Menelaus does conspicuously not engage with what has been said before, but breaks off the discussion):

[1b] Sophocles Ajax 1139-1141

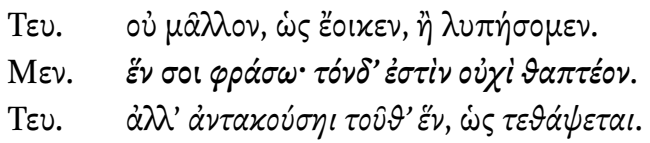

Teu. To no more pain, I think, for me than for you.

Men. I will say one word to you; this man must not be buried!

Teu. But you shall hear one word in reply, that he shall be buried!

In the following, I am going to look at several instances of interaction in the prologue of the Ajax where participants engage - or ostentatively refuse to engage, which is, of course, also a sort of engagement (cf. Menelaus' line 1140 above)with the preceding 'dialogue material'. Doing so will make it possible to better understand the clues Sophocles gives to his recipients, ${ }^{8}$ particularly how he creates audience involvement by the depiction of the ways his characters engage with preceding utterances.

The Ajax starts with what is often called a dumb-show: a Greek warrior is seen lurking around a hut, looking to the ground, obviously searching for something. This warrior-Odysseus - is then joined by the goddess Athena. Their exchange starts as follows:

7 Barker (2009: 299-302).

8 The word 'clue' is important: When talking about the audience, I do not claim to reconstruct the reaction of an 'empirical' recipient, but the signals contained in the text for its 'implied recipient' (see Iser 1978: 34). 
[2] Sophocles Ajax 1-17, 21-24, 31-35

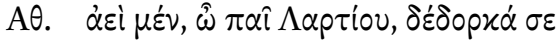

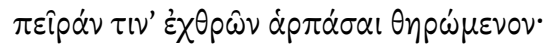

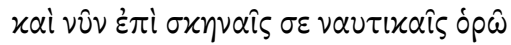

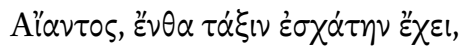

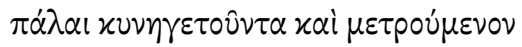

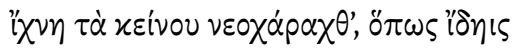

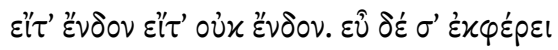

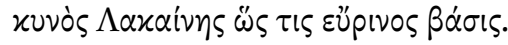

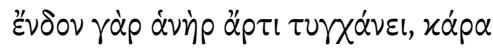

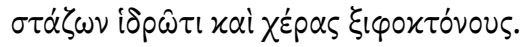

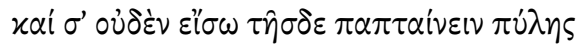

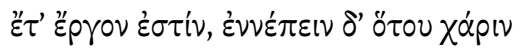

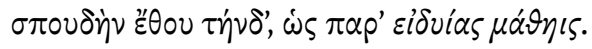

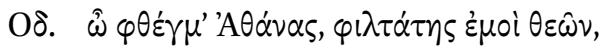

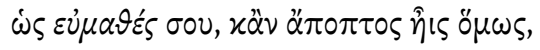

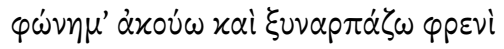

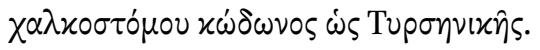
$[\ldots]$

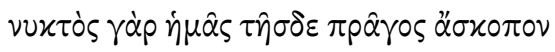

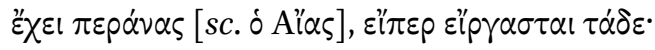

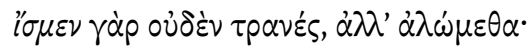

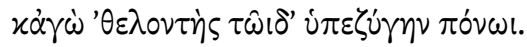
$[\ldots]$ $\varepsilon \dot{\jmath} \theta \varepsilon \dot{\varepsilon} \omega \varsigma \delta^{\prime} \bar{\varepsilon} \gamma \dot{\omega}$

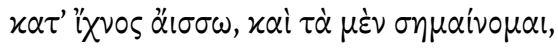

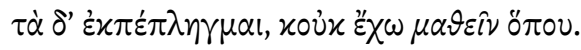

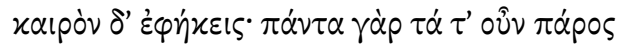

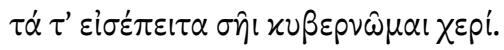

Ath. Always, son of Laertes, my eye is on you as you prowl about to snatch some opportunity against your enemies; and now I see you by the hut of Ajax near the ships, where he occupies the last position, a long while on his trail and scanning his newly made footprints to see whether he is inside or not; moving like a Spartan hound with keen scent, you travel quickly to your goal. Yes, the man is now inside, his face and hands that have slaughtered with the sword dripping with sweat. And now you no longer need to peer inside this gate, but you must tell me what is the reason for your efforts, so that you may learn from me who knows. 
Od. Voice of Athena, dearest of the gods to me, how easily do I understand your words and grasp them with my mind, even if I cannot see you, as though a Tyrrhenian trumpet spoke with brazen mouth. [...] during last night he [sc. Ajax] has perpetrated a thing appalling, if indeed he is the doer; we know nothing precise, but we are at sea, and I, as a volunteer, have been charged with this task. [...] and at once I darted off on the trail. Some things I can make out, but by others I am thrown off course, and I cannot discover [lit. 'learn'] where he is. You have come opportunely; because as in the past, so in the future it is your hand that steers me.

What is of interest here for our purposes is the motif of 'knowing' and 'learning'. It is brought up by Athena when she tells Odysseus to inform her on what he is up to, so that he may 'learn' from her, who is 'the one who knows'. Odysseus reacts to this by first expressing how well he understands the voice of the goddess (he calls it $\varepsilon \dot{u} \mu \alpha \theta \dot{\varepsilon} s$, using a word that derives from the root of 'learn') to whom he is linked by a particular closeness that is already established in the Iliad (note that he calls her 'the dearest of the gods' in line 14). ${ }^{9}$

Then, he goes on to describe the background of his quest: in the morning, the Greeks had seen that, during the night, someone had attacked and slain the cattle they had captured before Troy. This mysterious event had left them flabbergasted, as Odysseus says at line 23: 'We know nothing for certain, but we are at sea.' In this situation, however, the Greeks thought of Odysseus and gave him $^{10}$ the task of elucidating the events that had taken place-a task Odysseus energetically took on..$^{11}$ Although he has made some progress, some things remain unclear to him, as he says at line 33: '[...] I am thrown off course, and I cannot discover [lit. 'learn'] where he is'. He then closes his remarks by coming back to his closeness to Athena which he mentioned in the beginning. He reminds her of the fact that she has already 'steered' him in the past in everything and is going to do so in the future as well. These two closing lines are, of course, an implicit request to Athena to deliver the information, as she had promised at the end of her turn.

If one now looks at the way in which Odysseus takes up as well as develops the motif of 'knowing' and 'learning', two things become clear: first, if he

\footnotetext{
9 See, e.g., Il. 10.278-279.

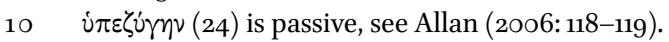

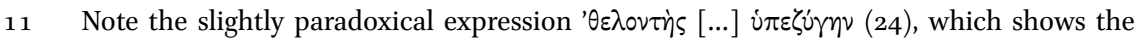
readiness with which Odysseus took over the task —an image he draws of himself also when he says that he 'at once darted off the trail' (31-32).
} 
says that the Greeks at large 'don't know anything precise' and that he still has only partly made up for this deficit (33), he positions himself vis-à-vis Athena as representing the Greeks, thus enlarging the initial participation framework established by the goddess. ${ }^{12}$

Second, 'knowing nothing precise' is not only the situation Odysseus and the Greeks find themselves in, it also describes the situation of an ancient audience at the beginning of a play: the mythical material, from which the poet derived his plot, was familiar to the audience, but the precise handling of it and the extent to which the playwright would innovate were unknown. If one now takes into account that precisely what Odysseus is about to discover, namely Ajax's attack on the Greeks' cattle, was probably an innovation by Sophocles, it becomes highly likely to see here a specific allusion to the audience's state of knowledge: ${ }^{13}$ Odysseus, in his partial knowledge vis-à-vis the 'knowing' Athena and his quest to 'learn' from her, acts as a focaliser for the audience. ${ }^{14}$ Thus, the first two utterances establish not only an internal, but also what one could call a 'metaleptic' participation framework.

Athena's reaction to Odysseus' implicit request is remarkable:

[3] Sophocles Ajax 34-40

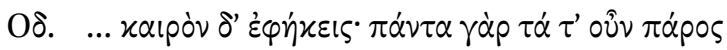

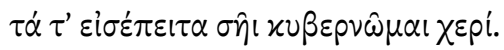

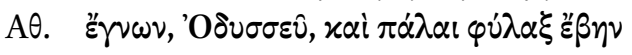

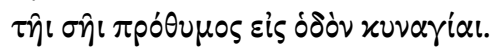

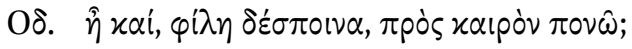

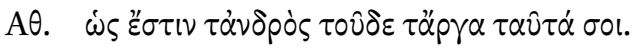

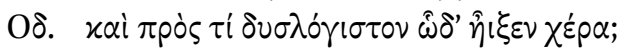

Od. ... You have come opportunely; because as in the past, so in the future it is your hand that steers me.

\footnotetext{
12 On the notion of 'participation framework', see Goffman (1981).

13 Heath and OKell (2007: 366).

14 Cf. Ringer (1998: 34); for the use of the concept of focalisation in drama, see Hose (1993: $36)$.
} 


\section{Ath. I knew it, Odysseus, and some time ago set out on the way, eager to guide you in your hunt.}

Od. Dear mistress, am I labouring to any purpose?

Ath. Know that these are the actions of that man!

Od. And why did he lash out so foolishly?

In her answer, she does not react to Odysseus' request. Instead, she just states that she had already known what he has just told her. By withholding further information, she makes him ask explicitly for the information she promised. Odysseus does this and she then provides him with the information in a brief stichomythia, capped by a longer rhesis (38-65): as a consequence of his having been denied Achilles' arms, which were awarded to Odysseus instead, Ajax went mad $^{15}$ and wanted to take revenge on the Greeks and, in a nightly attack, to slay as many of them as possible. He would have succeeded, had not Athena intervened by casting delusion upon him and making him attack the Greeks' cattle instead. At the moment of her encounter with Odysseus, Ajax's delusion still prevails and he is in his hut, torturing the ram he thinks is his foe, Odysseus.

The way in which Athena provides this information is interesting. For after having made Odysseus ask explicitly, she gives away the relevant information in piecemeal fashion (the beginning of which can be seen in the excerpt above). In this way, she prompts her interlocutor to ask further questions time and again - a behaviour that has been correctly described as 'gentle toying with her protégé. ${ }^{16}$ What enables her to do so is, of course, that she is a 'knowing' goddess, whereas Odysseus is a man whose knowledge is only partial. Moreover, as a goddess, she is under no threat at all, whereas the human Odysseus is dependent on learning what has happened in order to counter the danger presented by the nightly attacker. ${ }^{17}$ Sophocles thus makes the spectators follow the focaliser Odysseus through the stichomythia in the common quest for information. In a subtle but effective way, he creates awareness of the fact that Odysseus, notwithstanding his closeness to Athena, is still separated from her by the insurmountable gulf that exists between gods and humans. Importantly, this does not lead to any irritation on the part of Odysseus and, per extensionem,

15 The 'madness' of Ajax is a famous topic; Athena's report draws a picture according to which Ajax was mad before her intervention, which makes it natural to assume the judgement of the arms as tipping-point; that this picture will later be complicated (see the excellent treatment by Winnington-Ingram [1980: 11-56]) is not of interest here.

16 Finglass (2011: ad 36-37).

17 Cf. Heath (1987: 170). 
on the part of the spectators. The stichomythia thus not only reveals the gap between gods and humans but also the fact that this difference is a completely normal state of affairs even between exemplarily close figures such as Athena and Odysseus.

After the stichomythia has ended in a rhesis by Athena, she starts anew and wants to show the delusional Ajax to Odysseus. This utterance (66-77) is best juxtaposed with an earlier statement by Odysseus:

[4] Sophocles Ajax 23, 66-70

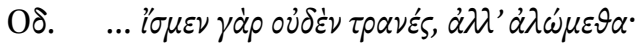

$[\ldots]$

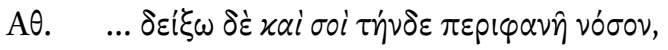

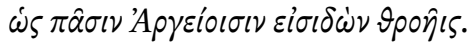

$\theta \alpha \rho \sigma \hat{\omega} \nu \delta \dot{\varepsilon} \mu i \mu v \varepsilon, \mu \eta^{\prime} \delta \varepsilon \sigma u \mu \varphi \circ \rho \dot{\alpha} \nu \delta \varepsilon \dot{\varepsilon} \chi 0 v$,

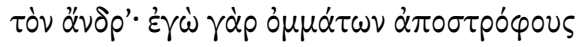

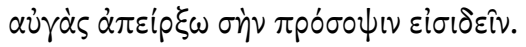

Od. ... we know nothing precise, but we are at sea,

$[\ldots]$

Ath. ... And I will show this madness openly to you also, so that you may tell all the Argives what you have seen. Stay to meet the man with confidence, do not expect disaster; I shall divert the rays of his eyes so that he cannot see you.

Odysseus had presented himself before Athena as representing the Greeks, who 'know nothing precise'. If she now wants to show Ajax to him so that he 'may tell all the Argives what he has seen', her intention is to enable him to fulfill his task as thoroughly as possible. By adding autopsy to her report, she lends Odysseus even greater credibility vis-à-vis the Greeks. ${ }^{18}$

18 Finglass (2011: ad 66-67); the scholiast already recognised this as a sign of Athena's 'goodwill' (schol. 66a). 
Odysseus, however, reacts negatively at line 74 , and this triggers a stichomythic exchange in which Athena presents several arguments to convince him to give in (75-88). The first one is a reproach of cowardice, which can again be best understood by juxtaposing it with a part of the preceding dialogue:

[5] Sophocles Ajax 24, 31-32, 75

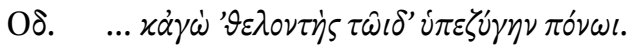

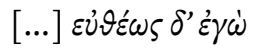

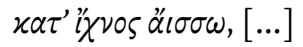

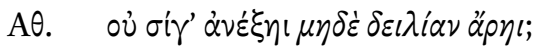

Od. ... and I, as a volunteer, have been charged with this task. [...] and at once I darted off on the trail [...]

Ath. Will you not be quiet, and not show yourself a coward?

Odysseus had presented himself, quite confidently, as the person the Greeks had charged with investigating the mysterious massacre, who then energetically took over this task (cf. n. 11 above). Yet now, he rejects the occasion to complete his task. Given that Athena's reproach can be read as taking up Odysseus' previous self-presentation, ${ }^{19}$ that reproach does not seem totally unjustifiedeven more so, since Odysseus not only endangers the Greeks in their desire to learn what has happended as precisely as possible but also risks to disappoint the spectators who have been following him closely in his quest for information (note that Athena has promised she would make sure Ajax would not see him, which could further justify her charge of cowardice). However, should the spectators go so far as to share Athena's reproach? Odysseus, at least, stands his ground, to which Athena reacts with a rhetorical question, varying the cowardice argument, followed by another implicit rejection by Odysseus:

19 In this context, it is remarkable that the subject to which Odysseus would 'show himself a coward' remains unspecified: sure, Athena means herself, but could her words also point to the Greeks at large? 
[6] Sophocles Ajax $76-78$

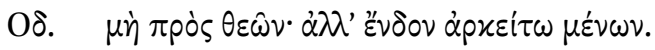

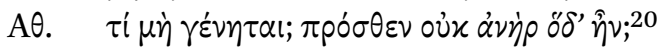

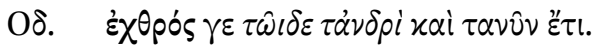

Od. No, I beg you! Be content for him to stay inside!

Ath. What are you afraid of? Was this one not before a man?

Od. Yes, an enemy to this man here, and he still is.

This is an illuminating exchange: Athena asks whether Ajax was not 'a man' before. Odysseus replies that he was indeed but points out what is important to him: not Ajax's humanity but his enmity (note the particle $\gamma \varepsilon$ at $78^{21}$ ). He provides a reason for this by taking up Athena's words, i.e. ¿ $\alpha \eta^{\prime} \rho$ and 'o $\delta$ ', by his self-designation as 'this man here' (78 $\tau \hat{\omega} 1 \delta \varepsilon \tau \dot{\alpha} v \delta \delta$ i): he, Odysseus, is 'a man' himself, and thus what matters to him is that 'the man' Ajax was and is an enemy — or, to put it differently: vis-à-vis a god, Athena's argument would be good, but vis-à-vis a man, it is not. This justifies Odysseus' rejection of Athena's plan as an understandable human reaction, thereby deepening the status of focaliser: the spectators become aware of the fact that the natural difference between god and human that was subtly established in the beginning can be problematic. The most important point, however, is that, in this way, Sophocles establishes a pattern that is the key to the rest of the prologue: Athena tries to do justice to Odysseus' needs, as she infers them. She does not, however, succeed; this is not because her presuppositions are false - Ajax was 'a man'but because she does not seize on what is relevant for her human interlocutor. This can be clearly seen in the next exchange, which is best understood when presented in two separate juxtapositions:

[7a] Sophocles Ajax 78-80

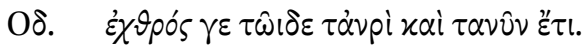

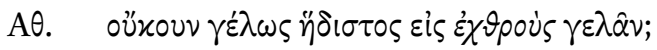

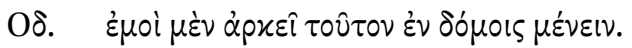

$20 \quad$ Punctuation as in the text of Finglass (2011, cf. $a d 77$ ).

21 On $\gamma \varepsilon$ in such contexts of resonance, see Drummen (2016b: $\S \S 77-79) ; \alpha \dot{\nu} \dot{\rho}$ has been taken to mean 'hero' (see Finglass 2011: $a d$ 77); however, this meaning would demand rather $x \alpha$ í than $\gamma \varepsilon$ in Odysseus' answer: 'Was this one not a hero before?'-'Yes, and an enemy to this man here.' (on this continuing function of $\chi \alpha$, see Drummen 2016b: §§ 89-94). 
Od. Yes, an enemy to this man here, and he still is.

Ath. Is not laughter at one's enemies the sweetest kind of laughter?

Od. I am content for him to stay inside.

[7b] Sophocles Ajax 76, 78

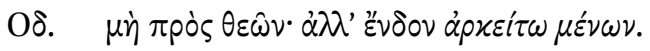

$[\ldots]$

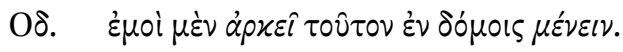

Od. No, I beg you! Be content for him to stay inside!

$[\ldots]$

Od. I am content for him to stay inside.

Odysseus has pointed out the relevance of Ajax's enmity. Very well then, Athena answers, what could be 'sweeter' than to laugh at than one's enemies in utter defeat (note the inferential particle oüxouv at $79^{22}$ )? In his answer, Odysseus does not deny that laughing at one's enemies is the 'sweetest' thing, ${ }^{23}$ he simply restates the fact that he wants Ajax to stay inside, repeating his initial rejection and thus making it clear that the fundamental issue, the danger that Ajax constitutes, has not been grasped by Athena.

Then, the exchange gets slightly more complicated: Athena brings forward a new argument, initiating a new stage of the conversation:

[8] Sophocles Ajax 81-88

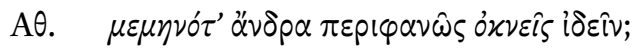

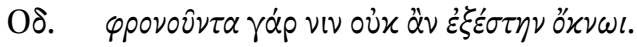

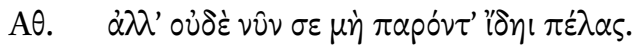

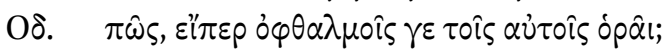

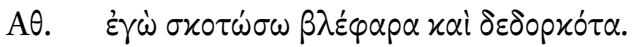

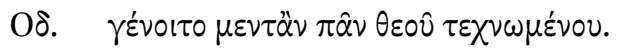

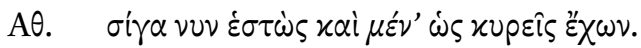

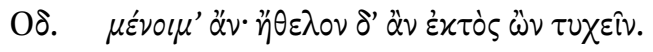

22 Cf. Denniston ( $\left.{ }^{2} 1954: 431\right)$ and Drummen (2016a: §§ 81-82, on oûv).

23 Cf. Heath (1987: 168). 
Ath. Do you fear to see a man directly who is mad?

Od. Yes, for if he were sane, I would not have shrunk back from him in fear.

Ath. But now he will not even see you near him.

Od. How so, if he is seeing with the same eyes?

Ath. I shall place his eyes in darkness, even though they see.

Od. Indeed anything can happen if a god contrives it.

Ath. Then stand in silence and remain as you are.

Od. I shall remain; but I wish I were not here.

Whether it is Ajax's madness that made him reject her offer, she asks. As Odysseus' taking up 'mad' by 'sane' and 'Do you fear ...?' by '[I would not have shrunk back] in fear' shows, the goddess has hit the mark with her question: were Ajax sane, Odysseus would not have 'shrunk back'. Athena counters this by pointing out once more that Ajax will not see him, a claim of which Odysseus at first remains sceptical: how could he not see him if his eyes do see? She then explains more clearly what she will do, and Odysseus agrees: he had indeed not understood how her protection measures would work and will 'remain' where he is. However, even after Athena seems to finally have convinced Odysseus, he closes the encounter at line 88 by saying that he still would prefer not to see Ajax. So even after he has given in, the basic pattern remains intact: Athena still does not meet Odysseus' needs, and his fear, although becoming somewhat diffuse, remains understandable as a human reaction to an enemy who, being mad, is dangerous to the point that Odysseus does not want to stand directly next to him even if he cannot not see him. ${ }^{24}$

24 Note the continued presence of the god(-and-man) theme in line 86. The only real challenge to this understanding of Odysseus' fear (which was already that of the scholiast, see schol. 74) has come from LaCourse Munteanu (2010: 188), who claims that it is a fear suigeneris caused by the awesome and destabilising potential that is inherent to the act of directly seeing a madman. This interpretation has the undeniable advantage of doing away with the diffuse character Odysseus' fear takes on when he, at line 88 , still does not want to see Ajax, although he has accepted that he will not see him. It is, however, somewhat problematic in that it essentially reads the exchange of Athena and Odysseus from this line 88. For before it, there is no hint that Odysseus' fear could be due to anything else than the fact that his enemy has become even more dangerous in his current state (at line 82 he says that Ajax's madness made him 'shrink back', but line 84 shows that the possibility of being seen by the mad Ajax does bother him). 


\section{$5 \quad$ The End of the Exchange and the Beginning of the Drama}

Athena then speaks to the delusional Ajax, who triumphs in the middle of the carcasses of the cattle he thinks are his enemies, whilst cruelly mocking him in front of the onlooker Odysseus (lines 89-117). Thereafter, she suggests a lesson to Odysseus from what he has just seen: she asks him to acknowledge the gods' power who can bring down even someone as 'prudent' as Ajax. Odysseus, however, draws his own conclusion, opposing Athena's suggestion by taking up the word ópów, 'to see':25

[9] Sophocles Ajax 118-126

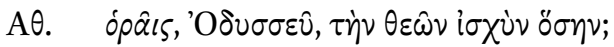

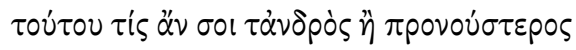

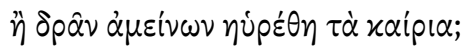

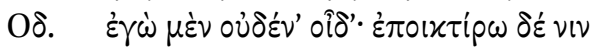

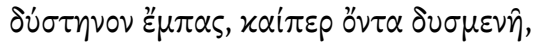

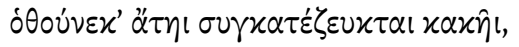

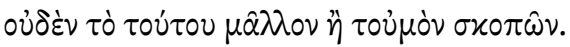

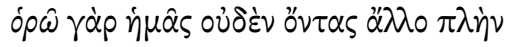

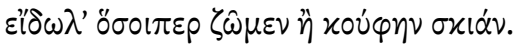

Ath. Do you see, Odysseus, how great is the power of the gods? What man was found to be more prudent than this one, or better at doing what was right?

Od. I know of none, and I pity him in his misery, though he is my enemy, not thinking of his fate, but my own; because I see that all of us who live are nothing but ghosts, or a fleeting shadow.

In his answer, Odysseus acknowledges the awesome power of the gods. His reaction, however, is to pity his disgraced fellow human being Ajax. For he recognises that, from a human perspective, divine power means first and foremost human frailty. Again, we see Odysseus correcting the goddess Athena's assumptions from a human perspective. He does not prove them false but points out what is relevant to him-again, the same pattern occurs that has been established in the first part of the prologue and has been discussed above. Odysseus' more humanly adequate reaction entails also a thorough re-

25 Cf. Segal (1989: 397-398). 
evaluation of Ajax: Athena had said that no one had been 'more prudent and better at doing what is right'. Whereas these qualities had just served to make Ajax's downfall even more impressive in her account, Odysseus' pity brings out their ethical implications. It marks Ajax's downfall as something that is, in a certain sense, unmerited. This becomes clear if one remembers how intimately, as far as we can assess, pity is bound up in classical Greek thought with the unmerited character of a person's sufferings. ${ }^{26}$ The message is clear: the Ajax whom the spectators have just seen cruelly triumphing over his 'enemies' and wanting to torture 'Odysseus' to death cannot be the whole story. In a certain sense, Ajax's attack on the cattle and Athena's intervention must be a 'misfortune, ${ }^{27}$ a 'tipping' of a fundamentally 'good' character. This becomes even clearer if one remembers that the qualities attributed to Ajax-prowess in counsel and action - are akin to traditional heroic virtues. ${ }^{28}$

A major point has been established: Odysseus has, from his human perspective, found an adequate reaction to the thwarted hero Ajax. His reaction is based on the tragic notion of human frailty which he expresses in traditional terms already found in Pindar. ${ }^{29}$ However, the prologue is not over yet; the last word belongs to Athena, who again takes up Odysseus' preceding answer:

[10] Sophocles Ajax 125-133

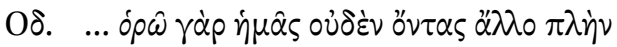

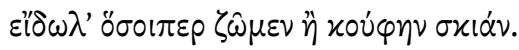

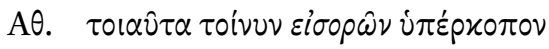

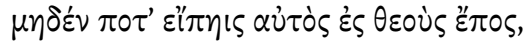

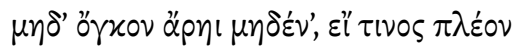

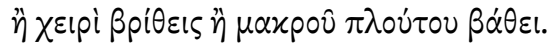

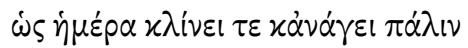
$\ddot{\alpha} \pi \alpha \nu \tau \alpha \tau \dot{\alpha} \nu \theta \rho \dot{\omega} \pi \varepsilon 1 \alpha \cdot \tau 0 \dot{\zeta} \varsigma \delta \dot{\varepsilon} \sigma \dot{\omega} \varphi \rho \circ \nu \alpha \varsigma$

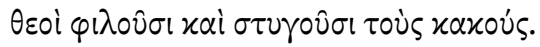

Od. ... because I see that all of us who live are nothing but ghosts, or a fleeting shadow.

Ath. Look, then, at such things, and never yourself utter an arrogant word against the gods, nor assume conceit because you outweigh another

\footnotetext{
26 Konstan (2001: e.g. 125).

27 Konstan (2001: 108).

28 March (1993: 18).

29 See Finglass (2011: ad 125-126).
} 
in strength or in profusion of great wealth. Know that a single day brings down or raises up again all mortal things, and the gods love the prudent and hate the base.

Odysseus had 'seen' Ajax as a pitiable paradigm of human frailty. Athena, in her turn, takes up Odysseus' 'I see' when she admonishes him to 'look at such

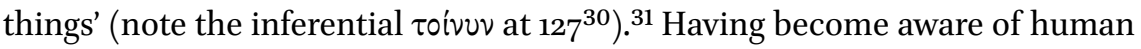

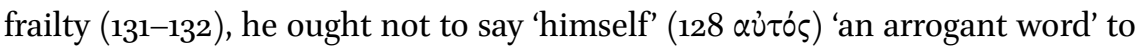
the gods, since they 'love the prudent and hate the base' (132-133). This answer contains, as said above, a new piece of information: if Athena calls on Odysseus not to say an arrogant word to the gods himself, we may infer that this is precisely what Ajax has done. The spectators have now just heard Ajax speak such a 'word' towards Athena in the direct exchange, in which he rudely had his will against the - albeit hypocritical—objections of Athena. This 'word', however, cannot be the one Athena has in mind here, for the 'hatred' which made her thwart Ajax's revenge plot against the Greeks must of course be prior to her intervention. ${ }^{32}$ Rather, Athena links Ajax's speaking an arrogant word with his character by calling him, indirectly, imprudent and base. This challenges the re-evaluation brought about by Odysseus: was Ajax out of character during his appearance after all? Was his behaviour really a 'misfortune', a 'tipping' of a fundamentally noble character? Ajax, having just been rehabilitated, becomes problematic again.

But how definitive is Athena's verdict? The entire conversation between Athena and Odysseus has been marked by the pattern discussed above: Athena tries to be relevant to her interlocutor but, while not saying anything false, does not meet the latter's human needs, whereupon he discreetly opposes his own point of view to Athena's. The prologue is thus structured according to a dialectical pattern between divine and human, which, after Ajax's appearance, becomes one between a negative and a more positive (and more humanly adequate) evaluation of Ajax. This dialectical pattern suggests that, this time as well, Athena's information is not false, but that, at the same time, her damning verdict is not an adequate human reaction to Ajax. This time, however, Odysseus does not provide a more adequate reaction on stage. This is precisely where the central dramatic effect of the prologue lies: the spectators have, since the beginning, been following Odysseus through the dialogue, which was

30 Denniston (21954: 569-570).

31 Cf. Segal (1989: 398).

32 Cf. Heath (1987: 171) for the implications of Athena's utterance. 
marked by Athena's repeated attempts at being relevant for her human interlocutor and his repeatedly opposing his human perspective to the goddess' divine perspective-a process that we have retraced by looking at the way both characters take up preceding utterances in pursuit of their communicative goals. This dialectical process, however, breaks off after Athena's statement in 127-133, the spectators lose their focaliser who had provided them with an adequate human reaction to Athena's contributions. At the end of the prologue, they thus 'inherit' Odysseus' function of dealing from a human perspective with Athena's information that is not likely to be false but needs to be accommodated by the spectators from their human perspective in a more positive image of Ajax. But how can they do so? The answer is clear: by watching the tragedy of Ajax that has just begun and that will provide them with a more comprehensive picture of its complex hero. They are thus left behind with the question 'How do I judge Ajax?' and called upon to look for an answer to this question in the continuation of the play: by having the spectators follow Odysseus through the dialectic of the conversation and by then breaking off this dialectic and leaving them behind in the way described, Sophocles generates audience involvement for the play to follow.

The further development of the tragedy will indeed enable an accommodation of Athena's information in a more positive image of Ajax: in the report from the seer Calchas at $762-777$, it will become clear that Athena was right and that Ajax had indeed, long before the judgement of the arms, uttered an 'arrogant word' against the goddess (note $\dot{\psi} \psi(x o ́ \mu \pi \omega \varsigma$ at 766 ), thereby causing her wrath. However, by then, the play will have presented a more nuanced picture of Ajax, thereby also confirming his heroic character that lies at the base of Odysseus' rehabilitation in the prologue; it will no longer be possible to condemn him simply as 'imprudent' and 'base'. This process of finding an adequate evaluation of the complex figure of Ajax that does justice both to his undeniable greatness and to his deeply problematic character starts with the prologue. There, the spectators are prepared for this nuanced reaction through the depiction of the 'chsracter interaction', as they watch the characters try to do things together with words. This makes it clear that it is wrong to privilege Odysseus' human perspective, as some critics tend to do with regard to the prologue: ${ }^{33}$ the prologue is marked by deliberate ambiguity, and the most productive critical attitude towards it is acknowledging the dramatic potential to generate audience involvement that lies in it. ${ }^{34}$

33 See Parker (1997: 152-153, especially n. 34).

34 In this focus on the dramatic effect of this ambiguity as rooted in the dialectical structure that marks the dialogue from a very early stage, the present paper adds to previous dis- 
With this conclusion in mind, it is possible, as a sort of 'coda', to return to Kirkwood's statement mentioned at the beginning of this paper. According to Kirkwood, 'character interaction' is of particular importance to Sophoclean drama. Whereas references to Aeschylus and Euripides (and to other Sophoclean plays) are beyond the scope of this paper, it can at least be said that the Ajax shows how the dialogic nature of the prologue is ingenuously used by the poet for great dramatic effect. If one now remembers that dialogic prologues are a particularly Sophoclean phenomenon, ${ }^{35}$ it could indeed be the case that he was more interested in exploiting the dramatic potential of 'character interaction' than the other two great dramatic poets.

Another corollary may be added: the prologue of the Ajax is the only direct encounter between a man and a god in Sophocles' extant tragedies. ${ }^{36}$ The interaction between the two parties is marked by the fact that they have fundamentally different outlooks - a fact that is inculcated in spectators as they follow the focaliser Odysseus through the dialogue.

There are at least two famous passages in the Sophoclean corpus where characters reproach the gods for having let them down: At ot 1329-1335, Oedipus accuses Apollo of being responsible for his downfall because he had given the oracle that ordered him to find Laius' murderer. At Trach. 1264-1278, Hyllus accuses 'the gods' in general and Zeus in particular after a misunderstood oracle by Zeus contributed to the catastrophe and demise of his father Heracles. The prologue of the Ajax suggests a possible and genuinely tragic answer to these reproaches: maybe we humans just do not understand the gods-and vice versa.

\section{Acknowledgements}

I would like to thank Gunther Martin, Federica Iurescia, and Giada Sorrentino for their comments on my paper, as well as the attendants of the conference in Zurich for the discussion. The research for this paper was funded by the Swiss National Science Foundation (Project PPooP1_183707).

cussions that have acknowledged the multiperspectivity or 'polyphony' of the prologue (Diller 1963; Segal 1989; de Jong 2006; Burian 2012; cf. Budelmann 2000: 184-185). Women) and Aeschylus sometimes has no prologues at all, e.g. Persians.

$3^{6}$ The appearance of Heracles at the end of the Philoctetes is something very different; on gods on stage in Sophoclean drama, see Parker (1999: 11-12). 


\section{References}

Allan, R.J., (2006), 'Sophocles' Voice: Active, Middle, and Passive in the Plays of Sophocles', in I.J.F. de Jong \& A. Rijksbaron (eds.), Sophocles and the Greek Language: Aspects of Diction, Semantics and Pragmatics, Leiden/Boston, 111-126.

Bakhtin, M.M., (1981), 'Discourse in the Novel', in M.M. Bakhtin, The Dialogic Imagination: Four Essays, Austin, 259-422.

Bakhtin, M.M., (1986), 'The Problem of Speech Genres', in M.M. Bakhtin, Speech Genres and Other Late Essays, Austin, 6o-102.

Barker, E.T.E., (2009), Entering the Agon:Dissent and Authority in Homer, Historiography and Tragedy, Oxford.

Budelmann, F., (2000), The Language of Sophocles: Communality, Communication and Involvement, Cambridge.

Burian, P., (2012), 'Polyphonic Ajax', in K. Ormand (ed.), A Companion to Sophocles, Malden/Oxford/Chicester, 69-83.

Clark, H.H., (1996), Using Language, Cambridge.

Cook-Gumperz, J. \& Gumperz, J.J., (1976), 'Context in Children's Speech', in J. CookGumperz \& J.J. Gumperz, Papers on Language and Context, Working Paper 46 , Berkeley.

Denniston, J.D., ( ${ }^{2} 1954$ [1934]), The Greek Particles, Oxford.

Diller, H., (1963), 'Göttliches und menschliches Wissen bei Sophokles', in Gottheit und Mensch in der Tragödie des Sophokles: Vorträge von Hans Diller, Wolfgang Schadewaldt, Albin Lesky, Darmstadt, 1-24.

Drummen, A., (2016a), 'Varying One's Speech: Discourse Patterns', in A. Bonifazi, A. Drummen, \& M. de Kreij, Particles in Ancient Greek Discourse: Five Volumes Exploring Particle Use across Genres, Washington, D.C., vol. 3/2. https://chs.harvard.edu/ CHS/article/display/621o.iii-2-varying-one's-speech-discourse-patterns [o1/o6/ 2019].

Drummen, A., (2016b), 'Reusing Others' Words: Resonance', in A. Bonifazi, A. Drummen, \& M. de Kreij, Particles in Ancient Greek Discourse: Five Volumes Exploring Particle Use across Genres, Washington, D.C., vol. 3/3. https:/chs.harvard.edu/CHS/ article/display/6211.iii-3-reusing-others'-words-resonance [01/06/2019].

du Bois, J.W., (2014), 'Towards a Dialogic Syntax', Cognitive Linguistics 25, 359-410.

Finglass, P.J., (2011), Sophocles, Ajax, Cambridge.

Goffman, E., (1981), 'Footing', in E. Goffman, Forms of Talk, Philadelphia, 129-159.

Heath, M., (1987), The Poetics of Greek Tragedy, London.

Heath, M. \& OKell, E., (2007), 'Sophocles' Ajax: Expect the Unexpected', Classical Quarterly $57,363-38$ o.

Hose, M., (1993), Studien zum Chor des Euripides, vol. 1, Stuttgart.

Iser, W., (1978), The Act of Reading: a Theory of Aesthetic Response, Baltimore (Engl. transl. of Der Akt des Lesens: Theorie ästhetischer Wirkung, Munich 1976). 
Jong, I.J.F. de, (2006), 'When Narratology Meets Stylistics: the Seven Versions of Ajax' Madness', in I.J.F. de Jong \& A. Rijksbaron (eds.), Sophocles and the Greek Language: Aspects of Diction, Semantics and Pragmatics, Leiden/Boston, 73-94.

Jucker, A.H. \& Locher, M.A., 'Introducing Pragmatics of Fiction: Approaches, Trends, and Developments', in M.A. Locher \& A.H. Jucker (eds.), Pragmatics of Fiction, Berlin/Boston, 1-22.

Kirkwood, G.M., (1958), A Study of Sophoclean Drama, Ithaca.

Konstan, D., (2001), Pity Transformed, London.

LaCourse Munteanu, D., (2010), Tragic Pathos: Pity and Fear in Greek Philosophy and Tragedy, Oxford.

Linell, P., (1998), Approaching Dialogue: Talk, Interaction and Context in Dialogical Perspectives, Amsterdam/Philadelphia.

Lloyd-Jones, H., (1994), Sophocles, vol. 1, Cambridge, Mass./London.

Lloyd-Jones, H. \& Wilson, N.G., (1990), Sophoclis fabulae, Oxford.

March, J.R., (1993), 'Sophocles' "Ajax”: The Death and Burial of a Hero', Bulletin of the Institute of Classical Studies 38, 1-36.

Parker, R.C.T., (1997), 'Gods Cruel and Kind: Civic and Tragic Theology', in C.B.R. Pelling (ed.), Greek Tragedy and the Historian, Oxford, 143-160.

Parker, R.C.T., (1999), 'Through a Glass Darkly: Sophocles and the Divine', in J. Griffin (ed.), Sophocles Revisited: Essays Presented to Sir Hugh Lloyd-Jones, Oxford, 11-30.

Pfister, M., (1988), The Theory and Analysis of Drama, Cambridge (Engl. transl. of Das Drama: Theorie und Analyse, Munich 1977).

Ringer, M., (1998), Electra and the Empty Urn: Metatheater and Role Playing in Sophocles, Chapel Hill.

Segal, C., (1989), 'Drama, Narrative and Perspective in Sophocles' Ajax', Sacris erudiri 31, 395-404.

Vološinov, V.N., (1973), Marxism and the Philosophy of Language, New York/London.

Winnington-Ingram, R.P., (1980), Sophocles: an Interpretation, Cambridge. 


\title{
Pentheus und Dionysos in den Bakchen: Die Grenzen des klaren Dialogs
}

\author{
Camille Semenzato
}

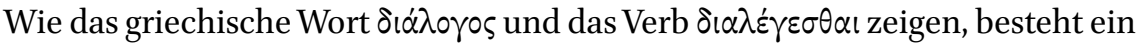
Dialog aus Worten ( $\lambda$ ó $\bigcirc \iota)$, die zwischen $(\delta\llcorner\alpha-)$ zwei oder mehreren Personen geäußert werden. ${ }^{1}$ Das Ziel eines solchen Gesprächs hängt von der Situation $\mathrm{ab}$, setzt aber ein gewisses offenes Verhalten der Beteiligten voraus, ohne dass sie sich am Ende unbedingt einigen und das Ziel auch tatsächlich erreichen müssen. Die sprachlichen Mittel, die sie verwenden, um sich zu verstehen und zu überzeugen, werden heutzutage von der Gesprächsanalyse untersucht. ${ }^{2}$ Der Dialog, den die zwei Hauptfiguren von Euripides' Bakchen miteinander führen, bietet ein sehr interessantes Beispiel, das aber von der Forschung selten behandelt wird: ${ }^{3}$ vielleicht weil dieser Dialog, auch wenn seine Struktur der gewöhnlichen Gesprächsorganisation entspricht, an seine Grenzen stößt, bis er tödlich scheitert? Ziel dieses Aufsatzes ist zu untersuchen, inwiefern der Sprachgebrauch selbst für dieses Scheitern verantwortlich ist.

\section{Ein Kommunikationsproblem}

Der Dialog der Bakchen ergibt sich aus einer problematischen Situation: Ein Fremder, ein Lydier, ist in Theben aufgetaucht. Er hat die thebanischen Frauen dazu verführt, ihre Männer, ihre Kinder, die Stadt sowie ihren Rang und Platz zu verlassen. Man erzählt, dass die Thebanerinnen (unter denen sich auch die Töchter des ehemaligen Königs, des berühmten Kadmos, finden) sich heimlich in den Bergen fragwürdigen sexuellen Handlungen hingeben unter dem Vorwand, dass sie einen neuen Gott, den sie Dionysos nennen, verehren. Die

1 Der Begriff wird hier in einem generellen Sinn gebraucht. Für die antike Gattung des Dialogs als Gespräch in Prosa siehe Jazdzewska (2014); Dubel (2015: 11-19).

2 Für die Anwendung der Gesprächsanalyse auf die griechische Tragödie siehe insbesondere Bonifazi u.a. (2016: III.4); Drummen (2017: 198-253); van Emde Boas (2017a, 2017b: 1-50).

3 Was die Gesprächsanalyse der Tragödie von Euripides betrifft, werden die Bakchen nach Schwinges Analyse (1968) selten erwähnt. Schuren (2015) zitiert zum Beispiel einige Stellen in Fußnoten, analysiert sie aber nicht gründlich. Drummen (2017:303-309) konzentriert sich auf die Verwendung von Partikeln. 
Ordnung und das Gleichgewicht des thebanischen Lebens werden durcheinandergebracht; Maßnahmen müssen ergriffen werden. Um die Situation zu klären und zu korrigieren, um das Problem zu lösen, initiiert der amtierende König Pentheus mit dem direkten Verantwortlichen dieser Unruhe, dem sogenannten Fremden - er wird einfach $\xi_{\varepsilon} \dot{v}_{0} \varsigma^{4}$ genannt -, den er hat verhaften lassen, einen Dialog.

Dieser Dialog wird das Problem aber nicht lösen, zumindest nicht in der Weise, wie Pentheus denkt. Auch wenn er im Laufe der Handlung vier Mal mit dem Fremden spricht, auch wenn beide während zweihundert Versen versuchen, sich zu verständigen und gegenseitig zu überzeugen, verstehen sie sich kaum. Es liegt, modern gesprochen, ein Kommunikationsproblem vor: Ein Problem mit schlimmen Folgen, da Pentheus schließlich einen furchtbaren Tod findet.

Heute würde ein externer Schlichter, der gerufen worden ist, um das Problem zu lösen, wahrscheinlich die unterschiedliche Herkunft der Beteiligten als erste mögliche Erklärung nennen: Pentheus ist Thebaner und spricht Griechisch; der Fremde kommt aus Lydien, spricht also Lydisch und ist ein sogenannter $\beta \alpha \dot{\rho} \beta \alpha \rho \rho_{0} .{ }^{5}$ In der Situation einer griechischen Tragödie gilt diese Erklärung aber nicht. Alle Figuren sprechen Griechisch, auch die fremdländischen. ${ }^{6}$ Dasselbe in den Bakchen: Die lydischen Frauen, aus denen der Chor besteht, ${ }^{7}$ erklären zwar einmal einem Boten, der sie nicht verstanden hat, dass sie als Fremde barbarische Lieder singen. ${ }^{8}$ Es ist aber mehr eine Ausrede: Der Chor hat sich gerade erlaubt, über Pentheus' Tod zu jubeln - ein Verhalten, das der Bote als Untertan des thebanischen Königs natürlich nicht verstehen kann. Ansonsten spricht der Chor griechisch. Fazit: Die Möglichkeit, dass der Fremde die griechische Sprache vielleicht nicht beherrscht, den üblichen Gebrauch der Sprache nicht kennt, und so Pentheus' Worte nicht versteht, ist keineswegs relevant.

4 Der griechische Text wird nach der Ausgabe von Diggle (1994) zitiert, außer wenn eine andere Lesart (der Handschriften L und P und des P.Ant. I 24) angegeben wird. Alle Übersetzungen sind meine.

5 Nach Hall (2004: 168) wird der Fremde durch seine Charakterisierung als छ́vvos durch Pentheus nicht als Barbar, sondern als "one of the eastern Greeks who were thought to have adopted the destructive luxury of the Lydians" betrachtet. Für die etymologische Analyse von $\beta \alpha \dot{\alpha} \beta \beta \alpha \rho \circ$ siehe Chantraine ( ${ }^{2} 1999$ : s.v.); Hall (2002: 112-117: Erörterung des onomatopoetischen Ursprungs).

6 Für die Ausländer bei Euripides siehe Saïd (1984).

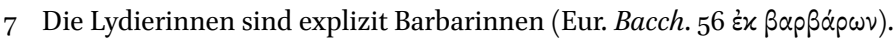

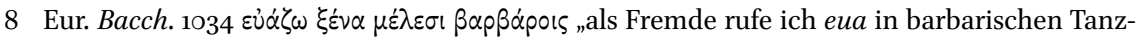
liedern". 
Eine zweite Erklärung könnte von der Natur des Fremden abhängen. Logischerweise denkt Pentheus, mit einem Menschen zu sprechen. Dank der generellen Hinweise, die im Prolog geäußert werden, wissen aber die Leser wie die Zuschauer, dass ein Gott hinter dem Fremden steckt. Und nicht irgendeiner: Dionysos selbst hat sich in den Fremden verwandelt. Die Kommunikationssituation und -schwierigkeiten werden selbstverständlich dadurch nicht vereinfacht. Dionysos präsentiert sich aber völlig menschlich ${ }^{9}$ und wird auch von Pentheus und den anderen Figuren für einen Menschen gehalten. Sogar die lydischen Frauen des Chors, welche als Anhängerinnen des dionysischen Kultes in Theben singen und tanzen, sehen im Fremden zwar ihren Anführer, aber nicht den Gott. Anders gesagt: Die doppelte Natur des Fremden als Mensch und Gott ist für die verschiedenen Figuren auf der reinen Handlungsebene nicht spürbar und so als Grund des Missverständnisses wenig relevant.

Deswegen wird für die folgende Analyse die Situation zuerst aus Pentheus' Sicht, dann aus demjenigen des Fremden betrachtet. Im Gegensatz zu Schwinge (1968: 339-433), der die Dialogszenen zwischen Pentheus und dem Fremden „Vom Standpunkt des alles überblickenden Zuschauers aus“ (342) ausführlich paraphrasiert, hat eine solche innovative Analyse den Vorteil, die Worte des einen und des anderen ohne Apriori oder Vorkenntnisse, die sonst in die Interpretation eingreifen, betrachten zu können, also die kommunikative Dynamik in den Blick zu nehmen. Auf diese Weise wird es vermieden, Pentheus von Anfang an als tyrannisch oder gar verrückt und somit an funktionierender Kommunikation nicht interessiert zu betrachten, oder aber die Worte des Fremden als typisch göttliche Äußerungen anzusehen, die dem Menschen Pentheus gar keine Verständnischance lassen.

Die leitenden Fragen sind die folgenden: Warum ist die Kommunikation zwischen Pentheus und seinem Gesprächspartner begrenzt? Wer ist dafür verantwortlich? Und aufgrund welchen (sprachlichen) Verhaltens? Die Analyse des Dialogs, der Konversationsdynamik, insbesondere der Redebeiträge und Sprecherwechsel ${ }^{10}$ im Zusammenhang mit dem Themenmanagement, sowie der Partikeln, welche auf diese Schritte und Wechsel hinweisen, wird herausstellen, inwiefern das Problem im Sprachgebrauch jedes Gesprächspartners, der mit seiner eigenen Weltanschauung zusammenhängt, liegt.

$9 \quad$ Eur. Bacch. 53-54.

10 Zu Redebeiträgen vgl. Meibauer ( ${ }^{2} 2001$ : 131-133). 


\section{Der Dialog als Lösung?}

Pentheus möchte die Situation, ihre Ursache, den Antrieb des Fremden verstehen. Deswegen lässt Pentheus ihn nach seiner Verhaftung nicht sofort töten, sondern stellt ihm zuerst eine Reihe von Fragen. Die Auseinandersetzung zwischen Pentheus und dem Fremden, die in Stichomythien und Distichomythien verfasst ist, ${ }^{11}$ besteht aus vier Teilen. Alle befinden sich in der Mitte der Tragödie, zwischen dem zweiten und dem vierten Epeisodion. Ihre Struktur und Rolle in der Handlung können folgendermaßen beschrieben werden:

\subsection{Erster Teil (Eur. Bacch. 460-5o8)}

Nach dem ersten Stasimon beginnt die zweite Szene mit den Worten eines Dieners, der am Ende der ersten Szene mit einigen Kollegen mit der Suche nach dem sogenannten Fremden beauftragt wurde. Nachdem der Diener unter anderem erklärt hat, wie der Fremde sich bei seiner Verhaftung benommen hat - er war erstaunlich ruhig und gutgelaunt -, beginnt Pentheus das Verhör seines Gefangenen.

Über den Fremden weiß Pentheus schon einiges. Er hat vom ihm und seinen Umtrieben gehört ${ }^{12}$ und sieht jetzt, inwiefern diese Gerüchte zutreffen: Anziehend, wie der Fremde aussieht, kann Pentheus gut verstehen, dass er die Frauen verführt. Diese äußerlichen Zeichen genügen dem König aber nicht: Das Versteckte interessiert ihn; er möchte all das Unklare klären. Deswegen fängt Pentheus, nachdem er das Aussehen des Fremden während sieben Versen kommentiert hat, ${ }^{13}$ damit an, Fragen zu stellen. Mit dem Eröffnungsmarker $\pi \rho \hat{\omega} \tau o v ~ \mu \varepsilon ́ v$ am Anfang des Verses 46o weist er klar darauf hin, dass er nun mit dem Gespräch beginnt; mit dem Imperativ $\mu \circ \iota \lambda \hat{\varepsilon} \xi \circ v$ gleich danach befiehlt er seinem Gesprächspartner, zu antworten. Auf diese erste Frage und ihre Antwort, welche die ersten Worte des Fremden darstellt, ${ }^{14}$ folgen siebenundvierzig Verse, welche die erste Dialogstelle bilden.

\subsection{Zweiter Teil (Eur. Bacch. 645-656)}

In der dritten Szene tritt Pentheus aufgeregt aus dem Palast: Der Fremde befindet sich nicht mehr im Gefängnis, wohin er nach der ersten Dialogstelle ge-

\footnotetext{
11 Die Standarddefinition der Stichomythie wurde von Gross (1905:9) formuliert. Siehe auch Seidensticker (1971: 183-184); Collard (1980); Schuren (2015: 1-4).

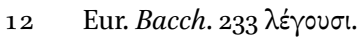

13 Eur. Bacch. 453-459.

14 Seine ersten Worte als Fremder, da der Gott Dionysos schon den ganzen Prolog gesprochen hat.
} 
bracht wurde. Da dieser ruhig vor dem Palast steht und auf den König warten scheint, nimmt Pentheus' Aufregung zu. Wie schon im ersten Gespräch versucht Pentheus, die unklare Situation mit deutlichen Fragen zu klären.

So beginnt dieser Abschnitt mit zwei von Pentheus nacheinander gestellten

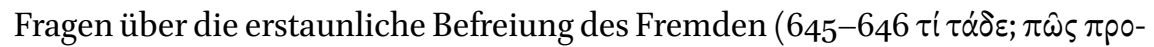
$\nu \omega^{\prime} \pi 10 \varsigma$ $\varphi \alpha^{\prime} i \eta \eta$; ,Was ist das? Wie erscheinst du am Eingang?"). Da sie so dicht und ohne bestimmtes Bindewort hintereinandergestellt sind, weisen sie auf Pentheus' Aufregung hin. Sie dienen zum Teil gleichzeitig der Aufforderung zum Sprecherwechsel: Die erste Frage stellt sich Pentheus selbst; die Verbform in der zweiten Person am Anfang des folgenden Verses zeigt deutlich, dass die zweite Frage an den Fremden gerichtet ist. Dieser wird auch gleich danach das Wort ergreifen. Nach elf Versen unterbricht aber das Eintreten eines Boten den Dialog. ${ }^{15}$

\subsection{Dritter Teil (Eur. Bacch. $787-846$ )}

Nach der Rede des Boten setzen Pentheus und der Fremde ihr Gespräch fort. Im Unterschied zu den vorigen Dialogstellen ist Pentheus' Wut nicht mehr auf den Fremden gerichtet. Ab diesem Moment ist er auf die in Wahnsinn versetzten Thebanerinnen konzentriert, nachdem der Bote ihre erstaunlichen und gewaltigen Taten beschrieben hat.

In dieser dritten Dialogstelle wird der Fremde aktiver als zuvor. Er übernimmt die Gesprächsleitung, indem er zum Beispiel anfängt zu sprechen, ohne

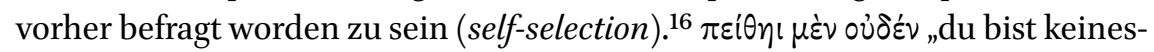
wegs überzeugt", sagt er am Anfang dieses Dialogteils (787) und weist, nachdem Pentheus den Boten angesprochen hat, ${ }^{17}$ mit $\mu \varepsilon^{\prime} \nu$ darauf hin, dass er einen neuen Sprechakt plant und das Wort für eine Weile (fünf Verse) ergreift. ${ }^{18}$ Danach versucht er während 58 Versen, Pentheus zu überzeugen, nicht auf die Frauen zuzumarschieren. Seine Strategie basiert auf zwei Vorschlägen. Der erste - dass er die Frauen allein und unbewaffnet zurückbringt - ist angesichts von Pentheus' königlichem Status selbstverständlich ungeeignet. Der Fremde scheint ihn auch nur als Trick zu äußern, damit Pentheus den zweiten Vorschlag annimmt. Denn nachdem Pentheus den ersten Vorschlag mit einem

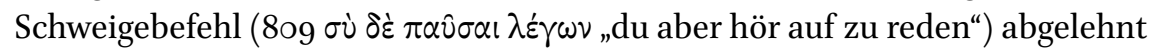

\footnotetext{
15 Die Länge dieser Stichomythie ist wahrscheinlich der Grund, warum sie nicht zu den von Schwinge (1968) bearbeiteten Stellen gehört. Als vierten Dialog analysiert er denjenigen zwischen Kadmos und Agaue, der für das Thema dieses Aufsatzes nicht relevant ist.

16 Vgl. zu diesem Phänomen Sacks u.a. (1974: 704).

17 Eur. Bacch. $77^{8-786 .}$

18 Bonifazi u.a. (2016: III.4 §28).
} 
hat - ein Befehl, der sich mit der ausdrücklichen Erwähnung von tig an den Fremden richtet, von diesem aber einfach ignoriert wird -, lockt der Fremde ihn mit der Äußerung seines innigsten Wunsches: die Frauen in den Bergen zu sehen. ${ }^{19}$ Diese Idee nimmt Pentheus nicht direkt an: Er muss sich vorher die Reise in allen Einzelheiten genau vorstellen können und stellt dafür wieder Fragen.

\subsection{Vierter Teil (Eur. Bacch. 918-972)}

Die vierte Dialogstelle erstreckt sich über 54 Verse in der vierten Szene: Der vom Fremden überzeugte Pentheus hat sich während des dritten Stasimons verkleidet. Als er neu gekleidet die Bühne wieder betritt, ist er bereit, dem Fremden zu folgen, um in die Berge zu den Frauen zu gehen.

Das Gespräch enthält keine Überredungsversuche oder -ziele mehr. Pentheus stellt zwar einige Fragen; sie dienen ihm aber alle dazu, zu versichern, dass seine Ausrüstung für eine Reise in die Berge angemessen ist, dass er gut und richtig aussieht. Von dieser Reise wird Pentheus aber nicht zurückkommen. Nachdem die erste Dialogstelle das erste Wort des Fremden dargestellt hat, bringt das Ende dieser vierten Stelle Pentheus' letzte Worte: ${ }^{20}$ fünf Verse in $\alpha \dot{\tau} \tau \lambda \alpha \beta \dot{\eta}$ welche das fehlende Verständnis zwischen den Gesprächspartnern augenfällig machen und so das Scheitern des Dialogs ankündigen. ${ }^{21}$

\section{3}

\section{Pentheus' Sprachgebrauch}

Wenn Pentheus spricht, tut er dies logischerweise nach seiner Art. Er stützt sich auf seine Kenntnisse, seine Einstellungen, kurz gesagt: auf seine Denkweise und Weltanschauung. Wichtig ist für ihn die Klarheit: was man deutlich sieht, in Kategorien einordnet, klar versteht, worauf man sich tatsächlich stützt. Im Dialog mit dem Fremden verwendet er wiederholt Vokabular der Klarheit und

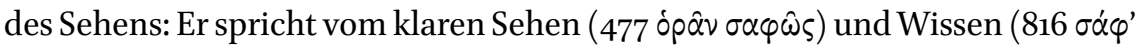

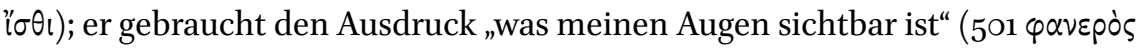

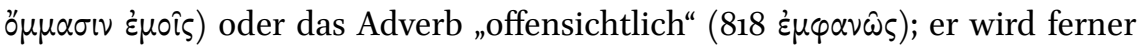

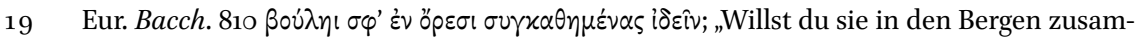
mensitzen sehen?" Der Fremde schlägt ganz genau Pentheus vor, heimlich und verkleidet in die Berge zu gehen, um die Frauen unbemerkt zu beobachten und so entscheiden zu können, ob sie wirklich schändlich handeln, bevor er mit ihnen schließlich nach Theben zurückkehrt.

20 Pentheus' letzte direkte Worte: Einige werden noch vom Boten (Eur. Bacch. 1059-1062, 1118-1121) und von Kadmos (1320-1322) wiedergegeben.

21 Siehe noch unter Abschnitt 6. 


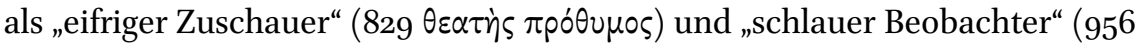

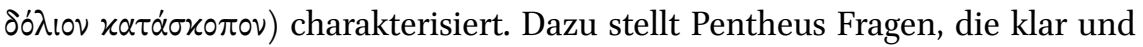
deutlich eingeleitet und gebildet werden. Sein Ziel ist, das Wer, Was, Wie und Warum zu bestimmen, um das für ihn Wichtige zu erfassen und einzuschätzen, zwischen den Möglichkeiten zu entscheiden und diese klassifizieren zu können.

In der ersten Dialogstelle gibt es zehn solche Fragen:22

[1] Euripides Bakchen 46o, 465, 467, 469, 471, 473, 477, 481, 485, 501

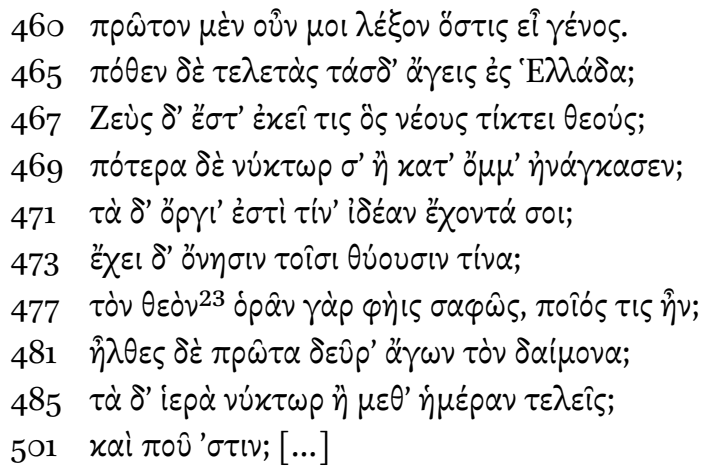

46o Sag mir also zuerst, welches Stamms du bist.

465 Woher bringst du diese Feiern nach Griechenland?

467 Ist dort ein Zeus, der neue Götter zeugt?

469 Hat er dich bei Nacht oder vor den Augen gezwungen?

471 Die Zeremonien, welches Äußere haben sie für dich?

473 Welchen Nutzen gibt es für die Opfernden?

477 Der Gott - du sagst nämlich, du siehst ihn klar-, was für einer war er?

481 Bist du zuerst hierher gekommen, die Gottheit bringend?

485 Die heiligen Dinge vollbringst du sie bei Tag oder bei Nacht?

501 Und wo ist er? [...]

Sieben dieser Fragen sind mit einem Interrogativpronomen oder -adverb gebil-

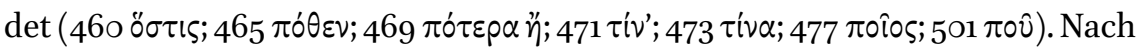
der ersten Frage, welche den Eröffnungsmarker $\pi \rho \hat{\omega} \tau o v ~ \mu \varepsilon^{\prime} v$ enthält, weisen

22 Pentheus stellt noch vier Fragen in der zweiten Dialogstelle sowie zwölf in der dritten und fünf in der vierten.

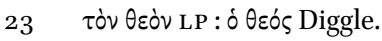


die fünf folgenden sowie noch zwei andere die Partikel $\delta \varepsilon ́$ auf, die einen Themawechsel markiert. ${ }^{24}$ Diese dauernden Wechsel deuten auch auf Pentheus' Führungsrolle hin: Sobald er eine Antwort bekommt, setzt er das Verhör mit einer anderen Frage über ein anderes Thema fort. ${ }^{25}$ In Vers 5 or hingegen markiert $x \alpha i$ die Fortsetzung des vorigen Themas. Dasselbe in Vers 477, der sich auf die eben ausgesprochenen Worte des Fremden bezieht: Pentheus strebt nach Genauigkeit, indem er das letzte Wort des vorigen Verses ( $476 \theta \varepsilon \circ \hat{v})$ wiederholt

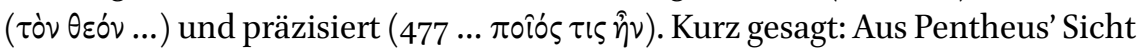
gibt es keinen Grund, dass ein so gut gegliederter Dialog die problematische Situation nicht klärt.

Pentheus' Sprachgebrauch zeigt, wer er ist: Der geschickte König, der die Vollmacht hat. Seinem Gefangenen gegenüber ist er der mächtigere (505 xupl$\omega \dot{\omega} \tau p \circ \varsigma \sigma \varepsilon \dot{\varepsilon} \theta v)$. Diese Selbstsicherheit ist in seinem Gebrauch der Verbformen sichtbar: Die Verben, die seine Taten ausdrücken, stehen im Futur: ${ }^{26}$ Als König weiß er genau, was er will. Er äußert auch zahlreiche Befehle im Imperativ, ${ }^{27}$ welche der Fremde oder seine Untertanen befolgen müssen. Im Allgemeinen zeigt er deutlich, dass er die Gesprächsthemen beherrscht. Obwohl er das spezifische Vokabular, das mit dem neuen Gott verbunden ist, nicht wirklich kennt, verwendet er es: Er hat von den $\tau \varepsilon \lambda \varepsilon \tau \alpha i$ gehört und gebraucht das Wort richtig. ${ }^{28}$ Wenn der Fremde von den öpүı $\alpha$ spricht, die er von seinem Gott bekommen hat (470), nutzt Pentheus sofort die Gelegenheit, um sich

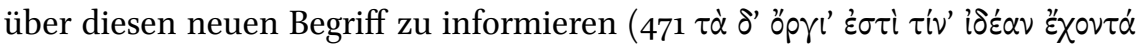
$\sigma 0 l ;) .{ }^{29}$

Die königliche Selbstsicherheit zeigt sich auch in Pentheus' Reaktion, nachdem der Fremde gesprochen hat: Seine Redebeiträge sind selten responsiv. ${ }^{30}$

\footnotetext{
24 Bonifazi u.a. (2016: III.4 §35).

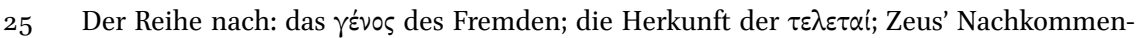
schaft; die Zeit der göttlichen Erscheinung; die Art und Form der őpүı $\alpha$; der Nutzen der Opfer; wie der Gott ist; die Reise des Fremden; der Ablauf der iєpó; wo der Gott steht.

26 Eur. Bacch. 493, 497, 792, 793, 796, 840, 843, 845, 846, 942, 954. Und außerhalb der Dialogstellen: 228, 232, 239, 240, 351, 512, 514 .

27 Eur. Bacch. 46o, 495, 503, 8o9, 816, 820, 934, 96o. Und außerhalb der Dialogstellen: 346, $35^{\circ}, 352,509,511,672,780,781$.

28 Eur. Bacch. 238 und 26o, 465 .

29 Diese Information, mit i $\delta \varepsilon \dot{\alpha} \alpha$ gebildet, gehört gewissermaßen auch zum Wortschatz des Sehens.

30 Bei Redebeiträgen (bzw., in seiner Terminologie, Gesprächsschritten) unterscheidet Mroczynski (2014: 76-78) zwischen iniitierenden (entsprechend in etwa dem englischen first pair-parts), respondierenden (second pair-parts) und reaktivierenden. Mit der früheren Literatur klassifiziert er die respondierenden in responsive, nonresponsive und teilresponsive Gesprächsschritte.
} 
Sobald eine Frage seiner Meinung nach geklärt ist, verweigert er die Fortsetzung des bisherigen Themas und führt ein neues ein.

Die Stelle, in der Dionysos' Herkunft diskutiert wird, ist ein gutes Beispiel:

[2] Euripides Bakchen 466-469

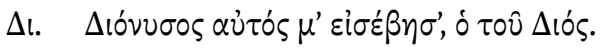

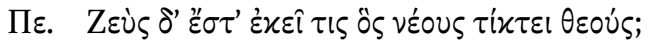

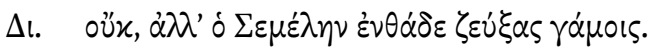

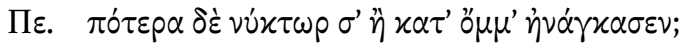

Di. Dionysos selbst hat mich eingeführt, der von Zeus.

Pe. Ist dort ein Zeus, der neue Götter zeugt?

Di. Nein, aber er hat sich hier mit Semele in Ehe vereint.

Pe. Hat er dich bei Nacht oder vor den Augen gezwungen?

Wenn der Fremde von Dionysos als Sohn des Zeus spricht, antwortet Pentheus ironisch mit einem reaktivierenden Gesprächsschritt, indem er gleichzeitig Zeus' Namen wiederholt (respondierte Komponente), mit $\delta \dot{\varepsilon}$ einen Themawechsel markiert und eine neue Frage stellt (initiierende Komponente). Wenn der Fremde aber bestätigt, dass der Dionysos, von dem er spricht, in Theben ( $\dot{\varepsilon} v \theta \alpha \dot{\delta} \delta \varepsilon)$ von Semele, Kadmos' Tochter und Pentheus' Tante, geboren worden ist, wechselt Pentheus ganz und gar das Thema: seine neue Frage - mit

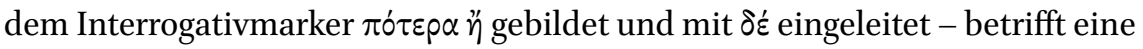
ganz neue Idee, die mit noch nicht verwendeten Wörtern geäußert wird. Denn die Frage nach Dionysos' Herkunft ist von da an für ihn geklärt. Da er schon vor seiner Begegnung mit dem Fremden gehört hat, dass dieser Dionysos für Zeus' göttlichen Sohn hält, ${ }^{31}$ und da der Seher Teiresias ihm auch die ganze Geschichte von Dionysos' Geburt erzählt hat, ${ }^{32}$ braucht er nichts mehr darüber zu wissen.

Pentheus' respondierte Gesprächsschritte sind oft nonresponsiv: ${ }^{33}$ Er ignoriert die Antworten des Fremden, als ob sie nicht geäußert worden wären, und weist damit die implizite Aufforderung zurück. Pentheus' dreiteilige Antwort auf die Frage des Fremden zu seiner Bestrafung könnte zum Beispiel sehr gut als ein ununterbrochener Redebeitrag geäußert werden:

$31 \quad$ Eur. Bacch. 242-243.

32 Eur. Bacch. 286-297.

33 Zur Terminologie s.o. Anm. 3 o. 
[3] Euripides Bakchen 493-499

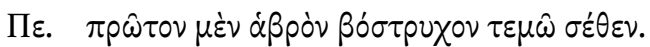

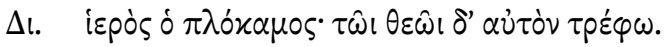

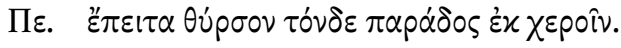

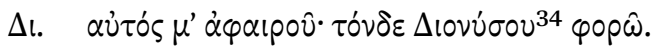

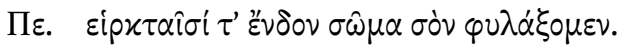

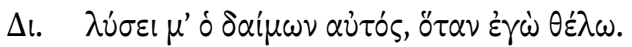

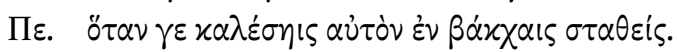

Pe. Zuerst werde ich deine zarten Locken schneiden.

Di. Mein Haar ist heilig; ich lasse es für den Gott wachsen.

Pe. Dann übergib mir diesen Thyrsos aus deinen Händen.

Di. Nimm ihn selbst weg; als den des Dionysos trage ich diesen.

Pe. Und wir werden deinen Körper im Gefängnis bewachen.

Di. Die Gottheit selbst wird mich befreien, wann ich es will.

Pe. Na ja, wann du ihn rufen wirst, in der Mitte der Bakchen stehend.

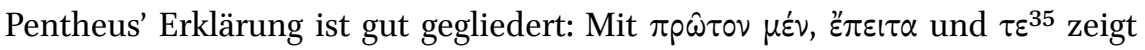
er klar, dass die Bestrafung, die er sich für den Fremden ausgedacht hat, drei Teile oder Momente hat. Pentheus' Beiträge sind alle vollständig, so dass jedes Mal ein unproblematischer Sprecherwechsel erfolgt. Sobald der Fremde fertig ist, setzt Pentheus aber seine Rede fort, ohne sich um seinen Gesprächspartner zu kümmern. Erst in Vers 499 zeigt er, dass er die Beiträge des Fremden oder zumindest den letzten - gehört hat: Er greift das zuletzt geäußerte Thema auf, indem er die Konjunktion ö $\tau \alpha \nu$ wiederholt, und wandelt es spöttisch - mit einem $\gamma \varepsilon$, das seinen Standpunkt markiert - um. ${ }^{36}$

Pentheus' Sprachgebrauch ist klar: Aus seiner Sicht gibt es kein anderes mögliches Verhalten, keinen einzigen Grund, sich und seine Sprache infrage zu stellen. Dank seinem Sprachgebrauch bekommt er die Antworten, die er erwartet hat, da sie Gerüchte über den Fremden bestätigen. Von diesem Sprachgebrauch ist Pentheus überzeugt, auch wenn er an die Grenzen stößt, welche

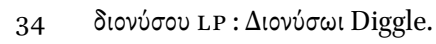

35 Nach Drummen (2017: 212 Anm. 37, 305 Anm. 113) wird ein solches initiierendes $\tau \varepsilon$ in der Tragödie selten geäußert.

36 Bonifazi u.a. (2016: III.4 §63). Nach Drummen (2017: 306), the addition of $\gamma \varepsilon$ in resonating utterances emphasizes the speaker's hostile goal in echoing his opponent's words, and thereby implies anger or hate. In diesem spezifischen Fall erfordert aber der Kontext, die Partikel als spöttisch zu interpretieren, wie die Kommentare zu den Bakchen (die Drummen in ihrer Anm. 114 auch zitiert) es betonen. Siehe auch Eur. Bacch. 796.
} 
der Fremde durch seine fehlende Angst vor der sicheren, klar ausgesprochenen Macht und durch seinen im Unterschied dazu mehrdeutigen Sprachgebrauch darstellt.

\section{Der Sprachgebrauch des Fremden}

Als Gefangener kooperiert der Fremde gut: Er wird nie wütend, er weigert sich nie, zu antworten. Ab und zu erlaubt er sich, den König zu korrigieren. ${ }^{37}$ Wenn diese Korrekturen einen nonresponsiven Gesprächsschritt darstellen, haben sie aber keine negativen Folgen. Sie helfen eher der Dialogfortsetzung, da Pentheus nie in Verlegenheit gebracht wird und immer weiß, wie er zu reagieren hat.

Im ersten Dialogteil ist der Fremde eher passiv: Er stellt mit dem Interrogativpronomen $\tau i$ eine einzige Frage, um zu erfahren, ${ }^{38}$ welche Bestrafung Pentheus für ihn bereithält. Niemals ergreift er die Initiative, das Thema zu wechseln. So enthalten seine ersten Gesprächsschritte keine initiierenden Marker. Dasselbe in der zweiten Dialogstelle und in der ersten Hälfte der dritten: Die zwei Fragen des Fremden sind beide mit den kurz vorher geäußerten Bemerkungen von Pentheus verbunden und fragen nach einer Präzisierung. ${ }^{39}$

Ab dem Vers 810 (in der zweiten Hälfte der dritten Dialogstelle) ${ }^{40}$ wird der Fremde aktiver: Er stellt mehr Fragen, verwendet mehr Partikeln, bringt dadurch seinen Standpunkt aktiver ins Gespräch ein. Diese markieren meistens keinen Themenwechsel, sondern helfen ihm, dem Gespräch die gewünschte Richtung zu geben. Denn als folgsamer Gefangener eines machtvollen Königs äußert er seine Ideen und Meinungen nie explizit. Als selbstbewusster Mensch, ${ }^{41}$ der vom Sprachgebrauch seines Gesprächspartners keineswegs beeindruckt ist, bringt er mit kleinen Hinweisen Pentheus aber dazu, seine Vorschläge und Meinungen anzunehmen. Zum Beispiel kurz nach diesem Wendepunkt:

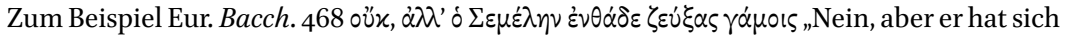
hier mit Semele ehelich vereinigt".

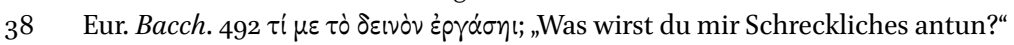

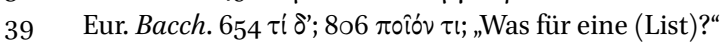

40 Der Ausruf $\hat{\alpha}$ in Vers 810 wird gewöhnlich (zum Beispiel Dodds ${ }^{2} 1960$ : 175; Roux 1972: 493; Seaford 1996: 213; Susanetti 2010: 239) als Wendepunkt der Tragödie betrachtet, da der Fremde ab diesem Moment die Oberhand über Pentheus gewinnt.

41 Wie schon gesagt, spielt es hier keine Rolle, dass der Fremde eigentlich ein Gott ist. 
[4] Euripides Bakchen 816-818

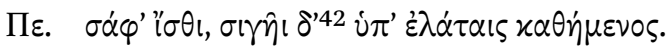

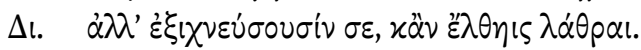

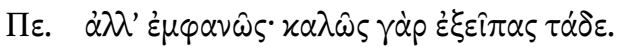

Pe. Wisse es klar, aber in Schweigen unter den Fichten sitzend.

Di. Sie werden dich aber aufspüren, auch wenn du unbemerkt kommst.

Pe. Dann sichtlich; denn du hast gut dazu gesprochen.

Mit $\sigma \alpha \varphi^{\prime}{ }^{\prime}{ }^{\prime} \sigma \theta_{l}$ bestätigt Pentheus, dass er die Frauen gerne sehen möchte, auch wenn diese vom Wein berauscht sind. Er fügt aber eine zusätzliche Information hinzu, die den vorigen mit einem adversativen $\delta \dot{\varepsilon}$ entgegengesetzt ist: $\mathrm{Er}$ möchte nicht gesehen werden. Da dies dem Plan des Fremden nicht entspricht, wählt dieser einen nonresponsiven Gesprächsschritt aus, den er mit $\alpha \lambda \lambda \dot{\alpha}$ markiert und der die Unangemessenheit von Pentheus' Idee zeigt. So wird Pentheus dazu gebracht, seine erste Idee, wiederum mit $\dot{\alpha} \lambda \dot{\alpha}$, zu korrigieren: Er gibt die Absicht auf, zu schweigen, sich zu verstecken, unbemerkt zu bleiben; er will sich jetzt offen zeigen. Von dieser neuen Idee ist Pentheus ganz überzeugt; er dankt dem Fremden auch dafür: Sein Sprachgebrauch war richtig!

Im Vergleich zu Pentheus benützt der Fremde eine weniger klare Sprache. Er beantwortet zwar Pentheus' Fragen und beteiligt sich am Gespräch, scheint sich aber leicht daneben zu bewegen. Seine Antworten sind meistens indirekt, ungenau. Wenn Pentheus ihm im zweiten Dialogteil zum Beispiel fragt, wie

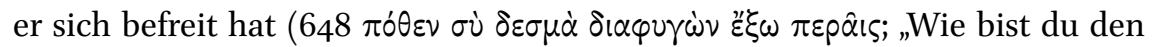
Fesseln entkommen und trittst heraus?"), weist der Fremde auf die anschei-

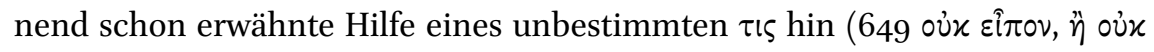

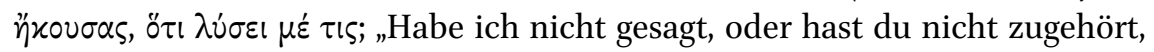
dass jemand mich befreien wird?"). Die zahlreichen Informationen, welche der Fremde als Sequenzerweiterungen (expansions) äußert, verkomplizieren auch die Struktur des Dialogs. Pentheus' allererste Frage betrifft logischerweise das

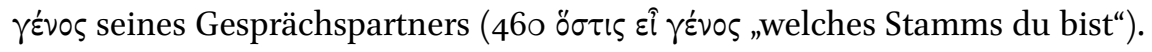
Die erwartete Antwort würde den Namen des Fremden mit demjenigen seines Vaters und/oder seiner Familie enthalten. Der Fremde wird aber nur von sei-

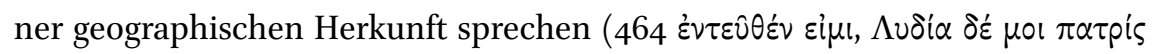
„Von dort bin ich, Lydien ist meine Heimat“), und dies erst vier Verse später. Dazwischen erweitert er die Gesprächssequenz mit einem reaktivierenden

$42 \quad \delta^{\prime} \mathrm{P}: \gamma^{\prime}$ Diggle. 
Gesprächsschritt, ${ }^{43}$ als ob sicherstellen möchte, dass Pentheus seine bevorstehende Antwort verstehen wird. Diese Erweiterung sowie die sofortige Antwort von Pentheus auf seine indirekt gestellte Frage, die mit dem Indefinitpronomen $\pi$ ov gebildet ist, ${ }^{44}$ erlauben ihm aber, nicht mehr als seine geographische Herkunft anzugeben und so ungenau zu bleiben. ${ }^{45}$

Dass der Fremde nur undeutlich antwortet und sogar ein Katz-und-Maus-Spiel treibt, merkt Pentheus schnell. Als selbstsicherer König lässt er sich nicht verunsichern. Aus seiner Sicht kann der Verantwortliche für die Unklarheiten in ihrem Dialog nur der Fremde sein. Und als mächtiger König lässt Pentheus es seinem Gesprächspartner auch wissen: Im ersten Dialogteil stellt er drei Mal mit einem expliziten Beweis fest, dass er den Versuch des Fremden, ihn irrezuführen, bemerkt hat:

1. In Vers 473 möchte Pentheus wissen, welchen Nutzen - eine klare Frage mit einem Interrogativpronomen, nach einem $\delta \dot{\varepsilon}$ als Themawechsel-

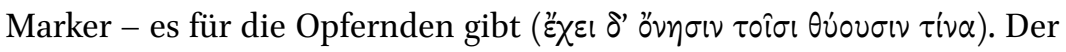
Fremde weigert sich zu antworten, indem er sich in einem nonresponsiven Gesprächsschritt hinter einem religiösen Grund versteckt: Die $\theta \varepsilon ́ \mu ı \zeta$,

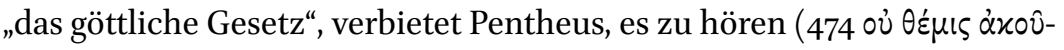
$\left.\sigma \alpha i \sigma^{\prime}\right)$. Dieser Grund entspricht einer sozialen Erwartung: Jeder weiß, dass es unziemlich ist, gegen die témuऽ zu handeln, dass man sonst eine ¿ßßpıৎ, eine „Freveltat" begehen würde. Der Fremde setzt das Versteckspiel aber fort, indem er noch hinzufügt, dass es eigentlich wertvoll ist, es zu

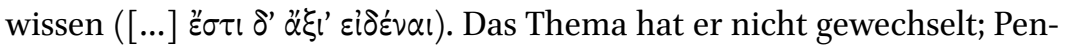
theus könnte noch darauf zurückgreifen. Als mächtiger König beschließt er aber, sich seinem Gefangenen nicht zu unterwerfen, sondern ihm zu zeigen, dass er seine Sprachspielerei bemerkt hat. Ohne sich zu ärgern,

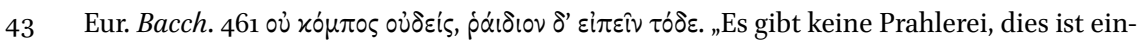
fach zu sagen." (oủ xó $\mu \pi \circ 5$ LP : oủx öxvos Diggle).

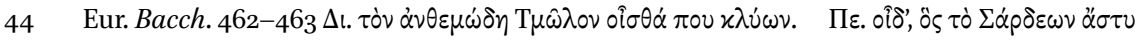

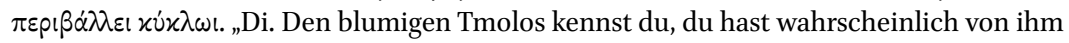
gehört. Pe. Ich weiß, derjenige, der sich im Kreis um die Stadt Sardes legt." Die lydische Herkunft des Fremden kennt Pentheus eigentlich schon. Sie gehört zu den Gerüchten, die

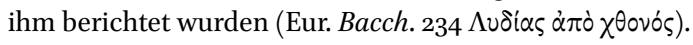

45 Für die überblickenden Zuschauer ist die Antwort auf diese Frage selbstverständlich ironisch, denn $\gamma$ Évos spielt auch auf die doppelte Natur des Fremden als Gott und Mensch an. 
setzt er das Spiel fort. Er antwortet auf die Bedeutung von $\alpha \xi_{10 \varsigma}$ als das, was einen großen Wert oder einen angemessenen Preis hat, mit dem Verb $\varkappa \varkappa \delta \eta \lambda \varepsilon \varepsilon \dot{\varepsilon \varepsilon v}$, das „eine Münze durch Zusatz von minderwertigem Metall verfälschen "46 bedeutet: Der Fremde hat seine Argumente gut verfälscht,

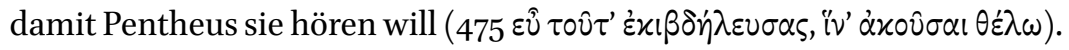
Der König wird sich aber nicht dazu herablassen.

2. In der Fortsetzung des Dialogs interessiert sich Pentheus nicht mehr für den Kult, sondern direkt für den Gott. Er möchte wissen, was für einer

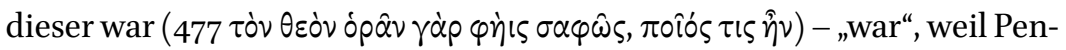
theus an den Moment denkt, in dem der Fremde seinem Gott begegnet ist, von ihm eingeweiht wurde, und der für Pentheus ganz klar zur Vergangenheit gehört. Als Antwort auf das Interrogativpronomen $\pi$ oîऽ wählt der Fremde das indefinite Interrogativpronomen ó $\pi \circ \hat{\imath} о \varsigma$ aus. So scheint seine Antwort responsiv zu sein, während sie nonresponsiv ist: Der Gott war, wer auch immer er wollte, ohne dass der Fremde etwas zu sagen hatte

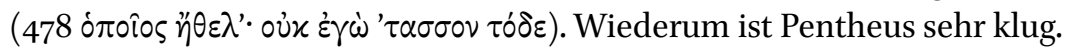
Er merkt selbstverständlich, dass sein Gesprächspartner seine Frage nur ungenau beantwortet hat, und lässt es wiederum mit einem klaren Verb

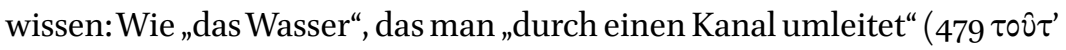
$\alpha \hat{\jmath} \pi \alpha \rho \omega \chi \varepsilon ́ \tau \varepsilon \cup \sigma \alpha \varsigma),{ }^{47}$ hat der Fremde Pentheus' Frage mit der Veränderung ins Indefinite abgelenkt.

3. Zehn Verse später äußert Pentheus wieder eine solche Bemerkung, mit der er das Verhalten und die Worte des Fremden beschreibt. Diese Beschreibung zerfällt in zwei Teile: Zuerst wirft Pentheus dem Fremden vor, schlechte $\sigma \circ \varphi i \sigma \mu \alpha \tau \alpha$ vorzubringen, wofür er bestraft werden muss (489

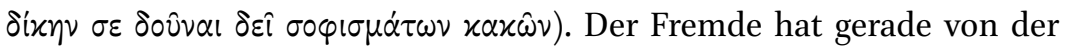

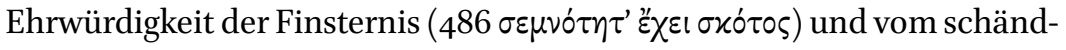

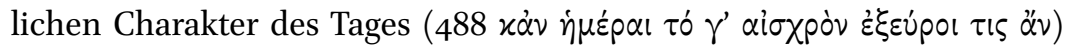
gesprochen. Zwei Charakterisierungen, die zu Pentheus' Begierde nach

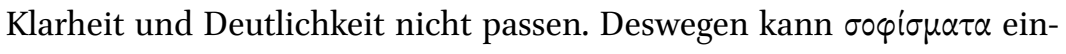
fach mit „Sophismen“ übersetzt werden: Pentheus wirft dem Fremden vor, schlechte Argumente zu äußern, die scheinbar logisch sind, die aber zu einem Fehlschluss führen. Und diejenigen des Fremden führen nicht nur zu einem Fehlschluss, sondern sind einfach $x \alpha x \alpha$, „schlecht“. Auch dafür muss der Fremde bestraft werden. ${ }^{48}$ Der Fremde reagiert sofort, indem

46 Siehe noch Eur. Med. 516, El. 550, Hipp. 616.

47 Siehe auch Eur. Supp. 1111, Plat. Leg. 844a.

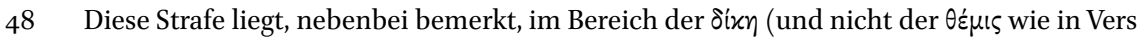

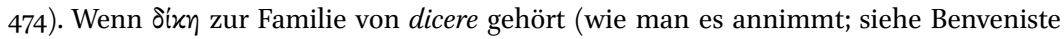


er auf die Satzstruktur von Pentheus zurückgreift, aber ein neues Objekt (mit $\delta \varepsilon \dot{)}$ ) hinzufügt: Auch Pentheus muss bestraft werden. Nicht wegen seiner guten oder schlechten Redekunst, sondern wegen seiner Unwissen-

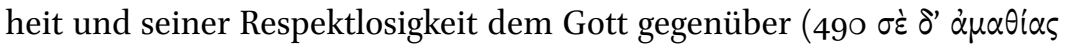

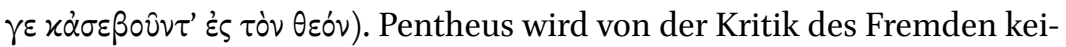
neswegs berührt. Er zeigt sich offen. Er anerkennt die Kühnheit ${ }^{49}$ und die

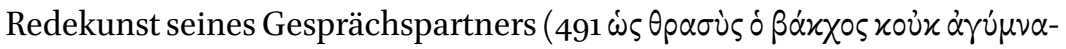
$\sigma \tau \circ \varsigma \lambda \gamma^{\prime}(\omega \nu)$. Und noch einmal zeigt er sich auch geschickt: Indem er die dritte Person braucht, verhindert er, dass der Fremde auf das scheinbare Kompliment direkt reagieren kann. ${ }^{50}$ Dieser muss (auf seine Art, ohne bestimmte Partikel) ein neues Thema einfügen und stellt so selbst eine Frage.

Aus der Sicht des Fremden ist aber Pentheus verantwortlich. Denn er strebt so sehr nach Klarheit, nach deutlichen Strukturen, dass er die mögliche Mehrdeutigkeit, die in den Worten steckt - und insbesondere in denjenigen des Fremden - nicht ernst nimmt. Dass ein Wort mehrere Bedeutungen besitzen kann, ist Pentheus klar. Am Ende der zweiten Dialogstelle zum Beispiel geht es um die Weisheit des Fremden:

\section{[5] Euripides Bakchen 655-656}

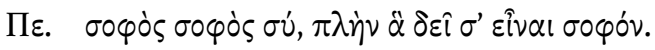

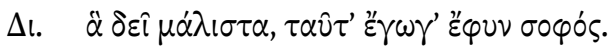

Pe. Weise, weise du, außer worin du weise sein musst.

Di. Worin es in ganz besonderem Maße sein muss, darin bin ich weise.

Pentheus nach ist der Fremde zwar weise, aber nicht in dem, worin er weise sein muss. Und dies betont er, indem er das Adjektiv zwei Mal wiederholt, am Anfang (noch mit dem Personalpronomen $\sigma u ́)^{51}$ und am Ende des Verses. Im Gegensatz dazu ist der Fremde überzeugt, genau darin weise zu sein. Und auch

1969: 107-110; Du Sablon 2014: 242), bedeutet das Wort eine „autoritative Aussage“, das „Recht“, die „Gerechtigkeit“, die ein König oder ein Richter verkörpert, den „Rechtsspruch“, den „Entschluss“ oder das „Urteil“, die man annehmen muss. Pentheus bemerkt aber nicht, dass seine $\delta \dot{x} x \eta$ weniger mächtig ist als die $\theta \dot{\varepsilon} \mu \iota \varsigma$, das „göttliche Gesetz“, das über die ganze Welt herrscht und sie reguliert.

49 Nach Roux (1972: 340) wird im letzten Drittel des fünften Jahrhunderts der Rhetor, der

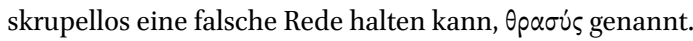

$50 \quad$ Di Benedetto (2010: 370 ).

$5^{1} \quad$ Siehe auch Eur. Bacch. 186, Andr. 245. 
er zeigt es durch die Syntax seiner Antwort: Wie in einem Chiasmus greift er auf den Relativsatz zurück, ändert aber gleichzeitig $\sigma \varepsilon$ selbstverständlich zu है $\gamma \omega \gamma \varepsilon$

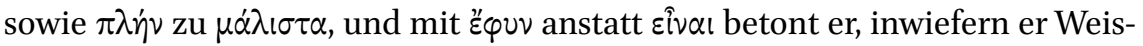
heit besitzt. ${ }^{52}$ Dass $\sigma \circ \varphi o ́ \varsigma$ zweideutig ist, wissen sowohl der Fremde als auch Pentheus: Die Wahl der Wortbedeutung hängt in diesem Fall von der Interpretation und Weltanschauung jeder Figur ab. ${ }^{53}$

Ein Wort kann aber auch gleichzeitig mehrere Bedeutungen ausdrücken, ohne dass es seine Kohärenz verliert. Ein gutes Beispiel dafür ist das Adjektiv $\delta \varepsilon เ v o ́ s$, das sowohl "furchtbar, schrecklich“ als auch "außerordentlich, erstaunlich" bedeutet. Als Einleitung zum zweiten Dialogteil, wenn Pentheus aus dem Palast kommt, spricht er von den $\delta \varepsilon เ \nu \alpha$, von denen er erfahren hat (642 $\pi \dot{\varepsilon} \pi \circ v \theta \alpha$

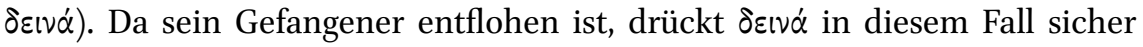
"schreckliche Dinge“ aus. Es sind gleichzeitig aber auch „außerordentliche, erstaunliche Dinge“, denn einen solchen Gefangenen hatte er noch nie. ${ }^{54}$

Deswegen ist Pentheus aus der Sicht des Fremden für das Scheitern ihres Dialogs verantwortlich: Er versteht die subtilen Unterschiede nicht, die den Sprachgebrauch des Fremden bilden und auf die Mehrdeutigkeit der Sprache hinweisen. Er hat den Eindruck, dass der Fremde immer neue Wörter beibringt

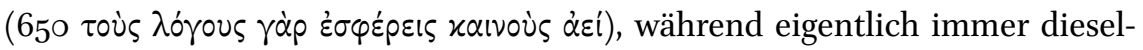
ben gebraucht werden. Damit der Dialog zur Lösung einer problematischen Situation wird, müssen die Gesprächspartner ein offenes Verhalten an den Tag legen. Pentheus kann aber keinen Kompromiss schließen. Er ist nicht bereit, den Sprachgebrauch und die Weltanschauung des anderen zu verstehen, nicht einmal zu akzeptieren. Zum Beispiel verwendet der Fremde, wenn er von sei-

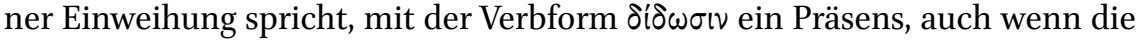
Handlung nicht zeitgleich zu seiner Äußerung stattfindet: Der Gott gibt dem

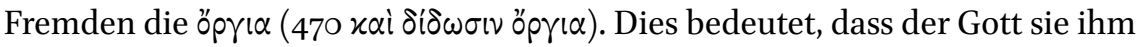
gegeben hat (so versteht es Pentheus, da er in Vers 477, wenn er gewissermaßen zu diesem Thema zurückkehrt, das Verb im Imperfekt gebraucht), aber auch, dass der Gott sie dem Fremden immer wieder gibt und immer wieder geben wird, so dass er sie ihm schlicht und einfach gibt. ${ }^{55}$ Die klaren Zeitstrukturen von Vergangenheit, Gegenwart und Zukunft, die Pentheus' Welt bilden, sind

\footnotetext{
52 Für diejenigen, die hinter dem Fremden den Gott hören, weist er so auch auf seine göttliche Natur, welche das Hauptziel seiner thebanischen Erscheinung ist, indirekt hin.

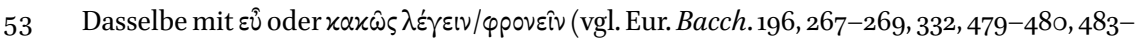
484, 1123).

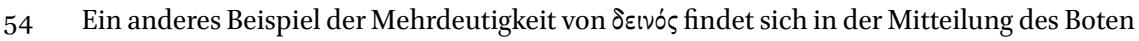
über die Taten der Thebanerinnen ausgedrückt (Eur. Bacch. 667, 716).

55 Rijksbaron (1991: 73) spricht von „a past state of affairs with present relevance“. Diese Verbform kann als Beispiel einer zyklischen Zeitvorstellung verstanden werden.
} 
für den Fremden nicht relevant. Ein anderes Beispiel: Der Gott kann anwesend

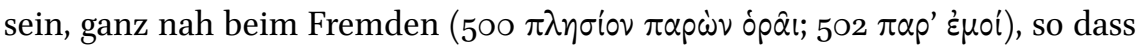

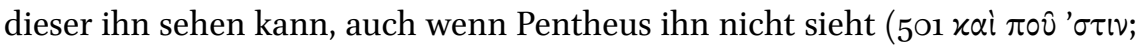

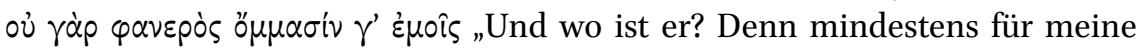
Augen ist er nicht sichtbar."). Die Mehrdeutigkeit ist hier stark mit der doppelten Natur des Fremden, der gleichzeitig auch der Gott ist, verbunden. Aber nicht nur: Auch wenn der Fremde als reiner Mensch betrachtet wird, ist die Mehrdeutigkeit verständlich. Dionysos' Anwesenheit muss nicht faktisch, tatsächlich stattfinden: Er ist da und nicht da, einfach nicht wirklich oder klar sichtbar. ${ }^{56}$

Pentheus bekommt jedes Mal die Möglichkeit, seine Ansicht und Einstellung zu ändern. Zum Beispiel erklärt ihm der Fremde nach seinen zwei ersten kritischen Bemerkungen, inwiefern seine Worte nicht „gefälscht“ oder „abgelenkt" sind. ${ }^{57}$ Diese Erklärungen enthalten zwar keine bestimmten Partikeln oder Marker. Wenn Pentheus auf die Worte hören würde, würde er aber merken, inwiefern sie kohärent sind und welche neue Information sie liefern. Vergeblich: Wie schon dargestellt, lehnt Pentheus in dieser Situation jede Art von responsiven Gesprächsschritten ab. Er hört seinen Gesprächspartner nicht, ignoriert ihn, stellt sofort eine neue Frage mit einem neuen Thema.

Dasselbe ganz am Ende der ersten Dialogstelle: Pentheus versteht nicht oder tut, als ob er nicht verstanden hätte -, dass der Fremde keine Frage mit einem Interrogativpronomen, sondern eine bloße Feststellung über Pentheus

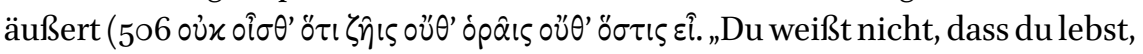
noch was du siehst noch wer du bist.") ${ }^{58}$. Sobald Pentheus ö $\sigma \tau \iota \varsigma$ हî hört, nutzt er die Chance, von sich selbst sprechen zu können, und antwortet ganz klar und präzis (im Unterschied zu dem Fremden in Antwort auf die Frage ö $\sigma \tau \iota \varsigma \varepsilon \hat{\imath}$ $\gamma^{\varepsilon ́ v 0 \zeta ~ " w e l c h e n ~ S t a m m s ~ b i s t ~ d u “ ~ i n ~ V e r s ~ 46 o): ~ E r ~ i s t ~ P e n t h e u s, ~ d a s ~ K i n d ~ A g a u e s, ~}$

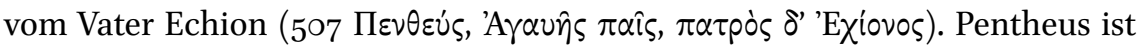
stolz, seine erhabene Mutter Agaue und seinen Vater Echion nennen zu können: Die erste verbindet ihn über den berühmten Kadmos mit der königlichen Macht; der zweite verleiht ihm als einem sogenannten Spartos, der bewaffnet aus der Erde erschienen ist, nachdem Kadmos den Drachen, der über das thebanische Land herrschte, getötet und seine Zähne ausgesät hatte, die Stärke der Erde, die kriegerische Kraft und die thebanische Legitimität. Was Pentheus

$5^{6}$ Dieselbe Interpretation gilt für die zwei Sonnen und die zwei Theben, die Pentheus nach seiner Verkleidung sieht (Eur. Bacch. 918-919).

57 Eur. Bacch. 476, 480.

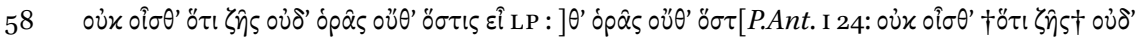

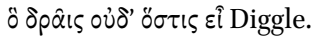


aber nicht hört, ist die mögliche Bedeutung seines eigenen Namens. Denn Пєv$\theta \varepsilon u ́ \varsigma$ lässt $\pi \varepsilon \dot{\varepsilon} v \theta 0 \varsigma$ anklingen, aus der Familie von $\pi \dot{\alpha} \sigma \chi \varepsilon เ \nu$, das den "Schmerz" und besonders die „Trauer" ausdrückt. ${ }^{59}$ Wie der Fremde es im darauffolgenden Vers erklärt, ist Pentheus durch seinen Namen prädestiniert, ein schlechtes

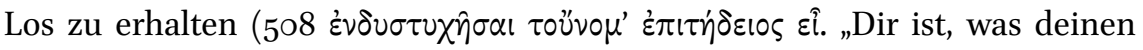

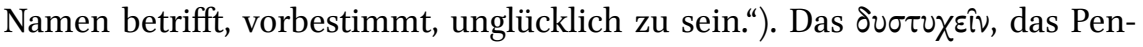
theus zum Unglück und zu einem furchtbaren Tod führen wird, könnte sich

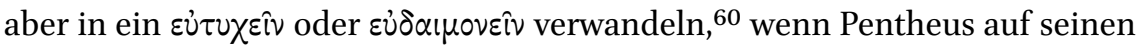
Gesprächspartner hören, seinen Sprachgebrauch akzeptieren und Dionysos' göttliche Macht anerkennen würde. Darauf reagiert Pentheus natürlich nicht. Im Gegenteil: In Vers 509 bekräftigt er seine königliche Position durch zwei deutliche Imperativformen ( $\chi \omega^{\prime} \rho \varepsilon l$ und $\left.\varkappa \alpha \theta \varepsilon i p \xi \alpha \tau^{\prime}\right)$ und beendet das Gespräch.

Die Grenzen des klaren Dialogs

Die subtilen Unterschiede der Sprache versteht Pentheus also nicht. Während aller vier Dialogstellen bleibt er in seinem Sprachgebrauch der Gleiche in seinem Streben nach Klarheit und Deutlichkeit. Auch nachdem Pentheus den Vorschlag des Fremden angenommen hat, sich zu verkleiden, um in die Berge zu gehen, ändert er sich nicht. Und dies obwohl Dionysos - der Fremde ruft explizit den Gott darum an ${ }^{61}$ - eine "leichte Raserei“ über Pentheus kom-

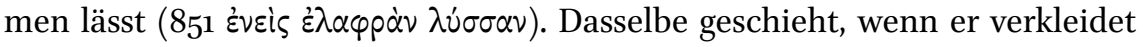
aus dem Palast tritt: Ab diesem Moment der Handlung sieht er, was er sehen

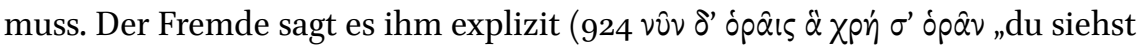
nun, was du sehen musst"). Durch seine Verkleidung hat Pentheus ein neues Sehvermögen erhalten. Es ändert aber nichts, denn er weiß dieses nicht zu gebrauchen: es ist zu wenig eindeutig. Für Pentheus zählt seine eigene Sicht, sein eigenes Aussehen. ${ }^{62}$ Und dies bis im kleinsten Detail wie eine Falte seines peplos. ${ }^{63}$

Wichtig ist ihm auch sein erster Gedanke über die Unruhe in Theben: Er bleibt bis zum Schluss überzeugt, dass die Frauen sich schändlichen Handlun-

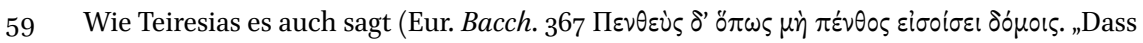
Pentheus aber keinen Schmerz in dein Haus hineinlasse!"). Eine Anspielung darauf findet

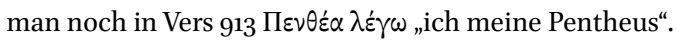

6o Zum Beispiel Eur. Bacch. 73-74.

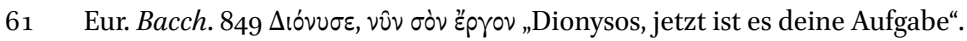

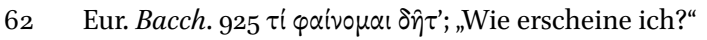

63 Eur. Bacch. $937-938$. 
gen hingeben. ${ }^{64}$ Seine Überzeugung ist so stark, dass er die Thebanerinnen nie sieht, auch wenn er vor ihnen steht. ${ }^{65}$

Pentheus versteht so wenig von der Sprachmehrdeutigkeit, die der Fremde beherrscht, er ist so selbstsicher, dass er am Ende der vierten Dialogstelle, in den letzten Worten, die er auf der Bühne ausspricht, die Sätze des Fremden unterbricht und sie auf seine Weise, nach seinem Sprachgebrauch und seiner Weltanschauung, vervollständigt. Er merkt aber nicht, dass er so seinen eigenen Tod inszeniert. ${ }^{66}$

Mit Pentheus' Tod ist das Problem, das sich in Theben abspielt, gelöst aber nicht dank einem klaren Dialog. Denn mit Klarheit und Deutlichkeit ist es unmöglich, einen solchen Gott wie Dionysos - der anwesend und abwesend, sichtbar und unsichtbar ist, und der die klaren Kategorien verschleiert und zerstört - zu erfassen und einzuordnen. Genereller gesagt ist es unmöglich, die Mehrdeutigkeit mit klaren Worten und Strukturen zu erklären und darzustellen. So stößt der klare Dialog im Leben an seine Grenzen.

\section{Bibliographie}

Benveniste, É., (1969), Le vocabulaire des institutions indo-européennes, tome 2: pouvoir, droit, religion, Paris.

Bonifazi, A., Drummen, A., \& Kreij, M. de, (2016), Particles in Ancient Greek Discourse. Five Volumes Exploring Particle Use Across Genres, Washington, D.C. http://chs.harva rd.edu/CHS/article/display/6391 (13.06.2019).

Chantraine, P., (21999 [1968-1980]), Dictionnaire étymologique de la langue grecque. Histoire des mots, Paris.

Collard, C., (1980), ,On Stichomythia', Liverpool Classical Monthly 5, 77-85 (Nachdr.:

C. Collard, Tragedy, Euripides and Euripideans, Bristol 2007, 16-30).

Di Benedetto, V., (22010 [2004]), Euripide, Le Baccanti, Mailand.

Diggle, J., (1994), Euripidis fabulae, vol. 3, Oxford.

Dodds, E.R., ( ${ }^{2} 1960$ [1944]), Euripides, Bacchae, Oxford.

Drummen, A., (2017), Language on Stage. Particles in Ancient Greek Drama, Dissertation

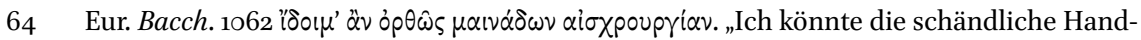
lung der Mänaden richtig sehen." Siehe auch 957-958. Im Gegenteil zu Pentheus sieht der

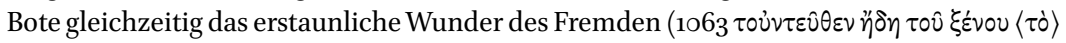
$\theta \alpha \hat{\nu} \mu^{\prime} \dot{\rho} \hat{\omega}$. „Danach sehe ich das Wunder des Fremden.").

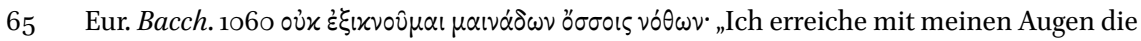

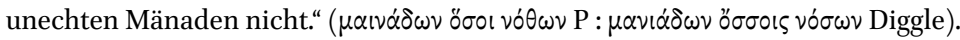

66 Eur. Bacch. 966-970. 
(Universität Heidelberg). http://www.ub.uni-heidelberg.de/archiv/23002 (14.06 $.2019)$.

Du Sablon, V., (2014), Le système conceptuel de l'ordre du monde dans la pensée grecque à

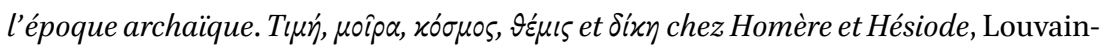
la-Neuve.

Dubel, S., (2015), ,Avant-propos: théories et pratiques du dialogue dans l'Antiquité, in S. Dubel und S. Gotteland (Hg.), Formes et genres du dialogue antique, Bordeaux, 1123.

Emde Boas, E. van, (2017a), ,Analyzing Agamemnon: Conversation Analysis and Particles in Greek Tragic Dialogue', Classical Philology 112, 411-434.

Emde Boas, E. van, (2017b), Language and Character in Euripides' Electra, Oxford.

Gross, A., (1905), Die Stichomythie in der griechischen Tragödie und Komödie. Ihre Anwendung und ihr Ursprung, Berlin.

Hall, J.M., (2002), Hellenicity: between Ethnicity and Culture, Chicago.

Hall, E., (2004), Inventing the Barbarian: Greek Self-definition through Tragedy, Oxford. Jazdzewska, K., (2014), ,From Dialogos to Dialogue: the Use of the Term from Plato to the Second Century CE', Greek, Roman and Byzantine Studies 54, 17-36.

Meibauer, J., (22001 [1999]), Pragmatik. Eine Einführung, Tübingen.

Mroczynski, R., (2014), Gesprächslinguistik. Eine Einführung, Tübingen.

Rijksbaron, A., (1991), Grammatical Observations on Euripides'Bacchae, Amsterdam.

Roux, J., (1972), Euripide, Les Bacchantes, tome 2: Commentaire, Paris.

Sacks, H., Schegloff, E.A., \& Jefferson, G., (1974), ,A Simplest Systematics for the Organization of Turn-taking for Conversation', Language $5^{\circ}$, 696-735.

Saïd, S., (1984), ,Grecs et Barbares dans les tragédies d' Euripide. La fin des différences?‘, Ktèma 9, 27-53.

Schuren, L., (2015), Shared Storytelling in Euripidean Stichomythia, Leiden/Boston.

Schwinge, E.-R., (1968), Die Verwendung der Stichomythie in den Dramen des Euripides, Heidelberg.

Seaford, R., (1996), Euripides, Bacchae, Warminster.

Seidensticker, B., (1971), ,Die Stichomythie', in W. Jens (Hg.), Die Bauformen der griechischen Tragödie, München, 183-220.

Susanetti, D., (2010), Euripide, Baccanti, Rom. 


\title{
Iphigenie und ihre Mutter: Pragmatische Bemerkungen zur Iphigenie in Aulis
}

\author{
Giada Sorrentino
}

Einleitung: Interaktion und Charakterisierung in der Iphigenie in Aulis

Die Iphigenie in Aulis zeichnet sich durch die besondere Bedeutung aus, die im Plot den Schwierigkeiten und dem Scheitern der zwischenmenschlichen Kommunikation beigemessen wird. Die Handlung entwickelt sich um die Aufrechterhaltung und Enthüllung eines von Agamemnon gegen seine Familie und seine Tochter Iphigenie ersonnenen Trugs. Der Vater hat sie unter dem Vorwand, sie solle Achill heiraten, nach Aulis, wo er mit der griechischen Flotte nach Artemis' Willen festsitzt, kommen lassen. In Wirklichkeit soll sie geopfert werden, da dies die von der Göttin gestellte Bedingung ist, damit die Expedition beginnen kann. Der dauernde Widerstand einiger Figuren gegen die Opferung einerseits und andererseits die Meinungsumschwünge anderer erschweren die Entwicklung des Plots solange, bis das Mädchen durch seine Meinungsänderung selbst entscheidet, sich seinem Schicksal zu fügen.

In diesem dramatischen Gerüst liegt der Hauptgrund meiner Untersuchung des Dialogs in diesem Stück als Mittel zur Konstruktion und Gliederung des Plots sowie zur Charakterisierung der Figuren und ihrer Beziehungen. Die Pragmatik, die die Sprache als Form der Handlung betrachtet und sie mit den spezifischen Eigenschaften ihres Gebrauchskontexts in Beziehung setzt, kann einen grundlegenden Beitrag zu einer solchen Untersuchung leisten. Die Kategorien und Erklärungsmodelle, durch die sie den Gebrauch der Sprache in den kommunikativen Prozessen analysiert, haben sich seit langem auch als geeignete Instrumente erwiesen, um den aktionalen, interaktionalen und sozialen Aspekt der dramatischen Sprache zu erfassen. ${ }^{1}$ Daher verwende ich diese Instrumente - von der Sprechakttheorie über die Gesprächsanalyse bis zu den politeness-Studien - neben den traditionellen auf die Literatur angewandten Untersuchungsmethoden, um deutlicher hervorzuheben, wie die Figuren

1 Zur Anwendbarkeit der Pragmatik auf den Dialog des Dramas und zu ihren heuristischen Vorteilen vgl. u. a. Elam (2002: 142-167) und Hess-Lüttich (1980: 5-22, 2001: 1640-1655); van Emde Boas (2017) verwendet die verschiedenen Bereiche der Pragmatik in seiner Studie zur sprachlichen Charakterisierung der Figuren in Euripides' Elektra. 
durch ihr Interagieren die Handlung fortführen und gleichzeitig ihre dramatischen Rollen sowie ihre Beziehungen gestalten.

In diesem Beitrag beschränke ich mich darauf, einige Resultate meiner Untersuchung vorzustellen, die besonders die Charakterisierung der Figuren von Iphigenie und Klytaimestra im Dialog betreffen. Ich werde zeigen, wie die beiden Frauen im ganzen Stück hinsichtlich einiger grundlegender Aspekte ihres interaktionalen Verhaltens einander entgegengestellt werden und wie der Meinungsumschwung Iphigenies gegenüber der Opferung (ab Vers 1368) ihren Gegensatz nicht beendet, sondern unter umgekehrten Vorzeichen weiterführt und die Beziehung Mutter-Tochter im Schlussteil der Tragödie beeinflusst. ${ }^{2}$

\section{Selbstsichere Ehefrau, Mutter und Königin: die Charakterisierung Klytaimestras}

In den Gesprächen, an denen Klytaimestra beteiligt ist, zeigt sie interaktionale Verhaltensweisen, die trotz der Verschiedenheit der einzelnen Situationen bis zu Iphigenies Wandel konstant bleiben.

Ein erstes Kennzeichen betrifft die Art und Weise, wie sie das Wort ergreift bzw. übergibt. In der Mehrheit der Fälle wählt sie sich selbst als Sprecherin autonom aus, vor allem um Paarsequenzen zu eröffnen, also um Handlungen (wie z.B. Fragen) zu verwirklichen, die von den Gesprächspartnern bestimmte Reaktionen erwarten. ${ }^{3}$ Auf diese Weise gelingt es ihr, das Verhalten der Gesprächspartner zu beeinflussen und die Interaktion leicht in die von ihr gewünschte Richtung zu lenken.

Dies bemerkt man von ihrem ersten $\left(685^{-740}\right)$ bis zu ihrem letzten Gespräch vor dem Wandel Iphigenies (1345-1368). Im ersten folgen etwa 30 Verse lang

2 Der Text der Iphigenie in Aulis hat zahlreiche philologische Kontroversen ausgelöst, von denen viele immer noch offen sind: es lässt sich nämlich nicht bestreiten, dass das euripideische Grundgerüst verschiedenartige Änderungen erfahren hat, die es unmöglich machen, das ursprüngliche Werk von den Zusätzen zu unterscheiden. Ich folge der von Collard und Morwood (2017) besorgten Edition, welche die neueste ist und die meisten textkritischen bisher erschienenen Studien berücksichtigt. In den Anmerkungen werde ich nur auf die Fälle hinweisen, in denen ich von ihrem Text abweiche oder in denen sie selbst unsicher sind. Vgl. zu den wichtigsten Textproblemen außer Collard und Morwood (2017: 50-62) wenigstens die ausführlichen Darlegungen von Stockert (1992: 63-87).

3 Eine Paarsequenz (adjacency pair) ist die Abfolge von zwei Aussagen, die von verschiedenen Gesprächspartnern geäußert werden und so strukturiert sind, dass ein bestimmter erster Teil einen dazu passenden zweiten verlangt, z. B. Frage/Antwort, Gruß/Gegengruß usw. Vgl. Schegloff (2007:13-21). Die deutsche Terminologie folgt grundsätzlich Eberle (1997) und Meibauer $\left({ }^{2} 2001\right)$. 
Fragen der Königin an Agamemnon über von ihr gewählte Themen aufeinander, im zweiten wählt sie sich ständig selbst als Sprecherin aus, um ihren Gesprächspartner Achill zum Erzählen zu bringen, dessen Absichten zu erfahren und mit ihm zusammen den letzten Versuch zu unternehmen, Iphigenie zu retten.

Klytaimestras interaktionale Fähigkeit gewinnt im zweiten Dialog mit Agamemnon (1106-1145) an dramatischer Relevanz. Darin gelingt es der Königin, die inzwischen die wahren Absichten Agamemnons erfahren hat, in wenigen Zügen die Führungsrolle im Gespräch zu übernehmen und den Trug des Ehemanns zu entlarven. Der Dialog beginnt zwar auf Agamemnons Initiative, aber es ist Klytaimestra, die die verbale Auseinandersetzung gesucht hat, wie sie selbst in einem kurzen vorausgehenden Monolog (1098-1105) offenbart. Am Anfang zeigt sie sich fügsam und reagiert auf die Sprechhandlungen ihres Mannes, ohne zu zeigen, dass sie um seinen Plan weiß. ${ }^{4}$ Nachdem sie seinem Befehl, Iphigenie aus dem Zelt herausgehen zu lassen, gehorcht hat, zeigt sie ihre Fertigkeit, die aktive Rolle im Wortwechsel zu übernehmen. Zunächst erklärt sie sich zur einzigen Gesprächspartnerin des Ehemannes, indem sie sagt, dass sie für sich und für ihre Tochter sprechen wird (1121). Die von Agamemnon an das Mädchen gerichteten Fragen über die Gründe für seinen ausweichenden Blick und seine betrübte Miene rufen die folgenden Redebeiträge (turns) hervor:

[1] Euripides Iphigenie in Aulis 1124-1131
$\mathrm{K} \lambda . \varphi \varepsilon \hat{v}$.

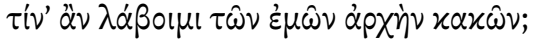

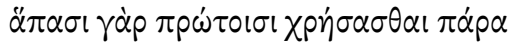

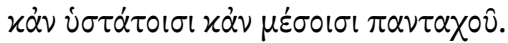

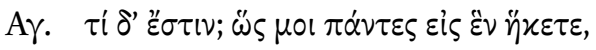

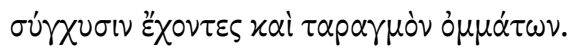

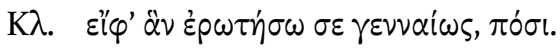

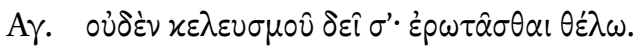

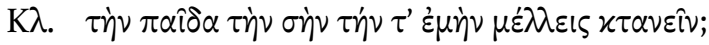

4 Der einzige Hinweis auf ihr Wissen, den Klytaimestra in dieser Passage des Dialogs gibt, ist

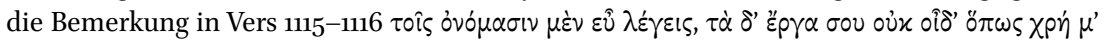

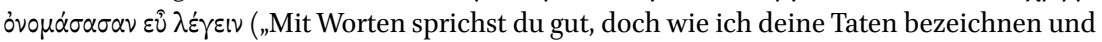
gut reden soll, das weiß ich nicht."). Diese wird aber durch das Wortspiel mit dem Ausdruck $\varepsilon \hat{}$ $\lambda \varepsilon^{\prime} \gamma \varepsilon เ v$, der sowohl, gut (wohl) reden' als auch ,das Richtige treffen` bedeutet, für Agamemnon zweideutig gemacht; vgl. Stockert (1992: 516). 
Kl. Ach, welchen Anfang meines Leidens soll ich wählen? Ein jedes kann ich ja als erstes nehmen, als letztes oder mittleres: Leid ist überall.

Ag. Was ist? Wie ihr beide doch einander gleicht: bedrückt erscheint ihr und mit verstörtem Blick.

Kl. Antworte ehrlich auf meine Frage, mein Gemahl.

Ag. Dazu brauchst du mich nicht aufzufordern: frage nur!

Kl. Hast du die Absicht, dein Kind und meines zu töten? ${ }^{5}$

Die Königin gibt zunächst eine allgemeine Antwort, in der sie über schwer zu beschreibende Übel spricht. Dies veranlasst Agamemnon, die Frage erneut zu stellen. Aber nicht einmal jetzt liefert sie eine klare Antwort, sondern fügt in die von Agamemnon eröffnete Frage-Antwort-Sequenz ein weiteres adjacency pair ein. Gemäß der Gesprächsanalyse eröffnet sie eine Einschubsequenz. ${ }^{6}$ In einer Aufforderung kündigt sie eine Frage ihrerseits an ihren Mann an. Diese Einschubsequenz bereitet also eine neue Paarsequenz vor, die nach Agamemnons Zustimmung von Klytaimestra eröffnet wird (1131 „Hast du die Absicht, dein Kind und meines zu töten?"). ${ }^{7}$ Durch diese konversationellen Züge gelingt es ihr, ihrem Mann die Rolle des Fragenden und damit die Zügel der Interaktion zu entreißen. Sie will, dass Agamemnon selbst auf seine Anfangsfrage antwortet und dabei seinen Plan offenbart. Ihre Anklage erscheint in Form einer Ja/Nein-Frage, die zwar schroff, aber weniger aggressiv als eine Anklage in assertiver Form ist. ${ }^{8}$ Dem Gesprächspartner würde eine einfache Verneinung genügen, um sie zurückzuweisen. Wegen seiner Unfähigkeit, eine solche zu liefern, wird ihn jedoch die Königin in den folgenden Versen (1132-1145) in die Enge treiben. Auf die Redebeiträge, mit denen der König versuchen wird, der Anklage auszuweichen, wird Klytaimestra mit ebenso vielen, in denen sie auf der Frage beharrt und das Fehlen einer Antwort immer signifikanter macht, reagieren. Von der so erreichten überlegenen Position aus wird sie schließlich explizit Agamemnons Spiel entlarven.

5 Die Übersetzung stammt, wo nicht anders angegeben, aus Blume (2014).

6 Einschubsequenzen (insertion sequences) sind Folgen von Redebeiträgen (etwa Paarsequenzen), die zwischen dem ersten und dem zweiten Teil einer umrahmenden Paarsequenz eingefügt werden und deren Vervollständigung derjenigen dieser vorausgeht. Vgl. Schegloff (2007: 97-114).

7 Die Paarsequenzen, die wie diese das Vorkommen einer folgenden vorankündigen, werden in der Gesprächsanalyse als Präsequenzen (pre-sequences) bezeichnet, vgl. dazu Schegloff (2007: 28-57).

8 Die Form der Frage kann die illokutionäre Kraft eines Sprechakts abmildern (Brown und Levinson ${ }^{2} 1987$ : 132-133). 
Die Sprechakte, welche Klytaimestra im Dialog verwirklicht, und ihre relative Frequenz in den verschiedenen Kontexten, in denen sie interagiert, bilden im Stück ebenfalls ein wirksames Instrument zu ihrer Charakterisierung. ${ }^{9}$

In dieser Hinsicht ist die erste Replik, die Klytaimestra bei der gemeinsamen Ankunft mit Iphigenie und dem kleinen Orest in Aulis ausspricht (6o7-63o), besonders interessant. Sie beginnt mit einem Dank an die Frauen des Chors, welche die königliche Familie willkommen geheißen haben, und entwickelt sich als lange Abfolge von direktiven Sprechakten (hauptsächlich Befehlen) ${ }^{10}$ an alle erreichbaren Anwesenden: begleitende Diener, die Frauen des Chors, Iphigenie und Orest. Die Zahl der Direktiva und ihrer Adressaten, ihre direkte Form (sie werden immer in Imperativsätzen geäußert), die unterschiedlichen Bereiche, die sie betreffen - vom Aussteigen der Sprecherin und ihrer Kinder aus dem Wagen über den Transport von Iphigenies Mitgift bis zur Versorgung der Pferde -, zeigen bereits bei Klytaimestras erstem Bühnenauftritt die Sicherheit, mit der sie die von ihren sozialen Rollen herrührende Autorität ausübt, und die Sorgfalt, mit der sie ihre Aufgaben erledigt. Diese werden sich in der Folge als die wichtigsten Merkmale ihres Charakters erweisen. ${ }^{11}$

Die in dieser Passage dominierenden Sprechakte nehmen auch sonst in Klytaimestras Sprechen bis zum Wandel Iphigenies eine wichtige Rolle ein. Die Königin macht reichlich von Direktiva Gebrauch, die sie an all ihre Gesprächspartner richtet, um ihre sozialen Rollen auszuüben und ihre Beziehungen zu gestalten. An Kinder und Untergebene richtet sie vor allem Befehle und Aufforderungen, die zu einer Mutter und Hausherrin passen. Gegenüber Achill äußert sie anfangs - schon in der Rolle der künftigen Schwiegermutter - Sprechakte des Vorschlags und der Aufforderung, nach der Entdeckung des unmittelbar bevorstehenden Opfers der Tochter dagegen eindringliche Bitten um Hilfe. ${ }^{12}$

Ich folge in der Regel der Einteilung der Sprechakte von Searle (1976). Die Fälle, in denen ich mich auf jüngere Studien stütze, die Searles Kategorien auf der theoretischen Ebene oder hinsichtlich der Anwendung auf reale bzw. literarische Interaktionen präzisiert oder korrigiert haben, werden jeweils in Anmerkung angegeben.

10 Gemäß Searle (1976:11) können die direktiven Sprechakte als „attempts (of varying degrees [...]) by the speaker to get the hearer to do something" definiert werden. Auf Risselada (1993: besonders 32-49) aufbauend, verfeinert und korrigiert teilweise Denizot (2011: 2324) Searles Kriterien der Einteilung. Sie liefert somit eine m.E. befriedigendere Klassifizierung der Unterarten der Direktiva, die den Akt der Frage ausschließt und Befehl/Aufforderung (injonction), Forderung/Bitte (requête), Flehen (prière), Vorschlag (proposition), Ratschlag (conseil), Anweisung (instruction) usw. klarer zu unterscheiden vermag.

11 Diesen von vielen für unecht oder suspekt gehaltenen, aber von anderen verteidigten Redebeitrag halten Collard und Morwood in ihrer Ausgabe mit Vorbehalt. Vgl. Collard und Morwood (2017: 401-402) und Stockert (1992: 380-381). 
Interessant ist, wie sich ihr Verhalten Agamemnon gegenüber ändert: Ihr Mann ist von Direktiva für eine bestimmte Dauer fast ganz ausgenommen, und zwar solange, bis Klytaimestra sich entschließt, seinen Plan zu entlarven. Von da an wendet sie sich an ihn immer häufiger mit diesen Sprechakten, die anzeigen, dass sie die Autorität des Gatten infrage stellt. ${ }^{13}$

Eine umfassende Untersuchung der von Klytaimestra verwirklichten Sprechakte zeigt ihre Vorliebe für Direktheit. Das gilt auch bezüglich der Sprechakte, welche einige politeness-Modelle als FTAs ( face threatening acts) bezeichnen, ${ }^{14}$ da sie das Bedürfnis nach Bestätigung sowie das Bedürfnis nach Freiheit, die das soziale Selbstbild ( face) eines Individuums darstellen, verletzen. ${ }^{15}$

Unter den politeness-Strategien, durch die Klytaimestra ihre FTAs abmildert, ist die Indirektheit selten und immer nur formal, da die FTAs aus dem Kontext und dem Kotext unmittelbar deutlich werden. ${ }^{16}$ Ein interessantes Beispiel begegnet vor der Entdeckung des Trugs und betrifft ihren FTA der Weigerung, dem Befehl Agamemnons, vor der Hochzeit Iphigenies nach Hause zu gehen, zu gehorchen:

\section{[2] Euripides Iphigenie in Aulis 733-740}

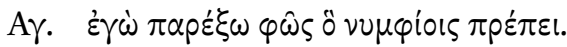

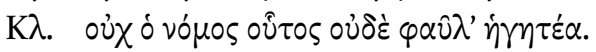

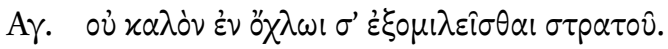

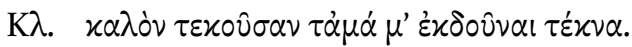

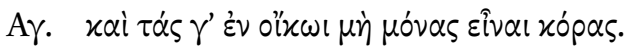

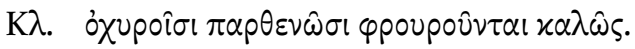

alten Diener $(867,872)$. Vor der Entdeckung des Truges wendet sie sich an Achill mit einer Aufforderung und einem Vorschlag (831-832), danach fleht sie ihn an (9oo-916, 985-989) und richtet wieder eine Bitte an ihn (995-996).

13 Die von Klytaimestra an Agamemnon gerichteten Direktiva sind eine Aufforderung (1129), die mehrmals wiederholt wird (1133 und 1135), ein Befehl in Form eines Rates (1143) und eine Bittrede (1146-1208). Der direktive Sprechakt in Vers 740 ist in Wirklichkeit Teil eines kommissiven Sprechakts der Ablehnung.

14 Das Modell, auf das ich mich hauptsächlich beziehe, ist das von Brown und Levinson $\left({ }^{2} 1987\right)$.

15 Vgl. Brown und Levinson (21987: 62-68) und Sektion B dieses Bandes.

16 Zur Tatsache, dass die Indirektheit (off-recordness) eines FTA nur formal ist, wenn der extralinguistische Kontext, der Kotext (d.h. die umgebenden Redebeiträge), sowie paralinguistische und nonverbale Hinweise nur eine einzige Interpretation dieses erlauben, vgl. Brown und Levinson ( ${ }^{2} 1987$ : 211-213). 


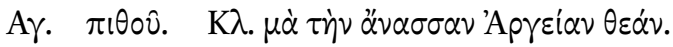

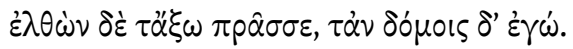

Ag. Ich werde das Licht scheinen lassen, das dem Brautpaar gebührt.

Kl. Das ist nicht der Brauch! Man darf dergleichen nicht geringschätzen.

Ag. Es ziemt sich nicht, dass du dich in der Masse des Heeres aufhältst.

Kl. Es ziemt sich aber, dass ich als Mutter mein Kind vermähle.

Ag. Aber auch, dass die Töchter zu Hause nicht allein bleiben.

Kl. In festen Mädchenzimmern leben sie wohlbehütet.

Ag. Gehorche!

Kl. Nein, bei der Göttin, die in Argos herrscht! Geh du und besorge die Dinge draußen; die im Haus besorge ich.

Agamemnon hat soeben Klytaimestra versichert, dass er auch die für die Feier von der Mutter zu verrichtenden Aufgaben erfüllen wird. Sie wendet ein, dass dieses Verhalten vom vópos (734) abweiche, der nicht unterschätzt werden dürfe. ${ }^{17} \mathrm{Ihr}$ Sprechakt ist zwar formal indirekt, wird aber in der kommunikativen Situation, in der er vorkommt, deutlich und löst einen Schlagabtausch über die Angemessenheit des Befehls aus. Auf die Bemerkung des Mannes, dass es nicht angebracht sei, dass Klytaimestra sich unter das Heer mische, antwortet sie in Vers 736, indem sie die Schicklichkeit der Anwesenheit der Mutter an der Hochzeit betont. Unmittelbar darauf (738) neutralisiert sie den Einwand des Gatten, dass das Verbleiben ihrer Töchter allein zu Hause unschicklich sei, durch die Versicherung, dass diese in Argos wohlbehütet sind. Trotz der formalen Indirektheit wird in diesen letzten Redebeiträgen ihre Ablehnung durch eine zweifache Wiederholung sogar verstärkt. Dient die exakte Wiederholung (736) des von ihrem Mann ausgesprochenen $x \alpha \lambda$ óv dazu, Klytaimestras Standpunkt demjenigen des Gatten deutlich entgegenzusetzen, schafft die variierte Selbstwiederholung mit $x \alpha \lambda \omega \hat{\omega}$ (738) eine Verbindung zum letzten eigenen Redebeitrag und verstärkt den darin verwirklichten Sprechakt. ${ }^{18}$

17 Zur politeness-Strategie des "give hints“, die im ersten Satz ihres Redebeitrags verwendet wird, um indirekt (off-record) einen FTA zu begehen, vgl. Brown und Levinson ( ${ }^{2} 1987$ : 213215). Der zweite Satz, der die Aufforderung, den vónoৎ nicht zu unterschätzen, enthält, macht den Sprechakt durch die passive Konstruktion mit dem Verbaladjektiv ohne die Erwähnung des Agens unpersönlich. Zu dieser Strategie vgl. Brown und Levinson ( ${ }^{2} 1987$ : 194-197).

18 Zur Wiederholung von Wörtern des Gesprächspartners (Fremdwiederholung), um Uneinigkeit auszudrücken, und zur Selbstwiederholung, um den eigenen Standpunkt zu verstärken, vgl. Bazzanella (1992: 438-439) und Locher (2004: 137-142). Zu den Formen und 
Diese Ausdrucksmodalitäten verdecken die illokutionäre Kraft des FTA der Weigerung nicht, sondern werden von Klytaimestra so lange verwendet, wie sie es für möglich hält, ihren Gatten durch die Begründung der Ablehnung seines Befehls umzustimmen. Zunächst erinnert sie Agamemnon an die Bedeutung des vómos, in der nachfolgenden Diskussion fordert sie gleiches Recht wie ihr Ehemann bei der Festsetzung dessen ein, was für sie und ihre Familie moralisch $x \alpha \lambda o ́ v$ ist. Damit verteidigt Klytaimestra ihre Rolle als Mutter und Hausherrin. Sobald sie begreift (739), dass es für den Meinungsaustausch keinen Raum mehr gibt, erwidert sie mit einer deutlichen Ablehnung, die durch die Schwurformel noch verstärkt wird, ${ }^{19}$ steckt dabei die Kompetenzsphären bei der Führung des oikos explizit ab und beendet autonom das Gespräch.

Klytaimestra mildert oft ihre FTAs durch die Erwähnung der Gründe, aus denen sie verwirklicht werden, ab. ${ }^{20}$ Diese werden in der Regel von ihr in den sozialen Rollen (gesellschaftliche Stellung, Geschlecht usw.), die sie oder ihre Gesprächspartner bekleiden, und in den Verhaltensweisen, die jeweils für sie vorgeschrieben sind, identifiziert. Außer den angeführten Beispielen sind diesbezüglich die Verse 903-908 besonders eindrücklich. Darin begründet die Königin ihre Bitte an Achill, das Leben Iphigenies zu retten, mit den Pflichten des Ehegatten, selbst wenn Achill, wie sie zugibt, nur zum Schein und ohne sein Wissen mit dieser Rolle bekleidet worden ist. ${ }^{21}$

Bevor sie merkt, dass sie betrogen worden ist (847), findet man hingegen sogar in den expressiven Sprechakten, ${ }^{22}$ die bisweilen kalt und formal erscheinen, kaum Hinweise auf ihre eigenen Gefühle. ${ }^{23}$ Bedeutsam ist der Gruß, den sie bei ihrer Ankunft an Agamemnon richtet:

Funktionen der Wiederaufnahme der vorhergehenden Redebeiträge im tragischen Dialog vgl. die Literaturangaben bei Bonifazi u. a. (2016: III.3.1.3).

Zu $\mu \alpha \dot{\alpha}$ mit Akkusativ als negative Erwiderung auf einen Imperativ (z. B. Ar. Thesm. 748) vgl. LSJ s.v. III.1.b (1070).

20 Zur Angabe der Gründe für einen FTA, um ihn abzumildern, vgl. Brown und Levinson $\left({ }^{2} 1987: 128\right)$.

21 Ein weiteres Beispiel begegnet in Vers 992-996: Bevor die Königin Achill explizit darum bittet, Iphigenies Leben zu retten, ohne dass das Mädchen das Zelt verlasse und ihn persönlich anflehe, unterstreicht sie (993), dass das Verhalten, welches sie ihrer Tochter ersparen will, sich für ein Mädchen nicht zieme. Zur Beachtung dessen, was angemessen ist, durch Klytaimestra vgl. Chong-Gossard (2008: 231-237).

Gemäß Searle (1976: 12) offenbaren die expressiven Sprechakte psychische Zustände, Einstellungen und persönliche Gefühle. Vgl. Risselada (1993: 4O-41) zur Schwierigkeit, diese und ihre Unterarten (z.B. Gruß, Glückwunsch, Dank, Entschuldigung, Beileid, je nach Kontext aber auch Wunsch, Ausruf usw.) zu definieren.

Die einzigen Hinweise darauf kommen in Vers 6o9, 691-692 und 844 vor. 
[3] Euripides Iphigenie in Aulis 633-634

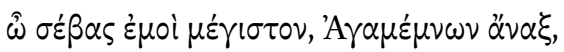

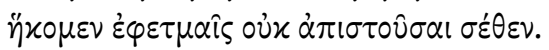

O höchste Majestät, Agamemnon, Herrscher! Nicht ungehorsam gegenüber deinen Befehlen sind wir gekommen. ${ }^{24}$

Die Königin wendet sich an ihren Gatten, den sie nach einiger Zeit wiedersieht, mit einer feierlich und kalt klingenden Hochachtung: Zuerst spricht sie ihn

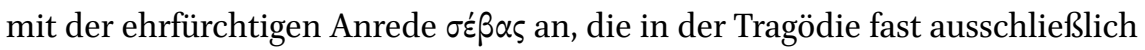
an Gottheiten gerichtet wird; ${ }^{25}$ die zweite Anrede mit dem Nominativ 'A $\gamma \alpha \mu \varepsilon$ $\mu \nu \omega \nu \alpha ٌ \nu \alpha \xi$ unterstreicht die Autorität des Ehemanns, aber nicht die Gefühle, die sie an ihren Gatten binden, was sonst in der Tragödie oft geschieht, wenn sich die Eheleute wiederbegegnen. ${ }^{26} \mathrm{Zu}$ den beiden Anreden passt die folgende Aussage gut, durch die Klytaimestra signalisiert, dass sie sich als gehorsame Ehefrau benommen hat.

Die beschriebenen interaktionalen Verhaltensweisen scheinen auf kohärente Weise dazu beizutragen, das Bild einer selbstsicheren und entschlossenen Figur zu entwerfen, die sich stark mit ihren gesellschaftlichen Rollen als Königin, Mutter und Ehefrau identifiziert. In ihrem Handeln spielen die sozialen Normen und Konventionen (im Gegensatz zu den Gefühlen) eine grundlegende Rolle. Diese Charakterisierung schafft einen scharfen Gegensatz zwischen Klytaimestra und Agamemnon, der sich vom Anfang an in jeder seiner

\footnotetext{
24 Übersetzung von mir.

25 Aesch. Cho. 157 ist der einzige sichere Passus einer Tragödie, in dem die Anrede an einen Menschen gerichtet wird, und zwar noch einmal an Agamemnon: In diesem Fall wendet

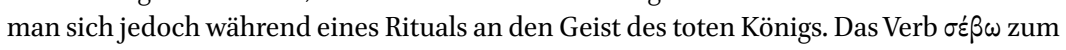
Ausdruck der Achtung innerhalb einer Ehe wird z. B. in Aesch. Ag. 925, Soph. oт 70o verwendet.

26 In der Tragödie richten Ehegatten Vokative und Ausdrücke der Zuneigung nicht nur bei unerwarteten Wiedererkennungen und Wiedervereinigungen aneinander - wie diejenigen in Eur. $H F$ 531, in dem Megara Herakles mit dem Vokativ $\hat{\omega} \varphi\left(\lambda \tau \alpha \tau^{\prime} \alpha \nu \delta \rho \hat{\omega} \nu\right.$, , liebster unter den Männern“ (531) grüßt, und Hel. 625 und 636, in denen die beiden Gatten, die sich endlich wiedererkannt haben, ähnliche Anreden aneinander richten -, sondern manchmal auch bei alltäglichen Treffen: so spricht z. B. in Eur. El. 345 die Protagonistin ihren Gatten mit dem Vokativ $\hat{\omega} \varphi\left(\lambda \tau \tau \alpha \tau^{\prime}(\varepsilon)\right.$ „o liebster“, an. Im Agamemnon wendet sich die aischyleische Klytaimestra, die nach dem Troianischen Krieg ihren Mann wiedersieht, mit

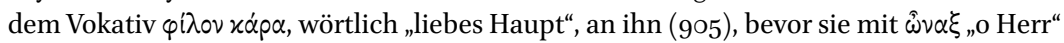
(907) den Ausdruck der Zuneigung mit demjenigen der Ehrerbietung verbindet.
} 
Rollen als inadäquat entpuppt. ${ }^{27} \mathrm{Im}$ folgenden werde ich zeigen, wie das kommunikative Verhalten der Königin auch in starkem Gegensatz zu demjenigen Iphigenies steht.

\section{Gefühle ausdrücken und austauschen: Iphigenies Kommunikation vor dem Wandel}

Einen ersten Einblick in die Unterschiede zwischen Tochter und Mutter geben schon die beiden über weite Strecken stichomythischen Dialoge, in denen zuerst Iphigenie (640-685) und dann Klytaimestra mit Agamemnon sprechen (685-740).

Der Dialog zwischen Iphigenie und Agamemnon ist der erste lange Wortwechsel, an dem das Mädchen teilnimmt. Dieser beginnt mit dem Austausch von Grüßen (640-643), fährt mit der Verwunderung Iphigenies über das Weinen des Vaters fort, das sie zu beenden versucht (644-650), entfaltet sich in der Folge um die Ankündigung Agamemnons einer Iphigenie bevorstehenden Reise (651-671), wird durch Hinweise des Königs über Opfer verlängert, die seiner Abreise von Aulis vorangehen werden (673-677), und endet damit, dass er der Tochter befiehlt, in sein Zelt zu gehen, und sich von ihr weinend verabschiedet $(678-685)$.

Die Unterschiede zwischen dem Verhalten Iphigenies und demjenigen Agamemnons in diesem Dialog hängen vor allem von ihrem Wissensgefälle bezüglich der Fakten ab. Iphigenie, die noch nichts über ihr künftiges Schicksal weiß, nimmt aktiv am Gespräch teil. Sie eröffnet es und führt es fort, indem sie fast immer autonom das Wort ergreift. Ihre Sprechakte sind immer explizit und klar und ihre nonverbale Kommunikation stimmt vollständig mit ihren Worten überein. ${ }^{28}$ Dagegen verhält sich Agamemnon eher reaktiv und nicht immer kollaborativ. Er begnügt sich in der Mehrzahl seiner Redebeiträge damit, der Tochter zu antworten, und erwidert auf ihre Fragen, die manchmal von ihm selbst eingeführte Themen betreffen, oft mit wenig klaren Antworten oder mit der Weigerung, eine Antwort zu geben. ${ }^{29}$ Seine Gesten stehen mehrmals mit

27 Zur Unzulänglichkeit Agamemnons in den verschiedenen Rollen, die er innehat, vgl. z.B. Michelakis (2006: 33-35) und die von ihm zitierte Sekundärliteratur.

28 Durch die vor dem Beginn des Dialogs (631-632) angekündigte Geste, dem Vater entgegenzulaufen und ihn zu umarmen, äußert Iphigenie ihren Enthusiasmus, ihn zu sehen, den sie darauf verbal ausdrücken wird (640-642). 
seinen Worten offenkundig in Widerstreit, so etwa, wenn er sagt, er sei glücklich, seine Tochter wiederzusehen, aber nicht aufhört zu weinen $\left(645^{-646}\right.$, 648-65o).

Andere konversationelle Verhaltensweisen Iphigenies verraten ihre Unreife in ihrem interaktionellen Gebrauch der Sprache. So bemerkt man etwa, dass sie nicht immer von ihrem Gesprächspartner Klarheit verlangt, was sonst in der Interaktion gewöhnlich geschieht. Manchmal geht sie nicht genauer auf den Sinn seiner dunklen Aussagen ein:

[4] Euripides Iphigenie in Aulis 658-66o

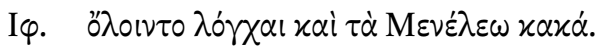

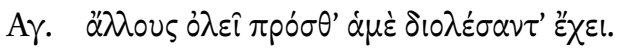

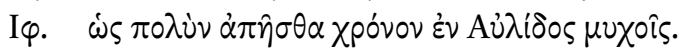

Iph. Verflucht seien die Waffen und das Unrecht an Menelaos!

Ag. Andere wird erst noch vernichten, was mich schon ganz vernichtet hat.

Iph. Wie lange schon bist du fort in der Bucht von Aulis!

Nachdem Iphigenie den Krieg und Menelaos' Übel verflucht hat, deutet Agamemnon ihr das traurige Schicksal an, das sie, die allgemein mit ä $\lambda_{0}$ ov bezeichnet wird, erwartet. Eine Frage Iphigenies würde genügen, damit die Wahrheit ans Tageslicht käme, aber sie stellt keine Forderung an den König, das Gesagte zu klären. Stattdessen knüpft sie an ihren letzten Redebeitrag an, um sich über die Länge seines Aufenthalts in Aulis zu wundern. ${ }^{30}$ In anderen Fällen akzeptiert sie seine Weigerung, auf ihre Fragen zu antworten. ${ }^{31}$ Dagegen vertieft sie mit weiteren Fragen alles, was der Vater über seine Gefühle und die sie beide betreffenden Angelegenheiten sagt. ${ }^{32}$

Dem Mädchen kommt es nicht darauf an, alles, was der Vater sagt, genau zu begreifen. Es beschränkt sich vielmehr darauf, über die Themen zu kommunizieren, in die es persönlich involviert ist, während es die Probleme übergeht,

hin- und herschwankt zwischen dem Wunsch zu sprechen und dem Unvermögen, diesen Wunsch zu realisieren" (Schwinge 1968: 189).

30 Zu Vers 659 sagt Schwinge (1968: 188): „Nur eine darauf bezogene Frage, und Agamemnon sähe sich durch Iphigenie selbst dazu aufgefordert, die Wahrheit auszusprechen. Doch Iphigenie überhört diesen Hinweis“. Dasselbe Verhalten registriert man einige Verse danach (661-662).

31 Das geschieht nach Vers 671 und 677-685.

32 Das passiert in Vers 644, 648-65o, 668-67o, 675-676. 
mit denen er sich als König und Feldherr beschäftigt. ${ }^{33}$ Iphigenie selbst bestätigt in diesem Dialog mit einem expliziten Hinweis auf die Verwendung der Sprache ihre Vorstellung von der Kommunikation. Nachdem ihr Vater gesagt

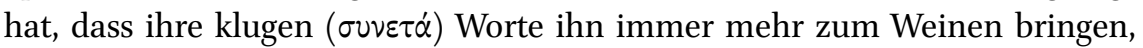

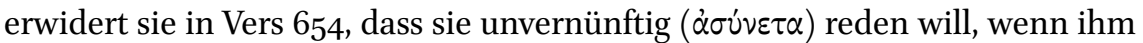
dies Freude bereiten $(\varepsilon \dot{\jmath} \varphi \rho \alpha v \hat{\omega})$ kann. Die Behauptung ist eine klare Äußerung der Zuneigung zum Vater. Zugleich zeigt Iphigenies geringe Beachtung rationaler Argumente, dass sie die verbale Kommunikation vorwiegend als Instrument auffasst, um Gefühle auszudrücken und hervorzurufen.

Die hohe emotionale Spannung ihrer Kommunikation wird von der hohen Zahl expressiver Sprechakte, die sie im gesamten Verlauf des Dialogs verwirklicht, bezeugt.

[5] Euripides Iphigenie in Aulis 640, 642, 644, 664, 666, 674

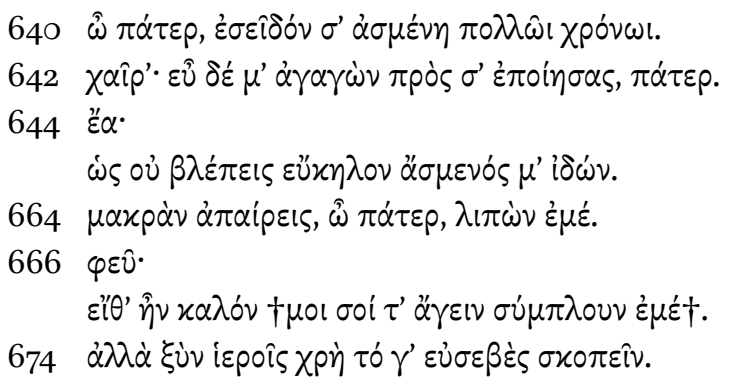

640 Vater, ich sehe dich mit Freuden nach langer Zeit.

642 Sei gegrüßt, wie gut, dass du mich herbeigerufen hast, Vater.

644 Ach, du blickst unruhig, und hast mich doch froh gegrüßt.

664 Auf eine weite Fahrt begibst du dich und lässt mich zurück.

666 Ach! Dürftest †du mich doch mitnehmen auf der Fahrt $\uparrow^{34}$

674 Ja, mit Hilfe heiliger Riten muss man auf Frömmigkeit achten.

Wie die zitierten Verse zeigen, gehören die von Iphigenie ausgedrückten expressiven Sprechakte den verschiedensten Untergattungen an: Gruß, Dank,

33 Iphigenies Verhaltensweisen zeigen, wie von Mellert-Hoffmann (1969: 68) beobachtet, „ihre Liebe zum Vater“, aber auch „ihre rührende Kindheit“, die sie dazu verleiten, die Dinge „nur von der persönlichen Seite, insofern diese Auswirkungen auf ihr Verhältnis zum Vater haben“, zu sehen.

34 Die cruces sind entsprechend dem gewählten griechischen Text von mir in die Übersetzung eingefügt worden. 
Ausdruck des Staunens, des Leidens, der Sehnsucht und der Zustimmung. In der vorangehenden Passage [4] kommen auch eine Verfluchung und ein weiterer Ausdruck der Sehnsucht vor.

Sowohl die angeführten als auch die übrigen Sprechakte Iphigenies sind auf der formalen Ebene voll von Zeichen des Affekts: Zahlreiche werden als Ausrufe ausgedrückt, ${ }^{35}$ bisweilen gehen ihnen verstärkende Interjektionen voraus ( $\left.{ }^{\prime \prime} \alpha, \varphi \varepsilon \hat{)}\right),{ }^{36}$ die Häufigkeit des Vokativs $(\hat{\omega}) \pi \dot{\alpha} \tau \varepsilon \rho$ bekräftigt den Kontakt zum Gesprächspartner, ebenso kommen gehäuft Personalpronomina der 1. und 2.

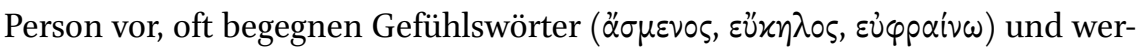
tende Begriffe ( $\varepsilon \hat{v}, x \alpha \lambda o ́ s) .{ }^{37}$

Ein nicht besonders reifes kommunikatives Verhalten, da in höchstem Maß auf den Ausdruck und Austausch von Emotionen und Gefühlen innerhalb einer Beziehung ausgerichtet, wird Iphigenie bis zu ihrem Wandel charakterisieren. Dieses unterscheidet Iphigenie nicht nur und nicht so sehr von Agamemnon, der in der Interaktion auf den Ausdruck seiner Gefühle nicht verzichtet, sondern auch und vielmehr von Klytaimestra.

Der Kontrast zwischen dem kommunikativen Verhalten der Tochter und demjenigen der Mutter zeichnet sich deutlich in der unmittelbaren Fortsetzung des Epeisodion mit dem schon erwähnten Dialog zwischen Klytaimestra und Agamemnon (691-740) ab. ${ }^{38}$ Darin treten die Konkretheit und die Rationalität Klytaimestras, die sich schon in ihrer ersten Replik (6o7-63o) gezeigt haben, schärfer zutage, da sie nur sachliche Themen wählt, und resultieren in einem Verhalten von Kälte gegenüber dem Gesprächspartner, an den nach dem Gruß (siehe [3]) nicht einmal eine Anrede gerichtet wird. Dazu kommen die umsichtige und gewissenhafte Aufmerksamkeit Klytaimestras in ihren Fragen und ihre Selbständigkeit in der Gesprächsführung (siehe [2]), die in klarem Gegensatz zur Naivität und Nachgiebigkeit der Tochter stehen.

35 Gemäß Risselada (1993: 41) nehmen die Ausrufe eine Mittelposition zwischen expressiven und assertiven Sprechakten ein, da sie „involve the expression of an emotion about a state of affairs whose existence is presupposed" und zugleich "describe this state of affairs".

36 Zur Funktion von है $\alpha$ in Vers 644 und von $\varphi \varepsilon \hat{~ i n ~} 666$ vgl. Biraud (2010: 47 bzw. 110).

37 Der Vokativ kommt in acht der 18 von Iphigenie geäußerten Repliken vor (640, 642, 662, 664, 656, 670, 672, 676). Gemäß Biraud (2010: 98) verstärkt in diesem Stück das häufige Vorkommen von $\hat{\omega}$ vor dem Vokativ die Nähe zum Gesprächspartner. Die Personalpronomina fehlen in sieben Repliken Iphigenies $(648,658,66 \circ, 662,668,674,676)$. $\alpha \sigma \mu \varepsilon v o \varsigma$ kommt in

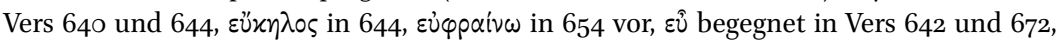

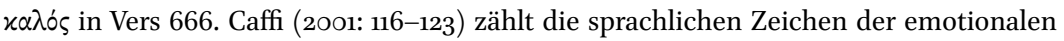
Beteiligung in der realen Kommunikation auf.

$38 \quad$ S. Abschnitt 2. 
Nach diesen beiden Stichomythien unterstreichen zwei ebenfalls nebeneinandergestellte rheseis im vierten Epeisodion die kommunikative Besonderheit Iphigenies und damit den Gegensatz zu Klytaimestra. Jede der beiden Frauen wendet sich an Agamemnon, um ihn zu bitten, auf die Opferung zu verzichten. Der Gegensatz zeichnet sich noch deutlicher ab, da beide Reden einen direktiven Sprechakt mit demselben perlokutionären Ziel verwirklichen und an denselben Adressaten innerhalb des gleichen Kontextes gerichtet sind. ${ }^{39}$ Eine komplexe Analyse der ganzen Reden nicht nur aus der pragmatischen, sondern auch aus der stilistischen und rhetorischen Perspektive, wäre wichtig, um alle Aspekte angemessen zu bewerten. ${ }^{40}$ Ich beschränke mich hingegen auf einige Bemerkungen, um das hervorzuheben, was am meisten die Kommunikation Iphigenies von derjenigen ihrer Mutter unterscheidet.

Dieses Mal spricht Klytaimestra als erste (1146-1208). Wie gewohnt behandelt sie der Reihe nach die Argumente, die sie für nützlich hält, um ihren Mann zu überreden, und offenbart dabei großes rhetorisches Geschick. ${ }^{41}$ Der Stil ihrer Rede ist oft emotionserregend, ohne dass sie selbst jemals ihren Gefühlen nachgibt. Von den rhetorischen Fragen über die sarkastischen Ausrufe bis zur Verwendung der oratio recta in imaginierten Situationen und zur Anrufung der Götter dient jedes Mittel dazu, das Unrecht und die Sinnlosigkeit der Tötung der Tochter zu belegen. ${ }^{42}$

Wenige Verse später beginnt Iphigenies Rede (1211-1252): Sie kündigt an, dass sie sich den Tränen als ihrer einzigen Fertigkeit anvertrauen wird. ${ }^{43}$ Von Anfang an thematisiert sie die eigene Unerfahrenheit im persuasiven Gebrauch des Wortes.

39 Beide Reden sind an Agamemnon gerichtete Bitten, auf das Opfer zu verzichten. Sie können also als direktive Makrosprechakte bezeichnet werden. Unter Makrosprechakt versteht man einen Text, der zwar aus mehreren Sprechakten bestehen kann, dessen kommunikative Hauptfunktion aber ein bestimmter Sprechakt bildet. Das Konzept von Makrosprechakt wurde von van Dijk (1977: 238-247) entwickelt.

40 Zur Bedeutung einer komplexen linguistischen und rhetorischen Methode zur Untersuchung der tragischen rheseis vgl. van Emde Boas (2017:47-50). Eine integrierte Perspektive zu deren Untersuchung ist indessen noch nicht vollständig entwickelt worden.

41 Aretz (1999: 165-169) liefert eine vertiefte rhetorische Analyse der Rede. Vgl. auch Gibert (2005: 230).

42 Rhetorische Fragen begegnen in Vers 1167, 1171-1178, 1185, 1186, 1187, 1188, 1191, 1192-1193, 1194-1195. Ein sarkastischer Ausruf erscheint in Vers 1168-1169. Die Verwendung der oratio recta in fingierten Situationen kommt in Vers 1177-1178 und 1197-1198 vor. Die Anrufung der Götter, die auf emphatisches $\mu \grave{\eta} \delta \hat{\eta} \tau \alpha$ („nein“, vgl. Denniston ${ }^{2} 1954: 276$ und Bonifazi u. a. 2016: III.3 § 49) folgt, erscheint in Vers 1183-1184.

43 Zum rhetorischen Gebrauch der Tränen in der antiken Literatur vgl. etwa Hagen (2016) und die von ihr angegebene Bibliographie sowie Calabrese in diesem Band. 
Tatsächlich entwickelt Iphigenie keine durchgehende Argumentation. Sie beschränkt sich auf die Bemerkung, dass es besser ist, (selbst unehrenhaft) zu leben, als zu sterben (1218-1219 und 1249-1250); außerdem stellt sie weinend nur einige erschrockene Fragen, was Helenas und Alexandros' Liebesaffäre mit ihr zu tun hat (1236-1237), und fleht Agamemnon im Namen seiner Vorfahren und ihrer Mutter Klytaimestra an. Sie bevorzugt die ihr vertrauten kommunikativen Modalitäten, wie der Kern ihrer Rede verdeutlicht:

[6] Euripides Iphigenie in Aulis 1220-1230

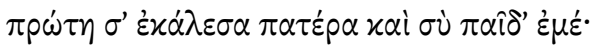

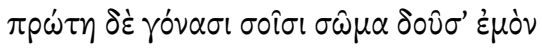

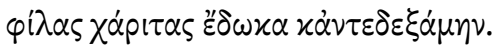

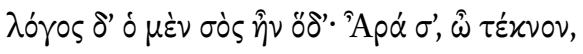

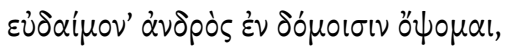

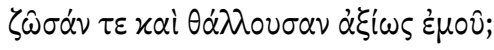

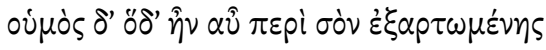

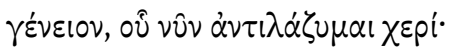

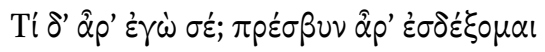

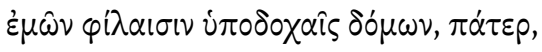

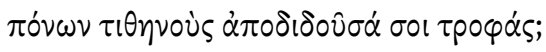

Als erste rief ich dich,Vater', und du mich ,Kind', als erste setzte ich mich auf deine Knie und streichelte und küsste dich und liess mich küssen. Da sprachst du so: „Werde ich dich, mein Kind, glücklich im Hause deines Ehemannes sehen, lebensfroh und blühend, meiner würdig?" Und ich erwiderte, während ich deinen Bart gefasst hielt, nach dem ich auch jetzt greife mit meiner Hand: „Und werde ich dich also, wenn du alt bist, aufnehmen und liebevoll in meinem Haus beherbergen, Vater, als Entgelt für die Mühen, dass du mich aufgezogen hast?“

Iphigenie versucht, ihre Bitte wirksam zu machen, indem sie dem Vater die gegenseitige Zuneigung, die sie seit jeher verbindet, in Erinnerung ruft. ${ }^{44}$ Sie beschränkt sich nicht darauf, die verbalen und nicht-verbalen Handlungen,

44 Die Erwähnung der Zuneigung, die Vater und Tochter seit jeher verbunden hat, ist ein Mittel, um die Reziprozität in den Gefühlen und die Gemeinsamkeit der Ziele auch in der Gegenwart zu verlangen. Zum Verlangen von Gegenseitigkeit und Kooperation als politeness-Strategie bei Forderungen und anderen FTAs vgl. Brown und Levinson $\left({ }^{2} 1987\right.$ : 125-129). 
die sie mit dem Vater auszutauschen pflegte, erneut zu erwähnen, sondern vergleicht sie mit denjenigen, die sie in diesem Augenblick verwirklicht: Die emotionsgeladenen Anreden an den Vater, die Gesten, ihren Körper zum Vater hin zu bewegen und seine Knie und sein Kinn zu berühren - alles Elemente, die zum Ritual des Flehens (Hikesie) gehören - sind zum großen Teil dieselben, die sie in der Vergangenheit nur in der Absicht, ihre Zuneigung zum Vater zu zeigen, eingesetzt hat. Anders formuliert: Die üblichen Worte und Gesten, die sie an den Vater richtete und die plötzlich in die Vergangenheit gerutscht waren, leben jetzt wieder auf und füllen sich mit neuer illokutionärer Kraft auf. Handlungen, die vorher nur expressiv waren (Ausdrücke der Zuneigung), werden zu einem integrierenden Bestandteil des aktuellen, ritualisierten direktiven Sprechakts. Sind diese in der Vergangenheit vom Vater auf angemessene Art angenommen und erwidert worden, so erfordern sie auch jetzt, dass der Vater sie annimmt und auf die von der Tochter gewünschte Weise darauf reagiert.

Dies könnte einen Weg darstellen, um den rechten Ton gegenüber dem Vater zu treffen. ${ }^{45}$ Indessen wird die Sprecherin bald von ihren Gefühlen überwältigt. Die andauernde Unbeweglichkeit des Vaters, der sogar den Blick von ihr abwendet, veranlasst sie einige Verse später, vorübergehend das perlokutionäre Ziel der Rede aus den Augen zu verlieren und folgende Bitte zu formulieren:

[7] Euripides Iphigenie in Aulis 1238-1240

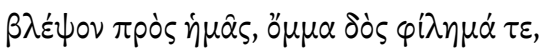

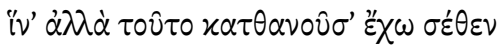

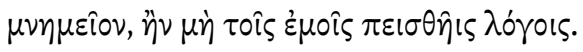

Schau mich an, schenk mir deinen Blick und einen Kuss, damit ich sterbend wenigstens dies als Erinnerung an dich behalte, wenn du dich nicht durch meine Worte bewegen lässt.

Durch Iphigenies Bitte an den Vater, sie anzublicken und ihr einen Kuss zu geben, selbst wenn er sich nicht durch ihre Worte umstimmen lasse, scheitert

45 Die Gegenseitigkeit des vergangenen verbalen und nicht-verbalen Verhaltens wird von Iphigenie wirksam durch das Nebeneinanderstellen von Verben des Gebens und Erhaltens (1222), durch den Chiasmus und den Parallelismus in der syntaktischen Struktur einiger Sätze (wie z.B. 1220) und durch das Zitieren der expressiven Sprechakte, die sie und ihr Vater austauschten, in oratio recta (1223-1225 bzw. 1228-1230) ausgedrückt. Vgl. dazu Aretz (1999: 169-173). 
der strategische Gebrauch der affektiven Kommunikation. Er weicht der Sehnsucht, diese wie in der Vergangenheit als Ausdruck gegenseitiger Zuneigung wieder zu erleben, und schwächt schließlich den Sprechakt des Flehens (ix£$\tau \varepsilon \dot{\varepsilon} \varepsilon(\nu)$ ab, anstatt ihn wirksamer zu machen.

Die Einbeziehung des kleinen Bruders Orest in die Bitte stellt Iphigenies letzten Versuch dar, die affektive Kommunikation zu verwenden, um der Rede Wirksamkeit zu verleihen: Sie bedient sich eines stummen Bittstellers als Gehilfen, den sie bittet, gemeinsam mit ihr zu weinen. Doch geschieht dies nicht, da er ihre Worte nicht versteht (1241-1248).

Die tiefgreifenden Unterschiede zwischen Iphigenie und der Mutter erscheinen vor allem in der Kommunikation mit Dritten (insbesondere mit Agamemnon). Die direkte Kommunikation zwischen den beiden Frauen auf der Bühne beschränkt sich bis zu Iphigenies Wandel auf kurze Wortwechsel, in denen Iphigenie ständig eine unterwürfige Position gegenüber ihrer Mutter einnimmt: Sie sucht Klytaimestras Zustimmung bezüglich des Verhaltens, das sie annehmen will (so in Vers 631-632, wenn sie zum Vater laufen will, um ihn zu umarmen), gehorcht ihren Anweisungen (so nach Vers 1343-1344, wenn sie auf die Aufforderung der Mutter vor Agamemnons Zelt bleibt), oder schließt sich einfach den Handlungen der Mutter an (so etwa, wenn sie in Vers 12791282 auf die Klage der Mutter mit einer Klage antwortet, die bezüglich der Töne, des Vokabulars und des Rhythmus jener ähnlich ist). ${ }^{46}$

Der Wandel Iphigenies hinsichtlich ihres Schicksals (ab Vers 1368) zeigt sich auch anhand einer tiefgreifenden und ebenso plötzlichen Änderung ihrer kommunikativen Modalitäten, der ein symmetrischer und entgegengesetzter Wandel bei Klytaimestra entspricht. Dadurch wird auch die Beziehung MutterTochter vor ihrer endgültigen Trennung beeinflusst.

\section{Iphigenies und Klytaimestras kommunikativer Wandel}

In der Rede in Vers 1368-1401 sind die wichtigsten Änderungen des kommunikativen Verhaltens Iphigenies sofort sichtbar. Darin verknüpfen sich eine ihr bisher unbekannte argumentative Fähigkeit, ein ebenso neues Vertrauen in die Wirksamkeit ihrer Worte und wichtige Änderungen auf der konversationellen und illokutionären Ebene derart miteinander, dass dadurch die Form und Struktur der Rede bestimmt werden.

46 Die Echtheit der Verse 1276-1282 ist sehr umstritten, vgl. Collard und Morwood (2017: 556). 
Hatte Iphigenie sich kurz zuvor einer Rhetorik der Tränen und Gefühle anvertraut und war Opfer derselben geworden, erscheint sie jetzt unverkrampft und entschlossen im Gebrauch des Wortes. Dies zeigt schon die Art und Weise, auf die Iphigenie das Wort ergreift, deren unerwarteter Charakter während einer Interaktion, an der sie nicht beteiligt war, von der $\alpha \dot{\nu} \tau i \lambda \alpha \beta \dot{\eta}$ unterstrichen wird. ${ }^{47}$ Im Laufe der Rede entwickelt sie verschiedene Argumente zugunsten ihrer plötzlichen Entscheidung, den Tod zu erleiden. Sie hält eine geordnete und gut gegliederte Rede, deren grundlegende Momente (den Beginn, die Ankündigung der eigenen Entscheidung, den Anfang des argumentativen Teils, den Übergang zu einem neuen Argument) sie durch explizite Hinweise auf die Worte, die sie ausspricht, unterteilt. Diese Hinweise haben meistens die Form von Aufforderungen an die Gesprächspartner (insbesondere an die Mutter), auf ihre Rede zu hören und deren Richtigkeit zu beachten. ${ }^{48}$ Ihre Funktion besteht darin, die in der Rede enthaltenen Sprechakte zu verstärken. Dabei dominiert die kommissive Illokution, ${ }^{49}$ da die Verpflichtung, den eigenen Körper zur Rettung Griechenlands herzugeben, im Mittelpunkt der Rede steht (z.B. 1383).Zahlreich sind die dazu komplementären direktiven Sprechakte, die nicht nur an ihre Mutter (1371-1373), ${ }^{50}$ sondern an ganz Griechenland (1398) und in dritter Person an Achill (1392-1393) gerichtet werden. Das Mädchen, welches sich kurz zuvor von der Mutter leiten ließ und in der Kommunikation expressive Sprechakte bevorzugte, lässt Illokutionen dominieren, die den Sprecher bzw. den Adressaten verpflichten, den Status der Dinge zu verändern. ${ }^{51}$

Im letzten Wortwechsel zwischen Iphigenie und Klytaimestra nach Achills Abgang von der Bühne (1433-1466) - der ersten und einzigen langen verbalen Auseinandersetzung zwischen den beiden in dieser Tragödie - wird eine totale Umkehrung der von ihnen in der Vergangenheit geführten kommunikativen

47 Der Beginn einer rhesis durch die Unterbrechung eines laufenden Dialogs mitten im Vers ist besonders signifikant, da er in der Tragödie selten und auf spezielle Situationen wie auf den unerwarteten Bühnenauftritt des neuen Sprechers beschränkt ist (so etwa in Vers 414 dieser Tragödie). Vgl. dazu Collard und Morwood (2017: 584-585), Aretz (1999: 19o).

48 Diese Hinweise findet man in Vers 1368-1369 (Redebeginn), 1374 (Ankündigung der Entscheidung), 1377 (Beginn des argumentativen Teils), 1392 (Übergang zu einem neuen Argument).

49 Searle (1976: 11) folgend, bezeichne ich diejenigen Sprechakte als Kommissiva, die den Sprecher auf die Ausführung einer zukünftigen Handlung verpflichten, wie z. B. das Versprechen oder die Drohung.

$5^{\circ}$ Im übrigen verschont Iphigenie ihre Mutter nicht mit Kritik (1369-1370).

$5^{1}$ Kommissiven und direktiven Sprechakten ist nach Searle (1976: 11-12) die Beziehung von Wort und Welt, die sie bewirken, gemeinsam: mit beiden Typologien von Sprechakten versucht man, die Welt an die eigenen Worte anzupassen und nicht umgekehrt. 
Verhaltensweisen offenbart. Schon die ersten Verse zeigen einen deutlichen Wandel in der Interaktion zwischen Mutter und Tochter:

[8] Euripides Iphigenie in Aulis 1433-1436

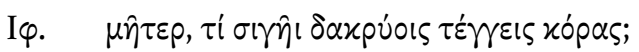

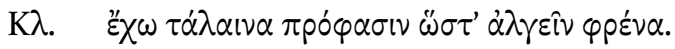

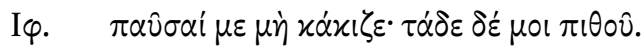

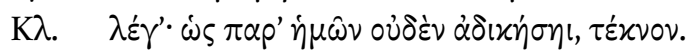

Iph. Mutter, warum bist du still und füllst deine Augen mit Tränen?

Kl. Ich Arme habe Grund, von Herzen betrübt zu sein.

Iph. Halt ein! Mach nicht weich und gewähre mir dies eine.

Kl. Nun, was? Von mir erfährst du kein Unrecht, Kind.

Der Anstoß, die Interaktion wiederaufzunehmen, geht vom Mädchen aus, das sich darüber wundert, dass die Mutter nach seiner Rede nicht mehr zu Wort gekommen ist, sondern schweigend weint. Nachdem Klytaimestra ihren $\mathrm{Zu}$ stand mit einer Klage begründet, antwortet Iphigenie auf unerwartete Weise: Mit drei aufeinanderfolgenden Imperativen fordert sie von der Mutter explizit und ohne jegliche Abmilderung, mit ihrem Verhalten, das sie feige macht, aufzuhören, und befiehlt ihr, auf das zu achten, was sie sagen wird. Die Mutter gibt ihr Einverständnis und überlässt ihr das Wort. ${ }^{52}$

Iphigenie dominiert das Gespräch vom Beginn bis zum Ende. Auch wenn sie die Mutter nicht daran hindert, autonom das Wort zu ergreifen, führt sie das erste Thema ein, bestimmt den Augenblick der Beendigung des Gesprächs (1458-1466) und zögert in seinem Verlauf nicht, die Regeln der Konversation zu verletzen, sooft die Mutter den Dingen einen anderen Lauf zu geben versucht (etwa durch die Unterbrechung des Redebeitrags der Mutter in Vers 1459 oder durch die Unterlassung des Abschiedsgrußes in 1464-1466).

Auf der illokutionären Ebene stellt man die hohe Zahl der direktiven Sprechakte in Iphigenies Sprechen fest. Auf das Verbot an die Mutter, nach ihrem Tod Trauerkleider zu tragen (1437-1438), folgen unter anderem Anordnungen, wie man ihren Leichnam zu ehren habe (1442, 1444), Forderungen betreffend die Familienmitglieder $(1448,1450,1454)$ und Anweisungen, mit denen Iphigenie ihren Abgang zum Ort des Opfers organisiert (1459-1461, 1466).

$5^{2}$ In Klytaimestras Redebeitrag dient m.E. der Satz „von mir erfährst du kein Unrecht“ als Beweis für die unerwartete Schroffheit von Iphigenies Befehlen. 
Die Direktiva werden direkt und explizit ausgedrückt (in den meisten Fällen mit Imperativ oder $\mu \eta \dot{~ u n d ~ I m p e r a t i v ~ P r a ̈ s e n s ~ b z w . ~ K o n j u n k t i v ~ A o r i s t) . ~ A u f ~}$ diese folgt oft als Abmilderung die Erklärung ihrer Gründe, aber nicht unmittelbar, sondern in der Regel nach Einwänden der Mutter. Im Gegensatz zu früher

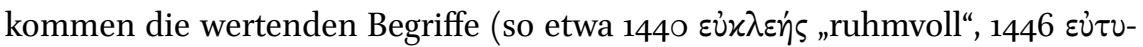

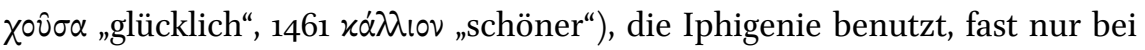
der Begründung ihrer Direktiva vor.

Der Bevorzugung der Direktiva entspricht eine Abneigung, verbale und nonverbale Gefühlsäußerungen zu verwirklichen. Diesbezüglich ist folgende Passage signifikant:

[9] Euripides Iphigenie in Aulis 1447-1452

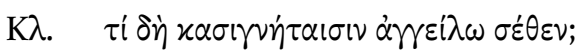

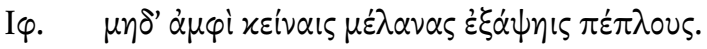

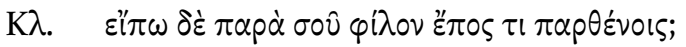

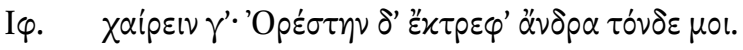

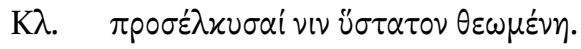

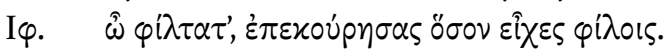

Kl. Was aber soll ich deinen Schwestern melden?

Iph. Auch sie kleide nicht in schwarze Gewänder.

$\mathrm{Kl}$. Soll ich von dir ein liebes Wort den Mädchen sagen?

Iph. Ein frohes Lebewohl. Und meinen Orest ziehe auf zum Mann.

Kl. Umarme ihn, denn du siehst ihn zu letzten Mal.

Iph. Du mein Liebster, du hast uns geholfen, so gut du es vermochtest.

Die Mutter, die das Wort vor allem dazu ergreift, um Iphigenie die Erfüllung einiger letzter Gefallen nach dem Tod anzubieten, fragt, was sie ihren Schwestern von ihr ausrichten soll. Iphigenie antwortet mit einem Befehl, wobei sie ein Verhalten annimmt, das ganz weit von demjenigen vor dem Wandel entfernt ist. Die Mutter muss im folgenden Redebeitrag ausdrücklich nach einem

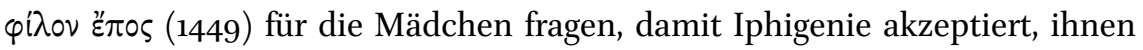
einen raschen Gruß zu senden, worauf sogleich wieder ein Befehl an die Mutter folgt. An den kleinen Orest richtet sie in Vers $145^{2}$ einen liebevollen Sprechakt des Dankes, aber auch in diesem Fall auf Klytaimestras Bitte. ${ }^{53}$

53 Die wenigen von Iphigenie gebrauchten Gefühlswörter werden in den expressiven Sprechakten an die Geschwister (z. B. $\hat{\omega} \varphi \hat{i} \lambda \tau \alpha \tau \varepsilon$ 1452) und in der Bitte an ihre Mutter, den Vater 
Ihr gegenüber zeigt das Mädchen einen wachsenden emotionalen Abstand. Dieser zeigt sich durch zahlreiche kommunikative Zeichen. Zunächst ist beachtenswert, dass Iphigenie nur zweimal - im Aufruf des bereits erwähnten ersten Redebeitrags (1433) und kurz vor ihrem Abgang (1460) - ein farbloses $\mu \hat{\eta} \tau \varepsilon \rho$ an die Mutter richtet, während diese den Vokativ $(\widehat{\hat{\omega}}) \tau \varepsilon \dot{\varepsilon}$ xvov doppelt so häufig $(1436,1439,1445,1464)$ gebraucht. Zum schon erwähnten Fehlen eines Abschiedsgrußes gesellt sich die Tatsache, dass Iphigenie sich weigert, das Weinen mit der Mutter zu teilen. Mit dem kalten und distanzierten Satz oủx $\dot{\varepsilon} \hat{\omega}$

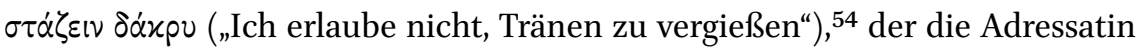
nicht einmal erwähnt, spricht sie sogar ein Verbot zu weinen aus und beendet damit das Gespräch (1466). ${ }^{55}$

Seitdem Iphigenie die Rolle der siegenden Heldin angenommen hat, bedient sie sich eines radikal veränderten kommunikativen Verhaltens und nimmt eine resolute, direkte und autoritäre Haltung ein. Sie ergreift entschlossen die Zügel des Lebens, das ihr bleibt, und emanzipiert sich vom Willen und der Kontrolle der Mutter. Von dieser verlangt sie die Annahme ihrer Entscheidungen sowie ihrer neuen Definition und Festsetzung der moralischen Werte, die ihr Handeln motivieren. ${ }^{56}$

Ihrem Wachstum entspricht eine Schwächung Klytaimestras. Die Königin erfährt den Entschluss Iphigenies als eine Aushöhlung ihrer Rolle als Mutter, da sie unfähig gewesen ist, ihre Tochter zu retten. Das Schweigen und das Weinen sind die kommunikativen Signale für ihren Gemütszustand. Sie kann nur noch ihre affektive Bindung zur Tochter ausdrücken. Aber Iphigenie weiß ihrerseits, dass sie auf ihre emotionalen Bindungen verzichten muss, um ihre Entschei-

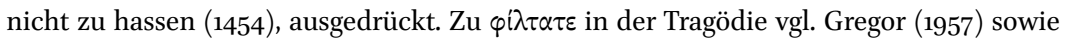
van Emde Boas (2017: 99), in der Prosa vgl. Dickey (1996: 119-120, 135-138).

54 Übersetzung von mir. Das Fehlen des Akkusativs des Adressaten macht den Befehl allgemeiner. Was sonst eine negative politeness-Strategie ist (vgl. Brown und Levinson ${ }^{2} 1987$ : 190), kann in einer so intimen und heiklen Interaktion wie dieser nur dazu dienen, die Sprecherin von der Adressatin zu distanzieren (vgl. Brown und Levinson 21987: 93).

55 Nach Ende des Gesprächs wendet sich das Mädchen noch einmal während der Schlussmonodie an seine Mutter, nur um zu bestätigen, dass es ihre Tränen nicht erwidern wird (1487-149o). Das Fehlen des Abschiedsgrußes und des gemeinsamen Weinens sticht besonders hervor, wenn man diese mit anderen analogen Situationen der euripideischen Tragödie vergleicht. Sowohl in Hec. $415^{-431}$ als auch in Heracl. 574-596 verzichten die Mädchen, die zum Sterben gehen, nicht darauf, den Gesprächspartnern spontan einen Abschiedsgruß zu geben und Grüße an ihre abwesenden Lieben auszurichten. In Hec. 433-434 steckt das Weinen der Protagonistin dasjenige ihrer Tochter und umgekehrt an. Zum „contagio delle lacrime“ als Zeichen einer affektiven Bindung zwischen zwei Figuren in der antiken Literatur vgl. Ricottilli (2000: 192-193).

Vgl. dazu Chong-Gossard (2008: 238-240). 
dung umsetzen zu können. Je mehr daher die Mutter versucht, sich der Tochter zu nähern, desto mehr entfernt sich diese bis hin zur definitiven, kalten Trennung.

Die Anwendung der Kategorien der Pragmatik auf den Dialog der Iphigenie in Aulis hat m.E. ein tiefer greifendes Verständnis und eine wirksamere Beschreibung des kommunikativen Verhaltens Iphigenies und Klytaimestras ermöglicht. Insbesondere hat sie erlaubt, die Kohärenz aufzuzeigen, mit der die Mutter und die Tochter hinsichtlich der Kommunikation sowohl vor als auch nach dem Wandel Iphigenies einander entgegengestellt werden. Ihr Gegensatz dient sicherlich dazu, die Einzigartigkeit der Reifung Iphigenies zu unterstreichen: Das zuvor naive und emotionale Mädchen ist nicht nur plötzlich erwachsen geworden, sondern hat sogar den Status einer Heldin erlangt, die imstande ist, die Schranken einer starken, aber konventionellen Frau wie ihrer Mutter zu überwinden.

Die Tatsache schließlich, dass die beiden Frauen sich zwar in vielen Gesichtspunkten unterscheiden, aber am Ende der Tragödie als die stärksten und entschlossensten Figuren hervorgehen, bildet einen weiteren Gegensatz zwischen ihnen und den männlichen Helden dieses Stücks, welche von Anfang an als wankelmütig und gleichzeitig starr, ehrgeizig und feige, gewalttätig und dennoch unfähig dargestellt werden. ${ }^{57}$

\section{Danksagung}

Dieser Beitrag stellt einige Resultate des Forschungsprojektes „Kommunikation, Handlung und Figuren in der Tragödie des Euripides" vor, das ich 20152017 an der Albert-Ludwigs-Universität Freiburg i. Br. durchgeführt habe. Die Fritz Thyssen Stiftung hat das Projekt finanziell unterstützt. Bernhard Zimmermann und David Konstan haben die Ergebnisse meiner Forschung gelesen und mir wertvolle Ratschläge erteilt. Severin Hof, Federica Iurescia und Gunther Martin haben mir mit wichtigen Anregungen bei der Gestaltung dieses Aufsatzes geholfen. Ihnen allen gebührt großer Dank.

57 Dass Iphigenie sich, wie Andò (2008) und Battezzato (2017: 173-174) gezeigt haben, mit ihrem Wandel die Werte zu eigen macht, die der politischen und patriotischen Sphäre angehören und somit für den männlichen Bereich typisch sind, macht m. E. die Unzulänglichkeit der männlichen Figuren, diese Werte zu verteidigen, nur noch deutlicher. 


\section{Bibliographie}

Andò, V., (2008), ,Un corpo di donna per fare la guerra. Lettura della Ifigenia in Aulide di Euripide', Storia delle donne 4, 71-82.

Aretz, S., (1999), Die Opferung der Iphigenia in Aulis: Die Rezeption des Mythos in antiken und modernen Dramen, Stuttgart.

Battezzato, L., (2017), ,Change of Mind, Persuasion, and the Emotions: Debates in Euripides from Medea to Iphigenia at Aulis', Lexis 35, 164-177.

Bazzanella, C., (1992), ,Aspetti pragmatici della ripetizione dialogica', in G. Gobber (Hg.), La linguistica pragmatica. Atti del XXIV Congresso della SLI, Rom, 433-454.

Biraud, M., (2010), Les interjections du théâtre grec antique. Étude sémantique et pragmatique, Louvain-la-Neuve.

Blume, H.-D., (2014), Euripides, Iphigenie in Aulis, Stuttgart.

Bonifazi, A., Drummen, A. und Kreij, M. de, (2016), Particles in Ancient Greek Discourse: Five Volumes Exploring Particle Use Across Genres, Washington, D.C. https:// chs.harvard.edu/CHS/article/display/6391.particles-in-ancient-greek-discourse [25/06/2019].

Brown, P. und Levinson, S.C., ( ${ }^{2} 1987$ [1978]), Politeness: some Universals in Language Usage, Cambridge.

Caffi., C., (2001), La mitigazione: un approccio pragmatico alla mitigazione nei contesti terapeutici, Münster.

Chong-Gossard, J.H.K.O., (2008), Gender and Communication in Euripides' Plays: between Song and Silence, Leiden.

Collard, C. und Morwood, J., (2017), Euripides, Iphigenia at Aulis, 2 Bände, Liverpool.

Denizot, C., (2011), Donner des ordres en grec ancien: étude linguistique des formes de l'injonction, Mont-Saint-Aignan.

Denniston, J.D., ( ${ }^{2} 1954$ [1933]), The Greek Particles, Oxford.

Dickey, E., (1996), Greek Forms of Address: from Herodotus to Lucian, Oxford.

Dijk, T.A. van, (1977), Text and Context: Explorations in the Semantics and Pragmatics of Discourse, London.

Eberle, T.S., (1997), ,Ethnomethodologische Konversationsanalyse‘, in R. Hitzler und A. Honer (Hg.), Sozialwissenschaftliche Hermeneutik, Opladen, 245-279.

Elam, K. (22002 [1980]), The Semiotics of Theatre and Drama, London/New York.

Emde Boas, E. van, (2017), Language and Character in Euripides' Electra, Oxford.

Gibert, J., (2005), ,Clytemnestra's First Marriage: Euripides' Iphigenia in Aulis', in V. Pedrick und S.V. Oberhelman (Hg.), The Soul of Tragedy: Essays on Athenian Drama, Chicago/London, 227-248.

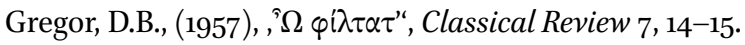

Hagen, J., (2016), ,Emotions in Roman Historiography: the Rhetorical Use of Tears as a Means of Persuasion', in E. Sanders und M. Johncock (Hg.), Emotion and Persuasion in Classical Antiquity, Stuttgart, 199-212. 
Hess-Lüttich, E.W.B., (1980), ,Literatur und Konversation. Der literarische Dialog als Gegenstand empirischer Textwissenschaft', in E.W.B. Hess-Lüttich (Hg.), Literatur und Konversation, Wiesbaden, $5^{-22}$.

Hess-Lüttich, E.W.B., (2001), ,Gesprächsanalyse in der Literaturwissenschaft', in K. Brinker, G. Antos, W. Heinemann und S.F. Sager (Hg.): Text- und Gesprächslinguistik / Linguistics of Text and Conversation, Teilband 2, Berlin/New York, 1640-1655.

Locher, M.A., (2004), Power and Politeness in Action: Disagreements in Oral Communication, Berlin/New York.

Meibauer, J., (22001 [1999]), Pragmatik. Eine Einführung, Tübingen.

Mellert-Hoffmann, G., (1969), Untersuchungen zur „Iphigenie in Aulis“ des Euripides, Heidelberg.

Michelakis, P., (2006), Euripides, Iphigenia at Aulis, London.

Ricottilli, L., (2000), Gesto e parola nell'Eneide, Bologna.

Risselada, R., (1993), Imperatives and other Directive Expressions in Latin: a Study in the Pragmatics of a Dead Language, Amsterdam.

Schegloff., E.A., (2007), Sequence Organization in Interaction, Cambridge.

Schwinge, E.-R., (1968), Die Verwendung der Stichomythie in den Dramen des Euripides, Heidelberg.

Searle, J.R., (1976), ,A Classification of Illocutionary Acts', Language in Society 5, 1-24.

Stockert, W., (1992) Euripides, Iphigenie in Aulis, 2 Bände, Wien. 
-978-90-04-44026-5

Downloaded from Brill. com $04 / 26 / 2023$ 11:30:38AM via free access 


\section{PART 2}

\section{Verbal Communication II:
g More or Less Kind with Words \\ Verbal Communication II:
Being More or Less Kind with Words}


-978-90-04-44026-5

Downloaded from Brill. com $04 / 26 / 2023$ 11:30:38AM via free access 


\title{
Oedipus and Tiresias: $\mathrm{Im} /$ politeness Theory and the Interpretation of Sophocles' Oedipus Tyrannus
}

\author{
Luigi Battezzato
}

\section{1 \\ Theoretical Approaches: Politeness Theory, Theory of Mind, and Possible-World Theory}

The present paper analyses the dialogue between Oedipus and Tiresias in Oedipus the King (297-462) from three angles: politeness theory, theory of mind, and theory of possible worlds. The paper will argue that the approaches are compatible from a theoretical point of view and complement each other. Politeness theory helps us make sense of the dialogue at the micro-level; theory of mind and theory of possible worlds can be fruitfully combined with politeness theory to make sense of the whole dialogic sequence.

These approaches are crucial for understanding the two main interpretive problems of the scene: Oedipus' shift from politeness to impoliteness and Tiresias' (apparent?) incoherence. Oedipus is, at first, extremely polite to Tiresias but ends up having one of the most aggressive clashes known in Greek tragedy. Tiresias, on arriving onstage, refuses to reveal what he knows about the killer of Laius (316-333); he then reveals the truth (350-442); at the end, he claims that he has said 'what I came here for' $(447),{ }^{1}$ thus suggesting in retrospect that his original intention was the opposite of what he said. ${ }^{2}$

Most pragmatic theories focus on short dialogic or textual sequences. Conversation Analysis and politeness theory developed from pioneering studies of the 1970s, by Sacks as well as Brown and Levinson respectively, and developed into a highly formalised subfield of linguistics. ${ }^{3}$ Brown and Levinson's frame-

1 Unless indicated otherwise, all references in the paper are to Sophocles' Oedipus the King; the Greek text and the translation are taken from Finglass (2018). I thank the volume editors, Marco Catrambone, and Catherine Conybeare for useful comments and corrections. The Università del Piemonte Orientale contributed to support this piece of research.

2 On this scene, see esp. Lattimore (1975), Reinhardt (1979: 104-110), Bain (1979), Heath (1987: 149-151), Ahl (1991: 67-102), Gianquinto (1994), Pfeiffer-Petersen (1996: 74-85), Edmunds (2000), Dorati (2015: 205-209), Worman (2014), Manuwald (2012a), Condello (2016), and Finglass (2018: ad 297-462) with further references.

3 On conversation analysis, see Sacks et al. (1974), Sidnell (2010); Sidnell and Stivers (2012); for classics, see van Emde Boas (2017a), van Emde Boas (2017b). On politeness theory, see the following note. 
work is now widely used, ${ }^{4}$ in spite of criticism. ${ }^{5}$ Some of the more general concepts introduced by Brown and Levinson are heuristically useful: 'face redress', 'bald on record', positive and negative face (respectively the 'positive consistent self-image' and the wish that one's action 'be unimpeded by others'), ${ }^{6}$ and 'off record. ${ }^{7}$ Of special importance for the present paper is the concept of being 'off record', which describes a 'communicative act' which 'is done in such a way that it is not possible to attribute only one clear communicative intention to the act'. ${ }^{8}$ Applying this methodology to ancient texts involves special problems: for instance, intonation is normally crucial for evaluating ironic or insulting passages, but the intonation of an ancient Greek is inaccessible for us. Moreover, bald-on-record and off-record utterances are potentially ambiguous, since they can be used in polite, ironic, or insulting ways. It is not simple to determine these nuances and objective criteria are difficult to find. This is especially complex in the case of the scene that is to be studied, which stages an angry quarrel which includes many ironic statements. ${ }^{9}$

A second problematic area is the ambiguity of 'politeness' itself: does it refer to the interpretation of speakers in the conversation ('first-order politeness' or 'politenessi') or is it simply a theoretical construct ('second-order politeness' or 'politeness2'), or a label to describe a linguistic strategy which may be actually impolite? ${ }^{10}$ We will see that Oedipus and Tiresias use 'polite' strategies, such as the 'off-record' strategy defined above, but that their clash is actually impolite.

Brown and Levinson based their approach on Grice's theory of language, in particular on his principle of co-operation..$^{11}$ Grice, in turn, presupposes 'rationality' as a general principle of human behaviour and linguistic interaction. Many scholars question whether this model is useful for all conversations (human beings often act irrationally ${ }^{12}$ and fail or refuse to co-operate) and

Brown and Levinson ( ${ }^{2} 1987$ ), Lloyd (2004), Brown (2006), Lloyd (2006), Lloyd (2009), Ferri (2009), Hall (2009), Barrios-Lech (2016), Catrambone (2016), van Emde Boas (2017b), and Catrambone (2019).

$5 \quad$ See e.g. Watts (2003).

6 See Brown and Levinson (21987: 61-62) and passim. Positive and negative politeness are linguistic strategies that try to 'redress' or minimise the threats that a linguistic act poses against the positive and negative face of the interlocutor.

7 For methodological discussions and definitions, see above, n. 4.

8 Brown and Levinson ( ${ }^{2} 1987$ : 211). For an extensive discussion of the phenomenon in Sophocles, see Catrambone (2016).

9 See esp. 364, 432, 435-436, 440.

10 Watts (2003: 8-9); Culpeper (2011: 396-397).

11 Grice $(1975: 45=1989: 26)$.

12 On irrationality in psychology, see e.g. Kahneman (2011); on the linguistic implications of this, see Culpeper (2011: 32), with references. 
whether it can really account for non-polite conversations (in what way is an angry argument a co-operative linguistic exchange?). As Culpeper points out:

Grice was aware of problematic cases such as quarrelling, which is why his description of the Cooperative Principle refers not only to 'a common purpose or set of purposes' but adds 'or at least a mutually accepted direction.'13

These three main problematic areas relate to the fact that, in order to interpret the dynamics of the conversation, we need to infer the 'intentions' of the speakers. ${ }^{14}$ We can do that from the general drift of the dialogue and/or from statements from the speakers, but we should bear in mind that, as Haugh points out, intention is often a post-factum construct. ${ }^{15}$

This does not stop human beings from attributing intentions and states of minds to other human beings, mostly on the basis of their actions and words. This mental faculty is called Theory of Mind (ToM); it is an endowment peculiar to the human species. ${ }^{16}$ Human beings use ToM in order to interpret both real people and fictional characters. As Zunshine notes:

Works of fiction manage to 'cheat' these mechanisms [i.e. ToM cognitive mechanisms] into 'believe' that they are in the in the presence of material that they were 'designed' to process, that is, that they are in the presence of agents endowed with a potential for a rich array of intentional stances. ${ }^{17}$

A growing corpus of research focuses on ToM in ancient and modern fiction. ${ }^{18}$

ToM focuses on long narrative and dialogic sequences. Even larger sections of narrative texts are discussed in 'possible-world theories', i.e. theories that discuss narrative as a set of possible worlds. When a story is communicated to an audience (of readers, spectators, etc.), the audience imagines possible ways in which the story could evolve or reconstruct past events in the world of fiction. ${ }^{19}$ These possible worlds are part of the mental image of the recipi-

\footnotetext{
13 Culpeper (2011: 158) referring to Grice (1989: 26). See also Culpeper (2011: 32).

14 On intentions in pragmatics, see Haugh (2008), Haugh and Jaszczolt (2012).

15 Haugh (2008: 101).

16 On ToM in general, see e.g. Apperly (2012), Epley (2014), Heyes (2018).

17 Zunshine (2006: 10).

18 On ToM and fiction, see Zunshine (2006), Herman (2013); see also the papers collected in Zunshine (2015). On ToM and Greek texts, see Budelmann and Easterling (2010), Scodel (2012), Battezzato (2019).

19 See e.g. the early approaches of Iser (1978).
} 
ents of a narrative. Ryan pointed out that readers imagine fictional worlds as the closest possible to the 'actual' world, and they only make changes that are mandated by the text. Ryan calls this interpretive rule 'the principle of minimal departure. ${ }^{20}$ Applying our innate mind-reading abilities (or ToM) to literary characters amounts to subjecting them to the principle of minimal departure. ToM is thus crucial for these approaches (politeness theory, conversation analysis, possible-world theory), which are often applied one by one rather than combined.

The possible-world theory is especially useful for interpreting texts in which fate and prophecies play a part, such as Oedipus the King. Is the storyworld of the play totally determined by fate? Or is it only partially determined? How can knowledge of future events and freedom coexist? And what do characters think about their own freedom of action? These questions will be explored in section 3 .

\section{Oedipus and Tiresias}

After many years in a department, a friend of mine moved to a different academic institution. This friend was unhappy: 'I cannot quarrel well with my new colleagues.' Quarrels require linguistic collaboration: people need to continue to speak and, in order to do so, must understand each other at least in part. In Greek tragedy, quarrels may end in walkouts and/or silence. ${ }^{21}$ Quarrels normally entail impoliteness, and impoliteness, just like politeness, can be a strategy to achieve a goal. Culpeper, in one of the most important contributions to this topic, distinguishes between affective, coercive, and entertaining impoliteness. ${ }^{22}$ It is easy to find examples of affective and coercive impoliteness in Greek tragedy. ${ }^{23}$ Do these categories apply to the dialogue between Tiresias

$20 \quad$ See Ryan $(1991,2013)$. Dorati (2015) discusses these theories in relation to ancient Greek texts.

21 See esp. Iurescia and Martin (2019). Many quarrels end when a character leaves whilst making a final parting statement (see e.g. in Soph. Aj. 1159-116o, Phil. 1257-1258, oc 10361037 and 1443-1446). On scenes of quarrel in Sophocles in general, see Pfeiffer-Petersen (1996).

22 Culpeper (2011: 221-239).

23 According to Culpeper (2011: 59), affective impoliteness 'is characterised by the fact that it is emotionally driven'; see e.g. Soph. Phil. 991. According to Culpeper (2011: 226), '[c] oercive impoliteness is impoliteness that seeks a realignment of values between the producer and the target such that the producer benefits or has their current benefits reinforced or protected [...]. It involves coercive action that is not in the interest of the target.' For 
and Oedipus in Oedipus the King? Bain considers this scene a 'psychologically convincing depiction of a quarrel between two angry men'24 but some difficulties are evident. Oedipus and Tiresias, in their quarrel, accuse each other of the gravest crimes but fail to understand each other. They act and speak in a way that has been judged incongruous by many interpreters. Voltaire claimed that the incongruity derives from Sophocles' incompetence as a playwright:

So much ignorance in Oedipus and Jocasta is only a crude artifice of the poet, who, to give his play a reasonable length, spins out into the fifth act a realisation already made obvious in the second. ${ }^{25}$

Tycho von Wilamowitz-Moellendorff claimed that the scene between Tiresias and Oedipus was 'far removed from all psychological subtleties'. ${ }^{26}$ Reinhardt considered Tiresias inherently incoherent: 'indecisive and forgetful, coming and yet anxious to go, concealing and yet revealing; he is half a capricious, irritable old man, half-in the midst of his anger-possessed of second sight; he is a walking enigma.'. ${ }^{27}$

The main inconsistency concerns Tiresias' intentions. When he arrives onstage, he refuses to reveal what he knows:

[1] Sophocles Oedipus the King 332-333

$$
\text { ... } \tau^{\prime} \tau \alpha \hat{\tau} \tau^{\prime}
$$

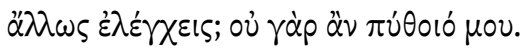

Why do you pointlessly carry out this investigation? For you will not learn anything from me.

examples in tragedy, see [9] (Soph. oт 334-336) and Creon's utterances in Soph. Ant. 280331. According to Culpeper (2011: 234), entertaining impoliteness is 'designed as much for the over-hearing audience as for the target addressee' and aims at entertaining the audience. In fact, entertainment can be a side effect of coercive impoliteness (I thank G. Martin for pointing out this problem in Culpeper's definition).

24 Bain (1979: 143).

25 Translation Hester (1993: 3) from Voltaire (1877: 24) (originally from 1719). The 'second act', in Voltaire's terminology, corresponds to the first episode, and includes the dialogue between Tiresias and Oedipus.

26 Wilamowitz-Moellendorff (1917: 78): 'sehr weit entfernt [...] von allen psychologischen Feinheiten'.

27 Reinhardt (1979: 104). 
As Edmunds notes,

The opening exchanges between Oedipus and Teiresias create an absurdist atmosphere in which one of the characters has come at the bidding of the other but then refuses to answer his questions. ${ }^{28}$

In the course of the scene, Tiresias repeats his refusal several times $\left(3^{28}-3^{29}\right.$, $\left.33^{2}-333,343^{-344}\right)$; he then, in fact, reveals what he knows $\left(35^{\circ}-353,362,366-\right.$ $367,413-428)$. When he finally walks away, he says:

\section{[2] Sophocles Oedipus the King 447-448

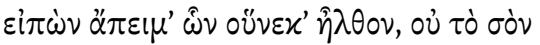

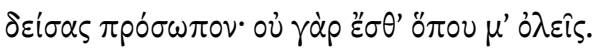

I will go when I have said what I came here for, not fearing your face; for there is no way that you can destroy me.

Does he mean that he came with the purpose of telling what he refused to tell? Or does he simply mean that he said what he was asked to come for? The first interpretation is far more plausible, as he hints at fear of Oedipus as a possible reason for not saying 'what he came for'. The interpretive problem centres on Tiresias' intentions and states of minds.

Interpreters offer different explanations for the perceived incoherence; these can be divided into four different general categories:

(a) there is an inconsistency at the level of characterisation; it has dramatic purposes; ${ }^{29}$

(b) there is an inconsistency, but it is to be explained as an instance of characterisation; 30

(c) the inconsistency is apparent: Tiresias is manipulating Oedipus and only feigns reticence; ${ }^{31}$

28 Edmunds (2000: $34-35)$.

29 Wilamowitz-Moellendorff (1917: 78); Finglass (2018: ad 447-448): 'Formal inconsistency is outweighed by dramatic gain'; Lloyd (2018: 339): 'the play could not continue if Oedipus had immediately accepted Tiresias' statements of his true identity (от 362 etc.), although this does not rule out an additional explanation in terms of character.'

30 Reinhardt (1979: 104); Lattimore (1975: 108); Bain (1979: 143); Roisman (2003: 4-5).

31 Ahl (1991: 67-102). 
(d) there is an inconsistency, but it is not related to characterisation or dramatic gain; it is determined by the logically impossible coexistence of freedom and fate within the storyworld of the play. ${ }^{32}$

A different explanation can be advanced:

(e) Tiresias is (apparently) incoherent because he faces a very difficult linguistic task.

In fact, Tiresias must break strong linguistic taboos if he is to reveal the truth (see the analyses in sections 5 and 6). Tiresias explains that he must overcome the 'fear' for the 'face' of Oedipus (see [2]). He first resists disclosing what he knows and only under strong verbal aggression from Oedipus does he reveal the truth. At the end of the scene, he attributes the intention of revealing the truth to himself, either as a post-factum explanation or as a revelation of a strategy he had in mind from the beginning. An analysis in terms of politeness strategies helps make sense of the 'incoherence'.

The four approaches listed above (a-d) will be analysed in inverted order. Section 3 will use possible-world theory to discuss whether the incoherence is logically inevitable or not (interpretation d). Section 4 will use ToM to discuss whether Tiresias is manipulating Oedipus (interpretation c). Sections 5 and 6 will use politeness theory and ToM to discuss the linguistic hurdles faced by Tiresias and to offer a linguistic analysis of the scene (interpretations a, b, and, especially, e).

Are incoherencies inevitable within the storyworld of the play? Dorati argues that that is the case. He notes that, in a partially determined storyworld,

it is always possible to imagine normal anthropomorphic actions (Achilles kills Agamemnon [...]) or different material circumstances (Oedipus and Laius fail to meet at the crossroad) that are in contrast with it [fate $]^{33}$

However, Dorati argues that, at the beginning of the play, the audience does not know whether the storyworld is determined or not. ${ }^{34}$ This is questionable:

32 Dorati (2015: 205-209). Manuwald (2012a: ad 316-318) also stresses that Tiresias could not have revealed the truth in the past, since this would have made the plot impossible. Manuwald (2012a: ad 447-448) and Manuwald (2012b) eliminates the incoherence of 447448 by deleting the whole sequence 447-462, but see Finglass (2018: $a d$ 447-462).

My translation from Dorati (2015: 39).

34 Dorati (2015: 39, 256-257). 
as Aristotle noted, some events in tragedy are fixed and inevitable as opposed to what happens in comedy (Poetics 1453a17-22 and 39). At the beginning of the play, characters presuppose that they can act freely: the verdict of Apollo reported by Creon implies that the citizens of Thebes are free to act and terminate the plague, and Oedipus' edict, banning the killer of Laius and threatening the accomplices, presupposes that people can choose their course of action. ${ }^{35}$ However,

[t]he entrance on stage of a mantis - a man that places himself on the same level as the god for knowledge (284ff.) - reveals further internal contradictions within the storyworld. Tiresias poses again and amplifies at the human level the problem posed by Apollo at the divine level. [...] The question Oedipus will later ask Creon (568f.) - if Tiresias knows, why does he not speak? - is symmetrical to that asked of Oedipus by the chorus leader about the role of Apollo [278-281]. ${ }^{36}$

The dialogue between Oedipus and Creon is especially telling:

[3] Sophocles Oedipus the King 568-569

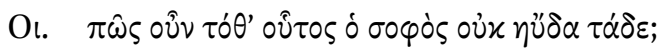

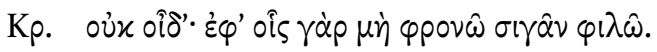

Oe. Why then did this wise man not declare these things at the time?

Cr. I do not know; on matters where I do not understand, I like to be silent. ${ }^{37}$

As Dorati points out:

Oedipus' accusations highlight a crucial problem [...]. If Tiresias is omniscient $[\ldots]$ and decided not to speak for some reason, why did he come onstage only to refuse to speak, and, at least according to his original intentions, to go back right away without revealing what he knows? ${ }^{38}$

Already Aristotle (Eth. Nic. 1113b21-26) points out that punishments imposed by legislators presuppose that actions depend on human beings and are voluntary.

36 My translation from Dorati (2015: 257).

37 Was this the source of Wittgenstein's 'Wovon man nicht sprechen kann, darüber muss man schweigen'?

38 My translation from Dorati (2015: 206). 
The problem is that the storyworld of the play combines a modicum of freedom with a large number of events determined by fate.

Prophetic abilities also pose a difficulty. Why does Tiresias not act to prevent parricide and incest? Why did he not solve the riddle of the Sphinx (391-398; see also $562-565$ )? Oedipus infers from this that Tiresias is not a true prophet (390-394), but the audience knows that Tiresias does indeed possess prophetic knowledge, as Oedipus will later realise (747). According to Dorati, these questions point to an impossibility in the storyworld of Oedipus the King: it is impossible to avoid fate, but Sophocles minimised the intervention of the gods within the play. ${ }^{39}$

One could explain the events of the play on the hypothesis that the gods intervene at the right moment in the story; for instance, we can infer that Apollo does not let Tiresias know what would stop the course of action envisaged by Apollo himself. ${ }^{40}$ This would imply that the gods are malevolent. Dorati rules this out, ${ }^{41}$ but there is internal ${ }^{42}$ and external evidence to the contrary. ${ }^{43}$

Moreover, the audience does not need to suppose that Tiresias is omniscient. Oedipus and the chorus presuppose that he 'grasp[s] all things' (300: see [6]) and that he knows everything that Apollo knows (284-286: see [7]), but these statements come from human, not divine, sources and are only part of a politeness strategy. ${ }^{44}$ One can infer that Apollo did not reveal to Tiresias how to solve the enigma of the Sphinx precisely because the god (377) 'takes an interest' (377 $\mu \dot{\varepsilon} \lambda \varepsilon ı)$ in bringing Oedipus to his downfall, as Tiresias himself reveals:

\footnotetext{
39 Dorati (2015: 226).

40 See Kovacs (2009).

41 Dorati (2015: 175).

42 See [4] discussed below; Dodds (1966: 44-46 = 1973: 73-74); Cairns (2013: 127-138, 159, and passim); Kovacs (2019: 108-109), discussing [4], and lines 720-722, 1329-1333.

43 Soph. Trach. 1278, which is the final line of the play, states that 'no element of this was not

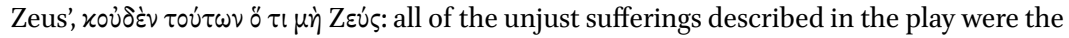
action of Zeus.

44 See below, section 6. Note that in 305-309, Oedipus explains that he does not presuppose that Tiresias knows the response of the oracle reported by Creon; Oedipus suspects that Tiresias heard the news but cannot be sure about it. As Finglass (2018: ad 305-309) notes, Oedipus' statement 'if indeed you have not heard this from the mes-

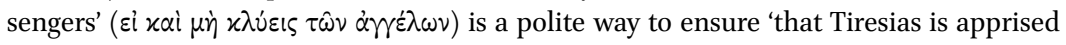
of the situation, without implying that the all-knowing seer is ignorant'; the introductory words $\varepsilon i$ xal 'if indeed' can be used 'in a protasis that the speaker suspects to be false'.
} 
[4] Sophocles Oedipus the King 376-377

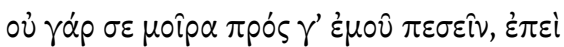

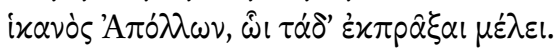

Indeed, since it is not fated that you should fall by my hand, since Apollo is sufficient, who takes an interest in bringing that to its conclusion. ${ }^{45}$

Tiresias does not reply to Oedipus' accusation at 390-394 about his failure to solve the riddle of the Sphinx because he does not want to damage his own 'positive face' by admitting partial ignorance in a confrontation that focuses on the reliability of his own prophetic skills. The prophet only knows what Apollo reveals to him when Apollo sees fit. ${ }^{46}$ This does not imply that Tiresias knew everything from the beginning. In fact, we only know that Tiresias knows the truth about Oedipus at the moment when the play takes place; we are never told that he knew Oedipus' fate in the past. From 376-377 ([4]), we positively know that Apollo is a 'malevolent' god who is intent on causing the fall of Oedipus. This explains why Tiresias' prophetic abilities cannot prevent fate.

\section{$4 \quad$ Tiresias the Manipulator?}

Another approach to the problem, a very extreme one, was suggested by Ahl. ${ }^{47}$ According to Ahl, there is no inconsistency in the scene: Tiresias always meant to reveal his message; his message is false; he only pretends to have access to divine revelations, but in fact he is part of a plot and wants to convince Oedipus of his guilt. Extreme interpretations such as Ahl's are fascinating because they explore the limit of our ToM. Murnaghan, in response to Ahl, points out

45 Finglass (2018) ad loc. translates 'whose business it is to bring that to its conclusion'.

46 On the role of Apollo in the play, see Cairns (2013: 127-138 and passim), Kovacs (2009), (2019). As Gunther Martin points out to me (in a personal communication), 'I believe we do not know what a seer sees when', nor could any non-seer in antiquity know what a mythical seer saw. This of course 'opens the doors for the poet to manipulate information and plots'; 'trying to construct a coherent view may be doomed to fail'. In any case, the text, by posing the very interpretive problems we are addressing, is asking the audience to explore possible answers.

47 Ahl (1991). Goodhart (1978) already argued that Oedipus was innocent and Tiresias untrustworthy. 
that this kind of reading presupposes treating characters in literature as if they were part of real life. ${ }^{48}$ As Dodds put it:

There is only one branch of literature where we are entitled to ask such

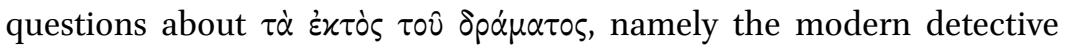
story. 49

This means that extreme interpretations use ToM in a way that seems illegitimate. However, we cannot completely abandon ToM when we interpret texts. Characters that act without motives and in a way that is unintelligible are not characteristic of Greek tragedy but of very different modern genres. ${ }^{50}$

In fact, ToM is crucial to the play. It is used by Oedipus in the first part of the play, when he, on the basis of his (false) belief in his own innocence, infers that Tiresias and Creon must have some other reasons for accusing him. Oedipus concludes that they are plotting against him in order to rob him of his kingdom $(380-403)$. He bases his confidence on his ability to 'read the mind' of the Sphinx when he solved the riddle. Even the chorus leader claims he reads the mind of Oedipus and Tiresias, namely when he 'conjectures' that the

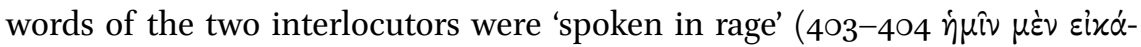

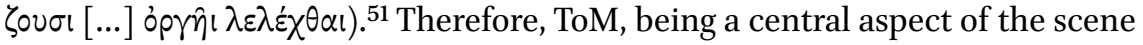
under discussion, cannot be completely dismissed as a tool for interpreting the play.

If we approach the scene from the politeness point of view of Tiresias and Oedipus, we find that they both have very difficult linguistic tasks.

The dynamics of power between the two interlocutors are unbalanced. Oedipus has supreme political power but Tiresias has a special connection with the gods. There is no established hierarchy between these two powerful people. Tiresias himself points out the ambiguity in ranking:

48 Murnaghan (1993: 164). For a brief but persuasive criticism of Ahl (1991), see Bain (1993).

49 Dodds (1966: 40-41 = 1973: 68).

50 See Easterling (1973): a classic paper on the 'human intelligibility' of tragic characters. On characterisation in antiquity, see now De Temmerman and van Emde Boas (2018) with further references.

$5^{1} \quad$ On anger in the play, see below, p. 199 n. 57. 
[5] Sophocles Oedipus the King 408-411

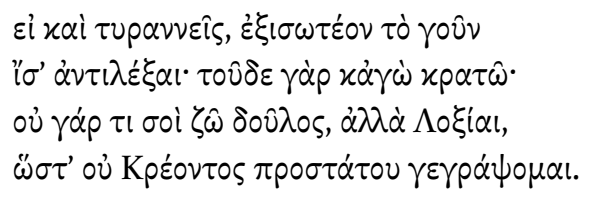

Even if you are a monarch, the right of equal reply must be equalised, at least; for of that I too am master. For my life is enslaved not at all to you, but to Loxias; so I will not be inscribed as having Creon as my patron.

Tiresias does not claim to be superior to Oedipus but equal. Ranking of power is a crucial sociolinguistic variable and of prime importance for im/politeness mechanisms. ${ }^{52}$ The lack of a precise ranking between the two speakers leads to frank and explicit verbal exchanges and makes the situation potentially explosive from a linguistic and social point of view, as the two interlocutors vie for linguistic and political supremacy.

Clashes between prophet and king are common in Greek epic and tragedy as well as in other genres and literatures..$^{53}$ One could ask whether a prophet feels the need to be perceived as polite by his interlocutors (politenessi: in this section 'politeness' and 'polite' will be used in this meaning): a prophet is after all protected by the gods and reveals the messages or even the very worlds he receives from the gods. ${ }^{54}$ However, from the very beginning of Homer's Iliad, we learn that priests and prophets need to speak with caution in front of a king for fear of retaliation (1.17-32, 62-115). This implies the need for facework from the prophet.

Moreover, Oedipus has access to special intellectual abilities which make him think he is, in some respects, more authoritative than the prophet; these abilities push him to extremes in attributing intentions to other agents, using ToM to an unprecedented level. Finally, Tiresias and Oedipus are speaking in front of a chorus of Theban citizens, and Tiresias must avoid using taboo words or expressions.

Oedipus, at the beginning of the scene, asks Tiresias to tell the truth. Tiresias faces three politeness problems. First of all, if he accepts to do what Oedipus

$5^{2}$ Brown and Levinson (21987: 29-33, 74-83, and passim); Culpeper (2011: 186-193 and passim).

53 See e.g. Bremmer (1993). On the roles of prophet and king in this scene, see Worman (2014: sections 6-7).

$54 \quad$ I thank M. Lloyd for this observation. 
asks him to do, he must threaten the negative face of Oedipus. Tiresias has to tell Oedipus that he must leave town (as a consequence of his own edict). Secondly, Tiresias must also make admissions that threaten his own negative face: he is asked by Oedipus to admit his inability to help now and in the past. Thirdly, and more importantly, if the prophet is to reveal what happened, he must attack the 'positive' face of Oedipus and break several linguistic taboos. He must tell Oedipus that

(a) he is a murderer;

(b) he is the murderer of Laius, i.e. he is the person that he himself banned from the city;

(c) he committed parricide since Laius is his father;

(d) he committed incest since Jocasta, his wife, is in fact his mother.

These are all extreme aggressions to the positive face of Oedipus. In fact, 'par-

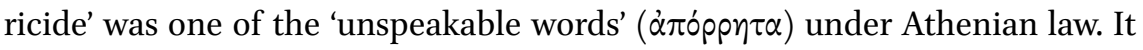
was, from a legal point of view, a taboo word. The person making a (false) accusation of parricide could be brought to trial. ${ }^{55}$ Within the drama, incest is perceived as being linguistically even more problematic than parricide. At the end of the play, the messenger pronounces the word 'parricide' (1288 $\pi \alpha \tau \rho \circ-$ $x \tau$ tovov) but cannot bring himself to repeat the terms Oedipus used to describe the nature of his relation to his mother (note the harsh aposiopesis at 1289: tòv

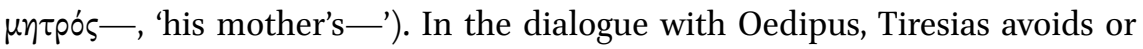
delays revealing explicitly what Oedipus did. This linguistic approach can be interpreted both as a politeness strategy ('off record') and as a social strategy (avoiding words that are unacceptable in some social contexts: euphemism). ${ }^{56}$ These two possibilities are not in principle mutually exclusive, but in this case, politeness can be ruled out: Tiresias repeatedly clarifies that it is only anger that makes him reveal the facts (412 [13]), ${ }^{57}$ and he is reluctant to explain what happen explicitly. His euphemistic statements are therefore not a politeness strategy directed to Oedipus.

55 See Lys. 10.6 with Todd (2007: ad loc.); Clay (1982).

56 On euphemism in ancient Greece, see Sommerstein and De Martino (1999), Pellucchi (2013), Caroli (2017), with further bibliography.

57 Oedipus repeatedly mentions that Tiresias made him angry (335, 339, 345), and Tiresias comments on Oedipus' anger $(337-338,344)$. Anger is often seen as causing bad deliberations: see Thuc. 3.42.1 and, in the context of impolite accusations to an interlocutor, Eur. Med. 446-447, 615. See Battezzato (2017: 169). On anger in this scene, see Worman (2014: section 6). On conceptions of anger in antiquity, see Harris (2001), Braund and Most (2003). 
A general overview of the scene shows that, after an initial positive politeness act from Oedipus (300-315) and an off-record reply from Tiresias (317-319), both interlocutors speak 'bald on record' with occasional attempts at negative politeness from Oedipus ('give reasons': 303, 305-314) and frequent off-record and ironic utterances from Tiresias. Tiresias' off-record utterances include a general maxim (spoken in order to avoid answering a request [317-319]), indirect revelations about Oedipus' fate $\left(35^{\circ}-353,366-367,372-373,379,413-428\right.$, $438,442)$, and ironic utterances $\left(364,432,435^{-436}\right.$, an ironic indirect accusation, 440). The difficulties of Tiresias' linguistic task will emerge from a detailed analysis of the scene.

Oedipus starts the dialogue by failing to understand the gravity of the linguistic problems of his interlocutor; he nonetheless appreciates that his request is a threat to the negative face of Tiresias. For this reason, Oedipus tries to mitigate the face threat with standard positive politeness techniques. He welcomes the seer expressing exaggerated praise:

[6] Sophocles Oedipus the King 300-301

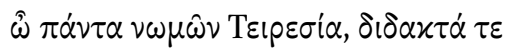

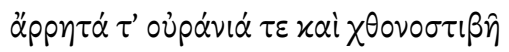

Tiresias, you who grasp all things, what can be taught and what cannot be spoken, the things of heaven and the things that tread the earth

As Finglass observes: "Tiresias attempts to leave words unspoken that Oedipus wishes to be said. ${ }^{58}$ More than that: by mentioning the need to speak 'what

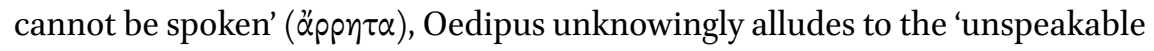
words' (à $\dot{\alpha} \rho p \eta \tau \alpha)$, i.e. to the accusation of parricide.

In his positive facework, Oedipus echoes a similar statement made earlier by the chorus:

[7] Sophocles Oedipus the King 284-286

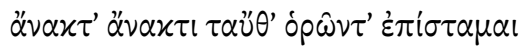

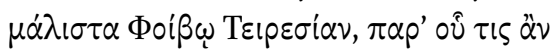

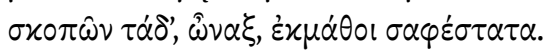

$5^{8} \quad$ Finglass (2018: $a d$ 30o-301). 
I know that lord Tiresias sees the same things as does lord Phoebus, and from him, my lord, one might learn these things most truly in the course of investigation.

The words of Oedipus and the chorus leader do not imply that Tiresias is in fact omniscient, as Dorati and others concluded. ${ }^{59}$ The chorus leader praises Tiresias' prophetic ability as part of his attempt to mitigate the face threat he is making in telling Oedipus what he should do (see already the tentative question of the chorus leader at 282). Oedipus' words can simply be interpreted as an instance of positive politeness: they introduce the request (made at 310-315) that the prophet use all his prophetic arts to help discover the identity of the murderer of Laius.

At the beginning of the dialogue, Oedipus thus mitigates the face threats by using positive politeness, namely by praising Tiresias' prophetic abilities (300301,304 ) and negative politeness ('give reasons') when he orders him to speak $(303,305-314)$. The city is in danger: therefore, Tiresias must speak (310-315). This request puts him in a difficult situation. He reacts with-what conversation analysis calls - a 'pre-expansion', in which he gives reasons for the refusal that he will make explicit at $328-329$ :

[8] Sophocles Oedipus the King 316-318

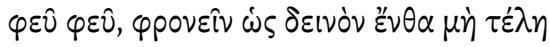

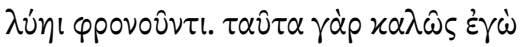

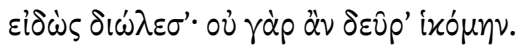

Pheu pheu, how terrible is wisdom when being wise brings no advantage! I knew this well but forgot it; for otherwise I would not have come.

The interjection pheu pheu and the (exact) wording of these remarks allow the interlocutors to draw an inference about Tiresias' state of mind: he is 'emotionally upset' (Bain 1979: 134). His language is peculiar: he says he 'destroyed' ( $\delta\left(\omega \dot{ } \lambda_{\varepsilon \sigma \sigma \alpha)}\right.$ his knowledge, a verb that many interpreters consider as equivalent to 'forgetting'.60 Other scholars suggest that Tiresias is saying that

59 Dorati (2015: 205).

6o Finglass (2018: ad loc.): “For $\delta \iota \omega \dot{\lambda} \varepsilon \sigma \alpha$ “I forgot" cf. Ter. Phor. 386 nomen perdidi, and also $\sigma \omega \dot{\omega} \zeta \omega$ "I remember" at Eur. Hel. 266 (and LSJ ${ }^{9}$ s.v. $\sigma \omega \dot{\zeta} \zeta \omega$ i 4 [the second 4 under i] for $\sigma \dot{\omega} \zeta 0 \mu \alpha$ l with this sense); perhaps the unusual term somehow emphasises Tiresias' personal agency in 
"Teiresias, for his part, did not "forget" this conventional wisdom [...] but deliberately put it out his mind, in order to comply with Oedipus' summons' (Edmunds 2000: 37). ${ }^{61}$ This ambiguous statement amounts to an off-record response.

The dialogue rapidly escalates into an angry argument. Oedipus immediately attacks Tiresias' face with a bald on record statement, accusing him of 'breaking the law' and acting as an enemy of the city that reared him (322$333)$. Tiresias tries to explain that Oedipus' request is inopportune (324-325), a typical positive polite strategy ('give reasons'). ${ }^{62}$ Oedipus supplicates the prophet, thus applying the strongest religious pressure he can $\left(3^{26-327)}\right)^{63}$ Tiresias utters his first direct ('bald-on-record') statement, claiming that Oedipus and the citizens of Thebes lack understanding (328). He categorically refuses to reveal what he knows (329), a stance that Oedipus considers tantamount to treason (330-331). Tiresias states, once again, his refusal (332-333), which makes Oedipus break into open coercive impoliteness:

[9] Sophocles Oedipus the King 334-336

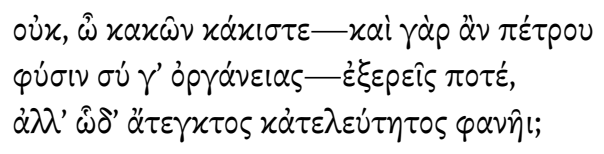

You utter wretch - for you would enrage a very stone-will you never speak out? Will you appear thus intransigent and inconclusive?

Oedipus points out that Tiresias' behaviour is provocative: the prophet's words cause anger in him. ${ }^{64}$ But is Tiresias being intentionally provocative? Or is this just a consequence of his intention to avoid threatening Oedipus' 'face'? The exchange that follows focuses on Oedipus' anger (337-343) and concludes with another bald-on-record refusal from Tiresias, who defiantly challenges Oedipus to rage as much as he likes (344-345). Oedipus takes up the challenge and reveals what he had been thinking already for a while:

suppressing the thought more than e.g. $\delta\llcorner\varepsilon \lambda \alpha \theta o ́ \mu \eta \nu$ would.' The lack of Greek parallels is striking.

61 For a discussion of the interpretations, see Dorati (2015: 206 n. 205, 207 n. 201 and 203).

62 Brown and Levinson (21987: 128-129).

63 On supplication, see Gould (1973), Naiden (2006).

64 See above n. 57 . 
[10] Sophocles Oedipus the King 345-346

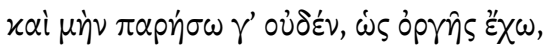

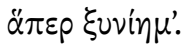

Well, I will leave out nothing — such is my anger—of what I understand.

This utterance marks a turning point in the scene: Oedipus, saying that he 'will leave out nothing', reveals his previous and future linguistic strategies. ${ }^{65}$ Until this moment he has 'left out' something, i.e. he has not completely revealed his thoughts. It is his present state of anger, which he has just reached ('such is my anger'), that allows him to say what he thinks. Anger allows him to express the face-threatening utterances that he had repressed so far. Oedipus goes on to accuse Tiresias of being an accomplice in the murder of Laius (346-349), a grave accusation, which entails exile or death. These violent attacks to Tiresias' face take the conversation away from all politeness strategies, which in turn allows Tiresias to speak the truth. Tiresias crosses the first linguistic boundary, explicitly accusing Oedipus of being the murderer of Laius (above, section 5, p. 199: points [a] and [b]). However, he only indirectly accuses Oedipus of being the murderer of Laius; he states that the king is the "unholy polluter of the

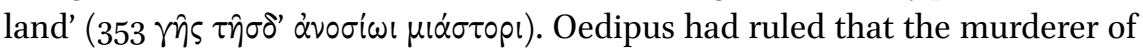
Laius, because of his impure status, should be excluded from any conversation with the citizens of Thebes (238), and Tiresias states that any conversation with Oedipus should stop now $\left(35^{\circ}-353\right)$. The prophet stresses that it was Oedipus who forced him to speak:

\section{[11] Sophocles Oedipus the King $35^{8}$

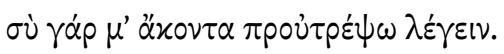

For you made me speak although I was unwilling.

Tiresias' revelation becomes explicit (362) at Oedipus' request (361). After this, Oedipus crosses another boundary and resorts to physical threats (363). This menaced aggression makes Tiresias in turn cross another linguistic boundary (above, section 5, p. 199, [e]): the prophet finally hints at Oedipus' incest:

65 On some such strategies, see van Emde Boas in this volume. 
[12] Sophocles Oedipus the King 364-367

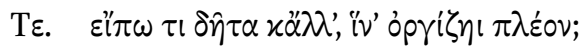

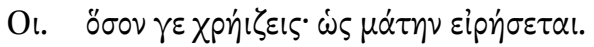

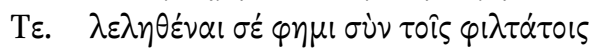

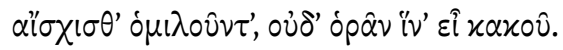

Ti. Shall I say anything else, then, so that you can get angrier?

Oe. As much as you like, as it will be spoken in vain.

Ti. I say that you are unknowingly associating most shamefully with those closest to you, and do not see in what a disaster you are.

Tiresias sarcastically asks Oedipus for permission, noting that he will make the king even angrier. In this way, no one can blame Tiresias for 'destroying' or 'forgetting' (318: [8]) what wise people know. Tiresias makes, as Catrambone notes, 'sarcastic use of the deliberative subjunctive' ( 364 'shall I say'), to which Oedipus replies 'with equally sarcastic positively-polite exaggeration' at $365 .{ }^{66}$ Tiresias stresses that he intends to stir Oedipus' anger (364 'so that you can get angrier'); he is able to control Oedipus' emotions, reactions, and language. Oedipus gives permission (365), erroneously thinking that he is in control, but must immediately resort to uttering further physical threats (368, repeating the threat of 363 ), and, finally, expressing disbelief (370-371, 374-375). Oedipus' disbelief culminates in a long speech where he denies that Tiresias has any sound knowledge of the past and the future, thus taking back what he said at the beginning of the episode ([6] = 300-301; 304); Oedipus questions Tiresias' prophetic ability and suggests that greed and lust for power motivate his words $(380-403)$. Tiresias answers with a symmetrical speech (408-428), where he specifies that he is speaking because Oedipus insulted him:

[13] Sophocles Oedipus the King 412

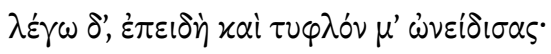

I speak, because you even insulted me as blind.

66 Catrambone (2019: 258 n. 408). For a similar request in a polite contest, see Eur. Supp. 293

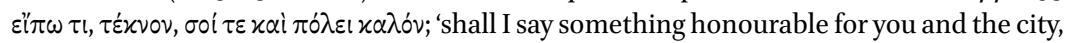
my son?' 
Tiresias thus states that he caused Oedipus' anger, which in turn caused Oedipus' insults, which allowed Tiresias to speak the truth. Tiresias' control of the dialogue is complete. His metalinguistic observation stresses anger again as a motivation for linguistic acts in continuity with similar previous observations by both speakers and the chorus leader $(335,337-338,339-340,364$ [12 ], 404405). Tiresias restates, in allusive and indirect language, that Oedipus 'does not see' (413) his situation and does not understand what he did to his father and mother. Tiresias finally resorts to direct attacks to the face of Oedipus, prophes-

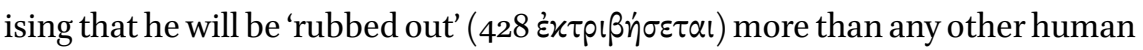
being. ${ }^{67}$

Oedipus rejects Tiresias' words as absurd insults and utters new threats against the prophet (429-431, 433-434). Tiresias replies by pointing out that it was Oedipus who asked him to come and speak (432) and claims that he will be considered 'wise' ( 436 है $\mu \varphi p o v \varepsilon \varsigma$ ) by Oedipus' parents. Oedipus asks who his parents are, and Tiresias answers that 'this day will be your parent'. This is an off-record reply, shifting the focus from the biological to the metaphorical level:

[14] Sophocles Oedipus the King 438-439

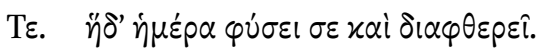

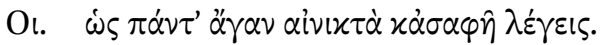

Ti. This day will be your parent and your destroyer.

Oe. How everything you say is full of riddles and obscurity!

Oedipus reads Tiresias' words as 'full of riddles', and this is consistent with Tiresias' role as a prophet. Oedipus, however, does not understand that Tiresias, even at this point of their clash, is, in fact, being euphemistic, i.e. not polite or prophetic. ${ }^{68}$ At 440 , Tiresias sarcastically alludes to Oedipus' pride in his ability to interpret riddles, in reference to 390-397, where Oedipus accused Tiresias of being a useless prophet because he was unable to solve the riddle of the Sphinx. This is another direct attack to Oedipus' face: Tiresias notes that Oedipus' abil-

67 Tiresias uses prosaic terms: see esp. $427 \pi \rho 0 \pi \eta \lambda \dot{\alpha} x \iota \zeta \varepsilon$ with Worman (2014: n. 12) and Finglass (2018: ad 426-428).

68 Brown and Levinson $\left({ }^{2} 1987: 217,223,226\right)$ discuss euphemisms as an off-record politeness strategy intended to minimise the face threat to the interlocutor. Here, Tiresias does not intend to minimise the face threat to Oedipus but elicits further questions from him, which will authorise Tiresias to use more explicit language. 
ity was in fact to his disadvantage (442) and implies that he is unable to use his ability to his own advantage now.

At this point, Tiresias expresses his intention to accept Oedipus' order and walk out (444). ${ }^{69}$ He delivers a final speech (447-462), introduced by the passage quoted above (see [2]), where he states his intention to reveal what he came for. Tiresias' revelations about incest and parricide finally become direct and explicit.

\section{[15] Sophocles Oedipus the King 457-46o}

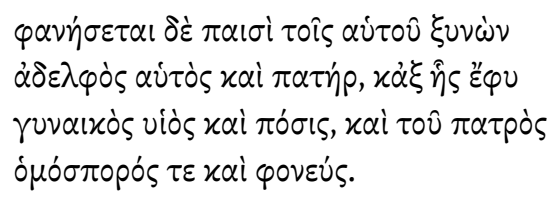

He will be revealed as both brother and father of the children he is living with, and the son and husband of the woman from whom he was born, and the fellow-sower and killer of his father.

Tiresias avoids using the taboo word 'parricide', which was considered extremely shocking; however, he resorts to a very explicit periphrasis ( $\tau 0 \hat{v}$ $\pi \alpha \tau$ pò [...] بoveús 'killer of the father'). ${ }^{70}$

This scene ends in a walkout, as many arguments do in real life. ${ }^{71}$ Tiresias obeys Oedipus' order to leave the stage ${ }^{72}$ but has the last word in the scene: there is nothing that Oedipus can say at this point.

69 Oedipus orders Tiresias to leave at 430-431, stops him at 437 ( $\mu$ घivov 'stop!'), and orders him, once more, to leave at $445^{-446}$. Tiresias says he will leave at 444 but delivers his final speech (447-462) before doing so.

70 Athenian law explicitly prohibited the slanderous use of the taboo word 'parricide'. The law was probably interpreted as prohibiting also the use of periphrases, as argued in Lys. 10: cf. above, section 5, p. 199 with n. 55. Oedipus, in any case, is a parricide (and therefore, one would assume, not covered by the law). He shockingly uses that very word ( $\pi \alpha \tau$ poxtóvov 'parricide') in reference to himself at 1288, in an indirect speech reported by the messenger. Plato Laws $944 \mathrm{~b}-\mathrm{e}$, in discussing 'shield-flinger', another word considered 'unspeakable' under Athenian law, stresses that periphrases or less common turns of phrases are felt to be less hurting and damning than the words covered by the law.

71 See the studies by Dersley and Wootton (2000) and Dersley and Wootton (2001).

72 See Finglass (2018: $a d$ 447-462) for a review of staging and authenticity problems. See also above, p. 193 n. 32. 


\section{$7 \quad$ Conclusions}

We have now returned to our original question about ToM: is Tiresias' stated intention a post-factum explanation or a revelation of his original intention? Is Tiresias allowed to be 'insincere' in his refusal to speak? We find that a contemporary of Sophocles interpreted the Oedipus the King scene in this way. In Euripides' Phoenician Women, Creon summons Tiresias onstage, asking the prophet to reveal what he knows about the future. The prophet again refuses to speak:

[16] Euripides Phoenissae 891-895

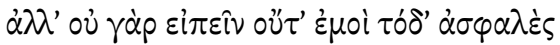

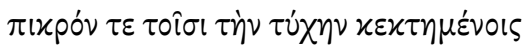

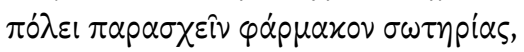

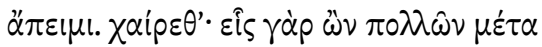

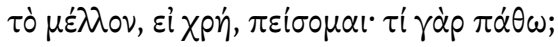

But it is unsafe for me to speak these words, and it will be galling to those who are touched by this fate that I should give the city its life-saving medicine: I'm going away. Farewell! If I must I will suffer, as one man among many, what is to come. What can I do? ${ }^{73}$

As Mastronarde and others noted, Euripides modelled this scene on that between Tiresias and Oedipus in Oedipus the King. ${ }^{74}$ In Euripides, Tiresias reinstates his refusal after Creon's repeated requests (896-897); however, when the king points out the need to help the city in peril $(898,900)$, he rapidly accedes to the king's request. Tiresias repeatedly asks his interlocutor to confirm his will to know the truth, especially in the presence of his son (901-910). Tiresias' shift from refusal (891-895) to compliance (910) occurs in the span of a very brief dialogue ( 85 words in lines $891-909) .{ }^{75}$ This suggests that Tiresias only meant to obtain preventive reassurances from Creon. For he was afraid he might face Oedipus' anger when confronting him with the possibility of negative con-

73 Translation from Kovacs (2002).

74 Mastronarde (1994: ad 865-895) and Medda (2006: 46-5o, 219 n. 156), with further references.

75 The dialogue might have been even shorter since lines 903-904 are suspected of being unauthentic by some scholars: see, however, Mastronarde (1994) and Medda (2006: ad loc.). 
sequences. The linguistic difficulties are much weaker here than in Oedipus the King: Tiresias is about to reveal that the king's son needs to be sacrificed if the city is to be saved, but no shameful secrets or accusations are involved, nor is the king forced to act on the revelation because of a binding legal and religious commitment he himself proclaimed in public, as in Oedipus the King. ${ }^{76}$

Of course, the king is expected to act on behalf of the city, but the threats to the positive and negative face of the king are much weaker than in Sophocles. In Euripides, Tiresias' refusal is meant to show solidarity with, not hostility against, the king; his words (see [16]) imply that he is willing to die rather than make revelations that can lead to the death of the king's son.

Euripides, in recreating the scene from Oedipus the King, simplifies the linguistic challenges for the speakers and the interpretive problems for the audience: he creates a dialogue that clearly suggests that the prophet meant to reveal what he knew if he received appropriate reassurance. Does this interpretation work for the Oedipus the King scene as well? In Oedipus the King, we are left without conclusive evidence on whether Tiresias attributes to himself the intention of revealing the truth only post factum or whether this was his intention all along.

Based on psychological parallels, interpreters may conclude in favour of the post-factum explanation, which is compatible with the claim that the scene contributes to the characterisation of the two interlocutors.

Alternatively, one can offer a weaker version of the insincerity interpretation advanced by Ahl (1991): Tiresias meant to reveal his message from the beginning, thus saving the city, but felt he could not do this because of the face threats involved and the linguistic taboos he had to break. The prophet revealed the truth only when compelled by Oedipus' anger, which the prophet himself caused. This may imply that he elicited Oedipus' anger on purpose. In this interpretation, Tiresias in Oedipus the King is being insincere when he states that he wants to leave without revealing the truth. A true prophet that is insincere may sound paradoxical. But, as we saw in Euripides' Phoenician Women, it is not unparalleled.

Prophets are proverbially obscure; audiences expect them to clash with kings. The text of Sophocles weaves these typical strands of characterisation into an unexpected tapestry: the obscurity is in fact not a divine challenge to human fallibility, but a necessary choice under complex circumstances. Oedipus fails to decipher Tiresias' obscurity, just as he failed to decipher Apollo's

76 The king, in fact, tries to avoid the death of his son, who eventually kills himself to save the city: Eur. Phoen. 985-1012. 
prophecy. Mistakenly overconfident in his ability to read the mind of the prophet, he ironically breaks the linguistic barrier of respect and politeness, thus allowing Tiresias to deliver the message he asked for-and again failing to understand what Tiresias says in very plain words. The text thus exploits the external constraints of the communicative situation by making Tiresias' clarity appear opaque to an Oedipus who is led astray by his own interpretive fury.

The storyworld of Oedipus the King is partially determined by fate and we must assume that the gods intervene to avoid outcomes that do not conform to fate or predictions. This helps to make sense of Tiresias' initial statement about the uselessness of advance knowledge. Tiresias' linguistic difficulties help understand why he is reticent about his failure to help in the past: admitting the uselessness of his knowledge would be a threat to his own positive face.

We see how the linguistic interpretation of this scene is strictly linked to the themes of human freedom and fate, to the attribution of intent to human agents, and to the dynamics of linguistic interaction. That Tiresias is insincere is a possibility suggested but not made unambiguous by the text. Does this interpretation push ToM too far, as Dodds would claim? Or is thinking about language, fate, gods, and human freedom the whole point of Oedipus the King?

\section{References}

Ahl, F., (1991), Sophocles'Oedipus: Evidence and Self-conviction, Ithaca.

Apperly, I., (2012), Mindreaders: the Cognitive Basis of 'Theory of Mind', Hove/New York. Bain, D., (1979), 'A Misunderstood Scene in Sophokles, Oidipous (O.T. 300-462)', Greece \& Rome, 26, 132-145.

Bain, D., (1993), Review of Ahl 1991, The Journal of Hellenic Studies 113, 189-19o.

Barrios-Lech, P., (2016), Linguistic Interaction in Roman Comedy, Cambridge.

Battezzato, L., (2017), 'Change of Mind, Persuasion, and the Emotions: Debates in Euripides from Medea to Iphigenia at Aulis', Lexis 35, 164-177.

Battezzato, L., (2019), Leggere la mente degli eroi: Ettore, Achille e Zeus nell'Iliade, Pisa. Braund, S.M. \& Most, G.W. (eds.), (2003), Ancient Anger: Perspectives from Homer to Galen, Cambridge.

Bremmer, J.N., (1993), 'Prophets, Seers, and Politics in Greece, Israel, and Early Modern Europe', Numen 40, 150-183.

Brown, H.P., (2006), 'Addressing Agamemnon: a Pilot Study of Politeness and Pragmatics in the "Iliad"', Transactions of the American Philological Association 136, 1-46.

Brown, P. \& Levinson, S.C., ( ${ }^{2} 1987$ [1978]), Politeness: some Universals in Language Usage, Cambridge. 
Budelmann, F. \& Easterling, P.E., (2010), 'Reading Minds in Greek Tragedy', Greece \& Rome 57, 289-303.

Cairns, D., (2013), 'Divine and Human Action in the Oedipus Tyrannus', in D. Cairns (ed.), Tragedy and Archaic Greek Thought, Swansea, 119-171.

Caroli, M., (2017), Il velo delle parole:l'eufemismo nella lingua e nella storia dei Greci, Bari.

Catrambone, M., (2016), 'Off-record Politeness in Sophocles: the Patterned Dialogues of Female Characters', Journal of Politeness Research 12, 173-195.

Catrambone, M., (2019), Tragic Conversation: Politeness Strategies in Sophocles' Patterned Dialogues, PhD Thesis (Scuola Normale Superiore, Pisa).

Clay, D., (1982), 'Unspeakable Words in Greek Tragedy', The American Journal of Philo$\operatorname{logy} 103,277-298$.

Condello, F., (2016), Sofocle: Edipo Re, Santarcangelo di Romagna.

Culpeper, J., (2011), Impoliteness: Using Language to Cause Offence, Cambridge.

De Temmerman, K. \& van Emde Boas, E., (2018), Characterization in Ancient Greek Literature, Leiden.

Dersley, I. \& Wootton, A.J., (200o), 'Complaint Sequences within Antagonistic Argument', Research on Language and Social Interaction 33, 375-406.

Dersley, I. \& Wootton, A.J., (2001), 'In the Heat of the Sequence: Interactional Features Preceding Walkouts from Argumentative Talk', Language in Society 30, 611-638.

Dodds, E.R., (1966), 'On Misunderstanding the Oedipus Rex', Greece \& Rome 13, 3749 (repr.: The Ancient Concept of Progress and Other Essays on Greek Literature and Belief, Oxford 1973, 64-77).

Dorati, M., (2015), Finestre sul futuro: fato, profezie e mondi possibili nel plot dell'Edipo re di Sofocle, Pisa.

Easterling, P.E., (1973), 'Presentation of Character in Aeschylus', Greece \& Rome 20, 3-19. Edmunds, L., (2000), 'The Teiresias Scene in Sophocles' Oedipus Tyrannus', Syllecta Classica 11, 34-73.

Emde Boas, E. van, (2017a), 'Analyzing Agamemnon: Conversation Analysis and Particles in Greek Tragic Dialogue', Classical Philology 112, 411-434.

Emde Boas, E. van, (2017b), Language and Character in Euripides' Electra, Oxford.

Epley, N., (2014), Mindwise: how we Understand what Others Think, Believe, Feel, and Want, New York.

Ferri, R., (2009), 'Politeness in Latin Comedy: some Preliminary Thoughts', Materiali e discussioni per l'analisi dei testi classici $61,15^{-28}$.

Finglass, P.J., (2018), Sophocles, Oedipus the King, Cambridge.

Gianquinto, A., (1994), 'Strategie della memoria: Tiresia ad Atene. I vv. 316-318 dell'Edipo Re', Orpheus 15, 430-443.

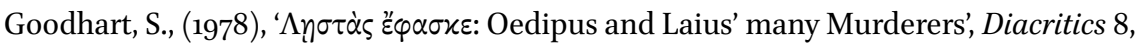
$55^{-71 .}$

Gould, J., (1973), 'HI KetEIA', The Journal of Hellenic Studies 93, 74-103. 
Grice, P., (1975), 'Logic and Conversation', in P. Cole \& J.L. Morgan (eds.), Speech Acts, New York, 41-58 (repr.: Studies in the Way of Words, Cambridge, Mass./London 1989, 22-40).

Hall, J., (2009), Politeness and Politics in Cicero's Letters, Oxford/New York.

Harris, W.V., (2001), Restraining Rage: the Ideology of Anger Control in Classical Antiquity, Cambridge/Mass.

Haugh, M., (2008), 'Intention in Pragmatics', Intercultural Pragmatics 5, 99-110.

Haugh, M. \& Jaszczolt, K.M., (2012), 'Speaker Intentions and Intentionality', in K.M. Jaszczolt and K. Allan (eds.), The Cambridge Handbook of Pragmatics, Cambridge, 87112.

Heath, M., (1987), The Poetics of Greek Tragedy, London.

Herman, D., (2013), 'Cognitive Narratology', in P. Hühn (ed.), The Living Handbook of Narratology (Hamburg). https://www.lhn.uni-hamburg.de/node/38.html [26/o4/ 2019].

Hester, D.A., (1993), 'The Ignorance of Oedipus', Prudentia 25, 1-23.

Heyes, C. (ed.), (2018), Cognitive Gadgets: the Cultural Evolution of Thinking, Cambridge/Mass.

Iser, W., (1978), The Act of Reading: a Theory of Aesthetic Response, Baltimore.

Iurescia, F. \& Martin, G., (2019), 'Conversational Strategies across Greek and Roman Tragedies', Lingue e Linguaggi 31, 233-254

Kahneman, D., (2011), Thinking, Fast and Slow, New York.

Kovacs, D., (2002), Euripides, vol. 5, Cambridge, Mass./London.

Kovacs, D., (2009), 'The Role of Apollo in Oedipus Tyrannus', in J.R.C. Cousland \& J.R. Hume (eds.), The Play of Texts and Fragments: Essays in Honour of Martin Cropp, Leiden, 357-368.

Kovacs, D., (2019), 'On Not Misunderstanding Oedipus Tyrannos', Classical Quarterly 69, 107-118.

Lattimore, S., (1975), 'Oedipus and Teiresias', California Studies in Classical Antiquity 8, 105-111.

Lloyd, M., (2004), 'The Politeness of Achilles: Off-record Conversation Strategies in Homer and the Meaning of kertomia', The Journal of Hellenic Studies 124, 7589 .

Lloyd, M., (2006), 'Sophocles in the Light of Face-threat Politeness Theory', in I.J.F. de Jong and A. Rijksbaron (eds.), Sophocles and the Greek Language: Aspects of Diction, Syntax and Pragmatics, Leiden/Boston, 225-239.

Lloyd, M., (2009), 'The Language of the Gods: Politeness in the Prologue of the Troades', in J.R.C. Cousland \& J.R. Hume (eds.), The Play of Texts and Fragments: Essays in Honour of Martin Cropp, Leiden, 183-192.

Lloyd, M., (2018), 'Sophocles', in K. De Temmerman and E. van Emde Boas, 337-354.

Manuwald, B., (2012a), Sophokles, König Ödipus, Berlin. 
Manuwald, B., (2012b), 'Wann verlässt Ödipus die Bühne? Zum Schluss der TeiresiasSzene in Sophokles' König Ödipus', Rheinisches Museum für Philologie 155, 128-141.

Mastronarde, D.J., (1994), Euripides, Phoenissae, Cambridge.

Medda, E., (2006), Euripide, le Fenicie, Milan.

Murnaghan, S., (1993), Review of Ahl 1991, Classical Philology 88, 162-167.

Naiden, F.S., (2006), Ancient Supplication, Oxford/New York.

Pellucchi, T., (2013), 'Euphemism and Dysphemism', in G.K. Giannakis and V. Bubenik (eds.), Encyclopedia of Ancient Greek Language and Linguistics, vol. 2, Leiden, 582585 .

Pfeiffer-Petersen, S., (1996), Konfliktstichomythien bei Sophokles: Funktion und Gestaltung, Wiesbaden.

Reinhardt, K., (1979), Sophocles, Oxford (Engl. tr. of: Sophokles, Frankfurt a.M. ${ }^{4} 1976$ [1933]).

Roisman, H.M. (2003), 'Teiresias, the Seer of Oedipus the King: Sophocles' and Seneca's Versions', Leeds International Classical Studies 2.5. https://web.archive.org/web/2O14 1129151559/http://lics.leeds.ac.uk/2003/200305.pdf [13/08/2020].

Ryan, M.L., (1991), Possible Worlds, Artificial Intelligence, and Narrative Theory, Bloomington/Indianapolis.

Ryan, M.L. (2013), 'Possible Worlds', in P. Hühn (ed.), The Living Handbook of Narratology, Hamburg. https://www.lhn.uni-hamburg.de/node/54.html [26/o4/2019].

Sacks, H., Schegloff, E.A., \& Jefferson, G., (1974), 'A Simplest Systematics for the Organization of Turn-taking for Conversation', Language 5o, 696-735.

Scodel, R., (2012), ' $\hat{\eta}$ and Theory of Mind in the Iliad', in M. Meier-Brügger (ed.), Homer, gedeutet durch ein großes Lexikon, Berlin, 315-330.

Sidnell, J., (2010), Conversation Analysis: an Introduction, Malden.

Sidnell, J. \& Stivers, T., (2012), The Handbook of Conversation Analysis, Malden.

Sommerstein, A.H. \& De Martino, F. (eds.), (1999), Studi sull'eufemismo, Bari.

Todd, S.C., (2007), A Commentary on Lysias, speeches 1-11, Oxford.

Voltaire, (1877), OEuvres complètes: Théâtre, vol. 1, Paris.

Watts, R.J., (2003), Politeness, Cambridge.

Wilamowitz-Moellendorff, T. von, (1917), Die dramatische Technik des Sophokles, Berlin.

Worman, N., (2014), 'Oedipus Abuser: Insult and Embodied Aesthetics in Sophocles', Cahiers Mondes anciens 5. http://journals.openedition.org/mondesanciens/1237 [26/04/2019].

Zunshine, L., (2006), Why we Read Fiction, Columbus.

Zunshine, L. (ed.), (2015), The Oxford Handbook of Cognitive Literary Studies, Oxford. 


\title{
Politeness and Impoliteness in Aristophanes
}

\author{
Michael Lloyd
}

The difference between an interpretation of dramatic dialogue in terms of pragmatics (what speakers do with words) and an interpretation in terms of semantics (what words mean) can be illustrated by the following exchange:

[1] Aristophanes Knights 725-727

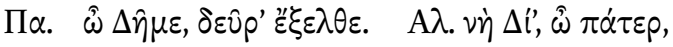

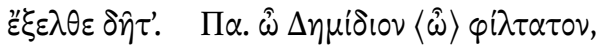

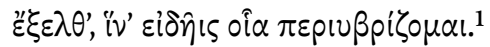

Pa. Demos, come out here!

Sa. Yes, father, come out by Zeus!

Pa. Little Demos, dearest, come out and see how outrageously I am being treated!

Demos, a stupid and bad-tempered old man, represents the Athenian people. He has bought a new slave called Paphlagon, representing the demagogue Cleon, who flatters and indulges him. The play deals with Paphlagon being usurped by an even more unscrupulous figure, the Sausage-Seller, a purely fictional character who does not represent anyone in the real world of Athens. The present passage comes just before Demos' first appearance, as Paphlagon and the Sausage-Seller call him out of his house to decide between them. The Sausage-Seller addresses Demos as $\pi \dot{\alpha} \tau \varepsilon \rho$ ('father'), a respectful term of address to an older man who is not necessarily the speaker's real father. ${ }^{2}$ Paphlagon addresses him as $\varphi$ i $\lambda \tau \alpha \tau$ \% ('dearest') and uses an affectionate diminutive of his name. Alan Sommerstein sees only the locutionary force of these expressions of affection: 'Paphlagon speaks thus because he claims to be Demos' "lover" $(732)^{\prime}{ }^{\prime}$ Stephen Halliwell takes a similarly literal view of such terms in Plato, remark-

1 Aristophanes is cited from the Oxford Classical Text edited by Wilson (2007). All translations are my own unless otherwise stated. The eleven surviving plays date from $425 \mathrm{BC}$ (Acharnians) to 388 в (Wealth).

2 Cf. Men. Dys. 107, 171; Dickey (1996: 78-81).

3 Sommerstein (1981: ad 726). 
ing that $\varphi$ i $\lambda \varepsilon$ ('friend') 'carries a normal presumption of affection, attachment or some stronger feeling'.

Sommerstein's interpretation fits neither the portrayal of Paphlagon elsewhere in the play nor Aristophanes' use of diminutives in other plays. Paphlagon does indeed explain to Demos that he is suffering on his account 'Because I feel affection for you, Demos, and am your lover' (732), but only a few lines earlier he had boasted of his ability to control the old man (719-720). Another slave, usually identified with the Athenian general Demosthenes, characterises Paphlagon's treatment of Demos with the following three verbs, all meaning 'flatter' or 'fawn upon': $\alpha i x \alpha \lambda \lambda \omega, \theta \omega \pi \varepsilon \dot{v} \omega$, and $\varkappa 0 \lambda \alpha x \varepsilon v^{\prime} \omega(48) .{ }^{5}$ Paphlagon's expressions of affection are exaggerated and manipulative. There are other examples in Aristophanes of diminutives and terms of affection being used in requests or to get someone's attention when there is no other evidence of the speaker having any particular liking for the addressee, e.g. Dicaeopolis' Eujpl-

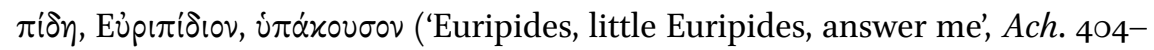

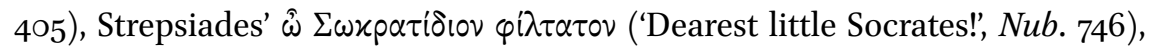

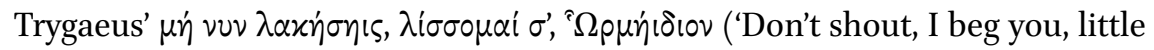

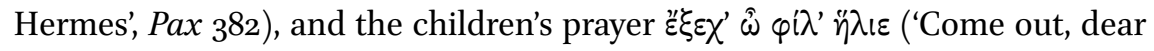
sun', fr. 404, from Islands). ${ }^{6}$

Paphlagon's request to Demos can be interpreted in terms of politeness theory. The most influential model for understanding politeness is the 'face-threat' theory of Brown and Levinson $\left({ }^{2} 1987\right)$, according to which every act of politeness is oriented to a specific 'face-threatening act'. They distinguish two kinds of face, which are assumed to be universal. The first, termed positive face, is the want to be approved of or admired. The second kind of face, termed negative face, is the want not to be imposed upon or impeded. Brown and Levinson's theory accordingly distinguishes two different types of politeness. Positive politeness offers redress to positive face, by expressions of affection, compliments, or limited agreement. Negative politeness is oriented to negative face, and thus aims to leave an 'out' (i.e., scope for evading or ignoring the face-threatening act) and to minimise the imposition.

4 Halliwell (1995: 91).

5 Cf. Unceta Gómez pp. 292-293 in this volume on expressions of flattering (e.g. 'blandiri', 'adulare') as part of the Latin metalanguage of over-politeness.

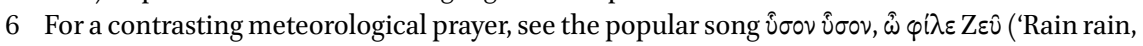
dear Zeus', Carm. Pop. fr. 8 PMG). The ingratiating nature of this prayer means that it is at best only indirectly relevant to the question whether the Greeks could ever be said to love Zeus: Aristotle, $M M$ 1208b30; Dodds (1951: 35); Lloyd-Jones ( ${ }^{2} 1983$ : 193 n. 34). 
Terms of affection and respect are often used in Aristophanes, as in other Greek authors, to mitigate face-threatening acts. ${ }^{7}$ The most common in his plays are $\varphi$ i $\lambda \varepsilon$ ('friend'), $\varphi$ í $\lambda \tau \alpha \tau \varepsilon$ ('dearest'), $\alpha \gamma \alpha \theta \dot{\varepsilon}$ ('good'), and $\delta \alpha \mu o ́ v v \varepsilon$ ('marvellous'). The similarity of their illocutionary force is more significant than any difference in lexical meaning. ${ }^{8}$ They are especially common in Aristophanes with directives (Ach. 296, 305, 929, 1020; Eq. 240, 86o; Nub. 38, 1138; Vesp. 962, 967, 1052, 1149, 1152; Av. 206, 846, 961, 1436, 1638; Lys. 95, 140, 762, 883, 945; Thesm. 64; Ran. 44, 175, 835, 997, 1227; Eccl. 564, 784; Plut. 360), but also occur with other face-threatening acts such as disagreement (Eq. 843), rebuke (Nub. 816; Vesp. 1145), and rejection ( $\operatorname{Pax} 1238 ; A v .1577 ; E c c l .784)$.

The question then arises of how we can distinguish between positive politeness and straightforward expressions of affection where the locutionary force of the friendship terms is to be taken at face value. ${ }^{9}$ Brown and Levinson remark, 'the linguistic realizations of positive politeness are in many respects simply representative of the normal linguistic behaviour between intimates'; compare, more concisely, 'Positive-politeness utterances are used as a kind of metaphorical extension of intimacy'.10 They argue that positive politeness is distinguished by an element of exaggeration. It is not always easy to distinguish what is exaggerated from what is appropriate, but in cases like that of Paphlagon we have other evidence for the speaker's real attitude which suggests that his expression of affection is indeed exaggerated. Another clue is the proximity of a face-threatening act. Richard Watts quotes the (fictional) utterance 'Jim, you're really good at solving computer problems', which in itself is merely face-enhancing, but can readily be analysed as polite when followed by 'I wonder if you could just help me with a little formatting problem I've got'.11

Similar issues arise in a more developed form in the following passage:

7 Dickey (1996: 107-145, 274-283) calls these vocatives 'friendship terms,' which will be followed here although some of them appear to be complimentary rather than friendly.

8 Sommerstein (1977: 272) alleges that Aristophanes' characters employ $\delta \alpha \mu \mu^{\prime} v \varepsilon \varepsilon$ 'in rebuking, admonishing, or pleading with a respected person, always with an element of deference', but that is clearly not true of (e.g.) Ran. 175 where Dionysus is bargaining with a corpse to act as a porter to the underworld. Contrast Dickey (1996: 109): 'polite or affectionate,' treated as equivalent; Watts (2003: 1217); Willi (2003: 166).

10 Brown and Levinson $\left({ }^{2} 1987: 101,102\right)$.

11 Watts (2003: 89). 
[2] Aristophanes Clouds 80-89

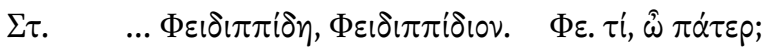

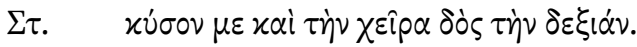

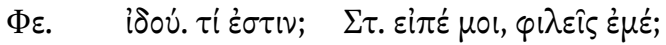

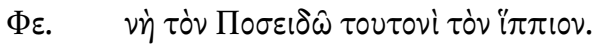

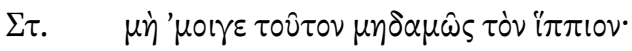

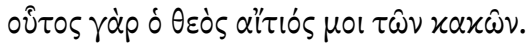

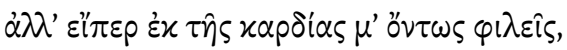

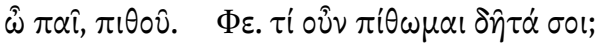

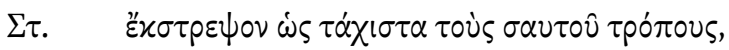

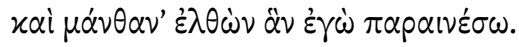

St. $\quad$... Pheidippides, little Pheidippides!

Phei. What, father?

St. Kiss me and give me your right hand.

Phei. There. What is it?

St. Tell me, do you love me?

Phei. Yes, by Poseidon here, the god of horses.

St. Don't mention the god of horses to me, for he is the cause of my troubles. But, my son, if you really love me from your heart, obey me.

Phei. How should I obey you then?

St. Change your ways at once, and go and learn what I recommend.

Strepsiades wants to evade his debts by persuading his extravagant son Pheidippides, who despises intellectual pursuits, to give up horses and learn the sophistic art of clever speaking. He has made clear in the immediately preceding lines $\left(75^{-77}\right)$ that his affectionate behaviour has a specific purpose, and it leads up to a significant face-threatening act in the last two lines of this passage. The scene ends with threats and insults when Pheidippides refuses to co-operate (121-123). Unusually sensitive requests have polite pre-expansion

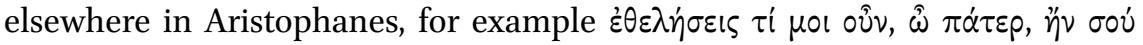
$\tau \iota \delta \varepsilon \eta \theta \hat{\omega}$; ('Would you be willing to give me something, father, if I ask you?',

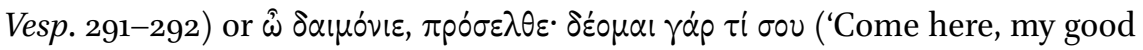
man, I have something to ask you', Ran. 44). Strepsiades' positive-politeness gambit 'if you really love me from your heart' (86) is used elsewhere in Aris-

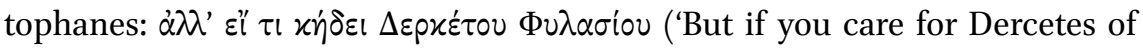

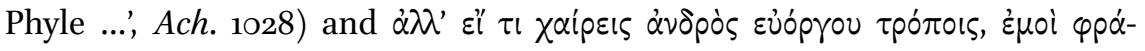


бov ('But if you rejoice in the character of a good-tempered man, tell me', Plut. 61-62). ${ }^{12}$

The low $\mathrm{P}(\mathrm{S})$ implied by Strepsiades' politeness strategy expresses the humility of his approach to Pheidippides. ${ }^{13}$ Aristophanes' heroes are ordinary people faced with challenges which require them to approach important or intimidating individuals who might assist their plans, and their manner in doing so is accordingly deferential. Their use of supplicatory language is particularly

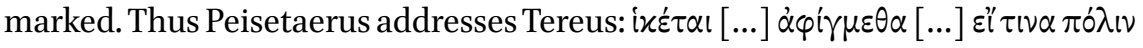

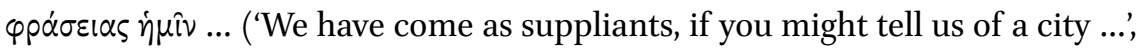
Av. 120-122). Euripides approaches Agathon in a similar fashion: $\bar{y} \gamma \dot{\omega} \delta \dot{\varepsilon} x \alpha \iota v \hat{\imath}$

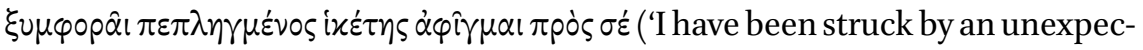
ted disaster, and have come to you as a suppliant', Thesm. 179-180). Agathon's initial response is favourable, but his attitude soon changes when he hears the actual request. ${ }^{14}$

Passage [2] seems to be an example not just of politeness but of overpoliteness. Strepsiades has made clear that his affectionate tone is manipulative (75-77), and he introduces it with the metapragmatic comment that he wants to treat Pheidippides 'most pleasantly' ( sequence of pre-expansions is appropriate only to an extremely face-threatening request (e.g. Eur. Tro. 48-58), and in terms of Greek cultural norms it is difficult to imagine any normal situation in which Strepsiades' level of politeness would be appropriate for a father addressing his son. Over-politeness might be expected to attract adverse comment from third parties or from the hearer, but in this case no-one else is present and it is part of the joke that the arrogant Pheidippides is not surprised by his father addressing him in

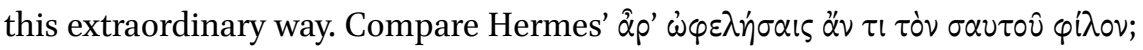
('Would you help your friend?', Plut. 1134), where the joke is that his request is incongruously ingratiating for a god addressing a slave. Brown and Levinson's theory focuses on generating politeness, but using it for literary interpretation requires reverse-engineering in order to determine the implications of the

12 Eúópyou ('good-tempered') is Schaefer's conjecture for codd. Eủóprou ('keeping his oath').

$13 \mathrm{P}(\mathrm{S})=$ the relative power of the speaker, $\mathrm{P}(\mathrm{H})=$ the relative power of the hearer, $\mathrm{D}=$ the social distance between them, and $\mathrm{R}=$ the absolute ranking of an imposition in a particular culture. For these abbreviations, and the sociological variables to which they refer, see Brown and Levinson $\left({ }^{2} 1987\right.$ : 15-17, 74-84).

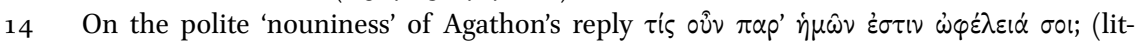
erally, 'What assistance is there from us for you?', Thesm. 183), see Lloyd (2009: 188189). 
politeness strategy in a particular text. In this case, we can deduce from Strepsiades' over-politeness that he is humbling himself, as Aristophanes' heroes often do early in a play. This shows the unusual balance of power in their relationship which is due to the habits and attitudes which Pheidippides has derived from his aristocratic mother.

Brown and Levinson themselves include over-politeness under the heading 'Trying to re-rank $\mathrm{R}, \mathrm{P}$, or $\mathrm{D}$ ', in particular the use of a non-expectable strategy to insult: 'if $\mathrm{S}$ is too [original emphasis] polite (overestimating $\mathrm{W}_{\mathrm{x}}$ ) he may insult $\mathrm{H}$ (or simply wound his feelings) by implying that $\mathrm{D}$ or $\mathrm{P}(\mathrm{H})$ is greater than it is'. ${ }^{15}$ Their example is of a man switching from the $\mathrm{T}$ pronoun to the more formal $\mathrm{V}$ when challenging a former comrade to a duel. Vimala Herman (1995: 241) cites a similar strategy in Oscar Wilde's The Importance of Being Earnest: 'initial friendliness is displayed in the change of address forms, mutually agreed upon, from the formal "Miss Cardew", "Miss Fairfax" to "Cecily" and "Gwendolen". When antagonism owing to misunderstanding occurs between them, the change in address forms to formality signals distance, while the highly indirect "polite" methods of disagreement used regarding which of them is actually engaged to Ernest constructs not comity, but an acute frostiness in their relations'. It is not common in Aristophanes for over-politeness to be perceived as inappropriate or sarcastic, although the Sausage-Seller wrongly interprets Demosthenes' effusive approach in these terms: $\tau i$ [...] $x \alpha \tau \alpha \gamma \varepsilon \lambda \hat{\alpha} \iota \zeta ;$ ('Why are you making fun of me?', Eq. $160-161) .{ }^{16}$ One possible interpretation of the over-politeness of the shopkeeper described by Dickey (2016: 202-203), 'So sorry to trouble you, but do you suppose you could possibly pay twelve pounds and forty-five pence for that, please?', rather than (e.g.) 'That'll be twelve pound forty-five, then', is that that the customer was delaying unreasonably in paying, or even making to leave the shop without paying at all. The shopkeeper sarcastically adjusts the politeness of the request to an exaggerated assessment of R.

The most elaborate example of politeness in Aristophanes is the scene in Acharnians in which Dicaeopolis tries to obtain from Euripides the costume and props of a suitably pathetic character in order to make a speech to the bellicose Acharnians justifying his private peace with Sparta (Ach. 414-479). He begins as follows:

\footnotetext{
15 Brown and Levinson ( $\left.{ }^{2} 1987: 229-230\right) . \mathrm{W}_{\mathrm{x}}=$ the 'weightiness' of the face-threatening act $x$.

16 For modern examples, see Culpeper (2008: 24-27, 2011: 100-103, 178-180).
} 


\section{[3] Aristophanes Acharnians 414-417}

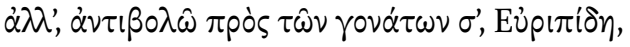

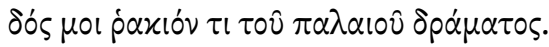

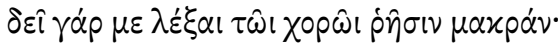
$\alpha u ̛ \tau \eta \delta \dot{\varepsilon} \theta \dot{\alpha} v \alpha \tau 0 \nu, \hat{\eta} \nu \varkappa \alpha \kappa \hat{\omega} \varsigma \lambda \varepsilon^{\prime} \xi \omega, \varphi \varepsilon \dot{\varepsilon} \rho \varepsilon$.

I beg you by your knees, Euripides, give me a bit of rag from that old play. I need to make a long speech to the chorus, and it means death if I speak badly.

Dicaeopolis is thinking of Telephus, but cannot remember his name and rejects four suggestions by Euripides before he hits on the right character. There is a series of insert expansions before he finally specifies Telephus in his request (430-431). A further negative politeness technique here is to describe the overwhelming reasons for the imposition; compare Euripides' approach to Agathon (Thesm. 179-180, quoted above). ${ }^{17}$ Supplicatory language is common in

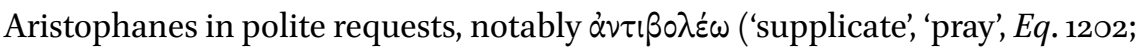
Nub. 155, 224, 314; Vesp. 1388; Pax 87, 376-377, 400; Av. 207; Plut. 103, 444), ixع$\tau \varepsilon \dot{\omega} \omega$ ('supplicate', 'pray', Ran. 167, 299; Eccl. 970), and $\pi$ pòs $\tau \hat{\omega} \nu \theta \varepsilon \hat{\omega} \nu$ ('by the gods': Vesp. 76o; Plut. 1176). The literal meaning of these words is stronger in some cases than in others, but sometimes they mean little more than 'please. 18

Dicaeopolis then requests a further item of Telephus' costume:

[4] Aristophanes Acharnians 437-439

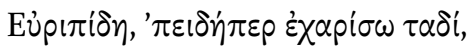
$x \dot{\alpha} x \varepsilon i v \alpha \dot{\alpha} \mu o l \delta o ̀ s \tau \dot{\alpha} x \dot{\lambda} \lambda \circ v \theta \alpha \tau \hat{\omega} v \dot{\rho} \alpha x \hat{\omega} v$,

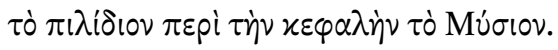

Euripides, since you have done me this favour, give me also what goes with the rags, the little Mysian felt cap for my head.

Euripides is happy to oblige with this too, and his favourable response indicates that Dicaeopolis is still being acceptably polite. The da-quia-dedisti ('give

\footnotetext{
17 Cf. Brown and Levinson ( $\left.{ }^{2} 1987: 189\right)$.

18 Cf. Willi (2003: 25); Lloyd (2006: 243).
} 
because you have given') formula, familiar in prayers, is a positive politeness gambit, establishing common ground and good will. ${ }^{19}$

In the rest of the scene, Dicaeopolis combines politeness with increasingly intrusive demands. He gives a metapragmatic signal of his more face-

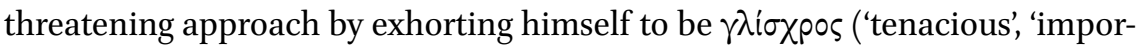
tunate', 452). Euripides asks him why he needs a little basket, and he replies

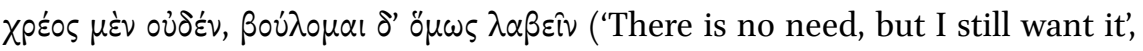
455), which is in notable contrast with the overwhelming need he had politely expressed earlier (417). The climax comes with the following lines:

\section{[5] Aristophanes Acharnians 475-478}

\section{Eủpı

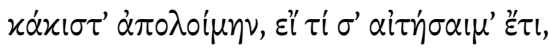

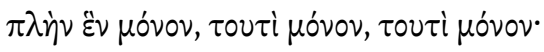

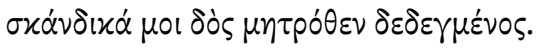

My sweetest and dearest little Euripides, may I perish most wretchedly if I ask you for anything else, except one thing alone, this alone, this alone: give me some chervil from your mother.

The endearments in line 475 are a positive politeness feature, more exaggerated than those in 404 and 467 , but his politeness is mostly negative. For minimising the imposition $(458,462-463,477)$, compare Strepsiades' $\hat{\omega} \delta \dot{\varepsilon} \sigma \pi \circ v \alpha$,

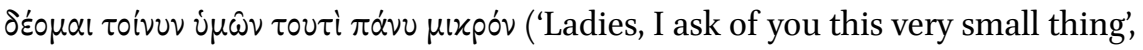

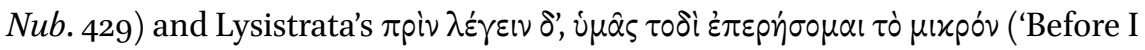
speak, I shall ask you this small question', Lys. 97-98). ${ }^{20}$ Dicaeopolis' exaggerated politeness is itself face-threatening, even without the concluding allusion to Euripides' mother's alleged trade as greengrocer. Euripides responds with increasing impatience, and Dicaeopolis is characterised as $\lambda v \pi \eta \rho^{\circ} \varsigma$ ('annoying',

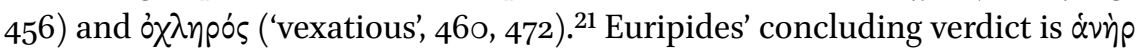

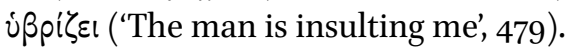

\footnotetext{
19 Pulleyn (1997: 32) discusses the same strategy in line 405. Contrast the da-quia-dedi ('give because I have given') strategy at $\operatorname{Pax} 384-388$.

20 The diminutive in Wealth's description of someone 'asking to borrow a small sum of

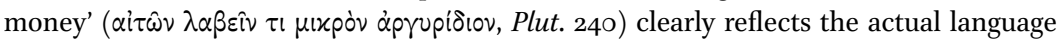
of the request.

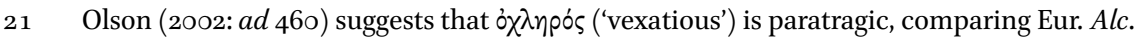
540, Hel. $45^{2}$.
} 
It is obvious from halfway through this passage (line 447) that, for all his use of polite expressions, Dicaeopolis is increasingly impolite. Discursive theorists like Richard Watts argue that 'no linguistic structures are inherently polite.'22 This is sometimes presented as an objection to Brown and Levinson's theory, although they do in fact take account of such situations, e.g. 'our system "overgenerates" and needs to be complemented with a set of "filters" that check that a chosen utterance form has no impolite implicatures for other reasons. ${ }^{23}$ In this case, a filter might be that utterances which are formally polite can threaten negative face if they are disproportionately extended. This would apply to the example given by Dickey (2016: 202): 'a child who wants an ice-cream cone might say "Please, please, please, Mummy, please gimme ice cream, please, please!"; in this request "please" makes it harder, not easier, for the mother to refuse the child's demands'. Geoffrey Leech offers a qualified defence of his much-criticised notion of absolute politeness, which he now terms 'pragmalinguistic' as opposed to 'sociopragmatic' politeness, although he only commits himself to recognising relative degrees of politeness in the absence of context, e.g. 'Thank you very much' is invariably more polite than 'Thank you'.24 The Acharnians passage discussed above seems to show that there is not necessarily a contradiction between individual expressions being polite in themselves while being used as part of an overall strategy which is not polite, and indeed the comic effect here depends on the ostensible politeness of Dicaeopolis' approach.

This passage resembles others in Aristophanes in which the hero approaches someone to help him, often an expert in the field in question. The hero is usually very polite, as noted above. There is however more at stake in Dicaeopolis' approach to Euripides. This hero is uniquely close to Aristophanes himself, and the politeness strategy in the scene reflects the dramatist's own complex relationship with Euripides. ${ }^{25}$ Dicaeopolis' negative politeness expresses deference to a distinguished playwright, and in particular serves to establish $\mathrm{D}$ and $\mathrm{P}(\mathrm{H})$. The positive politeness is also respectful, but implies a greater degree of intimacy. The overt face threat, and in particular Dicaeopolis' irrepressible persistence, conveys that aspect of Aristophanes' relationship with Euripides which

\footnotetext{
22 Watts (2003: 168).

23 Brown and Levinson ( $\left.{ }^{2} 1987: 11\right)$; cf. 22: 'politeness is implicated [original emphasis] by the semantic structure of the whole utterance, not communicated by "markers" or "mitigators" in a simple signalling fashion which can be quantified'.

24 Leech (2014: 15-17); he reasonably observes that ironic politeness is a second-order phenomenon which is not covered by this principle (2014: 232-238).

25 See (e.g.) Foley (1988).
} 
is not respectful at all, but rather focuses on mundane and disreputable features of his plays such as heroes dressed in rags. Dicaeopolis' politeness strategy combines elements which could hardly be found together in any normal social interaction, but which vividly express the complexity of Aristophanes' attitude to Euripides.

Politeness implies $\mathrm{P}(\mathrm{S})$ or $\mathrm{P}(\mathrm{H})$ in ways which Aristophanes can exploit for comic incongruity. Both are at stake at the end of Birds, when the gods are obliged to send a delegation to seek terms with the now all-powerful Peis-

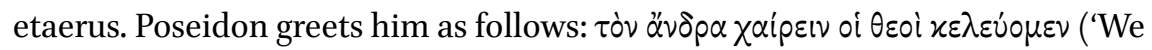
gods bid you greeting', $A v .1581$ ). This doubtless reflects the formal language of diplomacy, in which there is face vulnerability on both sides, and it is amusing that such an important god needs to be so polite to a mortal. Socrates' 3 rdperson greeting $\Sigma \tau p \varepsilon \psi 1 \alpha \dot{\delta} \eta \nu \dot{\alpha} \sigma \pi \alpha \dot{\zeta} \sigma \mu \alpha$ l ('I greet Strepsiades', Nub. 1145; cf. Eur. Tro. 48-50) has a similar effect. Strepsiades had earlier incurred Socrates' contempt for his stupidity (Nub. 789-79o), but now we hear the dignified tones of a teacher addressing the father of a student at the end of an expensive course of study. Strepsiades responds in a similarly gracious style (1146-1147). The formal greeting of the chorus to the Spartan delegates $\alpha^{\prime} v \delta \rho \varepsilon \varsigma \Lambda \alpha \alpha \omega \nu \varepsilon \varsigma, \pi \rho \hat{\omega} \tau \alpha \mu \varepsilon^{\prime} v \mu \mathrm{ol}$

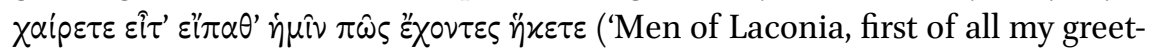
ings, and secondly tell us what brings you here', Lys. 1074-1075) is incongruous with their comically distressed state.

A rather different kind of incongruity may be seen in the following passage:

[6] Aristophanes Birds 1010-1011

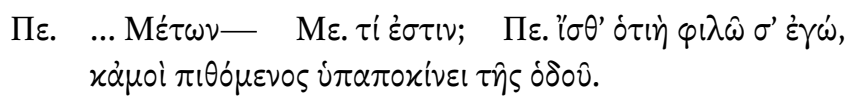

Pe. ... Meton-

Me. What is it?

Pe. Please understand that I like you: take my advice, and get out of the way.

The geometer Meton is one of the unwelcome visitors whom Peisetaerus expels from his new city. The introductory expression of affection is a positive-polite-

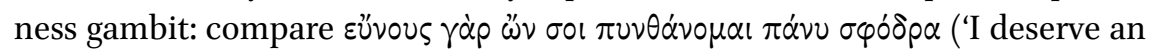
answer to my question because I am extremely well-disposed to you', Plut. 25).

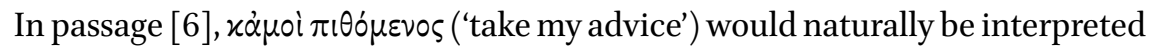
as the introduction to a friendly and constructive suggestion (cf. Ar. Vesp. 76o; 
Pl. Grg. 486c). What follows is a bluntly face-threatening order. Meton continues to speak as though he is receiving friendly advice, until he is threatened and then physically attacked before he manages to escape. He is identified as an $\alpha \lambda \alpha \zeta \omega^{\prime} \nu$ ('charlatan', 1016-1017), ${ }^{26}$ and his failure to recognise Peisetaerus' strategy exposes his lack of self-awareness. Jonathan Culpeper has discussed 'verbal formula mismatches' of this kind, and suggested that the ostensible politeness exacerbates the face threat. ${ }^{27}$ This is plausible, although there seems to be additional significance in Peisetaerus' use of this gambit. He affects rather a grand air in this part of the play, and polite forms of expression are an

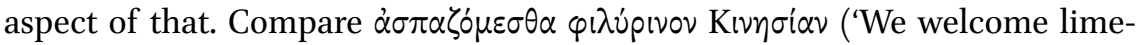
wood Cinesias', 1377), where the respectful greeting is combined with what seems to be an uncomplimentary reference to the poet's unhealthy appearance. $^{28}$

Peisetaerus' dismissal of Meton in Birds is typical of the way the comic hero treats unwelcome visitors after his triumph, and these passages are the most interesting examples of impoliteness in Aristophanes. As we have seen, the hero is often polite or even ingratiating in the earlier part of a play, and this expresses the low $\mathrm{P}(\mathrm{S})$ of an ordinary man trying to deal with overwhelming problems. The situation is reversed at the end of a play, where the hero is now in control and treats other people impolitely. This implies high $\mathrm{P}(\mathrm{S})$, demonstrating that he no longer needs to mitigate threats to the face of the hearer and that he is indeed in a position to aggravate them. ${ }^{29}$ This can involve actual or threatened physical violence, as when Strepsiades prods the Second Creditor with a goad as if he were a horse $(N u b .1298)$ or Peisetaerus threatens to rape Iris $\left(A v \cdot 1253^{-1256)}\right.$. More frequently, the hero subjects his victims to jokes and taunts, as when Trygaeus makes a series of insulting suggestions about uses to which the Arms-Dealer's wares could be put ( $P a x 1228,1242-1244,1262-1263$ ), or Dicaeopolis contrasts his tasty peacetime food with Lamachus' frugal campaign diet (Ach. 1115-1116).

The 'discursive turn' in politeness theory stresses the wider context of any given interaction, and in particular its ongoing evaluation by the participants. ${ }^{30}$

26 On the meaning of $\dot{\alpha} \lambda \alpha \zeta \dot{\omega} \omega$, see Dunbar (1995: ad 825).

27 Culpeper (2011: 174-178, 193). Leech (2014: 238) observes that the polite element tends to precede the impolite element in such cases.

28 See Dunbar (1995: $a d$ 1378) for discussion of the meaning of $\varphi$ i $\lambda$ úpเvov. Cf. 916, 1025-1026 for further examples of Peisetaerus' combination of politeness and abuse.

29 Cf. Brown and Levinson $\left({ }^{2} 1987: 69,97\right)$. On impoliteness and power generally, see Bousfield and Locher (2008).

$3^{\circ}$ Locher and Watts (2005) is fundamental; cf. Kádár and Haugh (2013: 36, with references to earlier discussions). 
A response by the addressee can give some indication of what should be regarded as polite or impolite, but is in itself only a personal opinion which does not necessarily reflect accepted social norms. Further illumination may come from the wider context, with third parties expressing their views and commenting on the interaction, but this rarely happens in Aristophanes. Another clue is if consistent terminology is used in similar situations. One word which is especially common as a description of the heroes' impoliteness is üßpis. ${ }^{31}$ This and cognate words are used of Dicaeopolis (Ach. 479, 1117), Strepsiades (Nub. 1299), Philocleon (Vesp. 1303, 1319, 1441), Trygaeus (Pax 1229, 1264), and Peisetaerus ( $A v$. 1259). The victims in these situations often also say 'you are mocking me' ( $\varkappa \alpha \tau \alpha \gamma \varepsilon \lambda \hat{\alpha} \iota \varsigma)$, sometimes as a question ('are you mocking me?') or directive ('stop mocking me!'). This word is used of Dicaeopolis (Ach. 1081, 1107; cf. 1126), Strepsiades (Nub. 1238), Philocleon (Vesp. 1406), Trygaeus (Pax 1245), and Peisetaerus (Av. 1407). $\sigma x \omega \dot{\omega} \pi \tau \omega$ has a similar meaning, and is used of Strepsiades (Nub. 1267) and Philocleon (Vesp. 1320). ${ }^{32}$ Some of the victims respond with threats of their own, especially summoning witnesses with a view to legal action (e.g. Ach. 926; Nub. 1297; Vesp. 1406-1408, 1417-1418, 1436; Pax 1119; Av. 1031, 1259; Plut. 932, 944-950). Brown and Levinson $\left({ }^{2} 1987: 69\right)$ write of cases 'where $S$ is vastly superior in power to $\mathrm{H}$, or can enlist audience support to destroy H's face without losing his own'. In the particular context of Aristophanic comedy, there is no effective internal audience and it is the implied audience in the theatre which endorses the heroes' behaviour.

Conversely, Aristophanes confirms Brown and Levinson's theory that baldon-record directives can be polite in certain contexts. Invitations are in the interests of the hearer, and thus do not need mitigation, e.g. $\varepsilon \pi i \quad \delta \varepsilon i \pi v o v \tau \alpha \chi \dot{\nu}$

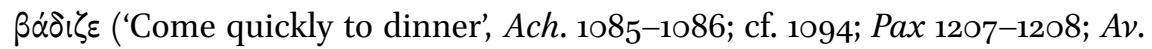
640-642; Ran. 503, 507, 512, 517, 669; Eccl. 695). Other examples of unredressed imperatives to the hearer's advantage include $N u b .189$ ('Don't worry about that!') and Vesp. 248 ('Be careful!'). Bald-on-record imperatives are also not impolite in task orientation (e.g. Pax 1-2), emergencies (e.g. Vesp. 829), and commands to slaves (e.g. Vesp. 138, 529). There is no evidence in any of these cases that the hearers regarded the bald-on-record directives as impolite.

31 Olson (2002: ad 479) defines üßpı as 'outrageously hostile behaviour designed not so much to injure as to humiliate its victim', with references to other discussions. Cf. 'Insults' in Baron (2020).

32 Cf. $\mu \grave{\eta} \sigma \varkappa \hat{\omega} \pi \tau \varepsilon \dot{\varepsilon} \mu \varepsilon$, ('Do not mock me!') at Ran. 96; Eccl. 1005, 1074. 
Wealth ends, as do Acharnians, Peace, and Birds, with a series of scenes involving characters whose circumstances have changed for better or worse as a result of the new dispensation brought about by the hero. Chremylus has cured the god Wealth of his blindness, so that he is now able to bestow his favours with more discrimination. The first character to appear in this sequence is a just man who has regained the prosperity which he had lost through helping his friends. A sycophant then complains that he has fallen into poverty, and is driven off with insults and blows. ${ }^{33}$ In describing what is being done to him, he uses what we have seen to be the three key terms for impolite behaviour by the hero at the end of a play, although in this case Chremylus

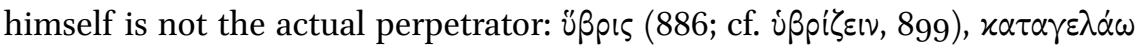
(880), and $\sigma x \dot{\omega} \pi \tau \omega$ (886). ${ }^{34}$ Insulting language culminates in violence (928943), and the Sycophant threatens retaliatory legal action as he departs (944950).

The third character to appear is an old woman, who addresses the chorus as follows:

[7] Aristophanes Wealth 959-961

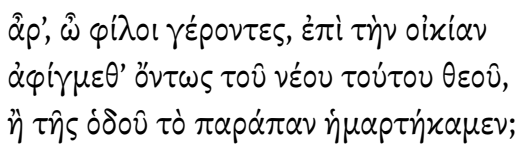

Dear old men, have we really arrived at the house of this new god, or have we completely missed the way?

The Old Woman is characterised by her polite manner of speaking. She uses positive politeness by addressing the old men as $\varphi$ i $\lambda$ ol ('dear'), and uses the vocative of $\varphi$ ì $\lambda$ os ('dear') and $\varphi$ í $\lambda \tau \alpha \tau \circ$ ('dearest') on three other occasions (967, $1025,1034)$. She also uses negative politeness by framing her question in such a way that the preferred answer 'yes' can truthfully be given whether or not this is in fact the right house. Compare the words of the chorus to Cassandra (Aesch.

33 The word 'sycophant' is not used here in its usual English sense, but as an equivalent of

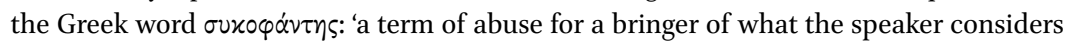
unjustified charges from discreditable motives' (Dunbar 1995: ad 674, with discussion and references).

34 Olson (1989: 197 n. 15) gives the leading role in the assault on the Sycophant to the Just Man, while Sommerstein (2001: ad 926-934) hesitantly prefers Carion (cf. 20o1: ad 824). 


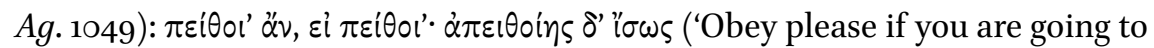
obey, but perhaps you will disobey'); also Hom. Il. 14.19o-192, 15.201-204. Potential optatives are also used in these introductory questions, sometimes in the

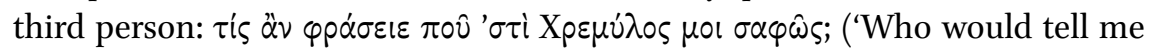

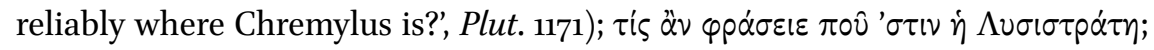

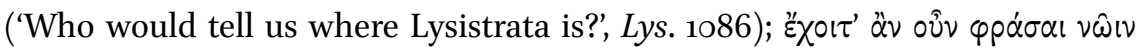

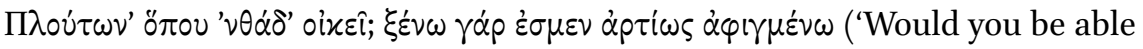
to tell us where around here Pluto lives? We are strangers who have just arrived', Ran. $431-433){ }^{35}$

The chorus-leader's response is not so easy to assess:

[8] Aristophanes Wealth $962-963$

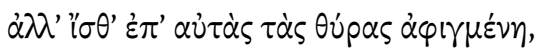

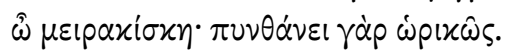

You have come right to his door, young woman—for you ask youthfully.

The first line here is a formulaic polite response. ${ }^{36}$ The chorus-leader's ironic comment on the Old Woman's 'youthfulness' must relate to her appearance or intonation rather than to the actual content of what she says, which is polite but not otherwise remarkable, unless he is provoked by her addressing the chorus as 'dear old men'. The chorus-leader's reply seems to be another example of verbal formula mismatch, as it can hardly be polite to allude to her attempt to look younger than she really is. Compare $\mathrm{Nub} .35^{8-363}$, where disrespectful remarks take the place of the expected compliments after the Clouds' initially polite greeting to Socrates. The chorus-leader's impoliteness here foreshadows the way the Old Woman is treated in the rest of the scene.

Her complaint is that a young man to whom she has been giving frequent and substantial gifts rejects her now that he is rich. Chremylus initially assumes that she resents the new dispensation because she has behaved unjustly (Plut. 970-972). This appears not to be the case, as she denies the offences which he suggests she might have committed, and does not seem otherwise to be partic-

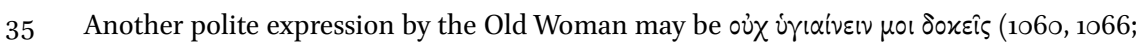
lit. 'you do not seem to me to be healthy', i.e. 'in your right mind'; cf. the ladylike Iris at $A v$. 1214).

36 Cf. Ran. 436. On the similar exchange at Soph. El. 66o-662, see Lloyd (2006: 233). 
ularly bad. ${ }^{37}$ In any case, she does not complain about having lost her wealth, and thus does not resemble the Sycophant in being a bad person who is now deservedly poor. On the other hand, the Young Man does not seem to deserve his new wealth. The previous scene suggested that the result of Wealth regaining his sight is that good men become rich while bad men lose their ill-gotten gains, and it has often been suggested that this scene implies a different plot in which everyone becomes rich. ${ }^{38}$

MacDowell sees no redeeming features in the Young Man: 'He was making money by disgraceful means, and now that he no longer needs to do so he is drunken and boorish'. ${ }^{39}$ Sommerstein defends him, but does not distinguish between his behaviour before and after becoming rich: 'With no marketable asset except his good looks, he has been forced into a life that he finds repugnant, and his reaction when able to escape is natural. ${ }^{40}$ The Old Woman, however, stresses the change in his behaviour (994), as does Chremylus (10031005, 1047-1048), although he takes a different view of it. Chremylus criticises his treatment of the Old Woman and insists that he should continue his relationship with her $(1071-1087,1201) \cdot{ }^{41}$ On the other hand, there is no particular reason to find fault with his behaviour in the past. The Old Woman gives a favourable account of his character (975-979), and his language as she describes it is impressively eloquent. Wealth himself notes that people become bad when they become rich (107-109, 567-570), and the Young Man seems to be an example.

He is often described as a gigolo, and some scholars take rather a narrow view of this profession, e.g. 'it becomes clear that he is a gigolo who has been giving her sexual satisfaction in return for payment'.42 The Oxford English Dictionary offers a less specific definition: 'a young man supported financially by an older woman in return for his attentions'. This gives a more accurate impression of the relationship as this woman describes it. The following passage is an excerpt from her conversation with Chremylus:

37 Halliwell (1998: 208) reasonably remarks 'the woman is not a convincingly moral target'. MacDowell (1995: 341) is more censorious.

38 On the 'double plot' in Wealth, see e.g. Flashar (1967: 161 = 1996: 318); Konstan and Dillon (1981); Olson (1990: 223-224).

39 MacDowell (1995: 341); cf. Flashar (1967: $170=1996:$ 324-325).

40 Sommerstein (1984: 324-325 = 1996: 267-268).

41 Chremylus twice expresses approval of the Young Man's behaviour (1003-1005, 10231024), but only in the context of a cynical interpretation of it which has the rhetorical purpose of undercutting the Old Woman's romantic view.

MacDowell (1995: 340); cf. Halliwell (1998: 207). 
[9] Aristophanes Wealth 1018-1024

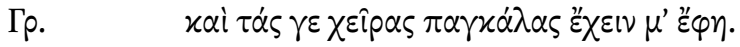

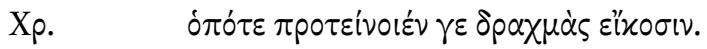

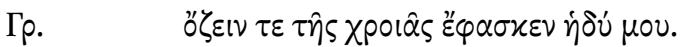

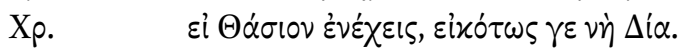

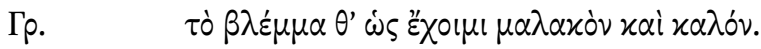

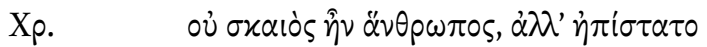

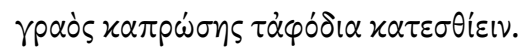

Old Wom. He used to say that I had the most beautiful hands.

Chr. At any rate when they were holding out twenty drachmas.

Old Wom. And he would say that my skin smelled sweet.

Chr. Very likely, by Zeus, if you were pouring out Thasian wine.

Old Wom. And that I had a gentle and beautiful expression.

Chr. The man was not stupid: he knew how to eat up the wealth of an old sow on heat.

The Old Woman seems to take pleasure in being flattered and describes what she does for the Young Man in terms of gifts rather than payment. Chremylus, by contrast, believes that everything good depends on money (144-146), and relentlessly reduces the relationship to a transaction in which fine words are mere camouflage for the purchase of sex..$^{43}$ Sommerstein further suggests that the scene contains a number of sexual euphemisms. The Old Woman introduces her account of the relationship as follows:

[10] Aristophanes Wealth $975^{-978}$

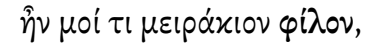

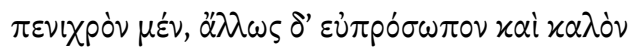

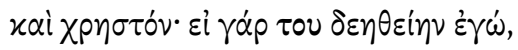

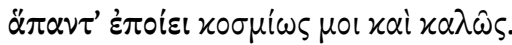

I had a young friend, poor but good-looking and honourable and decent:if I wanted something, he would do everything for me dutifully and nicely.

Sommerstein detects three euphemisms in these lines:

43 On the importance of money in the play, see Olson (1990: 227-228). 


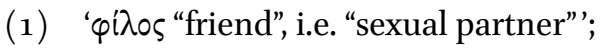

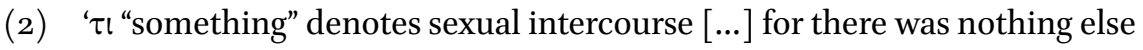
which the impoverished young man was capable of supplying to the elderly woman on whom he was sponging';

(3) " $\pi \circ \varepsilon \hat{\imath} \ddot{\alpha} \pi \alpha \nu \tau \alpha$ "do everything" means "copulate". 44

He finds two further sexual euphemisms in the scene. The Old Woman suggests that Wealth should force the Young Man to 'treat her well in return' for

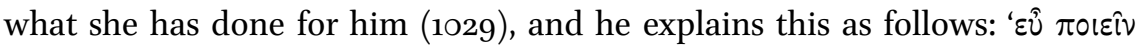
"do good to" means "copulate with". 45 The most plausible of these supposed euphemisms is the one spoken by the Young Man, when he asks if she would like to 'play with' him (1055); Sommerstein glosses $\pi$ pós $\mu \varepsilon \pi \alpha \hat{\sigma} \sigma \alpha$ l as 'have sexual intercourse with.' ${ }^{46}$ The Old Woman stresses her pleasure in the Young Man's flattering words, so it seems incorrect to say that he has nothing else to contribute, and Sommerstein's view of the relationship is unnecessarily reductive. Aristophanes was well able to portray sexual coercion in explicit terms, as we can see from Epigenes' interaction with the old women at Eccl. 877-1111. The

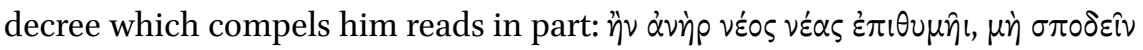

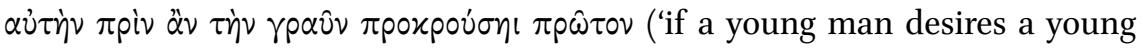
woman, he shall not bonk her until he screws an older woman first', 10151017).

James Davidson begins a subtle discussion of the important if sometimes elusive distinction between commodity exchange and the exchange of gifts with a quotation from Wealth:

[11] Aristophanes Wealth 149-159

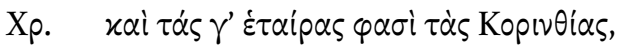

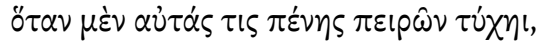

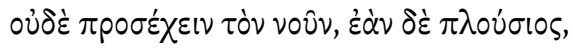

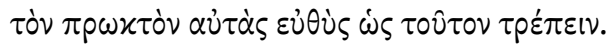

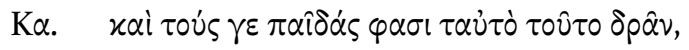

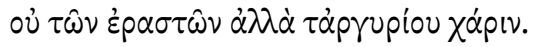

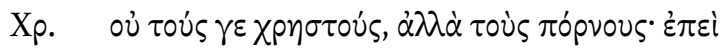

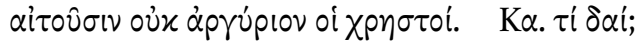

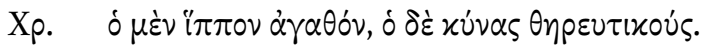

44 Sommerstein (2009: 93, 92, and 91); cf. Sommerstein (20o1: ad 977-978).

45 Sommerstein (2009: 87).

46 Sommerstein (2009: 92, 101). Contrast Dunbar (1995: ad 1098-1101), observing more cautiously '( $\sigma \nu \mu-) \pi \alpha i \zeta \varepsilon v$ sometimes has erotic overtones'. 


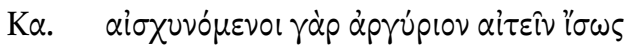

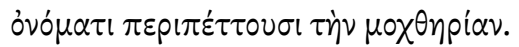

Chr. They do say those Corinthian hetaeras pay no attention whatsoever when a man without means tries to seduce them but if a rich man comes along they bend over and present themselves in no time at all.

Ca. Yes and they do say that boys do the same, not for the sake of their lovers, but for money.

Chr. Only the whores among them, not the decent ones; decent boys never ask for money.

Ca. And what do they ask for, then?

Chr. Well, one might ask for a thoroughbred, another might ask for a pack of hunting dogs.

Ca. That's just euphemism. They are ashamed to ask for money and gloss over their vice with words. ${ }^{47}$

Aristophanes presents the effect of the new dispensation on financially asymmetrical relationships and it would be interesting to consider a play in which the gender roles were reversed, as they doubtless were much more frequently in real life. Davidson (1997:124) writes: 'Misrecognition, beating about the bush, the avoidance of specifics, the uncertainty of favours in return, are all strategies designed to keep "friendship" out of the market-place.' One may add that they can all be interpreted in terms of politeness, and many members of the audience may well have preferred such transactions not to be too crudely bald-onrecord.

This chapter has focused on the politeness or over-politeness of Aristophanes' heroes in the earlier part of a play, which expresses the need of ordinary individuals to ingratiate themselves with those who are more powerful in order to gain their ends. Impoliteness conversely demonstrates their power after they have succeeded, an aspect of the comic fantasy of having no need to respect the face of others. The means by which Chremylus gains good fortune in Wealth do not require him to be ingratiating, but he takes full advantage of the freedom to be impolite at the end of the play, as does his slave Carion. The usual reversal from politeness to impoliteness is shown more clearly by the Young Man. Universal wealth does away with the need to earn money in potentially disagreeable ways, but also allows people to say whatever they like 
without having to worry about the consequences of being offensive. It could be argued that this is not an altogether good thing, and that Wealth, like others of Aristophanes' plays, is open to an 'ironic' interpretation which brings out the darker side of the hero's success. ${ }^{48}$ It is notable that the Old Woman is one of the most polite characters in Aristophanes, and gives the impression that it is gracious speech which she found most desirable in her lover. Chremylus may show little or no interest in politeness, and is indeed extremely offensive to her, but he eventually agrees that the Young Man has treated her unjustly (10711085), compels him to resume his relationship with her (1201), and includes her in the final procession. There is no evidence that Chremylus himself has experienced a conversion to the merits of polite speech in particular, but the scene with the Old Woman nevertheless explores with a subtlety that is unique in Aristophanes the question whether there is more to politeness than hypocrisy.

\section{Acknowledgements}

I am indebted to the editors for their helpful comments on an earlier draft of this chapter.

\section{References}

Barkhuizen, J.H., (1981), 'The Plutus of Aristophanes', Acta Classica 24, 17-22.

Baron, C. (ed.), (2020), The Herodotus Encyclopedia, Malden/Oxford/Chichester.

Bousfield, D. \& Locher, M.A. (eds.), (2008), Impoliteness in Language:Studies on its Interplay with Power in Theory and Practice, Berlin/New York.

Bowie, A.M., (1993), Aristophanes: Myth, Ritual and Comedy, Cambridge.

Brown, P. \& Levinson, S.C., ( ${ }^{2} 1987$ [1978]), Politeness: some Universals in Language Usage, Cambridge.

Culpeper, J., (2008), 'Reflections on Impoliteness, Relational Work and Power', in Bousfield \& Locher, $17-44$.

Culpeper, J., (2011), Impoliteness: Using Language to Cause Offence, Cambridge.

Davidson, J.N., (1997), Courtesans and Fishcakes: the Consuming Passions of Classical Athens, London.

48 For the 'ironic' interpretation of Wealth, see (e.g.) Flashar (1967); Barkhuizen (1981); Bowie (1993: 284-291). 
Dickey, E., (1996), Greek Forms of Address: from Herodotus to Lucian, Oxford.

Dickey, E., (2016), 'Politeness in Ancient Rome: Can it Help Us Evaluate Modern Politeness Theories?', Journal of Politeness Research 12, 197-220.

Dodds, E.R., (1951), The Greeks and the Irrational, Berkeley/Los Angeles.

Dunbar, N.V., (1995), Aristophanes, Birds, Oxford.

Flashar, H., (1967), 'Zur Eigenart des aristophanischen Spätwerks', Poetica 1, 154-175 (Engl. transl.: E. Segal [ed.], [1996], Oxford Readings in Aristophanes, Oxford, 314$328)$.

Foley, H.P., (1988), 'Tragedy and Politics in Aristophanes' Acharnians', Journal of Hellenic Studies 108, 33-47 (repr.: E. Segal [ed.], [1996], Oxford Readings in Aristophanes, Oxford, 117-142).

Halliwell, S., (1995), 'Forms of Address: Socratic Vocatives in Plato', in F. De Martino \& A.H. Sommerstein (eds.), Lo spettacolo delle voci, Part 2, Bari, 87-121.

Halliwell, S., (1998), Aristophanes, Birds and Other Plays, Oxford.

Herman, V., (1995), Dramatic Discourse: Dialogue as Interaction in Plays, London.

Kádár, D.Z. \& Haugh, M., (2013), Understanding Politeness, Cambridge.

Konstan, D. \& Dillon, M., (1981), 'The Ideology of Aristophanes' Wealth', American Journal of Philology 102, 371-394.

Leech, G., (2014), The Pragmatics of Politeness, Oxford.

Lloyd, M., (2006), 'Sophocles in the Light of Face-threat Politeness Theory', in I.J.F. de Jong \& A. Rijksbaron (eds.), Sophocles and the Greek Language: Aspects of Diction, Syntax and Pragmatics, Leiden/Boston, 225-239.

Lloyd, M., (2009), 'The Language of the Gods: Politeness in the Prologue of the Troades', in J.R.C. Cousland \& J.R. Hume (eds.), The Play of Texts and Fragments: Essays in Honour of Martin Cropp, Leiden/Boston, 183-192.

Lloyd-Jones, H., ( ${ }^{2} 1983$ [1971]), The Justice of Zeus, Berkeley/Los Angeles/London.

Locher, M.A. \& Watts, R.J., (2005), 'Politeness Theory and Relational Work', Journal of Politeness Research 1, 9-33.

MacDowell, D.M., (1995), Aristophanes and Athens: an Introduction to the Plays, Oxford.

Olson, S.D., (1989), 'Cario and the New World of Aristophanes' Plutus', Transactions of the American Philological Association 119, 193-199

Olson, S.D., (1990), 'Economics and Ideology in Aristophanes' Wealth', Harvard Studies in Classical Philology 93, 223-242.

Olson, S.D., (2002), Aristophanes, Acharnians, Oxford.

Pulleyn, S., (1997), Prayer in Greek Religion, Oxford.

Sommerstein, A.H., (1977), 'Notes on Aristophanes' Wasps', Classical Quarterly 27, 261277 .

Sommerstein, A.H., (1981), Aristophanes, Knights, Warminster.

Sommerstein, A.H., (1984), 'Aristophanes and the Demon Poverty', Classical Quarterly 
34, 314-333 (revised repr.: E. Segal [ed.], [1996], Oxford Readings in Aristophanes, Oxford, 252-281).

Sommerstein, A.H., (2001), Aristophanes, Wealth, Warminster.

Sommerstein, A.H., (2009), Talking about Laughter and Other Studies in Greek Comedy, Oxford.

Watts, R.J., (2003). Politeness, Cambridge.

Willi, A., (2003), The Languages of Aristophanes: Aspects of Linguistic Variation in Classical Attic Greek, Oxford.

Wilson, N.G., (2007), Aristophanis fabulae, Oxford. 


\title{
Developments in Politeness from Aristophanes to Menander and Beyond
}

\author{
Peter Barrios-Lech
}

\section{$\mathbf{1}$ \\ Introduction: Developments in Politeness from the Fifth to the} Third Centuries BCE

My aim is to describe developments in the polite language of late fifth century BCE Athens, when Aristophanes wrote, to the time when Menander was active (early third century BCE). By 'polite language,' I mean those expressions, routines, and scripts by which a speaker expresses consideration for the other. They are an ubiquitous part of our own daily language use. Polite expressions (in English, 'please'; 'can you + verb'); routines (for instance, facilitating closure to a conversation); and scripts (enabling predictable structure to even the most informal talk); these provide quarry for students of politeness because they demonstrate how people express, negotiate and manage the sometimes unpredictable terrain of face-to-face interaction. And this polite language, so defined, changes over time, just as the language's phonology, morphology, or syntax.

Now, Aristophanes wrote when Athenian democracy was in full bloom. In fifth-century Athens, every citizen enjoyed the right to speak his mind in assembly and he benefitted from legal protections. The reforms of Cleisthenes had succeeded to some extent in eliminating distinctions of wealth or family background as a meaningful basis of political involvement. Any violenceverbal or physical_-done to a free Athenian citizen was $\ddot{\beta} \beta \iota \varsigma$, an actionable offense. Menander wrote when democracy was effectively dead, a Macedonian garrison ensuring order in the polis. Is it possible that the death of democracy produced changes in the polite language of Classical Athens?

Answering such a question might, at first sight, seem challenging. We cannot eavesdrop on the gossip of the fishmonger with his client in the agora of fifth-century Athens; nor hear two Athenians wrangling about the quality of Sophocles' recent production; still less can we question them, like modern-day linguists, about any polite usages peppering their speech. Spontaneous conversation and questionnaires, however, are precisely the forms of evidence used by sociolinguists of modern languages. What evidence do Classicists have available?

We have access to text-genres that capture living voices in conversation (dialogue, drama, epistles). We also have the ancients' comments-often casual, 
obiter dicta - on 'pragmatic' characteristics of certain expressions; for instance, whether the imperative was indeed felt to be rude. Parallels from modern languages are helpful, as long as we do not equate these parallelisms with the ancient phenomena. In doing so we risk 'familiarising' the politeness of the ancients, and so effacing how alien to us that politeness may be.

In fact, we, as students of ancient politeness, are not that badly off compared to our peers who study modern languages. As Michael Lloyd (2004: 75) points out:

Literary dialogue has the advantage of being completely transparent in terms of context. All relevant factors are in principle available for anyone to test. Experimental data, by contrast, are inevitably incomplete and opaque, as well as being subject to distortion by the prejudices of the investigator or the artificial nature of the experiment.

Here we think of the 'Observer's Paradox': that is, we want spontaneously produced speech, but the presence of the observer inevitably elicits the opposite. Labov famously found this when researching how members from various social classes produced a certain phonological variable. He found that members from the working class, when questioned by him, would assume a higher register of speech (Labov 1972: 61, 209). Questionnaires and role-plays are also problematic each in their own way. For instance, the questionnaire-prompt, including description of the real-world context, might influence the respondent's answer; and his or her written response might be more formal than a spoken one (Márquez-Reiter 2000: 73). ${ }^{1}$

So we have texts that imitate dialogue, dialogue which, however artificial compared to spontaneous conversation, allows the observer to isolate all relevant variables: speaker and addressee status, context, both global (genre), and local (specific topic; the surrounding 'co-text'); and the social and historical matrix giving rise to the text. Besides, students of ancient Greek politeness have plenty of data at their disposal: the corpus of Classical Greek-and beyond. We can take a snapshot, say, a synchronic study of ancient Greek politeness in the fifth century $\mathrm{BCE}$, relying mainly on dramatic texts, or we can view the whole from a bird's eye perspective, as we will try to do: taking in developments

1 An example of a questionnaire prompt from Márquez-Reiter (2000: 73) illustrates this: 'You missed a lecture yesterday and would like to borrow the notes from a class mate/ You:

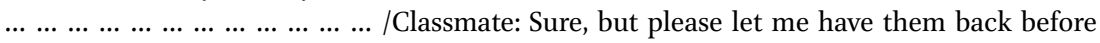
the lecture next week.' Note also that the Classmate's answer-unknowable in an actual conversation-might also condition the response. 
over the course of a century and a half, from the late fifth to the early third centuries BCE in Athens.

In this contribution to the study of ancient Greek 'language of politeness', I focus on one particular category of data, the directive (essentially, commands and requests), drawn from the plays of Aristophanes, Menander, Hellenistic Mime, and one Platonic dialogue (the Cratylus). These authors-Aristophanes, Menander, Herodas (contemporary with Theocritus and mime-writer) and Plato-did not have the same goals that we do, and this is an advantage for us. While theirs was to entertain and edify audiences and readers, they routinely overlook the kinds of linguistic detail that we are interested in: perfunctory salutations, conversation closings and pre-closings, dialogue transition devices, and, of importance for us, routine requests and commands.

Now it is true that some authors-like Menander and Xenophon-were happy to repeat the same formulae over and over again. The repetition of conversational formulae and colloquial expressions is also an advantage for the researcher attempting to recover the polite language of the Athenians. But other authors, like Plato and Homer, aim to vary such expressions. ${ }^{2}$ So our data, it must be said, come from authors disparate in style and in their relation to the spoken idiom.

Can we turn this difference in authorial style to our advantage? To anticipate the description of our corpus, most of our data will come from Aristophanes and Menander. There could not exist two more different playwrights. Plutarch famously wrote on those differences, simultaneously expressing his distaste, if not contempt for Aristophanes. To take an example, Menander suits his language to context; Aristophanes does not, according to Plutarch:

\section{[1] Plutarch Comparison of Aristophanes and Menander 853b5-8}

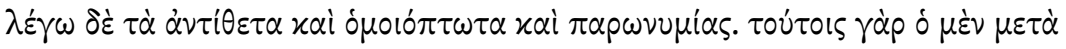

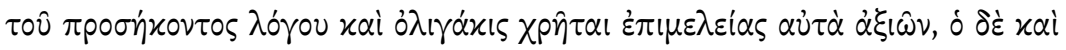

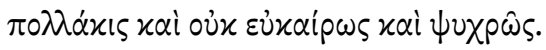

I'm talking about antitheses and successive words with the similar endings; puns. Menander, deeming their usage worth careful attention, employs them in suitable contexts, and infrequently. But Aristophanes uses them frequently, not at the right moment, and insipidly.

2 Dickey (2016a: 247-248). 
And Plutarch distinguishes the comic poets in other ways. ${ }^{3}$ Although Plutarch is, of course, biased, no-one will dispute that these two authors have divergent styles. Each wrote at a different historical moment, under a different regime, and in a different genre. Suppose, then, a pattern shows up in Aristophanes and recurs in Menander; for instance, that the proportion of all imperatives softened in each author is the same. Menander was hardly likely to imitate Aristophanes in this subtle particular. We could argue, instead, that both authors reproduce a speech pattern which had remained stable for over a century. In fact, the statistics calculated from our congeries of Attic authors writing in different genres and at different historical moments suggests a surprising stability in the polite language of the ancient Greek polis, specifically Athens, despite regime changes.

Indeed, Dickey, writing on the Greek imperative, says '[i]n literature there appears to be no change in the way requests are made at any period of antiquity, just as there appears to be no change in Greek grammar or spelling' (Dickey 2016a: 244). This claim is based on the survey of an ample corpus of directives, with particular attention to how requests are framed. ${ }^{4}$ Any continuity in the politeness system of these texts, then, may be due to the conservatism of the authors - with regard to grammar, spelling, and 'pragmatic' features of the language.

Still, even Dickey (2016a: 247) concedes that colloquial language must surface in our Attic texts, with certain authors (Aristophanes, Aeschylus, Plato) avoiding conversational formulae while others (Menander, Xenophon) employ them frequently. Following this line of reasoning, we can view the continuities across these disparate authors as evidence for actual speech habits. Or, if one prefers, the cross-genre regularities of language will be worth documenting, for they can provide comparanda for similar regularities as represented in the texts of other languages, most obviously, Latin; or comparanda for texts in the same language-Greek-but written at different places and times.

For instance, the mimes of Herodas - coeval of Callimachus, and perhaps active in the intellectual circles of Ptolemy II-and the mimes from imperial Rome present patterns strikingly different from those in our Attic corpus,

3 For further contrasts in Plutarch see esp. Plut. Comp. Ar. et Men. 853b5-8 (Menander characterises on the linguistic level, Aristophanes does not); Menander has achieved the remarkable feat of creating a language which gives the impression of uniformity while in fact suiting itself to characters of various kinds: Plut. Comp. Ar. et Men. 853d10-853e4.

4 Dickey (2016a) surveys Homer, Odyssey 1-4; Sophocles, Philoctetes, Antigone; Euripides, Hippolytus, Medea; Aristophanes, Acharnians, Knights; Menander, Dyscolus, Aspis, Epitrepontes; Herodotus (all); Plato, Symposium. 
TABLE 1 Classical and Hellenistic

Greek directive database

Author Directives

\begin{tabular}{lr} 
Aristophanes & 3223 \\
Menander & 830 \\
Mime & 278 \\
Plato (Cratylus) & 139 \\
Total & 4470 \\
\hline
\end{tabular}

although the data culled from these mimes is, unfortunately, limited. Still, that major shifts in the politeness system did happen from the Classical to the Hellenistic period has been attested with the help of other evidence-Hellenisticera letters preserved on papyrus (Dickey 2016a: 247).

I have four sub-corpora, drawn from distinct points in the temporal flow: fifthcentury Old Comedy, represented by Aristophanes, whose language preserves with more or less fidelity a colloquial Attic spoken in the fifth century BCE; Plato, writing in the mid-fourth century BCE, whose language imitates the more learned discourse of an Athenian élite; the early third century Menander, whose plays similarly reflect an Attic, but an every-day idiom, spoken about a century later, and one which was well on its way to becoming the Koine; finally, Hellenistic Mime, whose language also comes close to the colloquial idiom. This latter 'Mime' corpus should be subdivided into two: we have data from the mimes of Herodas and from scripted mimes presumably performed during the Roman imperial period. All of this data is summarised in Table $1 .^{5}$ (The figure given under 'Mime' in Table 1 adds both the directives from Herodas and those from imperial-era mime.)

All texts were read at least once, and the data collected by hand. itur in antiquam siluam: that is let us begin our journey into this silua, or ü $\lambda \eta$, the stuff or material of our directive database.

5 Wilson (2007) for Aristophanes, Arnott (1979-2000) for Menander, Cunningham (2004) for Mime, and Burnet (1905) for Plato. 
Appendix 1 lists the types of directive that occur in this corpus. A glance at this Appendix hints at the rich variation in the ancient Greek directive system. ${ }^{6}$ As mentioned, we investigate in this essay that most prototypical of the Greek directive, the imperative. There are several reasons for doing so.

First, of all directives, the imperative is the most frequently attested. It constitutes $64.0 \%$ of the directives in Aristophanes, $70.3 \%$ in Menander, $41.7 \%$ in Plato, and $75.2 \%$ in the mime. It's worth noting, incidentally, that those authors who represent every-day conversation-Aristophanes, Menander, and the mime-writers-yield the highest proportion of imperatives. The proportion is remarkably lower in the Platonic dialogue, perhaps because it conveys the cultured conversation of educated Athenians. Second, if we are to generalise based on a sample of data, we should like our sample to be as large as possible - and our sample of Greek imperatives is sufficiently large. Third, in many languages, the imperative attracts mitigators to itself, like our English 'please'; and 'if you wouldn't mind'; the equivalent Greek mitigators being

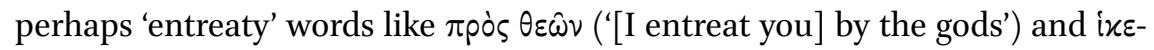
$\tau \varepsilon \dot{\omega} \omega$ ('I beseech you'), in addition to conditional phrases like $\varepsilon \grave{l} \delta 0 x \varepsilon \hat{\imath}$ ('if it's ok with you'), among others. As we will see, these are rare, and their very rareness indicates that, in these words, we do not have softeners per se, but polite 'boosters' - expressions used when the routine way of requesting is not enough (Dickey 2016a: 241).

One may object that my scope-imperatives only—is arbitrary. There are other ways of expressing requests that are not imperatives, which, however, convey similar speech act force(s). For instance, while the present imperative $\left(\pi 0^{\prime} \varepsilon l\right)$ exists in negated form ( $\left.\mu \dot{\eta} \pi 0^{\prime} \varepsilon l\right)$; there exists no similar complement for the aorist imperative, that is, we have $\pi$ oin $\sigma \alpha$ or or $\pi$ oin $\sigma 0 v$ but not * $\mu$ '

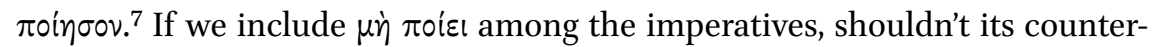

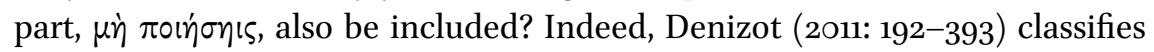
her data in this way: verb morphology that directly conveys commands or requests is identified as 'injunctive'. And while there is an aspectual difference between forms like $\mu \eta \dot{~ \pi o i \varepsilon ı ~ a n d ~ t h o s e ~ l i k e ~} \mu \dot{\eta} \pi \circ i \dot{\sigma} \sigma \varsigma$ - with the former generally expressing inhibitives ('stop doing'), and the latter prohibitives ('don't

6 Denizot (2011) is an excellent overview of the semantic and pragmatic characteristics of many of these forms.

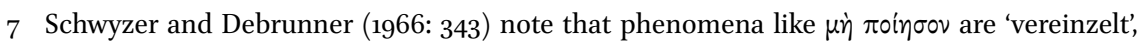
isolated. 
do') — there does not seem to be any difference in politeness. ${ }^{8}$ But I leave out the latter, forms like $\mu \eta \dot{\eta} \pi \circ i^{\prime} \sigma \eta \varsigma$, for this study. For even if we assume that the

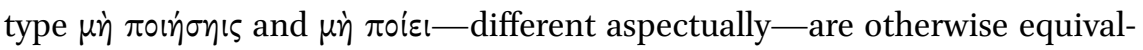
ent, the former type are few in number, constituting between $1.0 \%$ to $4.0 \%$ of the total directives, depending on the author. ${ }^{9}$ Including them would probably not change our results.

The Greek imperative is the chameleon of the directive system, assuming its particular tone from the speech situation and context within which it is embedded. Consider the following examples. ${ }^{10}$

$$
\begin{aligned}
& \text { [2] Herodotus 1.155.3 (Croesus advises Cyrus) }
\end{aligned}
$$

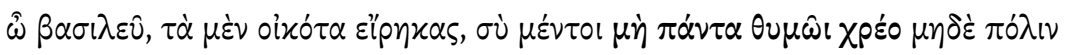

O King, you've spoken what's fitting, but don't vent your anger and destroy an ancient city.

Croesus, given the role of advisor to the Persian king, accordingly advises the king on what not to do, using an imperative form.

[3] Menander Dyscolus 375 (the Slave Daos responds to Sostratos, who has expressed his desire to work in the country)

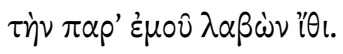

Take this [mattock] from me and go.

Sostratos, the young man in love of the play, wants a mattock in order to depart to Knemon's farm. His slave offers him his own and tells him to go ahead to the farm. (Similarly, a parent would offer an ice cream cone to a child who wants ice-cream, saying 'take it'.) Thus the imperative in passage [2] gives the

8 Schwyzer and Debrunner (1966: 343, section 3) on possible differences; but see now especially Denizot (2011: 287-290).

9 Herodas and imperial mime, 11 of the total 278 directives (4.0\%); Menander, 18 of the total 830 (2.2\%); in Plato these are less than $1 \%$ of the total directives ( 1 of the 139 total); in Aristophanes, the type constitutes 61 of the total 3223 directives, or $1.9 \%$.

10 I use the same examples presented by Dickey (2016a: 239-240), who, however, employs them to a different purpose. 
'green light' to an addressee, allowing the hearer to do whatever desire he or she had previously made manifest. Thus, the imperative constitutes a permission.

In this passage, Pan, rustic god, with a shrine in the deme of Phyle, addresses the audience viewing Menander's Dyscolus.

[4] Menander Dyscolus 1-3, 45-46

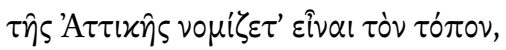

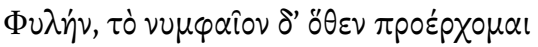

$\Phi v \lambda \alpha \sigma^{\prime} \omega \nu$

$[\ldots]$

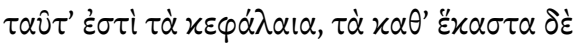

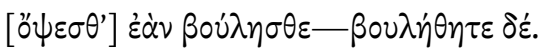

Take this place to be in Attica, Phyle, to be precise; and the Nymphaeum whence I came as belonging to the Phylasians

$[\ldots]$

These are the chief points; but as for the particulars, you will see them if you want. Do want!

Here Pan tells the audience how he wants them to view the stage; he then commands them, with an aorist imperative, to 'want' to view the drama.

In assigning the illocutionary point (whether advice, permission or command) conveyed by the imperative, I have used my own judgment. Different researchers may see the same imperative differently: alii aliis modis. Thus, a reader might plausibly understand [2] as a command.

But all scholars agree that the imperative can convey one of a variety of directive speech acts: advice, permission, commands, and more. Denizot notes that we find imperatives addressed to a god just as we find the imperative used in insulting language, and she concludes that 'the palette of the effects of the sense linked to the imperative is [...] great' (2011: 488). Considered in isolation, wrested from any context, the imperative appears to be neutral with respect to politeness. It must be so, for speakers to employ it in a wide variety of speech situations, and to convey all kinds of illocutions (commands, requests, permissions, advice). ${ }^{11}$

11 To this extent, then, I do agree with Denizot (2011: 488) when she says 'that we must certainly admit that this form [...] is itself neutral from the point of view of politeness.' 
But the imperative always appears in a context, and in some contexts, the imperative alone won't do. Some added politeness is called for, specifically when the imperative represents an imposition on the hearer, when that hearer is of equal or greater status than the speaker (as in passage [2], above) or when the addressee is not known to the speaker (passages [7] and [9], below).

Yet for Greek authors, the imperative was the paradigmatic form for com-

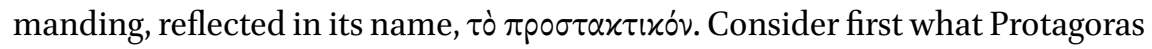
says about the imperative. Aristotle quotes Protagoras' statement in the Poet$i c s$. The philosopher of Stagira has been discussing style, and says that the parts of speech - what we would call the various illocutionary forces an utterance could take-fall under the head of style, or $\lambda \dot{\varepsilon} \xi \iota \varsigma$, that is,

\section{[5] Aristotle Poetics 1456b11-19}

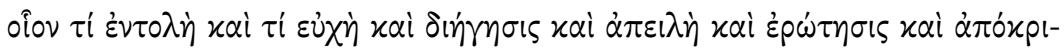

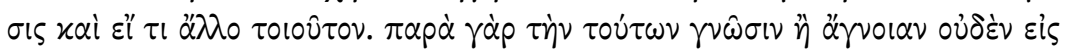

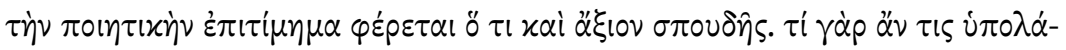

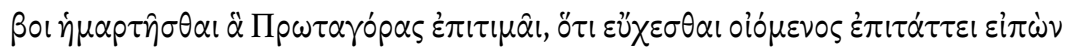

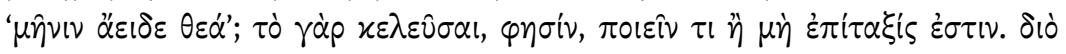

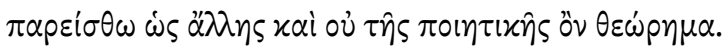

what sort of thing a command is, a prayer, a statement, a threat, a question, an answer, and so on. For as to knowledge or ignorance of these things, no censure worth the effort is imputed to Poetry. What would anyone suppose to have been done wrong in what Protagoras criticises? Since Homer, intending to pray, instead commands, when he says, 'Of the Rage, Sing, Goddess.' 'For ordering someone to do something or not,' he says, 'is a command.' Being an investigation more appropriate to another field than that of poetry, let this be left to the side.

Aristotle chooses to forgo discussing the precise speech-act value of the imperative, $\alpha^{\prime} \varepsilon ı \delta \varepsilon$, but we should not. Invocations at the beginning of hexameter poetry often contain the imperative (Homer Od. 1.1; Hes. Op. 1-2). Incidentally, particularly aorist imperatives are typical in prayers to a divinity. ${ }^{12}$ Finally, the vocative, $\theta \varepsilon \dot{\alpha}$ or the like, must be considered in conjunction with the imperative, since it frames the entire interaction as one taking place between a human worshiper and a god. In such a speech situation, there is no question of commanding. 
Some five centuries later, Apollonius Dyscolus, the late second century CE grammarian from Alexandria, concurs with Protagoras, in his work On Syntax (Apollonius had been talking about whether there exists a first-person command, and presents an argument against):

\section{[6] Apollonius Dyscolus De constructione 3.105.2-5 Lallot}

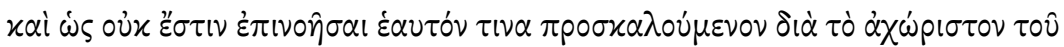

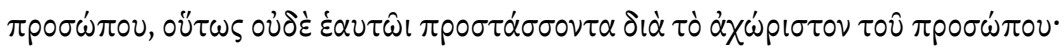

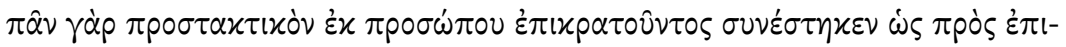

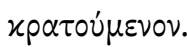

And as it is not possible to imagine a person addressing himself on account of the indivisibility of the person, so it is not possible to imagine a person commanding $(\pi \rho \circ \sigma \tau \dot{\alpha} \sigma \sigma o v \tau \alpha)$ himself for the same reason. For

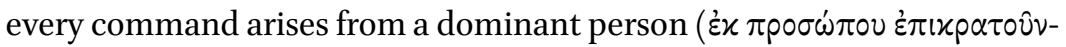

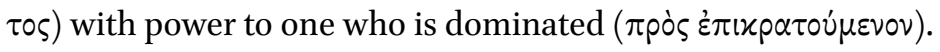

Apollonius had been discussing the distinction between first- and secondperson imperative; and he had had just given as examples of the latter the forms $\varphi \varepsilon \hat{\gamma \varepsilon}, \lambda \varepsilon \dot{\gamma} \varepsilon$, and $\gamma \rho \alpha \dot{\varphi} \varphi \varepsilon$ (3.104.9). But Apollonius considers only one speech

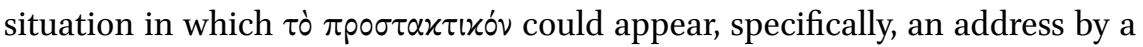
superior to an inferior. In such situations, when superiors command inferiors, we might indeed expect imperatives with little to no mitigation.

In other words, the bare imperative is expected in such situations; while more elaboration is necessary when a power difference exists between the interlocutors, as a first century BCE writer on style indicates (Demetr. Eloc. 7 Radermacher): 'orders are concise and brief and every master is curt towards his slave. Supplication and lamentation, on the other hand, are lengthy' ( $\propto$ ai

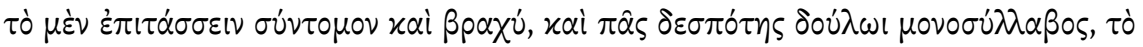
$\delta \varepsilon \dot{~ i x \varepsilon \tau \varepsilon v ं \varepsilon I \nu ~ \mu \alpha x p o ̀ v ~ x a i ~ \tau o ̀ ~ o ́ \delta u ́ p \varepsilon \sigma \theta \alpha i) . ~ A c c o r d i n g l y, ~ t h e ~ b a r e ~ m i n i m u m-e v e n ~}$ a verbless imperative like $\delta \varepsilon \hat{p o}$ ('[come] hither!')—suits addresses by superiors to inferiors; conversely, more elaboration-using vocatives and 'polite boosters'-are necessary when inferiors address superiors or when the imposition is great. 


\section{Characterising the Data in Broad Strokes}

\subsection{Proportion of Imperatives in the Greek Directive Database}

Of course, this is not the first synoptic treatment of the Greek imperative. Here I want to focus on two important, and recent, claims. First, Dickey shows us that the Greeks of the Classical Period very rarely used softeners. ${ }^{13}$ To put this in perspective, compare the proportion of softened imperatives in two very similar authors, the Latin comic poet Terence and the Greek comic poet Menander, both of whom give the impression, if not an actual reflection, of 'real' speech. As I have shown elsewhere, $11.2 \%$ of all imperatives in Menander are softened; while $15.4 \%$ in Terence are. The difference between the proportions is statistically significant. ${ }^{14}$ Terence mimics Menander-he is called by Julius Caesar a dimidiatus Menander (Suet. de poetis 11.103 Reifferscheid) - but not with respect to the softened imperative. The Latin poet probably does not imitate Menander with regard to conversational patterns, preferring instead to model these on what his Roman audience will have heard in their own spoken interactions. This result is tentative-after all, we do not have much Menander or Terence-but it does underscore Dickey's claim, that the Greeks did not incline to softening imperatives.

The second important claim in recent literature is that the bare Greek imperative was used in preference to almost any other form of directive, $65 \%$ of all directives in an ample corpus spanning from Homer to Plato. ${ }^{15}$ Overall, as Denizot says, 'imperatives represent between $75 \%$ and $90 \%$ of the occurrences of verbal types typical of orders' (Denizot 2011: 192) ${ }^{16}$ Based on the numerical

13 Dickey (2016a: 239-240). Perhaps, however, we need to broaden our definition of what counts as a directive softener. For instance, it is possible that vocatives and particles like $\delta \eta$ do play a role in mitigating the directive; on the former, see Barrios-Lech (forthcoming); on the latter, see Denizot (forthcoming).

14 Barrios-Lech (forthcoming); I use the $z$-test to calculate the probability of significant difference. Using the z-test, we can decide whether proportions calculated from two different populations are more likely to originate from two different populations or represent the same population; in other words, whether the difference between the two proportions, calculated from two independent samples, is statistically significant. For further information on this statistical test, see Butler (1985: 92-95).

15 Dickey (2016a: 239), specifically Table A, where the bare imperative represents $65 \%$ of the total directives in her corpus.

16 '[L]es impératifs représentent entre $75 \%$ et $90 \%$ des occurrences de formes verbales typiques de l' injonction.' Her corpus contains Archaic and Classical Greek: Iliad, Odyssey, the extant tragedies of Aeschylus; Herodotus, Aristophanes, Lysias and the early dialogues of Plato (Denizot 2011: 191-192). According to her, Hesiod is the only outlier, in whose texts imperative forms make up only $28.2 \%$ of the texts. 
TABLE 2 Imperatives as a percentage of directives in the Greek directive database

Total directives Imperatives as \% of total

\begin{tabular}{lrl} 
Aristophanes & 3223 & $64.0 \%(2063)$ \\
Plato & 139 & $41.7 \%(58)$ \\
Menander & 830 & $70.6 \%(586)$ \\
Mime & 278 & $75.2 \%(209)$ \\
Total & 4470 & $65.2 \%(2916)$ \\
\hline
\end{tabular}

prevalence of the bare imperative in her Classical Greek corpus, Dickey (2016a) has argued that the present imperative was the 'unmarked' way of 'doing' a request in Classical Greek, much as the 'can you' request is an unmarked way of carrying out a request in English.

In our Aristophanes corpus, we find 3223 directives; of these $2063(64.0 \%)$ are imperatives. Now, in a corpus representing a later stage of Greek, our Menander corpus, there are 830 directives (less $5^{2}$ dubious instances). Of these, there are 219 aorist imperatives, and 292 present imperatives, totalling 511. When we add to this total 28 perfect imperatives (forms like " $\sigma \theta_{l}$ 'know ye'), 47 tokens like $\mu \grave{\eta} \varphi \dot{\varepsilon} \rho \varepsilon$, ('don't bring,' that is, $\mu$ ' + present imperative), we arrive at an overall total of 586 imperatives in our Menander corpus, which represents $70.3 \%$ of all directives in Menander. This proportion (70.3\%) comes close to that calculated by Denizot, $75^{-90} \%$ (depending on the author). So, too, does the proportion calculated from our Hellenistic-era mime corpus: of the 278 directives there, 209 , or $75.2 \%$, are imperatives. Finally, $41.7 \%$ of the directives in Plato's Cratylus are imperatives, so 58 imperatives of 139 directives total. Thus, apart from the Aristophanes and Plato sub-corpora, our figures accord with those of Denizot. And in sum, of the total directives in our corpus, $65.2 \%(2916$ out of 4470) constitute imperatives. Table 2 presents the data in summary form.

In other work, I have shown that, as a whole, the proportion claimed by imperatives in the Greek database differs significantly from that in my Roman Comedy database, the latter corpus representing all the directives in extant Roman comedies: Plautus and Terence. From this Roman comedy corpus imperatives claim $58.4 \%$ of the total directives. ${ }^{17}$ Note the difference, between this proportion $(58.4 \%)$ and that for the Greek corpus, $65.2 \%$ : it is statistic-

17 Barrios-Lech (forthcoming). 
ally significant. Also notice we are not comparing only comedy with comedy, that is Plautus and Terence on the one hand (of all directives $58.4 \%$ are imperatives) with Greek comedy and mime on the other (66.o\%). If we did, the difference between the resulting proportions would be even less likely to be owing to chance.

We have corroboration for Dickey's claim: compared to Roman speakers, Greek speakers appear to have been significantly more inclined to employ the imperative whenever they needed to command, request, instruct, permit, advise, and suggest. Of course, the question naturally arises: what accounts for this difference?

The type of social structure which organised relations between members of a community may have much to do with this difference. In a typical Greek polis, élites or members of the 'in-group' lived together as equals, whether these were citizens of fifth-century Athens or the ojoîo of Sparta. The absence of hierarchical relations between individuals means that the imperative, when used, lacks a context that would give it the value of 'order.'18 By contrast, élite Romans were hyper-aware of factors like auctoritas - roughly the social influence of a person - and dignitas - the esteem to which his standing in society, his family, and accomplishments entitled him. Differences in the dignitas and auctoritas between speaker and hearer needed to be taken into account by the speaker. The resulting wariness about the other's status relative to one's own, and the heightened fear of potentially injuring the other with an untoward remark, might result in the relatively lower proportion of imperatives we see in our Roman texts. ${ }^{19}$

\subsection{How Often Did the Ancient Greeks Soften Their Imperatives?}

4.2.1 Positively and Negatively Polite Softeners; or 'Polite Boosters' and 'Polite Down-Toners'

To anticipate a little, the Greeks in our period seemed disinclined to use what we would consider the most obvious candidates for 'please', again, words like $\dot{\alpha} \nu \tau i \beta 0 \lambda \hat{\omega} \sigma \varepsilon, \pi \rho \dot{\varsigma} \varsigma \theta \varepsilon \hat{\omega} \nu$, i $\varkappa \varepsilon \tau \varepsilon \dot{\omega} \omega$. Dickey demonstrates not only that these are rarely used, but that they did not go down the path of grammaticalisation over time (Dickey 2016a: 242-243, 245-246). Nevertheless, let us try to characterise the Greek 'words for please.' On the one hand, 'polite boosters', entreaty-words, simultaneously make the request urgent and ingratiate the speaker with the

18 Dickey (2016a: 249) and (2016b).

19 Barrios-Lech (forthcoming) on the Roman disinclination to the present imperative compared to the Greek; on social factors, see Unceta-Gómez (2009: 43) and Kaster (2005: 28): the relevant social emotion is uerecundia. 
addressee. Vocatives, for instance $\gamma \lambda \nu$ to the hearer's close connection with the speaker, or instantly forge such a close connection (much like the British-English address-term 'love'). In Greek, we also have 'polite down-toners', words that minimise ( $\mu$ óvov, 'just' do this) or Bpaxu ('just a bit'); and phrases that make the imposition optional for the

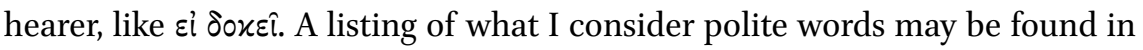
Appendix 2.

Two concepts familiar in politeness theory can help us to organise this data: negative and positive politeness. ${ }^{20}$ Positive politeness emphasises a connection with the addressee ('hey brother, can you spare a dime?'; or 'be a dear and hand me my scarf, will you?'), while negative politeness maintains respectful distance from the addressee ('I was wondering if you wouldn't mind covering my shift this Wednesday' or 'Sir, may I offer you some advice?'). These terms form part of a theory of Politeness meant to describe modern politeness cultures, but they have proven useful in studies of the language of ancient Greek and Latin. ${ }^{21}$

Positively polite, then, is Habrotonon's - the good courtesan in Menander's Epitrepontes - request of a young woman. Habrotonon, aware that her addressee may in fact be the mother of an abandoned child, asks a key question:

[7] Menander Epitrepontes 862-863

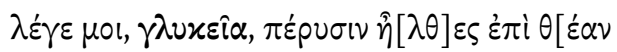

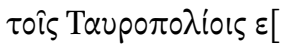

Tell me, honey, did you go last year to the Tauropolia?

The vocative $\gamma \lambda u x \varepsilon i \alpha$, here, expresses the courtesan's affection for the young woman; similar is $\varphi$ i $\lambda \tau \alpha \alpha \tau \varepsilon$ (or $\varphi i \lambda \tau \alpha \dot{\tau} \tau)$ ), 'one of the most common friendship terms and expresses very strong and genuine affection' (Dickey 1996: 358). This, too, can express positive politeness. The nurse in Menander's Dyscolus makes a positively polite request of her addressee, to go down a well to rescue the misanthrope - in addition to a mattock - that have fallen in. Certainly, this is not a routine request, nor is she in the position to be making requests-she is a servant—so she must frame it politely: $\varphi(\lambda \tau \alpha \tau \tau \varepsilon, \kappa \alpha \tau \dot{\beta} \beta \alpha$. (Dys. 632). It bears not-

20 The seminal text is that of Brown and Levinson (1978), reprinted with new introduction in 1987 .

21 A full bibliography is not possible here: for a good starting point in Greek, see Denizot (2011); for Latin, see now Unceta-Gómez (2018). 
ing that her addressee, the cook Sikon, is also of low-status. In fact, the cook had made a similar request of the old woman, to 'finish the work' by throwing rocks on top of the unlikeable old man in order to murder him. The cook softens the urgent—and joking—appeal with the similar $\hat{\omega} \varphi 1 \lambda \tau \dot{\alpha} \tau \eta \eta \gamma \rho \alpha \hat{v}$ ('It's your job now, love, to take a mortar or a stone and thrown it down on him': $\hat{\omega} \varphi i \lambda \tau \dot{\alpha} \tau \eta \eta \gamma p \alpha \hat{v}$,

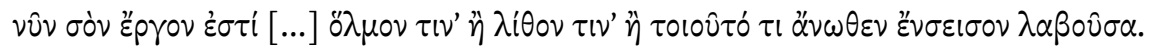
Men. Dys. 630-632).

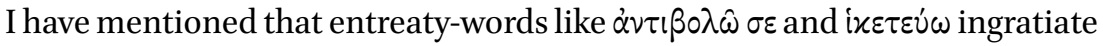
the speaker with the hearer. They would appear to be tokens of positive politeness, but prove, in practice, more difficult to classify. Consider the following passage, in which Dicaeopolis asks Euripides for some rags so he can dress up like Telephus and take a charcoal basket hostage (just as Telephus had taken the baby Orestes hostage in the lost Euripides play).

\section{[8] Aristophanes Acharnians $43^{1}$}

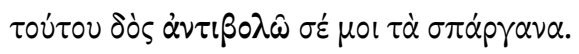

Give me, I beg you, the rags of this man.

$\dot{\alpha} \nu \tau i \beta \lambda \hat{\omega}$ may count as an instance of positive politeness, since with it the speaker pays the addressee the compliment of elevating his or her status, while humbling himself. But this move, self-humbling, distances self from other. So $\dot{\alpha} \nu \tau i \beta \circ \lambda \hat{\omega}$ and the like may function as a negative politeness particle-this is how Sorrentino (2013: 191-192) sees it, for example. In either case, such entreaties leave the addressee very little option to refuse fulfilling the request. When we consider what other words appear alongside the recurrent $\alpha \nu \tau i \beta 0 \lambda \hat{\omega} \sigma \varepsilon$ and

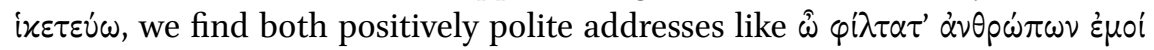
(Ar. Nub. 110), but also the negatively polite $\hat{\omega} \delta \dot{\varepsilon} \sigma \pi 0 \tau \alpha$ (Ar. Eq. 960). Most fre-

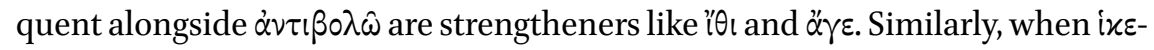
$\tau \varepsilon \dot{v} \omega$ appears with other modifiers, we find both positively and negatively polite

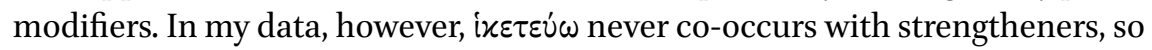
that there is a case to be made either that, of the two, it was the less-urgent form of entreaty. ${ }^{22}$

These 'entreaty' words originate from the language of prayers. In prayers

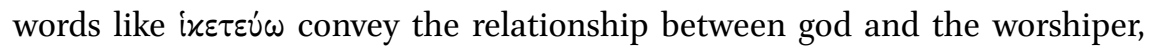

22 Of course, one could make the opposite argument: that it was already urgent enough so that no added strengtheners were felt necessary. 
at once distant and intimate, so that, appearing with 'entreaty' words we find

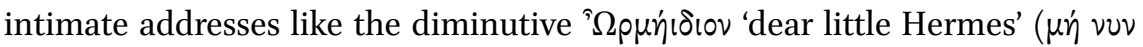

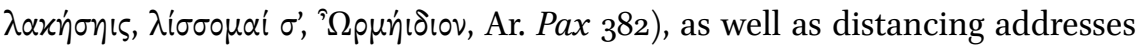
like $\Theta \varepsilon \sigma \mu \circ \varphi o ́ \rho \omega ~ \pi \circ \lambda v \pi \circ \tau v i \alpha$, 'O Almighty Goddesses of the Thesmophoria', ad-

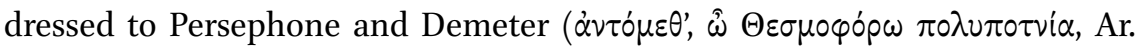
Thesm.1155).

Dickey (2016a: 243) also acknowledges that these entreaty words are difficult to categorise. She prefers to see them as 'markedly' polite, since they deviate from the otherwise unmarked ways of carrying out requests. It makes sense, then, to count them as a different kind of strategy altogether.

Let us consider the following passage which illustrates another kind of negative politeness, that is, 'minimising' requests with phrases like, $\beta p \alpha \chi[\dot{v} \tau$ ':

[9] Menander Dyscolus 299-300 (Sostratos, the city youth, replies to the rustic youth, Gorgias)

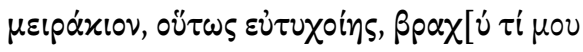

äxovoov.

Young man, may you be fortunate, listen for just a little while.

We first consider the context. Gorgias had accused the rich young man Sostratos of abusing his privilege by taking advantage of a poor young woman (in fact, Gorgias' sister). Sostratos, innocent of the charge, will clear himself, but first he needs to secure Gorgias' attention and good will. It is a crucial moment. ${ }^{23}$

Dickey (1996: 74) notes that in Menander, the address-term $\mu \varepsilon ı \alpha$ xi ı૦ 'appears to be a neutral one, and the usage from one youth to another, as in Lucian, is more polite than otherwise.' The vocative is typical in addresses from one youth to another, so that we may take $\mu \varepsilon ı \rho^{\alpha} \varkappa x_{10 \nu}$ 'young man' as unmarked; that is, it is expected in this kind of interaction. ${ }^{24} \beta p \alpha \chi[\dot{v} \tau i$ ('some little bit'), however, is clearly needed as some form of 'extra' politeness: the unmarked request form will not do, after all. Gorgias is not known to Sostratos, nor can Sostratos be sure that Gorgias wants to listen. So the rich youth promises that the imposition will be a small one, thus indicating respect for Gorgias,

23 Sorrentino (2013: 259-26o, 272) notes the difference in their approaches, with Sostratos inclining to positive politeness; Gorgias by contrast prefers off-record strategies and negative politeness.

24 The address-term varies according to context: for analysis of usage in Menander, see Sorrentino (2013: 257 n. 46$)$. 
as someone who does not deserve or want to be imposed upon at all. He furthermore adds a positively-polite device, wishing Gorgias' success in the future

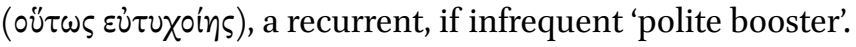

The particular polite value of vocatives-a favoured means of softening directives-depends on the context. When the chorus in Acharnians tell the Theban guest to take a sycophant with him, they make the request polite by adding the address term $\hat{\omega} \xi \dot{\varepsilon} v \omega \nu \beta \varepsilon \dot{\lambda} \tau \tau \iota \tau \varepsilon:$ "reap" him too, in your harvest, and add him to your cargo, bringing him wherever you want, an informer for

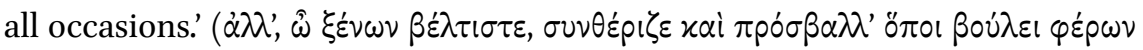

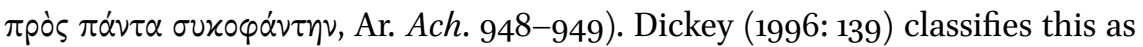
a friendship term, but notes its usages vary depending on the author. Outside of Plato 'authors do not make a [...] distinction between $\beta \dot{\varepsilon} \lambda \tau$ $\sigma \tau \varepsilon$ and other friendship terms.' She adds (1996: 139), however, that in Menander, the term is 'polite and respectful' but it can be used in moments where the speaker claims superiority over the addressee. I have, in general, classified all friendship terms as positively polite. I acknowledge here that, since other readers may classify a given vocative differently, the classification that I rely on for this essay must remain provisional.

\subsubsection{Analysing the Data-Polite Boosters and Down-Toners in the Greek Directive Database}

Scrutiny of the 2063 imperatives in Aristophanes reveals 239 softeners; this means that in Aristophanes, imperatives are softened $11.6 \%$ of the time. In Menander, $11.2 \%$ of all the imperatives are softened (66 out of 586 ), and in Plato's Cratylus, $11.8 \%$ of the imperatives are modified ( 6 out of 51 ). The relevant statistical test shows no significant difference amongst these proportions. ${ }^{25}$ In other words, we see a surprising continuity across genres and time-periods in this respect-at least for the Athens-centred authors.

In Herodas' Mimes, however, 8.5\% of the imperatives are softened (11 out of 129), and the proportion does differ significantly from that given for our Athenian corpus. Herodas, a coeval of Callimachus, probably had connections with the court of Ptolemy II (Cunningham 1971: 2-3), and his mimes convey scenes from the everyday life of individuals inhabiting the lower strata of society. Consider some representative situations: in the first mime, a maid advises a courtesan; in the second, a pimp delivers a courtroom speech; in the fifth, a woman accuses a slave she has been sleeping with of infidelity; in the sixth and seventh, women discuss and shop for $\beta \alpha \nu \beta \hat{\omega} v \varepsilon s$. As for the mimes from 
the Roman imperial period (collected and edited in Cunningham 2004), these show $9.0 \%$, or 7 softeners out of 78 imperatives, similar to the figure that we find in Herodas. The figures for Herodas and imperial mime do not differ significantly, but we have very little data, making statistical tests unreliable.

The Athenian corpus - consisting of different authors writing in different genres and at different times - shows a surprising stability in the percentage of imperatives softened. That continuity is put into striking relief when we compare texts written outside of Athens - the mimes of Herodas-or those texts written during the Roman imperial era.

If we compare data from Roman texts, we can better appreciate the stability of the politeness system across the various Attic texts. In the plays of Plautus and Terence, $9.8 \%$ and $15.4 \%$ respectively of the total imperatives in each author are softened. If we compare, again, two authors quite similar in their approach to the genre, Menander $(11.2 \%$ of all the imperatives are softened) and Terence ( $15.4 \%$ softened), the difference is significant. Further let us compare two similar texts, the Cratylus of Plato and the de Oratore of Cicero, a dialogue on the place of oratory within the traditional 'academic' disciplines. In Plato's dialogue, we found that $11.8 \%$ of imperatives are softened $(6$ out of 51 ); while in Cicero's $17 \%$ of the present imperatives are softened ( 7 of 41).

\subsection{What Kind of Politeness Did the Greeks Incline To?}

We saw that about $11-12 \%$ of the imperatives are softened in our Attic Greek corpus. When we compared Menander with Terence and Platonic with Ciceronian dialogue, we appreciated the Greek disinclination to soften imperatives compared to Latin authors. This difference may point to an underlying reality in language use.

The distinction noted between negative and positive politeness can help us to characterise our data in another, general, way. And one may ask, of the two, which kind did the Greeks incline to? Before beginning, I must admit to misgivings. We have already seen that entreaties perform both positive and negatively polite functions, so that I have found it impossible to categorise the entreaty as one or the other.

As we saw above, entreaty performs both negatively and positively polite functions at once, so that I thought it best to consider it a separate category. In general, we see a preference for positively polite softeners in Aristophanes (see Table 3).

When we compare the Menandrian and Aristophanic corpora (see Tables 3 and 4), we find that are no significant differences in the proportions for Aristophanes and those calculated for Menander. That is, as far as softened imper- 
TABLE 3 Percentage of softeners that are negative, positively polite in Aristophanes

\begin{tabular}{lllll}
\hline & Softeners & NP & PP & Entreaty \\
\hline Total softeners & 239 & 71 & 126 & 42 \\
Percent of total & $100 \%$ & $29.7 \%$ & $52.7 \%$ & $17.6 \%$ \\
\hline
\end{tabular}

TABLE 4 Percentage of softeners that are negative, positively polite in Menander

\begin{tabular}{|c|c|c|c|c|}
\hline & Softeners & $\mathbf{N P}$ & $\mathbf{P P}$ & Entreaty \\
\hline Total softeners & 66 & 23 & 26 & 17 \\
\hline Percent of total & $100 \%$ & $34.8 \%$ & $39 \cdot 4 \%$ & $25.8 \%$ \\
\hline
\end{tabular}

atives go, the sets of data-negative, positive, and entreaty-type imperative softeners - come from the same population, and that population can be characterised as either (1.) the language of Athenian comedy; or (2.) the colloquial idiom of Athens.

Let us turn to the Platonic subcorpus. Here, we find 10 imperative softeners. Of these imperative softeners in Cratylus, 6 are negatively polite (6o\%) and 4 are positively polite (40\%); one entreaty-form is used, representing $10 \%$ of the total softeners. The relevant statistical test indicates no significant difference between our Platonic subcorpus and either the Aristophanic or Menandrian. But we would need more data to be certain of this result; for with the data we have the test is not reliable.

Let us tentatively conclude from this agreement across our three Attic genres-Old Comedy, New Comedy, and Platonic dialogue — that the language of Greek politeness across the period we are considering shows a stability that is perhaps surprising. While we can interpret the continuities we have observed, with Dickey, as owing to the conservativism of authors using an established literary idiom, I personally am inclined to think that those regularities across different authors point to actual and pervasive habits of speech. To characterise the politeness culture, however, will take a more ample study than can be attempted here: we need to take into account more relevant data from Plato's and Xenophon's dialogues and to consider other kinds of im/politeness phenomena. 
TABLE 5 Percentage of softeners that are negative, positively polite in Herodas

\begin{tabular}{lllll}
\hline & Softeners & NP & PP & Entreaty \\
\hline Total softeners & 11 & 3 & 7 & 1 \\
Percent of total & $100 \%$ & $27.3 \%$ & $63.6 \%$ & $9.1 \%$ \\
\hline
\end{tabular}

Let us now consider the Mime subcorpora, both the mimes written by Herodas and those dating from the Roman imperial era. These give us an indication - although no firm proof - that the polite language — specifically the softeners - of the Attic authors stands apart.

Under a third of the softeners are negatively polite; nearly two-thirds are positively polite. There are very few data, and even fewer from the imperialera mime, where all of the strategies consist of respectful vocatives like xupia and $\delta \dot{\varepsilon} \sigma \pi \circ v \alpha$. For our data (culled from imperial-era mime), the use of these vocatives appears to be a negatively polite strategy (although I grant that such characterisations retain an element of subjectivity).

In particular, and again, for the imperial period, the addresses xúpı and xupi $\alpha$ derived from a Greek translation for the Latin domine. Their use increased in the second century $\mathrm{CE}$; the forms could be directed equally to superiors as to friends, relatives, and equals. In the same century, $\delta \dot{\varepsilon} \sigma \pi 0 \tau \alpha$ and $\delta \dot{\varepsilon} \sigma \pi \circ v \alpha \alpha$ were most often used toward superiors. ${ }^{26}$ The evidence from our Roman imperial mime database shows the forms being directed in all cases to superiors. ${ }^{27}$ Indeed, there are too few data to perform a reliable statistical test. Future work will need to look at texts imitating spontaneous speech from the later periods. Probably most illuminating will be to consider the wealth of data available from the second sophistic, and particularly the dialogues of Lucian; and compare these with the conclusions given here, for Athens.

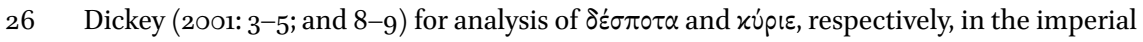
period. All examples of the vocative xupi $\alpha$ in my mime database come from the papyrus P.Oxy. 413 (accessible both in the Cunningham volume and also in the Loeb edition, Page [1941: no. 76]), dated to the Roman Imperial period, second century CE.

27 In P.Oxy. 413, at lines 27, 42, 107, 123, 135, a (presumably) lower-status character addresses a superior (I say 'presumably' because the state of the papyrus permits only guesses at speaker-identity for some verses). In the same papyrus at line 106, Charition prays to a goddess, addressing her with $\delta \dot{\varepsilon} \sigma \pi \circ \vee v \alpha$. 
TABLE 6 The top 4 styles of politeness used in Aristophanes

Type of softener Totals

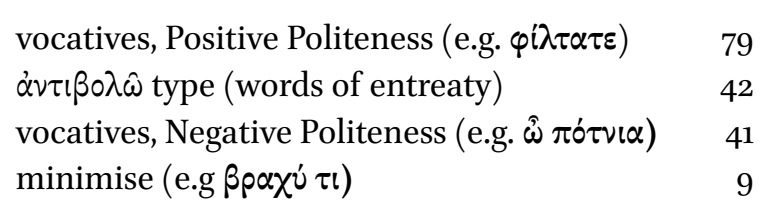

TABLE 7 The top 4 politeness styles used in Menander

\section{Type of softener Totals}

\begin{tabular}{|c|c|}
\hline vocatives, PP & 18 \\
\hline$\dot{\alpha} \nu \tau i \beta \circ \lambda \omega \hat{\omega}$ type & 17 \\
\hline minimise & 11 \\
\hline vocatives, NP & 6 \\
\hline
\end{tabular}

\subsection{What Kinds of Polite Expression Are Used?}

Tables 6 and 7 show the four most recurrent Politeness strategies in our comedies. Other kinds of Politeness are used, of course, but these are by far the most prevalent. Appendix 2 lists other kinds of politeness that we find in the Aristophanes corpus, in addition to the types mentioned above. What do we find in Menander, writing about a century later, in a different genre, and under a different regime?

Again, we find continuities. Even though entreaty words like $\alpha \dot{\nu} \tau \beta \circ \lambda \hat{\omega}$ and

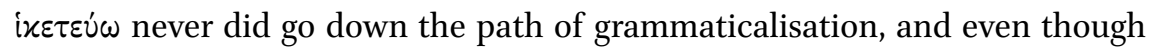
the Greeks, compared to the Romans, were disinclined to soften their imperatives, when they did, words of entreaty were often used, as were vocatives. Here, again, there is a stark difference from the material we find in the Latin data, where vocatives were significantly less often used. ${ }^{28}$

28 Barrios-Lech (forthcoming); on entreaty-words in the Greek data, see Dickey (2016a: 246). 
TABLE 8 Politeness styles used in Herodas' Mimes

Type of softener Totals

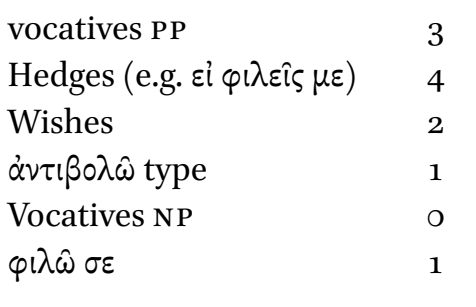

\section{Conclusion}

The data from Herodas can be considered, even though there are too few items for reliable conclusions to be drawn.

Here, vocatives again stand out as a recurrent means for softening imperatives. The expression of a wish in the addressee's benefit, that is, variations on 'may you be blessed' ov́] $\tau \omega \varsigma$ ơvalo (Men. $P k .400$ ), recurs as a politeness phrase throughout our corpus, and appears twice in Herodas. It may have been a colloquial feature. ${ }^{29}$ Herodas diverges from what we have seen in the types of expression used, particularly the use of hedges like $\varepsilon i \varphi(\lambda \varepsilon \hat{\varsigma} \varsigma \mu \varepsilon$ and formulas like oư $\tau \omega \varsigma$ o ovalo. The latter do appear in Aristophanes and Menander but claim only a small percentage of the total softeners (though it should be noted that expressions like oü $\tau \omega \varsigma$ ővaı are used fifth-most-often in Menander).

The figures from the mimes presented in Cunningham's Teubner volume also diverge from the corpus of Greek comedy: there, all seven imperative softeners are negatively polite. Six of the total seven are vocatives, which, as we have seen, is a characteristically Greek way to soften imperatives. We also find one minimiser ( $\mu$ óvov, 'just' do). These latter texts date mainly to Rome's imperial period.

Thus, it looks like the Attic subcorpus, consisting of all the plays of Menander and Aristophanes, as well as Plato show stability in the percentage of imperatives softened and the kinds of politeness used. The mime corpus stands apart, but that divergence may be only an illusion, since our mime subcorpus yields

29 Ferri (2015: 503-504) collects some examples of this and related expressions. It was probably a polite formula, with elegant variations possible. 
few data to work with. To appreciate the uniqueness of the politeness system in the Attic subcorpus, we will need more ample data from a different place or time; a suitable candidate will be the Greek of the second sophistic, when the Hellenistic world will have felt the impact of Romanisation. ${ }^{30}$

\section{Appendix 1: Types of Directives, Aristophanes (Items in Bold Are Polite $)^{31}$}

- 1st plural hortatory subjunctive (ex. Ach. 627 the chorus has been convinced by Dicaeopolis. They exhort each other to take off their garments and begin

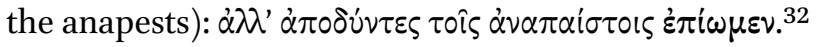

\section{- Questions}

- 2nd person future indicative in a question (ex. Ach. 55, the divine Amphitheos, under arrest by Skythian archers, calls upon the gods for help): $\hat{\omega}$

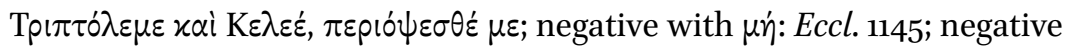
with ov่ $\mu \eta \dot{~(e x . ~ N u b . ~}{ }_{367}$, Strepsiades asks whether Zeus isn't a god, and

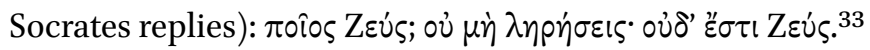

- 1st person plural future indicative in a question (ex. Lys. 356).

- oủ +2 2nd person future indicative in a question (ex. Ach. 822, see below for

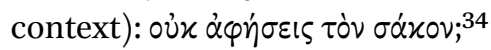

- 2nd person present or perfect indicative in a question (ex. Ach. 483-484, Dicaeopolis encourages his spirit to go forward and debate with the

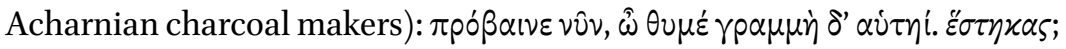

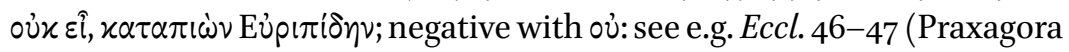

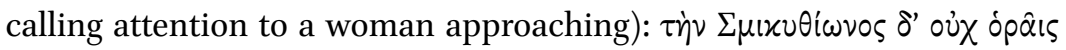

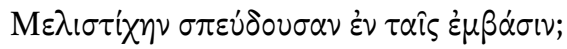

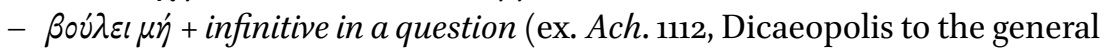

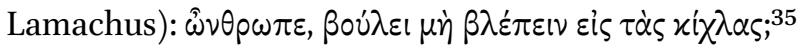

$30 \quad$ For one step in this direction, see Dickey (2009).

31 The items marked as polite are requests documented as polite in the secondary literature; if the item is not in bold, it is either not polite; its politeness is context-dependent; or I have not been able yet to ascertain its politeness. I refer throughout in the notes for further reading to Denizot (2011), an up to date and comprehensive account of the Greek directive.

32 Polite: Denizot (2011: 268).

33 On the difficulty of identifying the former as true questions, see Denizot (2011: 457): on the latter, with ov $\mu$ '́, see Denizot (2011: 476-483): not polite.

34 Impolite: Denizot (2011: 469-473).

35 Polite; but can be used to convey ironic politeness: Denizot (2011: $45^{8-459)}$. 
- $\tau i($ o $)+$ present or perfect (ex. Ach. 410, Euripides tells Dicaeopolis to keep

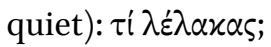

- Tag questions (ex. Ran. $5^{22}$ and 526, Xanthias in the latter asks Dionysus

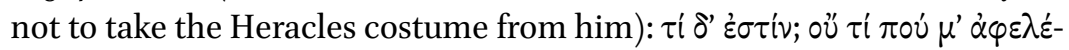

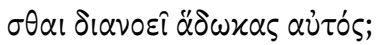

- 'Whynot'-questions (ex. Ran. 635-636, where Dionysus suggests that since

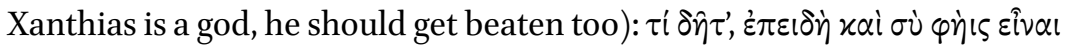

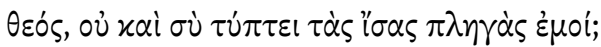

\section{- Statements}

- 2nd person future indicative in a statement with $x \lambda \alpha \dot{\alpha} \omega$ : (ex. Ach. 822, the informer tries to seize contraband from a Megarian): $x \lambda \dot{\alpha} \omega \nu \mu \varepsilon \gamma \alpha p เ \varepsilon \hat{\varsigma}$, 'you'll be sorry if you side with the Megarians.' ${ }^{36}$

- 1st person future indicative in a statement (ex. Lys. 1230).

- ov $\mu \dot{y}^{\prime}+2$ 2nd person present indicative in a statement (ex. Ach. 165-166, the ambassador tells Dicaeopolis not to approach the Thracian mercenaries,

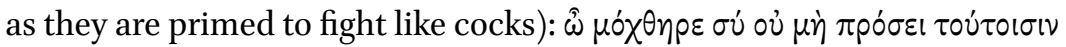

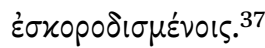

- 1st person plural aorist indicative (ex. Lys. 181-182, the title character

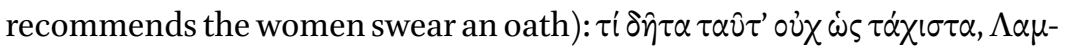

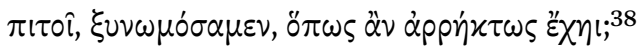

- Imperatives

- Aorist Imperative

- Perfect Imperative

- Present Imperative

- Infinitives

- Aorist Infinitive (ex. Ach. 130-131, Dicaeopolis asks Amphitheos to go

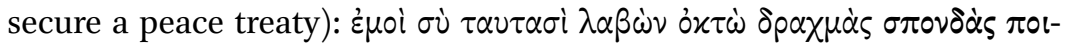

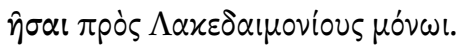

- Present Infinitive (ex. Ach. 172, the herald tells the Thracians to come the

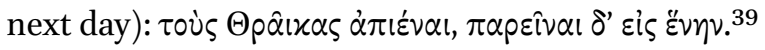

36 Speech act value and politeness of the and person future indicative in statements are highly context-dependent; when used alone like this they tend to be impolite: see Denizot (2011: 431-433).

37 A strong prohibition: see further Olson (2002: ad loc.).

38 Here we might be tempted to see an example of what Lloyd (1999: 33-35, esp. 33) calls ' $[\mathrm{t}]$ he distancing effect of the tragic aorist' which 'is often used to make a verb more polite than it would have been in the present'. But these types of question with $\tau i$ and the aorist do also convey urgent commands: see Denizot (2011: 46o).

39 On the infinitive, a neutral form, most like the imperative in its morphology, see Denizot (2011: 336-339). 
- Speech Act Verb (ex. Ach. 169, Dicaeopolis does not want to have an assembly called about the matter of wages for the Thracian mercenaries): $\dot{\alpha} \lambda \lambda^{\prime} \dot{\alpha} \pi \alpha \gamma 0-$

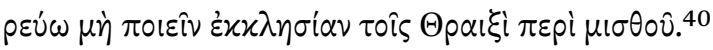

- Impersonals ${ }^{41}$

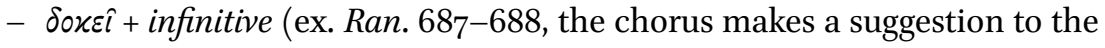

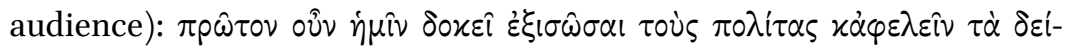
$\mu \alpha \tau \alpha$

$-\chi \rho \dot{n}+$ infinitive

- $\delta \varepsilon \hat{\imath}+$ infinitive (ex. Ach. 233, the chorus looks for the person who has con-

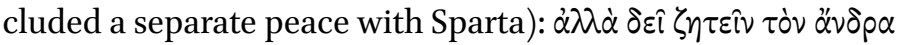

- है $\sigma \tau l+$ infinitive (ex. Pl. 576-577, Dicaeopolis allows Peloponnesians to

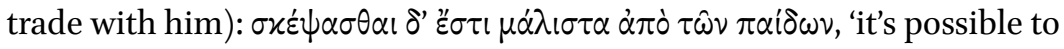
see this especially using the example of children' (= 'consider the example of children'). ${ }^{42}$

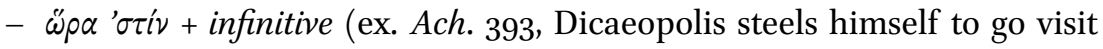

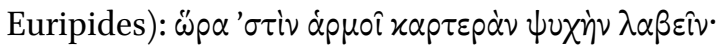

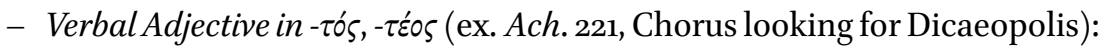

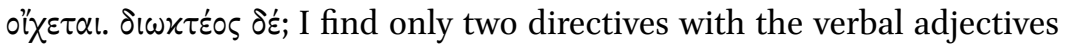

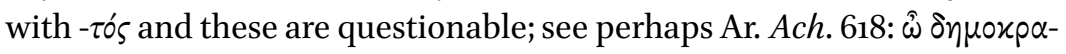

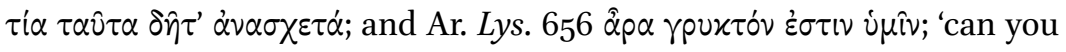
possibly grumble?'

- Eixós + copula + infinitive (ex. Eccl. 493-494, the chorus of women does

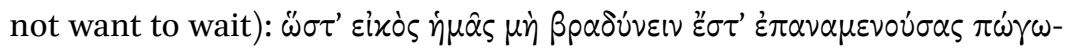
vas $\dot{\varepsilon} \xi \eta \rho \tau \eta \mu \dot{\varepsilon} v \alpha \varsigma$

- бov हैpyov + infinitive (ex. Eccl. 514, where the chorus asks Praxagora to tell

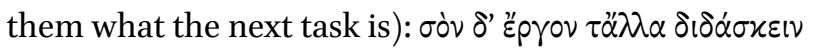

\section{- Conditional Clause}

- $\varepsilon i+2 n d$ person present indicative, 2nd person future indicative (ex. Nub.

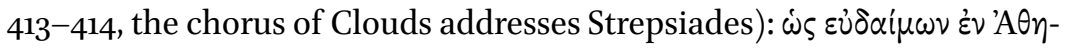

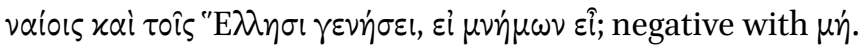

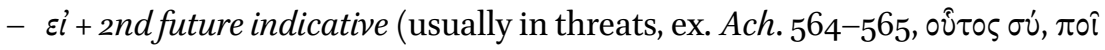

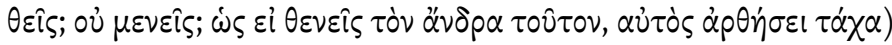

40 The politeness value will, of course, very much depend on the speech-act verb. Here $\dot{\alpha} \pi \alpha-$ ropev́w presents a strong prohibition.

41 On the deontic impersonals, see Denizot (2011: 400-409): since these propose the action as something that 'should or ought' to be done, they can be used to express polite directives.

42 These can have a directive function in the right context; admittedly interpretation is difficult, and opinions will vary on whether a given example counts as a directive. 


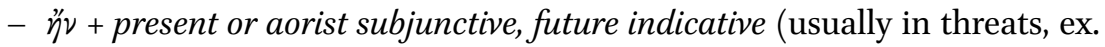

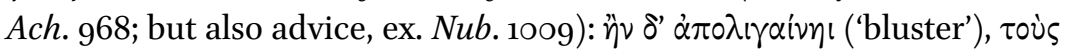
àopavónous $x \alpha \lambda \hat{\omega}$

- $\varepsilon i \mu \eta^{\prime}+$ future indicative, ov( $(x) \ddot{\alpha} v+$ aorist optative (ex. Eccl. 162-163, Praxagora insists the women get things right before they proceed in disguise to

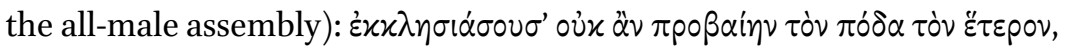

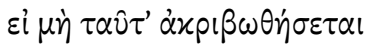

- (öpa) ö $\pi \omega \varsigma+2 n d$ person future indicative (ex. Ach. 253-254, Dicaeopolis asks his daughter to lead a procession in honor of Dionysus): $\alpha^{\prime} \gamma^{\prime}, \hat{\omega} \theta \dot{\gamma} \gamma \alpha \tau \varepsilon p$, ö $\pi \omega \varsigma$

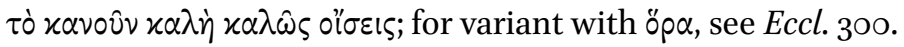

- Prohibitives

- $\mu \eta^{\prime}+2 n d / 3 r d$ person aorist subjunctive (ex. Ach.334, the chorus tries to prevent Dicaeopolis from murdering a charcoal basket, à la Telephus): $\alpha \lambda \lambda \dot{\alpha}$

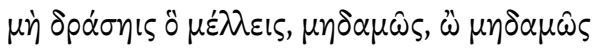

- $\mu \eta^{\prime}+2 n d / 3 r d$ person present imperative (ex. Ach. 334, the chorus does not

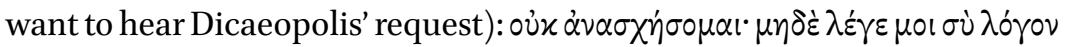

$-\mu \dot{\eta}+2$ 2nd person present subjunctive (ex. Eccl. 437):

- Optative

$-o \dot{v}(\varkappa)+1 s t$ person aorist plural optative + àv (ex. Lys. 309; the chorus of old men exhort each other to kindle the fire and charge the gates):

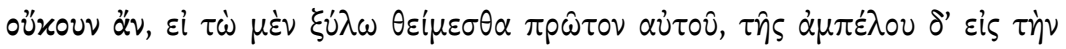

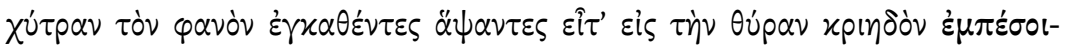
$\mu \varepsilon v$.

- 2nd person present optative $+\ddot{\alpha} \nu$ (ex. Eccl. 132, Praxagora tells someone to speak in the mock-assembly): $\lambda \varepsilon^{2} \gamma o r \varsigma \alpha \alpha \nu$ (but see Ran. 436, Dionysus to his

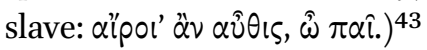

- $\varepsilon \vartheta^{\prime \prime} \varepsilon+2 n d$ person aorist optative in a wish-like construction (ex. Eq. 618-619, where the Knights ask the sausage-seller to relate what happened in the

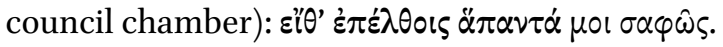

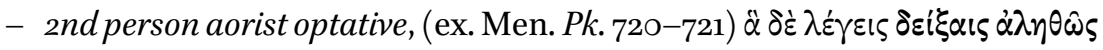

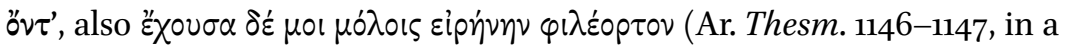
prayer to Athena; cf. Thesm. $368-371$; and $1229-1231) .{ }^{44}$

43 See Schwyzer and Debrunner (1966: 329) on the use of the potential optative as a polite form 'einer Willensäußerung, Bitte, Aufforderung'. But the expression may not be polite per se; context will be important in determining whether it is polite or not. For, as in the the example from Aristophanes' Frogs, cited above, the 2nd person present optative $+\alpha 2 v$ can also be used to express peremptory commands; see also, from a tragedy, Soph. El. 1491

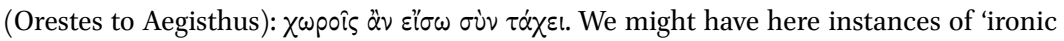
politeness' where politeness is employed to express its opposite.

On this kind of optative, where the speaker dissociates himself from the 'situation d'énon- 


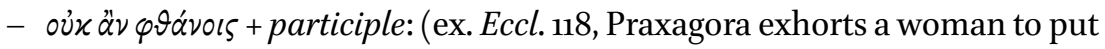

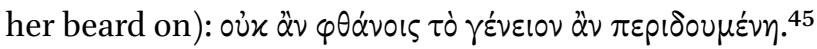

- Verbless Imperatives (ex. Ach. 864, Dicaeopolis speaking to the Theban and

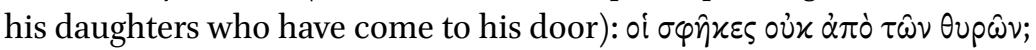

\section{Appendix 2: Types of Politeness Used in Greek Comedy}

\section{Type of softener / Politeness type Example phrase}

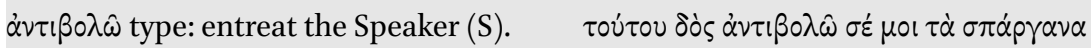
Positive and Negative Politeness. ${ }^{46}$ (Ar. Ach. 431)

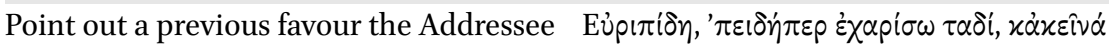
(A) had done. Positive Politeness. ${ }^{47}$

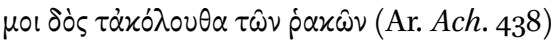

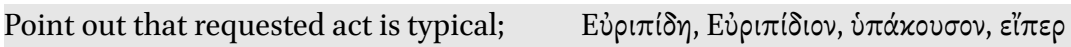
one that A has done before, often. Positive $\tau \dot{\omega}^{\prime} \pi \circ \tau^{\prime} \alpha \dot{\alpha} \theta \rho \dot{\omega} \pi \omega \nu \tau \tau i v i($ Ar. Ach. 405) Politeness. ${ }^{48}$

Minimise. Negative Politeness. ${ }^{49}$ róvov

Don't assume A is willing. Negative Polite- $\alpha i \lambda \hat{\eta 1 s ~(A r . ~ A c h . ~ 772) ~}$ ness. ${ }^{50}$

Don't assume A has time. Negative Politeness. ${ }^{51}$

$\sigma i \dot{~ \delta ’ ~ \eta े \nu ~ \sigma \chi \chi ~}$

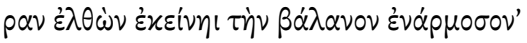
(Ar. Lys. 411-412)

ciation', expressing a desire, and leaving it up to others to carry out the implicit request, see Denizot (2011: 445-455).

45 On this as a prevalently polite act, see Denizot (2011: 468).

46 Brown and Levinson ( ${ }^{2} 1987$ ): positive politeness strategy 2 (pp. 106-108): 'Exaggerate (interest, approval, sympathy with $\mathrm{H}$ )' and negative politeness strategies 5 (178-187) 'Give deference', see esp. Brown and Levinson [ $\left.{ }^{2} 1987: 178\right]$ ) and 6 'Admit the impingement' (188189). From now on, strategies identified and page ranges will come from Brown and Levinson ( $\left.{ }^{2} 1987\right)$. 'S' refers to speaker; ' $\mathrm{H}$ ' to hearer.

47 Positive politeness strategy 14 'Assume or assert reciprocity' (129).

48 Positive politeness strategies 7 'Presuppose, raise, assert common ground' (117-124) and 14 'Assume or assert reciprocity' (129). Ar. Nub. 357.

49 Negative politeness strategy 4 'Minimize the imposition' (176-178).

$5^{\circ}$ Ar. Lys. 1188. Negative politeness strategy 2 'Don't assume H is willing/able' (145-172, esp. 162-163).

$5^{1} \quad$ Negative politeness strategy 2 'Don't assume $\mathrm{H}$ is willing/able' (145-172, esp. 162-163). 
(cont.)

\section{Type of softener / Politeness type Example phrase}

\begin{tabular}{|c|c|}
\hline $\begin{array}{l}\text { Out of respect or love for god, standards, } \\
\text { parents, etc. Negative Politeness. }{ }^{52}\end{array}$ & 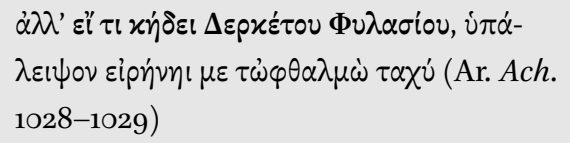 \\
\hline $\begin{array}{l}\text { Express wish of some benefit for A. Posit- } \\
\text { ive Politeness. }{ }^{53}\end{array}$ & 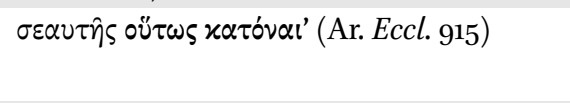 \\
\hline $\begin{array}{l}\text { Show that you take the A into consid- } \\
\text { eration in some way. Positive Polite- } \\
\text { ness. }{ }^{54}\end{array}$ & 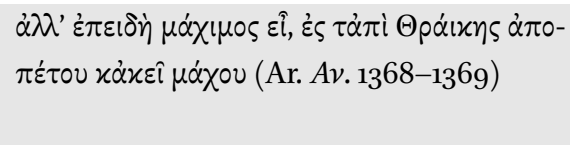 \\
\hline $\begin{array}{l}\text { Promise something to A. Positive Polite- } \\
\text { ness. } 55\end{array}$ & 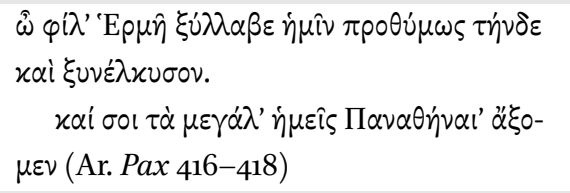 \\
\hline Vocatives PP & 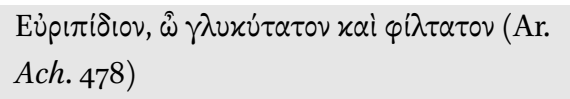 \\
\hline Vocatives NP & $\begin{array}{l}i \dot{\omega} \Lambda \alpha \dot{\alpha} \mu \alpha \chi^{\prime}, \hat{\omega} \beta \lambda \varepsilon \dot{\tau} \pi \omega \nu \dot{\alpha} \sigma \tau \rho \alpha \pi \alpha \dot{\alpha} \text { (Ar. Ach. } \\
568)\end{array}$ \\
\hline
\end{tabular}

\section{References}

Arnott, W.G., (1979-200o), Menander, 3 vols., Cambridge, Mass./London.

Bakker, W.F., (1966), The Greek Imperative: an Investigation into the Aspectual Differences between the Present and Aorist Imperatives in Greek Prayer from Homer up to the Present Day, Amsterdam.

Barrios-Lech, P., (forthcoming), 'Towards a Comparison of Greek and Roman Politeness Systems', in Ł. Berger \& L. Unceta-Gómez (eds.), Approaches to Ancient Greek and Latin Im-/politeness.

$5^{2} \quad$ Negative politeness strategy 8 'State the imposition as a general rule' (206-207). Ar. Plut.

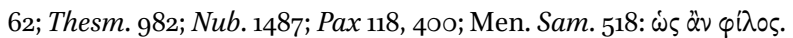

53 Positive politeness strategy 1 'Notice, attend to H. (his [sic.] interests, wants, needs, goods)' (103-104). Ar. Nub. 510.

54 Positive politeness strategy 9 'Assert or presuppose S's knowledge of and concern for H's wants' (125). Ar. Thesm. 763, Men. Dys. 41.

55 Positive politeness strategy 10 'Offer, promise' (125). 
Brown, P. \& Levinson, S.C., ( ${ }^{2} 1987$ [1978]), Politeness: some Universals in Language Usage, Cambridge.

Burnet, J., (1905), Platonis opera, vol. 1, Oxford.

Butler, C., (1985), Statistics in Linguistics, Oxford.

Cunningham, I.C., (1971), Herodas, Mimiambi, Oxford.

Cunningham, I.C., (2004), Herodas, Mimiambi, cum appendice fragmentorum mimorum papyraceorum, Munich/Leipzig.

Denizot, C., (forthcoming), 'How to Be Polite without Saying "Please" in Ancient Greek? The Role of $\delta \dot{\eta}$ in Polite Requests', in L. Unceta Gómez \& Ł. Berger (eds.), Im/politeness Research in Ancient Greek and Latin, Cambridge.

Denizot, C., (2011), Donner des ordres en grec ancien: étude linguistique des formes de l'injonction, Mont-Saint-Aignan.

Dickey, E., (1996), Greek Forms of Address: from Herodotus to Lucian, Oxford.

Dickey, E., (2001), 'Kúpıє, $\Delta \varepsilon \dot{\sigma} \tau о \tau \alpha$, Domine: Greek Politeness in the Roman Empire', Journal of Hellenic Studies 121, 1-11.

Dickey, E., (2009), 'Latin Influence and Greek Request Formula', in T.V. Evans \& D. Obbink (eds.), The Language of the Papyri, Oxford, 208-220.

Dickey, E., (2016a), 'Emotional Language and Formulae of Persuasion in Greek Papyrus Letters', in E. Sanders \& M. Johncock (eds.), Emotion and Persuasion in Classical Antiquity, Stuttgart, 237-262.

Dickey, E., (2016b), 'How the End of Democracy Made the Greeks more Polite', in Aeon, 10 August, 2016. https://aeon.co/ideas/how-the-end-of-democracy-made-the -greeks-more-polite [21/o6/2019].

Ferri, R., (2015), 'Graeca in Latin Texts and Other Emendations', Hermes 143, 503-507.

Kaster, R.A., (2005), Emotion, Restraint, and Community in Ancient Rome, Cary.

Labov, W., (1972), Sociolinguistic Patterns, Philadelphia.

Lloyd, M., (1999), 'The Tragic Aorist', Classical Quarterly 49, 24-45.

Lloyd, M., (2004), 'The Politeness of Achilles: Off-record Conversation Strategies in Homer and the Meaning of Kertomia', The Journal of Hellenic Studies 124, 7589 .

Márquez-Reiter, R., (200o), Linguistic Politeness in Britain and Uruguay: a Contrastive Study of Requests and Apologies, Amsterdam.

Olson, S.D., (2002), Aristophanes, Acharnians, Oxford.

Page, D.L., (1941), Select Papyri: Poetry III. Cambridge, Mass.

Schwyzer, E. \& Debrunner, A., (1966), Griechische Grammatik, Band 2: Syntax und Stilistik, Munich.

Sorrentino, G., (2013), Comunicazione e relazioni interpersonali nelle commedie di Menandro: un'indagine sul Dyscolos e sulla Samia, PhD thesis (University of Freiburg). https://freidok.uni-freiburg.de/fedora/objects/freidok:9582/datastreams/FILE1/ content [18/06/2019]. 
Unceta Gómez, L., (2009), La petición verbal en Latín: estudio léxico, semántico y pragmatico, Madrid.

Unceta Gómez, L., (2018), 'Gli studi sulla (s)cortesia linguistica in latino. Possibilità di analisi e proposte per il futuro', Studi e Saggi Linguistici 56(2), 9-37.

Wilson, N.G., (2007), Aristophanis fabulae, Oxford. 


\title{
Advice-Giving in Roman Comedy: Speech-Act Formulation and $\mathrm{Im} /$ politeness
}

\author{
Łukasz Berger
}

\section{$1 \quad$ Introduction}

The present chapter examines several pragmatic aspects of giving advice in Roman comedy, a speech act particularly concerned with the speakers' selfrepresentation and their social bonds during critical moments of the plot. While orders and threats are mechanisms of exerting power and dominance, good advice in comedy serves to portray father-son and amical relations on stage (Raccanelli 1998: 190). On the other hand, seeking, giving, and receiving advice-planned over many utterances - comprises entire scenes, in which interlocutors manage rapport, while the pragmatic meaning emerges from the on-going interaction. Accordingly, the studies on advice describe multiple possibilities of expressing advice and acknowledge 'a certain fuzziness of the concept itself' (Locher 2012: 7), which is also recognised in Latin scholarship (e.g. Unceta Gómez 2009: 33-34; Barrios-Lech 2016: 274). The following pages set out to address the complexity of the phenomenon of advising in Plautus and Terence, its discursive realisation and its contribution to the Latin system of politeness, as represented in the comedy texts. To this end, I will need to combine various pragmatic perspectives. The speech-act theoretical description of advising (Section 2) will be followed by its analysis in light of the research on im/politeness (Section $3-4$ ). In doing so, I am most indebted to two studies on Latin directives and their im/politeness value: Risselada (1993) and Barrios-Lech (2016). ${ }^{1}$ The existing accounts, arguably, can be further developed by a data-driven analysis of Latin conceptualisations of advising and its consequences for the management of social relations.

In addition, the formulation of speech acts will be investigated in relation to their position within an interaction (Section 5 ) as described by Conversational

1 Cabrillana (2016) combines pragmatics with a sociolinguistic approach to all directive subtypes in one comedy. For studies on Latin requests, see Dickey (2012, 2016). According to Unceta Gómez (2018:13), the directive speech acts are a quintessence of face-threatening acts (see Section 3) and, hence, they are a core issue for the im/politeness studies also in Classical languages. 
TABLE 1 Giving advice in twelve comedies by Plautus and Terence

Plautus Terence Total

\begin{tabular}{llrr}
\hline advisory episodes & 41 & 53 & $\mathbf{9 4}$ \\
turns of advising & 60 & 73 & $\mathbf{1 3 3}$ \\
advisory acts & 75 & 79 & $\mathbf{1 5 4}$ \\
\hline
\end{tabular}

Analysis. ${ }^{2}$ I am also interested in how the act of advising is carried out, starting from the beginning of the adviser's turn. Thus, I shall make a distinction between advisory acts, which are linguistic expressions of a particular piece of advice, and turns of advising, i.e. stretches of talk, carried out by one speaker, which host the advisory act(s). The whole situation of giving advice in one interaction, moreover, will be treated as an episode-this can take the form of a single act (in one turn) or an entire sequence of advising, planned across one or many turns. In order to obtain a more balanced corpus of both authors, to the six plays by Terence I have added six of Plautus' comedies from which I intend to retrieve my data. ${ }^{3}$

As Table 1 shows, the overall number of acts in both authors' corpus are fairly similar, while the selected Plautine comedies seem to contain fewer advisory episodes. On the basis of this limited corpus, I will attempt to establish what types of advisory situation show the highest degree of imposition and how the interpersonal tensions influence both the linguistic expression of the acts and their conversational sequencing.

\section{Advising as a Directive Sub-type}

According to most typologies, advising belongs to a wider group of directives, i.e. speech acts by which the speaker attempts to change the hearer's actions. ${ }^{4}$

2 Hoffmann (1983) first adapted the tools of Conversational Analysis to Roman comedy dialogues, whereas Müller (1997) offered the first systematic account for the dialogues in Terence. See Schegloff (2007) for a comprehensive introduction to the methodology.

3 The two authors, in fact, differ in their storylines and their pursuit of comic effect, as is also visible in their favourite set of stock-characters. For Plautus, I have selected Casina, Curculio, Epidicus, Menaechmi, Stichus, and Trinummus. If it seems profitable, I will sporadically recur to examples from the rest of the plays.

4 Austin (21975: 155-157) mentions the act of advising as pertaining to his group of exercitives, 
The persuasion may take various forms and degrees. Searle (1969: 67) constructs his rule-based definition of advice out of two elements: by advising some future act, the adviser must have some reason to believe that the recipient (from here on: the advisee) will benefit from carrying it out, whereas it is not obvious for either of them that the advisee would carry it out in the normal course of events (i.e. without the advice being given). On the other hand, advice differs from 'stronger' directives such as requests or orders since, as Searle points out, '[a]dvising is more like telling you what is best for you'. From this follows that there is a connection between advice and opinions, assessments, or judgments. Bach and Harnish (1979:49), for instance, point out that 'what the speaker expresses is not the desire that [the hearer] do a certain action but the belief that doing it is a good idea, that it is in [the hearer's] interest'.

The ambiguous status of advisory illocutions will be better explained if, following Risselada (1993: 33), one opts for a prototype classification of speech acts. In her view, advising is a less prototypical member of the directive group; some scholars place it halfway towards assertives, i.e. acts which describe the state of affairs. Accordingly, the uptake of advice, apart from signals of compliance (see tuo consilio faciam in [3]), often includes elements of appreciation and evaluation (see bene mones in [1]), the latter being also a typical reaction to opinions and statements.

The directive sub-type of advising may be further characterised by applying Risselada's (1993: 46-47) criteria of (i) benefit and (ii) bindingness. Accordingly, the future action contained in advice (i) serves the interest of the addressee and (ii) is more optional than orders but more binding than suggestions. Both parameters, however, are not to be understood as fixed in advance or static. In example [1], the old citizen, Periplectomenus, manages to convince the slave, Sceledrus, that his previous accusations towards his neighbour's girlfriend are false. After the servant has apologised, his interlocutor advises him rather insistently to be more discreet from now on. Sceledrus believes in the senex's good intentions, so he takes his words for good advice (bene me mones). The spectators know, however, that Periplectomenus, by persuading the servant to keep his mouth shut, is solely serving his own interest, i.e. he wants to stop the slave from exposing the girl.

which were later included, along with some behabitives, in Searle's (1976: 11) directives. In the typology proposed by Risselada (1993: $36-37$ ), directives may be classified as speech acts about action oriented towards the addressee.

5 Searle (1969: 67). 


\section{[1] Plautus Miles gloriosus 570-573}

Per. ... ignoscam tibi istuc. Sce. at tibi di faciant bene!

Per. ne tu hercle, si te di ament, linguam comprimes, posthac, etiam illud quod scies nesciueris nec uideris quod uideris. Sce. bene me mones. ${ }^{6}$

Per. ... I'll forgive you for this.

Sce. May the gods bless you!

Per. Seriously, if the gods love you, you'll keep your mouth in check. From now on don't know even what you do know and don't see what you do see.

Sce. You're giving me good advice.

In another excerpt, the parasite Peniculus, after having been asked for advice by a high-status Roman matrona, modifies the level of bindingness during the progression of his turn. He formulates a directive act in the subjunctive and then adds a hedge sic censeo 'that's what I think', as if he wanted to reformulate the utterance as an assertive act. Thus, by stressing the subjectivity, Peniculus manages to lower the peremptoriness of his own advice.

[2] Plautus Menaechmi 568-569

Mat. quid ego nunc cum illoc agam?

Pen. idem quod semper: male habeas; sic censeo.

Mat. What should I do with him now?

Pen. The same as always: give him a hard time. That's what I think.

Examples like this show that the optionality and the benefit of the action conveyed in directive sub-types depend on the perception of the participants (see [1]). During the ongoing interaction, that perception may be subject to readjustment (see [2]) and negotiation. In order to grasp this phenomenon, we need to be aware when adopting the prototype approach that there is a 'gradual transition from one speech act [sub-] type to another' (Risselada 1993: 34). Bach

6 Plautus' text and its English translation follow the edition by de Melo (2011-2013). For Terence, I have used Barsby (2001). I will not modify the translations, even though in many occasions the translator's interpretation of the illocutionary force (and the tone of the whole interaction) is different from this presented in the main argument. 
(i) bindingness: BINDING OPTIONAL

(ii) benefit:

$\begin{array}{r}\text { SPEAKER } \\ \text { ADDRESSEE }\end{array} \mid \begin{gathered}\text { supplicate } \\ \text { advisory acts: }\end{gathered}$

FIGURE 1 Advisory acts in the classification of directives MODIFIED FROM RISSELADA (1993: 48)

and Harnish (1979: 49), for instance, propose a general group of 'advisories' in which they include admonishing, counselling, recommending, urging, and warning. In this paper, I will focus on a similar chain of advisory acts that are differentiated according to the degree of compliance they demand (see Figure 1$){ }^{7}$

In spite of using the English speech-act denominations, I will seek, whenever it is possible, to apply a native speaker's taxonomy, retrieved in a bottom-up analysis of the corpus. ${ }^{8}$ Therefore, in order to distinguish particular illocutions, I will take as a starting point the participants' pragmatic metalanguage, i.e. how the interlocutors denominate or describe their own speech activity. Other indications will be provided by further linguistic (e.g. verbal surrounding) and contextual (e.g. type of the interlocutors' relation) cues. ${ }^{9}$

Firstly, Risselada (1993: 48) is right in placing advice 'on the binding side of the scale', but - as will be demonstrated in the following section - this feature depends on other contextual factors such as the authority and the expertise of the adviser, either presupposed or emerging during the interaction. I will start with the speech act covered by the Latin consilium; this type of advice concerns a more symmetrical relation among interlocutors, who, in a troublesome situation, consult one another in search of a solution. This would be the case of the slave Trachalio (see [3]), who accepts the advice (consilium) from another low-status character, even if he himself had a different idea initially. It seems important, nonetheless, that consilium is usually presented as a new

7 Barrios-Lech (2016: 274) chooses to use a wider definition of advice, pointing out that the distinction with suggestions 'proved difficult to make'. My advisory acts, however, will also include instructions and warnings.

8 Using only lay categories, recognised and used by the non-expert participants in conversations, is one of the main premises of the ethnomethodologists and, later on, conversation analysts (see Levinson 1983: 294-296 for a short overview).

9 Compare the methods described by Barrios-Lech (2016: 30-31). 
plan that is yet to be discovered (see reperiamus in [4]). Accordingly, this type of act is connected to the adviser's sphere of expertise (see tuo consilio faciam in [3]), which is understood in relative terms as a level of competence in offering advice claimed for oneself or attributed by others. ${ }^{10}$ Moreover, in a peer-to-peer interaction, this type of advisory episode often entails some further negotiations (see [3] and the continuation of [4]).

[3] Plautus Rudens 96o-962

Tra. ... quid inde aequom est dari mihi? dimidium uolo ut dicas. Grip. immo hercle etiam amplius, nam nisi dat, domino dicundum censeo. Tra. tuo consilio faciam. ${ }^{11}$

Tra. ... What is a fair part I should be given from it? I want you to say half.

Gr. No, even more: if he doesn't give it to you, I think the owner has to be told.

Tra. I'll follow your advice.

[4] Plautus Epidicus 255-256

Per. quid ego faciam? nunc consilium a te expetesso, Apoecides.

Ap. reperiamus aliquid calidi, conducibilis consili.

Per. What should I do? Now I'm seeking your advice, Apoecides.

Ap. Let's find some fresh, expedient plan.

As for monere - another frequent lay denomination of advisory acts - it has a different semantic content. Given its etymological connection with 'memory' (memoria) and 'remembering' (meminisse), this speech act sub-type frequently

10 Thus, it would correspond to Heritage's (2012: 7) relative epistemic status defined 'as a consensual and thus effectively "real" state of affairs, based upon the participants' valuation of one another's epistemic access and rights to specific domains of knowledge and information.'

11 It seems important to add that in this passage the low-status characters do not know each other (cf. Plaut. Rud. 938-958). Trachalio asks Gripus for advice-supposedly—in an unrelated matter which, as it turns out, concerns his interlocutor (962a-963). Hence the (relative) expertise in advising is attributed by Trachalio to his addressee in order to be used, later on, against Gripus' own benefit. 
appears when advisers indicate the solution by simply reminding their interlocutors of the correct way of acting. ${ }^{2}$ Thus, depending on the situation, the act can be understood as an unnecessary admonishment (see [5]) or as good advice (see [6]). On the other hand, monere also encompasses warnings, where the speaker presumes the presence of some likely source of danger or trouble for [the hearer]' (Bach and Harnish 1979: 49)—Periplectomenus in [1] may serve as an example.

\section{[5] Plautus Miles gloriosus 354}

Pal. praecepta facito ut memineris. Phil. totiens monere mirum est.

Pal. Make sure you remember my instructions.

Phil. I'm surprised that you remind me so often

[6] Plautus Menaechmi 344-345

Mes. ... nunc in istoc portu est nauis praedatoria, aps qua cauendum nobis sane censeo.

Sos. mones quidem hercle recte.

Mes. ... Now in that harbor there's a pirate ship which I think we need to be on our guard against.

Sos. You're giving me proper advice.

Finally, if the adviser's authority and/or expertise are markedly higher than the advisee's, as in the case of the cunning slave Palaestrio [7], the advisory acts are referred to as praecepta ('instructions'). In this example, the bindingness of the directive illocution is confirmed by the uptake of the hearer, who will obediently follow (parere) the described course of action. Pyrgopolinices conveys the idea that the source of knowledge is clearly his adviser, whose competence and expertise is foregrounded.

12 Latin monere derives from PIE *mon-eie- 'to make think of, remind' which is a causative suffixed form of the stem *men- 'to think' present in mens 'mind' and meminisse 'to remember' (see de Vaan 2008: 387 ). For the connection between reminding and admonishing being transparent for the interlocutors, see Plaut. Capt. 191: Erg. ... numquid uis? Heg. uenias temperi. Erg. memorem mones. ('Erg. ... Is there anything you want? Heg. Come early. Erg. You're reminding someone who remembers.'). 
[7] Plautus Miles gloriosus 1034-1036

Pyrg. iube adire. Pal. at scin quid tu facias? facito fastidi plenum, quasi non lubeat; me inclamato, quia [sic] tam te uolgo uolgem.

Pyrg. memini et praeceptis parebo.

Pyrg. Have her come here.

Pal. But do you know what you should do? Be full of disdain, as if you weren't interested. Shout at me because I publicize you to the public like this.

Pyrg. I remember it and I'll obey your instructions.

On the opposite end of the bindingness scale, I have found lay denominations of opinions and judgments, like sententia. Accordingly, this highly optional variant of advising is introduced by performative verbs used in assertions, such as censeo in [8]. Moreover, the advisee's autonomy of action, which is salient in this sub-type, will be related to particular (negative-)politeness strategies (see Section 4). Indirectness and minimal bindingness of the act of censere, however, may be perceived as vagueness and a sign of adviser's low personal commitment, as the reaction of the disappointed Demipho confirms below:

[8] Terence Phormio 452-459

Dem. dic nunc, Hegio.

Heg. ego sedulo hunc dixisse credo. uerum itast: quot homines tot sententiae: suos quoique mos. mihi non uidetur quod sit factum legibus rescindi posse; et turpe inceptust. Dem. dic, Crito.

Cri. ego amplius deliberandum censeo: res magnast. Heg. numquid nos uis? Dem. fecistis probe: incertior sum multo quam dudum.

Dem. Now you. Hegio.

Heg. I'm sure that he (pointing to Cratinus) has given you excellent advice. But the truth is, there are as many opinions as there are people; everyone has his own way of looking at things. My own view is that what has been done in accordance with the law cannot be rescinded, and it is dishonorable to try.

Dem. Now you, Crito. 
Cri. I suggest that this needs further deliberation. It's a weighty matter.

Heg. (to Demipho) Is that all?

Dem. (ironically) You've been very helpful. (aside) I'm even more uncertain than I was before.

At this point, it seems important to stress that the illocutionary force of advisory acts does not depend strictly on the linguistic tokens used by the adviser but, as Locher (2012: 4) reminds us, 'the embeddedness of the speech act in the wider speech event is crucial for its interpretation'. It follows that the expectations of the advisee also play a role in how the advice needs to be framed. In the next example [9], the young boy Chaerea is engaging in a 'trouble-telling sequence' with his slave Parmeno. After the servant has jokingly described some audacious course of action, his words are taken up in earnest by Chaerea, who calls the idea a great consilium. ${ }^{13}$

[9] Terence Eunuchus 376-378

Chae. dixisti pulchre: numquam uidi melius consilium dari.

$[\ldots]$

Par. quid agis? iocabar equidem.

Chae. It's a brilliant idea. I've never known better advice.

$[\ldots]$

Par. What are you thinking of? I was only joking.

The advisory acts discussed above can be further categorised by source of competence, i.e. by distinguishing whose expertise and knowledge is salient in designing the future course of action (see Figure 2). ${ }^{14}$ The acts of praecipere, consulere, and censere are anchored within the adviser's competence (with different degrees of bindingness). The monere-type of advice, by contrast, arguably implies that the advisee already knows the solution and only needs to be induced in order to implement the correct action.

13 Thus, Terence seems to be playfully remodelling a typical scene of a slave explaining the deceit to the adulescens who is in love-already Donatus was impressed by this technique (Don. ad Eun. 292, 356, 370). The contrast between planned and accidental action in Eunuchus was studied by Saylor (1975).

14 Accordingly, the competence management would be similar to what Riccioni et al. (2014: 53-54), drawing on Heritage (2012), call epistemic negotiations. The scholars use this framework to analyse face mitigation in Italian conversations. 
bindingness:

binding optional

source of competence: adviser praecipere consulere censere advisee monere

FIGURE 2 Classification of advisories in Roman comedy

The modifications of claimed and perceived source of competence, moreover, seem to run parallel to the negotiations of authority in the on-going advisory episode. The relationship between the interlocutors changes according to whether the advisee agrees to follow the proposed course of action (e.g. tuo consilio faciam) or is willing to admittedly rectify their behaviour out of their own intellectual resources (bene mones, etc.). Interestingly enough, this distinction is humorously exploited by Plautus in the following excerpt.

[10] Plautus Stichus 577-578

Epi. $\quad . .$. atque eccum tibi lupum in sermone: praesens esuriens adest. Pam. ludificemur hominem. Epi. capti consili memorem mones.

Epi. ... And look, here you have the wolf in the fable: he's present hungry.

Pam. Let's make fun of him.

Epi. You're reminding someone who remembers the plan that has been made.

The two brothers, Epignomus and Pamphilippus, see a somewhat tedious hanger-on approaching them on the stage. Pamphilippus makes a proposal to his brother to tease him, but Epignomus, in a turn of a typically Plautine stylistic colouring, responds that there is no need for proposals since his mind has already been made up and the consilium accepted, as if he himself had created the plan. Accordingly, he claims to be the source of the idea along with the competence and authority implied in launching the proposal.

\section{Face-Threat of Giving Advice}

The intricacies of the directive speech act system will prove relevant in the management of social relations. Brown and Levinson $\left({ }^{2} 1987\right)$, who formulated the universal model of politeness, were interested in the consequences that certain illocutions have on the speakers' self-presentation and how it affects their 
relationship. According to Goffman (1955: 213), the participants of an interaction claim a 'face' for themselves, i.e. a public image they construct (in close interrelation with each other) out of positive social values. Brown and Levinson ( ${ }^{2} 1987$ : 62) choose to reinterpret face as 'basic wants, which every member knows every other member desires, and which in general it is in the interests of every member to partially satisfy'. These face needs, in turn, can be subsumed into two categories: 'the desire to be ratified, understood, approved of, liked or admired' (positive-face wants) and the desire that one's own 'action is not impeded' (negative-face wants). In this politeness model, most of the speech acts interfere implicitly with either or both types of face wants and are called face-threatening acts.

According to Brown and Levinson ( $\left.{ }^{2} 1987: 65\right)$, giving advice, just as other directives, primarily threatens the addressee's negative-face want by indicating (in its worst possible interpretation) that the speaker is attempting to impede the hearer's freedom of action. The imposition on the advisee's autonomy strongly correlates with the degree of bindingness conveyed by the directive (sub-)type. On the other hand, performing an act whose felicity conditions include the hearer's benefit must also enhance their positive-face wants. The correct management of face depends on the estimation of interactional risk and possible face damage corresponding to a given advising situation.

Brown and Levinson ( $\left.{ }^{2} 1987: 74\right)$ proposed to calculate the level of face-threat on the basis of-broadly defined-factors of social distance (D) between the interlocutors, their relation of power $(\mathrm{P})$, as well as the ranking $(\mathrm{R})$ of imposition ascribed to the act. The last variable can be further elaborated on by the findings of Goldsmith and MacGeorge (2000: 256), who concluded that the perception of face-threat also depends on the types of goals attributed to advice givers and receivers, the types of problems (for which the degree of $\mathrm{P}$ and $\mathrm{D}$ may be relevant), as well as the content and the sequencing of an advice message.

As for the ranking of the imposition of advising in Roman culture, according to Burton (2004: 224), 'provision of candid advice' is essential for a healthy friendship among free-born of equal status (amicitia), being one of the reciprocal amical favours they perform..$^{15}$ From this set of mutual obligations and expectations, it follows that advisory acts between intimate characters are not very imposing - in fact, they may serve to enhance the social relation by flattering the positive face of both the adviser and the advisee. ${ }^{16}$ Thus, the young

\footnotetext{
15 See Plaut. Epid. 112-113 and Ter. Heaut. 416-419 on young and old men's in-group solidarity and mutual support.

16 In the case of the contemporary Spanish speaking community, Hernández-Flores (1999)
} 
citizen Charinus in [11] may freely and openly ask his friend for advice at the very beginning of the interaction, right after the greeting.

[11] Terence Andria $318-320$

Pam. Charinum uideo. salue. Cha. o salue, Pamphile. ad te aduenio spem, salutem, auxilium, consilium expetens.

Pam. neque pol consili locum habeo neque ad auxilium copiam.

Pam. It's Charinus. Good day.

Cha. Oh. good day Pamphilus. I am coming to you in need of hope, salvation, help, advice.

Pam. Heaven knows I'm in no position to advise and I've no means to help.

Still, the face threat in friendly advice can be considerably high, depending on the goals attributed to the advisers. The Plautine adulescens Lysiteles insists on marrying his friend's sister without a dowry as a way of helping him out in his financial troubles. The other youth, Lesbonicus, does not agree with this generous concession since he does not believe that his friend has his best interest at heart (male consulis ${ }^{17}$ ) (see [12]). From Lesbonicus' point of view, not giving a dowry will humiliate him and put his sister in a shameful marriage.

[12] Plautus Trinummus 633-636

Les. $\quad . .$. [qui] bene quom simulas facere mihi te, male facis, male consulis.

Lys. egone? Lesb. Tune. Lys. quid male facio? Lesb. quod ego nolo, id quom facis.

Lys. tuae rei bene consulere cupio. Lesb. tu [mihi] es melior quam egomet mihi?

sat sapio, satis in rem quae sint meam ego conspicio mihi.

indicates that candid advice is a responsibility of relations and does not need to be balanced against a need to symbolically recognise the other's autonomy.

17 Note that the verb consulere means 'to reflect on something', 'to ask for advice' as well as 'to have in mind the best interest of somebody'. It captures both facets of the advisory episode: reflecting on the problem and seeking to use someone else's expertise. Serving the benefit of the other party during the process is also implied. 
Les. $\quad$... While pretending to do me a good turn, you do me a bad one and treat me badly.

Lys. I?

Lesb. Yes, you.

Lys. In what respect am I doing you a bad turn?

Lesb. In doing what I don't want.

Lys. I wish to act in your best interest.

Lesb. Are you better to me than I am myself? I am intelligent enough, I can see well enough for myself what's in my best interest.

Reluctant to see good intentions in his interlocutor's act, Lesbonicus stresses his autonomy of decision and self-sufficiency (sat sapio 'I am intelligent enough'). Further on in the dialogue, Lysiteles does not hesitate to remind his friend that his impoverished conditions are related to his own indulgent lifestyle while urging him to change his mind. Harsh criticism is interwoven with a more insistent tone in this passage, and the friendly consilium turns into a strong admonishment (674 te moneo hoc etiam atque etiam 'I urge you again and again'). Lesbonicus, however, cannot appreciate his friend's concern and feels rebuked (68o tu obiurgans me 'while you're chiding me').

Furthermore, one could identify a direct relation between the role of expertise and the source of competence with the management of the participants' positive and negative faces in this scene. By considering the act of consulere unhelpful, the advisee implicitly questions the adviser's expertise, threatening his positive face. ${ }^{18}$ Hence, Lysiteles implies by his intensified use of moneo that the hearer should already know and appreciate the proposed course of action. On the other hand, Lesbonicus' competence first seemed damaged by Lysiteles' advice presented as a consilium — now the adviser is implying his resistance to admonishment. ${ }^{19}$

In conclusion, in this short episode we have identified some Roman (emic) correlates of Brown and Levinson's $\left({ }^{2} 1987: 76\right)$ social factors. In order to cal-

18 See also the criticism which the old man Chremes directs towards another senex in Ter. Heaut. 922-923: Chr. ... nonne id flagitiumst te aliis consilium dare, foris sapere, tibi non posse te auxiliarier? ('Chr. ... Isn't it a disgrace that you should give advice to others, be so wise to outsiders and be unable to help yourself?').

19 In the context of this admonitory dialogue, Burton (2004: 224) states that candour (libertas) is 'a potential minefield of misunderstanding and wounded feelings' due to which friends 'need to walk a fine line of admonition'. On the connection between frankness and monere in friendship, see also Cic. Amic. 44, briefly discussed in Hall (2009: 127128). 
culate the imposition of the act, the participants of the advisory episode in comedy have shown to be taking their intimacy, assumed authority (understood as expertise or experience), perceived interactional goals, and contents of the types of action contained in the advisory message into account, especially if the advice entailed elements of criticism. Advice, finally, proved to be facethreatening for all parties involved due to the fact that it changes the relation of power and distribution of competence among the interlocutors. ${ }^{20}$ Hence the 'riskiest' configurations in the social reality depicted by Plautus and Terence are: (i) peer-to-peer advice of free-born characters and (ii) low characters advising a non-intimate superior.

\section{Speech-Act Formulation and Im/politeness}

According to the classical theory of im/politeness, in case of any face-threatening acts, the face wants are addressed by specific formulation types (strategies). After reading through my corpus, I grouped the linguistic tokens of different advisory acts according to Brown and Levinson's $\left({ }^{2} 1987\right.$ : 68-70) classification. They organised the strategies into a hierarchy (I-IV) based on their level of imposition, where the lowest risk of face threat corresponds with the first major formulation type (I) and, respectively, the highest risk leads to the last strategy (IV) or to renouncing from doing the act altogether (which would be $\mathrm{v) \text {. }}$

Thus, giving advice baldly on-record (I) 'involves doing it in the most direct, clear, unambiguous and concise way possible'. I have listed all the forms which express the propositional content of telling others what, in a given situation, is right (decet, aequomst, etc.), what is better for them (melius est) or what they should do (opus est, oportet, and periphrastic gerundival construction). I included all of the imperative sentence types (present and future imperative forms, subjunctive) as well as the directive use of future indicative into this scheme. Even though these forms may convey different advisory acts in specific contexts, they nevertheless tend to imply a higher level of bindingness and are typically used as praecepta - see, for instance, the instructions in future imperative directed by Philto to his son in [13].

20 Similarly, in the context of giving advice, Hall (2009: 118) states that the interaction of Roman aristocrats in the times of Cicero can 'be viewed as an arena for competition rather than cooperation.' 
[13] Plautus Trinummus 297-298

Phil. ... meo modo et moribus uiuito antiquis, quae ego tibi praecipio, ea facito.

Phil. ... Live my way and by the old standards, do what I teach you.

Next, formulations can contain some redressive action 'that attempts to counteract the potential face damage' of the advisory act by a series of modifications and additions which are designed to address either the positive- or the negative-face wants (Brown and Levinson ${ }^{2} 1987$ : 69-70). The negativepoliteness strategies (III) entail, for instance, stressing the adviser's subjective point of view or the option of non-compliance by using the metalanguage of advice (Berger 2017: 270-271). Non-agentive advisory expressions seem to produce a similar redressive action (Brown and Levinson ${ }^{2} 1987$ : 191-194). As for positive-politeness mitigation (II), among the identified strategies, one could mention evoking a close bond with the advisee, searching for common ground, or including oneself in the realisation of the action..$^{21}$ These are the strategies used by the senex Demea, who has recently experienced a self-induced transformation and is now trying out being extremely polite and considerate with others (see [14]). Interestingly enough, the change of his habitual speech pattern is achieved mainly through positive politeness while elsewhere in comedy old men are depicted as mostly concerned with negative-face wants (BarriosLech 2016: 56-57; Berger 2017: 271).

[14] Terence Adelphoe 948-955

Dem. ... bene nos aliquid facere illi decet.

Mic. quid facere? Dem. agellist hic sub urbe paullum quod locitas foras.

huic demus qui fruatur. Mic. paulum id autemst? Dem. si multumst, tamen

faciundumst: pro patre huic est, bonus est, noster est, recte datur, postremo nunc meum illud uerbum facio quod tu, Micio, bene et sapienter dixti dudum: 'uitium commune omniumst,

21 See Brown and Levinson $\left({ }^{2} 1987: 127-128\right)$ for the strategy of including both the speaker and the hearer in the activity. 
quod nimium ad rem in senecta attenti sumus'? hanc maculam nos decet

affugere. et dictumst uere et re ipsa fieri oportet.

Dem. ... We should do something for him.

Mic. Do what?

Dem. There's that small plot of land just outside the town which you let out. Let's give him the enjoyment of that.

Mic. That's a little plot?

Dem. Even if it's a large one, we should do it. He's like a father to the girl, he's a good man, he's one of us. It's a gift well given. When all's said and done, can't I adopt for myself the remark which you made just now, Micio, so wisely and so well? 'It's a common fault of all of us that in old age we are too worried about money.' We should avoid that reproach. It's sound advice and we should carry it out in practice.

While Demea formulates his advice to his brother, he repeatedly states that the decision is to be made together (nos decet; demus). The old man also addresses his interlocutor directly in order to demonstrate that the compliance would simply be following the advisee's own rules of conduct. This searching for common ground and indicating shared values serves, at the same time, to include face-enhancing praise (bene et sapienter dixti; dictumst uere). ${ }^{22}$ Still, one cannot overlook that these tokens of positive politeness are interwoven with mitigation that attends to negative-face wants, e.g. syntactical deletion of the addressee through non-agentive directive expressions (faciundumst; fieri oportet). Moreover, the advice is supplied by argumentation and justification by which the described course of action does not seem arbitrary nor peremptory. Accordingly, the redressive action in advisory acts proves to be a complex, sometimes multi-turn, procedure which, moreover, combines the positive- and the negative-politeness strategies in the same formulation. ${ }^{23}$

The last way of giving advice (IV) is doing it off-record, i.e. in such a way that 'it is not possible to attribute only one clear communicative intention

22 On compliments in Plautus and their contribution to linguistic politeness, see Unceta Gómez (2019). Here the act of praising seems to be ambiguous. Evoking Micio's own words and his rules of behaviour is also important for the plot: through his transformation, Demea seems to be trying to ridicule Micio's generosity and gentle spirit.

23 See also Hall (2009: 118-127), who discusses extensively the politeness strategies of giving advice through letters between Cicero and his peers. 
to the act' (Brown and Levinson ${ }^{2} 1987: 211$ ). Thus, the speaker avoids taking full responsibility for the illocution, leaving the interpretation of the utterance to the addressee. The off-record formulation, therefore, should be associated with the least binding advisory acts such as the act of censere or giving suggestions and hints, whose directive illocutionary force is derived inferentially from the context. The question launched by the banker Lyco in [15] violates the Gricean maxim of relevance (he does not contribute with any new information responding to Cappadox' inquiry) and of sincerity (he does not expect to be given an actual answer). ${ }^{24}$ By making a correct inference, Cappadox interprets the turn as a helpful admonishment (monere).

[15] Plautus Curculio 457-46o

Lyco argentum accipias, cum illo mittas uirginem.

Cap. quid quod iuratus sum? Lyco quid id refert tua, dum argentum accipias? Cap. qui monet quasi adiuuat.

Lyco Take your money and send the girl off with that man.

Cap. What about the oath I gave?

Lyco What does that matter to you so long as you receive your money?

Cap. He who advises helps, so to speak.

On the other hand, if the off-record strategy comes after an explicit request for advice, the comprehension process is more straightforward. For example, the young citizen Antipho is hinting to his slave Geta that he should steal the money from the youth's own father. The boy is expressing the advisory act by means of a declarative sentence type.

[16] Terence Phormio 540-542

Get. quid faciam? Ant. inuenias argentum. Get. cupio; sed id unde edoce.

Ant. pater adest hic. Get. scio. sed quid tum? Ant. ah! dictum sapienti sat est.

Get. itane? Ant. ita. Get. sane hercle pulchre suades.

24 For rhetorical questions as a frequent off-record strategy, see Brown and Levinson $\left({ }^{2} 1987\right.$ : 223-225). In describing the process of interpreting the off-record politeness strategy, the scholars refer to Grice's (1975) conversational maxims (Brown and Levinson ${ }^{2} 1987$ : 211-212, with a brief discussion). 
Get. By doing what?

Ant. Finding the money.

Get. I'd like to. But explain where?

Ant. My father's back home.

Get. I know, but what follows?

Ant. Oh! Can't you take a hint?

Get. Really?

Ant. Really.

Get. That is fine advice, for god's sake!

This category (IV) includes rhetorical questions (see [15]) or opinions and statements in declarative sentence types (see [16]).

The final calculation based on 154 advisory acts extracted from twelve comedies by Plautus and Terence are presented in Table 2. The proportions between illocutions formulated baldly on record $(49.4 \%)$ and with some kind of mitigation $(42.9 \%)$ are very similar. It is, however, worth keeping in mind that for these statistics I have only counted the elements of redressive action that are contained in the host advisory turn, although we have already seen that some face-work can be achieved in wider conversational surroundings.

It might be surprising that features of positive politeness are more frequently used than negative-face mitigation but the proportions are somehow tainted by certain formulations that seem to be combining both formulation strategies (grouped under 'mixed strategies'). ${ }^{25}$ This also makes the attempt to search for preferences in the distribution of a given strategy among the character types problematic - at least in a limited corpus such as this.

It may be useful to see if the contexts with a high imposition do indeed lead to 'polite' strategies of act realisation, especially in the first turn, where the concern for face is at its highest (see Section 3).

For the next quantitative analysis (see Table 3), I selected only the 'risky' configurations of advising: (i) peer-to-peer interactions of free-born characters and (ii) episodes of low-status character advising a superior. Even if face management plays an important role in (i), there is still a surprisingly high proportion of the least 'polite' formulation, baldly on-record ( $38.9 \%)$; it is even higher in contexts in (ii) $(63 \%)$.

25 The study of Goldsmith and MacGeorge (2000) tested the perception of the face-threat of giving advice in English. Similarly to the findings in this chapter, their sample advice messages were not seen by the language users as very threatening for the negative face, while the concern for the positive face was almost as important. 
TABLE 2 Formulation of advisory acts in the corpus distributed according to politeness strategies

\begin{tabular}{lccc}
\hline Speech-act expression & N $^{\circ}$ Politeness strategy & Total \\
\hline future indicative & 1 & (I) bald on-record & $76(49.4 \%)$ \\
simple imperative & 35 & & \\
present subjunctive & 14 & \\
future imperative & 6 & \\
periphrastic gerundival construction & 3 & \\
oportet / opus est "You should" & 8 & \\
decet / licet / aequom est "It's (only) right" & 3 & \\
satiust / meliust / potiust "It's better" & 6
\end{tabular}

+ seeking for common ground and values, evoking interpersonal bond

30 (II) positive-politeness $30(19.5 \%)$ mitigation (etc.)

combination of (II) and (III)

11 (II-III) mixed strategies $11(7.1 \%)$

+ stressing the subjectivity and optionality, deletion of the participants

25 (III) negative-politeness $25(16.2 \%)$ (etc.) mitigation

rhetorical questions

non-modal assertives

6 (IV) off-record

$12(7.8 \%)$

6

total 154

The predictive inaccuracies that Brown and Levinson's $\left({ }^{2} 1987\right)$ classic model exhibits were addressed by later methodological proposals. One of the reservations of the so-called discursive approach to im/politeness was that politeness should be viewed as a dynamic, participant-oriented concept that exceeds boundaries of a single utterance (see van der Bom and Mills 2015: 181-184, with further references). Thus, in the following section, I will test the potential value of 'polite' act formulation against its position in the dialogical sequence. 
TABLE 3 Politeness strategies in highly face-sensitive social contexts (tested in 12 Roman comedies)

\begin{tabular}{lclll}
\hline & $\begin{array}{c}\text { Baldly on } \\
\text { record (I) }\end{array}$ & $\begin{array}{l}\text { With redressive } \\
\text { action (II-III) }\end{array}$ & $\begin{array}{l}\text { Off-record } \\
(\mathbf{I V})\end{array}$ & $\begin{array}{l}\text { Total } \\
(100 \%)\end{array}$ \\
\hline $\begin{array}{c}\text { male-to-male } \\
\text { senex-to-senex }\end{array}$ & $14(38.9 \%)$ & $18(50.0 \%)$ & $4(11.1 \%)$ & 36 \\
$\begin{array}{l}\text { adulescens-to-adulescens } \\
\text { low-to-superior }\end{array}$ & 2 & 16 & 3 & \\
$\begin{array}{c}\text { seruus-to-senex } \\
\text { seruus-to-adulescens }\end{array}$ & $29(63.0 \%)$ & $15(32.6 \%)$ & $2(4.3 \%)$ & 46 \\
total & 9 & 5 & 2 & \\
& $43(52.4 \%)$ & $33(40.2 \%)$ & $6(7.3 \%)$ & 82 \\
\hline
\end{tabular}

In order to identify the conversational pattern of the advisory episode, one should first make a distinction between advice that is on-demand and advice that is not-sought-for. In case one, the interlocutor is searching for advice and the prototypical sequence of talk consists of at least three turns: (i) request for advice, (ii) granting of the advisory act, and (iii) evaluation and/or promise of compliance. In terms of CA, the first pair of turns is an adjacency pair, which, moreover, tends to be minimally expanded by a third, sequence-closing element or evaluation turn which is designed not to project any further withinsequence talk beyond itself' (Schegloff 2007: 118). This prototypical three-turn sequence appears throughout the entire chapter but is presented-for clarity—in the following excerpt [17]: a conversation between two old men, Laches and Phidippus.

\section{[17] Terence Hecyra 715-719}

Lach. quid ergo agam, Phidippe? quid das consili? (i)

Phi. quid agas? meretricem hanc primum adeundam censeo.

oremus, accusemus, grauius denique.

minitemur si cum illo habuerit rem postea.

Lach. faciam ut mones. (iii)

Lach. What shall I do, Phidippus? What's your advice?

Phi. What should you do? I suggest that we approach this mistress of his first. Let's appeal to her, put the accusation in front of her, and 
finally threaten some firm action if she has anything to do with him in the future.

Lach. I'll do as you suggest.

Interestingly, here, the request for advice includes two elements: the expression of doubt as to what course of action to take (quid ergo agam?) and an actual demand for a consilium. As far as distribution of competence is concerned, Laches is willing to confer the authority to his interlocutor and thus enhance his positive-face wants. Phidippus, however, by his turn-opening rhetorical question (quid agas?) seems to be implying that the right course of action is quite obvious. In reaction, Laches tries to save his own positive face by anchoring the idea within his own expertise: he reinterprets the act not as an adviser-oriented consilium but as a kind of admonishment (faciam ut mones). The act of compliance-perhaps significantly—does not contain any element of praising (e.g. bene/recte/pulchre mones), which normally enhances the adviser's positive-face. Despite these tensions in the distribution of authority, the adviser still addresses the face-needs of his interlocutor: he combines the deletion of the hearer in the first act (negative politeness) with the inclusion of himself in the realisation of the action (positive politeness) in the following formulations (oremus, accusemus, minitemur). ${ }^{26}$ Finally, it is worth noting that the advisory acts are ordered from more (periphrastic gerundival construction with censeo) to slightly less (subjunctive) 'polite' formulationsboth, however, with redressive action. Thus, the arrangement of the elements inside the turn proves to be relevant also for the calculation of interactional risk.

Another available option in the sequencing of the act is giving advice that is not requested explicitly and, hence, potentially unwanted. Menaechmus talks to the slave Messenio, thanking him for his help in a violent incident on the street. Since the servant mistakes Menaechmus for his own master, he uses the opportunity to suggest that, in exchange, he himself deserves to be liberated. This type of self-offered advice might be analysed not as a reaction to a request but as (i) an initiatory action (offering advice) paired with (ii) the following evaluation:

26 While Phidippus could have also meant that they should go meet the courtesan together, in the following scene, she is only approached by Laches (Ter. Hec. 731)—Phidippus never gets to talk to the woman. The polite extension of the reference in the directive is also confirmed by its first-person uptake ( faciam). 


\section{[18] Plautus Menaechmi 1021-1024}

Men. at tibi di semper, adulescens, quisquis es, faciant bene. nam apsque te esset, hodie numquam ad solem occasum uiuerem.

Mes. ergo edepol, si recte facias, ere, med emittas manu. (i)

Men. liberem ego te?

Men. May the gods always bless you, young man, whoever you are: if it hadn't been for you, I'd never have lived till sunset today.

Mes. Then if you were to do the right thing, master, you'd set me free.

Men. I should free you?

Risselada (1993: 57) remarks that compliance to directives on demand (i.e. in a second-pair-part position) is partially 'guaranteed' by the initiating turn. She concludes that the act in a first-pair-part position is more likely to contain tokens of politeness. Analogously, it follows from the discussion on face-threat in section 3 that this variant of sequence includes a higher level of imposition. All the constraints mentioned until now that shape the predictions on politeness seem to be at work in Messenio's formulation. The servant, while giving unsolicited advice on a serious matter (his manumission) to a person he takes for his master, chooses the positive-politeness strategy. Messenio addresses the master directly (ere) and he appeals to values (recte facere) he presumes his interlocutor shares. ${ }^{27}$

This rule may also be verified in a single interaction. In [19], the slave Stasimus is called after by his master, but-unwilling to look back-he cannot recognise him. The first unsolicited advisory act launched by the servant is formulated baldly on-record with a moral-evaluative expression (meliust + inf.). The next act, however, which comes after an explicit request (quid ago?), contains a more binding token: an unmitigated imperative. The socially defined imposition should not have changed significantly over one turn of talk; therefore, much the same value of politeness may be conveyed through different linguistic tokens, depending on different conversational contexts.

27 For the positive-politeness strategy of presuming that the hearer has the same values as the speaker, see Brown and Levinson ( ${ }^{2} 1987$ : 123-124). 
[19] Plautus Trinummus 106o-1063

Char. aha nimium, Stasime, saeuiter!

Stas. emere meliust quoi imperes. Char. pol ego emi atque argentum dedi; sed si non dicto audiens est, quid ago? Stas. da magnum malum.

Char. bene mones, ita facere certum est.

Char. Ah, Stasimus, you're behaving too violently!

Stas. It's better to buy someone to order around.

Char. I did buy someone and paid money; but if he doesn't obey me, what am I to do?

Stas. Give him a big thrashing.

Char. You're giving me good advice, I'm resolved to act accordingly.

Still, if during a face-sensitive social interaction the character launches unsolicited and unmitigated advisory turns, there should, as an alternative to mitigation, be some face-managing mechanisms. One such politeness-motivated phenomenon may be localised in the act's verbal embedding and, more specifically, in the design of its turn-host.

Firstly, I argue that postponing the advisory act within the turn might have a redressive function. This effect is most visible if the adviser reverses the order of advice and its justification or explanation, which-as I have pointed out before-avoids the peremptoriness of the directive (see Section 3). In the trouble-telling sequence [20], the slave Byrria uses a bald on-record formulation (subjunctive uelis) but arguably mitigates the imposition by first presenting the reasons for offering this particular piece of advice. The postponed advisory act of a slave talking to his young master may be compared with the next example [21], where the old father fronts his urgent advice (directed to his daughter in danger) in a turn-initial position. Here, the content of the act and its early placement inside a turn is more important than any politeness feature.

[20] Terence Andria 305-306

quaeso edepol, Charine, quoniam non potest id fieri quod uis, id uelis quod possis.

Please, Charinus, for god's sake, since you can't have what you want, want what you can have. 


\section{[21] Plautus Menaechmi 850-851}

fuge domum, quantum potest, ne hic te optundat.

Run off home as fast as possible so that he doesn't beat you.

Moving on to more face-sensitive contexts, in [22] the speaker introduces the act by means of a mitigating preface that prepares the ground for a baldly onrecord performed directive: the advice given by the doctor. The introductory part is even separated from the rest of the speaker's utterance by a verse-final pause. This mechanism allows the adviser to create a fictitious scenario in which his advice is actually a reactive action—-towards his own words.

[22] Plautus Menaechmi 946

scin quid facias optimum est?

ad me face uti deferatur.

Do you know what you'd better do? Have him taken to my place.

[23] Plautus Menaechmi 1023

ergo edepol, si recte facias, ere, med emittas manu.

Then if you were to do the right thing, master, you'd set me free.

The imposition that self-selection in advisory acts constitutes can also be partially compensated through cohesive linguistic elements. Messenio (see [23] and [18] above), for instance, conveys that the advice is a logical consequence (ergo) of the advisee's previous talk.

Consequently, the positioning of advisory acts in the conversation might also be relevant for the politeness prediction and the actual interpersonal impact of certain types of formulation. Apart from high-imposition social configurations for speech activity, one should also look into 'risky' conversational contexts. The examples presented in this section suggest that the highest facethreat should be ascribed to unsolicited advice, fronted in turn-initial position, first in a series of acts (if there is any) and without perceivable connection to the previous conversational material. 
TABLE 4 Correlation between parameters of advisory acts and politeness strategy

(orders)

praecipere (I) baldly on-record

consilum dare (II-III) with redressive action consulere

monere

censere (IV) off-record

(statements)

\section{$6 \quad$ Conclusions}

This chapter proposes a wider pragmatic approach to advising in Roman comedy in order to better grasp its theoretical elusiveness as a protean illocution type with multiple expressive means. First, the phenomenon was analysed as a chain of directive sub-types (advisory acts), differentiated according to the factor of bindingness and distribution of the competence. Arguably the latter distinction-between the acts attributed only to adviser's intellectual resources (praeceptum, consilium, and sententiae) and the knowledge already stored in the advisee's mind (monere) — is more important than, for instance, the (English) one between advice and warning.

Further, I have tentatively connected the formulation of the advisory acts with Brown and Levinson's $\left({ }^{2} 1987\right)$ politeness strategies. Certain ways of compensating the face-threat tend to correspond with particular types of illocution identified in the corpus (see Table 4) since a more direct (i.e., baldly on-record) formulation normally conveys more binding speech acts, while the off-record strategy sometimes results in assertive-like expressions of the advisory act.

Despite the correlations, it was often necessary to stress that the illocution type, just like the politeness value, was a result of a rather complex interaction between social (power relation, distance, ranking of imposition) and contextual (verbal surrounding) constraints. Regarding the latter, I hope to have demonstrated some correlations between the act formulation, its evaluation in terms of politeness, and its position in a wider discursive environment: inside 
a sequence, in an adjacency pair, and inside a turn. Such discourse-oriented analysis might arguably be a more nuanced approach to investigate the ways of doing politeness and, from a wider perspective, of doing things with words in dramatic dialogues.

\section{References}

Austin, J.L., (21975 [1962]), How to Do Things with Words, Oxford.

Bach, K. \& Harnish, R.M., (1979), Linguistic Communication and Speech Acts, Cambridge, Mass.

Barrios-Lech, P., (2016), Linguistic Interaction in Roman Comedy, Cambridge.

Barsby, J., (2001), Terence. Comedies, 2 vols., Cambridge, Mass./London.

Berger, Ł., (2017), 'The Old Man and Linguistic Politeness in the Comedies of Plautus', Symbolae Philologorum Posnaniensium Graecae et Latinae 27, 249-273.

Bom, I. van der \& Mills, S., (2015), 'A Discursive Approach to the Analysis of Politeness Data', Journal of Politeness Research 11, 179-206.

Brown, P. \& Levinson, S.C., ( ${ }^{2} 1987$ [1978]), Politeness: some Universals in Language Usage, Cambridge.

Burton, P.J., (2004), 'Amicitia in Plautus: a Study of Roman Friendship Processes', American Journal of Philology 125, 209-243.

Cabrillana, C., (2016), 'Directives in Latin Comedy: Pragmatics, Dramatic Role and Social Status', Journal of Latin Linguistics 15, 179-214.

Dickey, E., (2012), 'How to Say "Please” in Classical Latin', Classical Quarterly 62, 731748.

Dickey, E., (2016), 'Politeness in Ancient Rome: Can it Help us Evaluate Modern Politeness Theories?', Journal of Politeness Research 12, 197-220.

Goffman, E., (1955), 'On Face-work: an Analysis of Ritual Elements in Social Interaction', Psychiatry 18, 213-231.

Goldsmith, D. \& MacGeorge, E., (2000), 'The Impact of Politeness and Relationship on Perceived Quality of Advice about a Problem', Human Communication Research 26, 234-263.

Grice, H.P., (1975), 'Logic and Conversation', in P. Cole \& J.L. Morgan (eds.), Speech Acts, New York, 41-58.

Hall, J., (2009), Politeness and Politics in Cicero's Letters, Oxford.

Heritage, J., (2012), 'Epistemics in Action: Action Formation and Territories of Knowledge', Research on Language \& Social Interaction 45, 1-29.

Hernández-Flores, N., (1999), 'Politeness Ideology in Spanish Colloquial Conversation: the Case of Advice', Pragmatics 9, 37-49.

Hoffmann, M.E., (1983), 'Conversation Openings in the Comedies of Plautus', in H. Pink- 
ster (ed.), Latin Linguistics and Linguistic Theory. Proceedings of the ist International Colloquium on Latin Linguistics (Amsterdam, April 1981), Amsterdam, 217-226.

Levinson, S.C., (1983), Pragmatics, Cambridge/New York.

Locher, M.A., (2012), 'Introduction to Advice in Discourse', in H. Limberg \& M.A. Locher (eds.), Advice in Discourse, Amsterdam/Philadelphia, 1-27.

Melo, W. de, (2011-2013), Plautus. Comedies, 5 vols., Cambridge, Mass./London.

Müller, R., (1997), Sprechen und Sprache. Dialoglinguistische Studien zu Terenz, Heidelberg.

Raccanelli, R., (1998), L'amicitia nelle commedie di Plauto: un'indagine antropologica, Bari.

Riccioni, I., Bongelli, R., \& Zuczkowski, A., (2014), 'Mitigation and Epistemic Positions in Troubles Talk: the Giving Advice Activity in Close Interpersonal Relationships. Some Examples from Italian', Language \& Communication 39, 51-72.

Risselada, R., (1993), Imperatives and Other Directive Expressions in Latin: a Study in the Pragmatics of a Dead Language, Amsterdam.

Saylor, C.F., (1975), 'The Theme of Planlessness in Terence's Eunuchus', Transactions of the American Philological Association 105, 297-311.

Schegloff, E.A., (2007), Sequence Organization in Interaction, Cambridge.

Searle, J.R., (1969), Speech Acts: an Essay in the Philosophy of Language, Cambridge.

Searle, J.R., (1976), 'A Classification of Illocutionary Acts', Language in Society 5, 1-23.

Unceta Gómez, L., (2009), La petición verbal en latín. Estudio léxico, semántico y pragmático, Madrid.

Unceta Gómez, L., (2018), 'Gli studi sulla (s)cortesia linguistica in latino. Possibilità di analisi e proposte per il futuro', Studi e Saggi Linguistici 56(2), 9-37.

Unceta Gómez, L. (2019), 'I complimenti e il loro contributo all'espressione della cortesia linguistica nelle commedie di Plauto', Dionysus ex machina 10, 283-311.

Vaan, M. de, (2008), Etymological Dictionary of Latin and the Other Italic Languages, Leiden/Boston. 


\title{
The Politics of Manipulation: Politeness and Insincerity in the Language of Parasites and Courtesans in Plautus' Comedies
}

\author{
Luis Unceta Gómez
}

In recent years, significant advances have been made in our understanding of linguistic politeness phenomena in Classical languages, especially in Latin. ${ }^{1}$ The analysis of impoliteness has also been addressed, although to a lesser degree. $^{2}$ However, the concept of over-politeness-that is inappropriate, excessive, and/or insistent use of politeness strategies - along with the problem of sincerity in politeness practices, has not been sufficiently explored in Latin, with the exception of Hall's notable approach to latent hypocrisy in certain polite fictions in Cicero's letters. ${ }^{3}$ This study seeks to further explore this issue by examining the comedies of Plautus, specifically, two stock characters from his works, namely the courtesan and the parasite, who make use of certain politeness strategies for manipulative purposes, aiming to control others for their own benefit. In both cases, these characters are known for their disingenuousness in the 'working' sphere, to the extent that their very sustenance might be said to depend on hypocrisy and feigned amiability. 4

If politeness is understood as a 'social lubricant', sincerity may tend to take second priority (in order) to maintain good social relations, ${ }^{5}$ something that was already noted by Goffman (1959). There is a variety of motives for expressing oneself insincerely, and not all lies are antisocial. This is especially observable in compliments, where certain insincere affirmations fulfil a clearly proso-

1 See Unceta Gómez (2018).

2 Iurescia (2019a) offers a complete analysis of the expression of impoliteness in Latin comedy and novel. See also Roesch (2019).

3 Hall (2009: 78-106). See also Unceta Gómez (2019a), on the in/sincerity of certain expressions of happiness as a positive politeness strategy in comedy.

4 I cannot embark here on the complex definition of the concept of 'insincerity'; see Stokke (2014, 2018: esp. 171-198) for a complete analysis.

5 See, for instance, Davidson (2004: 1). According to this author's claims, in 18th century Britain, the concept of hypocrisy was identified with good manners and politeness, becoming an exclusive privilege of the elite, and thus beyond the reach of the servant class. 
cial function. ${ }^{6}$ But there are also certain other insincere statements where the speaker seeks to obtain a benefit at the expense of someone else. The latter will be the focus of my interest here.

Schulze (1984) put forward the manipulative potential of politeness, and Sorlin (2017) has analysed it in detail. The latter questions the altruistic orientation of classical politeness models, such as those by Brown and Levinson $\left({ }^{2} 1987\right)$ and Leech (2014), and suggests the need to consider the speaker's personal motives and goals as well as the perlocutionary effects of his/her speech acts, in order to understand how manipulative discourse can 'parasitise' certain politeness strategies. ${ }^{7}$

At any rate, within a communicative exchange, it is not always easy to draw the line between sincerity and insincerity. From the viewpoint of politeness research, the degree of sincerity may be judged with regard to the propositional content of a specific utterance, or with regard to interest in maintaining good social relations, whereby the prosocial value of certain insincere utterances is justified. ${ }^{8}$

Things are more complicated in the case of ancient languages, where quite a number of fundamental parameters for correctly interpreting im/politeness phenomena are not accessible to us. For example, it is quite likely that insincerity in Latin could be perceived in suprasegmental or non-linguistic features, such as voice pitch or facial expressions: ${ }^{9}$ data that lies outside our reach. We may be sure, however, that these types of perception were possible for Latin speakers, as is confirmed by the lexicalisation of ideas such as 'manipulative amiability', 'adulation' and 'insincere flattery' in verbs like blandiri ${ }^{10}$ 'to behave

6 Talwar et al. (2007). Along these lines, the etymological connection between Spanish semblante (from Catalan semblant) 'facial expression, face, aspect', and Latin simulare 'to put up, pretend, simulate' (derivative of similis 'similar') is also instructive. On compliments in Plautus' comedies, see Unceta Gómez (2019b).

7 Sorlin (2017) defines the limits of the concept of 'manipulation' as follows: 'manipulation could be conceived on a spectrum between persuasion on the one hand and coercion on the other, bearing in mind that manipulation leaning on the side of persuasion would tend to be more belief-based than it is in coercive manipulation. In the latter case, the manipulator would seek to coerce the victims into acting in a certain way (through linguistic/pragmatic — not physical—means) rather than coercing them into adopting the Speaker's beliefs' (Sorlin 2017: 135). On manipulative uses of impoliteness in Plautus, see Iurescia (2016).

8 See, for instance, Pinto (2011: 231).

9 On English, see Fish et al. (2017).

10 According to Barrios-Lech (2016: 120), blanditia should not necessarily be considered a form of manipulation: 'women use the characteristic features of blanditia-amabo and $m i+$ vocative-even when they are not attempting to flatter. [...] blanditia could 
or speak ingratiatingly, flatter', adulare 11 'to flatter in a servile manner, fawn upon', assentari 'to flatter by agreeing', or palpari 'to act in a soothing or cajoling manner', and their corresponding lexical families.

Beyond these linguistic considerations, a few metapragmatic comments offer first-hand information about the in/sincerity of certain obsequious behavioural patterns. The greedy Euclio [1], for instance, thinks he sees a change of attitude in his neighbours after he has found a treasure, though he keeps it hidden: ${ }^{2}$

\section{[1] Plautus Aulularia 182-185}

Meg. saluos atque fortunatus, Euclio, semper sies.

Euc. di te ament, Megadore. Meg. quid tu? recten atque ut uis uales?

Euc. non temerarium est ubi diues blande appellat pauperem. iam illic homo aurum scit me habere, eo me salutat blandius.

Meg. (loudly) May you always be well and blessed, Euclio.

Euc. May the gods love you, Megadorus.

Meg. Well then? Are you in good health, just as you wish?

Euc. (aside) It's not by chance when a rich man addresses a poor one in such an ingratiating way. Now he knows I have the gold, that's why he's greeting me more politely. ${ }^{13}$

But, before going on to address this type of behaviour, certain general concepts about the principles that govern politeness in Latin must be presented.

simply describe a polite way of speaking typically ascribed to women. [...] The word blandus and its cognates have at least two main connotations, "flattering/manipulative" or simply "polite". Nevertheless, as Hall (20og: 80) points out, 'Cicero regularly uses the term blandus and its cognates to refer to language that seems overly effusive and manipulative'.

11 On the etymology of adulare, see Clackson (2017), who, after rejecting the previous proposals, considers it to be a parasynthetic formation originating from a syntagma ad culum, so that, starting from the canine custom of smelling the anus, it would have passed metaphorically to the meaning 'to flatter' (a similar movement is found in English expressions such as arse-licking and brown-nosing).

12 See also Plaut. Aul. 113-117. Pseud. 448-452 offers a reflection on the usefulness of amiability (blandis uerbis). And Most. 181 presents an explicit rejection of insincere praise.

13 Texts and translations are borrowed from the Loeb edition by Wolfgang de Melo (20112013). 
Politeness in Latin includes a whole constellation of different ideas whose common thread is the need to acknowledge oneself, and be acknowledged by others as well, in one's proper social position. Consequently, the linguistic behaviour of each individual in society must follow this pattern. Although social relations are subverted on many occasions in Plautus' comedies—or, perhaps, precisely because of that possibility—-these works may be considered a faithful, comical reflection of a very rigid social structure, where a well-established upper class interacts with characters belonging to the lower class, whether they be slaves or free. In harmony with the Roman sense of uerecundia'14 ('restraint, modesty, deference, respect') the latter must show deference to the former, thereby ensuring and strengthening the status quo. On some occasions, nonetheless, certain underprivileged characters can make use of other linguistic mechanisms to meet their self-serving objectives, on which their livelihood depends.

Within the theoretical framework that I am currently developing for the analysis of politeness phenomena in Latin, ${ }^{15}$ I make use of the difference between politic behaviour ${ }^{16}$ and polite behaviour. ${ }^{17}$ Similarly, following Arundale (2006), I propose substituting the positive/negative politeness dichotomy by another more generic, less ethnocentric opposition, articulated in terms of the concept of connectedness/separateness. ${ }^{18}$ To complete the panorama, along with further studies about impoliteness, consideration must also be given to over-polite behaviour, a negatively marked linguistic behaviour, which is underexplored to date. ${ }^{19}$ In this paper, I will consider 'over-politeness' not only to be an excessive or inappropriate show of politeness but also an insincere, manipulative use of certain strategies. As we will see, with regard to the linguistic habits of the chosen characters, these strategies are primarily mechanisms aiming to

14 Kaster (2005: 13-27).

15 See Unceta Gómez (2019c).

16 I.e. 'linguistic behaviour which is perceived to be appropriate to the social constraints of the ongoing interaction, i.e. as non-salient' (Watts 2003: 19).

17 I.e. 'behaviour beyond what is perceived to be appropriate to the ongoing social interaction, which says nothing about how members evaluate it' (Watts 2003: 21).

18 I'll come back to this model in Section 4. Even if reconceptualised in the light of Arundale's (2006) proposal, for the sake of clarity, throughout this paper I use the terms 'positive/negative politeness' and 'positive/negative face'.

19 See in Culpeper (2011: 100-103) a metapragmatic analysis of over-politeness. Paternoster (2012: 317-321) offers an interesting approach to over-politeness in literary texts. Regarding Latin, Iurescia $(2019 \mathrm{~b})$ presents some reflections on over-politeness as a response to impoliteness; and Konstan (2018) briefly deals with flattery in epic. 
shorten social distance, ${ }^{20}$ not in an effort to avoid conflict or manage social relations, but solely and exclusively in pursuit of one's personal benefit.

\section{$3 \quad$ Selfish Use of Politeness}

In Plautine comedy, there are two character types, the courtesan and the parasite, that share certain traits, such as their limited resources, their lack of social importance and their low hierarchical level. In other words, they share a situation of weakness which makes them dependent and limits their choices and, possibly, a pronounced sexual dimension..$^{21}$ Another very apparent common trait is their linguistic behaviour, characterised by their self-serving use of certain politeness strategies. In the following sections, I will examine how their use of certain manifestations of linguistic politeness becomes a mechanism for trying to manipulate the interlocutor and gain some benefit from him (the characters targeted by this procedure are always men).

\subsection{Parasites}

The parasite appears in eight of Plautus' twenty-one comedies that have survived to our day, ${ }^{22}$ although not all of them adopt this expected prototypical behaviour. ${ }^{23}$ Being a freeman, this character type makes use of his wit as a form of livelihood; ${ }^{24}$ by means of his obsequious behaviour, he tries to be invited to

20 According to Brown and Levinson (21987: $76-77)$, 'D [distance] is a symmetric social dimension of similarity/difference within which S [speaker] \& $\mathrm{H}$ [hearer] stand for the purposes of this act. In many cases (but not all), it is based on an assessment of the frequency of interaction and the kinds of material or non-material goods (including face) exchanged between $\mathrm{S} \& \mathrm{H}$ (or parties representing $\mathrm{S}$ or $\mathrm{H}$, or for whom $\mathrm{S}$ and $\mathrm{H}$ are representatives). An important part of the assessment of $\mathrm{D}$ will usually be measures of social distance based on stable social attributes. The reflex of social closeness is, generally, the reciprocal giving and receiving of positive face'.

21 I.e. if Fontaine (2010: 202, 221-241) is right in his assertion about the Plautine parasite; according to his interpretation, this character is the subject of veiled but substantive jokes that insinuate ongoing paedophiliac relations with their patrons.

22 Damon (1997: 37). On the features of this character and his language, see also Guastella (1988, 2002); Petrone (1989); Maltby (2000); Filoche (2014).

23 For instance, Diabolus in Asinaria or Curculio (Damon 1997: 44). By contrast, slaves, such as Palaestrio in Miles gloriosus (1037-1093, in the context of a trick), can take on certain linguistic habits of a parasite. On the similitudes and differences between Plautus' parasites and those of Greek New Comedy, see Crampon (1988) and Lowe (1989).

24 This characterisation is well developed in their respective monologues (see Maltby 2000; Guastella 2002): Capt. 69-9o, 133-137; Men. 96-103; Persa 53-6o; Stich. 155-195. 
meals in the home of his patron, so as to quiet his proverbial appetite while never being fully satisfied. His insincere nature is well reflected in certain lines from the lost Plautine comedy Colax ('the flatterer'), a Greek loan which this character is known by: ${ }^{25}$

[2] Plautus Colax fr. 2

... qui data fide firmata fidentem fefellerint, subdoli supsentatores, regi ${ }^{26}$ qui sunt proxumi, qui aliter regi dictis dicunt, aliter in animo habent.

Who have deceived the man who trusted them, after giving him their word and vouching for it, the tricky flatterers, who are closest to the king, and who speak words to the king in one sense, but have different intentions on their minds.

A paradigmatic example of this contradiction between the ideas and words of parasites is Artotrogus in Miles gloriosus. He uses a good number of positive politeness strategies in his conversation with his patronus Pyrgopolynices, but, on several occasions, he immediately places these strategies in doubt through asides. We thus find, for example, hyperbolic praise [3], ${ }^{27}$ obvious attempts to avoid conflict through a co-operative attitude and reiterated agreement [4] an example that includes an illustrative aside ${ }^{28}$ —or attention to the needs of the interlocutor, and asserted knowledge of the hearer's needs and concern for them $[5]:{ }^{29}$

25 The colax is a stock character-similar but different from the parasite in Greek literature-which Plautus inherits from Greek New Comedy and seems to gradually do away with, characterising him as a seruus callidus. Fontaine (2010:13) suggests that, in addition to reproducing the Greek $x \dot{\lambda} \lambda \alpha \xi$, colax might be understood, in the Latin speaker's mind, as an - ax formation of the verb colere, which would mean ' "excessively fond of cultivating friendship (with a superior)" and thus "fawning, adulatory, toadying, kowtowing, fulsome, obsequious".'

26 On rex used by parasites as a designation for their patroni, see Crampon (1988: 518-520).

27 An additional example is Mil. 55-6o.

28 See also Mil. 25-30, and a second aside in $33^{-} 35$.

29 The obsequious treatment that the miles receives here is even more obvious, if we compare it to how other characters treat him; see, among others, Mil. 947-99o and Poen. $470-503$. 
[3] Plautus Miles gloriosus 9-12

Pyr. ... sed ubi Artotrogus hic est? Art. stat propter uirum fortem atque fortunatum et forma regia. tum bellatorem Mars haud ausit dicere neque aequiperare suas uirtutes ad tuas.

Pyr. ... But whereabouts is Artotrogus?

Art. He's standing next to a real man, robust, rich and of royal beauty. Mars wouldn't dare to call himself such a warrior or compare his exploits to yours.

[4] Plautus Miles gloriosus 16-24

Art. memini. nempe illum dicis cum armis aureis, quoius tu legiones difflauisti spiritu, quasi uentus folia aut peniculus tectorium.

Pyr. istuc quidem edepol nihil est. Art. nihil hercle hoc quidem est praeut alia dicam ... quae tu numquam feceris. periuriorem hoc hominem si quis uiderit aut gloriarum pleniorem quam illic est, me sibi habeto, ei ego me mancupio dabo; nisi unum, epityra estur insanum bene.

Art. I remember. You mean the one with golden armour of course, whose legions you scattered with a breath as the wind does leaves or a plasterer's brush does plaster.

Pyr. That's a mere nothing.

Art. Indeed, it's a mere nothing compared with other things I might mention ... (aside) which you've never done. If anyone sees a man perjuring himself more than this one or more boastful than he is, he can have me for himself, I'll sell myself to him; but there's one thing: his olive spread tastes awfully good.

[5] Plautus Miles gloriosus 38-41

Pyr. habes- Art. tabellas uis rogare. habeo, et stilum.

Pyr. facete aduortis tuom animum ad animum meum.

Art. nouisse mores tuos me meditate decet curamque adhibere ut praeolat mihi quod tu uelis. 
Pyr. Do you have-

Art. (interrupting) You want to ask me for writing tablets. I do, and a pen.

Pyr. You mind neatly what's on my mind.

Art. I ought to know your ways studiously and take care that I get wind of what you wish in advance.

This amiability, quite obviously excessive, contrasts with the attitude of these characters when they are not assured of getting what they want, ${ }^{30}$ such as in the first meeting between Peniculus and Menaechmus I, who has quarrelled with his wife, thus limiting the possibilities for holding a banquet in his home:

[6] Plautus Menaechmi 143-151

Men. dic mi, enumquam tu uidisti tabulam pictam in pariete ubi aquila Catamitum raperet aut ubi Venus Adoneum?

Pen. saepe. sed quid istae picturae ad me attinent? Men. age me aspice.

ecquid assimulo similiter? Pen. qui istic ornatust tuos?

Men. dic hominem lepidissimum esse me. Pen. ubi esuri sumus?

Men. dic modo hoc quod ego te iubeo. Pen. dico: homo lepidissume.

Men. ecquid audes de tuo istuc addere? Pen. atque hilarussime.

Men. perge, $\langle$ perge $\rangle$. Pen. non pergo hercle nisi scio qua gratia. litigium tibi est cum uxore, eo mi aps te caueo cautius.

Men. Tell me, have you ever seen a mural painting where an eagle carries off Ganymede or Venus carries off Adonis?

Pen. Often. But what do those pictures have to do with me?

Men. Go on, look at me. Do I resemble them in a similar way?

Pen. (noticing the mantle) What are you dressed up for like that?

Men. Say that I'm a jolly good fellow.

Pen. Where are we going to eat?

Men. Just say what I'm telling you.

Pen. All right: jolly good fellow.

Men. Do you want to add something of your own to it?

Pen. And jolly charming fellow.

Men. Go on, go on!

30 See, for instance, the impoliteness of the parasite in Bacch. $577-583$. 
Pen. I'm not going, unless I know what for. You're having a quarrel with your wife, that's why I'm taking extra-careful care for myself against trouble from you.

Significantly, Peniculus' attitude changes immediately after Menaechmus I communicates his intention to celebrate a banquet without his wife knowing (Men. 162).

The self-serving nature of parasites is revealed even in the most delicate moments, such as in Captiui, when Ergasilus expresses his empathy to Hegio on the disappearance of his son [7]. The parasite makes his appearance by sobbing and expresses his condolences, in heartfelt fashion, winning Hegio's approval (laudo) even though the parasite explicitly expresses disagreement with him (something that is justified by the context and which contributes to the polite fiction). However, as is revealed immediately, it is all done in self-interest; the true pain is what is brought on by his hunger:

[7] Plautus Captiui 139-141, 146-153

Heg. ne fle. Erg. egone illum non fleam? egon non defleam talem adulescentem? Heg. semper sensi filio meo te esse amicum et illum intellexi tibi.

$[\ldots]$

Heg. alienus quom eius incommodum tam aegre feras, quid me patrem par facere est, quoi ille est unicus?

Erg. alienus? ego alienus illi? aha, Hegio, numquam istuc dixis neque animum induxis tuom; tibi ille unicust, mi etiam unico magis unicus.

Heg. laudo, malum quom amici tuom ducis malum. nunc habe bonum animum. Erg. eheu, huic illud dolet, quia nunc remissus est edendi exercitus.

Heg. Stop crying.

Erg. Should I not cry for him? Should I not weep without restraint for such a man?

Heg. I always felt that you were close to my son and I saw that he was close to you. [...]

Heg. Since you as an outsider find it so hard to bear his misfortune, what must I as his father do, for whom he is the only son?

Erg. Outsider? I an outsider to him? No, no, Hegio, never say that, and never believe that. To you he's the only one, but to me he's even more of an only one than an only one. (starts crying again) 
Heg. I praise you for considering a friend's misfortune to be your own misfortune. Now take heart.

Erg. Oh, oh, oh, this one (pointing to his stomach) is in pain about the eating force having been dismissed now.

Expressions of commiseration, as well as congratulations, are required speech acts in certain situations, thus absolute sincerity cannot be assumed in every case. ${ }^{31}$ On this occasion, however, the speech acts seek a result that goes beyond the mere expression of sympathy for the interlocutor's problems or suffering, and Ergasilus ends up by explicitly requesting an invitation to dinner. ${ }^{32}$

The parasite's manipulative disposition is especially noticeable when his strategies do not attain their desired objective. This happens with Gelasimus, the parasite in Stichus. After a long journey abroad, his patron Epignomus returns home with great wealth and an entourage of parasites who threaten to displace him. When Gelasimus first encounters his patron [8], his greeting conveys a highly exaggerated expression of happiness, quite conventionalised in this speech act, ${ }^{33}$ as well as his good wishes. Despite the grandiose expression, Epignomus looks favourably upon the parasite's words as is seen in his metapragmatic comment, where he extends his appreciation:

[8] Plautus Stichus 465-469

Gel. ... Epignome, ut ego nunc te conspicio lubens! ut prae laetitia lacrumae prosiliunt mihi! ualuistin usque? Epi. sustentatum est sedulo.

Gel. propino tibi salutem plenis ... faucibus.

Epi. bene atque amice dicis. di dent quae uelis.

31 Leech (2014: 212). On congratulations in Roman comedy, see Unceta Gómez (2016).

32 Erg. quia mi est natalis dies; propterea $\langle a\rangle$ te uocari ad te ad cenam uolo (Capt. 174-175) 'Erg. Because it's my birthday. That's why I want to be invited by you to a dinner at your place'. Similarly, when he conveys to Hegio the good news of his son's arrival, his main objective is to be invited to a sumptuous dinner (Capt. 780). At the moment when he shares the news, being fully assured of the reward it will bring him, he goes so far as to make formulations that clearly threaten the addressee's negative face, as in: Heg. Iuppiter te dique perdant. Erg. te hercle ... mi aequom est gratias agere ob nuntium (Capt. 868-869) 'Heg. May Jupiter and the gods destroy you. Erg. No, you ... should thank me for my message'.

Berger (2016); Unceta Gómez (2019a). 
Gel. ... (loudly) Epignomus, how happy I am to see you now! How my tears are gushing forth out of joy! Have you been well throughout?

Epi. I've taken good care of myself.

Gel. I'm drinking to your health with a full ... gullet.

Epi. It's kind and friendly of you to say so. May the gods grant what you wish.

The parasite's next move is clearly an affiliative act (in Hall's [2009] terminology): the invitation to dine at his house [9] and the completely unbelievable gesture, given the proverbial poverty of parasites. Epignomus politely rejects the invitation, offering excuses, ${ }^{34}$ but Gelasimus insists no less than eight times; such insistence is clearly inappropriate and may even be considered impolite, but Epignomus replies by presenting several reasons:

[9] Plautus Stichus 471-482

Epi. cenem illi apud te? Gel. quoniam saluos aduenis.

Epi. locata est opera nunc quidem; tam gratia est.

Gel. promitte. Epi. certum est. Gel. sic face inquam. Epi. certa rest.

Gel. lubente me hercle facies. Epi. idem ego istuc scio. quando usus ueniet, fiet. Gel. nunc ergo usus est.

Epi. non edepol possum. Gel. quid grauare? censeas. nescioquid uero habeo in mundo. Epi. i modo, alium conuiuam quaerito tibi in hunc diem.

Gel. quin tu promittis? Epi. non grauer si possiem.

Gel. unum quidem hercle certo promitto tibi: lubens accipiam certo, si promiseris.

Epi. ualeas. Gel. certumne est? Epi. certum. cenabo domi.

Epi. I should dine there at your place?

Gel. Since you've arrived safely.

Epi. My services are engaged at present; much obliged to you all the same.

Gel. Promise.

Epi. I'm resolved.

Gel. Do, I insist.

34 On this politeness strategy in Latin, see Ferri (2012: 133-134). 
Epi. It's settled.

Gel. You'll really do me a pleasure.

Epi. That I know too. When the need arises, it'll be done.

Gel. Then there's need now.

Epi. I really can't.

Gel. Why are you objecting? Reconsider it. Seriously, I have something in store for you.

Epi. Just go, find yourself another table companion for today.

Gel. Why don't you promise?

Epi. I wouldn't object if I could.

Gel. One thing I promise for certain: I'll accept with pleasure for certain, if you promise.

Epi. Goodbye.

Gel. Are you resolved?

Epi. Yes, I am resolved. I'll dine at home.

The objective, revealed immediately afterwards, is to get an invitation to dine. An explicit request follows, to which Epignomus replies again by giving excuses, and the parasite insists, while clearly threatening the negative face of his interlocutor (483-496).

According to Barrios-Lech, ${ }^{35}$ the parasite, along with the adulescens, are the male character types who 'speak most politely'; his quantitative data shows that this character typically makes use of softening hedges (almost three times as much as the senes, adulescentes and serui altogether); ${ }^{36}$ and of the pragmatic marker obsecro (second only to the adulescentes). ${ }^{37}$ In both cases, these mechanisms can contribute to the expression of negative politeness, where parasites underscore their position as inferior and dependent on the favours of others. More than these elements, however, the really unique aspect of their language is the abundant use of positive politeness strategies, whereby they show such familiarity toward their patrons that it may be considered excessive. In this strategy, parasites clearly go beyond appropriate, politic behaviour; their intensification of polite strategies is often judged negatively (whether by the addressee, the bystanders, or the audience).

37 Barrios-Lech (2016: 124-125 and Table 9·3). 


\subsection{Meretrices}

The second character that interests us here, with an even greater presence in the Plautine comedies, is the courtesan, who also uses politeness in selfinterest. Barrios-Lech's distinction between meretrix and pseudo-meretrixthe latter has freeborn status and is more careful and 'polite' in her speech ${ }^{38}$ - is helpful in determining certain interesting deviations, but it will not be taken into account in this analysis of over-polite strategies, which are used by both character types. ${ }^{39}$

The self-serving character of the meretrices is evidenced on numerous occasions, such as in the well-known passage that compares prostitution to the occupation of fowlers:

\section{[10] Plautus Asinaria 215-223}

non tu scis? hic noster quaestus aucupi simillimust. auceps quando concinnauit aream, offundit cibum; [aues] assuescunt: necesse est facere sumptum qui quaerit lucrum; saepe edunt: semel si captae sunt, rem soluont aucupi. itidem hic apud nos: aedes nobis area est, auceps sum ego, esca est meretrix, lectus illex est, amatores aues;

bene salutando consuescunt, compellando blanditer, osculando, oratione uinnula, uenustula.

Don't you know? This trade of ours is very similar to catching birds. When a fowler prepares a clearing, he spreads food there; they get used to it. He who seeks profit must make an investment. They eat often; but once they're caught they give the fowler his reward. It's the same at our place here: our house is our clearing, I'm the fowler, the prostitute is the bait, the bed is the decoy, and the lovers are the birds. They get used to us through nice greetings, sweet addresses, kissing, tender and delightful speech.

This amiability is used exclusively when there is some profit in sight, ${ }^{40}$ e.g. as Diabolus reproaches Cleareta in Asinaria [11]:41

38 See Barrios-Lech (2016: 123, 150, 269).

39 Similarly, even in cases where we can determine that the courtesan is truly in love, they make use of exaggerated expressiveness, as can be noted, for instance, with Lemniselene, the courtesan in Persa (cf. e.g. 766).

40 When possibilities for obtaining such a profit disappear, courtesans can become curt or even impolite, as, for instance, in Poen. 330-409.

Diniarchus in Truculentus (22-73) also complains about the behaviour of courtesans and 
[11] Plautus Asinaria 204-206, 208, 210-214

aliam nunc mi orationem despoliato praedicas, longe aliam, inquam, 〈iniqua $\rangle$, praebes nunc atque olim quom dabam, aliam atque olim quom illiciebas me ad te blande ac benedice.

$[\ldots]$

me unice unum ex omnibus te atque illam amare aibas mihi:

$[\ldots]$

meo de studio studia erant uostra omnia, usque adhaerebatis: quod ego iusseram, quod uolueram faciebatis, quod nolebam ac uotueram, de industria fugiebatis, nec conari id facere audebatis prius. nunc nec quid uelim nec nolim facitis magni, pessumae.

Now that you've robbed me you are using a different kind of rhetoric on me; I say, now you give me a kind of rhetoric far different from when I was providing for you, you criminal, different from the time when you were enticing me to you with flattery and kind words. [...] You used to say to me that out of all people you and she loved me and me only; [...] all your interests were in line with mine, you were clinging on to me all the time. You did whatever I ordered and whatever I wished, you deliberately avoided whatever I didn't wish and forbade, and you didn't dare try this earlier. Now you don't give a damn about what I like and what I dislike, you crooks.

This obsequious behaviour, whereby the meretrices are distinguished from the matrons, ${ }^{42}$ is usually directed toward lovers from whom there is hope of a profit. ${ }^{43}$ This is seen, for example, in Menaechmi, where the courtesan Erotium displays all of her charm (by the means of mechanisms such as the use of $m i+$ vocative, which is a term of affection, ${ }^{44}$ a form of affiliation, expres-

describes their manner in detail. See also his reproaches to Astaphium, servant of his beloved Phronesium (Truc. 162-163).

42 Cleo. non matronarum officiumst, sed meretricium, uiris alienis, mi uir, subblandirier (Cas. 585-586) 'Cleo. My dear husband, it's not the job of wives, but of prostitutes, to charm other men'.

Even so, use of these techniques is also confirmed outside the business exchange with one's client, as in Bacch. 39-100, where Bacchides, paradigm of the 'bad meretrix', manages to win the favour of Pistoclerus and overcomes his efforts to resist (50 uiscus merus uostra est blanditia; 'Your flattery is pure birdlime'). See also Rud. $435^{-438 .}$ 
sion of agreement, exaggerated sympathy and approval), in order to win her client's favour; this sharply contrasts with how she treats the slave of Menaechmus I, Peniculus, who makes a metapragmatic comment on the courtesan's attitude:

[12] Plautus Menaechmi 182-186, 190-193

Ero. anime mi, Menaechme, salue. Pen. quid ego? Ero. extra numerum es mihi.

Pen. idem istuc aliis ascriptiuis fieri ad legionem solet.

Men. ego istic mihi hodie apparari iussi apud te proelium.

Ero. hodie id fiet. Men. in eo uterque proelio potabimus;

$[\ldots]$

Pen. interim nequis quin eius aliquid indutus sies.

Ero. quid hoc est? Men. induuiae tuae atque uxoris exuuiae, rosa.

Ero. superas facile ut superior sis mihi quam quisquam qui impetrant.

Pen. meretrix tantisper blanditur, dum illud quod rapiat uidet.

Ero. My sweetheart, Menaechmus, hello.

Pen. What about me?

Ero. You don't count to me.

Pen. That same thing is always said to happen to supernumeraries like me in the army too.

Men. (to Erotium) I ordered that a battle should be prepared for myself here at your place today.

Ero. It shall take place today.

Men. In this battle we shall both drink. [...]

Pen. (aside) In the meantime you can't help wearing something of hers.

Ero. What is this? (points to the mantle)

Men. You are robed and my wife is robbed, my rose.

Ero. You easily gain the upper hand so that for me you are above any of those who command me.

Pen. A prostitute only flatters as long as she can see something she can snatch.

tion for strengthening a petition. See also the comical imitation of this resource in Cas. 134-138. 
In this same scene [13], there are other typical procedures of positive politeness: expression of agreement, attention to the interests and needs of the hearer, and even anticipation of these:

[13] Plautus Menaechmi 207-209, 213-215

Men. scin quid ${ }^{45}$ uolo ego te accurare? Ero. scio, curabo quae uoles.

Men. iube igitur tribus nobis apud te prandium accurarier atque aliquid scitamentorum de foro opsonarier, $[\ldots]$ atque actutum. Ero. licet ecastor. Men. nos prodimus ad forum. iam hic nos erimus: dum coquetur, interim potabimus.

Ero. quando uis ueni, parata res erit. Men. propera modo.

Men. (to Erotium) Do you know what I want you to take care of?

Ero. I know, I'll take care of what you want.

Men. Then have a lunch prepared at your place for the three of us, and have some delicacies brought from the market [...] and at once.

Ero. Yes, of course.

Men. We're off to the forum. We'll be back soon. While it's being cooked, we'll drink.

Ero. Come when you wish, it will be ready.

Men. Just hurry.

The intensification of familiarity produced by these expressive mechanisms becomes entirely evident when they are used with a stranger, as occurs in the comical recourse of twins in the same comedy: ${ }^{46}$

[14] Plautus Menaechmi 361-374

Ero. ... animule mi, mi mira uidentur

45 As Barrios-Lech (2016: 215-218) has noted, the pattern scin quid ...? allows courtesans to anticipate the client's wishes. The expression-which is not a real request for information but has the communicative function of getting the interlocutor's attention and leading up to a request-is treated literally by the courtesans, thereby intensifying the impression of interest toward their clients.

46 See also Men. 207-212, 677; Bacch. 1178-1179; Mil. 1161-1163. 
te hic stare foris, fores quoi pateant,

magis quam domus tua domus quom haec tua sit.

omne paratum est, ut iussisti

atque ut uoluisti, [...].

prandium, ut iussisti, hic curatum est:

ubi lubet, ire licet accubitum.

Sos. quicum haec mulier loquitur? Ero. equidem tecum. Sos. quid mecum tibi

fuit umquam aut nunc est negoti? Ero. quia pol te unum ex omnibus

Venus me uoluit magnuficare, neque id haud immerito tuo.

nam ecastor solus benefactis tuis me florentem facis.

Sos. certo haec mulier aut insana aut ebria est, Messenio, quae hominem ignotum compellet me tam familiariter.

Ero. ... My sweetheart, it seems strange to me that you're standing outside here: the door stands open for you, since this house is more yours than your own house is. Everything is prepared, as you ordered and as you wanted. [...] The lunch has been seen to, as you told me. We can go and recline at table as soon as you wish.

Sos. (to Messenio) Who is this woman talking to?

Ero. To you of course.

Sos. What business have I ever had with you or have I now?

Ero. Because out of all men Venus wanted me to hold you alone in esteem, and not undeservedly so: you alone let me flourish through your generosity.

Sos. (again to Messenio) This woman is definitely either mad or drunk, Messenio: she addresses me, a total stranger, so intimately.

The effect is quite comical, even ridiculous, since Sosicles does not know this woman. Intensification of closeness (when the distance between two strangers is great) is entirely improper despite Erotium emphasising her subsidiary position using, for instance, the verb iussisti.

In the case of [15], however, Stephanium, the courtesan of Stichus, addresses two fellow slaves. Even though the relationship is therefore different from the previous ones, there is nevertheless a great similarity between Stephanium's expressive resources and those we have seen on other occasions, e.g. apologies for lateness, interest in the hearer's wishes and expressions of affection: 
[15] Plautus Stichus 742-744, 750-753

Ste. morigerabor, meae deliciae. nam ita me Venus amoena amet, ut ego huc iam dudum simitu exissem uobiscum foras, nisi me uobis exornarem. nam ita est ingenium muliebre:

$[\ldots]$

Ste. utrubi accumbo? Sang. utrubi tu uis? Ste. cum ambobus uolo, nam ambos amo.

Sti. uapulat peculium, actum est. Sang. fugit hoc libertas caput.

Ste. date mi locum ubi accumbam, amabo, siquidem placeo. Sti. tun mihi?

Ste. cupio cum utroque. Sti. ei mihi! bene dispereo.

Ste. I'll humour you, my darlings: as truly as lovely Venus may love me, I'd have come out here together with you long ago, if I hadn't been making myself pretty for you; yes, a woman's nature is like this [...] In which place am I to recline?

Sang. In which do you want to?

Ste. I want to be with both, because I love you both.

Sti. My savings are getting a thrashing, I'm done for.

Sang. Freedom is running away from me.

Ste. Please, give me a place to recline, you two, if you like me.

Sti. I like you?

Ste. I wish to do so with each of you.

Sti. Dear me! I'm perishing in a good way.

In this case, we also see the use of a frequent form of blanditia and the pragmatic marker amabo, used mostly in combination with requests or questions. ${ }^{47}$ A characteristic element of the female sociolect and strongly associated with an erotic context, ${ }^{48}$ amabo is used mainly by courtesans ${ }^{49}$ and is also a trait that strikingly differentiates their language from that of pseudo-courtesans; according to the statistical data presented by Barrios-Lech, 'courtesans direct

\footnotetext{
47 But it is not an exclusive function: on the uses of this pragmatic marker, see Unceta Gómez (2015) and Fedriani (2017).

48 In five of the seven examples in Plautus in which it is pronounced by a man, it is addressed to a woman in an amorous context; the other two appear in a homoerotic context.

49 Courtesans use amabo almost five times more than matrons do, and, in Terence, only courtesans use amabo (Barrios-Lech 2016: 121-123 and Table 9.2). The reason for this, as Barrios-Lech (2016: 123) indicates, would have to be found in the ideology of the 'good wife', 'whose public conduct should be characterized by restraint'.
} 
two-thirds of all tokens of amabo put in their mouths to lovers. But the pseudocourtesan directs to a lover only one-fifth of the total tokens of amabo assigned to her. 50

Phronesium's behaviour in Truculentus is also rather interesting. After denying her professional favours to Diniarchus, she becomes agreeable towards him, be it in a strange type of relationship that might be considered as 'friendship' (see 434-440), although Phronesium continues to ask him for a gift (425-427). In [16], we can identify: the pragmatic marker amabo, a joke, flattery, the offer of a kiss, and an invitation to dine-in other words, an intensification of interest in the boy: ${ }^{51}$

[16] Plautus Truculentus 352-353, 355-356, 358-363

Phro. num tibi nam, amabo, ianua est mordax mea, quo intro ire metuas, mea uoluptas?

$[\ldots]$

Phro. quid tam inficetu's Lemno adueniens qui tuae non des amicae, Diniarche, sauium?

$[\ldots]$

Din. salua sis, Phronesium.

Phro. salue. hicine hodie cenas, saluos quom aduenis?

Din. promisi. Phro. ubi cenabis? Din. ubi tu iusseris.

Phro. hic; me lubente facies. Din. edepol me magis. nemp' tu eris hodie mecum, mea Phronesium?

Phro. uelim, si fieri possit.

Phro. Please, my darling, you don't think my door will bite you, do you, so that you should be afraid to go in? [...] Why are you so unmannered that on your arrival from Lemnos you won't give your girlfriend a kiss, Diniarchus? [...]

Din. My greetings, Phronesium.

Phro. And mine to you. Won't you have dinner here today, since you've arrived safely?

Din. I have a prior engagement.

$50 \quad$ Barrios-Lech (2016: 123).

51 This behaviour sharply contrasts with how she treats the soldier Stratophanes (Truc. 499542 ), from whom she seeks to obtain a nice profit. And the attitude of Diniarchus himself is also different than how he will act slightly later, when he wants to recover the child that he has lent to Phronesium in order to pull off a trick on the soldier (Truc. 86o-861). 
Phro. Where are you going to have dinner?

Din. Where you tell me to.

Phro. Here; you'll do me a pleasure.

Din. Myself even more. You'll be with me today, won't you, my dear Phronesium?

Phro. I'd love to, if it were possible.

Finally, the most expressive representation of this behaviour is found in Miles gloriosus, where Acroteleutium makes use of a further resource: intensifying the emotional element and simulating extreme lovesickness, including a fictitious faint, ${ }^{52}$ trembling, and a suicide threat. ${ }^{53}$

By the means of the preceding examples, we can appreciate the richness of manifestations of blanditia, the typical over-politeness of courtesans, as a form of manipulation that is primarily, though not exclusively, female. ${ }^{54}$

\section{Discussion and Conclusions}

Although most of the linguistic resources that have, thus far, been recognised as mechanisms of manipulation can also be found in the speech of other character types, it seems evident that both courtesans and parasites are the stock characters that most often draw on a battery of procedures for giving positive face to the persons whom they depend on for their own livelihood. Among the positive politeness strategies inventoried by Brown and Levinson, ${ }^{55}$ Table 1 presents those that are most easily recognised in the examples analysed in this paper. This table does not contend on being exhaustive, but merely indicative. However, one may note that certain passages are overloaded with this type of strategies.

Furthermore, at the expressive level, we see some consistency in the frequent use of flattery, and, in the case of courtesans, of affectionate terms,

52 The same stratagem is employed by the other courtesan in this comedy, Philocomasium (Mil. 1330-1332).

53 See Mil. 1239-1241, 126o-1261, 1272-1273. On this stereotype of lovers, see Dutsch (2012).

54 Cf. supra, n. 10. As Dutsch (2008: 75-77) notes, the man can be influenced by the prostitute and become a blandus amator, a type of behaviour that is completely unsuitable outside of the female sphere. 'Plautus routinely casts the vir blandiens in the following scenario: in order to satisfy his lust, the lover needs someone else's help and, in order to obtain it, adopts a woman's persuasive manner of speaking (blanditia)' (Dutsch 2008: 77). See Plaut., Trin. 245-247 and Cist. 449-46o.

55 Brown and Levinson ( ${ }^{2} 1987$ : 101-129). 


$\begin{array}{lll}\text { Positive politeness strategy } \quad \text { Parasites Courtesans } & \end{array}$

\begin{tabular}{|c|c|c|}
\hline $\begin{array}{l}\text { Notice, attend to } \mathrm{H} \text { (interests, wants, needs, } \\
\text { goods) }\end{array}$ & {$[6]$} & {$[12],[13],[14],[15],[16]$} \\
\hline $\begin{array}{l}\text { Exaggerate (interest, approval, sympathy } \\
\text { with } \mathrm{H})\end{array}$ & {$[3],[4],[7],[8]$} & {$[12],[14],[15]$} \\
\hline Seek agreement & [4] & {$[12],[13]$} \\
\hline Avoid disagreement & [4] & {$[14],[15]$} \\
\hline Presuppose/raise/assert common ground & {$[7]$} & \\
\hline Joke & & {$[16]$} \\
\hline $\begin{array}{l}\text { Assert or presuppose S's knowledge of and } \\
\text { concern for H's wants }\end{array}$ & {$[5]$} & {$[12],[13]$} \\
\hline Offer, promise & [9] & {$[12],[13],[15],[16]$} \\
\hline Give (or ask for) reasons & & {$[15]$} \\
\hline $\begin{array}{l}\text { Give gifts to } \mathrm{H} \text { (goods, sympathy, under- } \\
\text { standing, co-operation) }\end{array}$ & {$[8]$} & {$[16]$} \\
\hline
\end{tabular}

diminutives, the possessive $m i$ + vocative, and the pragmatic marker amabo. All these strategies seek to create a fiction on familiarity with the addressee.

Despite the occasional explicit expression of their position of dependence and submission, the most frequent attitude in parasiti and meretrices is that of attempting to reduce social distance with their addressee. It is to this end that they apply all these strategies of connectedness. ${ }^{56}$ This sharply contrasts with the acceptable politic behaviour for the lower classes (and even with the polite behaviour that behoves them), that is, with adopting a humble attitude and manifesting the social distance and hierarchical superiority of their interlocutor. The communicative style of these characters may, therefore, be considered unconventional, in that it is excessive and fails to follow the prevailing norm in Latin, something that is not justifiable even by the acquaintance that can be observed in most of the cases that were analysed. It can also be added that, outside of Plautine comedy, the same overlap exists between more or less sincere affiliative techniques and expressions typical of contexts of familiarity, as Hall has noted in Cicero's letters. ${ }^{57}$

$5^{6} \quad$ Brown and Levinson $\left({ }^{2} 1987: 103\right)$ consider positive politeness as a 'social accelerator'.

57 'The language, then, of affiliative politeness and blanditiae overlapped to a considerable degree. Both aimed at suggesting a sense of solidarity and familiarity with the addressee, 
Beyond that, these mechanisms are clearly conscious ones (not automated or routinised) and insincere; their effectiveness lies in constituting a nonstandard procedure to please the elite, an expectation that comedies discussed here may seek to ridicule. Moreover, the procedure brings about interesting comical effects, given that everyone (bystanders and audience) can see that such dealings are over-polite-being excessive and insincere at once-except for the addressees, who are fooled in most cases. ${ }^{58}$

The manipulative intent and self-serving nature of these forms of politeness are assured by the fact that the beneficiary of these strategies is always ultimately the one who utters them, not their recipient, who usually falls prey to the insincerity. Hall also reaches this conclusion and points to the difficulties faced by modern scholars in determining a manipulative intent in certain practices. ${ }^{59}$ In comedy, however, the plotlines allow us to determine the perlocutionary effect of these acts. The contextual information provides an external portrayal of the different characters' conduct and communicative styles. This is precisely why theatre constitutes an unsurpassed corpus with which one may test theories about pragmatics and linguistic politeness.

The analysis of communities of practice, ${ }^{60}$ such as those of prostitutes and parasites, with their characteristic linguistic behaviours, allows a glimpse into some Roman conceptualisations regarding the need to uphold politeness within reasonable limits and under a certain degree of control. The elite is-or should at least be-alien to any expressive excesses. In this way, the four-sided model proposed in Unceta Gómez (2019c) can be expanded with the inclusion of the notion of over-politeness (Table 2). ${ }^{61}$

often through the use of compliments and overstatement. The more conventionalized strategies, however, make these claims in a relatively restrained way that takes care to show respect to the addressee. blanditiae, by contrast, seem to be characterized in part by bolder assumptions of familiarity and intimacy, conveyed by the use of less formal idioms' (Hall 2009: 82).

58 See, for instance, the words of Diniarchus, the adulescens who is in love with Phronesium in Truculentus and who acknowledges the gullibility of lovers (Truc. 190-192).

59 'Their language is often similar and both often involve fictions; the difference lies largely in who benefits. If these fictions help to save the addressee's face and to promote mutually beneficial social harmony, they are likely to be viewed favorably. But if the writer seems to be angling for some advantage of his own, these civilities take on a rather more suspect character' (Hall 2009: 99).

6o That is, 'a loosely defined group of people who are mutually engaged on a particular task' (Mills 2003: 30).

61 Interestingly, the Handbook of Electioneering offers an indication that allows to interpret blanditia as a distorted form of comitas: deinde id quod natura non habes induc in animum ita simulandum esse ut natura facere uideare. nam comitas tibi non deest, ea quae 
TABLE 2 Politeness system in Latin

\begin{tabular}{llll}
\hline & $\begin{array}{l}\text { Politic } \\
\text { decorum }\end{array}$ & $\begin{array}{l}\text { Polite } \\
\text { honorificentia }\end{array}$ & $\begin{array}{l}\text { Over-polite } \\
?\end{array}$ \\
\hline Connection & Affiliation & Intensification of closeness & $\begin{array}{l}\text { Excessive intensification of } \\
\text { closeness } \\
\text { Separation }\end{array}$ \\
& Deference & Redress & clanditia, palpatio, assentatio \\
& uerecundia, & modestia, humilitas & \\
& humilitas & & \\
\hline
\end{tabular}

\section{Acknowledgements}

Many thanks are due to the editors of this volume, Gunther Martin, Federica Iurescia, Severin Hof, and Giada Sorrentino, for their helpful comments and feedback. Any remaining infelicities are entirely my own.

\section{References}

Arundale, R.B., (2006), 'Face as Relational and Interactional: a Communication Framework for Research on Face, Facework, and Politeness', Journal of Politeness Research 2, 193-216.

Barrios-Lech, P., (2016), Linguistic Interaction in Roman Comedy, Cambridge.

bono ac suaui homine digna est, sed opus est magno opere blanditia, quae etiamsi uitiosa est et turpis in cetera uita, tamen in petitione est necessaria. etenim cum deteriorem aliquem adsentando facit, tum improba est, cum amiciorem, non tam uituperanda, petitori uero necessaria est, cuius frons et uultus et sermo ad eorum quoscumque conuenerit sensum et uoluntatem commutandus et accommodandus est (Cicero, Comment. pet. 42-43) 'Now, my brother, you have many wonderful qualities, but those you lack you must acquire and it must appear as if you were born with them. You have excellent manners and are always courteous, but you can be rather stiff at times. You desperately need to learn the art of flattery-a disgraceful thing in normal life but essential when you are running for office. If you use flattery to corrupt a man, there is no excuse for it, but if you apply ingratiation as a way to make political friends, it is acceptable. For a candidate must be a chameleon, adapting to each person he meets, changing his expression and speech as necessary' (text and translation Freeman 2012). I thank J. Hall for pointing me to this reference. 
Berger, Ł., (2016), 'Escenas de bienvenida en las comedias de Plauto', Scripta Classica 13, $65^{-84 .}$

Brown, P. \& Levinson, S.C., ( ${ }^{2} 1987$ [1978]), Politeness: some Universals in Language Usage, Cambridge.

Clackson, J., (2017), 'Adulatio', in P. Duarte, F. Fleck, P. Lecaudé, \& A. Morel (eds.), Histoires de mots. Études de linguistique latine et de linguistique générale offertes en hommage à Michèle Fruyt, Paris, 27-34.

Crampon, M., (1988), 'Le parasitus et son rex dans la comédie de Plaute: la revanche du langage sur la bassesse de la condition', in Y. Yogue \& M. Doi (eds.), Forms of Control and Subordination in Antiquity, Leiden/New York/Copenhagen/Cologne, 507522.

Culpeper, J., (2011), Impoliteness: Using Language to Cause Offence, Cambridge.

Damon, C., (1997), The Mask of the Parasite. A Pathology of Roman Patronage, Ann Arbour.

Davidson, J., (2004), Hypocrisy and the Politics of Politeness. Manners and Morals from Locke to Austen, Cambridge.

Dutsch, D.M., (2008), Feminine Discourse in Roman Comedy. On Echoes and Voices, Oxford.

Dutsch, D.M., (2012), 'Genre, Gender, and Suicide Threats in Roman Comedy', Classical World 105, 187-198.

Fedriani, C., (2017), 'Quaepropter, quaeso? “Why, for Pity's Sake?": Questions and the Pragmatic Functions of quaeso, obsecro and amabo in Plautus', in C. Denizot \& O. Spevak (eds.), Pragmatic Approaches to Latin and Ancient Greek, Amsterdam/Philadelphia, 83-109.

Ferri, R., (2012), 'How to Say No in Latin: Negative Turns, Politeness and Pragmatic Variation', in M. Leiwo, H. Halla-aho, \& M. Vierros (eds.), Variation and Change in Greek and Latin, Helsinki, $115^{-137 .}$

Fish, K., Rothermich, K., \& Pell, M.D., (2017), 'The Sound of (In)sincerity', Journal of Pragmatics 121, 147-161.

Filoche, C., (2014), 'La parole du parasite Plautinien ou l' espace ludique d' un personnage de bouffon', Revue des Études Latines 92, 21-33.

Fontaine, M., (2010), Funny Words in Plautine Comedy, Oxford.

Freeman, P., (2012), How to Win an Election: an Ancient Guide for Modern Politicians, Princeton/Oxford.

Goffman, E., (1959), The Presentation of the Self in Everyday Life, New York.

Guastella, G., (1988), La contaminazione e il parassita. Due studi su teatro e cultura romana, Pisa.

Guastella, G., (2002), 'I monologhi di ingresso dei parassiti: Plauto e i modelli', in C. Questa \& R. Raffaelli (eds.), Due seminari plautini, Urbino, 155-198.

Hall, J., (2009), Politeness and Politics in Cicero's Letters, Oxford/New York. 
Iurescia, F., (2016), 'Strategies of Persuasion in Provoked Quarrels in Plautus: a Pragmatic Perspective', in E. Sanders \& M. Johncock (eds.), Emotion and Persuasion in Classical Antiquity, Stuttgart, 281-294.

Iurescia, F., (2019a), Credo iam ut solet iurgabit: pragmatica della lite a Roma, Göttingen.

Iurescia, F., (2019b), 'How to Assess Politeness in Response to Impoliteness? Some Examples from Latin Comedy', in L. van Gils, C. Kroon, \& R. Risselada (eds.), Lemmata Linguistica Latina, vol. 2: Clause and Discourse, Berlin, 431-447.

Kaster, R.A., (2005), Emotion, Restraint and Community in Ancient Rome, Oxford/New York.

Konstan, D., (2018), 'Praise and Flattery in the Latin Epic: a Case of Intratextuality', in S. Harrison, S. Frangoulidis, \& T.D. Papanghelis (eds.), Intratextuality and Latin Literature, Berlin.

Leech, G., (2014), The Pragmatics of Politeness, Oxford.

Lowe, J.C.B., (1989), 'Plautus' Parasites and the Atellana', in G. Vogt-Spira (ed.), Studien zur vorliterarischen Periode im frühen Rom, Tübingen, 161-169.

Maltby, R., (2000), 'The Language of Plautus' Parasites', in L. Hardwick, P.E. Easterling, \& S. Ireland (eds.), Theatre: Ancient \& Modern, Milton Keynes, 32-45.

Melo, W. de, (2011-2013), Plautus, Comedies, 5 vols., Cambridge, Mass./London.

Mills, S., (2003), Gender and Politeness, Cambridge.

Paternoster, A., (2012), 'Inappropriate Inspectors: Impoliteness and Overpoliteness in Ian Rankin's and Andrea Camilleri's Crime Series', Language and Literature 21, 311324.

Petrone, G., (1989), 'Campi Curculionii, ovvero il bestiario del parassita (Plauto Mi. 13 ss.)', Studi Italiani di Filologia Classica 7, 34-55 (repr.: G. Petrone, Quando le Muse parlavano latino. Studi su Plauto, Bologna 2009, 43-66).

Pinto, D., (2011), 'Are Americans Insincere? Interactional Style and Politeness in Everyday America', Journal of Politeness Research 7, 215-238.

Roesch, S., (2019), 'Impoliteness in Plautus' comedies', in L. Van Gils, C. Kroon, \& R. Risselada (eds.), Lemmata Linguistica Latina, vol. 2: Clause and Discourse, Berlin, 413430.

Schulze, R., (1984), 'Manipulative Politeness: Speaker-Oriented Strategies in Persuasive Interaction', AILA Brussels 84 Proceedings 3, 1191-1192.

Sorlin, S., (2017), 'The Pragmatics of Manipulation: Exploiting Im/politeness Theories', Journal of Pragmatics 121, 132-146.

Stokke, A., (2014), 'Insincerity', Nô̂s 48, 496-520.

Stokke, A., (2018), Lying and Insincerity, Oxford/New York.

Talwar, V., Murphy, S.M., \& Lee, K., (2007), 'White Lie-Telling in Children for Politeness Purposes', International Journal of Behavioral Development 31, 1-11.

Unceta Gómez, L., (2015), 'Sobre el proceso de subjetivación de algunas formas verbales 
en la lengua de la comedia romana', in G. Haverling (ed.), Latin Linguistics in the Early 21st Century, Uppsala, 468-479

Unceta Gómez, L., (2016), 'Congratulations in Latin Comedy: Types and Functions', Journal of Politeness Research 12, 267-29o.

Unceta Gómez, L., (2018), 'Gli studi sulla (s)cortesia linguistica in latino. Possibilità di analisi e proposte per il futuro', Studi e Saggi Linguistici 56(2), 9-37.

Unceta Gómez, L., (2019a), 'Expressing Happiness as a Manifestation of Positive Politeness in Roman Comedy', in L. van Gils, C. Kroon, \& R. Risselada (eds.), Lemmata Linguistica Latina, vol. 2: Clause and Discourse, Berlin, 393-412.

Unceta Gómez, L., (2019b), 'I complimenti e il loro contributo all'espressione della cortesia linguistica nelle commedie di Plauto', Dionysus ex Machina 10, 283-311.

Unceta Gómez, L., (2019c), 'Conceptualizations of Linguistic Politeness in Latin: the Emic Perspective', Journal of Historical Pragmatics 20, 286-312.

Watts, R.J., (2003), Politeness, Cambridge. 


\section{PART 3}

Verbal and Non-verbal Communication:

Doing Things NotJust with Words 
-978-90-04-44026-5

Downloaded from Brill. com $04 / 26 / 2023$ 11:30:38AM via free access 


\title{
Silence and the Failure of Persuasion in Tragic Discourse
}

\author{
Vanessa Zetzmann
}

\section{1 \\ Introduction}

In Greek tragedy, we often encounter characters being silent for an extended period of time and, especially in Aeschylus' works, as noted by Taplin (1972), ${ }^{1}$ these instances of silence convey a specific dramatic effect: they draw attention to the silent character. Whilst the significance of these extended stretches of silence has been duly explored, ${ }^{2}$ shorter instances also play a role in tragic discourse:

In the context of tragic persuasion and rhetoric, characters often fail to convey their intent or proposition ${ }^{3}$ — this has mostly to do with differing character opinions or dispositions. Sometimes, however, these characters are not even able to establish communicative contact and their interlocutors stay or fall silent. Frequently, then, speakers comment on this phenomenon by using

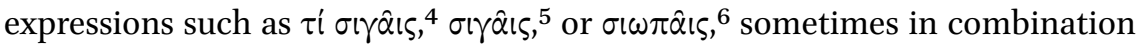

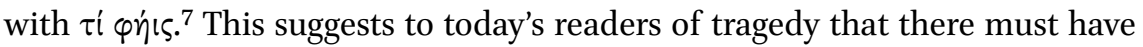

1 For Niobe und Achilles in Aesch. Myrmidones, see Taplin (1972: 58-76), also Montiglio (200o: $213^{-216)}$.

2 Cf. e.g. Chong-Gossard (2008: 113-204). For an extensive survey of silences in tragedy, see Montiglio (2000: 158-212).

3 For the case of Euripides, see Battezzato (2017).

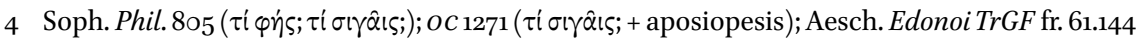

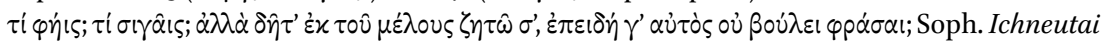

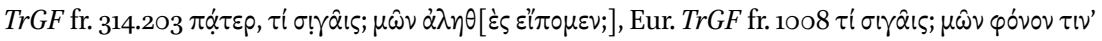

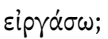

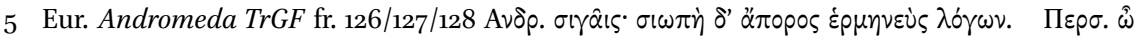

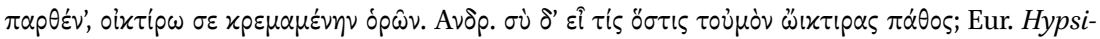

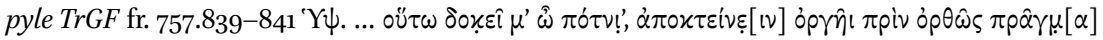

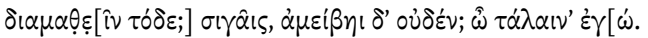

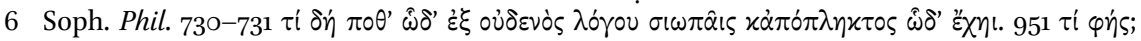

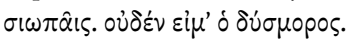

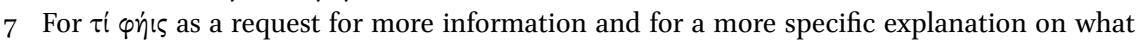
was said in conversations without silence, see e.g. Soph. El. 675, 855; ot 330, 654, 957, 1233;

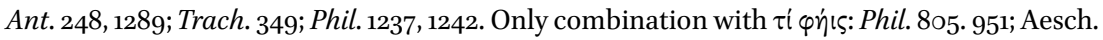
Edonoi $\operatorname{Tr} G F$ fr. 61.144 . 
been a performed and marked pause on stage: there is no communicative contact at all despite the persuasive intention of the interlocutors.

\section{Types of Silence and Their Linguistic Value}

Before asking how these breaks in contact work and what they convey in tragic discourse and on the tragic stage, an approach towards the causes ${ }^{8}$ of silence in tragedy and its possible mechanisms shall be taken by beginning with a look at Aeschylus' Agamemnon. Being probably the most famous silence scene in tragedy, ${ }^{9}$ Clytaemestra's appeal to Cassandra to enter the Argive palace offers an instructive intradramatic reflection and relevant starting-point for our survey and may even be profitably paired with modern pragmatics in order to explain other scenes: ${ }^{10}$

[1] Aeschylus Agamemnon 1035, 1039, 1050-1052, 1059-1065

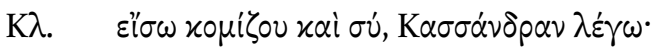

$[\ldots]$

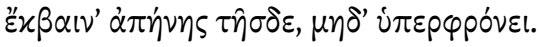

$[\ldots]$

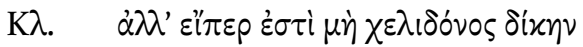

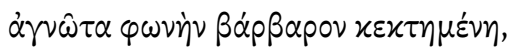

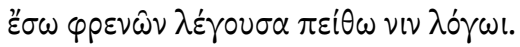

$[\ldots]$

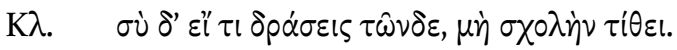

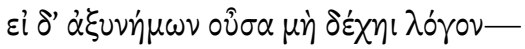

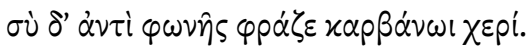

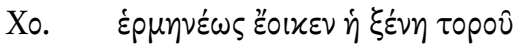

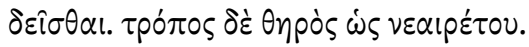

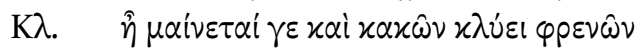

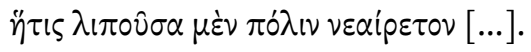

Clyt. You come along inside too-I mean you, Cassandra.

$[\ldots]$

8 Perceau (2014) offers 'réticence' and 'cri' as explanations. These binary categories, however, are, to my mind, inadequate, and I would like to search for more precise distinctions.

9 See Mastronarde (1979: 74).

10 Translations are taken from Sommerstein (2008). 
Come down from this carriage, don't be so proud.

$[\ldots]$

Clyt. Well, unless she has some unintelligible barbarian language, like the swallows do, what I say should be getting inside her mind and my words should persuade her.

$[\ldots]$

Clyt. If you want to take some part in this, don't hang around. If you don't understand my words, and they're not getting through to you, then instead of speaking, express yourself with gestures in the way foreigners do.

Cho. The foreign woman seems to be in need of a clear interpreter. She has the manner of a wild beast just trapped.

Clyt. She's mad, that's all, obeying the promptings of an unsound mind. And she doesn't yet know how to bear the bridle, not till she's foamed out her rage in blood [...].

It is striking how many unanswered imperatives ${ }^{11}$ are used by Clytaemestra and the chorus; this clearly marks Cassandra's silence as a behaviour out of the ordinary. But even more curiously, by distinguishing scenarios, ${ }^{12}$ Clytaemestra offers three possible explanations for Cassandra's unusual silence:

1) a lack of understanding of Clytaemestra's orders due to Cassandra's barbaric language (1050-1051);

2) the lack of persuasion on her own behalf (1052); and finally, as a result of her continued futile persuasive attempts,

3) Cassandra's insanity (1064). ${ }^{13}$

How can we distinguish these explanations of silence? In terms of speech act theory, the speaker's illocutionary acts are always performed in an infelicitous way when their interlocutor stays silent, meaning there is no uptake:

Unless a certain effect is achieved, the illocutionary act will not have been happily, successfully performed [...]. It cannot be said to have warned an audience unless it hears what I say and takes what I say in a certain

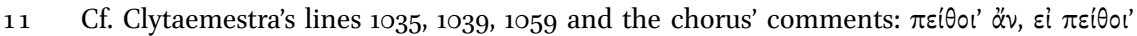
(1049) and हैं $\pi 0 v$ (1054).

12 The conditional in 1050 makes the alternative scenarios clear.

13 These interpretations given within the text are not necessarily right. Here, as the audience will have already known and as we can infer from Cassandra's very first utterance to Apollo (1073 $\hat{\omega} \pi 0 \lambda$ ov $\hat{\omega} \pi \circ \lambda$ ov), Cassandra might be insane, but in the sense of a divine madness induced by Apollo and the impact of her own prophecies. On the other hand, she might also simply be unwilling to answer.
} 
sense. An effect must be achieved on the audience if the illocutionary act is to be carried out [...]. Generally the effect amounts to bringing about the understanding of the meaning and of the force of the locution. So the performance of an illocutionary act involves the securing of uptake. $^{14}$

But we can further specify these infelicitous speech acts-none of which receives any uptake, but they are met with silence - and this is also roughly outlined in Clytaemestra's explanation:

1) locutionary ineffectiveness: the speaker's utterance achieves neither a locutionary nor an illocutionary effect. If one applies this to the example of Cassandra, one would explain her silence as a consequence of insanity or a failure to understand: Cassandra does not acoustically or mentally understand Clytaemestra's words (i.e. the locution), and therefore does not grasp their illocutionary meaning either. She indicates this by staying silent.

2) illocutionary ineffectiveness: the speaker's illocutionary speech act has been acknowledged but is wilfully ignored by the silent interlocutor, i.e. has no illocutionary effect. This would refer to Clytaemestra's plan to per-

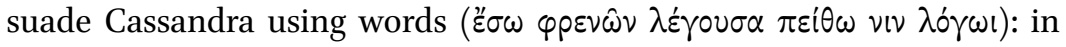
this scenario, she assumes that Cassandra has understood the meaning and the intention of her words, i.e. the illocution, perfectly, but refuses to follow. In either case, there are no perlocutionary consequences as no communicative contact is established.

But what function does silence serve in discourse? In the framework of Conversation Analysis, ${ }^{15}$ the categories of preferred and dispreferred response do not apply to an interlocutor's silence: it is neither the response usually expected ${ }^{16}$ by any speaker asking a question or making a request in their speech or turn (agreement by talking) nor a dispreferred response (rejection by talking). Since

14 Austin $\left({ }^{2} 1975: 116-117\right)$. On the correct perception of the illocutionary act as basic prerequisite for communication, see also Searle (1965: 222).

15 "'Preferred" and "dispreferred" [...] refer to sequential properties of turn and sequence construction, not participant desires or motivations.' Schegloff (1988: 445). See also Levinson (1983: 332-345). Whilst the preferred response would be agreeing by talking, rejection (i.e. not agreeing) can be classed as dispreferred responses. See Schegloff (1988: 445) and Pomerantz $(1975,1978)$.

16 Cf. the above-mentioned repeated imperatives towards Cassandra. Of course, not in every adjacency pair the preferred response is agreement by talking, e.g. self-deprecations: cf. Pomerantz (1984). 
it sometimes prefigures a dispreferred response to $\mathrm{come}^{17}$ but does not always do so (Cassandra does not answer at all to Clytaemestra), I suggest defining silence as a 'non-response.' ${ }^{18}$

Other causes of silence can also be classified by this framework, e.g. sickness or an unreceptive state of mind, as in similar scenes in Sophocles' Philoctetes and Euripides' Hippolytus. ${ }^{19}$ These examples can be termed locutionary ineffectiveness, because interlocutors were prevented from communicating by external factors and did not even grasp the implications of the request made to them.

Examples of illocutionary ineffectiveness-i.e. understanding the illocution but not being able to give a preferred response and not acting upon the recognised illocution - would be strong emotions on the interlocutor's part: in Euripides' Iphigeneia at Aulis (1238-1257), Agamemnon's grief and shame about his decision to sacrifice Iphigeneia keep him from talking, although he, of course, understands Iphigeneia's illocution. ${ }^{20}$ But there are also instances of illocutionary ineffectiveness in which the character simply refuses to answer, and their personal aversion becomes clear-they are wilfully reacting by not talking. The fathers Oedipus in Sophocles' $o c$ and Theseus in Euripides' Hippolytus when refusing to speak with their sons exemplify this use. ${ }^{21}$ Silence has therefore been shown to represent two different kinds of non-responses that are caused either by locutionary and illocutionary or merely by illocutionary ineffectiveness.

17 'Commonly, dispreferred responses are preceded by some delay component in their turn [...]' Schegloff (1988: 445).

18 See Stivers and Robinson (2006: 373); Levinson (1983: 300-301) calls this type of silence in general an 'attributable silence' as speakers have been selected to speak by their interlocutor but stay silent.

19 In Sophocles' Philoctetes (731-745), the main character falls silent and breaks contact with Neoptolemus because he is in pain and sick. In Euripides' Hippolytus (179-283), Phaedra's breaks in communication when talking to her nurse in the beginning of the play are said to be caused by sickness, which again is caused by a state of mental confusion-Phaedra herself calls this $\mu \alpha v i \alpha$, and the chorus call it vóros. Given that both her emotion and sickness are portrayed as severe, this failure to establish contact should be explained as locutionary ineffectiveness.

20 Cf. Creon's pain about the prophecy that his son Menelaus needs to be sacrificed in Euripides' Phoenissae (Eur. Phoen. 967-970).

21 Soph. OC 1271-1348: Oedipus does not want to talk to Polyneices and ignores him for a long time-there is a gap of nearly 80 lines between Polyneices' enquiring about the silence and his eliciting an indirect response by Oedipus. Likewise, in Euripides' Hippolytus (Eur. Hipp. 902-1101), Theseus does not want to acknowledge Hippolytus' arguments out of hatred. For the îंo of $o c$ 's Oedipus being represented by his silence, see Perceau (2014: $68)$. 
When considering the examples above, ${ }^{22}$ however, the paradoxical nature of silence in tragic dialogue becomes manifest: as it marks a pause in tragedy's metrical language, it must follow that silent speakers do still take up their turn despite not speaking, and, what's more, precisely by staying silent. For the types of silence discussed can also be said to have an illocutionary force and a perlocutionary effect: ${ }^{23}$ by choosing not to speak, hence by giving a non-response and still taking up a turn, interlocutors convey a deeper meaning to their reaction and a disturbing effect is achieved on the speaker. ${ }^{24}$ Silences in persuasive discourse are consequently either caused by external factors-i.e. sickness or insanity - or internal factors - such as intense emotional involvement or personal aversion. The terminology provided by speech act theory and Conversation Analysis can help classify silences and their explanations more adequately and clearly: as a result, we are able to distinguish between voluntary and involuntary silence, external or internal reasons, as well as the degree of influence of the speaker-interlocutor relationship. Observing that silent speakers take up their turn by filling it with silence points to an important dramatic meaning. ${ }^{25}$ These categories do not become eminently clear from performance or text.

\section{$3 \quad$ Strategies of Reconnecting}

We have seen what silences in persuasive discourse mean and how they are interpreted by the speakers. It will illuminate our understanding of the relev-

22 The Cassandra passage in A. Ag. offers a very clear turn-sequence, in which the chorus selects Cassandra as the next speaker, and Clytaemestra answers instead: 1049-1050 Xo.

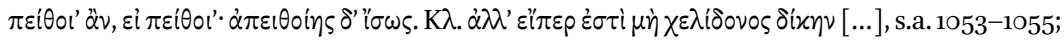
the same is true for Soph. Phil. 730-731, but Neoptolemos keeps talking after a diaeresis

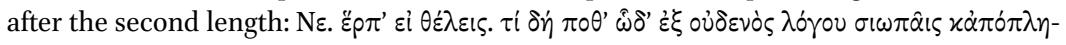

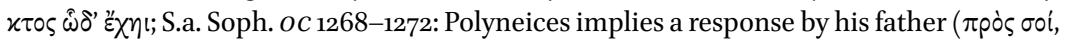

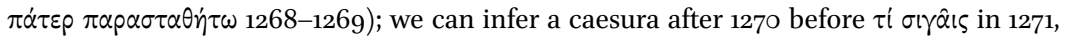
which again offers a pause as 1271 is an incomplete verse. In Eur. Hipp. 910-911, Hippolytus selects his father as the next speaker and then comments on his silence, which also sug-

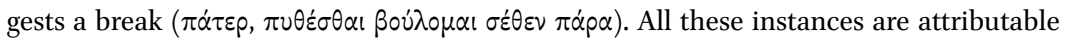
silences and effect breaks in conversational flow, which marks the absence of vocalised uptake. Therefore, attributable silences should be seen as a turn which speakers choose to or are forced (by emotional or physical impediment) to fill with a non-response.

23 I wish to thank Luis Unceta Gómez for this observation.

24 Cf. comments such as $\tau i$ $\sigma \nmid \gamma \hat{\alpha} \iota \varsigma$, which express a state of confusion and prompt the audience to wonder about the reasons.

25 Along the idea of Watzlawick et al. $(1967: 48-51)$ that one cannot not communicate, I suggest that silence is all the same a form of communication and therefore has the value of a turn. 
ant passages to examine the speakers' approach to an occurrence of silence in discourse and their attempts at reconnecting. Firstly, we should examine

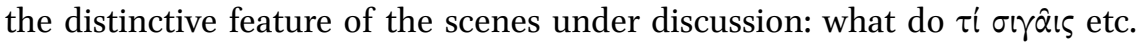
imply?26 The $\tau$ i-questions here considered seem to have a two-fold function: 1 ) they are the first verbal instance in discourse to mark this silence on stage (i.e. Wortregie) and 2) they already show some kind of reaction to the preceding silence-literally, by asking for the reason for the interlocutor's silence. ${ }^{27}$ But if

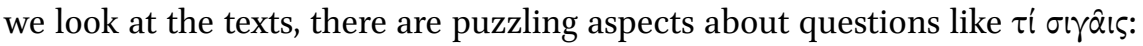
on their own, they are almost never answered in a straightforward way ${ }^{28}$ they tend not to entice a character to explain the reason for their silence, which would be the preferred response. ${ }^{29}$ Even when they are combined with

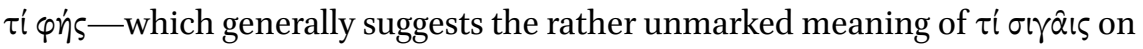
its own - they do not make the interlocutor speak instantly. ${ }^{30}$

Instances in which these questions do convince the previously silent interlocutor to reply are few and have one feature in common: they are always combined with other questions showing further personal interest for the silent interlocutor and the reason for their silence. ${ }^{31}$ So in fact, these short expressions are often only the prelude to a more engaged and interested approach by the speaker, ${ }^{32}$ and not so much a valid question of their own. Since we

26 Here, I also include the questions $(\tau i) \sigma \iota \gamma \hat{\alpha} \iota \varsigma$ and $\sigma \iota \omega \pi \hat{\alpha} \iota \varsigma$ as well as their combinations with

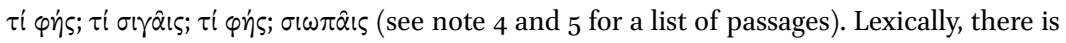
little difference between $\sigma i \gamma \hat{\alpha} \nu$ and $\sigma \omega \omega \pi \hat{\alpha} \nu$ when used intransitively: cf. Eur. IA $1245 i \delta o v$, $\sigma \omega \omega \pi \hat{\omega} \nu \lambda i \sigma \sigma \varepsilon \tau \alpha i \sigma^{\prime}$ ' $\delta \delta$ ', $\hat{\omega} \pi \alpha \dot{\alpha} \tau \varepsilon \rho$ (LSJ s.v. $\sigma \omega \omega \pi \dot{\alpha} \omega$ I. 'keep silence') and Telephus TrGF fr. 706.3-

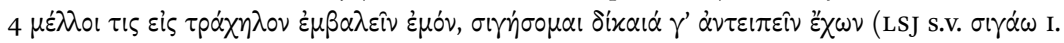
'keep silence'). For transitive use, cf. Eur. TrGF fr. $1037 \dot{\alpha} \tau \dot{\alpha} \rho \sigma \omega \pi \hat{\alpha} \nu \tau \dot{\alpha} \gamma \varepsilon \delta^{\prime}\left(x \alpha l^{\prime}\right.$ o $\chi \chi^{\prime} \chi \eta^{\prime} \pi 0 \tau \varepsilon$;

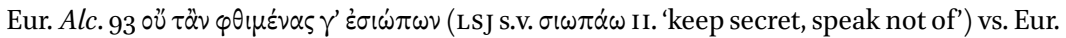

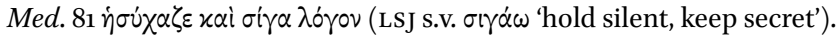

27 Montiglio (2000: 192) hints at this function when she observes: 'This phrase, by putting forward speech, betrays the agitation aroused by silence in those who try to understand this behavior and to bring it to an end.'

28 Exceptions are Soph. Phil. 806 und Eur. Andromeda TrGF fr. 126/127/128.

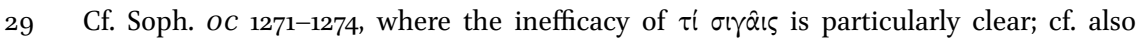
Soph. Phil. 730-735; Soph. Ichneutai, fr. 314.203-205; Eur. fr. 1008; Eur. Andromeda TrGF fr. 126/127/128; Eur. Hypsipyle TrGF fr. 757.839 .

$30 \quad$ Aesch. Edonoi $\operatorname{TrGF}$ fr. 61 (context uncertain, but at least ten more lines of rhesis); Soph. Phil. 951-952 (longer rhesis and choral song before interlocutor replies).

31 Such a case is e.g. Soph. Phil. 804-805, where we find the additional question $\pi \circ \hat{v} \pi \circ \tau^{\prime}$

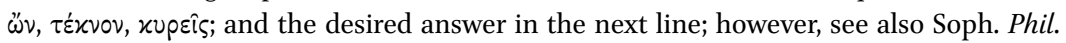
$730-73^{1}$ with the further question $\tau i$ है $\tilde{\sigma} \sigma \tau \nu$ after $\sigma \omega \omega \pi \hat{\alpha} \iota \varsigma$; cf. finally Eur. Andromeda $\operatorname{Tr} G F$

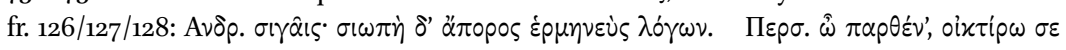

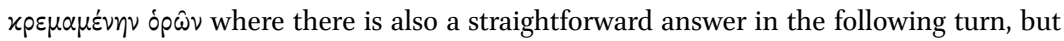
only after an additional comment on silence being hard to understand. 
have to assume a short pause after each of these questions, the interlocutor's silence is obviously marked by several missed turns. These missed turns make

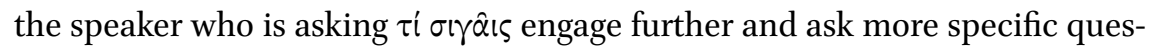
tions.

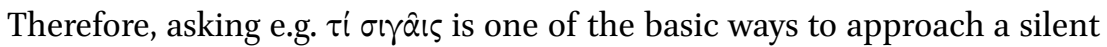

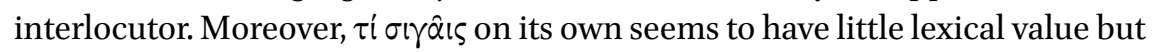
rather to be a formulaic or conventionalised expression, in the sense of a preferred response to a non-response turn within an established pattern ${ }^{33}$ - this might also be a marker for the audience, underlining the interlocutor's non-

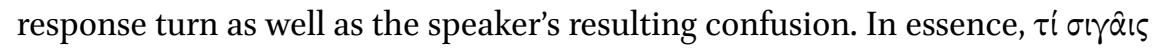
functions as a metadirective. ${ }^{34}$

Furthermore, we should examine cases in which several non-response turns are taken up by the silent interlocutor. Can we observe more involvement and interest in an interlocutor's silence than speakers using merely formulaic

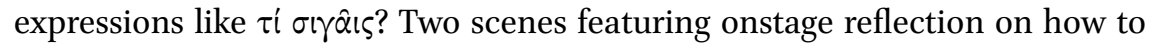
deal with someone's silence may help, as both of them refer to wilful silence due to illocutionary ineffectiveness:

Revisiting the scene in Aeschylus' Agamemnon, we find a situation without

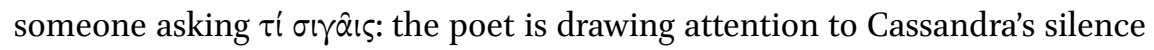
by making both Clytaemestra and the chorus each ask her three questions that do not receive an answer. As we have already seen, when pointing out a new welcoming home to Cassandra and a sacrifice within, Clytaemestra fails to make her move or talk. She hypothesises three possible reasons for Cassandra's silence: her barbaric language, her lack of understanding, or, if Cassandra does indeed rationally understand Clytaemestra, a lack of persuasive strategy on

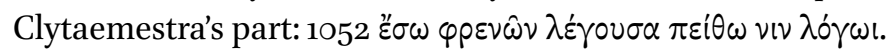

Scholars' explanations of the difficult expression है $\sigma \omega \varphi \rho \varepsilon v \hat{\omega} \nu$ differ: ${ }^{35}$ Whilst Fraenkel doubts the authenticity of हैं $\sigma \omega \rho \varepsilon v \omega \hat{\nu} \lambda \varepsilon \dot{\varepsilon} \gamma \circ v \sigma \alpha,{ }^{36}$ Denniston and Page accept it hesitantly ('I persuade her within her mind.') on account of a paral-

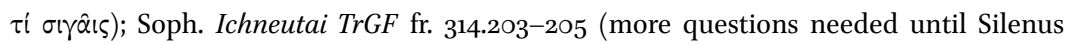
answers); Eur. $\operatorname{Tr} G F$ fr. 1008 (context unclear but combined with another question); Eur. Hypsipyle TrGF fr. 757.839 (no response for 30 lines).

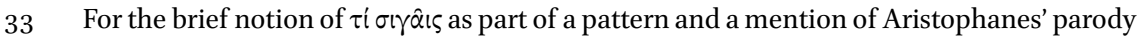
of it in Ar. Ran. 832, see Montiglio (2000: 192, 217). The need for more questions can also be explained by metrical reasons: asking only $\tau i$ $\sigma \gamma \hat{\text { â } \iota ~ m e a n s ~ t h a t ~ a n ~ e n t i r e ~ l i n e ~ w o u l d ~ b e ~}$ lost and therefore, another marked silence would occur. On metadirectives in Latin persuasive contexts and other contexts, see e.g. Risselada (1993: 44-45).

35 In Eur. Med. 316 it means 'in someone's mind'.

36 Fraenkel (1950: 477-478). 
lel from the Iliad ${ }^{37}$ However, much earlier than Fraenkel as well as Denniston and Page, namely in Scholefield's 1828 edition, ${ }^{38}$ and conversely, also in more recent works, ${ }^{39}$ है $\sigma \omega \varphi \rho \varepsilon v \omega \hat{\omega} \nu \lambda \varepsilon$ ' $\gamma 0 v \sigma \alpha$ is seen as Clytaemestra's adjustment to Cassandra's $\varphi \rho \varepsilon$ v́vऽ in a persuasive context. This reflection shows that here, as Budelmann and Easterling ${ }^{40}$ have pointed out for the following scene, we can see an example of Theory of Mind in action: Clytaemestra thinks about how to adjust to Cassandra's $\varphi p \varepsilon ́ v \varepsilon \varsigma$ and therefore has a concept of Cassandra's mind as differing from her own. ${ }^{41}$ Hence, without having commented on Cassandra's silence explicitly, there is an idea that an adjustment to someone's $\varphi$ pÉveৎ is required to make them talk -42 it is an acknowledgement of one's own failure to persuade.

Furthermore, there is another striking scene in which a break in contact marked by silence is reflected upon: when Polyneices tries to convince his father to support his cause in Sophocles' Oedipus at Colonus (Soph. oc 1271${ }^{1348)},{ }^{43}$ he begins his speech with a very negative description of Oedipus, selfdeprecation, and an appeal for pity. Then, Polyneices comments on his father's silence with $\tau i$ $\sigma \gamma \hat{\alpha} \iota \varsigma^{44}$ but in the end resorts to appealing to his sister for help in order to establish contact again. ${ }^{45}$ Antigone however refuses to do so and says the following lines-crucially, this is after Polyneices has asked $\tau i$ $\sigma \mid \gamma \hat{\alpha} \iota \varsigma^{46}$

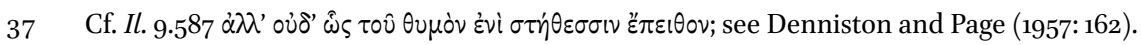
The same passage is already cited, but rejected as an insignificant parallel, by Fraenkel (1950: 477).

38 'ita loquens ut intellegat Cassandra.' Scholefield (1828: 246).

39 Raeburn and Thomas (2011: 183): 'transmitting words which Cassandra at least understands.'

40 Budelmann and Easterling (2010).

41 For a general approach to Theory of Mind in tragedy, but only with a short comment on line 1052, see Budelmann and Easterling (2010); see also Battezzato in this volume.

42 However, that adjustment of her argumentation does not, in fact, take place: she once again emphasises the upcoming sacrifice in the Argive palace and therefore implies ambiguity and imminent death for the prophetess, which the audience will have noticed as

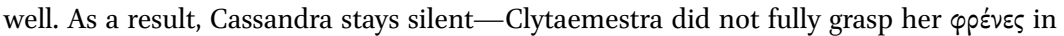
the end but assumed perlocutionary failure. But realising her $\varphi \rho \varepsilon ́ v \varepsilon \varsigma$ would have been a prerequisite for 1) establishing contact and 2) succeeding in her persuasion.

43 On the entire scene with an emphasis on Oedipus' response, see Saravia de Grossi (2002).

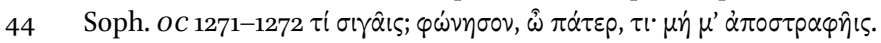

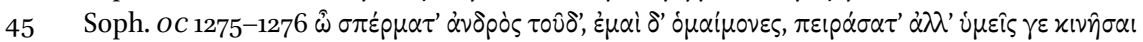

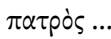

46 My translation is based on Lloyd-Jones (1994) and has been adjusted in doubtful cases such as l. 1282 . 
[2] Sophocles Oedipus at Colonus 1280-1283

$\lambda \varepsilon^{\prime} \gamma^{\prime}, \hat{\omega} \tau \alpha \lambda \alpha i \pi \omega \rho^{\prime}, \alpha \dot{\tau} \tau \dot{\jmath} \varsigma \hat{\omega} \nu \chi \rho \varepsilon^{\prime} \alpha l \pi \dot{\alpha} \rho \varepsilon l^{\circ}$

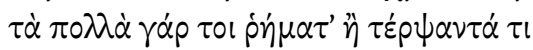

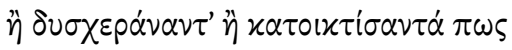

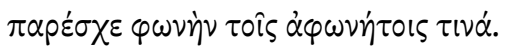

Tell him yourself, poor brother, what it is you need! For abundance of words, bringing delight or being full of annoyance or pity, can sometimes lend a voice to those who are speechless.

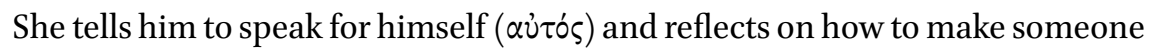

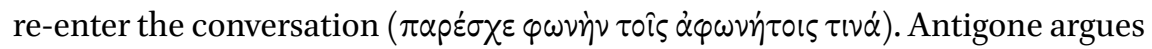
that words ( $\dot{p} \eta \dot{\mu} \alpha \tau)$ may help and specifies these as pleasing ( $\tau \dot{\varepsilon} p \psi \alpha \nu \tau \alpha)$, angry

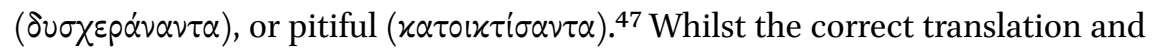
meaning of this advice has been correctly explained by Jebb, ${ }^{48}$ scholars have so far - to my knowledge - failed to see these words as a reflection on rhetorical strategy: pleasing, rebuking, or pitying someone using words in order to make them speak involves awareness of who they are and what arguments they might want to hear; and we are more likely to make them re-enter discourse if we adjust to them. In short, Antigone also implies a Theory of Mind.

By taking Clytaemestra's expression of persuading someone with regard to their $\varphi p \varepsilon ́ v \varepsilon \varsigma$ into account, we might be able to explain Antigone's advice more precisely: communicative contact, which is in the end a prerequisite for Polyneices' overall aim in this speech, i.e. persuasion, can, according to Antigone, be re-established by reacting to someone's mindset in one's speech. And as Antigone gives this advice after Polyneices has uttered $\tau i \sigma \gamma \gamma \hat{\alpha} \iota \varsigma$-in this instance probably functioning as a cue-she seems to demand that he do more than simply ask for reasons. Since this is an example of illocutionary ineffectiveness because of personal aversion, Antigone's advice makes perfect sense: interest in and engagement with the interlocutor's state of mind is crucial. Whilst at this specific point Polyneices and Antigone seem only concerned with Oedipus entering discourse again, ${ }^{49}$ Antigone's remark refers to Polyneices' general speech: it is clear that Polyneices means to achieve not just any reply from

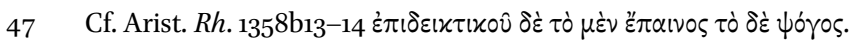

48 '[...] by giving some pleasure, —or by some utterance of indignation, or of pity' (Jebb 31900: ad 1281-1282); similarly, Saravia de Grossi (2002: 58).

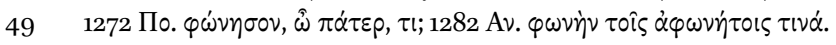


Oedipus; of course, he prefers a compassionate response from him, and so a persuasive strategy is required.

Polyneices does not entirely follow Antigone's advice: he may be using a proper captatio beneuolentiae by portraying Oedipus as the sole saviour of his Argive operation as well as arguing with his own unfortunate position as a refugee and suppliant, but then he begins his speech by addressing not Oed-

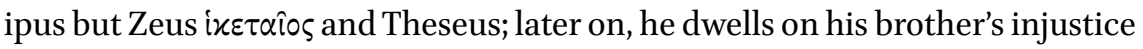
and the strength of his own army. ${ }^{50}$ Polyneices therefore does not adjust to the mind of his addressee, but focuses on himself and his own situation in order to portray himself as pitiful.

The effect this must have had on the audience is mirrored by the chorus who positively refuse Polyneices' proposition (Soph. oc 1346-1347), and later on by Oedipus, who, as we have already seen (cf. Soph. oc 1348-1396), ignores his son in his address and then rejects him. He only takes one step in a two-step process: he does, dutifully, at times, follow Antigone's advice of $\tau \dot{\varepsilon} p \psi \alpha \nu \tau \alpha$ pं $\eta^{\prime} \alpha \tau \alpha$ by stressing Oedipus' vital role in saving Thebes; but overall, he fails to do all the things necessary for effective and persuasive communication, such as addressing one's interlocutor or arguing from their point of view instead of one's own. So, it almost seems as if Polyneices makes Oedipus establish contact again by not doing what would be persuasive; instead he offers a speech that is outraged

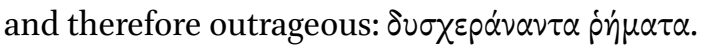

It has become clear that one needs more involvement than simply asking $\tau i$ oryâı to make someone enter discourse again, and there seems to be an awareness for the need of Theory of Mind, to speak in modern terms, within the characters' minds in order to establish contact and persuade their interlocutor. Showing interest in the interlocutor's mind was a feature in cases of both voluntary and involuntary silence (i.e. personal aversion vs. intense emotions) and underlined the speaker's confusion over this break in contact as well. $\tau i$ $\sigma \gamma \hat{\alpha} \iota \varsigma$ therefore acts as merely a marker of silence within a pattern of non-response turns, i.e. as an embedded stage direction.

50 For the clash of narratives between Oedipus and Polyneices in this passage, see Markantonatos (2007: 104-105). For a more detailed narratological interpretation, see Markantonatos (2002: 69-75). 


\section{Breaks in Contact as a Marker for Failure of Persuasion?}

By acknowledging that silence in tragedy usually represents breaks in contact due to a specific disposition of the interlocutor, questions inevitably arise about its relation to persuasion, i.e. perlocutionary force, within the dialogue in which it is embedded: does silence after one single persuasive utterance within a larger persuasive framework ${ }^{51}$ always signal the failure of all persuasive speech acts employed by the speaker? How likely is a character to give a preferred response after having already reacted with the most unwelcome non-response of all, namely silence?

Apart from Clytaemestra's failure to establish contact, it is more common for characters, such as Polyneices, to re-establish contact, but then fail in their persuasion. Two additional scenes feature a failure of persuasion prefigured by the interlocutor's silence:

In Euripides' Hippolytus (90o-945), Theseus refuses to establish communicative contact with his son after having read Phaedra's compromising letter. Hippolytus first has to establish contact but then fails to persuade him of his innocence because Theseus disrespects him. Despite Hippolytus' serious concern about his father's feelings (909-912), there is barely any straightforward communication between the interlocutors, and when Theseus finally addresses him he does so hatefully (948).

Similarly, in Euripides' Iphigeneia at Aulis (1238-1257), Agamemnon, told by the prophecy that sacrificing Iphigeneia is demanded by the gods, falls silent when his wife and daughter urge him to save Iphigeneia's life; ${ }^{52}$ Iphigeneia herself plays with her own rhetorical deficits and uses her silent young brother as a persuasive device. Although contact can be re-established, his emotional silence prefigures his emotional refusal, denying Iphigeneia her escape from the sacrifice because of his religious and moral convictions.

$5^{1}$ In this section, I exclude stichomythic passages in which contact is re-established within the next turn. See n. 27-29.

52 Agamemnon's reluctance to give a preferred response is already marked by the comments on his silence in 1141-1142, and in 1209 the chorus selects Agamemnon as the next speaker

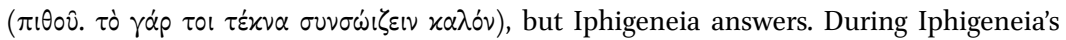
speech, this silent reluctance is made more obvious by his gestures: he looks away and refuses the physical contact with the suppliant (1239-1240). What is more, the obvious response expected by all three characters approaching Agamemnon (Clytaemestra, chorus, Iphigeneia) is a preferred response to their speech acts: Agamemnon should pledge not to kill Iphigeneia. Instead, Agamemnon wilfully refuses any contact, he gives a non-response by staying silent. 
In all these scenes (including Soph. $O c$ ), characters-after having experienced a break in contact due to illocutionary ineffectiveness-successfully re-establish contact by partially adjusting to their interlocutor, doing more than

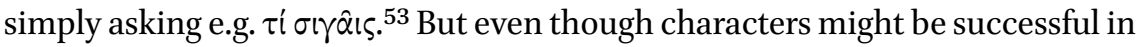
re-establishing contact, they then fail to persuade their counterparts anyway. $\tau i$

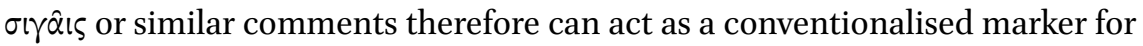
breaks in contact that typically lead to failure of persuasion, as simply uttering

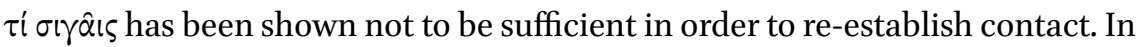
the scenes discussed in this section, silences due to illocutionary ineffectiveness and failure of persuasion are closely linked.

Successful Persuasion Despite Previous Loss of Contact: Sophocles' Philoctetes $^{54}$

Whilst the appalling aesthetic effect of Philoctetes' pain and his screaming has been noted since antiquity, ${ }^{55}$ the silences used in the very same scene also deserve attention. Earlier, we saw Neoptolemus struggling to have a proper conversation with Philoctetes (cf. Soph. Phil. 731-745 in Section 2). Philoctetes' silence due to locutionary ineffectiveness is only momentary as his pain flares up in waves. At this point, the intrigue is still in full effect with Neoptolemus pretending to save Philoctetes from the Atreidai, both have entered and exited Philoctetes' cave in order to pack up his things. But even though contact is reestablished instantly after Philoctetes' cry of pain, Neoptolemus goes on:

[3] Sophocles Philoctetes $755^{-761^{56}}$

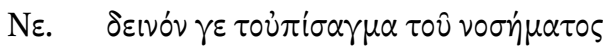

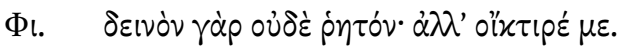

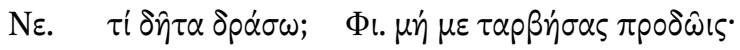

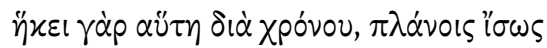

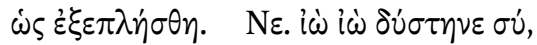

53 In Sophocles' oc, Polyneices uses a captatio; in Euripides' Hippolytus, Hippolytus asks his father questions about his pain and shows his general concern; in Euripides' $I A$, Iphigeneia asks her father to face her again and uses Orestes' presence as an emotional leverage on her father.

54 For this scene in general, see Perceau (2014).

55 See Männlein-Robert (2014).

$5^{6}$ My translation is based on Lloyd-Jones (1994) and has been adjusted in doubtful cases. 


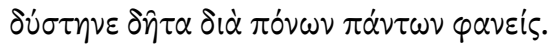

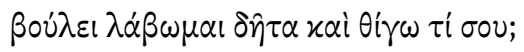

Ne. The burden of the sickness is grievous.

Phil. Grievous indeed, and indescribable!

Ne. What shall I do?

Phil. Do not take fright and betray me! It has come in person after a time, perhaps because it is weary of wandering, the sickness.

Ne. Ah, unlucky one! Unlucky you are found to be in every kind of trouble!

Do you wish me to take hold of you and hold you?

Neoptolemus acknowledges Philoctetes' wound as the source of his pain and asks what he may do about it - not only does this mean an adjustment to the interlocutor, but openly shows his intent to know the reason for his pain. Philoctetes, as a result, complies by repeating $\delta \varepsilon v v^{\prime} v$ in the same position, asks Neoptolemus to pity him, and even hands him his bow (762-773). This meaningful moment in the play when Philoctetes and Neoptolemus are portrayed as slowly developing a real emotional bond is visibly marked by contact that is lost and re-established.

Then, another bout of pain seizes Philoctetes and he cannot communicate coherently anymore. He once again screams and wishes for his death:

[4] Sophocles Philoctetes 799-806

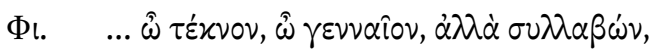

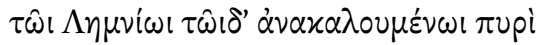

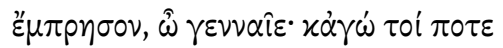

$\tau \dot{0} v \tau 0 \hat{v} \Delta$ iòs $\pi \alpha \hat{i} \delta^{\prime} \alpha \dot{\alpha} \tau i \tau \hat{\omega} \nu \delta \varepsilon \varepsilon \tau \hat{\omega} \nu$ ö $\pi \lambda \omega \nu$,

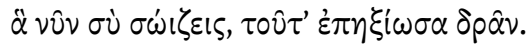

$\tau i \varphi \eta^{\prime} \iota \varsigma, \pi \alpha i$;

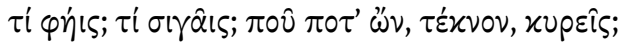

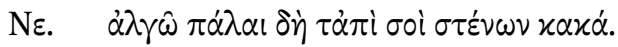

Phil. ... O my son, $\mathrm{O}$ my noble son, take me, and burn me with this fire that is invoked as Lemnian, noble one. I also once consented to do this to the son of Zeus in return for those weapons which you now are guarding! What do you say, boy? what do you say? Why are you silent? Where are you, my son?

Ne. I have been in pain long since, lamenting for your woes. 
Remarkably, Neoptolemus has now fallen silent. Philoctetes, in turn, has to

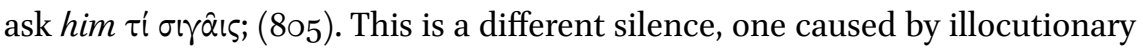
ineffectiveness, as Neoptolemus has understood Philoctetes' speech acts perfectly, but is prevented from speaking for different reasons. How does Philoctetes now, in return, re-establish contact?

He asks Neoptolemus about his current thoughts and mental state:57 805

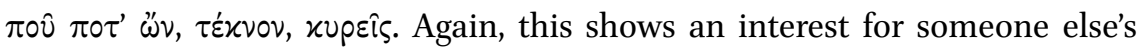
mind, which is slightly more involved than commenting on their silence. ${ }^{58}$ Neoptolemus' answer offers the reason for his silence: $\dot{\alpha} \lambda \gamma \hat{\omega} \pi \dot{\alpha} \lambda \alpha \mathrm{l} \delta \dot{\eta} \tau \dot{\alpha} \pi i$ бoi $\sigma \tau \varepsilon \dot{v} \omega \nu$ x $\alpha x \alpha \dot{\alpha}$ (806). Admittedly, this silence is an emotional one, ${ }^{59}$ having an ambiguous effect on the audience: 1) Neoptolemus is obviously affected by Philoctetes' excruciating pain - this has already been observed; 2) he is still pondering whether or not to follow Odysseus' plan to take Philoctetes by force. ${ }^{60}$ Again, this is a decisive moment in the play.

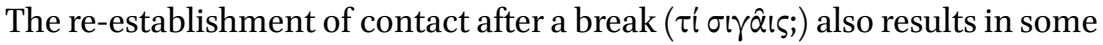
middle ground established between the interlocutors, which is unusual when comparing it to the examples we have seen: Neoptolemus even promises him to stay ${ }^{61}$ and, later on, admits that he and Odysseus had a plan (915). After hearing the revelation, Philoctetes shares his hateful monologue demanding his bow back. Neoptolemus, again, falls silent, as is marked by $\sigma \omega \tau \tilde{\alpha} \iota \varsigma$ :

[5] Sophocles Philoctetes 950-951, 961-962, 965-966

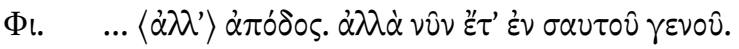

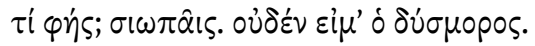

$[\ldots]$

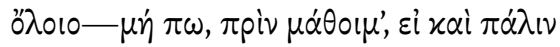

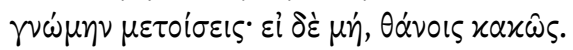

$[\ldots]$

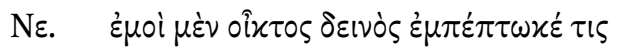

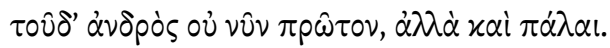

57 Schein (2013: 244).

58 Cf. Neoptolemus' engagement with the mind of his interlocutor in 729-755.

59 Cf. 'silence comme cri' Perceau (2014: 77).

6o Seth Schein rightly notices the choice of the word $\pi \dot{\alpha} \lambda \alpha \mathrm{l}$ as instructive, since it refers to the speaker's perspective and therefore implies relativity, see Schein (2013: 244).

$61 \quad 813 \dot{\varepsilon} \mu \beta \dot{\alpha} \lambda \lambda \omega \mu \dot{\varepsilon} v \varepsilon เ v$. 
Phil. ... Give it back! Even now it is not too late, come to yourself! What do you say? You are silent! I am nothing, miserable one! $[\ldots]$

May you perish — but not yet, before I learn whether you will once more change your decision. If you do not, may you die miserably! $[\ldots]$

Ne. As for me, a strange pity for this man has fallen upon me, not now for the first time, but since long ago.

Again, Philoctetes makes a comment on his interlocutor's thoughts and shows awareness that is beyond simply asking why someone is silent: he debates whether he could change his mind or not. Once again, this is a sign for illocutionary ineffectiveness, as his addressee has very well understood him: $\pi$ piv

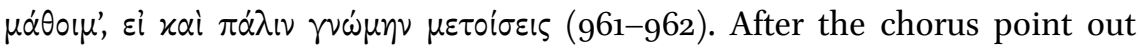
Neoptolemus' responsibility for the mission at hand, Neoptolemus finally answers with a positive response ( 965 oix $\tau$ เo $\delta \varepsilon เ v o ̀ s)$.

So why does this silence caused by illocutionary ineffectiveness-in contrast to the other scenes we have presented - raise the expectation of a positive outcome for Philoctetes? Two aspects can be employed to explain this specific outcome:

1) The interlocutor that fell silent — who was influenced by his emotionshas a reputation for his honest and friendly $\varphi v$ $\sigma \varsigma{ }^{62}$

2) Philoctetes' silence was the symptom of his severe pain; this caused Neoptolemus' silence, which was in turn a symptom of his pity and his qúrı (the two characters thus exemplify the difference between silence due to locutionary ineffectiveness and illocutionary ineffectiveness).

Characters' non-responses in the form of silence have to be interpreted by the audience and by other characters as a representation of the characters' minds: therefore, these non-responses convey the underlying dispositions of characters. Re-establishing contact that has been caused by illocutionary ineffectiveness made it possible that persuasion and synchronisation of interlocutors could be accomplished in this case. In fact, they are even furthered by silences, as Philoctetes' effectual silences only elicit the feeling of pity and concern in Neoptolemus - the embodiment of this feeling are his own silences.

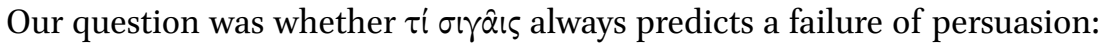
in this particular instance, we have seen that silence caused by positive emo-

$62 \quad$ Neoptolemus' distinctive character trait had already been established as early as the very first scene with Odysseus (Soph. Phil. 79-8o, 87-88). 
tions (such as pity) may predict a positive outcome. Breaks in contact therefore always ask for an engagement of Theory of Mind by the audience. To my knowledge, however, silence as a non-response seems to be more often an embodiment of negative emotions in tragedy, prefiguring a dispreferred response to the entire speech act of persuasion, and therefore predicting the failure of such.

We have considered the linguistic functions that can be attributed to silence and breaks in contact in tragedy. In the course of this study we have explored how characters tend to reconnect after a silence. Having investigated the impact of breaks in contact on the persuasive discourse they are featured in, we can draw three general conclusions:

1) Whilst silence in persuasive discourse is always a non-response, it can express either locutionary ineffectiveness, when the interlocutors did not grasp the meaning of the utterance made to them (in this case, silence in tragedy usually symbolises insanity or severe sickness); or it embodies illocutionary ineffectiveness, which mirrors positive or negative emotions on the interlocutor's part-which does not prevent them from understanding, but from answering. A special case of illocutionary ineffectiveness would be interlocutors refusing to communicate due to these emotions. Silence, marked by short pauses on stage, has also been shown to function as a turn featuring a non-response. Finally, silence can be a symptom as well as a persuasive device: it may force characters to adjust their speech, as a result of communicative contact lost. ${ }^{63}$

2) Tragic characters tend to have a concept of their interlocutor's mindwhich may be true or false-and understand that they have to use this knowledge in order to overcome silences caused by illocutionary ineffectiveness and to persuade. As we have seen, this calls for a deeper level of

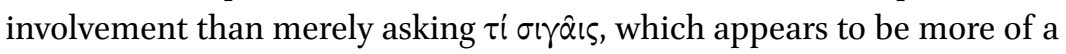
formulaic and conventionalised expression rather than conveying meaning or impact.

3) In most cases, persuasion in scenes marked by $\tau i$ $\sigma \nmid \gamma \hat{\iota} \iota \varsigma$ fails entirely because there silences express negative emotions or aversions-Philoctetes succeeds because Neoptolemus' silences are the symptom of his pity and honest $\varphi v$ vis. The notion of silence as a cue that is to be interpreted by

63 Cf. e.g. Antigone's advice and Polyneices' reaction in Soph. oc 1280-1283. 
the audience both on and off stage is therefore noteworthy, not because it draws attention to the character (as in the case of Cassandra or in Aeschylus' Myrmidones), but rather because they shift the focus towards the

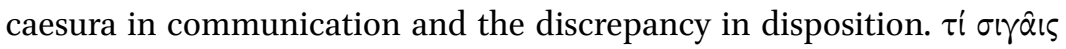
and the like therefore function as relational markers prompting the audience to pay attention to characters' $\varphi \rho \varepsilon$ ves and their ṕn $\mu \alpha \tau \alpha$ when they are trying to overcome silence in the only way in which tragic characters know how to do so: by talking.

\section{Acknowledgements}

I wish to thank the editors of this volume for their helpful remarks and thorough annotations.

\section{References}

Austin, J.L., ( ${ }^{2} 1975$ [1962]), How to Do Things with Words, Oxford.

Battezzato, L., (2017), 'Change of Mind, Persuasion, and the Emotions: Debates in Euripides from Medea to Iphigenia at Aulis', Lexis 35, 164-177.

Budelmann, F. \& Easterling, P.E., (2010), 'Reading Minds in Greek Tragedy', Greece and Rome 57, 289-303.

Chong-Gossard, J.H.K.O., (2008), Gender and Communication in Euripides' Plays: between Song and Silence, Leiden.

Denniston, J.D. \& Page, D.L., (1957), Aeschylus, Agamemnon, Oxford.

Fraenkel, E., (1950), Aeschylus, Agamemnon, vol. 2, Oxford.

Jebb, R.C., $\left({ }^{3} 1900\right.$ [1885]), Sophocles, Oedipus Coloneus, Cambridge.

Levinson, S.C., (1983), Pragmatics, Cambridge.

Lloyd-Jones, H., (1994), Sophocles, vol. 1, Cambridge, Mass./London.

Männlein-Robert, I., (2014), 'Schmerz und Schrei: Sophokles' Philoktet als Grenzfall der Ästhetik in Antike und Moderne', Antike und Abendland 6o, 90-112.

Markantonatos, A., (2002), Tragic Narrative: a Narratological Study of Sophocles' Oedipus at Colonus, Berlin/New York.

Markantonatos, A., (2007), Oedipus at Colonus: Sophocles, Athens, and the World, Berlin/New York.

Mastronarde, D.J., (1979), Contact and Discontinuity: some Conventions of Speech and Action on the Tragic Stage, Berkeley.

Montiglio, S., (200o), Silence in the Land of Logos, Princeton.

Perceau, S., (2014), 'De la réticence au cri. La gamme du silence dans la tragédie grecque', 
in L. Boulègue, P. Caye, \& C. Flament (eds.), Silence et sagesse. De la musique à la métaphysique: Les anciens Grecs et leur héritage, Paris, $65^{-89}$.

Pomerantz, A., (1975), Second Assessments: a Study of some Features of Agreements/Disagreements, Irvine.

Pomerantz, A., (1978), 'Compliment Responses: Notes on the Co-Operation of Multiple Contraints', in J. Schenkein (ed.), Studies in the Organization of Conversational Interaction, New York, 79-112.

Pomerantz, A., (1984), 'Agreeing and Disagreeing with Assessments: some Features of Preferred/Dispreferred Turn Shapes', in J.M. Atkinson \& J. Heritage (eds.), Structures of Social Action: Studies in Conversation Analysis, Cambridge, 57-101.

Raeburn, D. \& Thomas, O.R.H., (2011), The Agamemnon of Aeschylus, Oxford.

Risselada, R., (1993), Imperatives and other Directive Expressions in Latin: a Study in the Pragmatics of a Dead Language, Amsterdam.

Saravia de Grossi, M.I., (2002), 'El discurso de Polinices (vv. 1284-1345) en Edipo en Colono de Sófocles', Synthesis 9, 53-69.

Schegloff, E.A., (1988), 'On an Actual Virtual Servo-Mechanism for Guessing Bad News: a Single Case Conjecture', Social Problems 35, 442-457.

Schein, S.L., (2013), Sophocles, Philoctetes, Cambridge.

Scholefield, J., (1828), Aeschylus, Cambridge.

Searle, J., (1965), 'What is a Speech Act?', in M. Black (ed.), Philosophy in America, London, 221-239.

Sommerstein, A.H. (2008), Aeschylus, vol. 2, Cambrige, Mass./London.

Stivers, T. \& Robinson, J.D., (2006), 'A Preference for Progressivity in Interaction', Language in Society 35, 367-392.

Taplin, O., (1972), 'Aeschylean Silences and Silences in Aeschylus', Harvard Studies in Classical Philology $76,57-97$.

Watzlawick, P., Beavin, J.H., \& Jackson, D.D., (1967), Pragmatics of Human Communication: a Study of Interactional Patterns, Pathologies, and Paradoxes, New York. 


\title{
Doing Things with Words ... and Gestures on Stage
}

\author{
Matteo Capponi
}

This paper aims to demonstrate the importance of gesture in the analysis of dramatic texts. Expanding on the central theme of this book, I will focus specifically on the relationship between speech acts and gestures on stage. For some years I have been adapting and directing ancient texts for the stage and this frequently exposes me to this problematic. I always try to bring the benefit of my stage experience to my academic work, combining theory and practice, and my approach thus incorporates the effects in theatrical performance of what can be done with both words and gestures.

This principle is far from an obvious one. The problematic of speech acts, after all, was born in the world of words, in the works of Oxford philosophers of language ${ }^{1}$ in the 196os and 1970s who '[ont ouvert] véritablement la voie à la pragmatique, en observant que le rôle du langage n'est pas exclusivement de décrire le réel, mais aussi d'exercer une action (c'est la théorie des actes de langage).' ${ }^{2}$ The debate in these circles focused on the function of speech, eclipsing questions about its physical delivery. This imbalance led the linguist Alain Berrendonner to emphasise the fundamental distinction between saying and doing. The chapter dedicated to this in his 1982 work Éléments de pragmatique linguistique is eloquently entitled 'Quand dire c' est ne rien faire'. In it he reintroduces the idea that 'un acte est un geste ou ensemble de gestes'. ${ }^{3}$ Like speech act theory, the philological tradition is also rooted in texts (as the name implies). The rise of performance studies aside, we might say that this tradition shows reluctance to think three-dimensionally. ${ }^{4}$ It seems that caution is the watchword: if a text constitutes objective data, gesture always depends on conjecture.

Nevertheless we cannot deny that gesture plays an essential role in the performance of texts, particularly in the case of melic poetry, rhetorical speech,

1 Principally, John Austin (1911-1960), Paul Grice (1913-1988) and John Searle (*1932).

2 Bracops (2010: 28$)$.

3 Berrendonner is responding to Austin's 1955 lecture 'How to do Things with Words', which he refutes thus: 'Aussi bien la représentation 'naïve' du langage que la théorie béhavioriste mettent le faire du côté du geste. Selon elles, il n'y a d' actes que s' il y a pratique gestuelle. [...] Souscrivons, et posons: “Un acte est un geste ou ensemble de gestes".' (Berrendonner 1982: 81).

4 Alan Boegehold's 1999 book When a Gesture Was Expected is a significant exception. It focuses on the rare occurrences in which a gesture replaces a phrase, for instance in the case of the aposiopesis. 
and drama. The problem is that when gesture in drama is the focus of research, it is only rarely linked to spoken lines and thus to speech acts. For instance, you will not find 'pragmatics' or 'speech acts' in the general index of Greek and Roman Actors, ${ }^{5}$ which focuses instead on the 'art of the actor', 'body use', and 'type of performance'. Likewise, questions about pragmatics and interaction do not generally feature in canonical studies on gesture and acting. ${ }^{6}$ The reason is simple: the concepts had not yet been invented. This means that it is now necessary to review and complete these studies by adding new perspectives.

Of course, contemporary pragmatics does not completely ignore the gesture. It features prominently under the label of kinesics as an essential part of communication that is considered interaction. ${ }^{7}$ As we shall see, scholarly classifications aim to distinguish different types of gesture. These classifications, however, have not taken root in the study of ancient drama. A certain amount of work remains to be done to report the whole complexity of gestural analysis. This chapter represents a modest attempt to contribute to that end. It will highlight the significance of the gestural dimension to the pragmatic analysis of texts created for the stage. Through a comparison of the distinct dramatisations by Sophocles and Euripides of the same (or very similar) tragic scene, it will illustrate the benefits of a unifying approach that incorporates both words and gestures. Before that, however, we must define our terms.

\section{Gesture and/or Speech}

Everyday acts of language are usually accompanied and sometimes replaced by gestures. According to the interactionist approach, ${ }^{8}$ communication rarely occurs through one medium at the exclusion of the other. Catherine Kerbrat-

5 Easterling and Hall (2002).

6 By canonical studies, I mean works such as Sittl (189o), Capone (1935), Spitzbarth (1945) and Neumann (1965). Also worth mentioning is Kaimio (1988) on physical contact in tragic scenes and Telò (2002a, 2002b) on the performance of gesture. We will refer to them later.

7 For the cultural and definitional issues of gesture, see Thomas' introduction to A Cultural History of Gesture: 'Kinesics is a highly developed subject with a variety of subdivisions, ranging from proxemics (the study of the distance which people keep from each other when talking), to haptics (the study of the way in which they touch each other during the conversation).' (Thomas 1991: 3); see also Scolari in this volume.

8 'La perspective interactionniste confirme et même renforce l' idée selon laquelle parler c' est agir-ou plutôt interagir, en ce sens que tout au long du déroulement d' un échange communicatif quelconque, les différents participants exercent les uns sur les autres des influences de nature diverse.' (Kerbrat-Orecchioni ${ }^{2} 2005: 53$ ). See also Ricottilli and Raccanelli in this volume. 
Orecchioni defines it as both multi-channel (voice, look, touch) and multisemiotic (language, body signs). ${ }^{9}$ David McNeill refers to the 'inviolability of the speech-gesture unit'. ${ }^{10}$ There is no reason to believe it would have been different for the Greeks. In fact, in the Laws, Plato refers to the same principle:

[1] Plato Laws 7, 816a3-6

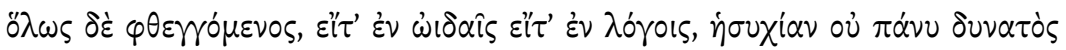

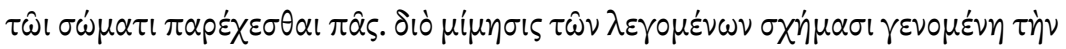

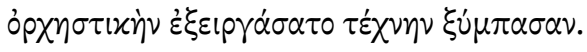

And in general, no one who is using his voice, whether in song or in speech, is able to keep his body wholly at rest. Hence, when the representation of things spoken by means of gestures arose, it produced the whole art of dancing..11

This complementarity of gesture and speech is echoed in ancient iconography. For example, the simple act of saying something, the locutionary act, ${ }^{12}$ is signified by an outstretched arm. ${ }^{13}$ The gesture is used to symbolise the voice dynamic. The same principle is applied in the comic representations depicted in Apulian vase painting. ${ }^{14}$ Thus the difference between drama and real life is unmarked. We can even draw a parallel between iconography, where the image remains silent forever, and the ancient theatre play, where masked actors perform to large audiences: in both, gesture is essential to understanding who is speaking.

It is legitimate therefore to attempt to systematically rebuild the presence of gesture in dramatic representation and understand the varied interactions it maintains with words. After all, the art of the actor is based on the controlled

\footnotetext{
$9 \quad$ Kerbrat-Orecchioni (2005: 150).

10 McNeill (2009: 301).

11 Tr. Bury (1926).

12 Austin distinguishes three types of speech act: locutionary (the act of saying something), illocutionary (the way of using language; the performance of the act in saying something), and perlocutionary (the effects on the feelings, thoughts or actions of participants brought about by performing an illocutionary act).

13 'Wo aber der Mantel die Arme nicht einengt, dürfte als Regel gelten, dass jeder Sprechende durch die Bewegung seiner Hand gekennzeichnet ist.' (Sittl 189o: 284).

14 See, for example, Taplin (1993: 30-31, 59) and Green (2002: 111-112) on the 'New York Goose Play' and 'Choregoi' vases.
} 
combination of gesture and speech. A lack of coordination can damage a scene and even result in the actor's dismissal!

[2] Philostratus Lives of the Sophists 1.78 .8

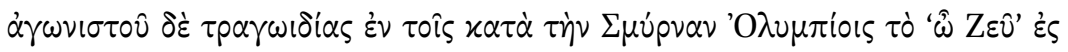

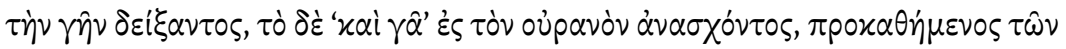

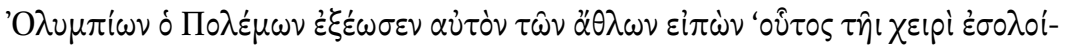

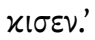

Again, when a tragic actor at the Olympic games in Smyrna pointed to the ground as he uttered the words, 'O Zeus!' then raised his hands to heaven at the words, 'and Earth!' Polemo, who was presiding at the Olympic games, expelled him from the contest, saying: 'The fellow has committed a solecism with his hand.15

Space does not permit us here to explore all forms of gesture performed on stage. Echoing the volume's central concern, we will focus on those gestures that accompany speech acts. Speech act theory questions precisely the line between saying and doing but attributes to speech the capacity to do as well as say. In doing so, it privileges speech over gesture and casts the illusion, perhaps unwittingly, of the independence of speech. Thus it runs against the grain of McNeill's principle of the inviolability of the speech-gesture unit, and brings us to questions about how we understand and classify both gestures and speech acts.

The concept of the speech-gesture unit, hinted at by Plato and theorised over two millennia later by McNeill, compels us to consider independently and simultaneously the roles of gesture and speech. If this distinction is maintained, it allows us to focus on the multiple variations that may exist in the relationship between the two as they form a unit. But how do we make such a distinction? Let us first review the typology outlined by Kerbrat-Orechioni in Les actes de langage dans le discours (see Table 1). ${ }^{16}$ In any interaction, she argues, there are

\footnotetext{
15 Tr. Wright (1922: 131).

16 Kerbrat-Orecchioni ( ${ }^{2} 2005$ : 153-154).
} 


\begin{tabular}{lll} 
Non-speech acts & Non-speech acts & Speech acts \\
\hline $\begin{array}{l}\text { Non-communicative } \\
\text { (praxical) }\end{array}$ & Communicative & Communicative \\
$\begin{array}{l}\text { Brushing a horse, run- } \\
\text { ning, picking olives, etc. }\end{array}$ & $\begin{array}{l}\text { Knocking at the door, rais- } \\
\text { ing a hand, shrugging the } \\
\text { shoulders, etc. }\end{array}$ & $\begin{array}{l}\text { Questioning, promising, sup- } \\
\text { plying, etc. (all the things } \\
\text { you can 'do' by speaking) }\end{array}$
\end{tabular}

communicative speech acts and communicative non-speech acts. The latter consist of gestures performed as a complement or an alternative to speech. They may take the place of a speech act in an interaction. Such communicative non-speech acts coincide with codified gestures of various types, including deictic and symbolic (terms we will discuss later). We find them in art and iconography, for example in the depiction of prayer, supplication, and order. The third category in Kerbrat-Orecchioni's typology is non-communicative nonspeech acts (or praxical gestures). Here again, the iconographic examples are numerous: brushing a horse, killing the minotaur, picking olives, etc. Any dramatic text includes gestures of this third kind: entering and leaving the stage, running, crawling, and so on. It will also likely include non-gestures such as characters who stand immobile for some reason. However, in an art form as highly symbolic as drama, even praxical gestures may carry communicative value, whereas in real life they do not. Gestures such as veiling, sitting on the ground, or looking up or down may take on a specific significance on stage. They may become communicative, whether to other characters or indeed to audience members.

Let us first consider the category of communicative non-speech acts, for it is the most closely linked to the theme of this volume. We may again distinguish different types, depending on the roles these acts play in relation to words. Kerbrat-Orecchioni distinguishes three: the subordinate gesture, which completely serves the speech act, the complementary gesture, which reinforces or fine-tunes (makes precise) the speech act, and the plain gesture, which performs an intervention. ${ }^{17}$ However, we may ourselves wish to fine-tune this classification as it might apply to drama, particularly concerning the distinc-

17 Kerbrat-Orecchioni (2005: 153-154). 
TABLE 2 Kendon's continuum ${ }^{\mathrm{a}}$

Gesticulations $\rightarrow$ Language-like gestures $\rightarrow$ Pantomimes $\rightarrow$ Emblems $\rightarrow$ Sign language

Type of gesture

Definition

Gesticulations

(= Kerbrat-Orecchioni's subordinate gesture)

Language-like gestures

(= complementary gesture)

Pantomimes

(= complementary or plain gesture)

Emblems

(= plain gesture)

Sign language 'the spontaneous movements of the arms and

hands that accompany speech'

'similar to gesticulations but [...] "integrated" into a linguistic string in the sense that they must occur at a certain point and contribute to the interpretation of the string as a whole'

'movements that depict objects or actions; accompanying speech is no longer obligatory'

'cultural-dependent symbolic gestures used to convey a wide range of both positive and negative meanings'

'languages proper, with their own syntactic, semantic and phonological rules'

a Presented, with these definitions, in Allan and Jaszczolt (2012: 583).

tion between subordinate and complementary roles. Arranging five kinds of gesture distinguished by Adam Kendon on a continuum running from involuntary movements to sign language, McNeill ${ }^{18}$ offers us an alternative, which he calls Kendon's Continuum (see Table 2): 'As we move from left to right on the continuum, the gestures become less natural, take on more "language-like" properties and depend less on the co-presence of language itself.' ${ }^{\prime 9}$ This typology better reflects the use of gesture in the theatre.

18 For a concise explanation, see McNeill ( $\left.{ }^{2} 2009\right)$.

19 Allan and Jaszczolt (2012: $\left.5^{83}\right)$. 
Rarely do the distinctions made by scholars account for how gestures are used in drama. For instance, in his study on the use of the body in acting, Kostas Valakas identifies three types of gesture without elaborating further. Nevertheless, note the attention he pays to bodily posture, significant in itself:

The meanings of body language can be expressed through postures as much as gestures and movements, and the dynamic aspect of a character could depend on the particular symbolic shape taken by the axis of the performer body. ${ }^{20}$

Oliver Taplin rules out the category of gesticulations but then draws no distinction between what we could describe as praxical gestures (such as sitting or lying down, running, kneeling, or striking) and communicative gestures, including language-like gestures (supplicating, embracing, etc.) and emblems (bowing the head, looking away, etc.):

But these run-of-the-mill bodily movements, while they are a concern for the actor and producer and while their economy and appropriateness are essential for a good performance, are not my chief concern here. I am preoccupied with the unique action which is brought about by, and which often epitomizes, the dramatic impact of a particular moment. [...] There is still a large residue: sitting and lying down, running, kneeling, supplicating, embracing, striking, bowing the head, looking away and so on. ${ }^{21}$

Finally, Mario Telò offers similar examples in his 'grammar of gesture' in Greek tragic drama, referring to praxical gestures such as falling down and bouncing back and gestures with emblematic value such as veiling and unveiling the face. ${ }^{22}$ In his second paper, however, he considers one kind of communicative gesture (which can be language-like or symbolic/emblematic) which doubles most often as a speech act: the plea. ${ }^{23}$

By focalising on specific gestures, neither Telò nor Taplin addresses the fundamental question of the formal interaction between gesture and speech. Doing so might enable us to shed light on the type of gesture favoured by ancient drama. After all, as any actor will testify, a line delivered before a gesture, during a gesture, and after a gesture are not the same. This raises aesthetic

\footnotetext{
$20 \quad$ Valakas (2002: 79).

21 Taplin (1978: 58).

22 Telò (2002a).

23 Telò (2002b).
} 
and practical questions. Each time he speaks and moves, the (masked) ancient actor must at the same time signify that his turn to speak has come, reinforce the content of his speech, and create an effect, a picture in the minds of his audience. This conjunction of two semiotic media, speech and gesture, is closely related to the codes and aims of ancient drama. We may apply to the dramatic gesture the same function David Wiles gives to the choreographic gesture: 'Rather than competing for the audience's attention, the physical action made it possible to grasp the complex words, and the words in turn made it possible to read the action. ${ }^{24}$ Thus we must go deeper into the analysis and look into the text for the precise traces of interactions between gesture and speech.

As mentioned above, we will study an emblematic scene from ancient drama that appears as a dialogue and for which we have different versions: the recognition between Orestes and Electra. It appears in three plays: Aeschylus' Choephoroe (The Libation Bearers), Sophocles' Electra, and Euripides' Electra. However, the same event is dramatised very differently by each author through their use of language and gestures. ${ }^{25}$ Here we will limit our focus to Sophocles and Euripides. We will follow step by step, gesture after gesture, the reunion of brother and sister in both plays. That way we can identify the precise moments where, depending on the text and its pragmatic data, some gesture is necessary.

However, before turning our attention to the texts, we must first make some observations about how, why and which gestures were used in ancient theatre. Fundamental technical principles of ancient theatre production, many the consequence of the construction and layout of the building, help to explain why gestures were necessary.

1) First of all, we must never forget that drama was played remotely before a huge audience by masked and dressed actors.

2) Acoustics were a crucial factor. When an actor spoke or sung, he would have to stand in front of the audience and face it directly most of the time, although there is some debate over whether he would do this from the 'stage' in front of the skênê or from the orchêstra (between the auditor-

\footnotetext{
24 Wiles (2000: 139).

25 For a comparison of how each play represents the proofs used in the recognition scene, see Solmsen (1967).
} 


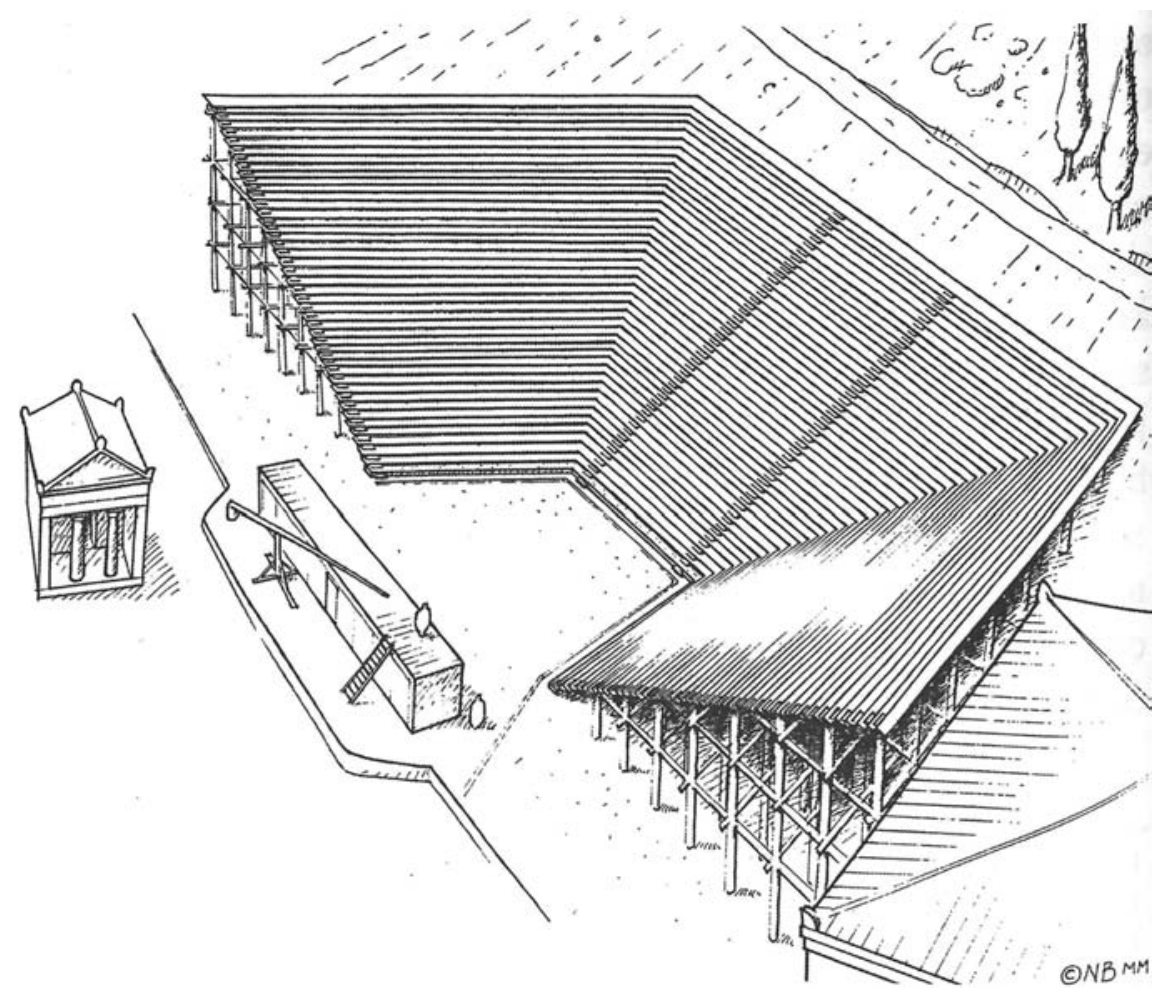

FIGURE 1 Sketch of the Athenian theatre in the second half of the fifth century BC

Note: From Moretti (2001: 124). As we observe, the actor cannot talk while having his head turned on the left or the right, risking that half of the audience would not have heard him. It goes the same for gesture: they must be performed frontally, so as to be seen by everyone.

ium and the skênê). Audience members in the centre of the auditorium would be able to perceive the performance head on, visually and aurally. Those at the sides could still take advantage of an approximately $60^{\circ}$ angle. However, an actor speaking side-on, in dialogue with another character for example, would not have been heard clearly. ${ }^{26}$ Figure 1 illustrates these constraints by sketching the layout of the Athenian theatre in the fifth century вс.

An image on a fragment of a calyx-crater excavated in Sicily illustrates this rule. It depicts what most believe to be a tragic scene from Sophocles'

26 'Because of the size of the audience, the first requirement of the Greek actor was audibility' (Wiles 2000: 151). 
canonical play Oedipus the King. ${ }^{27}$ Two characters (Oedipus and Jocasta?) are looking to one side at a third character, a messenger, who is facing the observer. J.R. Green, considering the 'performance style', describes the messenger thus:

He makes the conventional gesture of address with his left hand, two fingers and the thumb raised. [...] The gesture makes it clear that the person he is addressing is the king, Oedipus, but he is turned to face the spectator: he is performing for the audience. ${ }^{28}$

Thus this Sicilian artefact seems to hint at the intertwined relationship of speech and gesture in dramatic performance. Even while gesturing to one side, the actor still faces the audience head on. ${ }^{29}$ His performance requires both.

3) With each speech act, each delivery and response from the masked ancient actor, gesture is necessary to stress who is speaking. But it is also necessary to reveal intention and emotion. Thus the movements we are interested in are not of the gesticulation type. In fact, gesticulations are probably quite rare in ancient theatre since they risk interfering with the speech intent. Language-like gestures, too, have little or no effect in so large a setting as the theatre stage. Where such gestures do occur, they are generally used to strengthen aposiopesis (the rhetorical device of suddenly breaking off in speech), as Boegehold shows. ${ }^{30}$ We are then left with pantomimes and emblems, ${ }^{31}$ and it is the latter that we are most interested in since they may replace, reinforce or fine-tune the performed speech act on stage. Antipathy, surprise, laughing gestures: Sittl refers to these as symbolische Gebärden, 'symbolic gestures'. ${ }^{32}$ These emblems are codified gestures inspired by everyday life and reproduced with a spectacular dimension on stage. They imply the full body of the actor, including his mask and stage costume.

27 IGD (= Trendall and Webster 1971) III.2.8. Reproduced in Green (2002: 108) and Wiles (2000: 157).

28 Green (2002: 108).

29 Another point we find in Wiles (2000: 149): 'It is a fact that spectators listen more effectively when they focus on the face of the speaker'. And a few sentences later: 'In a large open-air theatre the effect of classical masks was to bring the face closer to the spectator and thus create intimacy.'

$30 \quad$ See Boegehold (1999: 53-66) on aposiopesis in tragedy.

31 For obvious reasons, the fifth category of gesture, sign language, is not relevant to our purposes here.

32 Sittl (189o: 81-116): 'Gebärden [...] welche Begriffe für das Auge des anderen illustrieren und dadurch das gesprochene Wort verdeutlichen oder sogar ersetzen sollen' (81-82). On gestures in drama, Sittl postulates 'eine Art von Symbolik der Bewegungen' (201). 


\section{Symbolic gestures (emblems)}

$\begin{array}{ll}\text { Address } & \begin{array}{l}\text { The character points their hand toward someone or } \\ \text { something. } \\ \text { The character makes an imperative gesture at another } \\ \text { character. } \\ \text { The character rises their hands for a request (question } \\ \text { or plea) } \\ \text { The character makes a gesture of denial. }\end{array} \\ \text { Interrogation }\end{array}$

Deictic gestures

Gazing
Pointing $\quad \begin{aligned} & \text { The character casts their gaze towards a specific object. } \\ & \text { The character points to a specific object. }\end{aligned}$

Symbolic gestures implying contact
Interlocking
hands
The character takes the hand of another character
Embracing
(holds hands, grips, shakes hands, etc.).
Two characters embrace one another.

ip

4) Gestures on stage thus refer less to the content than the form of speech. By expressing the speaker's stance or attitude, they embody the modalities of the speech act and make visible the illocutionary value of what is being said. ${ }^{33}$ In our comparative analysis of the texts by Sophocles and Euripides, we may identify six symbolic gestures or emblems associated with the following six modalities of speech: address, order, interrogation, denial, exclamation (joy, surprise), and lament.

33 On the matches between gestures and types of speech (both captured in Greek by the term $\left.\sigma \chi^{\prime} \mu \alpha \tau \alpha\right)$, see Capponi (2020: 207-232). 
5) To this list we should add two deictic gestures (indicative motions that can be manual or non-manual): pointing and gazing at a specific object. These are fundamental to drama and on stage they do not play the subordinate role Kerbrat-Orecchioni ascribes to them in everyday life. Rather, they accompany speech acts and serve to situate the speaker within the fictional setting created on stage or within the specific interaction taking place at that moment. Finally, we may add two emblems which imply physical contact: interlocking hands (holding, grabbing, shaking, etc.) and embracing. All these gestures are indexed by Sittl and find numerous equivalents in ancient iconography. ${ }^{34}$ Our typology could well include other examples (e.g. swearing, cursing, veiling, falling on the knees, etc.), but this list of ten gestures is sufficient to analyse the two scenes in question. Table 3 presents the icons used in our analysis. ${ }^{35}$

In our analysis, the role of the participants in the interaction is presented by naming the characters and describing the scene. Rows that are coloured grey describe gestures; plain rows give the accompanying lines of dialogue, as for example:

El. hor.

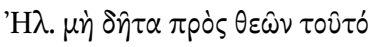

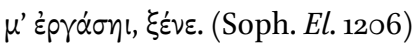

Or. El. // El. / Or.
Electra makes a gesture of denial at Orestes.

El. Do not do that to me, I beg you, stranger!

Orestes looks at Electra. Electra makes a gesture of denial at Orestes.

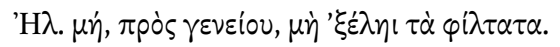
(Soph. El. 1208)

The definition of the setting and nature of the performed gesture may be based on textual elements. Here the pragmatic data and enunciation markers are

34 See the index in Sittl (189o): Begrüssung, Befehl, Bitte, Verneinen, Gemütsbewegungen, Schmerz, Zeigen. The classification presented in Spitzbarth (1945) overlaps with our own: 1. Zeigegebärde, 2. Enthüllen und Verhüllen, 3. Anrufung, 4. Lauschen und Spähen, 5. Begrüssung und Abschied, 6. Trauergebärden, 7. Gewalt, 8. Auf-und Abtreten.

35 These icons are strictly utilitarian to this paper. They do not coincide in a realistic way with the performed gestures. 
the most revealing. Indeed, spoken lines in drama tend to point out the modalities in accordance with which the words are to be pronounced: speaking verbs abound, and the markers of order, interrogation, denial or exclamation hold strategic positions. They are regularly found heading or ending a line of speech. Because speech acts have corresponding gestures and because gestures must appear between replies to be efficient, we see here the opportunity to detect the continuity between gesture and speech, determining a rhythm specific to the dramatic aesthetic. The gestures 'set the tone' for the next reply. Furthermore, they also address certain decorum and conventions prescribed by the form. For example, "[i]n tragedy as in everyday life, the wearing of the himation imposed a bodily discipline involving stillness, balance and restricted gesture. ${ }^{36}$

In the same vein, we must pay attention to the position held by deictic markers in speech. Often they occupy a strategic place in the sentence which links them to the gesture action. ${ }^{37}$ For example, space deictics and third-person markers are used to point to someone or something in the margins of an interaction; first- and second-person markers allow the speaker to draw attention to themselves or their interlocutor. In order to bring to light the importance of all these modalising and deictic elements, as well as their affinity with the characters' gestures, we will highlight them in bold in the text.

\subsection{The Recognition Scene in Sophocles}

Keeping these principles in mind, we may now observe the conditions of the recognition between Orestes and Electra in Sophocles' play (Table 4). It takes place in the fourth episode (1098-1231), quite late in comparison to Aeschylus (212-246) and Euripides (487-595). The recognition is deliberately delayed by Sophocles to maximise suspense and bring the scene to a climax. Orestes asks his maids to take to Electra the urn that is supposed to contain his ashes. While Orestes watches on, Electra laments the remains of her brother. The text specifies that she is holding the urn in her hands: 'Allow me, by the gods, to take it in

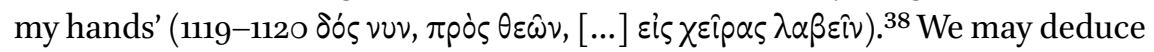

36 Wiles (2000: 159).

37 'There are many references to stage business in the dramatic texts. [...] Like the deictic expressions typical of dramatic texts, such as the use of first and second person, present tense etc., such references form a bridge between speech and gesture, the gestural signs being inscribed in the text. Frequent use of this form of deixis is typical of Greek tragedy' (Kaimio 1988: 7).

38 The text is from Jebb ( $\left.{ }^{3} 1894\right)$; all quotations and translations of Sophocles are from LloydJones (1994). 
that Electra is on her knees at this point, even if the text does not mention it, because standing and holding the urn in her hands would prevent any other kind of manual gesture. For instance, Electra's gesture of supplication at verse 1208 would be impossible: 'No, I beg you, do not rip from me what

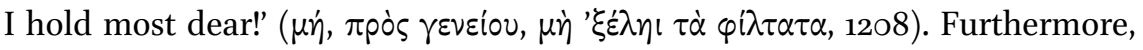
kneeling is universally regarded as a position fitting to grief. ${ }^{39}$ This inference of Electra's position also chimes with what we know about the destiny of the urn: as soon as she abandons it, it is picked up by Orestes' followers, who bring it to Clytaemestra. The recognition scene begins when Orestes tries to disabuse his sister by threatening to take the urn off her hands. For the reasons we have discussed concerning the constraints of the form and the stylisation of gestures, we can exclude the idea that Orestes did actually physically get his hands on the urn. Bodily contact between brother and sister only occurs at their reunion.

TABLE 4 Sophocles Electra $1205^{-1236}$

Orestes points to the urn. He speaks facing the audience (this
principle has been given as a condition for the play, so we will
not repeat it, but it must be considered systematically).

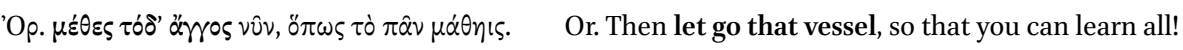

El. Hor. Electra makes a gesture of denial at Orestes.

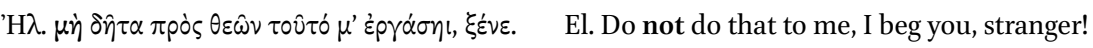

El. Or. // Or. 世 B El. $\begin{aligned} & \text { Electra turns to Orestes. Orestes makes an imperative gesture, } \\ & \text { then a gesture of denial. }\end{aligned}$

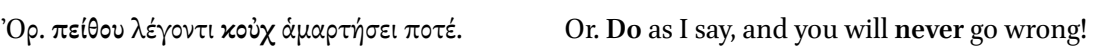

Or. El. // El. h Or. $\quad \begin{aligned} & \text { Orestes looks at Electra. Electra makes a gesture of denial at } \\ & \text { Orestes. }\end{aligned}$

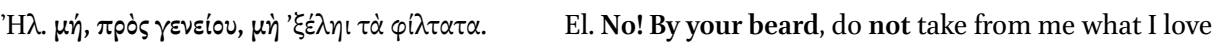
most!

39 Green (2002: 109) draws a similar conclusion in his analysis of another tragic scene: 'The woman in the centre of the group has thrown herself to her knees in a way all too familiar to us from images of recent events in the Balkans, and here too it must imply extreme distress, perhaps at the news of the death of a loved one.' 
TABLE 4 Sophocles Electra 1205-1236 (cont.)

\section{Or. $\mathrm{El}$.}

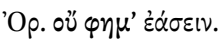

Or. urn // El. urn

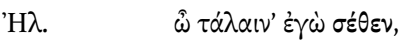

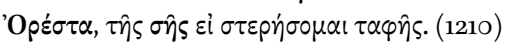

Or. 또 El.

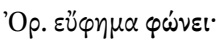

Or. h El.
Orestes makes a gesture of denial.

Or. No, I say I will not let you keep it!

Orestes stretches his hand to the urn. Electra puts her hands on the urn.

El. I am unhappy,

Orestes, if I am cheated of the power to give you burial.

Orestes makes an imperative gesture at Electra.

Or. Say nothing that is ill-omened!

Orestes makes a gesture of denial at Electra.

\section{El. Or.}

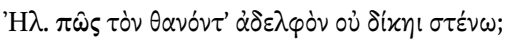

You have no reason to lament!

Electra makes an interrogative gesture, of aporia.
Or. El.

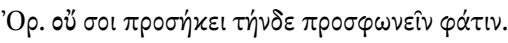

Or.

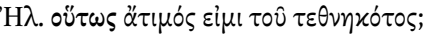

Or. $\mathrm{El}$.

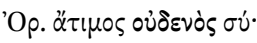

Or. urn // Or.

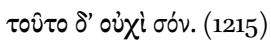

El. How can I have no reason to lament my dead brother?
Or. It is not right for you to call him that!

Electra makes an interrogative gesture.

El. Am I so refused honour with regard to the dead man?

El. urn

Electra points to the urn. 


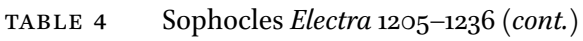

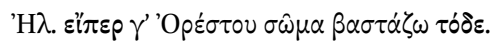

Or. $\mathrm{H}$ El.

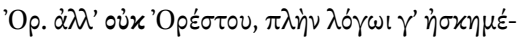
vov.

El. Or.

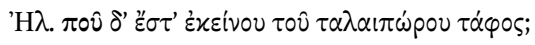

Or. $\mathrm{H}$ El.

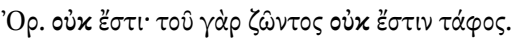

El. Or.

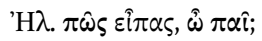

El. Or.// Or. El.// Or.

'Op.

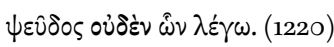

El.

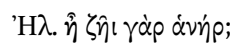

Or. Or.

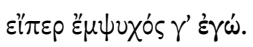

El. Or. // El. urn

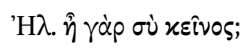

Or. ring

'Op. $\quad \tau \eta^{\prime} \nu \delta \varepsilon \pi \rho \circ \sigma \beta \lambda \varepsilon \dot{\psi} \psi \alpha \sigma \alpha \dot{\alpha} \mu 0 v$

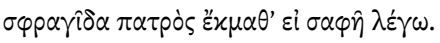

El. It does, if it is the body of Orestes that I hold here.

Orestes makes a gesture of denial.

Or. It is not Orestes, except in pretence!

Electra makes an interrogative gesture.

El. But where is the tomb of that unhappy one?

Orestes makes a gesture of denial.

Or. There is none; a living man does not have a tomb!

Electra makes an interrogative gesture.

El. What did you say, young man?

Electra looks at Orestes. Orestes looks at Electra. Orestes makes a gesture of denial.

Or. There is no lie in what I say!

Electra makes an interrogative gesture.

El. Then is the man alive?

Orestes makes a gesture directed to himself.

Or. If I am living!

Electra looks at Orestes, then points to the urn.

El. Then are you ... he?

Orestes displays the ring and shows it to Electra (praxical gesture).

Or. Look at this seal

that was my father's, and learn whether I speak the truth! 
TABLE 4 Sophocles Electra 1205-1236 (cont.)

El. Illy sky

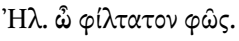

Or. Illy sky

'Op.

$\varphi{ }^{\prime} \lambda \tau \alpha \tau o \nu, \sigma u \mu \mu \alpha \rho \tau \nu \rho \hat{.}$.

El. Illy Or.

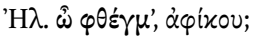

Or. El.

'Op.

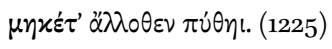

El.

Or.

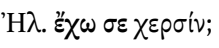

Or.

El.

'Op.

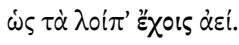

Or. Ill chorus

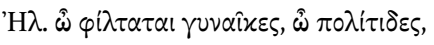

El. Or.

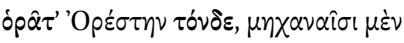

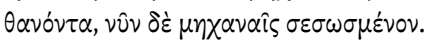

\section{Ch. Or. // Ch. I'/ $\left.\right|^{\prime \prime}$}

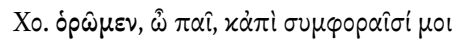

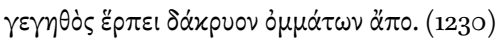

Electra stands up and stretches her arms to the sky.

\section{El. O dearest light!}

Orestes stretches his arms to the sky.

\section{Or. Dearest, I too can witness.}

Electra points to Orestes.

El. Voice, have you come?

Orestes makes a gesture of denial.

Or. Ask it of no other!

Electra takes Orestes's hand.

El. Do I hold you in my arms?

Orestes holds Electra's hand.

Or. So may you always hold me!

Electra stands aside. She stretches an arm to the chorus and talks to it.

El. Dearest women, fellow townswomen,

Electra stretches an arm to Orestes.

you see here Orestes, dead by a stratagem, and now by a stratagem preserved!

The chorus looks at Orestes, then speaks facing the audience mimicking joy and cries.

Cho. We see him, daughter, and a tear of rejoicing at your fortune comes from our eyes! 
TABLE 4 Sophocles Electra 1205-1236 (cont.)

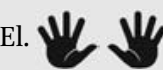

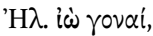

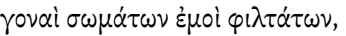

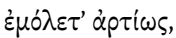

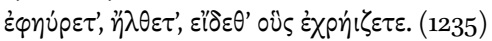

Electra starts singing and dancing, mimicking joy.

El. Io bodies!

dearest of bodies ever engendered, now you have come; you have found, you have arrived, you have seen those whom you desired!
Or.

'Oр. $\pi \dot{\alpha} \rho \varepsilon \sigma \mu \varepsilon v$.

Or.
Orestes makes a gesture to himself.

Or. I am here;

Orestes makes an imperative gesture at Electra. He speaks facing the audience.

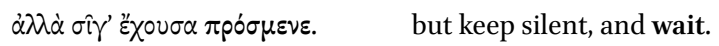

What may we conclude from this staging sketch? Foremost, we must underline that it is based on the text. Of course, we should be aware of the fragility of some suggestions, many of which cannot be guaranteed with absolute certainty. Nevertheless, the main point is that, if we agree with the assumption that the gesture of a speaker is necessary with or before each speech act, we may find an equivalent in the pragmatic and deictic markers (those we put in bold). Through these, in a regular and consistent manner, the text calls for action, of which praxical gestures (grabbing the urn, for example) are but one category. The technical principles we have highlighted, linked as much to the aural as to the visual perception of the play, explain the large number of deictic, selfreferencing, and modalising words that appear in the lines of dialogue. They also give sense to the syntactical construction of those lines.

This analysis of gesture also lays bare the specificity of the Sophoclean version. Sophocles dramatises the reunion of Orestes and Electra by foregrounding a tension in their relationship. This tension does, to a degree, emit from the story itself, since Orestes is trying to save Electra from her long period of grief and, more consistently, grab the urn from her hands, the symbol of this grief. Yet this tension is to be found in the speech acts and in the gestures. It is far from being an informational dialogue! The main parts of each spoken line are marked; as orders or denials for Orestes, as questions or laments for Electra.

Thus the construction of dramatic dialogue here is based on illocutionary acts and their corresponding gestures. The moments of contact are very short. 
However, the scene leads to a reversal, as can be seen from the end of this excerpt. It begins with Orestes trying to save Electra from her grief and it ends with him trying to contain her joy. Electra's emotional overflow is marked by the eruption of lyric verses, which the actor sings and dances to. At the climax of Electra's emotion, another form of speech and gesture takes place. The gesture becomes choreographic; prosody becomes melody. These modalities of representation only have reality for the audience. ${ }^{40}$ Through them Electra's character is as if thrown to another aesthetic level, detached from the story itself. Because for Orestes, of course, Electra is not singing nor dancing. He quantifies her behaviour instead as loud and inappropriate and commands her to keep silent with an order accompanied by an imperative gesture: 'I am here; but keep silent, and wait.' (1236). Orestes is overwhelmed by Electra's emotions, translated in a code other than his own. He struggles to bring the melodious Electra back into the (iambic) storyline. Thus, Sophocles builds his reunion scene by creating a mode of tension and playing with pragmatic values and aesthetic codes. The bodily contact between the two characters is minimal, and the gestures focus our attention first on the urn, the object of the debate between Orestes and Electra, then on Electra's expression of joy.

\subsection{The Recognition Scene in Euripides}

In contrast, Euripides chooses a completely different way to present the recognition scene. He differs from Sophocles in all aspects: pragmatic, aesthetic, gestural. The recognition staged by Euripides occurs in lines 576 to 599 , much earlier in the play than in Sophocles' Electra. It does not create a climax. Furthermore, it is mediated with the presence of an old servant, who is the first to recognise Orestes because of the scar on his eyebrow. Probably standing between Orestes and Electra, he invites them to fall into one another's arms. As before, we shall add the gestures as didascalies. They determine movements at precise moments, pauses and contacts (Table 5).

40 The singing and dancing of both the protagonists and the chorus are justified only at the level of the performance. With rare exceptions (such as the arrival of the chorus of Maenads in Bacchae or that of the chorus of girls celebrating the Feast of Hera in Euripides' Electra), they are not motivated by the story. 
TABLE 5 Euripides Electra $576-599^{41}$

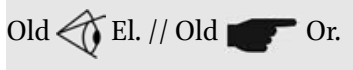

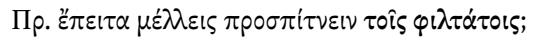

El. fy old

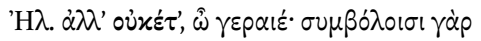

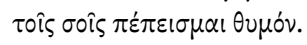

El.

Or. $/ /$ Or. $\&$ El.

$\varepsilon^{\prime} \chi \omega \sigma^{\prime} \dot{\alpha} \varepsilon \lambda \pi \tau \omega \varsigma-$

The old man looks at Electra. He stretches his right arm to Orestes. He is speaking facing the audience.

Old. Then do you hesitate to embrace your dearest one?

Electra does a denial gesture towards the old man.

El. Not any longer, old man; for my heart is persuaded by your tokens.

Electra goes to Orestes and grabs his right hand. Orestes is looking at Electra.

- O you who have appeared at last,

I hold you, beyond all hope.-

Or. $\mathrm{El}$.

Orestes speaks facing the audience and holds Electra's hand.

'Op.

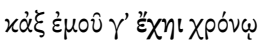

Or. And you are held by me at last.

El. fy Or.

Electra lets go of Orestes and does a denial gesture.

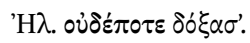

El. I never expected it.

Or. $\mathrm{El}$.

Orestes does a denial gesture.

'Op.

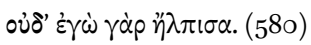

Or. Nor did I hope.

Or. El.// El. Or. // El. Or.

Electra looks at Orestes. Orestes looks at Electra. Electra lets go of Orestes and makes an interrogative gesture.

\section{'H}

El. Are you that one?

Or. Or.

Orestes makes a gesture to himself.

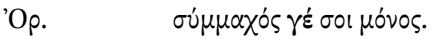

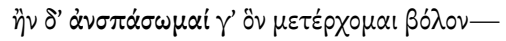

Or. Yes, your one ally.

If I draw back the cast of the net I am aiming for-

41 The text is from Diggle (1981), the translation from Coleridge in Oates and O'Neill (1938). 
TABLE 5 Euripides Electra 576-599 (cont.)

Orestes makes a gesture illustrating this metaphor (expressing a pantomime gesture in order to fulfil the aposiopesis)

$\pi \dot{\varepsilon} \tau \circ \bullet \theta \propto \delta^{\prime}$.

Or.

b

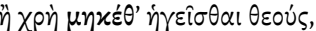

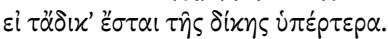

${ }^{\mathrm{O}} \ddot{\mathbf{\eta}}^{\mathrm{El}}$

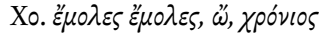

$$
\dot{\alpha} \mu \varepsilon \dot{\varepsilon} \rho,\left(5^{85}\right)
$$

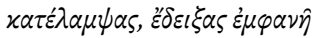

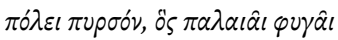

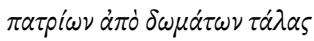

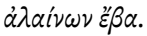

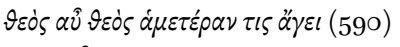

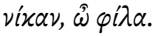

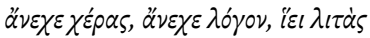

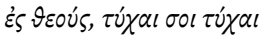

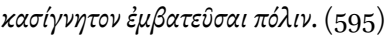

Or. $\mathrm{El}$.

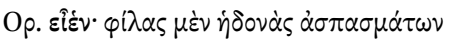

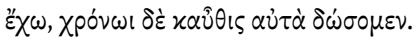

Or.

Old.

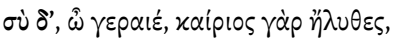

$\lambda \dot{\varepsilon} \xi \circ \nu$,

Or.

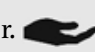

$\pi \alpha \tau$ рós;

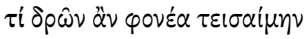

\section{I have confidence;}

Orestes does a denial gesture.

or else we must no longer believe in gods,

if wrong is to be victorious over right.

Orestes and Electra turn to face one another. They embrace (praxical gesture). The chorus sings and dances with this image as a background.

Ch. You have come, you have come,

oh, long-delayed day,

you have lighted up, you have made visible

a beacon to the city, who in long ago exile went forth from his

father's house,

unhappily wandering.

A god, now, a god brings

our victory, my dear.

Lift up your hands, lift up your words, send prayers to the gods for your brother with fortune, with fortune, to enter the city.

Orestes pulls himself out of Electra's embrace with a gesture of denial.

Or. Well; I have the loving pleasures of your greeting and later I will give them back in turn.

Orestes points to the old man.

You, old man-for you have come at the right time, tell me,

Orestes makes an interrogative gesture.

what should I do to avenge myself on my father's murderer? 
How does Euripides proceed? The first thing to recall, not contained in our analysis, is that the modalities of the recognition imply a clear reference to Aeschylus' Choephoroe. In Aeschylus' version, Electra is puzzled by the signs she finds on the grave, Orestes' hairlock and footprint, but accepts Orestes when he proves his identity by revealing a woven piece of clothing that she herself had made. Euripides' Electra rejects one by one all of these proofs. She only admits the scar on Orestes' eyebrow that identifies him (in Sophocles, it is the signet ring of Agamemnon that serves the same purpose). This intertextual game gives way in Euripides' play to a reunion essentially marked by bodily contact — unlike in Sophocles.

We may point to the first contact of hands at verse 578 . It corresponds to the verb " $₹ \chi \omega$, 'to have', a traditional expression for the recognition in tragedies, used here by both brother and sister. While marking the siblings' intimacy and the recovery of trust between them, this holding of hands means the actors can speak facing the audience. It is only at line 584 that Electra and Orestes truly embrace, evident from the use of $\dot{\alpha} \sigma \pi \alpha \sigma \mu \alpha \dot{\tau} \tau \nu$ ('embrace') at 596 . Yet to give way to this embrace, the emotion felt by the characters - as well as by the audience-has to be delegated to the chorus. Contrasting with Sophocles' dancing and joyful Electra, it is the chorus who assumes the lyric role and sing and dance while brother and sister continue to hug. The dramatic effect is a powerful one since it superimposes on an immobile image, the emblem of longawaited reunion, intense bustle. This is marked by the abundance of dochmiacs in the chorus' song.

As Sophocles does, Euripides exploits gesture in order to create a specific emotive and aesthetic effect, but he instead uses the chorus to do so. Furthermore, the gestures reveal the stakes in the interaction between brother and sister. In Sophocles' play, Orestes struggles to comprehend Electra's emotions, of grief as much as of joy. In Euripides' play, there is no tension in the gesture nor in the illocutionary value of the speech acts. Rather, the speech acts answer one another (assertion-assertion, denial-denial, question-answer). Orestes finds in Electra an equal, an ally who, at the right time, will work side by side with him. She would later remind us of that after helping her brother to murder Clytaemestra: 'And I urged you on and put my hand to the sword together with

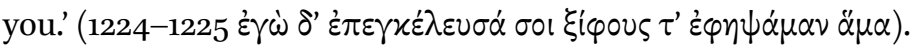


This albeit brief comparison demonstrates the rich interpretative potential that can result from a unifying analysis that takes account of both gesture and speech. Inspired by practical experience in the theatre, this approach invites us to picture very concretely the physical context of the speech act in textual studies. After all, how is one to grasp a text made for the stage if not by representing the scene in a manner that gives it sense and life? Describing the poet's task, Aristotle supports the same principle in the Poetics:

\section{[3] Aristotle, Poetics 1455a22-23}

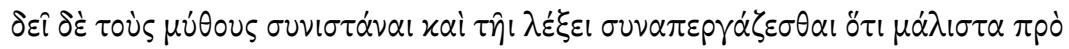
o $\mu \mu \alpha \dot{\alpha} \omega \nu \tau \imath \theta \varepsilon \dot{\varepsilon} \mu \varepsilon \nu \nu^{2}$

In constructing plots and completing the effect by the help of dialogue the poet should, as far as possible, keep the scene before his eyes. ${ }^{42}$

We have followed this injunction. It might be possible to apply it at a bigger scale, for example to comic and satyric drama where gestures, especially praxical gestures, have the biggest part to play! We should also try to understand

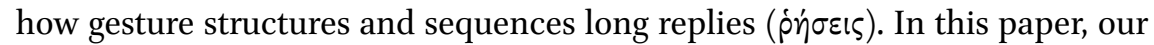
pragmatic method has been simple: it aimed to highlight the contribution of gesture in the performance of speech acts. To that end, it challenges the very notion itself that speech acts can be independent acts. No response by one character to another on stage can avoid the gestural support that initiates it. Thus a new aesthetic is emerging that sees the whole body as serving both gesture and speech. This perspective moves beyond the simple notion of 'making a gesture' to understanding the schêma of the body in its entirety; that is, its posture, its shape, its mode-indeed all the etymological senses of that word. Such a perspective already sees theatrical gesturality and dance as operating in the same way. ${ }^{43}$ Wiles' consideration of the use of the tragic mask ends with a similar conclusion: 'To perform successfully in a Greek-style helmet mask, the actor needs to find the point where language and body converge in the voice

42 Tr. Fyfe (1932).

43 On the polysemy of the term schêma, see Catoni 2005, and more precisely 133-143 for the use of the term in the field of dance. 
and the breath that produce sound. ${ }^{44}$ The evaluation of his talent depends on the success of this complex exercise.

It might be possible to affirm that there is also a kind of alternation between gesture and speech in the practice of ancient drama. As we have seen, gestures, translated into postures, are used pragmatically to prepare, strengthen and even speak for speech. As such we could reverse the notion in Kendon's Continuum of gesture being 'integrated into a linguistic string' 45 to that of speech being integrated into a gestural string! - or perhaps modify the image to one of two intertwined strings. Such an approach can help to develop a new pragmatics of the theatrical text, one that invites us to study not only the discursive strategies that preside over the interactions between characters, but also the gestures inscribed in the text's material that determine spectacular images and power relations.

Without taking gesture into account, it is hard to see how a dramatic text can be perceived accurately in the particular space of the ancient theatre. In pragmatic terms, the question to ask is therefore: What strategies, stylistic and gestural, does a theatrical speech put in place to be grasped by the audience? Because ultimately, the audience is the only recipient that matters.

\section{Acknowledgements}

I thank Magali de Haro Sanchez and Jon Wilcox for their excellent translation and editing of this article from the original French and for their valuable advice. Many thanks also to my colleagues Pierre Voelke and Severin Hof for their careful reading and feedback.

\section{References}

Allan, K. \& Jaszczolt, K.M., (2012), The Cambridge Handbook of Pragmatics, Cambridge. Berrendonner, A., (1982), Eléments de pragmatique linguistique, Paris.

Bracops, M., (2010 [2006]), Introduction à la pragmatique. Les théories fondatrices: actes de langage, pragmatique cognitive, pragmatique intégrée, Brussels.

Boegehold, A.L., (1999), When a Gesture was Expected: a Selection of Examples from Archaic and Classical Greek Literature, Princeton.

44 Wiles (2007: 290).

45 Allan and Jaszczolt (2012: $\left.5^{83}\right)$. 
Bury, R.G., (1926), Plato, Laws, vol. 2, Cambridge, Mass.

Capone, G., (1935), L'arte scenica degli attori tragici greci, Florence.

Capponi, M., (2020, forthcoming), Parole et geste dans la tragédie grecque à la lumière des trois "Électre", Neuchâtel.

Catoni, M.L., (2005), Schemata: communicazione non verbale nella Grecia antica, Pisa.

Diggle, J., (1981), Euripidis fabulae, vol. 1, Oxford.

Easterling, P.E. \& Hall, E. (eds.), (2002), Greek and Roman Actors: Aspects of an Ancient Profession, Cambridge.

Fyfe, W.H., (1932), Aristotle, vol. 23, London.

Green, R., (2002), 'Towards a Reconstruction of Performance Style', in Easterling and Hall, 93-126.

Jebb, R.C., ( ${ }^{3} 1894$ [1867]), Sophocles, The Electra, Cambridge.

Kaimio, M., (1988), Physical Contact in Greek Tragedy: a Study of Stage Conventions, Helsinki.

Kerbrat-Orecchioni, C., $\left({ }^{2} 2005\right.$ [2001] $)$, Les actes de langage dans le discours. Théorie et fonctionnement, Paris.

Lloyd-Jones, H., (1994), Sophocles, vol. 1, Cambridge, Mass./London.

McNeill, D., (22009 [1998]), 'Gesture and Communication', in J.L. Mey (ed.), Concise Encyclopedia of Pragmatics, Oxford, 299-307.

Moretti, J.-C., (2001), Théâtre et société dans la Grèce antique, Paris.

Neumann, G., (1965), Gesten und Gebärden in der griechischen Kunst, Berlin.

Oates, W.J., \& O'Neill Jr., E., (1938), Euripides. The Complete Greek Drama, vol. 2, New York.

Sittl, K., (1890), Die Gebärden der Griechen und Römer, Leipzig.

Solmsen, F., (1967), 'Electra and Orestes: three Recognitions in Greek Tragedy', Mededelingen der Koninklijke Nederlandse Akademie van Wetenschappen, Afd. Letterkunde, $30(2)$ Amsterdam.

Spitzbarth, A., (1945), Untersuchung zur Spieltechnik der griechischen Tragödie, Winthertur.

Taplin, O., (1978), Greek Tragedy in Action, Berkeley.

Taplin, O., (1993), Comic Angels and Other Approaches to Greek Drama through VasePaintings, Oxford.

Telò, M., (2002a), 'Per una grammatica dei gesti nella tragedia greca: cadere a terra, alzarsi, coprirsi, scoprirsi il volto', Materiali e discussioni per l'analisi dei testi classici 48, 9-75.

Telò, M., (2002b), 'Per una grammatica dei gesti nella tragedia greca: la supplica', Materiali e discussioni per l'analisi dei testi classici 49, 9-51.

Thomas, K., (1991), 'Introduction', in J. Bremmer \& H. Roodenburg (eds.), A Cultural History of Gesture. From Antiquity to the Present Day, Cambridge, 1-14.

Trendall, A.D. \& Webster, T.B.L., (1971), Illustrations of Greek Drama, London. 
Valakas, K., (2002), 'The Use of the Body by Actors in Tragedy and Satyr-Play', in Easterling and Hall, 69-92.

Wiles, D., (200o), Greek Theatre Performance: an Introduction, Cambridge.

Wiles, D., (2007), Mask and Performance in Greek Tragedy, Cambridge.

Wright, W.C., (1922), Philostratus and Eunapius: The Lives of the Sophists, London/New York. 


\title{
Reflections on Gestures and Words in Terence's Comedies
}

\author{
Licinia Ricottilli
}

The methodology that has been adopted in the present study is based on an adaptation of communication pragmatics (that has been identified in the field of cybernetics and psychiatry by G. Bateson and more broadly recalled by P. Watzlawick, J. Helmick Beavin, and D.D. Jackson $)^{1}$ to classical texts. ${ }^{2}$ Studies based on such a method have also enabled the in-depth study of gestural representation, where gestures are often endowed with the most explicit and intense expression of the quality of the relation at hand, while words more clearly express the content of the interaction itself. This re-elaboration revealed its particular relevance in the field of theatre studies, as its analysis is focused on the systemic dimension of interaction.

This method, starting from certain specific gestural indications that may be found in the written text, allows scholars to retrace the Roman audience's high level of competence in relation to gestural categories as well as their appropriateness and value around Terence's time. Without such competence, comedy playwrights would not have been able to use gestures to create comic effects through precise strategies that will be identified in the course of the present study in the paragraphs 1.1 and 1.2 .

1 Watzlawick et al. (1967). Since 1982, such adaption has been carried out by our research group (Licinia Ricottilli, Renata Raccanelli, and Evita Calabrese), which has published a series of studies that re-elaborated the methodological tools of pragmatics of human communication and provided new ones in order to make them more functional in relation to the analysis of literary texts and, in particular, those of ancient Greek and Latin cultures. This re-elaboration has been successfully tested in analysing Greek and Latin authors (e.g. Menander, Plautus, Terence, Virgil, and the philosopher Seneca). This method was easily integrated into the present study, given its shared pragmatic framework with the speech act theory of J.L. Austin.

2 For more on this, see Ricottilli (2009) and a preliminary review of contributions relating to theatre in Ricottilli (2010). The results of the research group until 2009, composed by Licinia Ricottilli, Renata Raccanelli, and Evita Calabrese, have been analysed in the two previously mentioned contributions; as far as the group's publications since 2009 are concerned, providing further confirmation of the validity of such a methodology, along with in-depth analyses that assist in improving and extending its possible applications, see the following selected bibliography: Ricottilli 2018c (including contributions by R. Raccanelli and E. Calabrese); Calabrese (2017a, 2017b, 2018); Raccanelli (2010, 2012, 2016); Ricottilli (2013, 2018a, 2018b). 
In paragraph 2.1, the analysis demonstrates how gestures significantly contribute to outlining the profound and noble qualities of the amicitia that Chremes offers to Menedemus and that the latter decides to reciprocate. In other words, the study of humanitas in Terence's works is enriched and perfected if one considers the characters' gestures as well as their linguistic expressions within a systemic dimension of interaction.

As today, in ancient Rome, face-to-face communication included the use of gestures - both in terms of body language and facial expressions-as well as words. Such gesturing accompanied verbal language in order to prepare, enhance, and emphasise certain specific aspects or to correct and adjust it. Sometimes gestures even substituted verbal messages in order to express something that could not be explicitly voiced, that words were incapable of expressing, or that simply could not be expressed with the same force. In this last case, we may speak of 'doing things with gestures' in the same way things can be done with words.

Unfortunately, recent definitions of gestures do not concur: in the present study, I shall adopt a definition that I elaborated in my book on gestures and words in the Aeneid: a definition which is well suited to aid the study of interactions with verbal language. With the word 'gesture', I refer to bodily or facial behaviour that takes on a communicative, informative, or interactive value in relation to a direct addressee or possible observer and that may be controlled by a sender. ${ }^{3}$

In Terence's comedies, interactions among characters present both cases: doing things with gestures and doing things with words and gestures.

3 Ricottilli (2000: 16). Since the present study provides examples of gestures that are more effective and suitable for the context than words, it carries forth the approach adopted by Corbeill (2004) and Aldrete (2017), who studied the importance and power of gestures in the ancient Roman cultural system and interactions, respectively. Nevertheless, the pragmatic framework that recalls the theories of speech act of J.L. Austin and that of agency of A. Duranti (which have already been used for "powerful words" in Bettini [2004]) and applies them to the gestures that may be found in Latin literature decisively differentiates the present contribution from those by A. Corbeill and G.S. Aldrete, which quote neither J.L. Austin (or J.R. Searle), nor A. Duranti. Another distinguishing element lies in the author's definition of gesture, in that it is narrower than that proposed by Aldrete (2017:151) but has the advantage of facilitating the comparison between gestural communication and linguistic communication, and therefore that of consolidating the application of "agency" (and more specifically Duranti [2007: 87-122]), which is typical of words, to gestures. Moreover, all of the studies on gestures in ancient Rome are indebited to the pioneering research of Sittl (189o); further useful information has also been provided by numerous more recent studies, among which Brilliant (1963) regarding the fine arts, Maier Eichhorn (1989) and Graf (1991) on orators and actors, Aldrete (1999) on gestural acclamations and Corbeill (2005) on Roman law. 


\subsection{Comical Limitations Regarding the Comprehension of Gestures}

\section{[1] Terence Eunuchus 735-737}

Pyth. nil dixit tu ut sequere sese? Chr. nil, nisi abiens mi innuit.

Pyth. eho nonne id sat erat? Chr. at nescibam id dicere illam, nisi quia correxit miles, quod intellexi minus; nam me extrusit foras.

Pyth. Didn't she suggest you should follow her?

Chr. No, except that she nodded to me as she left.

Pyth. Hey, wasn't that enough?

Chr. Well, I didn't know what she meant, but the soldier set me straight by throwing me out. ${ }^{4}$

The situation is the following: the courtesan Thais, who had brought the young Chremes to the soldier Thraso's home for dinner after a fight with Thraso, leaves while signalling to Chremes to follow her. The young man, who is rather naive, does not understand what Thais is trying to tell him with such a gesture but is given a hint by Thais' maid Pythias.

Innuere has the meaning of 'signalling' that is well known among Terence's contemporaries, precisely as other gestures pertaining to the same family: adnuere means 'to say yes, to consent' and abnuere 'to say no, to refuse'. According to the classification of Ekman and Friesen, they are emblems that correspond to immediate verbal translation ('Emblems are those nonverbal acts which have a direct verbal translation, or dictionary definition, usually consisting of a word or two, or perhaps a phrase'5) and are therefore gestures that could easily attain the value of a speech act. ${ }^{6}$

4 Texts and translations from Terence are taken from Barsby (2001).

5 Ekman and Friesen (1969: 63). From a different perspective, Poggi (1983) classifies these as lexical gestures that correspond to a single word of a language, like pointing to the ground near oneself instead of saying 'here' or rotating one's wrist loosely to say 'very' in modern Italy. On the contrary, holophrastic gestures are the equivalent of a sentence carrying out a performative: for instance, brushing the back of one's hand under one's chin with an outwards movement, in modern Italy, corresponds to the sentence 'I don't care at all'. It contains an informative performative (i.e. an 'expositive act' according to Austin [ $\left[{ }^{2} 1975\right.$ : $\left.161-163\right]$ ), consisting in my informing someone that I do not care about something or someone at all. Facial expressions are usually holophrastic: for example, a happy face expression conveys the mes-

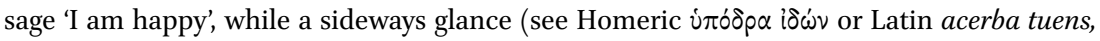


In Aelius Donatus' comment to Terence's comedies, Chremes' comical naivety is underlined, and, above all, the perfect comprehensibility of Thais' gesture is confirmed: ${ }^{7}$

\section{[2] Donatus ad Eunuchum 736.1}

EHO NONNE ID SAT ERAT adeo simplex hic inducitur adulescens, ut a Pythia reprehendi possit. Nam quid opus fuit dicere, si innuit?

'Hey, wasn't that enough?'] Here the young man [scil. Chremes] is portrayed as being so naive that he is scolded by Pythias. In fact, what need was there for Thais to speak if she had sent him a signal? ${ }^{8}$

Such a scholium provides explicit recognition of the fact that gestures, compared to verbal language, sometimes have the ability to express messages that are directed at the addressee more efficiently or in accordance with the needs of the context at hand. At that time, like nowadays, communicative competence required the ability to decode gestures that, among other things, were preferable to verbal messages in delicate situations such as the conflict between Thais and the soldier. Such gestures are often signs of understanding that the addressee must not miss: Chremes is a foreigner to the ways of life in the city so that he does not understand them, just as he does not understand the situation he finds himself in. Naturally, all of this has the effect of making the audience laugh. ${ }^{9}$

Once inserted in the context, a gesture like innuere acquires a specific value as a speech act (according to Poggi [1983], lexical gestures or emblems do not contain a particular performative value like holophrastic gestures, so they draw

lumine toruo) corresponds to the sentence 'I am angry with you' or 'I despise you'. In these cases, we have an informative performative as well.

6 Other emblems, along with the ones that have previously been seen, consist in gestures used to greet when meeting or leaving someone. See, for example, Capponi in this volume.

7 As is known, this is a comment in which the reflections of earlier scholars, e.g. Valerius Probus and Aemilius Asper, converged. For a comment by Donatus on Terence, see in particular Ferri (2016: 256): 'Donatus comments on another use of deictic pronouns and adverbs, in which the speakers use deixis to form elliptical, highly idiomatic sentences which need an accompanying gesture to acquire meaning for an interlocutor'; see also Basore (1908); Madyda (1953); Thomadaki (1989).

8 The translations of the Commentum Terenti are mine.

9 Some commentators explain that Chremes' inability to comprehend the nod was due to his drunkenness, but such a theory does not conform to his own words ( 736 at nescibam id dicere illam) or to the scholium quoted as text [2]. 
it from the context in which they appear). In this case, the performative value of the gesture appears to be the requestive 'follow me' gesture, which corresponds to sequere me in Latin. Austin ( ${ }^{2} 1975: 155^{-157)}$ speaks of 'exercitive acts. $^{\prime 10}$

From a relational point of view, the agreement on the action to be carried out, which is necessarily conveyed by Thais as not to be immediately grasped by the miles, does not take place right away, due to Chremes' comical inability to understand the language of gestures. Nevertheless, in the course of the comedy, such an agreement between the courtesan and the young man will be gradually instated and attain the relationship of amicitia that Thais desired: naturally, in this case, it consists of a clientele form of amicitia between patronus and cliens, with the meretrix taking on the role of cliens and young Chremes that of patronus.

Overall, the verb innuere, which recurs in Plautus and Terence, does not appear often in prose and even less frequently in poetry. ${ }^{11}$

In Terence's plays, the verb innuere occurs three times-one of which has already been examined — and in all three cases, there is a requestive performative (i.e. an exercitive act in the terminology of Austin $\left[{ }^{2} 1975: 155^{-157}\right]$ ). Thus, in Ter. Ad. 170, young Aeschinus commands a slave to beat the leno Sannio by means of a gesture.

\section{[3] Terence Adelphoe 170-171}

caue nunciam oculos a meis oculis quoquam demoueas tuos, ne mora sit, si innuerim, quin pugnus continuo in mala haereat.

Now make sure you don't take your eyes off mine. If I nod, don't wait. Plant your fist in his jaw instantly.

This passage represents, quite well, the need for the slave to be attentive to his owner's slightest gesture and ready to obey. The nod (nutus), which is generally executed with the head or sometimes with the eyes or eyebrows, conveys the order in precisely the same manner as verbal language and, not by coincidence the term nutus may also mean 'command'.

The confirmation of this other meaning is offered by

10 For more on this, see also Sbisà (1989: 113-130).

11 The use of the verb innuere in Plin Ep. 7.27.9 is also noteworthy. 


\section{[4] Cicero Tusculan Disputations 5.61}

tum ad mensam eximia forma pueros delectos iussit consistere eosque nutum illius intuentes diligenter ministrare.

Then he told chosen slave-boys of exceptional beauty to stand by the table, watch for his nods, and wait on him attentively. ${ }^{12}$

In its third appearance in Terence's plays, the value of innuere is the same as in the second, which may be found a few verses earlier:

[5] Terence Adelphoe 173-174

Aes. geminabit nisi caues. San. ei miseriam!

Aes. non innueram, uerum in istam partem potius peccato tamen.

Aes. He'll do it again if you don't look out.

San. (as Parmeno strikes him again) Ow! That hurts! (he loosens his grip on the girl)

Aes. (to Parmeno) I didn't nod. But it's a fault in the right direction.

[6] Terence Heautontimorumenos 369-373

sed heus tu, uide sis ne quid imprudens ruas. patrem nouisti ad has res quam sit perspicax. ego te autem noui quam esse soleas impotens. inuersa uerba, euersas ceruices tuas, gemitus, screatus, tussis, risus abstine.

But listen, please make sure you don't spoil everything by being careless. You know how keen-scented your father is for this sort of thing; and I know how headstrong you can be. None of your double meanings, side glances, sighs, throat clearing, coughs, laughs.

12 Text and translation are taken from Douglas (1990); this is the famous episode of Damocles' sword. 
Here the slave Syrus, while leading Bacchis, the courtesan beloved by Clitipho, to his owner's home while pretending that her lover is the young Clinia, reminds his young owner to not betray himself before his father, Chremes, with communicative behaviour that could reveal that he is the meretrix's lover.

Gestures of courtship and seduction appear, for instance, in the famous verses of Naevius' Tarentilla:

[7] Naevius Tarentilla $74-76^{13}$

$$
\text { quasi pila }
$$

in choro ludens datatim dat se et communem facit.

alii adnutat, alii adnictat, alium amat, alium tenet.

As though she were playing at ball, give-and-take in a ring, she makes herself common property to all men. To one she nods, at another she winks; one she caresses, another embraces. ${ }^{14}$

It seems to pay homage to such verses by emphasising the furtive nature of the gestures:

\section{[8] Plautus Asinaria 784}

neque illa ulli homini nutet, nictet, annuat.

She shall not nod, wink, or make any signs to any man. ${ }^{15}$

This is one of the clauses of the comical contract that the parasite drew up for young Diabolus; in exchange for twenty silver minae, this contract granted exclusive possession of the courtesan Filenia for one year.

If we compare the two preceding examples with Terence's verses, we may notice that in Syrus' list of prohibited behaviours there are certain comical modifications having the intent of highlighting Clitipho's excesses, like euertere ceruices, which indicates an unnatural position of the neck that is so unexpected and exaggerated that it made the audience laugh.

13 For more on this, see the excellent analysis in Traina ( $\left.{ }^{5} 2000: 34-35\right)$; for more on the complexity of the problems related to these verses, Barchiesi (1978: 67-15o) is of fundamental importance.

14 Text and translation are taken from Warmington $\left({ }^{2} 1961\right)$.

15 Texts and translations of Plautus are taken from de Melo (2011-2013). 
While the context specifies that this gesture has the intent of making his beloved notice him, the ancient commentator's various explanations do not clarify whether this entails tilting one's neck backwards which, by analogy with the term abnuo, could indicate a proud refusal, or pride in general, as Eugraphius asserted in his comment to Heautontimorumenos:

[9] Eugraphius ad Heautontimorumenum 372

EVERSAS CERVICES TUAS quod iactantia et superbia est.

YOUR SIDE GLANCES (gesture) that indicates exhibitionism and pride ${ }^{16}$ and is partially confirmed in

[10] Scholia Terentiana ad Heautontimorumenum 372 Schlee

EVERSAS dissolutas et supinas, huc illucque reuertentes.

SIDE the (neck) is relaxed, tilted backwards, and turns here and there. ${ }^{17}$

In this scholium, exhibitionism is associated with a sideways turn of the neck, which also has the aim of drawing attention.

Another possible interpretation refers to the opposite movement of the neck, i.e. downwards, as confirmed by

[11] Scholia Bembina ad Heautontimorumenum 372 Mountford

EVERSAS infractas, inflexas, amatorieque deiectas.

SIDE the (neck) is loose, bent, and directed downwards as is typical of a person in love. ${ }^{18}$

16 The translations of Eugraphius' Commentary are mine. An analogous use is present in Sen. Ben. 2.13.2 libet itaque interrogare, quid se tanto opere resupinet, quid uultum habitumque oris peruertat, ut malit personam habere quam faciem? 'And so I feel like asking why a donor is so stuck up, why he contorts his facial expression so much that he seems to prefer a mask rather than a normal face.' (the translation is taken from Griffin and Inwood 2011).

17 My translation.

18 My translation. 
More recent studies translate it with 'storcere il collo' ('to twist the neck') Ronconi (1960) and similarly: e.g. 'tes contorsions du cou' ('your contortions of the neck') Marouzeau (1942-1949 II); Lietzmann (1974) translates euertere with 'umdrehen, verdrehen'; Barsby (2001) recurs to the expression 'side glances', and Bianco (1993) 'storcere la testa' ('to twist the head'). ${ }^{19}$

It is very difficult to recreate with certainty a gesture that is executed in a singular and comical manner, even when it is located within a verbal context (although we do not have clear indications about the context, which could have been a banquet imagined by Syrus) and in the presence of a clear intent, i.e. drawing the attention of the woman one loves. The fact that the term euersas is chosen, among other things, in order to achieve a paronomasia with inuersa uerba, must be taken into consideration. After all, one must keep in mind that a gesture is never a perfect equivalent of words.

In this case, the performative is requestive along the same lines as saying 'look at me' or 'pay attention' to his beloved.

Moreover, if risus indicates laughter and not smiles, then this facial gesture would also be too obvious to be part of a sort of knowing and refined courtship that must only be understood by its addressee.

The series of paralinguistic behaviours that Syrus imagines could be attributed to Clitipho include gemitus, screatus, and tussis; however, while gemitus could be considered appropriate should it be executed with scarcely any sound, the other two (screatus - a hapax legomenon - and tussis) have a comical effect because they are more readily associated with an old phlegmy man than an amans ephebus.

Eugraphius (ad Heautontimorumenum 373) proposes a different explanation: GEMITUS SCREATUS TUSSIS haec omnia adulescentuli faciunt, quotienscumque uidere aut uideri uolunt ab his, quos desiderant, ita sub quodam metu, ut, quasi dum aliud necessitate conficiunt, sic impleant uoluntatem: 'young men do all this whenever they want to see or be seen by the people they care about, if they are under the influence of a certain fear, so they may satisfy their desire while, so to say, executing "something else" out of duty'. The mention of a secret sort of communication between the adulescentuli, despite their fear while they are compelled to accomplish something else, seems to be a scholastic situation, rather than a courtship that must remain a secret.

19 Different translations: Wagner (1872) compares it to Ov. Her. 16.233 uersa ceruice recumbo 'I stretch by turning my head in the opposite direction' and observes that 'dem gegenüber euersae komisch klingt beinahe "aus dem Gelenke gedreht"'. Brothers (1988) interprets it as 'those over-the-shoulder glances of yours', while Gray (1902) chooses 'to crane his neck in the hope of catching sight of her'. 
The scholia Bembina ad loc. refer to the furtive convening between the lovers GEMITUS-RISUS quae faciunt amantes ad conuertendos in se oculos eorum quos amant ut significare furtim aliquid mutuo nutu possint: 'things that lovers do to make their beloved's eyes turn towards them, so that they may communicate in secret by means of a mutual nod'. Interestingly enough, three paralinguistic notations (gemitus, screatus, and tussis) and one gesture (risus) are summarised and explained with a mutual nod (mutuus nutus). The situation is thus enriched with elements that are not present and defer to common forms of communication between lovers. The scholia Terentiana ad loc. have: SCREATUS screare est spuere et phlegma purgare 'coughing up phlegm involves spitting and eliminating moist humour', which is more faithful to the comical tone of the context.

We cannot exclude the possibility that the actor who personified Syrus could have emphasised these bodily and paralinguistic singularities in his reciting, thus increasing the audience's entertainment. ${ }^{20}$

The enjoyment of the spectators at seeing how Clitipho betrays himself before his father must have been even greater, surpassing the comical expectations that had been triggered by the slave. In fact, instead of the inappropriate and ridiculous use of gestures and paralinguistic behaviour, the young man, who is even more incapable of controlling himself than Syrus had foreseen, directly takes action and is discovered by his father, Chremes, while slipping his hand over the courtesan's breast. This obviously is an action rather than a gesture:

[12] Terence Heautontimorumenos 562-564

Chr. quid istuc, quaeso? qui istic mos est, Clitipho? itane fieri oportet?

Clit. quid ego feci? Chr. uidin ego te modo manum in sinum huic meretrici inserere?

Chr. Tell me, what are you up to? What sort of behaviour's this, Clitipho? Is this the proper way to act?

Clit. What have I done?

Chr. Didn't I see you just now putting your hand inside that woman's bosom?

20 For more on the margin of freedom that actors enjoyed when performing, see Panayotakis (2005). 
Clitipho is impotens, as Syrus claims (371), and incapable of controlling his amorous desires, but there is probably an anthropological factor in this sequence of behaviours that is relevant for that time, i.e. the possibility that simulating could be disreputable for an adulescens. In comedies, simulation is often naturally part of comical games based on successful or unsuccessful deceptions, and as such may also involve free characters (see, for example, Ter. Phorm. 210). Nevertheless, there may be reflections of the negative value that it had at the time-especially in political, judicial, and commercial contextsand that was destined to be expressed efficiently by Cicero. ${ }^{21}$ In the same comedy, Clitipho's father, Chremes, refuses to actively participate in the scam weaved by the slave Syrus:

\section{[13] Terence Heautontimorumenos 781-784}

Syr. ... non ego dicebam in perpetuom ut illam illi dares, uerum ut simulares. Chr. non meast simulatio. ita tu istaec tua misceto ne me admisceas. egon, quoi daturus non sum, ut ei despondeam?

Syr. ... I wasn't suggesting that you should give her to him permanently, but just pretend.

Chr. Pretence is not my way. You do your stirring but keep me out of the pot. Engage her to a man I don't intend to marry her to?

The fact that gestures of seduction are typical of courtesans in Naevius' Tarentilla does not seem to be a coincidence; likewise, the simulated seduction is only in Syrus', the slave's, mind, while his young free owner, Clitipho, is not pretending and reveals himself bluntly and directly.

The mentality of Ovid's time seems to have greatly changed and, in his Amores, the poet personally plays with the furtive gestures of hidden courtship:

\section{[14] Ovid Amores 1.4.17-19}

me specta nutusque meos uultumque loquacem;

excipe furtiuas et refer ipsa notas.

uerba superciliis sine uoce loquentia dicam.

21 In Cicero, the act of simulating damaged the credibility of a person and the accusation of simulating was used as a weapon to strike an adversary: see Cic. Pis. 1; Clu. 72; Rab. Post. 35; Red. Sen. 15; for more on this in general, see also Off. 2.43, 3.61; see also Sall. Cat. 31.7. 
Keep your eyes on me, to get my nods and the language of my eyes; and catch my stealthy signs, and yourself return them. ${ }^{22}$

\title{
2.1 Gestures That Intensify the Expression of a Feeling
}

In the opening scene of the Heautontimorumenos, Menedemus bursts into tears during his exchange with Chremes, who invites him to stop crying and confide in him and promises to help him.

[15] Terence Heautontimorumenos 83-86

\author{
Men. eheu!
}

Chr. ne lacruma atque istuc quidquid est fac me ut sciam. ne retice, ne uerere; crede, inquam, mihi. aut consolando aut consilio aut re iuuero.

Men. (sobbing) Oh dear, oh dear!

Chr. Don't weep. Whatever your trouble is, tell me all about it; don't keep it to yourself. Don't be afraid; trust me, I say. I'll help you whether you need consolation or counsel or money.

A senex who sheds tears on the stage amounts to a situation that is very different from those in Plautus' works due to the role of the character who is crying and Terence's respect for him. ${ }^{23}$ The different portrayal of the senex in Plautus is particularly evident in the case of the senex amator who becomes his son's rival over desire for a woman and, on the basis of the anthropological context, is destined to be defeated and even punished or at least mocked. ${ }^{24}$ At the end of this first scene, the two elderly men, who have become friends, take their leave and Chremes, now alone, speaks in a brief monologue of his profound compassion for his neighbour, one so intense that it made him cry. At this point, the audience learns that Chremes has also shed tears:

22 The translation is taken from Showerman (1963); analogous examples may be found in Ov. Am. 2.5.15-20; Her. 17.79-92.

23 See Dutsch (2008: 96-97) who, in referring only to flere and plorare, observes how Terence, as opposed to Plautus, avoids presenting characters who cry loudly on stage.

24 See Bettini (1982: 72-77). 
[16] Terence Heautontimorumenos 167-168

lacrumas excussit mihi

miseretque me eius.

He made me shed a tear, and I'm sorry for him.

The gesture of crying is holophrastic and generally presents an informative performative (a 'behabitive act' in the terminology of Austin [ $\left.{ }^{2} 1975: 160-161\right]$ ).

In this case, as opposed to the previous one, the mention of tears does not occur simultaneously, but in retrospect. The old man's emotional involvement before his neighbour's suffering was already perceivable from the conversation between the two. Then why does Terence have the senex say something that could have been understood by what preceded the monologue? In truth, there are various reasons for this.

One of these consists in a peculiar feature of Terence's monologues, which appear, from a communicative point of view, like a dialogue between one part of the 'Ego' that expresses its feelings, reflects on what has happened, informs on the facts, and another part of the 'Ego' that may be a silent speaker that only listens or an active conversant who asks, comments, and contests (e.g. in Phorm. 185-19o). ${ }^{25}$ For this reason, what a character says in the absence of others in a dialogue with one's self is conventionally considered a sincere expression of their feelings. In other words, the compassion that Chremes feels for Menedemus is not a ruse to gain something from the conversation but rather a true sentiment that Chremes perceives in himself and is therefore presented by the poet as sincere compassion.

In particular, the effect that is obtained by Chremes' tears, i.e. the intensification of mercy, is a valid reason for this retrospective mention. The gesture, in this case, is therefore a display of affection, or proof of emotions.

The third reason may be found in the author's desire to add an element that integrates and confirms the portrayal of the two senes as well as their relationship. In this case, in fact, we have contagious tears (or a contagion of tears): the fact that the friendship between the two senes had already been instituted is attested precisely by their mirroring one another's gesture of crying and is confirmed in the course of the comedy by the way in which the events unfold. ${ }^{26}$ The

25 For more on Terence's monologues, see Haffter ( ${ }^{2} 1969$ : 55 , with the comment of D. Nardo, 129); Denzler (1968); Minarini (1995).

26 See Lefèvre (1994). An important anthropological investigation on friendship in Plautus' 
contagion of tears reveals not only Chremes' emotional involvement before his friend's suffering but especially the intensity and nobility of such involvement. 27

The presence of painful situations that are indicated by tears must not be excluded in comedies: the expectation, however, is that situations of suffering are concentrated at the beginning of the comedy and gradually decrease as problems are solved by fate or the characters' intervention and reach a peaceful ending. In De comoedia, Evanthius underlines such a feature:

\section{[17] Evanthius De comoedia 4.2}

illic [scil. in comoedia] prima turbulenta, tranquilla ultima, in tragoedia contrario ordine res aguntur.

[In comedies] the opening scenes are turbulent, the final serene; in tragedies, the order of the scenes is the contrary. ${ }^{28}$

Such an expectation is confirmed by positioning tears in the initial scenes of the comedy and rigorously eliminating them in the final scene.

\section{Conclusions}

In conclusion, the most relevant findings of the present analysis, consisting of specific cases from Terence's works, include the following:

1. The significant knowledge of the second century вС Roman audience in relation to the use of gestures during face-to-face exchanges is confirmed. On the basis of such competence, comic playwrights may entertain the audience by emphasising, e.g., young Chremes' comical limitations in his ability to understand the meaning of gestures (1.1).

comedies may be found in Raccanelli (1998). For further details on contagious tears in Terence, see Ricottilli (2018a: 154-166).

27 Some critics do not seem to have paid much attention to the elements that reiterate the character's positive portrayal: as a result, an unjustified tradition of antipathy in relation to it has emerged. For example, Perelli (1973: 51) sustains that Chremes 'viene sempre fatto sentenziare a vanvera', while Brothers (1988: 20, 168) portrays Chremes as a busy body.

28 My translation. 
2. Specific types of relations, e.g. courtship, featured distinctive and appropriate gestures: the comical plot twists created by such gestures were an excellent opportunity to entertain the audience and were employed by the slave Syrus to underline young Clitipho's inability to control his passion for the meretrix Bacchis. The enjoyment of the spectators at seeing how Clitipho betrays himself before his father must have been all the greater, surpassing the comical expectations that had been triggered by the slave (1.2).

3. Small clues emerge from the written text by means of which it is possible to reconstruct some of the comical plays on gestures that were, for the most part, improvised by the actor during performances and otherwise would have been irretrievable (1.2).

4. The way in which interacting characters influence each other's behaviour may be studied in light of the methodology of communication pragmatics. Such a close connection between different characters' behaviour clearly surfaces in the course of the exchanges between Chremes and Menedemus (2.1). ${ }^{29}$

5. Gestural notations represent necessary keys to understanding the quality of the relationships that are established among characters in Terence's theatrical works, as well as Chremes' profound nobility, which is revealed by his contagion of tears (2.1).

\section{References}

Aldrete, G.S., (1999), Gestures and Acclamations in Ancient Rome, Baltimore/London. Aldrete, G.S., (2017) 'Gesture in the Ancient Mediterranean World', in F.S. Naiden \& R.J.A. Talbert (eds.), Mercury's Wings: Exploring Modes of Communication in the Ancient World, Oxford, 149-163.

Austin, J.L., ( ${ }^{2} 1975$ [1962]), How to Do Things with Words, Oxford.

Barchiesi, M., (1978), La Tarentilla rivisitata. Studi su Nevio comico, Pisa.

Barsby, J., (2001), Terence, 2 vols., Cambridge, Mass./London.

Basore, J. W, (1908), The Scholia on Hypokrisis in the Commentary of Donatus, Baltimore.

Bettini, M., (1982), 'Verso un'antropologia dell'intreccio. Le strutture semplici della trama nelle commedie di Plauto', Materiali e discussioni per l'analisi dei testi classici 7, 39-101.

Bettini, M., (2004), 'Parole potenti, parole screditate. L'atto del fari nella cultura roma-

29 See Ricottilli (1994: 191-205). 
na', in S. Beta (ed.), La potenza della parola. Destinatari, funzioni, bersagli, Fiesole (Florence), 33-78.

Bianco, O., (1993), Commedie di Publio Terenzio Afro, Turin.

Brilliant, R., (1963), Gesture and Rank in Roman Art: the Use of Gestures to Denote Status in Roman Sculpture and Coinage, New Haven.

Brothers, A.J., (1988), Terence, The Self-Tormentor, Warminster.

Calabrese, E., (2017a), Aspetti dell'identità relazionale nelle tragedie di Seneca, Bologna.

Calabrese, E., (2017b), 'Madri sul campo di battaglia. Rapporto tra relazione e identità nella vicenda delle Sabine di Livio', Paideia 72, 483-498.

Calabrese, E., (2018), 'Quartilla, ovvero la comunicazione in scena', in Ricottilli 2018c, 71-96.

Corbeill, A., (2004), Nature Embodied: Gesture in Ancient Rome, Princeton/Oxford.

Corbeill, A., (2005), 'Gesture in Early Roman Law: Empty Forms or Essential Formalities?', in D. Cairns (ed.), Body Language in the Greek and Roman Worlds, Swansea, 159-176.

Denzler, B., (1968), Der Monolog bei Terenz, Zurich.

Douglas, A.E., (1990), Cicero, Tusculan Disputations II and V with a Summary of III and $I V$, Warminster.

Duranti, A., (2007), Etnopragmatica. La forza nel parlare, Roma.

Dutsch, D.M., (2008), Feminine Discourse in Roman Comedy: on Echoes and Voices, Oxford.

Ekman, P. \& Friesen, W.V., (1969), 'The Repertoire of Nonverbal Behavior: Categories, Origins, Usage, and Coding', Semiotica 1, 49-98.

Ferri, R., (2016), 'An Ancient Grammarian's View of How the Spoken Language Works: Pragmalinguistic Observations in Donatus' Commentum Terentii', in R. Ferri \& A. Zago (eds.), The Latin of the Grammarians: Reflections about Language in the Roman World, Turnhout, 237-275.

Graf, F., (1991), 'Gestures and Conventions: the Gestures of the Roman Actors and Orators', in J. Bremmer \& H. Roodenburg (eds.), A Cultural History of Gesture. From Antiquity to the Present Day, Cambridge, 36-58.

Gray, J.H., (1902), P. Terenti Hauton Timorumenos, Cambridge.

Griffin, M. \& Inwood, B., (2011), Seneca, On Benefits, Chicago/London.

Haffter, H., ( ${ }^{2} 1969$ [1953]), Terenzio e la sua personalità artistica. Introduzione, traduzione e appendice bibliografica di D. Nardo, Rome.

Lefèvre, E., (1994), Terenz' und Menanders Heautontimorumenos, Munich.

Lietzmann, K., (1974), Terenz, Heautontimorumenos (Der Selbstquäler), Münster.

Madyda, L., (1953), De Donato Histrionum praeceptore, Wrocław.

Maier Eichhorn, U., (1989), Die Gestikulation in Quintilians Rhetorik, Frankfurt a.M./ Bern.

Marouzeau, J., (1942-1949), Térence, Comédies, 3 vols., Paris. 
Melo, W. de, (2011-2013), Plautus, 5 vols., Cambridge, Mass./London.

Minarini, A., (1995), Il monologo di Gnatone. Spunti e appunti sul metateatro terenziano, Bologna.

Panayotakis, C., (2005), 'Nonverbal Behaviour on the Roman Comic Stage', in Cairns 2005, 175-187.

Perelli, A., (1973), Il teatro rivoluzionario di Terenzio, Florence.

Poggi, I., (1983), 'Le analogie fra gesti e interiezioni: alcune osservazioni preliminari', in F. Orletti (ed.), Comunicare nella vita quotidiana, Bologna, 117-133.

Raccanelli, R., (1998), L'amicitia nelle commedie di Plauto: un'indagine antropologica, Bari.

Raccanelli, R., (2010), Esercizi di dono. Pragmatica e paradossi delle relazioni nel De beneficiis di Seneca, Palermo.

Raccanelli, R., (2012), Cicerone, Post reditum in senatu $e$ Ad Quirites. Come disegnare una mappa di relazioni, Bologna.

Raccanelli, R., (2016), 'Reti di amicitia nel Trinummus: paradossi delle relazioni e paradossi comici', in R. Raffaelli \& A. Tontini (eds.), Lecturae Plautinae Sarsinates XIX, Trinummus, Urbino, 35-61.

Ricottilli, L., (1994), 'Modalità e funzioni del silenzio nello "Heautontimorumenos", in C.A. Augieri (ed.), La retorica del silenzio, Atti del Convegno internazionale (Lecce, 2427 ottobre 1991), Lecce, 184-205.

Ricottilli, L., (2000), Gesto e parola nell'Eneide, Bologna.

Ricottilli, L., (2009), 'Appunti sulla pragmatica della comunicazione e della letteratura latina', in A. Barchiesi \& G. Guidorizzi (eds.), La stella sta compiendo il suo giro. Atti del convegno internazionale di Siracusa, 21-23 maggio 2007, Florence, 121170.

Ricottilli, L., (2010), 'Teatro latino e pragmatica della comunicazione', Dionysus ex Machina 1 , 36o-379.

Ricottilli, L., (2013), 'Strategie comunicative a carambola in Terenzio (Phorm. 350-377; Andr. 459-497; 740-795)', Dionysus ex Machina 4, 133-145.

Ricottilli, L., (2018a), 'Lacrime e sympatheia in Terenzio', in Ricottilli 2018c, 145-169.

Ricottilli, L., (2018b), 'Catullo e Virgilio: due scene a confronto (Catull. 64,212-237 e Verg. Aen. 8, 558-584)', Paideia 73, 2175-219o.

Ricottilli, L. (ed.), (2018c), Modalità della comunicazione in Roma antica, Bologna.

Ronconi, A., (1960), Terenzio, le commedie, Florence.

Sbisà, M., (1989), Linguaggio, ragione, interazione. Per una teoria pragmatica degli atti linguistici, Bologna.

Showerman, G., (1963), Ovid, Heroides and Amores, Cambridge, Mass./London.

Sittl, C., (189o), Die Gebärden der Griechen und Römer, Leipzig.

Thomadaki, M., (1989), 'La mise en scène du théâtre de Térence dans les commentaires de Donat', Dioniso 59, 365-372. 
Traina, A., (5200o [196o]), Comoedia. Antologia della palliata, Padua.

Wagner, W., (1872), P. Terenti Hauton Timorumenos, Berlin.

Watzlawick, P., Helmick Beavin, J., \& Jackson, D.D., (1967), Pragmatics of Human Communication: a Study of Interactional Patterns, Pathologies, and Paradoxes, New York.

Warmington, E.H., ( ${ }^{2} 1961$ [1936]), Naevius, in E.H. Warmington, Remains of Old Latin, vol. 2, Cambridge, Mass./London, 45-156. 


\title{
The Kiss in Plautus' Stichus: Notes on Gestures and Words in View of a Pragmatics of Comic Communication
}

\author{
Renata Raccanelli
}

In this paper, I aim to show how the pragmatics of communication can specifically contribute to the study of gestures in Plautus' comedies. Since gestural expressiveness is far from being a new and scarcely explored topic in studies on palliata in general and Plautus in particular, ${ }^{1}$ my observations are not intended to provide an exhaustive or systematic overview of the subject. Rather, I wish to reflect on some methodological insights through a case study in order to focus on how a pragmatic approach may lead to a better understanding of Plautus' texts.

It may be useful to begin by briefly mentioning some fundamental premises underlying the pragmatic approach to gesture. ${ }^{2}$ From the perspective of pragmatics, gesture is mostly a form of analogic communication (i.e. complementary to verbal communication) in which the specific function of transmitting referential data predominates in its logical and syntactical architecture, while the ability to express relational information remains limited. On the contrary, analogic communication entails the prevalence of the specific ability to express

1 Indeed, the topic lends itself to different-albeit closely connected-approaches. From our perspective, however, the stream of research into non-verbal behaviour, i.e. body language and mimicry, in Roman comedies - first introduced by Warnecke (1910) and taken up again by Taladoire (1951) — is particularly interesting. Some useful reflections on palliata may be found in Handley's essay on New Comedy (2002); Panayotakis (2005) provides a clear methodological framework, while Monda (2010, 2014) offers thought-provoking examples of specific case studies. A connected field of inquiry deals with the relationships between gestures, improvisation techniques, and mime, with particular reference to Plautus: see Arnott (1995), Hofmann (1995), Petrone (1995), and Zimmermann (1995); on the role of dance, see Moore (2012: 105-134). Other works present a comparative study (already familiar to ancient rhetoric) of the actor's and the orator's actio: among the many studies on this, see Graf (1991), Fantham (2002), Dutsch (2002, 2007, 2013) and Nocchi (2013). For a general overview of ancient gesture, see Sittl (189o) with his valuable and numerous observations on Plautine texts; as for the Roman world, see Aldrete (1999, 2017) and Corbeill (2004).

2 Watzlawick et al. (1967: esp. 29-52). On the application of methodological instruments borrowed from the pragmatics of communication to the study of Latin literary texts, see the comprehensive overview in Ricottilli (2009); more specifically, for an in-depth analysis of gesture, see Ricottilli (2000: esp. 81-116 for methodological observations on the contribution of the pragmatic approach to the analysis of Virgil's text).

(C) RENATA RACCANELLI, 2021 | DOI:10.1163/9789004440265_018

This is an open access chapter distributed under the terms of the CC BY-NC-ND 4.o license. 
the relational aspects of communication, while the syntax employed to define the nature of relationships remains elusive. As a result, human communication is based on the interaction of these two languages (verbal and gestural), which convey different levels of information in different ways. They therefore are mutually 'untranslatable' in general, if not at the cost of a significant loss of information.

Some implications of these general assumptions are particularly interesting for our study. Firstly, gestural language is ambiguous: tears can express either joy or pain, a smirk can signify either complicity or contempt, a raised fist can symbolise a threat or an expression of unity, etc. Secondly, gestural language may be used either as an alternative to verbal language or in combination with it. In any case, a gesture is seldom either an exact substitute for or a perfect equivalent of words; moreover, in virtue of its ability to express relationships, gestural language is particularly suited to assuming metacommunicative meaning. In other words, if a gesture accompanies words, it often shows how the referential contents that are conveyed by the words should be understood; ultimately, it expresses the nature of the relationship between the interactors.

Through the case study which will follow, I aim to demonstrate how these (inevitably generalised) pragmatic assumptions may foster the understanding of culturally specific texts, like Plautus' comedies. In particular, I wish to analyse an extreme case in which a misalignment between verbal and gestural language emerges.

The passage I will discuss is set within the second scene of Plautus' Stichus, where two sisters welcome their father with an osculum (Stich. 89-92) upon his arrival: in this greeting scene, the interaction between the verbal and gestural levels of communication is interesting in general, but I will mainly focus on the kiss between the elderly father and his daughters.

If we rely on Ekman and Friesen's classification of gestures, this kiss must be placed in the category of 'emblems', along with gestures of greeting, farewell, assent, denial, etc. ${ }^{3}$ Emblems generally express a meaning shared by a specific group of individuals who use them. Therefore, they feature a high level of awareness, in that their use is (much) more conscious and intentional than that of other non-verbal behaviour. Moreover, they often have an immediate verbal translation, 'usually consisting of a word or two, or perhaps a phrase,' ${ }^{4}$ e.g. clapping one's hands finds his linguistic equivalent in 'Bravo!'. From this point of

3 Ekman and Friesen (1969: 63-68, 94-95).

4 Ekman and Friesen (1969:63). 
view, they are, in a certain sense, one of the closest gestural categories to verbal language. Emblems are also characterised by strong social codification or, in other words, high cultural value: different cultures use different emblems and, conversely, the same emblematic behaviour may convey different meanings in different cultures.

This is why it is particularly important to examine this type of gesture within the framework of the Roman cultural context. Licinia Ricottilli's study Gesto $e$ parola nell'Eneide, which contextualises Ekman and Friesen's results with reference to the language of Roman gesture, is particularly useful here. ${ }^{5}$ In her reading of Virgil's Aeneid, Ricottilli observes how Roman emblems are generally enacted not only with great awareness and deliberate communicative intentions, but also, in many cases, with a specific 'componente rituale, che, implicando un forte controllo sociale, tende ad intensificare il grado di controllo personale nell'esecuzione del gesto stesso.' ${ }^{6}$

A Case Analysis: The Kiss in Plautus' Stichus 89-92

At the beginning of the comedy, the two sisters Panegyris and Pamphila ${ }^{7}$ complain about their absent husbands, who have been abroad for three years to improve their fortunes. The two matronae know that their father intends to make them divorce from their destitute absent husbands, in view of more illustrious marriages. The women are aware of their father's unchallengeable authority (see 69 cuius potestas plus potest) and, seeing that any open opposition would be both impious and shameful, plan to use the weapon of entreaty (exoratio), in order to dissuade him from his heinous plan. ${ }^{8}$

5 Ricottilli (2000) examines the relationship between gestures and words in Virgil's Aeneid with particular reference to the rhetorical treatment of gesture in antiquity (quasi sermo corporis, according to the famous definition in Cic. De or. 3.222) and to contemporary fields of research, such as the pragmatics of communication and Ekman and Friesen's classification (1969). A useful working definition of gesture is provided by Ricottilli (2000: 16): 'per gesto intendiamo un comportamento corporeo o facciale che assuma un valore comunicativo, informativo o interattivo nei confronti di un destinatario diretto o di un eventuale osservatore, e per il quale esista una possibilità di controllo da parte dell'emittente'.

6 Ricottilli (2000: 23): 'a ritual component which, by implying a strong degree of social control, tends to intensify the degree of personal control in the performance of the gesture itself.'

7 Regarding the names of the two matronae, which the manuscripts have transmitted rather uncertainly (the younger sister was quite likely a nameless character; indeed, many editors prefer the generic designation of Soror in place of Pamphila), see Petersmann (1973: 85).

8 Stich. $70-74$. 
As soon as the senex Antipho arrives, both daughters rush to welcome him and lavish him with attention:

[1] Plautus Stichus 89-96

Pan. is est ecastor. ferre aduorsum homini occupemus osculum.

Pamph. salue, mi pater. Ant. et uos ambae. ilico agite assidite.

Pamph. osculum - Ant. sat est osculi mi uostri. Pan. qui, amabo, pater?

Ant. quia ita meae animae salsura euenit. Pamph. asside hic, pater.

Ant. non sedeo istic, uos sedete; ego sedero in subsellio.

Pan. mane, puluinum - Ant. bene procuras. mi satis sic fultum est. sede.

Pamph. sine, pater. Ant. quid opust? Pan. opust. Ant. morem tibi geram. atque hoc est satis.

Pamph. numquam enim nimis curare possunt suom parentem filiae.

My proposal for the translation of this sequence is as follows: ${ }^{9}$

Pan. Oh, it's him, let's make the first move and kiss him.

Pamph. Greetings, father dear!

Ant. Same to you both. Come on, just sit down where you are.

Pamph. A kiss-

Ant. Enough with your kissing!

Pan. But why, father dearest?

Ant. Because that's how my breath has turned salty.

Pamph. Sit here near us, father.

Ant. I won't sit there. You both sit down; I will sit on a stool.

Pan. Wait, a cushion-

Ant. No need to fuss. I'm perfectly comfortable like this. Sit down.

Pamph. Allow me, father-

Ant. Is this really necessary?

Pan. Yes, it is.

Ant. All right, whatever makes you happy. Now that's enough!

Pamph. Daughters can never take enough care of their fathers.

9 For Plautus, I draw on de Melo (2011-2013) for both the Latin text and the English translation, unless otherwise stated (as in the present case). 
As we can see, the dynamics of interaction in this scene highlight the contrast between the exuberant acts of the daughters as they rush to welcome their father with deference on one hand and, on the other hand, the static and dry reactions of their father, who shields himself with brusque and imperious manners, and interrupts the matronae's words and gestures.

Let us now focus on the kiss sequence. The two sisters anticipate their father (occupemus $)^{10}$ and hurry to kiss him. From a pragmatic perspective, we might say that the women are trying to force the normal punctuation of the interactive sequence by forestalling a move they expect—and dread-from their interactor. Although they attempt to set up a harmonious interactive framework, their proposal is immediately rejected with a command that is aimed at keeping them lower than and at a distance from him (ilico agite assidite).

The proxemic framework of this sequence is particularly explicit in the text: we can observe the quick movement of the daughters towards their father and the rigid attitude of the senex, who stands stiffly before them and keeps his distance while maintaining his dominant position.

On the level of verbal communication, Antipho amasses various directive utterances within six lines (9o ilico agite assidite; 93 uos sedete; 94 sede, to which one may add the sharp invitation at 95 atque hoc est satis) and expressions indicating refusal (93 non sedeo; 94 bene procuras);11 most importantly, he interrupts his daughters' lines three times, i.e. when Pamphila asks for a kiss (91 osculum), as well as when each of the two sisters offers him a cushion (Panegyris at 94 mane, puluinum; Pamphila at 95 sine, pater). This represents a way for Antipho to get the upper hand by hijacking his daughters' turns to talk.

10 For occupare with the infinitive, see Petersmann (1973: 109) and Ussing (21972: II 435). See also Krauss (2008: 33) 'Panegyris announces her plan to kill their father with kindness: she says they will make the first move by kissing him [...]. This line has a military ring, despite the affectionate context, and echoes their father's own warlike plan'.

11 While it is true that simple imperatives do not necessarily convey harshness in directives in Latin (Risselada 1993: 111-122, 163; Unceta Gómez 2009: 65), in this context they are summed with various signals indicating urgency and irritation, especially with the threefold command to sit down as well as the presence of agite at 9o. This illocutionary device is opposed to amabo (91), a typical 'polite modifier' of female language in palliata: as Adams (1984: 67) observes, 'whereas obsecro, quaeso and amabo usually tone down a remark, sis and age can be described as "intensifiers"' and age / agite + imperative is often to be understood as 'urgent in tone [...] or hortatory'. The adverb ilico (90) may convey locative value if one considers the system of spatial references at 92 asside hic, pater and 93 non sedeo istic [...] sedero in subsellio, but it may also feature a sharp temporal connotation related to urgency (see Don. ad Ter. Andr. 514; v. ilico in TLL, 7.1, 330.77; Lodge 1924-1933: II 743). For more on bene procuras as a formula of polite refusal, see Petersmann (1973:110). 
The words of the senex express an abrupt and impositional attitude that is correlated with the proxemic requirement to mark a hierarchical distance between himself and his daughters. On the basis of this observation, I agree with the scholars who believe that Antipho avoids the kiss, rather than shielding himself after being assaulted by his daughters with kisses. ${ }^{12}$ In particular, line 91 (sat est osculi mi uostri) most likely expresses an absolute refusal of his daughters' osculum (singular, with an abstract connotation); i.e. he rejects the gesture of kissing in general, rather than the kisses that are being offered in the specific situation. In this light, we could contest the hypothesis of those who imagine such interaction at line 91:

\section{Pamph. A kiss-(they embrace him and kiss his cheeks) \\ Ant. (interrupting) I've had enough of your kissing. ${ }^{13}$}

The main reason for rejecting similar translations, however, lies in the nature of the gestures involved. Many commentators interpret the scene of the kiss as a simple clash between the women's expansiveness and the old man's gruffness, as he is afraid of becoming overwhelmed and being seen as weak and tender by his daughters, with whom he is about to argue: ${ }^{14}$ the dynamics of the situation certainly are an important component of the interaction between the characters on stage, but not all the implications of this gesture seem to have been fully investigated so far. As previously mentioned, the kiss belongs to the category of

12 'Osculum prohibet, quod offerebatur', noted Havekenthal, who also underlined the local value of ilico in line 9o (1607: 463). Ernout (1932-1938: vi 218) and Scandola in Questa (2005: 105) also interpret his gesture thus: 'Panfila (gettandogli le braccia al collo): un bacio .../ Antifonte (allontanandola bruscamente): Ne ho abbastanza dei vostri baci'.

13 De Melo (2013). This interpretation finds an influential precedent in Lambin (1577: 990): 'Satis vos osculatus sum.' Petersmann (1973: 109) acknowledges the difficulty of interpreting the passage but tends to believe that Antipho does not shield his face from his daughters' kisses immediately: 'dieser wehrt weitere Küsse ab, weil sein Gesicht davon schon naß und salzig ist'. Nixon (1916-1938: V 17) also leans in the same direction: 'Pan. Let's surprise him with a kiss as he comes in (they do so with high success)', as does Poster (1995: 324): 'Sister: Just one more hug! / Antipho: I've had enough of your hugs and kisses'. See also Petrone (1989: 94, 2015: 42-43): 'il particolare insistito del bacio con cui le figlie vanno ad accogliere il genitore, mentre questi tenta invano di sottrarsi. [...] non è il caso di dargli altri oscula'.

14 Stich. 79: scio litis fore-ego meas noui optume ('I know there will be arguments-I know my girls perfectly'). See, for example, Petrone (1989:210): 'È una gara tra furbi, come sempre nelle commedie plautine, ma anche tra persone che mescolano affetto e interesse: le figlie eccedono in carezze perché il padre, preso nei lacci dell'affetto, acconsenta alla loro scelta, questi cerca di stare sulla difensiva e di respingerne le tenerezze, per non cedere subito'. See also Petrone's previous work (1977:40). 
emblems: therefore, it entails a focus on the specific cultural meaning that the social context gives to the gesture itself. In fact, not only is the osculum included in this ritualised situation of greeting family members but it is, in itself, subjected to a strongly symbolic ritualisation in Roman culture, where the so-called ius osculi is a well-known institution, recommended by the mos maiorum. ${ }^{15}$

Petrone rightly points out that 'si tratta evidentemente del bacio di controllo che a Roma i parenti maschi danno alle donne di casa. ${ }^{16}$ Nevertheless, to the best of our knowledge, this insight stands alone among modern Plautine studies, which, moreover, seem to have failed to grasp the explicit reference to the ritual nature of this kiss in a fragmentary passage of Festus, which quotes the very line in question: ${ }^{17}$

\section{[2] Festus 214 Lindsay}

significatur etiam osculo sauium, ut Plautus in Neruolaria (Stich. 91): 'Osculum sat est osculi mihi 〈uostri〉. Qui, amabo, mi pater?'; quod inter cognatos, propinquosque institutum ab antiquis est, maximeque feminas $\cdots$

The kiss (sauium) is also referred to with the term osculum, as Plautus attests in Neruolaria (Stich. 91): 'Osculum —Enough with your osculum!But why, father dearest?'; a use which was introduced in antiquity among kinsmen and in-laws and especially women ...18

The passage-lacuna notwithstanding — clearly shows how Festus, in explaining the osculum as an ancestral Roman institutum, is perfectly aware of the ceremonial background underlying the interaction. Nevertheless, excepting

15 As far as the classification of kisses in Latin (ritual, erotic, or as a show of affection) - in other words, the differences between osculum, sauium, and basium-is concerned, it is well known that traces of an ancient debate remain: see, e.g., Moreau (1978), Flury (1988), Cipriani (1992). On the vocabulary concerning kisses in Plautus, see Plepelits (1972).

16 Petrone (2015: 42): "it is clearly the "kiss of control" that male relatives give to the women of their household'; see also Petrone's previous work (1989: 94).

17 The passage is mentioned by Giovanni Pietro Valla in his commentary on Plautus (1499) concerning the use of the word osculum in Stich. 91. Later on, however, the discussion of this important evidence of Plautus' indirect tradition was not as concentrated on the interpretative aspects as it was on the attribution of this verse, which Festus does not ascribe to Stichus, but rather to Neruolaria, one of the so-called non-Varronian comedies. For a recent and well-balanced discussion of this issue, see Monda (2015).

18 My translation. 
Petrone's mention, this rituality is neither perceived by Plautus' modern readers, nor-perhaps more importantly—does it seem that the anthropological, pragmatic, and dramaturgical implications of this ritual gesture have ever been explored in Stichus. ${ }^{19}$

Before returning to our comic situation, let us now briefly focus on the ius osculi: as is well known, many ancient records explain this ritual, in which cognati and propinqui (i.e. kin and in-laws) kissed the women of their family. Different interpretations of this gesture have been suggested in antiquity as well as in modern scholarship, but, in most cases, the classical authors sustained that the ius osculi is justified by the need to control and guarantee the reputation of women in the family. ${ }^{20}$ In particular, the following features (amongst others) may help us better understand the text we are examining:

19 Petrone (1989: 94) grasps the anthropological allusion to osculum but does not construct a specific analysis around it, believing that in this scene affection prevails over ritual: 'qui il fatto consuetudinario si fa pretesto di un sottile movimento sentimentale e psicologico, ricco di complicazioni e persino delicato, pur nella dimensione comica. [...] Il bacio 'di controllo' si trova invischiato in una rete di rapporti che lasciano indovinare uno spaccato domestico diverso da quello che ci si potrebbe immaginare alla luce della tradizionale severità paterna e delle norme del diritto. [...] l'auctoritas paterna vacilla, per affetto, nei confronti delle figlie.' See also Petrone (2015: 42). In our view, while the matronae are certainly reconfiguring the kiss as a show of affection, we should not overlook the implications of the osculum in Antipho's communicative intention: therefore, a pragmatic analysis of this gesture aids not only the investigation of its function in the interaction between the characters and in its interplay with the words, but also that of its cultural value and of the role it plays in Plautus' comedies.

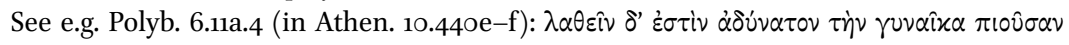

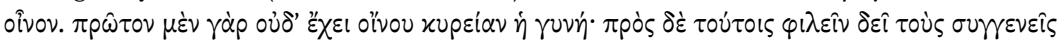

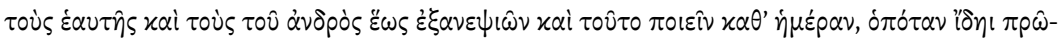

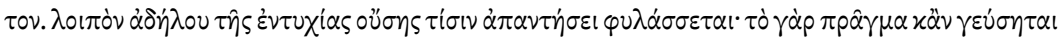
$\mu o ́ v o v$ ov $\pi \rho \circ \sigma \delta \varepsilon \hat{\varepsilon} \delta เ \alpha \beta \circ \lambda \hat{\eta} \varsigma$ ('It is impossible for a woman to drink wine in secret. Firstly, in fact, a woman cannot dispose of wine; secondly, she must kiss her relatives, as well as her husbands', up to her second cousins, and must do so every day as soon as she encounters them. Therefore, because she does not know whom she will meet, she will be cautious. For even if she only has a taste of wine, this custom makes any gossip superfluous'; my translation). On Cato's perspective, see Plin. nat. 14.9o: Cato ideo propinquos feminis osculum dare, ut scirent an temetum olerent ('Cato writes that male relations kiss their women in order to know whether they smell of wine': my translation from Pliny's text); as well as Gell. 10.23. See also the extensive analysis in Plut. Rom. Quaest. 6, which Moreau (1978) believes

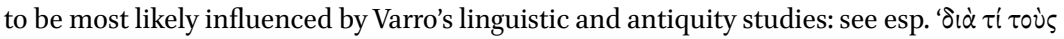




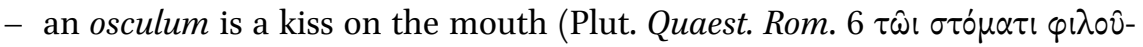
$\sigma(v)$ that is explicitly intended to check the woman's abstinence from wine (respectable women were prohibited from drinking wine, as it was, according to the mos maiorum, notoriously linked to adultery);

- furthermore, it is a sign of honour and power for women, who can thus display their bond with men of recognised standing in public (Plut. Quaest.

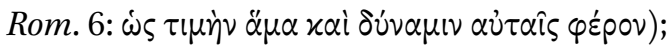

- inasmuch as it guarantees and displays a woman's connection to a certain household, it is a sign of recognition and acceptance; conversely, the act of rejecting the osculum sanctioned a woman's infamia and openly expressed her kinsmen's rejection of her, as Cicero clearly states in Rep. 4.6: si qua erat famosa, ei cognati osculum non ferebant. ${ }^{21}$

In short, the matter of recognition is a central node in the semantic system of the Roman osculum.

Confirmation of this may be found e.g. in a renowned exemplum narrated by Valerius Maximus that focuses on how exactly an osculum could be used as proof of belonging to a kinship group. Sempronia, the sister of Tiberius and Gaius Gracchus and wife of Scipio Aemilianus, when summoned by a tribune of the plebs to appear before the assembly of the people, does not surrender to the pressures of the crowd and refuses to kiss a certain Equitius, thereby refusing to acknowledge him as the son of her brother Tiberius:

\section{[3] Valerius Maximus 3.8.6}

coacta es eo loci consistere ubi principum ciuitatis perturbari frons solebat, instabat tibi toruo uultu minas profundens amplissima potestas, clamor imperitae multitudinis obstrepebat, totum forum acerrimo studio

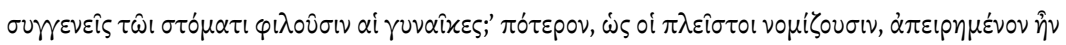

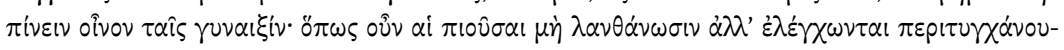

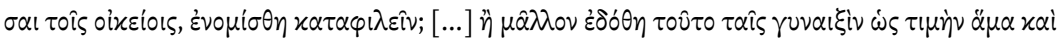

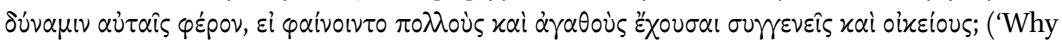
do the women kiss their kinsmen on the lips? Is it, as most authorities believe, that the drinking of wine was forbidden to women, and therefore, so that women who drunk wine should not escape detection, but should be detected when they chanced to meet men of their household, the custom was established? [...] Or was this rather bestowed upon the women as a privilege that should bring them both honour and power if they should be seen to have many good men among their kinsmen and in their household?': translation from Babbitt 1962). For a modern-day discussion of this issue, see Contini (1984); Bettini (1988, 1995); Timpanaro (1987); Cipriani (1992).

21 'If a woman had a bad reputation, her relatives would not have kissed her'. (my translation). 
nitebatur ut Equitio, cui Semproniae gentis falsum ius quaerebatur, tamquam filio Tiberi fratris tui osculum dares. tu tamen illum [...] execrabili audacia ad usurpandam alienam propinquitatem tendentem reppulisti.

You were forced to stand there, where leading citizens usually fail to hide their agitation, where the highest authority of the State pressed you and threatened you with an intimidating look, where the clamour of the ignorant mass resounded, where the entire forum pressured you to kiss Equitius, whose right to belong to the gens Sempronia as the son of your brother, Tiberius, was falsely claimed. But you [...] pushed away he who so boldly attempted to claim a bond of kinship to which he had no right. ${ }^{22}$

This moralising tale offers us a peculiar twist of the traditional custom of the osculum, as it recounts the deeds of a representative of a high-profile gens (in this case an irreprehensible matrona) by using the ritual of the kiss to ensure the purity of her kinship group: her public refusal to kiss him reveals the unworthiness of this impostor, who is trying to shamefully infiltrate an aliena propinquitas, thereby contaminating a noble lineage.

Moving from the level of the cultural implications of the osculum to its role in Plautus' plays, we notice some similarities with the tale of Sempronia-albeit in a strictly comical way-in Epidicus. The senex Periphanes, tricked by his slave Epidicus, believes that the citharist Acropolistis is the illegitimate daughter he had with Philippa many years earlier in Epidaurus. Later, when Philippa arrives in Athens to ask for his help to find their real daughter, who has been taken as a prisoner of war, Periphanes leads to her Acropolistis and urges her to kiss the girl, but Philippa refuses to grant her an osculum and the acknowledgement this would entail:

[4] Plautus Epidicus 570-576

Acr. quid est, pater, quod me exciuisti ante aedis? Per. ut matrem tuam uideas, adeas, aduenienti des salutem atque osculum. 
Acr. quam meam matrem? Per. quae exanimata exsequitur aspectum tuom.

Phil. quis istaec est quam tu osculum mi ferre iubes? Per. tua filia.

Phil. haecine? Per.haec. Phil. egone osculum huic dem? Per. quor non, quae ex te nata sit?

Phil. tu homo insanis. Per. egone? Phil. tune. Per. quor? Phil. quia ego hanc quae siet nec scio nec noui neque ego hanc oculis uidi ante hunc diem.

Acr. Why is it, father, that you called me out in front of the house?

Per. So that you can see your mother, go to her, and greet and kiss her on her arrival.

Acr. What mother of mine?

Per. The one who is almost dead while seeking to behold you.

Phil. Who is that woman you're asking to give me a kiss?

Per. Your daughter.

Phil. This woman?

Per. Yes, this woman.

Phil. I should give her a kiss?

Per. Why not, since she was born from you?

Phil. You're mad.

Per. I?

Phil. Yes, you.

Per. Why?

Phil. Because I don't know or recognize who she is and I haven't set eyes on her before this day.

As Raffaelli rightly points out, the situation in Plautus' Epidicus is 'l' opposto del canonico meccanismo dell'agnizione. ${ }^{23}$ While Periphanes anticipates an

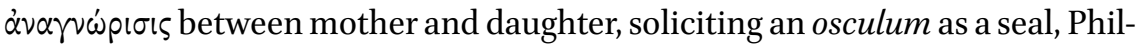
ippa affirms that she does not recognise Acropolistis precisely by denying her the kiss. We can also note how, in this interaction, the emblem is performed together with a verbal expression: Philippa's refusal to give the osculum (574

23 Raffaelli (2014: 94). This mechanism of inverting the agnitio, moreover, is pivotal in Epidicus, in which it is duplicated in a sequence with two interlinked non-recognitions, then followed by the traditional $\alpha v a \gamma v \omega$ piøı which resolves the whole situation in the end. For more regarding the centrality of agnitio in the construction of the plot of Epidicus, see also Philippides (2016). 
egone osculum huic dem?) is roughly 'translated' by her verbal explanation (575-576 quia ego hanc quae siet nec scio nec noui neque ego hanc oculis uidi ante hunc diem). ${ }^{24}$

While the verb osculari is very common in Plautus, as it encompasses ritual kisses as well as erotic ones, the noun osculum occurs in only three situations in Plautus: ${ }^{25}$ besides the two dialogues examined in [1] and [3], it is also featured in the famous scene from Amphitruo (676-86o) in which Alcmena reacts coldly to Amphitruo's salutatio upon his return from war: she believes she has just said good-bye to him after the longa nox (which, however, we know she really spent with Jupiter disguised as her husband). In the following dispute, Alcmena, indignant because she believes that Amphitruo is testing her (688 an periclitamini ...? and 692 temptas), claims that she has already greeted him and given him an osculum (716 and 80o-801) ${ }^{26}$

In short, the failure to obtain the requested salutatio, a ritual in which the osculum plays an important part, is interpreted by the husband as a symptom of a problem regarding his wife's pudicitia:

[5] Plautus Amphitruo 711-713

... salutare aduenientem me solebas antidhac, appellare itidem ut pudicae suos uiros quae sunt solent. eo more expertem te factam adueniens offendi domi.

You used to greet me on my arrival before and to address me the way modest wives normally greet their husbands. On my arrival I've found you at home without that habit.

24 See also Epid. 581-582 (Periphanes to Acropolistis): quid tu, quae patrem tuom uocas me atque osculare, quid stas stupida? quid taces? (What about you, who call me your father and kiss me? What are you standing here like an idiot? What are you silent for?).

25 See Lodge (1924-1933: I 272). For an examination of the use of osculum, sauium, and osculari in Plautus, see Plepelits (1972).

26 Amph. 714-716 Alc. ecastor equidem te certo heri aduenientem ilico et salutaui et ualuissesne usque exquisiui simul, mi uir, et manum prehendi et osculum tetuli tibi ('I certainly did greet you here on your arrival yesterday and asked you at the same time if you'd been well throughout, my husband, and I took your hand and gave you a kiss'); 799-801 adueniensque ilico me salutauisti, et ego te, et osculum tetuli tibi. Amph. iam illud non placet principium de osculo. ('on your arrival you immediately greeted me and I you, and I gave you a kiss. Amph. I already dislike that first point about the kiss.'). For more on greeting scenes in Plautus' comedies, see Berger (2016). 
From their omniscient viewpoint, the spectators are perfectly aware that Alcmena's failure to greet her real husband in her salutatio as expected from her is due to the fact that she had already welcomed a false Amhpitruo in his place. In facts, Alcmena's mistake regarding the osculum emblematises the misunderstanding around which the whole plot revolves. Once again, recognition is the central node of this ritual gesture on Plautus' stage.

Let us now return to the dramatic context of [1]. Having examined the two scenes from Plautus above, [4] and [5], the ritualistic meaning of the osculum should now be more evident. The two matronae demand the ritual osculum from their father as a sign of harmony in the family at a time of crisis and conflict. In light of the previous analysis, we now see that, in the eyes of the spectators, the father's avoidance of the osculum must have appeared as a much stronger gesture than an old man's gruffness in the face of his daughters' overwhelming affection.

Indeed, if we examine the immediate context, we can observe how, before meeting his daughters, Antipho thinks aloud and imagines two possible strategies for interacting with them:

\section{[6] Plautus Stichus $75^{-87}$}

principium ego quo pacto cum illis occipiam, id ratiocinor: utrum ego perplexim lacessam oratione ad hunc modum, quasi numquam quicquam in eas simulem, an quasi quid indaudiuerim eas in se meruisse culpam; an potius temptem leniter an minaciter? scio litis fore-ego meas noui optumesi manere hic sese malint potius quam alio nubere. non faciam. quid mi opust decurso aetatis spatio cum $\langle\mathrm{m}\rangle$ eis gerere bellum, quom nil quam ob rem id faciam meruisse arbitror? minime, nolo turbas, sed hoc mihi optumum factu arbitror: perplexabiliter earum hodie perpauefaciam pectora. sic faciam: assimulabo quasi quam culpam in sese ammiserint. postid [agam] igitur deinde, ut animus meus erit, faciam palam. multa scio faciunda uerba.

I'm considering the beginning, how I should start with them: should I vex them with my speech obscurely like this, as if I were never accusing them 
at all, or as if I'd heard something, that they'd become guilty; in other words, had I better handle them gently or threateningly? I know there will be arguments—I know my girls perfectly—if they prefer staying here to getting married to different men. I won't do it. What's the use of waging war with my girls now that I've reached the end of the course of my life, when I don't think they've done anything for which they deserve my doing this? No, I don't want commotions; rather, I think this is the best thing for me to do: I'll frighten their hearts in a confusing manner today. I'll act like this: I'll pretend that they've committed some offense. Then, after that, I'll reveal what my feelings are. I know that I'll have to use a lot of words.

What should Antipho do? Should he provoke them with ambiguous words (perplexabiliter), act as if nothing has happened, or pretend that he has heard rumours about some misdemeanour of theirs (quasi quid indaudiuerimeas in se meruisse culpam)? Endearments or threats? The old man considers his options but eventually decides that he will not go to the extremes. Therefore, he will make an attempt at intimidation (perplexabiliter earum hodie perpauefaciam pectora), but he will be ready to withdraw before the conflict escalates: he will frighten his daughters, behaving at first as if they were guilty, and only later dropping his pretence, and exposing his true feelings for them.

In the end, Antipho meets his daughters after revealing to the audience that he will adopt an accusatory attitude. As a result, the rejection of the kiss is a very strong gesture, when related to his resolve to accuse the matronae. It is tantamount to a refusal to recognise them as his daughters, almost an act of repudiation, and above all constitutes a serious threat to the daughters' reputation, as seen in Cicero's attestation (Rep. 4.6): si qua erat famosa, ei cognati osculum non ferebant.

However, the fact that not a single accusation is expressed on a verbal level in the entire scene is significant: in the text, there is not a single word of doubt about the women's behaviour.

When his daughter Pamphila asks why he refuses her an osculum (qui, amabo, pater?), Antipho answers (Stich. 92): quia ita meae animae salsura euenit (the literal translation of which is 'because that's how the saltiness has come to my breath'). This is not the place to enter a drawn-out debate surrounding this line, which is generally considered obscure in meaning: a detailed analysis of the bibliographical references and a new perspective on the line may be found in a recent article of mine. ${ }^{27}$ Here, it is sufficient to note that it 
is often a misunderstanding of the gesture that hinders the interpretation of the line, especially if one reads the scene while thinking of reciprocal kisses on the cheek. ${ }^{28}$ It becomes much clearer if we think about the ritual osculum on the mouth and its cultural implication in ensuring a woman's sobriety and pudicitia. By refusing his daughters' kisses, Antipho creates the expectation of saying something censorial on their breath, and therefore on the propriety of their behaviour, but indeed, at the very climax of the exchange, he releases the tension by drawing attention to his own breath. In other words, he is communicating perplexabiliter, just as he had promised before, in that he is combining his gesture of refusal with an elusive verbal message; he threatens an accusation with the gesture but does not confirm it with words. Instead, he withdraws with a vague allusion to his own breath, as if activating a kind of self-censorship mechanism to avoid explaining the real reasons for his irritation. In any case, he does not voice the terrible accusation that would sully his daughters' good name. Moreover, he removes the accusation hinted by his gestures immediately afterwards by pointedly saying:

\section{[7] Plautus Stichus 99-101}

Ant. bonas ut aequom est facere facitis, quom tamen apsentis uiros perinde habetis quasi praesentes sint. Pamph. Pudicitia est, pater, eos nos magnuficare qui nos socias sumpserunt sibi.

have been proposed in Plautine scholarship and suggests a new approach to read Antipho's words through a systematic comparison with the most appropriate loci paralleli. In particular, in Plautus the word salsura seems to refer to methods of conserving food that evoke olfactory and taste reactions of disgust. Antipho therefore seemingly motivates his refusal to kiss his daughters with the excuse that he has bad breath. In my view, Antipho's line is based on an ambiguous strategy (perplexabilis) which in terms of communicative pragmatics could be construed as a misalignment between the level of content (on which the character utters a trivial, self-denigrating witticism, in line with the Plautine topos of jokes about fetid breath; see e.g. As. 893-985; 929; Merc. 574-576) and the metacommunicative level of the interaction (in which a veiled threat is conveyed). Therefore, the off-handed remark is not an expedient that is adopted as an impromptu joke, but rather has the deliberate function of providing comic relief in a tense situation.

28 De Melo (2013: 27) supplements the translation with the comment: 'the girls' cheeks are still wet with tears, hence the reference to salting', drawing on the work of Ernout (19321938: VI 218) and Petersmann (1973: 109): 'd.h. die Schwestern weinen noch (vgl. zu v. 20) oder sie sind vom Weinen noch tränenbenetzt und küssen den Vater (osculum). Dieser wehrt weitere Küsse ab, weil sein Gesicht davon schon naß und salzig ist.' 
Ant. You're acting the way good women ought to act, since you treat your husbands as if they were present, absent though they are.

Pamph. It's a matter of womanly virtue, father, to honor the men who have taken us as their partners. ${ }^{29}$

On this foundation of restored harmony, the verbal skirmish between the pudicae matronae and the father continues, for he subjects them to witty questioning about feminine virtues. The sisters answer alternatingly in a kind of antiphonal competition, yet somehow the father still exercises the function of control evoked by the ritual osculum in the following agon:

\section{[8] Plautus Stichus 126}

edepol uos lepide temptaui uostrumque ingenium ingeni.

I've tested you two and the nature of your nature delightfully.

Indeed, his testing is nothing but a game (lepide temptaui ${ }^{30}$ ) and the contest between the sisters provides a new opportunity for them to highlight their virtues and their perfect conformity to the code of behaviour for matronae.

To summarise what has been observed so far: when enacting his intention to frighten his daughters, Antipho does not express his accusation in words. In fact, as far as verbal language is concerned, we only find sharp commands, denials, and - conversely_explicit recognition of the daughters' pudicitia. Only on the level of gestural language is there a feigned accusation (assimulabo quasi quam culpam in sese admiserint), expressed through the refusal of the osculum, a denial of the ritual recognition which is reserved, as previously seen, for women of dubious reputation (famosae).

Even if the emblematic gesture finds a correspondence on the verbal plane ('I acknowledge/do not acknowledge you as a worthy daughter/wife, etc.'), here

29 My adaptation of de Melo's translation is in italics. Preemptive reassurance about the two women's innocence was also granted by Antipho as early as line 82 (quom nil [...] meruisse arbitror?).

3o As previously seen, the issue of testing (periclitor, tempto) is also important in Amph. 688 and 692 . 
we can clearly confirm that gestures are not an exact equivalent of words. An explicit accusation of impudicitia, and therefore a verbal codification of such repudiation, would be quite incompatible with the comic context of Stichus; indeed, Antipho immediately rules out any blame through explicit words of confirmation of their good behaviour (99 bonas ut aequom est facere facitis).

If the refusal to grant recognition through the osculum can be performed on the stage elsewhere in Plautus, it is because:

- in Epidicus, the unacknowledged woman is a citharist with no reputation; she is part of a deceitful plan that must be thwarted;

- in Amphitruo, we are faced with the extreme case of an unwitting adulteress, a victim of mistaken identity; more importantly, we are dealing with a tragicomedy, in which the intermingling and substitution of men and gods subvert the rules of the genre and allow the tragic theme of adultery to be restructured and integrated into a comic context.

In Stichus, the denial of the ritual osculum is a gesture expressing what words do not (and cannot) say, not even as a pretence (assimulabo). In fact, casting a shadow on the reputation of a matrona would evoke a tragic scenario incompatible with the boundaries of palliata (if not at the cost of a metamorphosis in theatrical genre, which is precisely what happens in Amphitruo). ${ }^{31}$

It is not surprising, therefore, that the playwright chooses to represent a feigned threat by resorting to gestures while using words to reassure the audience that the infamous culpa (hinted at only in the gestural threat) will never materialise or even be evoked in verbal language. Indeed, the underlying communicative mechanism in the scene, where the wives, long left behind by their husbands, are tested by their father, seems to be based on the dispelling of an audience's anxiety. This becomes more plausible upon remembering that Stichus was first performed in $200 \mathrm{BC}$. in front of an audience that must have felt strongly about the Odyssean theme of veterans returning after years abroad at war. The 'proven fidelity' of the two wives - which had been anticipated at the beginning through Panegyris' line in the opening scene about their (self)identification with Penelope-has been extensively studied from this perspective. ${ }^{32}$

In conclusion, our case of the osculum in Plautus' Stichus demonstrates how important it is to more thoroughly comprehend ancient drama by focusing to an equal degree on verbal and gestural language: in fact, we tend to be less

\footnotetext{
$31 \quad$ Amph. 59-63.

32 Stich. 1-6. Along with Fraenkel (2007: 71), see also Wagenvoort (1931); Arnott (1971-1974: 552, 1972: 57-64); Petrone (1977: 35-36); Owens (2000); Rossi in Questa (2005: 61-82); Papaioannou (2016).
} 
vigilant and less trained in the critical perception of cultural difference when dealing with the gestures presented in ancient texts.

Translators who fall into the trap of imagining these to be affectionate kisses on the cheeks do not grasp the meaning of the scene: they focus on translating words but do not address the issue of also 'culturally translating' gestures. As a result, they modernise them by associating them with our social convention of kissing on the cheeks (perhaps due to the fact that from our cultural perspective we would consider it strange and quite morbid for fathers and daughters to kiss each other on the mouth). By doing so however, the ritual depth of the situation is lost, along with the ambiguity of Antipho's threats to his daughters with gestures rather than words.

In contemporary theatre studies, which are so attentive towards performative aspects as well as textual philology, the field of pragmatics of communication may offer a twofold contribution. On the one hand, it helps us better understand the dynamics of intersection and misalignment between the communicative levels of word and gesture and provides reliable tools in order to do so. On the other hand, it urges us to read both levels while paying critical attention to the anthropological contexts underlying the interaction, thus reminding us to culturally interpret not only words but also gestures in works of ancient theatre.

\section{References}

Adams, N.J., (1984), 'Female Speech in Latin Comedy', Antichthon 18, 43-77.

Aldrete, G.S., (1999), Gestures and Acclamations in Ancient Rome, Baltimore/London.

Aldrete, G.S., (2017), 'Gesture in the Ancient Mediterranean World' in F.S. Naiden, R.J.A. Talbert (eds.), Mercury's Wings. Exploring Modes of Communication in the Ancient World, New York, 149-163.

Arnott, W.G., (1971-1974), 'Réflexions sur le Stichus de Plaute', Dioniso 45, 549-555.

Arnott, W.G., (1972), 'Targets, Techniques, and Tradition in Plautus' Stichus', Bulletin of the Institute of Classical Studies 19, 54-79.

Arnott, W.G., (1995), 'The Opening of Plautus' Curculio: Comic Business and Mime', in

L. Benz, E. Stark, \& G. Vogt-Spira (eds.), Plautus und die Tradition des Stegreifspiels:

Festgabe für Eckard Lefèvre zum 6o. Geburtstag, Tübingen, 185-192.

Babbitt, F.C., (1962), Plutarch's Moralia, vol. 4, Cambridge, Mass./London.

Berger, Ł., (2016), ‘Escenas de bienvenida en las comedias de Plauto', Scripta Classica 13, 65-84.

Bettini, M., (1988), 'Il divieto fino al "sesto grado" incluso nel matrimonio romano', Athenaeum 66, 69-98. 
Bettini, M., (1995), 'In vino stuprum', in O. Murray \& M. Tecusan (eds.), In vino veritas, London, 224-235.

Cipriani, G., (1992), 'Il vocabolario latino dei baci', Aufidus 17, 69-102.

Contini, A.M.V., (1984), 'Ius osculi', in Studi Noniani 9, Genoa, 87-96.

Corbeill, A., (2004), Nature Embodied: Gesture in Ancient Rome, Princeton/Oxford.

Dutsch, D.M., (2002), 'Towards a Grammar of Gesture. A Comparison between the Types of Hand Movement of the Orator and the Actor in Quintilian's Institutio Oratoria 11.3.85-184', Gesture 2, 259-281.

Dutsch, D.M., (2007), 'Gestures in the Manuscripts of Terence and the Late Revivals of Literary Drama', Gesture 7, 39-71.

Dutsch, D.M., (2013), 'Towards a Roman Theory of Theatrical Gesture', in G.W.M. Harrison \& V. Liapis (eds.), Performance in Greek and Roman Theatre, Leiden/Boston, 408-431.

Ekman, P. \& Friesen, W.V., (1969), 'The Repertoire of Nonverbal Behavior: Categories, Origins, Usage, and Coding', Semiotica 1, 49-98

Ernout, A., (1932-1938), Plaute, 6 vols., Paris.

Fantham, E., (2002), 'Orator and/et Actor', in P.E. Easterling \& E. Hall (eds.), Greek and Roman Actors. Aspects of an Ancient Profession, Cambridge, $362-376$.

Flury, P., (1988), 'Osculum und osculari. Beobachtungen zum Vokabular des Kusses im Lateinischen', in S. Kramer \& M. Bernhard (eds.), Scire litteras. Forschungen zum mittelalterlichen Geistesleben, Munich, 149-157.

Fraenkel, E., (2007), Plautine Elements in Plautus, Oxford/New York (Engl. transl. of Plautinisches im Plautus, Berlin 1922).

Graf, F., (1991), 'Gestures and conventions: the Gestures of the Roman actors and orators', in J. Bremmer \& H. Roodenburg (eds.), A Cultural History of Gesture. From Antiquity to the Present Day, Cambridge, $36-58$.

Handley, E., (2002), 'Acting, Action and Words in New Comedy', in P. Easterling \& E. Hall (eds.), Greek and Roman Actors. Aspects of an Ancient Profession, Cambridge, ${ }^{16} 5^{-}$ 188.

Havekenthal, V., (1607), In Comoedias Plauti, quae extant, Divinationes et Interpretationes Valentis Acidalii, Frankfurt.

Hofmann, W., (1995), 'Die Körpersprache der Schauspieler als Mittel des Komischen bei Plautus', in L. Benz, E. Stark, \& G. Vogt-Spira (eds.), Plautus und die Tradition des Stegreifspiels: Festgabe für Eckard Lefèvre zum 6o. Geburtstag, Tübingen, 205-218.

Krauss, A.N., (2008), 'Panegyris Channels Penelope: Mêtis and Pietas in Plautus' Stichus', Helios 35, 29-47.

Lambin, D., (1577), M. Accius Plautus ex fide, atque auctoritate complurium librorum manu scriptorum opera Dionys. Lambini Monstrolinensis emendatus: ab eodemque commentariis explicatus, et nunc primum in lucem editus, Paris.

Lodge, G., (1924-1933), Lexicon Plautinum, 2 vols., Leipzig. 
Melo, W. de, (2011-2013), Plautus, 5 vols., Cambridge, Mass./London.

Monda, S., (2010), 'Callidamate e i suoi amici: scene di ubriachi nella Commedia nuova e nella Palliata', in R. Raffaelli \& A. Tontini (eds.), Lecturae Plautinae Sarsinates XIII, Mostellaria, Urbino, 59-95.

Monda, S., (2014), 'Palestrione e la tipologia del servus meditans in commedia', Pan n.s. $3,65-85$.

Monda, S., (2015), 'Stichus sive Nervolaria: origini, sviluppi e fortuna di una congettura', in R. Raffaelli \& A. Tontini (eds.), Lecturae Plautinae Sarsinates XVIII, Stichus, Urbino, $55^{-65}$.

Moore, T.J., (2012), Music in Roman Comedy, Cambridge/New York.

Moreau, P., (1978), 'Osculum, basium, savium', Revue de philologie, de littérature et d'histoire anciennes $52,87-97$.

Nixon, P., (1916-1938), Plautus, 5 vols., Cambridge, Mass./London.

Nocchi, F.R., (2013), Tecniche teatrali e formazione dell'oratore in Quintiliano, Berlin/ Boston.

Owens, W.M., (2000), 'Plautus' Stichus and the Political Crisis of 200 в.c.', American Journal of Philology 121, 385-407.

Panayotakis., C., (2005), 'Nonverbal Behaviour on the Roman Comic Stage', in D. Cairns (ed.), Body Language in the Greek and Roman Worlds, Swansea, 175-187.

Papaioannou, S., (2016), 'Plautus Undoing Himself-What is Funny and What is Plautine in Stichus and Trinummus?', in S. Frangoulidis, S.J. Harrison, \& G. Manuwald (eds.), Roman Drama and its Contexts, Berlin/Boston, 167-201.

Petersmann, H., (1973), T. Maccius Plautus, Stichus, Heidelberg.

Petrone, G., (1977), Morale e antimorale nelle commedie di Plauto. Ricerche sullo Stichus, Palermo.

Petrone, G., (1989), 'Ridere in silenzio. Tradizione misogina e trionfo dell'intelligenza femminile nella commedia plautina', in R. Uglione (ed.), Atti del III Convegno Nazionale di Studi su "La donna nel mondo antico", Turin, 87-103 (repr.: G. Petrone, Quando le Muse parlavano latino. Studi su Plauto, Bologna 2009, 203-218).

Petrone, G., (1995), 'Scene mimiche in Plauto', in L. Benz, E. Stark, \& G. Vogt-Spira (eds.), Plautus und die Tradition des Stegreifspiels. Festgabe für Eckard Lefèvre zum 6o. Geburtstag, Tübingen, 171-183 (repr.: G. Petrone, Quando le Muse parlavano latino. Studi su Plauto, Bologna 2009, 133-145).

Petrone, G., (2015), 'Stichus, commedia di situazioni', in R. Raffaelli \& A. Tontini (eds.), Lecturae Plautinae Sarsinates XVIII, Stichus, Urbino, 37-53.

Philippides, K., (2016), 'Symmetrical Recognitions in Plautus' Epidicus', in S. Frangoulidis, S.J. Harrison, \& G. Manuwald, Roman Drama and its Contexts, Berlin/Boston, 289-298.

Plepelits, K., (1972), 'Beobachtungen zu Plautus', in R. Hanslik, A. Lesky, \& H. Schwabl (eds.), Antidosis. Festschrift W. Kraus, Vienna/Cologne, 267-277. 
Poster, C., (1995), Stichus, in D.R. Slavitt \& P. Bovie, Plautus: The Comedies, vol. 4, Baltimore/London, 313-365.

Questa, C., (2005), Plauto, Stico, Milan.

Raccanelli, R., (2019), 'Salsura: Antifone e il fiato sotto sale (Plauto, Stichus 92)', Paideia 74, 667-684.

Raffaelli, R., (2014), TuttoPlauto. Un profilo dell'autore e delle commedie, a cura di R. Raffaelli, scritti di C. Questa e R. Raffaelli, Urbino.

Ricottilli, L., (2000), Gesto e parola nell'Eneide, Bologna.

Ricottilli, L., (2009), 'Appunti sulla pragmatica della comunicazione e della letteratura latina', in A. Barchiesi \& G. Guidorizzi (eds.), La stella sta compiendo il suo giro. Atti del convegno internazionale di Siracusa, 21-23 maggio 2007, Florence, 121-170.

Risselada, R., (1993), Imperatives and Other Directive Expressions in Latin: a Study in the Pragmatics of a Dead Language, Amsterdam.

Sittl, C., (189o), Die Gebärden der Griechen und Römer, Leipzig.

Taladoire, B.-A., (1951), Commentaires sur la mimique et l'expression corporelle du comédien romain, Montpellier.

Timpanaro, S., (1987), 'Il ius osculi e Frontone', Maia 39, 201-211.

Unceta Gómez, L., (2009), La petición verbal en latín. Estudio léxico, semántico y pragmático, Madrid.

Ussing, J.L., ( ${ }^{2} 1972$ [1875-1892]), Commentarius in Plauti Comoedias, denuo edendum curavit indicibus auxit A. Thierfelder, 2 vols., Hildesheim/New York.

Valla, G.P., (1499), Plautinae viginti comediae emendatissimae cum accuratissima ac luculentissima interpraetatione doctissimorum virorum Petri Vallae Placentini ac \& Bernardi Saraceni Veneti, Venice.

Wagenvoort, H., (1931), 'De Sticho Plautina', Mnemosyne 59, 309-312.

Warnecke, B., (1910), 'Gebärdenspiel und Mimik der römischen Schauspieler', Neue Jahrbücher für das klassische Altertum 13, 580-594.

Watzlawick, P., Helmick Beavin, J., \& Jackson, D.D., (1967), Pragmatics of Human Communication: a Study of Interactional Patterns, Pathologies, and Paradoxes, New York.

Zimmermann, B., (1995), 'Pantomimische Elemente in den Komödien des Plautus', in L. Benz, E. Stark, \& G. Vogt-Spira (eds.), Plautus und die Tradition des Stegreifspiels. Festgabe für Eckard Lefèvre zum 6o. Geburtstag, Tübingen, 193-204 ('Elements of Pantomime in Plautus' Comedy', in S. Frangoulidis, S.J. Harrison, \& G. Manuwald (eds.), Roman Drama and its Contexts, Berlin/Boston 2016, 317-327). 


\title{
Lacrimae and uultus: Pragmatic Considerations on Gestures in Seneca's Tragedies
}

\author{
Evita Calabrese
}

$1 \quad$ Introduction

The following analysis presents a pragmatic perspective on gesture. ${ }^{1}$ My point of departure will be the operational definition that has been developed by Licinia Ricottilli:

... per gesto intendiamo un comportamento corporeo o facciale che assuma un valore comunicativo, informativo o interattivo nei confronti di un destinatario diretto o di un eventuale osservatore, e per il quale esista una possibilità di controllo da parte dell'emittente. ${ }^{2}$

The present study focuses on Seneca's dramatic œuvre and investigates, without expecting to be exhaustive, two specific aspects of its gestures: tears and uultus.

1 In the wake of Sittl's seminal work dating back to 189o, research on gestures in ancient Greece and Rome has been resumed in recent years and led to numerous studies that would be difficult to cite in their entirety. Thus, it shall suffice to mention some of the most significant ones here, such as Bremmer and Roodenburg (1991); Lateiner (1995); Aldrete (1999, 2017); Corbeill (2004); Cairns (2005). More recently, Clark et al. (2015) inquired into the relation between gestures and emotions. Other studies have focused on specific aspects of gestures and include Fögen (2009) on tears in the Graeco-Roman world; Hagen (2016) on tears as a means of persuasion in Roman historiography; Rey (2017) on the power of tears in ancient Rome; Beard (2014), which faces the topic of laughter in ancient Rome; Naiden (2006) on supplication. I also permit myself to refer to Calabrese $(2018,2019)$, in which I deal with gestures in Petronius' Satyricon.

2 'By gesture we denote a behaviour of the body or the face that assumes communicative, informative or interactive significance towards a direct, intended recipient or a possible observer and over which the sender can exert control.' Ricottilli (200o: 16). Other studies by the same author, in particular Ricottilli (1992, 2016), constitute the starting point for the present study on gestures.

(C) EVITA CALABRESE, 2021 | DOI:10.1163/9789004440265_019

This is an open access chapter distributed under the terms of the CC BY-NC-ND 4.o license. 


\subsection{Not Shedding Tears: Andromache at the Beginning of Act III of Troades}

Among Seneca's tragic works, tears are extensively found in Troades with its dominant feminine presence. Here, tears appear at the very beginning, in the context of a funeral dirge. At the end of her first line, Hecuba encourages the chorus consisting of female Trojan prisoners to resume their cries, reminding them of the gestures that had to be associated with their tears: ${ }^{3}$

\section{[1] Seneca Troades $63-65$}

lamenta cessant? turba captiuae mea, ferite palmis pectora et planctus date et iusta Troiae facite ... ${ }^{4}$

Do your wailings falter? $\mathrm{O}$ throng of mine, captives as ye are, smite breasts with palms, make loud laments, due rites for Troy perform ...

The prisoners must let their hair down and cover it with ashes while beating their bare chests (Sen. Tro. 83-85, 87-89, 92-95): Hecuba thus invites them to perform a collective lament according to the typical Roman funeral ritual. ${ }^{5}$

In Troades, the collective feminine ritual of mourning is evoked and solicited in the beginning but also questioned in a sense by Andromache, who demonstrates that her own behaviour contrasts with the gestural aspects of mourning and funeral lamentations that are exhibited by the Trojan women. In fact, Andromache enters the scene at the beginning of Act III and distances herself from the very gestures that the queen had previously solicited:

\section{[2] Seneca Troades 409-413}

quid, maesta Phrygiae turba, laceratis comas

miserumque tunsae pectus effuso genas

3 Šterbenc Erker (2009: 142) observes that the subject of lamenting or performing solemn gestures of mourning is rather common in Latin poetry.

4 The excerpts from Seneca's tragedies are reproduced from Zwierlein's critical edition $\left({ }^{2} 1987\right)$. The translations are taken from Miller (1917).

5 For more on the various aspects of gestures that are associated with weeping and mourning lamentations, see Corbeill (2004: 67-106). 
fletu rigatis? leuia perpessae sumus, si flenda patimur. Ilium uobis modo, mihi cecidit olim ...6

Ye Phrygian women, mournful band, why do you tear your hair, beat on your wretched breasts, and water your cheeks with weeping unrestrained? Trivial woes have we endured if our sufferings can be told by tears. Ilium has fallen but now for you; for me she fell long since ...

Andromache claims that the Trojan women may give vent to recent losses through their tears, but her long acquaintance with pain has made her insensitive and numb (Tro. 417). Hector's wife is a stranger to the other women's mourning because her experience was different from theirs and she is in a different psychological condition. ${ }^{7}$ Her rigidity and listlessness affects her gestures and renders her unable to take part in the external manifestations of grief that, on the contrary, characterise the behaviour of the other prisoners.

The tears that Andromache is unable to share with the Trojan women are those that she sees Hector's ghost shed during a vision that occurs while in a strange state of psychic suspension between wakefulness and sleep:

\section{[3] Seneca Troades $448-451$}

non ille uultus flammeum intendens iubar, sed fessus ac deiectus et fletu grauis similisque nostro, squalida obtectus coma. $[\ldots]$ tum quassans caput ...

Not such his face, blazing with battle light, but weary, downcast, heavy with weeping, like my own, covered with matted locks. [...] Then, shaking his head [he said ...]

In these lines, gestural elements that are related to uultus 8 describe Hector's attitude and mark the clear distance between the exhausted shade and the hero

6 Cassandra has a similar reaction to Andromache in Sen. Ag. 659-663. See Tarrant (1976: 295296); Aricò (1996: 142).

7 See Caviglia (1981: 254) on Tro. 412-413: 'la contemporaneità ideale tra la caduta di Ettore e la caduta di Troia, che è "luogo comune" della tragedia, è qui sottolineata come esperienza personale, che riguarda soltanto Andromaca, non la comunità (uobis ... mihi).'

8 For more on the meaning of the term uultus, see n. 21. 
of the past: in addition to tears, these include defeated downwards glances and the despondent shaking of the head. ${ }^{9}$ As we know, the model for Andromache's dream is Verg. Aen. 2.269-297, Hector's apparition in Aeneas' dream. Virgil's Hector also sheds tears (271 largosque effundere fletus). A significant difference between the two passages consists in the fact that, while Aeneas cries in response (279 ultro flens ipse uidebar), Andromache is not even able to share Hector's tears. We shall return to this point later on when attempting to clarify the evolution that Andromache's gestures undergo in Troades.

\subsection{A Recurring Motif Made Estranged: False Feminine Tears}

In the course of Act III of Troades, we see Andromache weep. She does so before Ulysses after giving him false news on the death of Astyanax: her tears are produced within a fraus (see Tro. 482 and Scolari in this volume), i.e. an attempt to deceive. False feminine tears are frequent in Graeco-Roman literature, ${ }^{10}$ but Seneca managed to make particular use of this recurring motif to the point of making it seem estranged and paradoxical. Ulysses describes the weeping Andromache in the same line in which, addressing himself, he wonders whether or not to believe the vow of a mother:

\section{[4] Seneca Troades 615-618}

scrutare matrem: maeret, illacrimat, gemit;

sed huc et illuc anxios gressus refert

missasque uoces aure sollicita excipit:

magis haec timet, quam maeret ...

Watch the mother. She grieves, she weeps, she groans; now here, now there she wanders restlessly, straining her ears to catch each uttered word; this woman's fear is greater than her grief ...

In this passage, we observe how Andromache exhibits, on the one hand, the typical gestures of maeror, above all tears, and how, on the other hand, such ges-

9 A gesture 'of distress or angry frustration', according to Fantham (1982: 281). It is the same gesture found in Verg. Aen.7.292 tum quassans caput haec effunditpectore dicta, performed by Juno immediately before venting her sharp pain, in direct discourse, (see 291 stetit acri fixa dolore) upon seeing Aeneas and his followers happily disarm the ships after their peace with king Latino. The same gesture also appears, as a sign of sufferance (see Traina 1997: 182), before direct discourse in Aen.12.894 ille caput quassans [...]. In Seneca's theatre, the expression is also found at $O e d$. 913 regius quassat caput.

See Fögen (2004: 228-229, 2009: 187); Ricottilli (2016: 76-77). 
tures clash with the typical manifestations and attitudes of timor, e.g. nervously pacing back and forth and receiving every word with concern. It is precisely this inconsistency that causes the failure of the deception and leads the interlocutor to understand that the woman is lying. In particular, her tears, which are a gestural sign of sufferance, and her stride (referred to in Latin as incessus or gressus) do not harmonise. The heroine violates a behavioural principle of the utmost importance in Roman culture that is codified in oratory and philosophy, i.e. consistency between ideas, states of mind, and external behaviours (the latter made up of the union of various elements, including gestures, posture, and gait). ${ }^{11}$ Andromache attempts to deceive Ulysses by expressing pain caused by the death of her child, but her tears are mixed with concern, which is clearly revealed by her anxious way of pacing. For an attentive observer like Ulysses, all of these elements are clues that reveal the woman's true state of mind. ${ }^{12}$

From a preliminary reading (of course, a more in-depth study would be needed on the matter), we can notice that three elements (uultus, incessus, and habitus) substantially reveal a person's animus in Seneca's philosophical reflections $^{13}$ as much as in his dramas. For instance, these are the elements on which the identification between Hector and Astyanax is based:

\section{[5] Seneca Troades 464-466}

... hos uultus meus

habebat Hector, talis incessu fuit

habituque talis ... ${ }^{14}$

... such features my Hector had, such was he in gait, such in bearing ...

11 This principle is clearly codified in passages such as Cic. De or. 3.216; Cic. Brut. 141; Sen. Ep. 114.22; Quint. Inst. 11.3.66, 67; Sen. Ep. 52.12. See Ricottilli (2000: 84); Corbeill (2004: 114118). The common principle at the base of these texts is that a person's appearance reveals his or her character: see Graf (1991: 40).

12 In deciphering the state of mind of the interlocutor, attentive and precise observation assumes a fundamental role: see, for instance, the use of the verb scrutari in Tro. 615 (see [4]) and the importance that is attributed to the act of observation in Sen. Ep. 52.12. For more on the matter, see Bettini (2000: 326).

13 See Sen. Ep. 114.22. For an explanation on the meaning of the terms uultus and incessus, see n. 21.

14 uultus, habitus, and gait are also revealing signs of the grave ill that afflicts Phaedra in Phaedr. 363 proditur uultu furor, 372-373 semper impatiens sui mutatur habitus, 374 uadit incerto pede. 
Facial expression and gait are also the pivots of Ulysses' description upon entering the scene:

[6] Seneca Troades 522-523

adest Ulixes, et quidem dubio gradu uultuque: nectit pectore astus callidos.

Ulysses is here, with step and look of one in hesitation; in his heart he weaves some crafty stratagem.

In this case, they are completely coherent with one another, to the point of allowing Andromache to puzzle out the hero's intentions. ${ }^{15}$ On the contrary, when facial expression and gait are incoherent like in Andromache's case, they deprive words of their reliability and, for an attentive observer, signal the need to further investigate (Tro. 618, 625). By juxtaposing different and unreconcilable gestures, Seneca thus subjects the recurring motif of fake feminine tears to a paradoxical treatment that is such that this traditional means of deceit loses its efficiency and even becomes a revealing sign of the deceit itself.

False tears are the gestural element that dominates Act III of Phaedra, which opens with Theseus' return from the Underworld. The tired and weary sovereign is greeted with cries coming from within the palace, and he immediately requests an explanation:

\section{[7] Seneca Phaedra 850-852}

quis fremitus aures flebilis pepulit meas? expromat aliquis. luctus et lacrimae et dolor, in limine ipso maesta lamentatio?

But what is this tearful outcry that strikes my ears? Let someone tell me. Grieving and tears and woe, and on my very threshold sad lamentation?

The nurse tells him that Phaedra is resolved to die, and he hastens to her to ask why she longs for death. Phaedra pretends that her honour had been attacked

15 In other cases, e.g. that of Hippolytus (Phaedr. 431-434), the speaker draws mistaken conclusions from his interlocutor's facial expression and gait. 
by Hippolytus. Phaedra's false words are preceded by an interesting series of gestures, including weeping, as we may extract from the interlocutor's line:

\section{[8] Seneca Phaedra $886-887$}

quidnam ora maesta auertis et lacrimas genis subito coortas ueste praetenta optegis?

Why dost thou turn away thy sorrowing face and hide with veiling robe the tears that suddenly o'erflow thy cheeks?

The rapidity with which tears appear may certainly be a sign of their falsity. However, Phaedra turns her afflicted face away and covers her tears with garments. They are gestures with a twofold communicative value: ${ }^{16}$ as well as enforcing the lie by means of a typically feminine malicious attitude, they may indicate the difficulty in which the protagonist finds herself upon perpetrating the deception in the presence of her husband. The act of turning her head away is significant in this context, for it may also be interpreted as a gestural manifestation of refusal of the communicative situation in progress. It appears, in this sense, at the end of a long series of gestural and verbal messages that have an analogous meaning: starting from Theseus' use of the verb abnuo a few lines earlier (883) in a comment on his wife's silence and continuing to the frequent resort to abstract sententiae, with which she withdraws from the relational appeal in her husband's words. ${ }^{17}$

As far as Theseus' appeals to the relationship between the interlocutors are concerned, by which he tries to convince his wife to speak (see 873 and 875 ), it is interesting to notice how they culminate with an explicit reference to the tears that he sheds and expects his wife to reciprocate:

\section{[9] Seneca Phaedra 880}

lacrimae nonne te nostrae mouent?

Do not my tears move thee?

16 Casamento (2011: 218).

17 For more on sententiae as a means to avoid recalling relations, see Calabrese (2009: 93). For more on the stylistic value of sententiae in Seneca, see Traina (1974), as well as Casamento (1999a, 1999b), with their specific reference to tragic works. 
The tears that Phaedra refuses to shed in response to her husband's will be shed immediately afterwards in order to deceive him.

Also in Phaedra, Seneca resorts to the topos of fake feminine tears, and again he makes a complex and uncommon use of it: the fact that tears are located within a rather complicated communicative and relational context and that they are associated with other gestures of an ambiguous value indicates the need for an interpretation that is not unequivocal, but rather blurred and problematic.

\subsection{A Structural Use of the Gesture of Crying}

In Phaedra, Seneca makes thoughtful use of tears in relation to Theseus: in fact, this gesture accompanies and signals the fundamental moments of the character's on-scene story from his first entrance on the scene to the end of the tragedy. Just after returning from the Underworld, as he approaches the palace, a grieving sound of wailing reaches him (see [7]). In the course of the same act, he himself will cry (see [9]) in the attempt to convince his wife to speak by means of gestures that are not only characterised by strong relational value but are also supposed to be reciprocated by his wife. The gesture of crying frames Theseus' on-scene story within a ring composition, leading to the final amplification of the initial image:

\section{[10] Seneca Phaedra 1275-1276}

patefacite acerbam caede funesta domum;

Mopsopia claris tota lamentis sonet.

Open wide my palace, gloomy and foul with slaughter, and let all Athens with loud laments resound.

Theseus' entrance on the scene was accompanied by a grieving sound of wailing reaching him from inside the palace; now, in an amplified mirror image, he orders the doors of the palace to be opened, so the grief of the royal house may spread and all of Attica may resound with its laments.

\subsection{Tears, Kisses, and Torn Locks: Andromache at the End of Act III of Troades}

Act III of Troades concludes with a use of gestures (including tears) that I found remarkably innovative: on the one hand, this use determines, like in the case we have just seen, the ring-like closure of the entire act; ${ }^{18}$ on the other hand,

18 On the concentric structure of act III of Troades see Boyle (1997: 76-77). 
it solves some essential dramatic knots. When she sends Astyanax to death, Andromache entrusts him with a gestural token to be given to his father, i.e. her kisses, tears, and torn locks of hair:

[11] Seneca Troades 799-801, 806-8o9

oscula et fletus, puer,

lacerosque crines excipe et plenus mei

occurre patri

$[\cdots]$

sume nunc iterum comas

et sume lacrimas

$[\ldots]$ sume quae reddas tuo

oscula parenti.

Now, son, take my kisses and tears, take my torn locks and, full of me, hasten to thy sire [...] Take now once again these locks, and take these tears $[\ldots]$ take kisses to deliver to thy sire.

Notice how the gestural elements of this ending are endowed with particular significance by means of the chiastic structure of the lists in which they appear (oscula, fletus, and crines at 799-801; comas, lacrimas, and oscula at 8o6-809). Such elements are furthermore tied to those present in the initial verses (see [2]) and enclose the act within a ring composition whose end represents the evolution and resolution of the first. While, at the beginning of the act, Andromache strikes a pose that starkly distinguishes her from the Trojan women with their gestures of grief (tearing their hair, beating their chests, weeping), at the end, these gestural aspects (with the addition of kisses) are precisely the ones that round off Andromache's suffering and mark its final stage. ${ }^{19}$ At the end of her complex interaction with Ulysses, Andromache not only manages to express her grief, but through her gestures, she is also able to rebuild her lost relationship with Hector. All of this paradoxically occurs through the son who is sent to die. Astyanax even becomes the means of an exchange of kisses between husband and wife: in fact, not only will he bring

19 In Calabrese (2017: 73-148), I reflect extensively on Andromache's story in Seneca, which I interpret as relational and, at the same time, one concerning identity. From my point of view, a social ritual of utmost importance in Roman culture such as that of the collective (feminine) mourning is used by Seneca in order to convey meanings about the character's identity. 
Hector Andromache's oscula, but he will also allow the latter to enter into contact with her husband's ashes by rummaging through the clothing that had touched his tomb with her face:

[12] Seneca Troades 809-812

matris hanc solacio

relinque uestem: tumulus hanc tetigit meus

manesque cari. si quid hic cineris latet,

scrutabor ore ...20

This cloak leave as comfort for thy mother: my tomb has touched it, and my beloved shades. If any of his dust is hidden here, I'll hunt it with my lips ...

She finally makes good for the embrace with Hector's shade which she desired but was unable to perform at the end of the tormented nocturnal vision (Tro. 46o) with a kiss that seems as inevitably virtual as powerfully concrete. In Troades, Andromache's gestures therefore undergo a remarkable evolution that may be especially noticeable and pronounced in connection with tears: while her initial rigid numbness prevented her not only from sharing in the other captives' grief but also from crying in response to her husband's tears, at the end of the act, she is capable of transforming her tears into a gestural instrument that is necessary to reunite herself with her spouse.

\section{The Pragmatics of uultus}

3.1 uultus attollere

Gait and uultus ${ }^{21}$ are the elements on which one's attention is focused the moment a character makes their entrance on the stage and encounters other

20 Stok (1999: 130) notices similarities between this passage and Eur. Andr. 416-417, which presents gestural elements such as kisses, tears, and embraces within a situation devoid of the paradoxical features that are created by Seneca.

21 For more on not only the lexical but especially the cultural meaning of the term uultus, see Bettini (2000: 322-336), who defines it first and foremost as 'l'espressione dell'interiorità' (emphasis in original). Being connected to interiority, uultus is an ever-changing expression, i.e. a set of attitudes. For more on locating uultus in the upper part of the face, see in particular pp. 327-329. Another fundamental theoretical distinction for the present study 
characters. This, for instance, is a pertinent feature of the brief description that Andromache makes of Ulysses when she sees the deceitful hero approach (see $[6]) .^{22}$

Gait and uultus also have great relevance in the nurse's description when Phaedra re-enters the scene after failing to convince Hippolytus to indulge himself in passion:

\section{[13] Seneca Phaedra 583}

sed Phaedra praeceps graditur, impatiens morae.

But Phaedra is hurrying towards us, impatient of delay.

\section{[14] Seneca Phaedra 587-588}

attolle uultus, dimoue uocis moras:

tuus en, alumna, temet Hippolytus tenet.

Lift thy face, break silence. See, my daughter, thine own Hippolytus embraces thee.

A particular function is entrusted to the term uultus in combination with the verb attollo at 587: the invitation to raise one's eyes is closely associated to the

is that between uultus, indicating facial gestures, and gestus, mainly used instead to indicate corporeal gestures (although this distinction is not always clear in concrete linguistic use); for more on this, see Ricottilli (2000: 17-18). For more on the meaning of the word incessus, see Köstermann (1933) and Horsfall (1971). Corbeill (2004: 118-120) describes the particular use that Cicero makes of the term incessus when describing his political opponents. The terms that define physical appearance have a relevant cultural function, i.e. that of fixing personal identity: see Bettini (2000: $319-322)$, who singles out the traits that are capable of determining the identity of a person, including gait (incessus or gressus) and facial expression (uultus).

22 The extreme complexity of Seneca's theatre and the unsolved matter of the real scenic destination of these tragedies do not, in my opinion, allow us to speak of real implicit stage directions. Nor may any general conclusions be drawn from the present study's brief observations on the matter about the way in which entrances and encounters are characterised by Seneca. However, one may notice a certain recurrence that should be the object of a more extensive study. For more on the matter of gait interpretation by characters at entrances and exits in particular, as a type of stage direction, see O'Sullivan (2011). On the presence of implicit stage directions in Seneca's works, see also n. 27 . 
request that a person disperse whatever creates an obstacle for words: ${ }^{23}$ it is, therefore, an invitation to enact the interaction with Hippolytus, one that is made iconic through gestures. The gesture of raising one's eyes (attollere uultus) therefore has an eminently communicative and interactive function: ${ }^{24}$ it signals the need to start a communicative exchange.

Finally, we must notice the use of the gesture of raising one's eyes (uultus attollere) at the opening of the scene in which Phaedra confesses her love. There she reveals the truth about herself in the most painful and difficult way since she does so directly to the object of her incestuous love. The gesture balances the line immediately preceding the false accusation against Hippolytus (ora auertere) ${ }^{25}$ In both cases, the movement of the head assumes a communicative function, though with opposite meanings: while the gesture of raising one's eyes reveals the necessity to prompt direct interaction with the interlocutor, that of turning one's head, on the contrary, is a sign of refusal of the ongoing communicative act as well as of any relation with the present interlocutor. It is, moreover, possible to notice how the act of raising one's eyes signals a form of communication that, complex as it may be, is honest, while turning them away corresponds to deceptive messages.

\section{2 uultus auertere, uultus referre}

Gestures connected to uultus may therefore be characterised by an eminently relational aspect. If at Phaedr. $5^{87}$ attollere uultus is the iconic signal of the beginning of an interaction, the gaze fulfils an opposite function elsewhere. We are referring to the final act of Oedipus, in which the title character enters the scene after having blinded himself and declares the profound relief that the darkness that envelops his head has finally brought him (Sen. Oed. 998-1003).

With blindness, Oedipus feels to have finally attained a uultus, a face, an outside appearance that is suited for him (1003 uultus Oedipodam hic decet) ${ }^{26}$ At this point, Jocasta enters: the chorus describes the woman's attitude and

23 For more on the meaning of dimoue, see De Meo (1995: 178); for that of uocis moras, see Coffey and Mayer (1990: 144).

24 The expression attollere uultus seems to essentially have communicative value, even in a passage that is in many respects similar to that just commented on in Phaedra: Ov. Met. 4.142-144 'Pyrame' clamauit, 'quis te mihi casus ademit? Pyrame, responde! tua te, carissime, Thisbe nominat: exaudi uultusque attolle iacentes'.

25 See [8].

26 For more on the expression uultus Oedipodam hic decet, see Boyle (2011: 343): 'a strong metatheatrical conclusion to Oedipus' opening speech in the final act [...] The metatheatrical effect would have been enhanced here if the actor playing Oedipus had pointed to his bloody mask'. 
appearance ${ }^{27}$ and implicitly indicates the nature of the ongoing tragedy before her line makes it clear. Jocasta desires and fears, at the same time, to speak to the man who is already on the stage and then finally decides to do so, but her words remain stuck in her mouth (see Oed. 1004-1009).

As I have attempted to explain elsewhere, the last scene of Oedipus represents a powerful attempt on Seneca's part to tackle problems related to the impossibility to name that which cannot be named. ${ }^{28}$ For Jocasta, the main problem in initiating interaction with the man who has revealed himself to be her husband and son at the same time is disturbing in its simplicity: what should she call him (Oed.1009-1011)? In a scene centred on words, a significant gesture takes place at this point. The initial communicative blockade is overcome by Jocasta in virtue of her will to reactivate a dialogue (1011), and therefore a relationship, with Oedipus. He responds to the relational appeal contained in his mother's words by turning his head to the other side:

\section{[15] Seneca Oedipus 1011-1012}

quo auertis caput

uacuosque uultus?

Why dost thou turn away thy head, thy sightless face?

This type of gesture reveals his desire not to communicate and therefore transmits, on a relational level, a message that opposes the verbal one conveyed by his mother. ${ }^{29}$ Oedipus' gesture follows Jocasta's agitated questions and immediately precedes his utterance. The analysis of these words enforces the relational interpretation of the gesture that precedes them but also provides further important elements in order to deepen the analysis of the interaction:

27 In relation to the way in which the Chorus announces Jocasta's entrance on the scene, Boyle (2011:344) observes that their description contains implicit stage directions. According to Boyle, such instructions were erroneously interpreted as a supporting element of the thesis that Seneca's tragedies are 'Rezitationsdramen', and that Seneca could have been influenced by the pantomime genre, in which a narrative description (which is often performed by a Chorus) accompanies a dancer's gestures and movements.

28 See Calabrese (2008).

29 A similar gesture to Oedipus' is executed by Dido in Verg. Aen. 6.469 illa solo fixos oculos auersa tenebat, where the participle auersa represents the gesture of turning to the other side as having already been performed and also presents the element of the fixed gaze. With this series of gestures, Dido manifests her refusal to communicate with Aeneas, with whom there will, in fact, be no exchange (see Ricottilli 1992: 215). 
[16] Seneca Oedipus 1012-1014

quis frui tenebris uetat?

quis reddit oculos? matris, en matris sonus!

perdidimus operam ...

Who wills not that I enjoy my darkness? Who restores my eyes? My mother's, lo, my mother's voice! I have worked in vain ...

The compresence of these two types of communication, i.e. gestural and verbal, makes this part of the interaction particularly interesting. The gesture of turning one's head to the other side, as previously mentioned, indicates that the character does not wish to speak with his interlocutor. However, Oedipus' words contain more information than the gesture, whose relational function they indicate, along with its uselessness. As we have seen, the character enters the scene with a feeling of realisation, and more precisely that of now having a face that is suited to Oedipus: the black cloud that envelops his head finally makes him feel at peace with the gods. The darkness that he wants to be surrounded by is pierced and somewhat dissolved by his mother's voice, which attains the paradoxical effect of restoring his sight. This powerful synaesthesia contains the core of the tragedy of Seneca's Oedipus: his empty eye sockets, when diverted from his interlocutor as a gestural signal of desperate refusal (see [15]) are somewhat filled by the voice of his mother, who in fact gives him back his eyes (see [16]). His mother's voice has the power to bring Oedipus back into a relationship with her ${ }^{30}$ (one that has already been irreversibly contaminated by incest), thus thwarting the effects of his self-blinding, an act which, also in light of the part of the interaction that has just been analysed, may be interpreted as being finalised towards the interruption of every sort of relation and contact with the outside world. ${ }^{31}$

uultus is, therefore, a vehicle of relations. This very aspect of uultus, namely the relational aspect, comes to the fore in a scene that has similar features to the

30 The fact that the voice is a vehicle of relations also seems to be proven by passages such as Sen. Tro. 962-963 hac sola uocor iam uoce mater (see Calabrese 2017: 33), Phoen. 224-225 ego ullos aure concipio sonos, per quos parentis nomen aut nati audiam?

31 In recent years, Fornés and Puig have dealt with eye gestures in Latin literature. Fornés and Puig (2010) (which owes much to Ricottilli 2000) in particular is dedicated to the gestures that implicate movements of the iris, like diverting one's eyes and rolling them repeatedly. Fornés and Puig (2011) recalls other aspects of eye gestures. 
one from Oedipus analysed above. In Phoenissae, Jocasta, upon arriving on the battlefield, has a long discussion with her rival sons Eteocles and Polynices by first addressing both and then each one alternately. The first addressee of her words is the exiled Polynices: ${ }^{32}$

\section{[17] Seneca Phoenissae 471-474}

$$
\text { uinculo frontem exue }
$$

tegumenque capitis triste belligeri leua

et ora matri redde-quo uultus refers

acieque pauida fratris obseruas manum?

Unbind thy brow, take the grim helmet from thy warlike head, and let thy mother see thy face. Why dost thou look away, and with fearful glance watch thy brother's hand?

The invitations to disarm culminate in that of turning the son's face back towards his mother (ora matriredde). The process, however, is interrupted midway and Polynices, instead of facing Jocasta, turns away from her and looks fearfully towards his brother's armed hand. In this context, uultus referre means turning one's gaze to observe something other than the direct interlocutor, thus depriving the latter of the gaze and fixing it on other and different sources of interest (and concern). ${ }^{33}$ This type of uultus gesture is made all the more significant by the fact that (based on the configuration of the interaction that we can retrace through Jocasta's words) it seems to be how Polynices responds to the invitation to turn his face towards his mother-obviously a negative reponse, i.e. one of refusal. As the subsequent lines, which are centred on the matter of fides (Phoen. 475-480), demonstrate, the relationship itself is at stake in the midst of this movement of glances. It is a relationship that Jocasta tries to visually restore by means of Polynices' gradual disarmament but one that he, on the contrary, by means of gestures rather than words, shows to be incapable of re-establishing.

32 For more on Jocasta's complex change of interlocutors in the first sequence of the scene where she interacts with her sons, see Mazzoli (2002).

33 In the expression uultus referre, refero seems to be a synonym of conuerto. According to Frank (1995: 205), refero is used by Seneca here instead of auerto. Nevertheless, the use of refero in place of auerto seems to be suitable for the context since Polynices not only looks away but even focuses on another interlocutor, i.e. his brother Eteocles. 
The pragmatic analysis of gestures in Seneca's tragedies led to some new observations. In the case of Andromache, the focus on gestures allowed us to notice the evolution that they undergo in the course of Act II I of Troades. The gestural evolution, as I maintain in a more in-depth study, ${ }^{34}$ is the visual, iconic sign of the profound dynamics that the character undergoes on a level of identity and relationship. The study of gestures also allowed us to show the particular (alienated and paradoxical) use that Seneca makes of a traditional and recurrent motif. Moreover, gestures appeared to have a structural function. With specific regard to the gestures connected to uultus, their eminently interactive and relational aspect led to a better comprehension of the dynamics which take place in the passages analysed. Through these pragmatic considerations, Seneca's theatre should begin to appear not only as a theatre of words but also as a theatre of gestures.

\section{References}

Aldrete, G.S., (1999), Gestures and Acclamations in Ancient Rome, Baltimore/London. Aldrete, G.S., (2017), 'Gesture in the Ancient Mediterranean World', in F.S. Naiden \& R.J.A. Talbert (eds.), Mercury's Wings. Exploring Modes of Communication in the Ancient World, Oxford, 149-163.

Aricò, G., (1996), 'Lacrimas lacrimis miscere iuvat. Il Chorus Iliadum nell'Agamemnon di Seneca', in L. Castagna (ed.), Nove studi sui cori tragici di Seneca, Milan, 131-145.

Beard, M., (2014), Laughter in Ancient Rome: on Joking, Tickling, and Cracking Up, Berkeley/Los Angeles/London.

Bettini, M., (2000), Le orecchie di Hermes. Studi di antropologia e letterature classiche, Torino.

Boyle, A.J., (1997), Tragic Seneca: an Essay in the Theatrical Tradition, London.

Boyle, A.J., (2011), Seneca, Oedipus, Oxford.

Bremmer J., \& Roodenburg H.(eds.), (1991), A Cultural History of Gesture. From Antiquity to the Present Day, Cambridge.

Cairns, D. (ed.), (2005), Body Language in the Greek and Roman Worlds, Swansea.

Calabrese, E., (2008), 'Aspetti dell'interazione nell'ultima scena dell'Edipo di Seneca (vv. 998-1061)', in G. Sandrini (ed.), Studi in onore di Gilberto Lonardi, Verona, 2338 .

34 See n. 19. 
Calabrese, E., (2009), Il sistema della comunicazione nella Fedra di Seneca, Palermo.

Calabrese, E., (2017), Aspetti dellidentità relazionale nelle tragedie di Seneca, Bologna.

Calabrese, E., (2018), 'Quartilla, ovvero la comunicazione in scena', in L. Ricottilli (ed.), Modalità della comunicazione in Roma antica, Bologna, 71-96.

Calabrese, E., (2019), Prospettive relazionali della gestualità nel Satyricon, Bologna.

Casamento, A., (1999a), 'Lumina orationis. L'uso delle sententiae nelle tragedie di Seneca', Studi Italiani di Filologia Classica 92, 123-132.

Casamento, A., (1999b), 'Delitto chiama delitto: una sentenza ed un poliptoto nodo drammatico delle tragedie senecane', in G. Petrone (ed.), Scritti a margine di letteratura e teatro antichi. Lo sperimentalismo di Seneca, Palermo, 77-94.

Casamento, A., (2011), Seneca, Fedra, Rome.

Caviglia, F., (1981), Lucio Anneo Seneca, Le Troiane, Rome.

Clark, C.A., Foster, E., \& Hallett, J.P. (eds.), (2015), Kinesis. The Ancient Depiction of Gesture, Motion and Emotion. Essays for Donald Lateiner, Ann Arbor.

Coffey, M. \& Mayer, R., (199o), Seneca, Phaedra, Cambridge.

Corbeill, A., (2004), Nature Embodied: Gesture in Ancient Rome, Princeton.

De Meo, C., (1995), Lucio Anneo Seneca, Phaedra, Bologna.

Fantham, E., (1982), Seneca's Troades, Princeton.

Fögen, Th., (2004), 'Gender-specific Communication in Graeco-Roman Antiquity. With a Research Bibliography', Historiographia Linguistica 31, 199-276.

Fögen, Th., (2009), Tears in the Graeco-Roman World, Berlin.

Fornés, M.A. \& Puig, M., (2010), 'Apartar y girar los ojos en los textos latinos', Myrtia 25, 77-97.

Fornés, M.A. \& Puig, M., (2011), 'Mirar de reojo y fijar la mirada en los textos latinos', Cuadernos de Filología Clásica. Estudios Latinos 31, 213-234.

Frank, M., (1995), Seneca's Phoenissae, Leiden/New York/Cologne.

Graf, F., (1991), 'Gestures and Conventions: the Gestures of Roman Actors and Orators', in J. Bremmer \& H. Roodenburg (eds.), A Cultural History of Gesture. From Antiquity to the Present Day, Cambridge, $36-58$.

Hagen, J., (2016), 'Emotions in Roman Historiography: the Rhetorical Use of Tears as a Means of Persuasion', in E. Sanders \& M. Johncock (eds.), Emotion and Persuasion in Classical Antiquity, Stuttgart, 199-212.

Horsfall, N., (1971), 'Incedere and incessus', Glotta 49, 145-147.

Köstermann, E., (1933), 'Incedere und incessere', Glotta 21, 56-62.

Lateiner, D., (1995), Sardonic Smile: Nonverbal Behavior in Homeric Epic, Ann Arbor.

Mazzoli, G., (2002), 'Giocasta in prima linea', in A. Aloni \& E. Berardi (eds.), I Sette a Tebe. Dalmito alla letteratura. Atti del Seminario Internazionale (Torino 21-22 febbraio 2001), Bologna, 155-168.

Miller, F.J., (1917), Seneca, vol. 8: Tragedies I, Cambridge, Mass./London.

Naiden, F.S., (2006), Ancient Supplication, Oxford. 
O'Sullivan, T.M., (2011), Walking in Roman Culture, Cambridge.

Rey, S., (2017), Les larmes de Rome. Le pouvoir de pleurer dans l'Antiquité, Paris.

Ricottilli, L., (1992), 'Tum breviter Dido voltum demissa profatur (Aen. 1, 561): individuazione di un "cogitantis gestus" e delle sue funzioni e modalità di rappresentazione nell'Eneide', Materiali e discussioni per l'analisi dei testi classici 28, 179-227.

Ricottilli, L., (2000), Gesto e parola nell'Eneide, Bologna.

Ricottilli, L., (2016) 'L'emozione nel gesto: le lacrime in Terenzio', Dionysus ex Machina 7, 70-96.

Sittl, G., (189o), Die Gebärden der Griechen und Römer, Leipzig.

Šterbenc Erker, D., (2009), 'Women's Tears in Ancient Roman Ritual', in Th. Fögen (ed.), Tears in the Graeco-Roman World, Berlin, 135-16o.

Stok, F., (1999), Seneca, Le Troiane, Milan.

Tarrant, R.J., (1976), Seneca, Agamemnon, Cambridge.

Traina, A., (1974), Lo stile "drammatico" del filosofo Seneca, Bologna.

Traina, A., (1997), Virgilio. L'utopia e la storia. Il libro XII dell'Eneide e antologia delle opere, Turin.

Zwierlein, O., ( ${ }^{2} 1987$ [1986]), L. Annaei Senecae tragoediae, Oxford. 


\title{
Pragmatics of fraus: Encoding and Decoding of Deceit in Seneca's Troades and Thyestes
}

\author{
Lavinia Scolari
}

$\mathbf{1}$

Introduction

The Latin language has a broad range of words covering the semantic area of 'deception' and 'trick'. 'Among them, fraus occupies a central position in the dramaturgical contexts as a recurring pattern of tragic plots. ${ }^{2}$ Scholars have pointed out that it expresses the general notion of deceit but also the concept of 'harm through deception'. In fact, the basic meaning of fraus is 'injury' or 'damage' (malum, quod quis facit uel patitur, damnum, iniuria), as the connection to

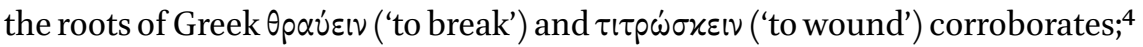
therefore, fraus is a 'detriment' that implies a certain measure of 'fraudulent responsibility'. In other words, it denotes a 'deceit' or a 'stratagem', 5 in which the notio nocendi ('the notion of doing harm') prevails and it comprises conducts involving guilt which are therefore liable to punishment: accedit quod iniuria fallendo fit ('it occurs that one commits an outrage by deceiving'). ${ }^{6}$

Frequently, fraus is combined with dolus, especially in non-legal texts, where they are, to some extent, interchangeable (one need only think that fraus corresponds to dolus malus in ThLL's definition). ${ }^{7}$ Nevertheless, they represent independent concepts: the former conveys the notion of 'damage' or 'harm' (like in the expression sine fraude), confirming its strictly negative (moral) sense; by contrast, the latter, which communicates the idea of 'malicious intent' (like in the expression dolo malo, 'evil device' or 'artifice', hence 'fraud', 'deceit'), ${ }^{8}$ may also have a positive connotation, even if the negative sense is predominant. According to Isidorus (Etym. 5.26.7), dolus is said to be

1 Abbot (1997:42 n.1) gives a list of the most common words associated with trickery and deceit. See also Brotherton (1926); Carcaterra (1970: 32); Wheeler (1988: 50-92).

2 See Michelon (2015: 17-71).

3 Brotherton (1926: 9); Ernout and Meillet ( ${ }^{4} 1985$ : s.v. fraus).

4 Rubenbauer (1926: c. 1267); Wheeler (1988: 63), who refers to Krüger and Kaser (1943).

5 Wheeler (1988: 50-52, 63-65).

6 Rubenbauer (1926: c. 1267, 1269). See also OLD, s.v. fraus, 1-4, p. 732.

7 Rubenbauer (1926: c. 1267). On dolus in juridical context, see Ter Beek (1999).

8 Wheeler (1988: 58). On the difference between dolus bonus and dolus malus, see Carcaterra (1970).

(C) LAVINIA SCOLARI, $2021 \mid$ DOI:10.1163/9789004440265_020 
from deludere (ab eo quod deludat), i.e. 'to play false', 'to mock', 'to deceive', and it consists in 'a cunning of the mind' (est mentis calliditas), or-as we should say-in its effects. ${ }^{9}$ Therefore, we can argue that the agent of dolus is able 'to play false' or 'deceive' in so far as he 'does one thing and fakes another' (aliud enim agit et aliud simulat) as stated by Isidorus (ibid.). ${ }^{10}$ Hence, as is stressed by Cicero (Off. 3.64) as well, dolus - especially dolus malus -intertwines itself with the concepts of simulatio and dissimulatio, which fall within a similar semantic field. In fact, simulatio is 'a falsely assumed appearance' or 'insincerity, deceit':11 a kind of pretence regarding physical or mental states, although the first meaning of this word more generally refers to an act of copying or imitation..$^{12}$ While the semantic bonds between dolus and simulatio/simulare as well as between fraus and dolus are mostly explicit, the link between fraus and simulatio is not. But in the tragic context of fraudulent imitation (of an attitude, a feeling, etc.), their bond becomes more evident, as it is the case in Seneca's tragedies, on which we will focus in this survey.

More specifically, we will explore the most relevant strategies of encoding and decoding of deceits in Seneca's Troades and Thyestes (which both show significant correlations, as we will try to illustrate further below) from a pragmatic, dramaturgical, and anthropological point of view, in the belief that such an interdisciplinary approach may provide a more comprehensive and detailed framework of the practice and the meaning of deception in Seneca's theatre and, more generally, in Roman culture. In this regard, we will follow the research methodology developed by Licinia Ricottilli and her school, who have successfully applied pragmatics to Classical Studies, combining them with the anthropological survey tools. ${ }^{13}$ Using this approach, we shall take the traditionally assumed — not incorrect, but only partly adequate - meaning of the term fraus (discussed below) as a starting-point; ultimately, we shall attempt to provide a more accurate definition of fraus, that takes Roman cultural categories into account that are involved in the communication dynamics portrayed by Seneca.

$9 \quad$ For this translation, we follow Barney et al. ( $\left.{ }^{4} 2008\right)$.

10 See Hey (1910: c. 1857) and OLD, s.v. dolus. See also Ulp. Dig. 2.14.7.9 dolus malus fit calliditate et fallacia.

11 Lewis and Short (1879: s.v. simulatio).

12 OLD, s.v. simulatio 1-2. See also OLD, s.v. simulo.

13 See Ricottilli (2000, 2009, 2011, 2018b: 7-19), who relies on Austin $\left({ }^{2} 1975\right)$; Watzlawick et al. (1967); Searle (1969); Bateson (1972). For a combination of anthropological and pragmatic approaches, see also Bettini and Ricottilli (1987); Duranti (1997); Beta (2004); Raccanelli (1998, 2010, 2011). On Seneca's tragedies (specifically on Phaedra), see Calabrese (2007, 2009, 2011). 


\section{$2 \quad$ Pragmatics of fraus in Troades}

\subsection{First Phase: The Concealment}

Seneca's Troades provides us with a very relevant case of (unsuccessful) deceit performed by Andromache. The plot of the play, mainly based on Euripides' Trojan Women and Hecuba, is well known: Troy has already fallen and the Trojan women are waiting to be assigned to the Achaean leaders. But, according to the herald Talthybius, the ghost of Achilles has returned from the Underworld to demand that the Trojan princess Polyxena be sacrificed at his tomb. The prophet Calchas, once consulted by Agamemnon, adds that Hector's son, Astyanax, must be slain too. Only then will the Greeks be able to return home. But meanwhile, the ghost of Hector appears in Andromache's dream and warns her of the danger. So, she orchestrates a fraud consisting in hiding her son in Hector's grave and pretending that he is dead in order to deceive Ulysses, who has been sent to hand over the child to the Achaeans.

Euripides' tragedy on the same subject lacks the entire scene of fraus as well as the agon between Andromache and Ulysses, which we shall discuss below. Actually, in Greek Trojan Women, Talthybius informs Hector's widow of the Achaeans' decision when Ulysses has already ordered to lead her son away (709-779). Hence, we can argue that Seneca's representation of this fraus conveys some aspects of the deceit dynamic closely interrelated with the Roman cultural categories of that time, which makes it particularly significant for our survey.

In Seneca's Troades, when Andromache first comes onto the stage, the only reason for keeping the Greeks from leaving is Astyanax, because of the danger he poses, since he is Troici defensor et uindex soli, 'Troy's defender and avenger' (471): being not only a future enemy to the Achaeans but also the potential uindex of his land, magni certa progenies patris, 'the true child of his great father' (461), and hence una spes Phrygibus, 'sole hope of the Phrygians' (462).

Therefore, Andromache needs to find a place where she can hide him:

\section{[1] Seneca Troades 476-477}

heu me, quis locus fidus meo

erit timori quaue te sede occulam?

O what place will not betray my fear, in what shelter shall I hide you? ${ }^{14}$

14 For the text and the translation of Seneca's Troades, we follow Boyle (1994), except where otherwise noted. 


\section{[2] Seneca Troades 481-482}

superestque uasta ex urbe ne tantum quidem, quo lateat infans. quem locum fraudi legam?

From that wasted city enough survives not even to hide a child. What place can I choose for my fraud? ${ }^{15}$

As the above-mentioned passages clearly show, the first phase of Andromache's deceit consists in the practice of concealment, strongly recommended by Hector's ghost (452-453): see occulam (477) and lateat (482). ${ }^{16}$ For it to succeed, Seneca stresses the importance of fides for the fraudatrix, i.e. her necessity to rely on someone or something in order to ensure that the fraus is successful. In fact, Andromache is looking for a locus fraudis (482), which is fidus as well (476), and ultimately, she will choose the cinus of her dead husband, literally his 'ashes', metonymically his 'tomb', inasmuch as it can be considered fidelis ( $5 \mathrm{O2}$ ), a 'safe' place, not exposed to danger or risk and, what is more, 'trustworthy' as Hector was. ${ }^{17}$

In this regard, if Andromache names her deceit fraus (loci) at 482, the old servant defines it as dolus at 492 (amoue testes doli, 'remove the witnesses to the deceit'). But at this stage, both of them refer only to the concealment of Astyanax in his father's tomb. However, Andromache's deception does not result merely in concealing.

In the development of the deceit, the old servant plays a significant role by pointing out the major element of the fraus:

\section{[3] Seneca Troades 489-49o}

haec causa multos una ab interitu arcuit: credi perisse.

One cause has saved many from destruction: the belief that they have perished. ${ }^{18}$

15 For the translation of this passage, we follow Boyle (1994), except for the translation of quem locum fraudi legam? (Boyle 'Where can I choose?').

16 Fabre-Serris (2015: 109).

17 Note that Hector's ghost himself calls Andromache fida coniunx, 'trustworthy wife' (453).

18 The translation of this passage is taken from Miller (1917). 
So the only chance of Astyanax to survive is to be supposed dead. This statement reveals that the main purpose of fraus is to affect and redirect the interpretative act of the receiver (i.e. his fides), to lead him to believe in the alternative reality the fraudator has shaped. In fact, the Latin credere ('to believe') is frequently considered to be the corresponding verb to fides, or at least as a word linked to its semantic field, given that fides is the actio uel facultas credendi siue confidendi ('the action or the property of believing and trusting').${ }^{19}$ Hence, the tragic representation of the first phase of Andromache's fraud leads us to reconsider the traditional meanings of fraus and dolus that we have provided above, by supplementing them with the notion of fides. More suitably, we can claim that fides is strictly involved in the dramaturgical frames of deceit, inasmuch as it acts on the victims' property or capacity of believing and trusting. In this view, deceits can be intended as damaging and cunning practices of simulation consisting of re-addressing, obtaining, or manipulating fides.

From the beginning, however, Andromache is presented as a fraudatrix doomed to fail because of her inability to hide her true state of mind. Even the servant (senex) does not seem to trust his mistress. That becomes evident when he suggests she move away: for otherwise, she might reveal the location of Astyanax's hideout by means of her non-verbal language and compromise the deceit by clearly showing her timor:

\section{[4] Seneca Troades $513-518$}

Sen. quem ne tuus producat in medium timor, procul hinc recede teque diuersam amoue.

An. leuius solet timere, qui propius timet; sed, si placet, referamus hinc alio pedem.

Sen. cohibe parumper ora questusque opprime: gressus nefandos dux Cephallanum admouet.

Old Man To stop your own fear from exposing him, step back from here and hold yourself apart.

An. Proximity of danger reduces fear. But, if you advise it, let us withdraw.

19 On this definition of fides, see Fraenkel (1926: c. 663, c. 686-687). On the meaning of fides as 'confidence', i.e. the fact of trusting someone or something, see also Scolari (2016: 112-114, 2018b: 91-96); Fraenkel (1916: 187-188); Hellegouarc'h ( ${ }^{2}$ 1972: 33); Benveniste (1969: I 115-121); Freyburger (1986: esp. 37-39, 319-320). 
Old Man Silence for a moment; stop your laments. Cephallenia's cursed chief approaches.

The senex begs Andromache to 'manage the impact' of her use of space (see 514), to be quiet (cohibe parumper ora), and to muffle her cries (517 questusque opprime), i.e. to reset or, at least, to control her verbal and non-verbal communication. In other words, he is concerned that Ulysses may decode Andromache's kinesic and paralinguistic signals (her lament, her weeping, etc. ${ }^{20}$ as well as her proxemic behaviour (her use and perception of space) because-as Andromache herself states, attempting a sort of kinesic exam on him (see [5])—Ulysses is a man who is accustomed to weaving cunning wiles:

\section{[5] Seneca Troades $5^{22-523}$}

An. adest Vlixes, et quidem dubio gradu uultuque: nectit pectore astus callidos.

An. Ulysses is here-with hesitant step and expression. His mind weaves some cunning trick.

Seneca here uses two other words of the semantic area of fraus: astus 'the craft', which implies the idea of 'sharpness', ${ }^{21}$ and callidus. As far as the latter is concerned, according to Cicero (Nat. D. 3.25), callidos ('hardy') are 'those whose minds have become shrewd with use as the hand is hardened and has become callous by work' (quorum, tamquam manus opera, sic animus usu concalluit). ${ }^{22}$ calliditas, astus, and the 'weaving' motive (nectere) thus co-operate to define the portrait of a consummate, gifted deceiver, who is not easily fooled. ${ }^{23}$

20 The kinesic system is one of the semiotic systems of non-verbal communication and it entails the interpretation of the body's movements such as facial expressions and gestures, including tears, as demonstrated by Ricottilli (2018a: esp. 145-147), who also highlights the relational connotation of the tears in Latin theatre, specifically in Terentius. See also Capponi in this volume.

21 Lewis and Short (1879: s.v. astus).

22 The translation is mine. On callidus, which it is said from callum ('callus'), see Ernout and Meillet ( ${ }^{4} 1985$ : s.v. callum).

23 See Michelon (2015: 24-27), who highlights in n. 23 that astus and the verb calleo ('to be callous') are already related to Ulysses by Accius, if Neopt. $184 \mathrm{D}$ (satin astu et fallendo callet?) refers to him, which seems very likely. 


\subsection{Scrutare matrem: Encoding and Decoding fraus}

If - in Attic tragedy - Ulysses is the one who convinces the Greeks that Astyanax must be killed (Eur. Tro. 721), in Seneca's drama, his step is hesitating (522 dubio gradu) and he introduces himself as a mere 'minister of harsh fate' (524 durae minister sortis). In fact, when the king of the Cephallenians comes onto the stage, he performs a very sophisticated suasoria, through which he tries

1) to remove all sense of responsibility from himself: ore quamuis uerba dicantur meo, non esse credas nostra: Graiorum omnium procerumque uox est, 'though these words are spoken by my mouth, you do not believe them mine. It is the voice of all the Greeks and chiefs' (525-527); hanc fata expetunt, 'him fate demands' (528); augur haec Calchas canit, 'so teaches Augur Calchas' (533).

2) to bridge the relational gap between Andromache and himself. Therefore, he does not hesitate to call her by name ( 531 Andromacha) and to use the possessive adjective to refer to Astyanax (natus [...] uester, 532-533) in order to pursue the goal of bringing her closer.

3) to induce a feeling of empathy by showing the convergence between the Phrygians' doom and what the Greeks have already suffered: neue crudelem putes, quod sorte iussus Hectoris natum petam: petissem Oresten. patere quod uictor tulit, 'don't think me cruel for seeking Hector's son commanded by the lot. I'd have sought Orestes. Accept what the victor bore' (553-555).

Therefore, from Ulysses' first speech, the conjunction emerges between emotive and conative function (the latter in a less emphatic form). The emotive function relates to the speaker and it focuses on his internal, emotive state or condition, while the conative function entails a communication or a linguistic act aiming at persuading the addressee, acquiring his adhesion to the message provided or influencing his behaviour. In the considered texts, the emotive function is used in order to activate the conative one, which is marked by the use of the imperative forms (e.g. non credas, ne putes), the vocative case Andromacha, and the possessive adjective uester. ${ }^{24}$ In other words, in order to persuade Andromache to hand over her son, Ulysses tries to connect the illocutionary act (which has a certain 'force' in saying something) with the perlocutionary act (which consists in the achieving of certain effects by saying something). ${ }^{25}$ But her reaction is not what he had hoped for.

24 On the functions of language, see Jakobson ( ${ }^{3} 1981$ : esp. 191 = 1960: 357 ).

25 On the theory of linguistic acts, and notably on the definitions of the illocutionary and perlocutionary act, see Austin ( ${ }^{2} 1975$ : esp. 126). 
[6] Seneca Troades $55^{6-558,} 5^{62-566}$

An. utinam quidem esses, nate, materna in manu, nossemque quis te casus ereptum mihi teneret $[\ldots]$ nate, quis te nunc locus, fortuna quae possedit? errore auio uagus arua lustras? uastus an patriae uapor corripuit artus? saeuus an uictor tuo lusit cruore?

An. O that you were in your mother's arms, my son, or that I knew what chance stole and keeps you from me [...]. My son, what place now, what fortune holds you? Do you wander the fields lost? Or has our country's vast conflagration consumed you? Did the savage victor sport with your blood?

Hector's widow responds with a sort of 'closing attitude', conveyed in pragmatic terms by the anaphora of the personal pronoun of the second person $(t u)$ and the possessive $t u o$, which always refers to Astyanax and never, in this passage, to Ulysses, her interlocutor. The use of this marker reveals that she is not inclined to activate a positive mutual communication with him. After the death of Hector, the only relationship she cares about is with her son, as the use of the personal pronoun mihi in the clause quis te ereptum mihiteneret stresses, combined with the vocative nate, very close to materna at 556 , both placed twice in emphatic positions. In this way, Seneca marks the emotive function of Andromache's locutionary act. However, Ulysses does not fall for her trickery:

[7] Seneca Troades $568-571$

simulata remoue uerba; non facile est tibi

decipere Vlixem: uicimus matrum dolos

etiam dearum. cassa consilia amoue;

ubi natus est?

Drop this pretence. You won't find it easy to fool Ulysses. I've beaten mothers' tricks, goddesses' too. Forget your futile ploy. Where's your son? 
Simulata remoue uerba, 'stop it with these false speeches'. Here, Ulysses has openly switched to the conative function of language because of the failure of the emotive one. ${ }^{26}$ In other terms, his locutionary act by which he tries to convince Andromache to hand over Astyanax has not achieved its perlocutionary intent since it has no effects. Nevertheless, Ulysses highlights a flaw in Andromache's deceptive system: the fact that she encodes her fraus - or rather her simulatio, i.e. her 'falsely assumed appearance' as we have said above ${ }^{27}-$ only on a verbal level, merely by means of a locutionary act (simulata uerba). He reminds her whom she is dealing with, namely the master of tricks and manipulation, and thereby evokes the literary memory of this character: that of the hero who has already unmasked a mother's fraud, not just anyone's but a goddess.' ${ }^{28}$ Here, Ulysses is referring to the doli of Thetis, who dressed and disguised her son Achilles as a girl, determined to keep him out of the war that would have caused his death. ${ }^{29}$ Thus, Ulysses' statement allows a key component of the fraud to emerge: the importance of becoming aware of the identity role of the interlocutor, if one wishes to perform a successful fraus.

Andromache, however, does not seem to care about the identity role of Ulysses or about his story. Even if she knows his reputation, she seeks to deceive him by using a strategy similar to his:

\section{[8] Seneca Troades 594-597}

inuita, Vlixe, gaudium Danais dabo.

dandum est. fatere quos premis luctus, dolor.

gaudete, Atridae, tuque laetifica, ut soles,

refer Pelasgis: Hectoris proles obit.

I hate, Ulysses, to give the Danai joy. Yet I must. Confess the sorrow you hide, grief. Gloat, sons of Atreus. You, take the Pelasgi, as usual, joyous news: Hector's child is dead.

Firstly, Andromache does not avoid naming him (see the vocative Vlixe in 594) to close the gap between them; secondly, she attempts to provide an alternate

\footnotetext{
26 See above n. 24.

27 See Section 1.

28 On the traditional representation of Ulysses as master of deceits underlined by Seneca in [7], see Michelon (2015: 27-28).

29 See Sen. Tro. 213 and Boyle (1994: ad loc.).
} 
reality, which can meet the Greek's expectations, as can be seen from the use of the semantic field of delight and joy: gaudium, gaudete, laetifica, etc. (in opposition to the field of dolor). Once again, Ulysses demands a concrete guarantee, which is able to ensure that what Andromache said is true:

\section{[9] Seneca Troades 598}

et esse uerum hoc qua probas Danais fide?

What proof do you give Danaans that this is true?

The question asked by Ulysses in this line brings the paretymology of fraus into play that is provided by Cicero (Off.1.23), according to whom fides comes from fiat and dico, because it implies that what you do matches what you said you would do, namely that there is no discrepancy between words and deeds: quia fiat, quod dictum est appellatam fidem, 'fides ('trust') is called this because one does what he has said'.30

But Andromache has no such proof, so instead of a tangible guarantee, she swears, to some extent, an assertory oath (599-604) to prove that Astyanax lies with dead men', inter extinctos iacet (603). And we know that assertory oaths in the ancient world were serious business since an oath was considered a selfcurse, inasmuch as oath-takers placed themselves directly under the threat of divine punishment, which everyone believed would surely be imposed on the perjurer. ${ }^{31}$ Ulysses stresses that the oath represents a guarantee of mutual fides ( fidem alligauit iure iurando suam, si peierat, timere quid grauius potest?, 'she had pledged her faith by swearing an oath. If she swears falsely, what worse can she fear?', 611-612). He is convinced that the Greeks will trust him, but the point is whom Ulysses trusts.

\section{[10] Seneca Troades 6o7-6o9}

Vl. quid agis, Vlixe? Danaidae credent tibi: tu cui? parenti? fingit an quisquam hoc parens, nec abominandae mortis auspicium pauet?

30 On this passage, see Dyck (1996: ad loc.). See also Cic. Rep. 4.7 (fr. 2.5-6) fides enim nomen ipsum mihi uidetur habere, cum fit, quod dicitur, 'for it seems to me that fides is called this because one does what he says'.

31 See Lecointre (1991: 9-10); Pageard (1991: 35); and Benveniste (1969: II 163-164). 
Ul. (Aside) What's this, Ulysses? The Danai will trust you. But you trust - a mother? Would any mother lie and not fear omens of frightful death?

Unlike Andromache, Ulysses asks himself about the prominent identity role of his interlocutor in the very context and in the very moment of their dynamic of communication: above all, she is a mother, as the polyptoton parenti / parens points out (6o8). This is her predominant role. The persona of Ulysses derives this information from Andromache, who implicitly introduces herself as a mater animosa, 'a dauntless mother', who 'admits no fears': animosa nullos mater admittit metus (588). Therefore, the only type of fides she can express is materna fides: maternam fidem umquam exuissem, 'I would never put off a mother's loyalty' (561-562).

\section{[11] Seneca Troades 613-618}

nunc aduoca astus, anime, nunc fraudes, dolos, nunc totum Vlixem; ueritas numquam perit. scrutare matrem: maeret, illacrimat, gemit; sed huc et illuc anxios gressus refert missasque uoces aure sollicita excipit: magis haec timet, quam maeret. ingenio est opus.

Now summon your guile, my soul, now tricks, deceits, now all Ulysses; truth is never lost. Examine the mother. She mourns, weeps, groans, but paces her anxious steps up and down and strains her troubled ears to pick up sounds. She's more afraid than grieving. We need our wits.

Thus, Ulysses sets out to examine Andromache's non-verbal communication, paying particular attention to her parental role (615 scrutare matrem).$^{32}$ In other words, he intends to make a pragmatic analysis of the non-verbal forms of her behaviour in order to assess their compliance with Andromache's locutionary act. In order to achieve this, he needs 'all of Ulysses', the entire master of manipulation and deceits: not surprisingly, he calls astus, fraudes and dolos (613) into question since he is convinced that they are especially apt not only for 'encoding' deceits and frauds but also for decoding them. On the other hand,

32 On the investing gaze of Ulysses, see Benton (2002: 34-35). On the meaning of scrutari, see OLD, s.v.: 'to look searchingly at', 'scan', 'scrutinize'. 
there is no part of him which completely exemplifies the characteristics of his persona - this is summed up in a single word at the end of the passage: ingenium (618), his 'innate quality'. It is evident that this is once again an implicit mention of the literary memory of this mythical character, of his identity features, and dramaturgical function. In fact, Ulysses is able to identify:

- paralinguistic features (within which all the meta-communication components are included, such as gasps and sighs) and kinesic signals (if we accept tears as gestures): ${ }^{33}$ maeret, illacrimat, gemit.

- proxemic communication and kinesic signals: sed huc et illuc anxios gressus refert.

- prosodic features, like the empty pause (the silence) of Andromache, which conveys her suspense, worry and anxiety (cf. sollecita), and the consequent chronemic signals, which reveal an irregular, non-fluent communication flow: ${ }^{34}$ missasque uoces aure sollicita excipit.

The decoding of Andromache's non-verbal communication, on all levels, conveys a discrepancy between words and paralinguistic, kinesic and proxemic language. In other words, the outcome of the decoding act is that Andromache magis [...] timet, quam maeret (618). Therefore, by his pragmatic investigation, Ulysses manages to detect that the prominent feeling of his interlocutor is fear.

\subsection{The Counter-Fraud}

After decoding fraus and individuating the weakness of Andromache (her timor), which emerges very clearly from her mimic, gestures, and non-verbal behaviour, Ulysses decides to reply with a sort of 'counter-fraud' to test his own interpretation. We will use this term on the basis of 'counter-gift', in so far as fraus is a perlocutionary act ${ }^{35}$ that belongs to the mechanism of negative reciprocity, consisting precisely in a dramaturgical pattern of iniuria (the 'offence') and ultio (the 'revenge'). ${ }^{36}$ Furthermore, we have already noted that iniuria is linked to the semantic field of fraus. ${ }^{37}$ Ernout and Meillet explain it as 'tort fait à quelqu' un', 'dommage', i.e. the same meaning as that of iniuria, ${ }^{38}$ 'et par suite "fraude, tromperie"':

33 On the kinesic system and tears classified as gestures, see above n. 20 and Calabrese in this volume.

For an analysis of the relationship between prosody and gesture, see Wharton (2009: 139149).

35 See Austin ( $\left.{ }^{2} 1975: 101-108\right)$.

36 See Courtois (1984: 109-124).

37 See Section 1.

38 See Scolari (2018a: 136-139). See also Manfredini (1977: esp. 135) and Krause (2006: $83=$ 2004: 90). 
Comme le dommage s' accompagne généralement de manœuvres dolosives, fraus est arrivé à signifier 'ruse, tromperie, fourberie' et même 'piège' dans la langue familière. ${ }^{39}$

Therefore, the mechanism of fraus works along the same principles as exchange, and notably gift-giving practices, but antithetically. In fact, iniuria is the first stage of the revenge system in that it upsets the beneficium process (and, more generally, the process of gift-giving); ${ }^{40}$ revenge, in a second step, constitutes the antithesis to gratitude and the 'counter-gift'. ${ }^{11}$ In this respect, Cicero reports a definition of iniuria, which confirms that even fraus forms part of the negative reciprocity systems as one of the two patterns of 'injustice' (iniuria), which is the most contemptible:

\section{[12] Cicero De officiis 1.41}

cum autem duobus modis, id est aut ui aut fraude, fiat iniuria, fraus quasi uulpeculae, uis leonis videtur; utrumque homine alienissimum, sed fraus odio digna maiore.

There are two ways in which injustice may be done, either through force or through deceit; and deceit seems to belong to a little fox, force to a lion. Both of them seem most alien to a human being; but deceit deserves a greater hatred. ${ }^{42}$

The counter-fraud of Ulysses consists in revealing the harsh truth (a strategy that complies with his sentence ueritas numquam perit [614]), by underlining the nature of the Astyanax's death decreed by the Achaeans, in order to intensify mother's emotions: ${ }^{43}$ quem mors manebat saeua praecipitem datume turre, lapsis sola quae muris manet, 'a savage death awaited him, hurled headlong from the only tower those ruined walls still have' (621-622). In the aside, which has a didascalic function, Andromache allows her non-verbal signals of fear to emerge:

39 Ernout and Meillet $\left({ }^{4} 1985: 25^{2}\right.$ s.v. fraus $)$.

40 Discussed more fully in Scolari (2018a: 136-142, 195-207).

41 In this regard, see Gouldner (196o: 169); Verdier (1980a: 30, 1980b: 11); Seaford (1998: 1); van Wees (1998: 24).

42 For the translation, see Griffin and Atkins (1991).

43 See Fabre-Serris (2015: 110-111). 
[13] Seneca Troades 623-631

An. reliquit animus membra, quatiuntur, labant! torpetque uinctus frigido sanguis gelu.

Vl. intremuit. hac, hac parte quaerenda est mihi. matrem timor detexit. iterabo metum. ite, ite celeres, fraude materna abditum hostem, Pelasgi nominis pestem ultimam. ubicumque latitat, erutam in medium date. bene est: tenetur. perge, festina, attrahequid respicis trepidasque? iam certe perit.

An. (Aside) Life seeps from my limbs. They quiver, give way. My blood congeals, bound fast by freezing ice.

Ul. (Aside) She trembled. This, this is where I must probe. Fear unmasked the mother. I'll double that fear. (Aloud) Go, go, men! Quickly! A mother's trick hides our enemy, the Pelasgians' last blight. Wherever he hides, root him out, bring him here! Good, we have him! Hurry, quick, drag him here-(To Andromache) Why look back and tremble? Surely he's now dead.

By decoding her uncontrolled trembling (625 intremuit), Ulysses can deduce that 'fear has unmasked the mother' (626 matrem timor detexit). By manipulating Andromache's emotions, Seneca's character proves that he has mastered the rhetorical art of persuasion, which lies in provoking the feelings useful to achieve the desired effect (Cic. De or. 2.115) ${ }^{44}$ In order to decode materna fraus (627), he clearly knows that he has to consider the parental role of Andromache more than any other aspect of her identity. Furthermore, he does not overlook to observe her eye movement attentively: quid respicis trepidasque? [12]. respicere signifies 'to look back' and it is properly applied to express the action of turning the head back to look at something or someone. ${ }^{45}$ As stated by Bettini, this verb also communicates the willingness to have contact or rather to take someone into account. ${ }^{46}$ Hence, Andromache's action

44 See also Arist. Rhet. 1356a4, 14-15, 20-25; Cic. De or. 1.17, 178; Quint. Inst. 1.2.30, 1.6.2. On the link between persuasive strategies and the manipulation of emotions in classical antiquity, see Sanders and Johncock (2016).

45 See Marchese (2016: 14-22).

46 Bettini ( $\left.{ }^{2} 1988: 135\right)$. 
of respicere is a kinesic signal that allows Ulysses to find Astyanax and to thwart his mother's plans.

When it is too late, all of a sudden, Andromache remembers whom she is dealing with, a machinator fraudis et scelerum artifex, 'genecist of deceit, craftsman of evil' (750), and she recognises the specific identity of Ulysses and the natural inclinations of his malefica mens (752), demonstrated by dolus and astus.

We can claim that from the very beginning of the tragedy Seneca's Andromache shows her incompatibility with the fraudator profile. In the hiding scene, she is portrayed as incapable of decoding non-verbal signals of her own son, when she interprets his fear as shame:

\section{[14] Seneca Troades 503-505}

An.

$$
\text { quid retro fugis }
$$

turpesne latebras spernis? agnosco indolem:

pudet timere.

An. Do you shrink back, spurn base refuge? I recognise your breeding: You're ashamed of fear.

She seems to be convinced of her ability to recognise Astyanax's proxemic and kinesic signals as hereditary traits (agnosco indolem), but, as stressed by Ulysses, 'grief is no impartial judge of things', est quidem iniustus dolor rerum aestimator (545).

But the failure of her tricks notably depends on the disregarding of the receiver's identity and his dramaturgical role, although the real value of Ulysses is well known: uirtus Vlixis [...] nota est satis (757). We could say that Andromache does not follow the advice that Thyestes, in the homonymous tragedy, gives to himself: cum quod datur spectabis, et dantem aspice, 'when you view a gift, look at the giver, too' (Thy. 416$).{ }^{47}$

47 For the translation of Seneca's Thyestes, we follow Boyle (2017), except where otherwise noted. Tarrant (1985: 151 ad 416) stresses that this sententia is grounded in symmetrically balanced nouns and verbs-quod datur-dantem, spectabis-aspice. But, at least, it will be Atreus who looks carefully at Thyestes: see 505 aspice. 


\section{Pragmatics of fraus in Thyestes}

\subsection{Post fratris dolos: Outrage and Revenge}

In Thyestes as well, the fraus practice seems to be related to a dynamic of negative reciprocity. ${ }^{48}$ We can note that much when we take into account the dialogue between Atreus and his attendant (satelles), in which Atreus states that his revenge will be performed post fratris dolos (178) and the anaphora of fraus at 224 ( fraude est adeptus, fraude turbauit domum, by fraud he filched our ancient mark of power, by fraud confounded our house'), which refers to the dramaturgical and pragmatic pattern of iniuria committed by Thyestes against his brother. Moreover, at the end of the drama, Atreus represents the ultio carried out by the fraus as a way to repay his brother for his crimes: sceleri modus debetur ubi facias scelus, non ubi reponas, 'evil has due measure when evil's done, not when it's avenged' (1052).49 Therefore, with his fraus, Thyestes has betrayed Atreus' fides first: in fact, the latter calls him perfidus (235), which indicates 'someone who breaks his promise', who has overturned the bond ensured by fides. ${ }^{50}$ Indeed, at 239, Atreus deplores that the imperi fides, i.e. his 'guarantee about the power', is disrupted (quassa est). ${ }^{51}$

Unlike Andromache, Atreus claims knowledge of the innate quality of Thyestes (noui ego ingenium uiri, indocile, 199-200), his untameable nature, and, consequently, his weakness. Therefore, in the light of this boon, grounded on 'relational knowledge', he will be able to lead Thyestes himself to cause his own ruin: quod est in isto scelere praecipuum nefas, hoc ipse faciet, 'the principal horror in this crime-he will perform himself' $\left(285^{-286}\right) .{ }^{52}$ The perlocutionary effect that Atreus intends to achieve with his fraus resides in this very aim, for which the knowledge of the interlocutor's disposition is essential:

[15] Seneca Thyestes 286-295

Sat.

sed quibus captus dolis

nostros dabit perductus in laqueos pedem?

\footnotetext{
48 See Paduano (1988-1989: 296).

49 On the topic of measure (modus) and on the maius-motif of revenge in Seneca's tragedies, see Schiesaro (2003: 130).

50 See Ernout and Meillet ( ${ }^{4} 1985$ : s.v. fides): '"perfide", que l' on explique par qui per fidem decipit (Plt., Mo. 50o, per fidem deceptus sum), mais où per- peut marquer la déviation'.

51 Picone (1984: 12, 61-66).

$5^{2}$ On Atreus as a machinator doli, see Picone (1984: 65).
} 
inimica credit cuncta. At. non poterat capi, nisi capere uellet. regna nunc sperat mea: hac spe minanti fulmen occurret Ioui, hac spe subibit gurgitis tumidi minas dubiumque Libycae Syrtis intrabit fretum, hac spe, quod esse maximum retur malum, fratrem uidebit. Sat. quis fidem pacis dabit? cui tanta credet? At. credula est spes improba.

Att. What tricks will draw his feet into our snares? He thinks the worlds his foe.

Atr. He couldn't be taken unless he aimed to take us. He hopes for my kingdom still. In this hope he'll meet Jove's menacing bolt, in this hope he'll face threats of swelling seas and enter Lybian Syrtes' dubious shoals. In this hope- to him the greatest trial—he'll see his brother.

Att. Who'll assure the peace? Whom will he trust on such things?

Atr. Vile hope trusts all.

Atreus underlines his intent of encoding a deceptive message able to meet the 'unfair expectation' (295 spes improba) of Thyestes (emphasised by the anaphora of hac spe at 290, 291, and $293^{53}$ ), who hopes to obtain Atreus' kingdom (289 regna nunc sperat mea). Though the courtier stresses the necessity to provide a tangible guarantee of peace ( fides pacis), Atreus has no reason to worry, because, focusing on the specific weakness of the victim of the fraus, he knows that it consists in his credulitas (namely an excess of fides): credula est spes improba (295). However, during the entire play, Thyestes has a presentiment regarding the oncoming deceit ${ }^{54}$ and urges himself not to trust his brother, who is described as a res incertissima alongside power (424-425 rebus incertissimis, fratriatque regno, credis ...?, 'do you trust the most faithless things, brother and throne?'). Moreover, he labels his heart as 'credulous' or-more suitably-'deluded' in the apostrophe at 963: credula praesta pectora fratri, 'offer your deluded heart to the brother. ${ }^{55}$ In this sentence, the adjective credu-

53 I follow Boyle (2017) and Fitch (2004: ad loc.); Tarrant (1985: ad loc.) and Zwierlein ( ${ }^{3} 2009$ : ad loc.) move 290 to after 292 . On the motive of spes regni as a trap against Thyestes, see Picone (1984: 61).

54 See Thy. 472-473, 482-484.

55 For the sense of credulus as 'deluded', 'too trusting', I follow Traina (1981: 131-132), who 
lus underscores the danger of excessive trust placed in Atreus. As Traina has noted, the opposition between the syntagm praesta and the semanteme credulum encapsulates the conflict between the two main themes in the monody: the will, voice of consciousness, and the premonition, voice of subconscious. ${ }^{56}$ Nevertheless, Thyestes proves unable to escape Atreus' fraus that is performing as a trap (see [15] for the use of captus and laqueos), for which the signifier of 'piège', provided by Ernout and Meillet, ${ }^{57}$ is more than appropriate.

Praestetur fides: The Performance of fraus between Encoding and Decoding Acts

[16] Seneca Thyestes 504-511

cum sperat ira sanguinem, nescit tegitamen tegatur. aspice, ut multo grauis squalore uultus obruat maestos coma, quam foeda iaceat barba. praestetur fides. fratrem iuuat uidere. complexus mihi redde expetitos. quidquid irarum fuit transierit. ex hoc sanguis ac pietas die colantur, animis odia damnata excidant.

When anger smells blood, it won't be hidden-yet hidden it must be. Look how matted, filthy hair overwhelms his gloomy face, how foul his drooping beard. Now for a show of faith. (To Thyestes) Brother-it's a joy to see you. Give me the hug I've longed for. (They embrace) What anger existed let it be gone. From this day let's cherish blood and family piety, rid out hearts of damned hate.

The 'encoding of the fraus' scene is divided into two brief dramaturgical moments, an aside and the proper dialogue between the brothers. In the first frame of the scene, Atreus notes the squalor of his brother, caused by his exile, the principal reason of his weakness, and suggests to himself to conceal his wrath and to be believable (507 praestetur fides), i.e. to provide evidence of

examines the occurrences of this term in Seneca's corpus from a semantic point of view to provide a more accurate translation.

56 Traina (1981: 132).

57 See supra, n. 39. 
his credibility to perform a non-verbal behaviour, which works as a 'display of loyalty'.58 The second part of the fraus act reveals not only a didascalic but a pragmatic function as well: the opening utterance fratrem iuuat uidere is not only an illocutionary act, but it also conveys some information about the kinesic and mimic signals that Atreus manipulates to affect the interpretation act of Thyestes. ${ }^{59} \mathrm{He}$ pretends to be glad to see his brother, and he asks him for a hug, involving even the haptic level of communication in the encoding of the fraus. The physical contact implied makes this an interaction entailing touch. ${ }^{60}$ He also provides to Thyestes a proof of loyalty, showing his intention of restoring (reddere) the paternum decus (528) to his brother, i.e. the crown and sharing the power with him.

This dynamic takes the form of a gift: Seneca represents the simulatio of forgiveness performed by Atreus as a mechanism of positive reciprocity ${ }^{61}$ aimed to overturn the nature of their relationships: from hostility and hatred into a positive reciprocity exchange. Even if Seneca does not use the verb simulare, the strategy of Atreus' fraus complies to its meaning: 'a falsely assumed appearance' and 'a kind of pretence regarding [...] mental states', or rather, 'regarding relational dynamic' as gift-giving. ${ }^{62}$ By the expedient of the simulated gift, Atreus is able to close the gap between his brother and himself (in this case, both relational and physical), taking advantage of the fascinating power of the gift, which is already described by Renata Raccanelli as 'il metalinguaggio analogico della relazione', or (more suitably) 'la comunicazione della proposta di comunicare.' 63

Thyestes does not waste any time: accipio, he says, 'I accept' (542). The same concept will be repeated in a different form at 983-984 with reference to the cannibalistic banquet provided by Atreus, which is ultrix daps (894) as well:

$5^{8}$ Even if this frame is generally regarded as an aside, it may imply an audience, i.e. a role that the satelles could play, even if his entry is not explicitly marked. On the presence on stage of minor characters, see de Jong (2007: 7-9) and Taplin (1977: 8). On aspice as a metatheatrical invitation to the real audience, see Boyle (2017: ad loc.).

59 Di Raimo (2019: 317-318) argues that Atreus simulates the reasons of his glee but not the feeling itself (conveyed by the verb iuvat): the awareness of approaching revenge makes the character delighted. See also the use of iuuat at 1101.

6o Atreus asks the same to his nephews in 521-524 a genibus manum aufer meosque potius amplexus pete. uos quoque, senum praesidia, tot iuuenes, meo pendete collo.

61 See the above-mentioned 416 cum quod datur spectabis, et dantem aspice, 536 dona fortunae, and 984 donum dapis.

62 See Section 1. See also Ernout and Meillet ( ${ }^{4} 1985$ : s.v. similis: 'simulo: [...] "faire semblant de"').

63 Raccanelli (2011: 307-309). 
capio fraternae dapis donum. ${ }^{64}$ Hence, Seneca uses a performative and complementary couple of verbs (reddere/accipere). ${ }^{65}$ The latter allows Thyestes 'to do things with words', namely to obtain the crown that Atreus puts on his head but, at the same time, to get caught.

Thus, in Thyestes, the decoding act is carried out by the fraudator himself since it belongs to the deceptive practice. Furthermore, Atreus has already clarified that he does not want to see him broken, 'but to see him being broken' (907 miserum uidere nolo, sed dum fit miser). ${ }^{66}$ In this purpose, the acknowledgement scene in which the ultor can reveal his fraud is an essential part of the revenge:

[17] Seneca Thyestes 1004-1005

Atr. $\quad$... natos ecquid agnoscis tuos?

Thy. agnosco fratrem.

Atr. ... I suppose you recognise your sons?

Thy. I recognise my brother.

\section{4}

\section{Conclusions}

As we sought to illustrate in this survey, in the plays considered, Seneca makes extensive use of the semantic field of deceit, especially of fraus and dolus. The latter is mostly used in the plural (see Tro. 213, 569, 613; Thy. 178, 286, 318) and, apparently, not only for metrical reasons. fraude materna [13, line 627], for instance, corresponds to matrum dolos [7, line 569] (not to the singular dolus); and fratris dolos (178) and fraude at 224 relate to the same deceit. ${ }^{67}$ Hence, we can argue that, even if Seneca employs fraus and dolus almost interchangeably, he prefers to use fraus to convey a more complex and sophisticated strategy of deception, in so far as dolus is apparently considered as a 'softer', less structured deceit.

\footnotetext{
64 See Mazzoli (2016: $341-35$ ).

65 On performative utterances, see Austin ( ${ }^{2} 1975$ : esp. 6-8, 25-36). On performativity applied to Latin literature, see Anscombre and Pierrot (1985).

66 Here I follow Fitch (2004).

67 See also fraudem (Thy. 316) and dolos (Thy. 318) that refer to the same deception. The only occurrence of the singular dolus in Thyestes is in 773: errat hic aliquis dolus, which can be more suitably translated as 'here there is some kind of deceit'.
} 
However, the success of fraus (and dolus) within the communication event represented in Seneca's two tragedies which we have examined (but we might as well widen the scope of our investigation), depends mainly on:

- knowledge of the interlocutor: the fact of having regard to his/her identity role, desires and weaknesses;

- credulitas of the receiver, or simply their willingness to trust (credere) the fraudator; conversely, the fraudator's ability to manipulate his interlocutor's fides;

- compliance between verbal and non-verbal communication;

- ability to manipulate relational contexts.

Therefore, in order to furnish a definition of fraus from a pragmatic and anthropological point of view, we can define fraus as a mimetic and performative act, which underlies 'a falsely assumed appearance' and 'a kind of pretence regarding [...] mental states' or 'relational dynamic' (the proper sense of simulatio provided in Section 1) with perlocutionary intent, i.e. the purpose of achieving certain effects, specifically of influencing someone's actions or forms of behaviour by saying something. This performative act forms part of the negative reciprocity system of iniuria and aims at driving the interlocutor's belief (his fides, taking advantage of his credulitas) and redirecting his interpretative acts, by means of the compliance between verbal and non-verbal communication, as well as the ability of the fraudator to manipulate the relational contexts, in order to provide tangible evidence to enforce the trustworthiness of the deceptive message.

\section{Acknowledgements}

I am grateful to Federica Iurescia, Giada Sorrentino, Severin Hof, and Gunther Martin for their generous commitment, constructive suggestions and support. I also wish to thank all the conference attendees for stimulating discussions that helped formulate this paper.

\section{References}

Abbot, J.C., (1997), Roman Deceit: Dolus in Latin Literature and Roman Society (Roman Republic, Roman Empire), PhD thesis (University of North Carolina at Chapel Hill).

Anscombre, J.C. \& Pierrot, A., (1985), 'Sulla performatività in latino', Paideia 40, 35-47. Austin, J.L., ( $\left.{ }^{2} 1975[1962]\right)$, How to Do Things with Words, Oxford/London. 
Barney, S.A., Lewis, W.J., Beach, J.A., \& Berghof, O., ( ${ }^{4} 2008$ [2006]), The Etymologies of Isidore of Seville, Cambridge.

Bateson, G., (1972), Steps to an Ecology of Mind, San Francisco.

Benton, C., (2002), 'Split Vision: the Politics of the Gaze in Seneca's Troades', in D. Fredrick (ed.), The Roman Gaze. Vision, Power and the Body, Baltimore, 31-56.

Benveniste, É., (1969), Le vocabulaire des institutions indo-européennes, 2 vols., Paris.

Beta, S., (2004), La potenza della parola. Destinatari, Funzioni, Bersagli, Atti del Convegno di Studi, Siena, 7-8 maggio 2002, Fiesole.

Bettini, M., ( ${ }^{2} 1988$ [1986]), Antropologia e cultura romana, Florence.

Bettini, M. \& Ricottilli, L., (1987), 'Elogio dell'indiscrezione', Studi Urbinati/B3 6o, 11-27.

Boyle, A.J., (1994), Seneca's Troades, Leeds.

Boyle, A.J., (2017), Seneca, Thyestes, Oxford.

Brotherton, B., (1926), The Vocabulary of Intrigue in Roman Comedy, Chicago.

Calabrese, E., (2007), 'Infrazione del silenzio e uso di verba nella Fedra di Seneca', Paideia 62, 171-192.

Calabrese, E., (2009), Il sistema della comunicazione nella Fedra di Seneca, Palermo.

Calabrese, E., (2011), 'Il dono e la relazione padre-figlio nella Fedra di Seneca', in G. Picone, L. Ricottilli, \& L. Beltrami (eds.), Benefattori e beneficati. La relazione asimmetrica nel De beneficiis di Seneca, Palermo, 25-46.

Carcaterra, A., (1970), Dolus bonus/dolus malus. Esegesi di D. 43,1,2-3, Naples.

Courtois, G., (1984), 'Le sens et la valeur de la vengeance chez Aristote et Sénèque', in R. Verdier, J.P. Poly, \& G. Courtois (eds.), La vengeance. Études d'ethnologie, d'histoire et de philosophie, vol. 4, Paris, 91-124.

Di Raimo, L., (2019), 'Gioia simulata e gioia indotta. Il godimento della vendetta in Seneca tragico', in M. De Poli (ed.), Il teatro delle emozioni: la gioia, Padova, 313-326.

Duranti, A., (1997), Linguistic Anthropology, Cambridge.

Dyck, A.R., (1996), A Commentary on Cicero, De Officiis, Ann Arbor.

Ernout, A. \& Meillet, A., $\left({ }^{4} 1985\right.$ [1932]), Dictionnaire étymologique de la langue latine. Histoire des mots, Paris.

Fabre-Serris, J., (2015), 'Women afterWar in Seneca's Troades. A Reflection on Emotions', in J. Fabre-Serris \& A. Keith (eds.), Women and War in Antiquity, Baltimore, 100-118.

Fitch, J.G., (2004), Seneca, Tragedies, vol. 2, Cambridge, Mass./London.

Fraenkel, E., (1916), 'Zur Geschichte des Wortes fides', Rheinisches Museum für Philologie 71, 187-199.

Fraenkel, E., (1926), Fides, in ThLL 6, pars prior, F, c. 661-691.

Freyburger, G., (1986), Fides. Étude sémantique et religieuse depuis les origines jusqu'à l'époque augustéenne, Paris.

Gouldner, A.W., (1960), 'The Norm of Reciprocity: a Preliminary Statement', American Sociological Review 15, 161-178.

Griffin, M.T. \& Atkins, E.M., (1991), Cicero, On Duties, Cambridge. 
Hellegouarc'h, J., ( ${ }^{2} 1972$ [1963]), Le vocabulaire latin des relations et des partis politiques sous la République, Paris.

Hey, O., (1910), dolus, in ThLL 5, pars prior, D, c. 1857-1864.

Jakobson, R., ( ${ }^{3} 1981$ [1966]), 'Linguistica e poetica' in R. Jakobson, Saggi di linguistica generale, Milan, 181-218 (Ital. transl. of 'Closing Statements: Linguistics and Poetics', in T.A. Sebeok (ed.), Style in Language, New York 196o, 350-377).

Jong, I.J.F. de, (2007), 'Sophocles' Trachiniae, Euripidean Prologues, and their Audiences', in R.J. Allan \& M. Buijs (eds.), The Language of Literature. Linguistic Approaches to Classical Texts, Leiden/Boston, 7-28.

Krause, J.-U., (2006), La criminalità nel mondo antico, Rome (Ital. transl. of Kriminalgeschichte der Antike, Munich 2004).

Krüger, H. \& Kaser, M., (1943), 'Fraus', Zeitschrift der Savigny-Stiftung für Rechtsgeschichte, Romanistische Abteilung 63, 117-174.

Lecointre, S., (1991), 'Ma langue prêta serment', in R. Verdier (ed.), Le serment, vol. 1, Paris, $5^{-22}$.

Lewis, C.T. \& Short, C., (1879), A Latin Dictionary, Oxford.

Manfredini, A.D., (1977), Contributi allo studio dell'iniuria in età repubblicana, Milan.

Marchese, R.R., (2016), Uno sguardo che vede. L'idea di rispetto in Cicerone e in Seneca, Palermo.

Mazzoli, G., (2016), Il chaos e le sue architetture. Trenta studi su Seneca tragico, Palermo. Michelon, F., (2015), La scena dell'inganno: finzioni tragiche nel teatro di Seneca, Turnhout.

Miller, F.J., (1917), Seneca, vol. 8: Tragedies I, Cambridge, Mass./London.

Paduano, G., (1988-1989), 'La climax della volontà di potenza nel Tieste di Seneca', Quaderni di Cultura e Tradizione Classica 6-7, 287-300.

Pageard, R., (1991), 'Les sanctions du serment du mythique au logique. Du social à l' intime', in R. Verdier (ed.), Le serment, vol. 1, Paris, 35-41.

Picone, G., (1984), La fabula e il regno. Studi sul Thyestes di Seneca, Palermo.

Raccanelli, R., (1998), L'amicitia nelle commedie di Plauto: un'indagine antropologica, Bari.

Raccanelli, R., (2010), Esercizi di dono. Pragmatica e paradossi delle relazioni nel De beneficiis di Seneca, Palermo.

Raccanelli, R., (2011), 'Cambiare il dono: per una pragmatica delle relazioni nel De beneficiis senecano', in G. Picone, L. Ricottilli, \& L. Beltrami (eds.), Benefattori e beneficati. La relazione asimmetrica nel De beneficiis di Seneca, Palermo, 303-356.

Ricottilli, L., (200o), Gesto e parola nell'Eneide, Bologna.

Ricottilli, L., (2009), 'Appunti sulla Pragmatica della Comunicazione e della letteratura latina', in A. Barchiesi \& G. Guidorizzi (eds.), La stella sta compiendo il suo giro. Atti del convegno internazionale di Siracusa, 21-23 maggio 2007, Florence, 121-170.

Ricottilli, L., (2011), 'Aspetti della rappresentazione gestuale nel De beneficiis', in 
G. Picone, L. Ricottilli, \& L. Beltrami (eds.), Benefattori e beneficati. La relazione asimmetrica nel De beneficiis di Seneca, Palermo, 399-429.

Ricottilli, L., (2018a), 'Lacrime e sympatheia in Terenzio', in Ricottilli 2018b, 145-166.

Ricottilli, L., (2018b), Modalità della comunicazione in Roma antica, Bologna.

Rubenbauer, I., (1926), fraus, in ThLL 6, pars prior, F, c. 1266-1277.

Sanders, E. \& Johncock, M. (eds.), (2016), Emotion and Persuasion in Classical Antiquity, Stuttgart.

Schiesaro, A., (2003), The Passions in Play: Thyestes and the Dynamics of Senecan Drama, Cambridge.

Scolari, L., (2016), 'La fides e la promessa. Forme di reciprocità tra dèi e uomini nella riscrittura di Ovidio', Quaderni del Ramo d'Oro on-line 8, 112-127. http://www.qro .unisi.it/frontend/sites/default/files/Scolari_La_fides_e_la_promessa.pdf [11/o3/ 2020].

Scolari, L., (2018a), Beneficium e iniuria. Rappresentazioni del dono e dell'offesa nel De beneficiis diSeneca, Palermo. https://www.classicocontemporaneo.eu/PDF/379.pdf [11/03/2020].

Scolari, L., (2018b), Donifunesti. Miti di scambi pericolosi nella letteratura latina, Pisa.

Seaford, R., (1998), 'Introduction', in C. Gill, N. Postlethwaite, \& R. Seaford (eds.), Reciprocity in Ancient Greece, New York, 1-12.

Searle, J.R., (1969), Speech Acts: an Essay in the Philosophy of Language, Cambridge.

Taplin, O., (1977), The Stagecraft of Aeschylus: the Dramatic Use of Exits and Entrances in Greek Tragedy, Oxford.

Tarrant, R.J., (1985), Seneca's Thyestes, Atlanta.

Ter Beek, L.J., (1999), Dolus: een semantisch-juridische studie, Nijmegen.

Traina, A., (1981), 'Due note a Seneca tragico. La fiducia di Tieste', in A. Traina, Poeti latini e neolatini: note e saggi filologici, $2^{\text {a }}$ serie, Bologna, 130-132. (first published in Maia, 1979, 273-276).

Verdier, R., (1980a), 'Le système vindicatoire. Esquisse théorique', in R. Verdier, J.P. Poly, \& G. Courtois (eds.), La vengeance. Études d'ethnologie, d'histoire et de philosophie, vol. 1, Paris, 11-42.

Verdier, R., (198ob), 'De l'une à l' autre vengeance', in R. Verdier, J.P. Poly, \& G. Courtois (eds.), La vengeance. Études d'ethnologie, d'histoire et de philosophie, vol. 2, Paris, 713 .

Watzlawick, P., Beavin, J.H., \& Jackson, D.D., (1967), Pragmatics of Human Communication: a Study of Interactional Patterns, Pathologies, and Paradoxes, New York.

Wees, H. van, (1998), 'The Law of Gratitude: Reciprocity in Anthropological Theory', in C. Gill, N. Postlethwaite, \& R. Seaford (eds.), Reciprocity in Ancient Greece, New York, $13-49$.

Wharton, T., (2009), Pragmatics and Non-Verbal Communication, Cambridge.

Wheeler, E., (1988), Stratagem and the Vocabulary of Military Trickery, Leiden.

Zwierlein, O., ( ${ }^{3} 2009$ [1986]), L. Annaei Senecae tragoediae, Oxford. 
Epilogue 
-978-90-04-44026-5

Downloaded from Brill. com $04 / 26 / 2023$ 11:30:38AM via free access 


\title{
Euripides: Von der Rhetorik zur Pragmatik
}

\author{
Carlo Scardino
}

\section{Einleitung: Rhetorik und Pragmatik}

Bezüglich des Verhältnisses zwischen der Rhetorik und der Pragmatik haben von linguistischer Seite die Pragmatisten Sperber und Wilson die traditionelle Rhetorik auf der theoretischen Ebene kritisiert und behauptet, dass ihr ein eigener Forschungsgegenstand fehle und sie vielmehr ein „disparate set of items rather than an autonomous category“ sei. ${ }^{1}$ Sie beschränken die Rhetorik auf die elocutio und betrachten sie als eine heterogene Sammlung von Regeln, durch die man die Kommunikation beeinflussen kann, die aber einer theoretischen Verankerung entbehrt. Alle rhetorischen Verfahren seien einem Redner eigentlich von selbst bewusst; die Rhetorik biete nur die Selbstvergewisserung eines natürlichen Wissens. ${ }^{2}$ Daher könne man ganz auf die Rhetorik verzichten und durch einen kognitiven Ansatz - die von Sperber und Wilson entwickelte Relevanztheorie - ersetzen.

Die Kritik an der Rhetorik ist fast so alt wie sie selbst. Schon Platon hat ihr im Gorgias 453a den Rang einer Wissenschaft - das von ihm verwendete $\tau \dot{\varepsilon} \chi \nu \eta$ kommt diesem Begriff mutatis mutandis am nächsten - abgesprochen

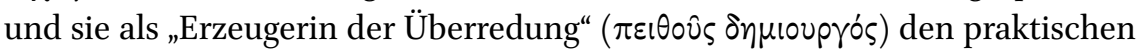
Beschäftigungen gleichgesetzt. Hingegen bezeichnet Aristoteles die Rhetorik (Rhet. 1355b25-34) analog zur Dialektik als $\tau \dot{\varepsilon} \chi \nu \eta$, deren spezielles Objekt, das sie zu einer $\tau \dot{\varepsilon} \chi \vee \eta$ macht, $\tau \dot{o} \pi \imath$ $\pi \nu$ ó $($ (das, was Überzeugung erweckt“) ist. Aristoteles' kommunikatives Modell bleibt in der Folge die wichtigste Grundlage, auch wenn sich die Rhetorik von der Antike bis in die Gegenwart weiterentwickelt hat. Von den im 20. Jh. entwickelten Ansätzen soll wenigstens der nach dem Zweiten Weltkrieg von Chaim Perelman und Lucie Olbrechts-Tyteca (1958) unternommene Versuch, eine ,Neue Rhetorik‘ zu begründen, erwähnt werden. Ebenso wie Aristoteles betten die beiden Gelehrten die Rhetorik in ein auf der Logik fußendes kommunikatives System ein. Dabei erfüllen etwa die rhetorischen Figuren neben der schmückenden auch eine ,pragmatische، Funktion und werden demgemäß funktional eingeteilt. ${ }^{3}$

1 Sperber und Wilson (1980: 96): „Rhetoric has no proprietary subject matter to study because the phenomena and issues it claims as its own amount to a disparate set of items rather than an autonomous category."

2 Sperber und Wilson (1980: 96).

3 Ähnlich haben die Linguisten der Lütticher Groupe $\mu$ die rhetorischen Figuren als Abwei-

(C) CARLO SCARDINO, 2021 | DOI:10.1163/9789004440265_021 
Standen Sperber und Wilson der Rhetorik ablehnend gegenüber, haben andere Linguisten versucht, die beiden Systeme miteinander in Einklang zu bringen. So betrachtet etwa Venier die Rhetorik als Teil der Pragmatik, die sich mit dem persuasiven Aspekt der Sprache auseinandersetzt. Als Disziplin beschäftigt sie sich vor allem mit der Perlokution, also mit der unmittelbaren Wirkung eines Sprechakts auf den Rezipienten, während die Pragmatik auch die Illokution, die Kraft eines Sprechakts, untersucht. ${ }^{4}$

Daneben darf nicht vergessen werden, dass die Aristotelische Rhetorik und Logik für viele Pragmatiker wichtige Inspirationsquellen waren. So sind das bekannte Kooperationsprinzip, auf dem gemäß Paul Grice die Konversation beruht, und die vier Konversationsmaximen, in denen es sich entfaltet, ${ }^{5}$ das Resultat seiner Anwendung der Logik auf die Kommunikation. Durch die Benutzung bzw. Verletzung der von ihm identifizierten Maximen verfolgt nach Grice ein Sprecher eine kommunikative Absicht. Mit dem System der Konversationsmaximen können die traditionellen rhetorischen Figuren hinsichtlich ihrer kommunikativen Funktion als spezielle Fälle in einem viel weiter gefassten System erklärt werden: Die Tautologie ist etwa eine klare Verletzung der Maxime der Quantität, gemäß der man nur soviel Information wie nötig liefern soll, während mit Hilfe von Ironie, Metapher, Litotes und Hyperbel die Maxime der Qualität, gemäß der man nur das sagen soll, was man nicht für falsch hält, manipuliert werden kann.

Auch das von John Austin, selbst ein Kenner des Aristoteles, entwickelte Modell der Sprechakte, das eine Äußerung gemäß ihrer illokutionären Kraft anstelle ihrer syntaktischen Form einteilt (Austin ${ }^{2}$ 1975), geht auf Protagoras zurück, der die Äußerungen funktional in Befehle, Bitten, Fragen, Antworten, Erzählungen, Appelle etc. eingeteilt hat. ${ }^{6}$

chungen von einer sprachlichen Nullstufe (degré zéro) verstanden. Vgl. zur Geschichte der Rhetorik von der Antike bis in die Gegenwart den ausgezeichneten Überblick von Mortara Garavelli ( ${ }^{15}$ 2014). Vgl. auch Cohen (1994), der antike und moderne Rhetoriktheorien miteinander vergleicht.

4 Venier (2008:11): „La retorica è la disciplina che si occupa del discorso persuasivo, del discorso la cui azione è finalizzata alla persuasione, la pragmatica linguistica è invece più in generale la disciplina che si occupa del potere azionale del linguaggio, che illustra perché ogni dire possa essere concepito come un fare, e in che termini debba essere concepito come un fare." Ähnlich Piazza (2011), die von einem Verwandtschaftsverhältnis zwischen beiden Disziplinen ausgeht.

5 Vgl. dazu Grice (1989: 26), der das Kooperationsprinzip folgendermaßen formuliert: „Make your contribution such as is required, at the stage at which it occurs, by the accepted purpose or direction of the talk exchange in which you are engaged."

6 Protagoras DK 8o A 13-17. Vgl. auch Arist. Poet. 19, 1456b9-19. 
Nicht nur die Sprechakttheorie, sondern auch einige Theorien der Höflichkeit (,politeness') lassen sich auf rhetorische Kategorien zurückführen. So wird die Idee der Abmilderung (mitigatio bzw. deminutio bzw. $\mu \varepsilon^{i} \omega \sigma \iota \varsigma$ ) bereits beim Auct. ad Her. 4.38.50 formuliert. ${ }^{7}$ Auch das Gegenteil, die Steigerung (amplifi-

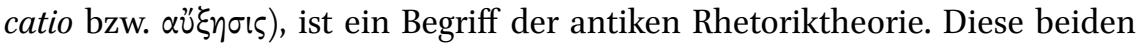
Figuren bilden mutatis mutandis die Grundlage eines Modells, mit dem die Strategien zur Abmilderung (bzw. zur Verstärkung) illokutionärer Akte in der Interaktion beschrieben werden. Gleichermaßen lassen sich etwa rhetorische Tropen und Figuren wie Litotes, Euphemismus, Periphrase oder Aposiopese als Erscheinungsformen der deminutio erklären. ${ }^{8}$

\section{$2 \quad$ Rhetorik und Pragmatik im antiken Drama}

Bei der Analyse des Dramas und speziell der Tragödien des Euripides sind bisher gelegentlich rhetorische und sporadisch pragmatische Ansätze angewendet worden, wobei das Potential dieser beiden Disziplinen bei der Analyse der Tragödie noch lange nicht ausgeschöpft ist. Allerdings ist bei der Anwendung besonders der Pragmatik, die zur Untersuchung realer verbaler Interaktionen entwickelt worden ist, zu berücksichtigen, dass sich der dramatische Dialog, die häufigste Form der Kommunikation unter den dramatis figurae, durch seinen fiktionalen und stets motivierten Charakter auszeichnet und sich sowohl an die Zuhörer innerhalb der dramatischen Fiktion als auch an ein Publikum außerhalb derselben richtet. Damit der Dichter die von ihm intendierte Wirkung in verständlicher Weise erzeugen kann, muss er einen sprachlichen code benutzen, den seine Rezipienten kennen, und der, obgleich es sich um eine Kunstsprache mit einem speziellen stilistischen Register handelt, mit der vom Publikum verwendeten Alltagssprache kommensurabel ist. Der dramatische Dialog ist daher meist dichter, kohärenter und reicher an Informationen als die alltägliche Konversation; seine Sätze sind in der Regel syntaktisch wohlgeformt und vollständiger, wobei die Missachtung der Regeln der verbalen Interaktion (wie Schweigen, Unterbrechen etc.) meistens bedeutungsvoll ist. Da also der dramatische Dialog denselben Regeln wie die übrigen Arten von verbalen Interaktionen gehorcht, ist er dazu geeignet, sowohl mit Hilfe von Methoden, die wie die Rhetorik zur Analyse der literarischen Kunstsprache verwendet werden, als auch mit solchen, welche

7 Vgl. Lausberg ( ${ }^{3} 1990: 145^{-146)}$.

8 Dazu vor allem Caffi (2001: 29-30, 141-150). 
wie die Pragmatik die Funktionsmechanismen der Alltagssprache untersuchen, analysiert zu werden, um seine Besonderheiten zum Vorschein zu bringen. ${ }^{9}$

Es gibt viele nützliche Arbeiten zur Sprache des antiken Dramas, die neben Fragen zur Grammatik und zur Stilistik ${ }^{10}$ vor allem die rhetorische Gestaltung einzelner ṕं $\sigma \varepsilon \zeta^{11}$ und der darin verwendeten rhetorischen Mittel untersucht haben. ${ }^{12}$ Mit Hilfe der Rhetorik läßt sich neben der Gliederung der Reden und der darin verwendeten Stilmittel vor allem die Argumentationstechnik der im Drama involvierten Figuren beschreiben. Ältere Arbeiten haben sich mit der rhetorischen Technik und den Quellen, aus denen Euripides diese entnommen haben könnte, befasst. ${ }^{13}$ Wie Riedweg mit Recht bemerkt hat, begnügten sich diese „mit der Aufzählung einschlägiger Euripidesstellen [...] bzw. mit eher oberflächlichen Strukturanalysen. ${ }^{14}$ Neuere Arbeiten, die einzelnen Phänomenen wie dem Agon, ${ }^{15}$ der Stichomythie, ${ }^{16}$ dem Botenbericht ${ }^{17}$ und dem ,speech in speech ${ }^{18}$ gewidmet sind, befassen sich partiell mit der rhetorischen Gestaltung. Es fehlen, wie Riedweg mit Recht bemerkt, systematische Untersuchungen zu den in den Tragödien verwendeten rhetorischen Verfahren und ihren Funktionsmechanismen innerhalb der einzelnen Passagen und Stücke. Eine derartige Analyse sollte sich indessen nicht auf die ṕńøঞı beschränken, sondern sollte auch die schnellen verbalen Schlagabtausche des Dialogs miteinbeziehen. Der dramatische Dialog kann trotz der relativen Starre und

9 Ungeheuer (1980: 46): „Solche Dialoge sind auch keinesfalls ,künstlich' in dem Sinne, dass sie gegen Regeln kommunikativen Gebarens verstoßen. Sie sind freilich (oder können es sein) unrealistisch in ihrer Konzentration, aber gerade dieses Merkmal macht sie für eine Analyse zum Zwecke kommunikationswissenschaftlicher Begriffsbildung interessant."

Zur Bedeutung der Rhetorik und Stilistik bei der Analyse antiker literarischer Texte vgl. allgemein Landfester (1997).

Mannsperger (1971: 143) definiert jede mehr als 5-6 Verse lange, nicht unterbrochene und

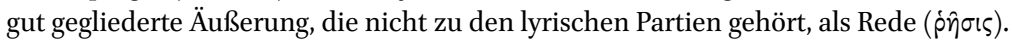

Vgl. zur Bedeutung der Rhetorik in der Tragödie Pelling (2005); bei Euripides Goldhill (1997), Dubischar (2001: 23-43) und Zimmermann (2011: 515). Die Bedenken gegen die Anwendung einer auf Aristoteles fußenden Rhetorik, wie sie Bers (1994: 182) äußert, der in Anlehnung an Gorgias die Überredung $(\pi \varepsilon \mid \theta \dot{)})$ untersuchen will, weisen in der Praxis gegenüber traditionellen Definitionen keine Vorteile auf. Vgl. z. B. Lechner (1874); Miller (1887); Tietze (1933).

14 Riedweg (2000: 6 Anm. 26).

15 Lloyd (1992); Dubischar (2001).

16 Vgl. Schwinge (1968); Seidensticker (1971).

17 De Jong (1991).

18 Bers (1997). 
Regelmäßigkeit seiner Struktur nicht auf eine Reihe von aufeinander folgen-

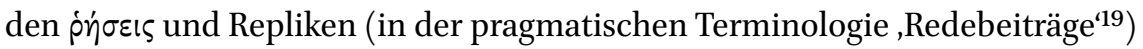
reduziert werden, ${ }^{20}$ sondern ist wie die reale Konversation das Produkt der Interaktion seiner Teilnehmer, deren verbale Handlungen nicht nur auf die kommunikativen Ziele der Sprecher, sondern auch auf die kontingenten Charakteristiken der Gesprächssituation und auf die Zuhörer ausgerichtet sind. ${ }^{21}$ Die rhetorischen Figuren und Techniken im Dialog müssen ebenso wie die linguistischen und stilistischen Merkmale der Euripideischen Kunstsprache, zu denen auch die metrische Form gehört, in einen weiter gefassten kommunikativen Rahmen eingefügt und unter dem funktionalen Aspekt untersucht werden.

Eine adäquate und tiefgreifende Studie des dramatischen Dialogs unter dem kommunikativen Aspekt benötigt eine weiter und allgemeiner gefasste Perspektive als die zwar nützlichen, aber beschränkten Betrachtungsweisen, die in den bisherigen Studien zur Anwendung gekommen sind und die jeweils nur einzelne Aspekte des Dialogs erfasst und analysiert haben. Die Pragmatik, die die Sprache als Form der Handlung und die Sprecher als Subjekte der énonciation, die sich in einem Kontext befinden, betrachtet, bietet einen ganzheitlichen und umfassenden Ansatz, da sie eine Untersuchung der verbalen Interaktionen in ihrer ganzen Komplexität ermöglicht. Infolgedessen kann sie die rhetorische Analyse der Reden ergänzen und erweitern ${ }^{22}$ Die Wirkung rhetorischer Mittel wird innerhalb der dramatischen Fiktion durch die Pragmatik funktional erklärt und durch die Berücksichtigung anderer, für das Verständnis der verbalen Interaktionen signifikanter sprachlicher Phänomene, welche die traditionelle Rhetorik und Stilistik nicht in ausreichendem Maße zu klassifizieren imstande sind, ergänzt. Mithilfe der Pragmatik können die Mechanismen, die den rhetorischen Figuren und Strategien zugrunde liegen, erklärt und hinsichtlich ihrer kommunikativen Funktionen erfasst werden. Die zahlreichen analytischen und interpretativen Möglichkeiten, die von der Pragmatik zur Untersuchung der dramatischen und theatralischen Kommunikation geliefert

19 Der Begriff ,Redebeitrag' ist die Übersetzung des englischen ,turn', so Meibauer (2001: 131); dagegen verwendet Pfister $\left({ }^{11_{2}}{ }_{2001}\right)$ dafür durchgehend ,Replik'.

$20 \quad$ Pfister bemerkt (11 2001: 212-213), dass „sich rhetorische Analysen bisher im wesentlichen auf die Analyse großer Reden im Drama beschränkt haben, ist daher zwar verständlich, heißt aber, das heuristische Potential der Rhetorik nicht voll auszuschöpfen.“

21 Vgl. dazu Pfister (112001: 179), der die Bedeutung des sprachlichen Verhaltens für die Charakterisierung der Figuren betont.

22 Vgl. dazu Caffi (2001: 141-165); Larrazabal und Korta (2002); Venier (2008); Piazza (2011). 
werden, ${ }^{23}$ sind erst seit kurzem auf die Erforschung der griechischen Tragödie angewendet worden.

Für die Untersuchung der Tragödie haben erst wenige Forscher die Pragmatik eingesetzt. Als erster hat Lloyd die Verwendung von Höflichkeitsstrategien bei Sophokles und Euripides untersucht. ${ }^{24}$ Schuren hat die Stichomythien in Euripides mit Hilfe der Gesprächsanalyse und der Soziolinguistik analysiert. ${ }^{25}$ Eine Pilotstudie zur Anwendung der Pragmatik und Soziolinguistik hat van Emde Boas anhand von Euripides' Elektra vorgelegt, wobei er, wenn auch unsystematisch, bisweilen die rhetorische Technik berücksichtigt hat. ${ }^{26}$

Eine Studie, welche beide Ansätze konsequent miteinander verbindet, eine methodologisch fundierte Grundlage zur rhetorisch-pragmatischen Analyse antiker Texte bietet und konkrete Anwendungsmöglichkeiten dieser Methode im antiken Drama auslotet, bleibt aber weiterhin ein Desiderat.

\section{$3 \quad$ Rhetorik und Pragmatik im Orestes}

Im folgenden soll anhand eines bisher bei der Interpretation des Orestes wenig untersuchten Abschnittes exemplarisch aufgezeigt werden, wie man die rhetorische Analyse mit der Pragmatik (Gesprächsanalyse, Sprechakt-Theorie und Höflichkeits-Modelle) verbinden und auch kurze, aus wenigen Versen bestehende Repliken analysieren kann, um die sprachliche Charakterisierung der handelnden Figuren, die Technik des Dialogs bei Euripides und die Konventionen der dramatischen Kunstsprache besser zu erfassen.

Der vierte Akt des Orestes $(1013-1245)^{27}$ umfasst die Ereignisse nach der Verurteilung des Orestes und seiner Schwester Elektra wegen Muttermords zum Tode und leitet zum zweiten Teil des Stücks, der Intrige, über.

Orest, dessen Herannahen der Chor gemeldet hat, wird von seiner Schwester Elektra, die durch den Botenbericht um das Todesurteil weiß, mit folgenden Worten empfangen.

\footnotetext{
23 Eine Übersicht über moderne Ansätze gibt Hess-Lüttich (1980: 5-22, 2001a, 2001b).

24 Lloyd (2006, 2009).

25 Schuren (2015).

26 Van Emde Boas (2017a). Ebenso hat van Emde Boas (2017b) die Gesprächsanalyse mit besonderer Berücksichtigung der Partikeln zur Untersuchung von zwei Dialogen aus Aischylos Agamemnon und Sophokles Aias verwendet.

27 Vgl. zum Kontext der Handlung Willink (1986: 258) und Wright (2008: 42-44).
} 
[1] Euripides Orestes 1018-1021 ${ }^{28}$

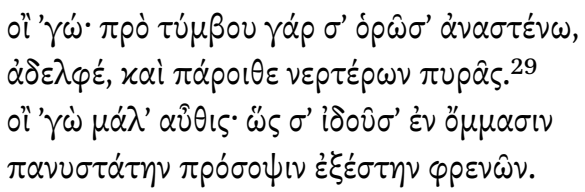

Weh mir! Ich seufze, da ich hier an Grabes Rand, so nah dem Scheiterhaufen, Bruder, dich erblicken muss. Und aber weh mir: heute sie mein Auge dich zum letzten Male - ganz vergehn die Sinne mir. ${ }^{30}$

Elektra beginnt, nachdem sie ihren Bruder Orestes gesehen hat, eine laute Klage. Die beiden leichten Enjambements (1018-1019 mit Hiat und 1020-1021) sprengen die enge Sinneinheit des Trimeters, passen ihre Äußerung dem natürlichen Fluss der Rede an und erweitern den Raum für den emphatische Ausdruck ihrer Gefühle. ${ }^{31}$ Mit einem Hysteron proteron ${ }^{32}$ äußert Elektra die furchtbare Vision ihres Bruders Orestes vor dem Grab (1018) und dem Scheiterhaufen (1019) und schließlich in zwei Versen ihr letztes Wiedersehen mit ihrem Bruder (1020-1021). Die beiden Perioden sind durch ein Verhältnis der Steigerung geprägt, welche die imaginierte (1018 $\left.\delta \rho \omega \sigma^{\prime}\right)$ neben die reale, pleonastisch mit

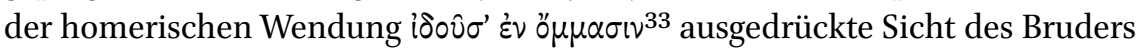
(1020) - Ausdrücke des Sehens bilden die Klammer ihrer Aussage - stellen:

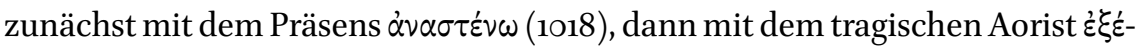
$\sigma \tau \eta \nu$ (1021), der mit Hilfe von Klangfiguren verstärkt wird und die Aufgeregtheit ihrer Stimmung anzeigt. ${ }^{34}$ Sie drückt ihre starken Emotionen in einem expres-

28 Der Text stammt, wo nicht anders angegeben, aus Diggle (1994).

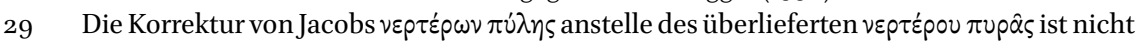

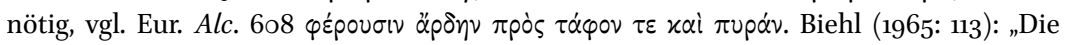
metaphorische Bezeichnung, Grab' bzw. ,Totenscheiterhaufen' (Suppl. 1058) enthalten die gleiche Vorstellung (,Tod') mit unterschiedlichem Gefühlsgehalt (als ,climax')." Dagegen

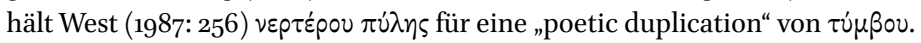

30 Die Übersetzung stammt, wo nicht anders angeben, von Donner u. a. (2016).

31 Zum Enjambement in der tragischen Dichtung Battezzato (2001).

32 Battezzato (2018:36) betont, dass „' 'hysteron proteron aggiunge un elemento specifico alle circostanze e utile a precisare i dettagli della narrazione o della conversazione.“

33 Vgl. etwa Hom. Il. 1.587 und 18.19o.

34 Kühner und Gerth (1898: II 163-164). Biehl (1965: 113) nennen ihn „Aorist zur Bezeichnung der im Augenblick vor sich gehenden Affektäußerung." Lloyd (1999: 43), der den tragischen Aorist auf performative Verben beschränkt, betrachtet Fälle wie diesen als "descriptive“ Aorist, bei dem „the reference is to a particular emotional impulse rather than to a settled attitude." 
siven Sprechakt ${ }^{35}$ aus, der auch die Funktion der Kontaktaufnahme erfüllt. Die Wiederholung der Formel oi ' $\gamma \omega^{\prime 36}$ an derselben Stelle zu Beginn des Verses und der Periode (1018 und 1020) verleiht der Aussage ebenso wie die Alliteration auf p-Laute (1019 und 1021) und das Homoioteleuton (1021) Emphase. Mit dem Vokativ $\alpha \dot{\delta} \varepsilon \lambda \varphi \dot{\varepsilon}$ (1019) wendet sie sich direkt an Orest, um seine Aufmerksamkeit auf sich zu ziehen, und versucht ihn dadurch an sich zu binden, dass sie das Verhältnis der Verwandtschaft betont.

\section{[2] Euripides Orestes 1022-1023}

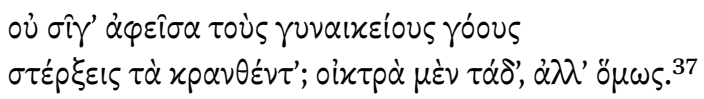

Dem, was verhängt ist, füge dich und lasse von der Weiberklage: zwar ist's schmerzlich - dennoch trag's.

Orestes äußert in seiner ersten Replik ebenso sehr emphatisch in eineinhalb Versen einen direktiven Sprechakt, ${ }^{38}$ mit dem er auch die Klage seiner Schwester indirekt rügt. Der negative Befehl wird durch die Sperrstellung mit Enjam-

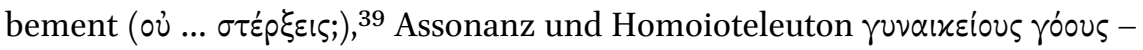
so deutet er tadelnd Elektras Klage im vorangehenden Redebeitrag - verstärkt. In Antinomie zur Klage gibt er im Befehl das seiner Meinung angemessene Verhalten, das im Schweigen $\sigma \hat{\gamma} \gamma^{\prime}$ (1022) besteht, an. Ist sein direktiver Sprechakt zunächst schroff und ohne Höflichkeitsstrategien, enthält die elliptisch ange-

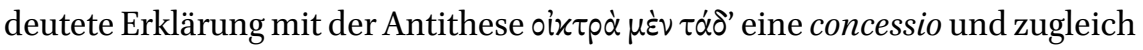
eine leichte Abmilderung des Befehls durch eine Strategie positiver Höflichkeit, ${ }^{40}$ da er für Elektras Verhalten Verständnis zeigt, auch wenn er mit der in

35 Mit einem expressiven Sprechakt drückt ein Sprecher einen psychischen Zustand aus, vgl. Meibauer (2001: 95).

36 Ebenso Hec. 1035-1037; Med. 10o8-10o9; Tro. 628-629; Aesch. Ag. 1343-1345; Cho. 876.

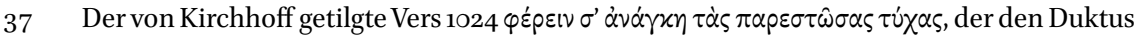
der Distichomythie zerstört und beim Scholiasten fehlt, ist wahrscheinlich eine spätere Interpolation.

38 Mit einem direktiven Sprechakt will ein Sprecher seinen Gesprächspartner zur Ausführung bzw. Unterlassung einer künftigen Handlung verpflichten. Direktive sind Verben wie ,befehlen', ,auffordern', ,bitten', ,einladen' etc., vgl. Meibauer ( $\left.{ }^{2} 2001: 195\right)$.

Zum verneinten Befehl mit ov̉ und Futur vgl. Kühner und Gerth (1898: I 176), die betonen, dass in dieser Frage „das Begehrte in strengem und drohendem Tone, zuweilen mit einer gewissen ironischen Bitterkeit ausgesagt wird."

40 Positive Höflichkeitsstrategien sind diejenigen, mit denen man den Gesprächspartner lobt oder ihm Solidarität bekundet, vgl. Meibauer (2001: 114-116). 
Antithese stehenden elliptischen Aussage $\dot{\alpha} \lambda \lambda^{\prime} \not \partial \mu \omega \varsigma^{41}$ an seiner Position festhält und der Gesprächspartnerin zu verstehen gibt, dass er nicht weiter sprechen will. Die Tatsache, dass die Abmilderung nur einen halben Vers umfasst und am Ende steht, sowie das Fehlen eines Vokativs zeigen, dass er der Gesprächspartnerin kaum Beachtung schenkt. ${ }^{42}$

\author{
[3] Euripides Orestes 1025-1026

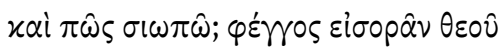

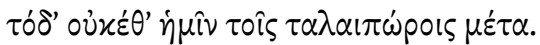

Wie kann ich still sein? Dieses Licht des Himmels hier zu schauen, ist uns Armen nicht vergönnt hinfort.

Elektra ihrerseits lehnt geschickt Orestes' Befehl zu schweigen mit der kurzen (bis zur Penthemimeres reichenden) rhetorischen Frage $x \alpha i$ ab, die durch die dunklen o-Laute Wucht erhält.. ${ }^{43}$ Formal eine Frage, die dem Gesprächspartner die Möglichkeit zur Antwort gibt, mildert sie als ,offrecord'-Strategie $^{44}$ die Ablehnung von Orestes' Befehl ab, die im Gegensatz zur Annahme desselben das nicht-präferierte Komplement der Paarsequenz Befehl-Annahme/Ablehnung ist, d.h. dasjenige Komplement, dessen Verwirklichung dem Sprecher schwerer fällt. ${ }^{45}$ Sie mildert diese zusätzlich mit einer Erklärung, also mit positiver Höflichkeit ab, die eineinhalb Verse umfasst, durch die Alliteration auf t-Laute emotional verstärkt wird und durch das gehobene poetische Vokabular feierlich erscheint: $\varphi \varepsilon ́$ Y

41 Ebenso Eur. Hec. 843; El. 753; IA 904; Ar. Ach. 956, 1024.

42 Nach Dickey (1996: 193) zeigt das Fehlen des Vokativs am Anfang an, dass der Sprecher ,is angry, or is being insulting."

43 Zu Fragen der Lautmalerei haben sich bereits in der Antike Grammatiker und Rhetoriker wie Dionysios von Halikarnass geäußert, der etwa in Comp. 14 die eu- und kakophonischen Qualitäten der Laute anhand mehrerer Beispiele beschreibt. Vgl. dazu auch Hofmann und Szantyr (1972: 712-714) und Ercolani (2003).

44 In der Terminologie der Höflichkeitstheorie von Brown und Levinson $\left({ }^{2} 1987\right)$ wird eine Aussage, die zur Gesichtswahrung des Adressaten nur indirekt gemacht wird, ,off record ${ }^{4}$ genannt, vgl. dazu Meibauer (2001: 114-116).

$45 \mathrm{Zu}$ den Paarsequenzen, englisch, adjacency pairs', vgl. Meibauer (22001: 133-135). Die Gesprächsanalyse hat gezeigt, dass bei der durch einen Befehl eröffneten Paarsequenz die Annahme leichter ist und daher schnell und mühelos ausgesprochen wird, also ,präferiert' ist, während die Ablehnung möglichst vermieden oder mit größerer Schwierigkeit und wortreicher ausgedrückt wird, weshalb sie ,nicht-präferiert‘ ist. Vgl. zum System der Präferenzen Schegloff (2007). 
onymisch statt $\dot{\eta} \lambda$ íou) ist die Periphrase des Begriffs „Leben“. Durch das beide Geschwister umfassende Personalpronomen $\dot{\eta} \mu i v(1026)$ markiert sie sodann Gemeinsamkeit mit ihrem Gesprächspartner.

$$
\begin{aligned}
& \text { [4] Euripides Orestes 1027-1028 }
\end{aligned}
$$

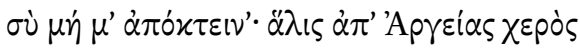

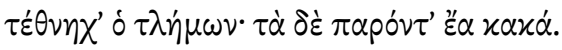

Nicht töte du mich! Schon genug von Volkeshand bin ich gemordet: denke nicht an dieses Leid!

Orest wendet sich wieder mit dem verneinten Imperativ Präsens $\alpha \dot{\pi}$ ó $x \tau \varepsilon v \nu^{\prime}$ $\left(\dot{\alpha} \pi \circ \kappa \tau \varepsilon i v \omega\right.$ wird hier metaphorisch gebraucht), ${ }^{46}$ in einem erneuten Befehlsakt bzw. einer Warnung sarkastisch an seine Schwester, die er ohne Vokativ nur mit dem Personalpronomen $\sigma \dot{v}$ - emphatisch an der Spitze des Satzes und keineswegs höflich - anspricht. Er fordert sarkastisch in einer Übertreibung, sie solle ihn nicht töten, wobei diesmal Orest neben emphatischen Mitteln wie Alliterationen und auf $\mathrm{m}$ - und t-Laute (1028) seine Aussage analog zum vorherigen Redebeitrag seiner Schwester durch das Enjambement erweitert und neben seinem impliziten Tadel vor allem seinen Unmut über ihr Verhalten und

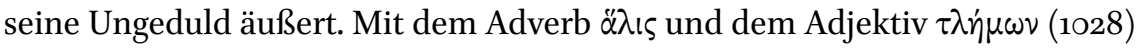
drückt Orest ein gewisses Selbstmitleid als Begründung für sein Verhalten aus, was als positive Höflichkeitsstrategie seine Aussage abmildert. Mit dem zwei-

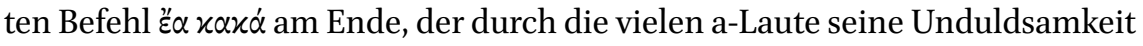
unterstreicht ${ }^{47}$ widerspricht er der Aussage seiner Schwester und fordert sie erneut auf, sich nicht um das gegenwärtige Leiden zu kümmern. Da dieser Befehl in einem gewissen Sinn Elektra trösten soll, also in ihrem Interesse ist, wird er nicht abgemildert.

[5] Euripides Orestes 1029-1030

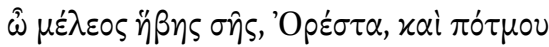

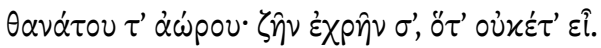

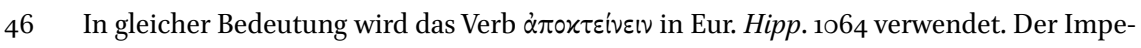
rativ Präsens drückt gemäß seinem Aspekt die Dauer bzw. den Verlauf der Handlung aus, ohne dass auf deren Abschluss Rücksicht genommen wird, vgl. Kühner und Gerth (1898: II 189).

47 Mit der Häufung von a-Lauten werden in der Tragödie oft Leiden und Schmerzen ausgedrückt, vgl. dazu Ercolani (2003: 187, 192) mit Beispielen aus den Persern des Aischylos. 
Mich jammert deine Jugend und dein früher Tod, o Bruder: leben sollst $\mathrm{du}$, und bist dahin.

Elektra fährt unbeeindruckt von Orestes' Redebeiträgen in ihrer Klage fort

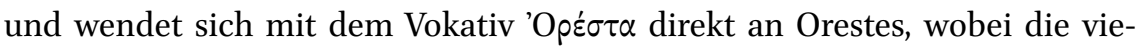
len Homoioteleuta dem mit der Partikel $\hat{\omega}$ verstärkten Ausruf des Kummers ${ }^{48}$

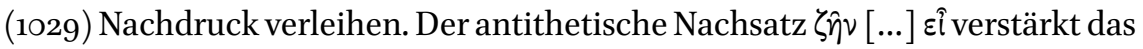

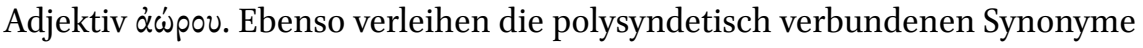

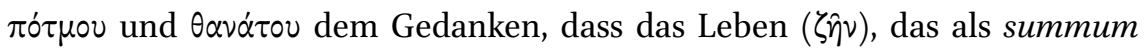
bonum aufgefasst wird, als dessen Negation ihrem Gedanken Tiefe. Dadurch, dass sie ihren Bruder ins Zentrum der Klage stellt, also sozusagen ihren expressiven Sprechakt in seinem Interesse verwirklicht, begründet sie indirekt ihre Missachtung der von Orest in der vorangehenden Replik ausgesprochenen Aufforderung.

[6] Euripides Orestes 1031-1032

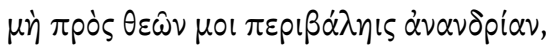

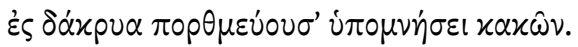

Nicht, bei den Göttern, treibe mich zu feiger Tat, die Träne weckend durch des Leids Erinnerung.

Emphatisch mit der Schwurformel $\mu \grave{\eta} \pi$ jò $\theta \varepsilon \hat{\omega} v$, also mit einer Strategie negativer Höflichkeit, ${ }^{49}$ bittet Orest in einem direktiven Sprechakt, der schwächer als ein Befehl ist, und mit dem prohibitiven Konjunktiv Aorist, der ebenfalls schwächer als die in den vorangehenden Repliken gebrauchten Imperative ist, ${ }^{50}$ seine Schwester, ihn mit ihrer Klage nicht zu einem unschicklichen Verhalten zu verleiten. Ihr Handeln beschreibt er metaphorisch mit zwei Bildern

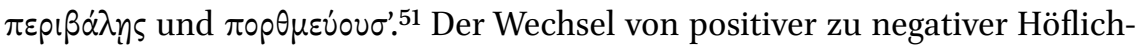
keit ist ein Anzeichen für Orestes' Hilflosigkeit gegenüber seiner Schwester; er

48 Vgl. 16 o und Hec. 425; IT 868; Med. 358 und Biehl (1965: 114).

49 Negative Höflichkeitsstrategien sind diejenigen, mit denen man sich beim Gesprächspartner für die mit dem Sprechakt verbundene (mögliche) Einschränkung seiner Handlungsfreiheit entschuldigt, vgl. Meibauer (2001: 114-116).

50 Kühner und Gerth (1898: I 238) ziehen die abmildernde Wirkung des Konjunktivs gegenüber dem Imperativ in Betracht.

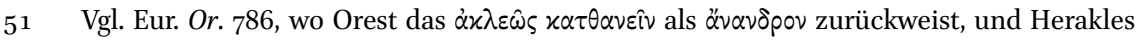
Soph. Trach. 1071-1074, der das Weinen als unmännlich ablehnt. 
hat keine guten Argumente, um sie von ihrem Verhalten abzubringen, nachdem in seinem Redebeitrag davor (1027-1028) die Selbstbemitleidung nicht die gewünschte Wirkung erzielt hatte. Er begründet sein Verhalten mit dem Ehrenkodex, also mit dem $\tau \varepsilon \lambda \iota x \dot{\nu} v \varepsilon \varepsilon \varphi \dot{\alpha} \lambda \alpha$ เov des $\varkappa \alpha \lambda \dot{o} v$, was auch als positive Höflichkeitsstrategie dient, da das Begründen des eigenen Verhaltens höflich ist.

[7] Euripides Orestes 1033-1034

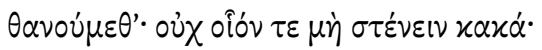

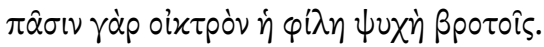

Wir gehn zum Tode: Seufzer weckt das Leiden stets, und jammernd lässt sein Leben nur der Sterbliche.

Elektra dagegen wiederholt die Feststellung, dass sie beide im Sterben liegen, indem sie asyndetisch die 1. Person Plural $\theta \alpha \nu \circ v_{\mu} \varepsilon \theta^{\prime}$ (1033) verwendet, und die Folge, dass es unmöglich ist, nicht zu klagen, durch die doppelte Negation (oن̉ $\chi$ oî́v $\tau \varepsilon \mu \grave{\eta}$...) verstärkt, wobei die unpersönliche und gnomische Ausdrucksweise als negative Höflichkeitsstrategie ihre Aussage, mit der sie indirekt Orestes' Bitte zurückweist, abmildert. Ebenso wie Orest begründet sie ihr eigenes Verhalten mit einer Gnome (1034), welche mit oixtpóv Orestes' oixtpá (1023) wiederaufnimmt und die allgemein anerkannte Maxime ( $\pi \hat{\alpha} \sigma \nu$ [...] Bporoîs als versumschließendes Hyperbaton) durch die Alliteration auf Labiale untermalt.

In der Folge wechselt Orestes, dem es nicht gelungen ist, die Schwester vom Klagen abzubringen, das Thema (1035) und spricht mit ihr über die verschiedenen Todesarten. Elektra akzeptiert, sich selbst zu töten. Orest ändert dabei allmählich seinen Ton und spricht seine Schwester nun liebevoll an. Dies geschieht nicht unmittelbar, sondern in mehreren Schritten, die wohl durch den körperlichen Kontakt und die nichtverbale Kommunikation verstärkt werden.

Zunächst reagiert Orestes sarkastisch auf Elektras Bitte (1042), ihn zu umarmen:

[8] Euripides Orestes 1043-1044

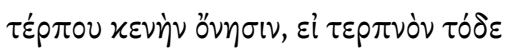

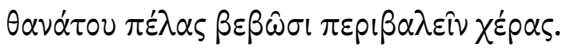

Sei froh der eitlen Freude, wenn dir's Freude macht, den Arm um die zu schlingen, die zum Tode gehn. 
Als Konzession ${ }^{52}$ gewährt er ihr diese als $\chi \varepsilon v \eta \dot{~-~ w a s ~ e i n e ~ k l a r e ~ K r i t i k ~ i s t ~-~}$

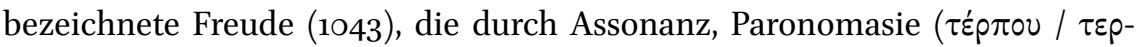
$\pi v o \dot{v})$ und die Alliterationen auf Dentale und Labiale im Enjambement verstärkt wird. Sein indirekt geäußerter Tadel wird dadurch, dass er in einem Konditionalsatz ausgedrückt wird, etwas abgemildert, da er die Möglichkeit, dass die Umarmung $\tau \varepsilon \rho \pi v o ́ v$ ist, offenlässt.

$$
\begin{aligned}
& \text { [9] Euripides Orestes 1045-1046 }
\end{aligned}
$$

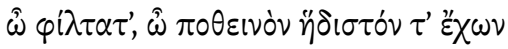

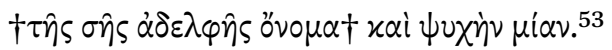

Du Liebster, der die Züge seiner Schwester trägt, die süßen, heißgeliebten, ganz ein Sinn mit ihr.

Trotz Orestes' Sarkasmus setzt Elektra ihre Rede unbeirrt fort und antwortet nicht mehr auf den Redebeitrag ihres Bruders, sondern drückt wieder in einem expressiven Sprechakt sehr erregt mit zweimaligem durch $\hat{\omega}$ eingeleitetem Ausruf, Superlativ, Enjambement und Hyperbaton ihre Emotionen aus. ${ }^{54}$ Sie betont ihre Verwandtschaft (1046) und sagt hyperbolisch, dass sie beide ein einziges Leben $(\psi v \chi \dot{\eta} \nu \mu i \alpha \nu)$ sind.

[10] Euripides Orestes 1047-1051

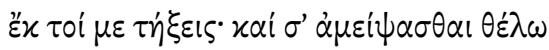

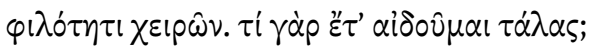

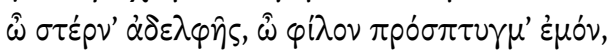

$\tau \alpha^{\prime} \delta^{\prime} \alpha \nu \tau i \pi \alpha i \delta \omega \nu$ xai $\gamma \alpha \mu \eta \lambda i o v \lambda \varepsilon \varepsilon^{\prime} \chi 0 u \varsigma$

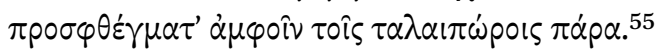

52 Biehl (1965: 115) weist auf den konzessiven Imperativ hin, vgl. Kühner und Gerth (1898: I 236-237).

53 West (1987: 131) hat dagegen $\tau \hat{\eta} \iota ~ \sigma \hat{\imath} \iota \gamma^{\prime} \dot{\alpha} \delta \varepsilon \lambda \varphi \hat{\eta} \iota \sigma \hat{\omega} \mu \alpha$ und übersetzt: „O my dearest, whose body is lovable and most delightful to your sister“. Biehl (1965: 115) hält mit Recht an

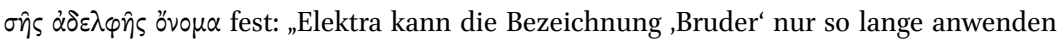
bzw. die Bezeichnung ,Schwester' hören, wie Orest lebt.“

54 Den Vokativ $\hat{\omega} \varphi \hat{i} \lambda \tau \alpha \tau^{\prime}$ verwendet Elektra auch Eur. El. gegenüber Orestes. Mit dem Superlativ $\varphi$ i $\lambda \tau \alpha \tau \varepsilon$ wird in der Tragödie ein nahes Familienmitglied angesprochen, vgl. van Emde Boas (2017a: 99).

55 West (1987: 257) betrachtet diese Verse, die die Distichomythie unterbrechen, analog zu 255-257 als echt. Willink (1986: 263) bezeichnet alle drei Verse als unpassend und hält eine Interpolation aus einem anderen Stück für möglich. 
Du wirst mein Herz erweichen, lass denn meinen Arm auch dich umfangen, denn was soll mich noch scheun? O Schwesterbrust! O Traute, die mein Arm umschlingt! Statt lieber Kinder, statt des Glücks der Ehe blieb uns Armen dieser Worte Trost allein vergönnt.

Elektras Strategie, die aus verbaler und nichtverbaler Kommunikation besteht, ist dabei, Orestes' Herz zu erweichen, wie er selbst feststellt. ${ }^{56}$ In hoher poetischer Sprache, wie die pathossteigernde Tmesis $\varepsilon^{\prime} x$... $\tau \eta^{\prime} \xi \varepsilon ı \varsigma$ mit der Metapher des Schmelzens zeigt, widerruft er seine frühere Aussage über die Männlichkeit (1031-1032) mit einer rhetorischen Frage (1048) off-record, wohl um sein Gesicht zu wahren. Er erwidert sodann die Umarmung, bedient sich also auch der nicht-verbalen Kommunikation, und drückt ähnlich wie seine Schwester mit zweimaligem, durch $\hat{\omega}$ eingeleitetem Ausruf - das erste Mal in diesem Gespräch, dass er Elektra liebevoll anspricht - seine Geschwisterliebe aus. Vom Selbstmitleid (1048 $\tau \dot{\alpha} \lambda \alpha \varsigma$; vgl. $1028 \tau \lambda \dot{\eta} \mu \omega \nu)$ geht er zum Mitleid mit dem

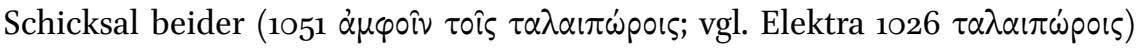
über und verrichtet ähnlich wie Elektra im Redebeitrag davor einen expressiven Sprechakt der Klage, wobei der Gegensatz durch Antithese mit Paradoxon (die geschwisterliche Umarmung anstelle von Kindern und Heirat, also ein Hysteron proteron), Hyperbaton und Enjambement (1050-1051) den Sprechakt verstärkt.

In der Folge (1052-1064) äußert Elektra den Wunsch nach einem gemeinsamen Grab und fragt erst jetzt (1056-1057), ob der als böse (1057) bezeichnete Menelaos ihm geholfen hat. In einer längeren p̂noı antwortet Orestes kurz, dass Menelaos nichts getan hat. Seine grimmige Entschlossenheit, seinen Wert und seine Abstammung (1060-1061) durch einen glorreichen Tod zu bewei-

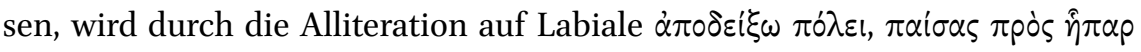

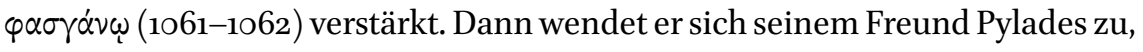
der das ganze Gespräch zwischen den Geschwistern stumm mitverfolgt hat.

[11] Euripides Orestes 1065-1068

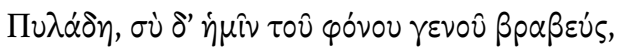

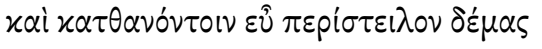

$5^{6}$ Das Futur hier und 1048 zeigt, dass „siamo quindi in presenza di un processo che viene descritto nel suo stesso sorgere“ (Di Benedetto 1965: 209), vgl. auch Kühner und Gerth (1898: I 173, Nr. 5). Im Gegensatz dazu erwidert Iphigenie in der IA 1433-1466 die Tränen und die Umarmungen der Mutter nicht, weil sie deren Wahrnehmung der Situation nicht teilt (siehe auch Sorrentino in diesem Band). 


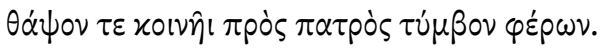

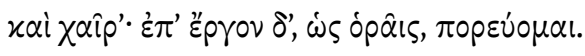

Du, Pylades, sollst unsers Todes Zeuge sein. Für unsere Leichen sorge wohl, sind wir dahin, vereint bestatte bei dem Grab des Vaters uns und lebe wohl. Ich schreite, wie du siehst, zur Tat.

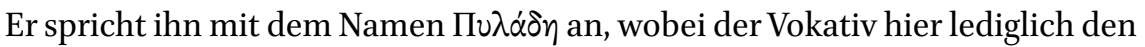

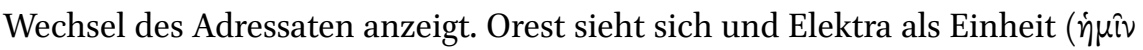
und 1067 xoเvî $\iota$ ), von der er Pylades unterscheidet ( $\left.\sigma \dot{\nu} \delta^{\prime}\right)$. Der Befehl, durch drei Imperative und Homoioteleuton verstärkt, findet erst durch den Abschiedsgruß am Ende xai $\alpha \propto i ̂ p^{\prime}(1068)^{57}$ eine leichte Abmilderung; dass Orest seitens seines Freundes keine Replik, sondern die stille Ausführung seines Befehls erwartet, zeigt die letzte Aussage, dass er jetzt zur Tat schreitet; mit dem starken affektiven Einschub ஸ́s ópâı s will er die Aufmerksamkeit und die (implizite) Zustimmung seines Freundes erreichen, mildert aber zugleich mit dieser Strategie positiver Höflichkeit den Befehl ab, indem er eine Begründung für sein Verhalten angibt.

[12] Euripides Orestes 1069-1070

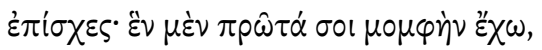

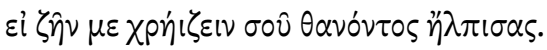

Halt ein! Vor allem muss ich eins dir tadeln, wenn du wähntest, dass ich leben will, wenn du mir stirbst.

Pylades erwidert auf Orestes' Befehl mit einer nicht-präferierten Ablehnung, die mit dem Imperativ ह̇ंí $\sigma \chi \varsigma \varsigma$ sehr stark und aufgrund der Dringlichkeit der Situation hier nicht abgemildert wird, also in der Terminologie der Höflich-

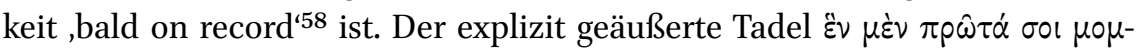

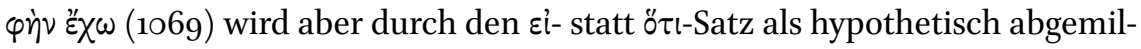

57 xai verbindet $\chi \alpha \hat{\imath} \rho^{\prime}$ nicht mit dem vorausgehenden Imperativ, sondern steigert $\chi \alpha \hat{\imath} \rho^{\prime}$, so

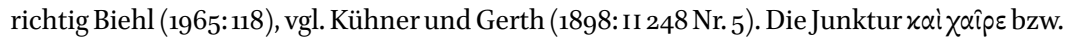

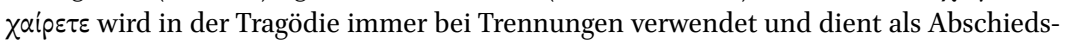
gruß, vgl. dazu Ercolani (2000: 187).

$5^{8}$ In der Terminologie der Höflichkeitsmodelle wird eine Aussage, die direkt und für den Adressaten ,gesichtsbedrohend' ist, ,bald on record' genannt, vgl. dazu Meibauer $\left({ }^{2} 2001\right.$ : 114-116). 
dert, ${ }^{59}$ wobei der zentrale Gedanke - Pylades mag nicht leben, wenn Orest stirbt - durch die kunstvolle rhetorische Ausarbeitung mit der Antinomie von Leben und Tod im äußeren sowie von Pylades und Orestes in inneren Ring ( $\zeta \hat{\eta} v$ $\mu \varepsilon \chi \varphi^{\prime}\left(\zeta \varepsilon \iota \nu \leftrightarrow \sigma 0 \hat{~ \theta \alpha v o ́ v \tau o \varsigma) ~ b e s o n d e r e s ~ G e w i c h t ~ e r h a ̈ l t . ~}{ }^{60}\right.$ Der Gegensatz zwischen beiden wird also durch den Gebrauch der Personalpronomina der ersten und zweiten Person ( $\sigma \circ, \mu \varepsilon, \sigma \circ \hat{)})$ markiert.

Nach diesem ersten Schlagabtausch wird das in Pylades' Replik vorgegebene

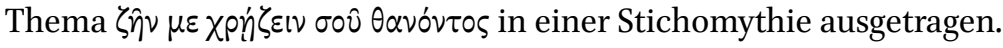

\section{[13] Euripides Orestes 1071}

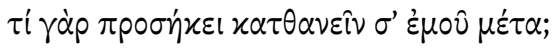

Warum gebührte dir, mit mir zu sterben, Freund?

Orest beginnt sein Gegenargument ,off record' mit der lebhaften rhetorischen

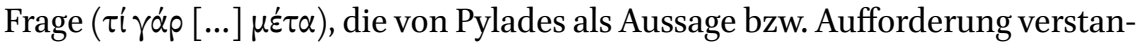
den werden soll, dem unpersönlichen $\pi \rho \circ \eta^{\prime} x \varepsilon เ$ und der Wiederaufnahme des Gegensatzes der beiden hinsichtlich des Sterbens. Er betrachtet das Opfer des

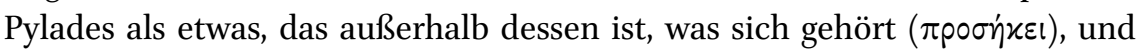
daher nicht gerechtfertigt ist.

\section{[14] Euripides Orestes 1072}

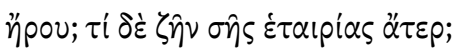

Du fragst? O Freund, wie kann ich leben ohne dich?

Durch ク̈pov61 zeigt Pylades, dass er Orestes' uneigentliche Frage nicht akzeptiert, sondern empört dessen Sprechakt zurückweist, wie die (rhetorische) Gegenfrage beweist, die statt des Todes nun wieder das Leben fokussiert und seine Aussage von Vers 1070 präzisiert. Als Prädikat des zweiten Fragesatzes ist $\pi \rho \circ \eta^{\prime} x \varepsilon$ l aus dem vorangehenden Satz zu ergänzen. Seine Aussage ist somit die

59 Di Benedetto (1965: 213): „हi introduce quindi inaspettatamente una attenuazione del rimprovero." Vgl. Kühner und Gerth (1898: II 369, Nr. 8).

6o Ähnlich äußert sich Pylades gegenüber Orest auch Eur. IT 674-686 in einer Rede, die wie hier in einem Dialog zwischen den beiden Freunden steht und vielleicht als Vorlage diente.

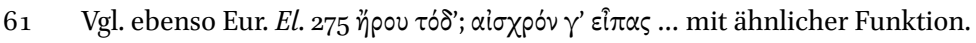


exakte Negation von Orestes' Redebeitrag, aber als neues Element kommt die

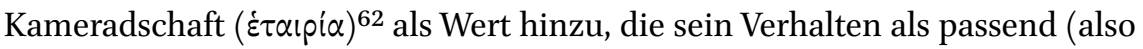
als $\pi$ poôिxov) rechtfertigt.

\section{[15] Euripides Orestes 1073}

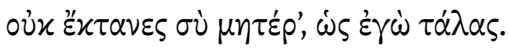

Du schlugest deine Mutter nicht, wie ich getan.

Da Pylades Orestes' Ansinnen erfolgreich widerstanden hat, wechselt Orest jetzt das Argument. Wiederum wird der Gegensatz zwischen den beiden durch

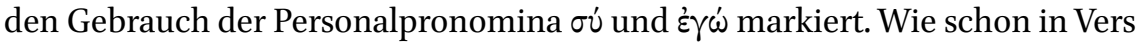
1048 nennt er sich $\tau \dot{\alpha} \lambda \alpha \varsigma$ und äußert damit Selbstmitleid.

\section{[16] Euripides Orestes 1074}

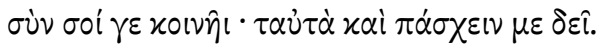

Ich tat es mit dir: teil ich denn dein Leiden auch!

Pylades übernimmt wieder die Satzaussage des Orestes, korrigiert sie aber

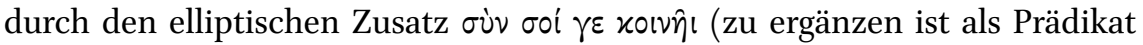
aus Orestes Replik, allerdings in der 1. Person हैx zwar pleonastisch wirken, aber die Einheit der beiden betonten, und durch die Alliteration und die Partikel $\gamma \varepsilon$ verstärkt werden, was eine starke emotionale Ergriffenheit anzeigt. Wie schon Elektra in Vers 1067 verwendet er das Adverb xoเvn̂, um ihre Einheit, die typisch für die Freundschaft ist, zu betonen. ${ }^{63}$

[17] Euripides Orestes 1075-1083

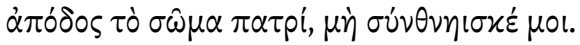

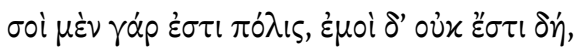

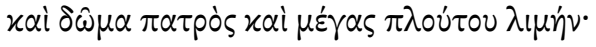

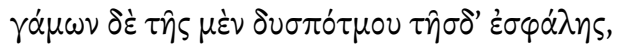

62 Dieser Ausdruck bezeichnet besonders im politischen Bereich eine spezielle Art der Freundschaft (etwa bei Konspirationen wie im vorliegenden Fall und bei Thuc. 3.82.46), vgl. dazu Konstan (1997: 6o-63).

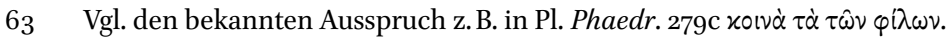




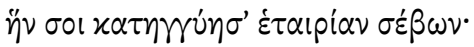

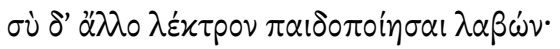

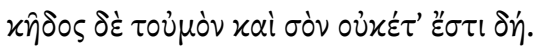

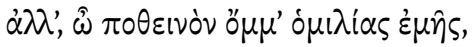

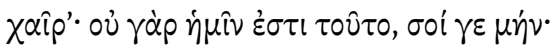

Gib Deinem Vater dich zurück, stirb nicht mit mir! Du hast noch eine Vaterstadt, ich keine mehr, ein Vaterhaus noch und des Reichtums weiten Port. Zwar dieser Unglückselgen Hand erhältst du nicht, die, deine Freundschaft ehrend, ich dir angelobt: Zum Ehesegen suche dir ein andres Weib; nicht mein Verwandter wirst du mehr, noch deiner ich. So lebe wohl, sei glücklich, du, mein lieber Freund: Ich kann es niemals werden, doch du kannst es noch; denn uns, den Toten, lächelt keine Freude mehr.

Orestes antwortet, nachdem es ihm vorher nicht gelungen war, Pylades zu überreden, in einer längeren Rede. Seine stark mit positivem und negativem Imperativ ausgedrückte Forderung wird nicht abgemildert, da sie im Interesse des Adressaten ist. Er soll sein Leben seinem Vater geben (also leben)

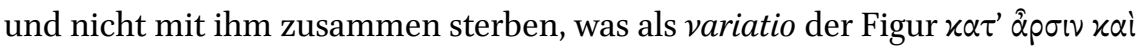

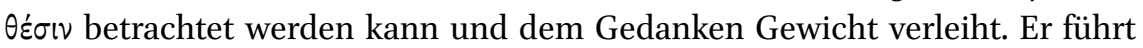

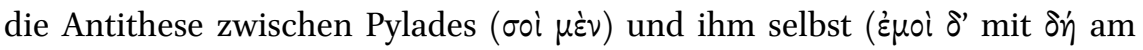
Ende $^{64}$ verstärkt) in einer polysyndetischen Aufzählung mit wachsenden Glie-

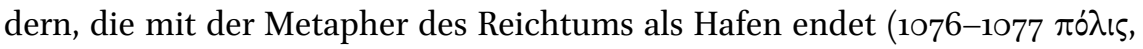

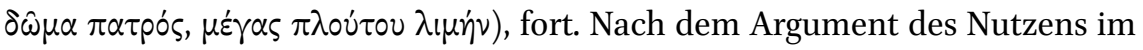
ersten Teil der Rede folgt dasjenige des Rechts (1078-1081). Da die von ihm versprochene Ehe mit Elektra nicht zustande kommt, rät er Pylades, eine andere Gattin zu suchen (1080), und endet mit der Erklärung, dass zwischen ihnen kein Verwandtschaftsverhältnis ( $x \hat{\eta} \delta \circ \varsigma)$ mehr besteht und Pylades ihm gegenüber keine Verpflichtung mehr hat, wobei die Partikel $\delta \dot{\eta}$ am Ende (1081 wie 1076) seine Aussage verstärkt. Zuletzt verabschiedet er sich wieder, ist aber im Gegensatz zu Vers 1068, ausführlicher, wie das Enjambement zeigt, und liebvoller, wie

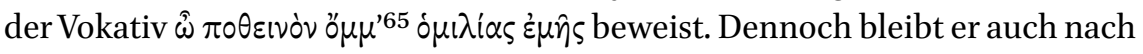

64 Di Benedetto (1965: 214) weist auf die merkwürdige Schlussstellung von $\delta \dot{\eta}$ hin: „Qui il $\delta \eta \dot{~ i n ~ p o s i z i o n e ~ d i ~ r i l i e v o ~ s e r v e ~ a ~ d a r ~ m a g g i o r ~ f o r z a ~ d i ~ c o n v i n z i o n e ~ a l l a ~ c o n t r a p p o s i-~}$ zione $\sigma \circ i-\varepsilon \dot{\varepsilon} \mu o$. Oreste vuole mostrarsi assolutamente convinto del suo rifiuto del sacrificio dell'amico." Zum emphatischen ón vgl. Denniston (21954: 214-215).

65 Zum liebevollen Gebrauch von ö $\mu \mu \alpha$ vgl. auch IT 905; IA 354; im Vokativ Alc. 1133 und Ion 1261; Soph. Aj. 977. 
dem Abschiedsgruß ${ }^{66}$ (1083) bei der Trennung zwischen ihm und Elektra ( $\dot{\eta} \mu i \nu$ wie schon 1065) auf der einen, und Pylades auf der anderen Seite, was durch den emphatischen Gebrauch adversativer Partikeln ( $\left.\sigma \circ i \gamma \varepsilon \mu \eta^{\prime} \nu\right)$ unterstrichen wird.

[18] Euripides Orestes 1085-1099

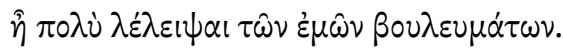

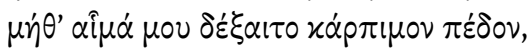

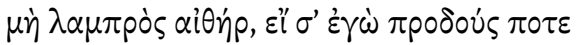

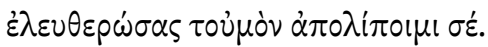

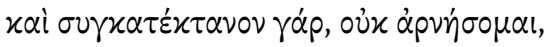

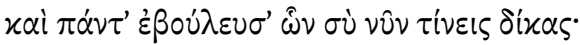

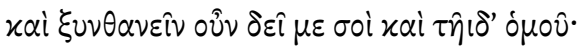

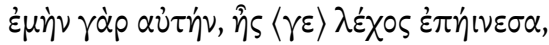

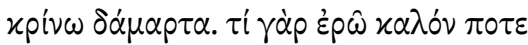

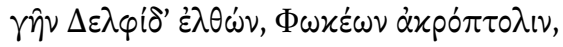

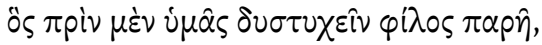

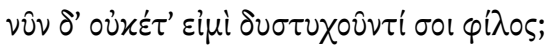

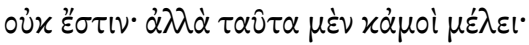

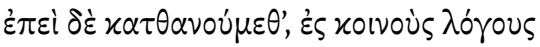

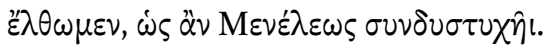

Was meine Worte wollten, hast du nicht erkannt. Fruchtbares Erdreich möge nie noch helle Luft mein Blut empfangen, wenn ich dich lasse, dich verrate, Freund, auf meine Rettung nur bedacht! Ich habe mitgemordet, ja, ich leugn' es nicht, und alles mitberaten, was du büßen musst: So muss ich auch mitsterben, wenn du stirbst und sie. Denn diese Jungfrau, deren Hand du mir gelobt, ist meine Gattin. Welchen Vorwand sänn' ich aus, nach Delphi kommend auf die Burg von Phokis, wenn ich euer Freund war, eh die Not euch heimgesucht, und jetzt in deinem Leide dich verleugnete? Niemals! - Doch eines liegt am Herzen mir wie euch: Da wir nun sterben sollen, lasst uns noch vereint beraten, wie Menelaos mit verderben mag.

Erneut drückt Pylades seine Ablehnung analog zu seiner Erwiderung in der ersten Rede (1069) aus. Emphatisch und feierlich stellt er mit der verstärkten

66 Di Benedetto (1965: 215): „La duplicità del significato di $\chi \alpha \hat{p} \varepsilon \varepsilon$ si prestava bene a una considerazione che intensificava l'effetto patetico della rhesis di Oreste." 
Schwurpartikel $\hat{\eta} \pi 0 \lambda \dot{u}$ und dem schweren Homoioteleuton tadelnd fest, dass Orest seine Pläne nicht versteht (1086-1088). Mit der agonistischen Metapher des Zurückbleibens suggeriert er, verbunden mit einem Tadel, Orestes' Rückstand in der Freundschaft. Seine Entschlossenheit unterstreicht er mit einer doppelten Selbstverfluchung, ${ }^{67}$ einem kommissiven Sprechakt, ${ }^{68}$ und mit der Anapher $\mu \dot{\eta}^{\prime} \theta^{\prime}$ und $\mu \dot{\prime}^{\prime}$ (1086-1087), wobei die beiden antithetischen Partizipien

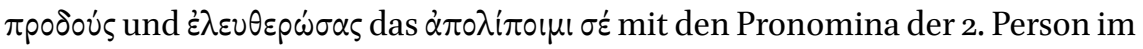
äußeren Ring chiastisch beschreiben (1087-1088); von Orest übernimmt er den Gegensatz zwischen beiden durch die Gegenüberstellung der Personalpronomina und gibt durch Enjambement seiner Aussage mehr Raum. In Anapher mit dreimaligem xai führt er (1089-1091) polysyndetisch die Begründung mit Hys-

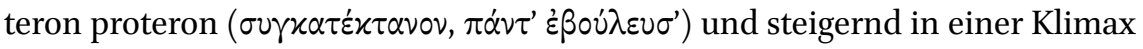
an, was als positive Höflichkeitsstrategie, mit der die feierliche Selbstverfluchung abgemildert wird, gedeutet werden kann: Sie haben gemeinsam getötet und müssen daher auch gemeinsam sterben ( $\xi \cup v \theta \alpha v \varepsilon i v)$, wie er 1091 betont. Die nur mit dem Pronomen $\tau \hat{\eta} \iota \delta$ erwähnte Elektra betrachtet er, was in dieser Situation ein Paradox ist, als seine Ehefrau (1093) und antwortet somit auf Orestes' zweites Argument (1078-1081) nach dem iustum. In einer rhetorischen

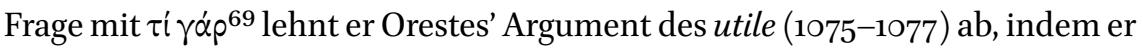
das honestum ( $\varkappa \alpha \lambda o ́ v)$ der heroischen Schamkultur und eng damit verbunden

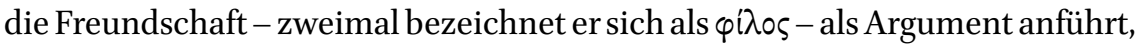
das, da es in den Bereich des Ethos fällt, ihn gleichzeitig als Sprecher positiv charakterisiert. Die Ablehnung der Vorstellung, in der Not seine Freunde zu verlassen, drückt er formal off record in einer rhetorischen Frage aus, die durch die Alliteration auf Labiale (1095), die Antithese von $\pi$ piv $\mu \dot{\varepsilon} \nu$ und vôv

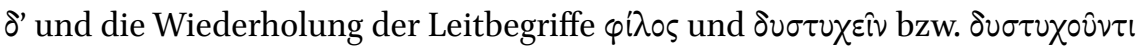
verstärkt wird. Bei der Gegenüberstellung von Personalpronomina der 1. und 2. Person Singular tritt jetzt die 2. Plural (1095 ن́ $\mu \hat{\alpha} \varsigma)$ an die Stelle der 2. Singular; Pylades betrachtet Orest und Elektra als Einheit. Die logische Folgerung

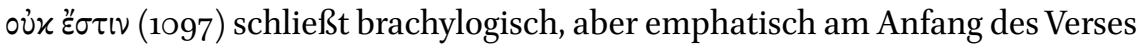
die Erwiderung auf Orestes' Rede ab; anstelle der peroratio folgert Pylades, der in den beiden letzten Versen durch die 1. Person Plural der Prädikate alle drei

\footnotetext{
67 Selbstverwünschungen als rhetorisches Mittel kommen schon in der archaischen Literatur (etwa Hom. Od. 24.433-436) und auch Eur. Hipp. 1028-1031 oder Soph. ot 1427-1428 vor.

68 Mit einem kommissiven Sprechakt verpflichtet sich ein Sprecher auf die Ausführung einer zukünftigen Handlung; dazu gehören Akte wie ,versprechen', ,geloben', ,drohen‘ etc., vgl. Meibauer (22001: 95).

69 Vgl. dazu Denniston ( $\left.{ }^{2} 1954: 62-63\right)$.
} 
als Einheit auffasst, dass sie in der Gewissheit des Todes gemeinsam planen

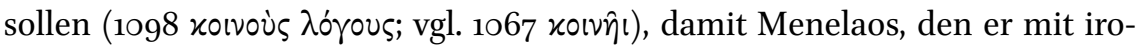
nischem Unterton zum Teilhaber des Leids macht, mitleide (das sehr seltene

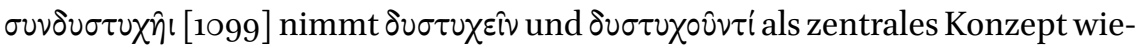
der auf). ${ }^{70}$

\section{[19] Euripides Orestes 1100

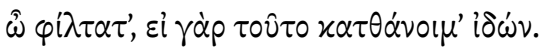

Ach, säh ich das geschehen, wenn ich sterbe, Freund!

Orestes' freudige Antwort zeigt an, dass er sich von Pylades' Rede hat überzeugen lassen. Den liebevollen Vokativ $\varphi$ i $\lambda \tau \alpha \tau^{\prime}$ hatte Elektra (1045) gegenüber Orest gebraucht. Der Wunsch ist, wie der Optativ zeigt, für ihn als erfüllbar angenommen und dient dazu, indirekt seine Zustimmung auszudrücken. ${ }^{71}$ In der Folge wird der Racheplan entworfen.

In der analysierten Passage setzen alle drei Sprecher rhetorische und argumentative Mittel ein: Elektra, die ihre Gefühle vor allem in expressiven Sprechakten äußert, gelingt es, Orestes' schroffe Ablehnung der Kommunikation durch eine Mischung von Klage und Trost zu überwinden und ihn zu überreden, seine Gefühle zu zeigen. Mehr als durch eine die condicio humana betreffende Gnome (1034) überwindet sie Orestes' auf dem adligen Ehrencodex beruhenden Einwand durch den Einsatz von emotionaler Sprache, also Pathos, wie die Klangfiguren zeigen, sowie durch positive Höflichkeitsstrategien und formale off recordness, Vokative, nichtverbale, körperliche Mittel (Tränen, Umarmung). Dagegen ist Pylades ,rationaler und argumentiert klar, ohne auf emotionale rhetorische Mittel, die seinen Argumenten Emphase verleihen, zu verzichten (er verwendet zugleich Ethos und Pathos). Er setzt Abmilderungen oder Höflichkeitsstrategien vor allem in der langen Rede ein, tadelt sonst aber Orest explizit, indem er sich auf den Wert der Freundschaft beruft; auch in diesen Fällen bedroht also die Direktheit das Selbstbild des Adressaten nicht,

$70 \quad$ Schwinge (1968: 76) meint, dass erst Pylades' Vorschlag am Ende der ṕñøऽ Orestes überredet und den Umschwung erreicht; dies ist aber nur deshalb möglich, weil Pylades in der vorangehenden Auseinandersetzung durch die Betonung der Freundschaft als wichtigstem movens das Feld vorbereitet hatte.

71 Denniston ( ${ }^{2}$ 1954: 92) weist darauf hin, dass solche Wünsche im Drama vor allem in Antworten vorkommen. 
weil die Akte zugunsten des Adressaten geäußert werden. Hat Orestes versucht, Pylades' Opfer mit den Argumenten der Angemessenheit, des Nutzens und des Rechts abzuwenden, rechtfertigt jener seine Opposition am stärksten mit dem Argument der Freundschaft. Er geht dabei sehr genau auf Orestes' Punkte ein und benutzt bei der Widerlegung in der Stichomythie sogar dessen Formulierungen, kommt aber zu entgegengesetzten Schlüssen. Sowohl bei Elektra als auch Pylades erkennt Orestes, der sich vor allem in direktiven Sprechakten an seine Gesprächspartner gewendet hat, ihre guten Absichten, weshalb er sich jeweils am Ende der beiden untersuchten verbalen Interaktionen mit sehr affektiven Vokativen an beide wendet. Elektra und Pylades gelingt es auf unterschiedliche Weise, Orestes' Wunsch nach Isolation und seine Resignation zu überwinden und alle drei zu einer Einheit zusammenzuschweißen.

Die Untersuchung der rhetorischen Gestaltung und der argumentativen Mittel, die im Dialog und in den ṕnбøı vorkommen und die keinesfalls nur dem ornatus oder der Ergötzung der extrafiktionalen Rezipienten dienen, sondern wichtige Instrumente sind, um die Bedeutung der geäußerten Gedanken und die emotionale Betroffenheit der Sprecher, die dadurch auch charakterisiert werden, zu verdeutlichen und zu verstärken, ist in Verbindung mit einem funktionalen Ansatz wie der Pragmatik für das Verständnis der verbalen Interaktionen von großem Nutzen. Die Pragmatik allein reicht, wie die Analyse einiger Passagen des Orestes gezeigt hat, angesichts der Konventionen der tragischen Kunstsprache, die mit der Umgangssprache zwar kommensurabel ist, aber ein eigenes stilistisches Register aufweist, dazu nicht aus, da durch die rhetorische Ausgestaltung emotionale Färbungen und gedankliche Nuancen ausgedrückt werden können, die in der alltäglichen Sprache mit anderen verbalen (und nicht-verbalen) Mitteln verwirklicht werden..$^{72}$ Gerade die vielen Klang-, Wort und Gedankenfiguren, die man in einer solchen Häufung in der alltäglichen Konversation vermisst, spielen, wie gezeigt, in der Kommunikation auf der Bühne eine wichtige Rolle und tragen als Indikatoren emotionaler Betroffenheit der Figuren zusammen mit der Verwendung weiterer rhetori-

72 Schon Elam (1983: 66) hat anhand von Beispielen aus Dramen gezeigt, dass bei der Interpretation eines Stücks, dessen Sprache nicht unmittelbar mit der alltäglichen Konversation kommensurabel ist, die von der Pragmatik gelieferten Kategorien durch weitere analytische Mittel wie die Rhetorik oder die Stilistik ergänzt werden müssen. 
scher Stilmittel in entscheidendem Maß zum Verständnis der Passage bei. Aus diesem Grund darf man, anders als Sperber und Wilson meinten, gerade bei der Analyse einer literarischen Gattung wie der Tragödie nicht auf den wertvollen Beitrag der Rhetorik verzichten.

\section{Bibliographie}

Austin, J.L., ( ${ }^{2} 1975$ [1962]), How to Do Things with Words, Oxford.

Battezzato, L., (2001), ,Enjambement, iati e stile di recitazione nella tragedia greca', Seminari Romani 4, 1-38.

Battezzato, L., (2018 [2008]), Linguistica e retorica della tragedia greca, Rom.

Bers, V., (1994), ,Tragedy and Rhetoric', in I. Worthington (Hg.), Persuasion: Greek Rhetoric in Action, London/New York, 176-195.

Bers, V., (1997), Speech in Speech: Studies in Incorporated Oratio Recta in Attic Drama and Oratory, Lanham.

Biehl, W., (1965), Euripides, Orestes, Berlin.

Brown, P. und Levinson, S.C., ( ${ }^{2} 1987$ [1978]), Politeness: some Universals in Language Usage, Cambridge.

Caffi, C., (2001), La mitigazione. Un approccio pragmatico alla comunicazione nei contesti terapeutici, Münster.

Cohen, D., (1994), ,Classical Rhetoric and Modern Theories of Discourse', in I. Worthington (Hg.), Persuasion: Greek Rhetoric in Action, London/New York, 69-82.

Denniston, J.D., ( ${ }^{2} 1954$ [1934]), The Greek Particles, Oxford.

Di Benedetto, V., (1965), Euripidis Orestes, Florenz.

Dickey, E., (1996), Greek Forms of Address: from Herodotus to Lucian, Oxford.

Diggle, J., (1994), Euripidis Fabulae, Band 3, Oxford.

Donner, J.J., (2016), Euripides, die Dramen; nach der Übersetzung von J.J. Donner und der Bearbeitung von R. Kannicht neu herausgegeben von B. Zimmermann, Band 2, Stuttgart.

Dubischar, M., (2001), Die Agonszenen bei Euripides, Stuttgart/Weimar.

Elam, K., (1983), ,Atti e giochi linguistici nel dramma', in G. Aston, W. Dodd, R. Mullini, P. Pugliatti und R. Zacchi (Hg.), Interazione, dialogo, convenzioni. Il caso del testo drammatico, Bologna, 63-73.

Emde Boas, E. van, (2017a), Language and Character in Euripides' Electra, Oxford.

Emde Boas, E. van, (2017b), ,Analyzing Agamemnon: Conversation Analysis and Particles in Greek Tragic Dialogue', Classical Philology 112, 411-434.

Ercolani, A., (2000), Il passaggio di parola sulla scena tragica. Didascalie interne e struttura delle rheseis, Stuttgart/Weimar.

Ercolani, A., (2003), ,Figure di suono nei Persiani di Eschilo. Una proposta d'indagine‘, 
in R. Nicolai (Hg.), PУгмог: Studi dipoesia, metrica e musica greca offerti dagli allievi a Luigi Enrico Rossi per i suoi settant'anni, Rom, 173-203.

Goldhill, S., (1997), ,The Language of Tragedy‘, in P.E. Easterling (Hg.), The Cambridge Companion to Greek Tragedy, Cambridge, 127-15o.

Grice, H.P., (1989), Studies in the Way of Words, Cambridge, Mass.

Hess-Lüttich, E.W.B., (1980), ,Literatur und Konversation. Der literarische Dialog als Gegenstand empirischer Textwissenschaft', in E.W.B. Hess-Lüttich (Hg.), Literatur und Konversation, Wiesbaden, $5^{-22}$.

Hess-Lüttich, E.W.B., (2001a), ,Gesprächsformen in der Literatur', in K. Brinker, G. Antos, W. Heinemann und S.F. Sager (Hg.): Text- und Gesprächslinguistik / Linguistics of Text and Conversation, Teilband 2, Berlin/New York, 1619-1632.

Hess-Lüttich, E.W.B., (2001b), ,Gesprächsanalyse in der Literaturwissenschaft', in K. Brinker, G. Antos, W. Heinemann und S.F. Sager (Hg.): Text- und Gesprächslinguistik / Linguistics of Text and Conversation, Teilband 2, Berlin/New York, 16401655 .

Hofmann, J.B. und Szantyr, A., (1972), Lateinische Syntax und Stilistik, München.

Jong, I.J.F. de, (1991), Narrative in Drama: the Art of the Euripidean Messenger Speech, Leiden/New York/Kopenhagen/Köln.

Konstan, D., (1997), Friendship in the Classical World, Cambridge.

Kühner, R. und Gerth, B., (1898), Ausführliche Grammatik der griechischen Sprache, Zweiter Teil: Satzlehre, 2 Bände, Hannover.

Landfester, M., (1997), Einführung in die Stilistik der griechischen und lateinischen Literatursprachen, Darmstadt.

Larrazabal, J.M. und Korta, K., (2002), ,Pragmatics and Rhetoric for Discourse Analysis: some Conceptual Remarks', Manuscrito 25, 33-48.

Lausberg, H., ( ${ }^{3} 1990$ [1960]), Handbuch der literarischen Rhetorik, Stuttgart.

Lechner, M., (1874), De Euripide rhetorum discipulo, Ansbach.

Lloyd, M.A., (1992), The Agon in Euripides, Oxford.

Lloyd, M.A., (1999), ,The Tragic Aorist', Classical Quarterly 49, 24-45.

Lloyd, M.A., (2006), ,Sophocles in the Light of Face-Threat Politeness Theory', in I.J.F. de Jong und A. Rijksbaron (Hg.), Sophocles and the Greek Language: Aspects of Diction, Semantics and Pragmatics, Leiden/Boston, 225-239.

Lloyd, M.A., (2009), ,The Language of the Gods: Politeness in the Prologue of the Troades', in J.R.C. Cousland und J.R. Hume (Hg.), The Play of Texts and Fragments: Essays in Honour of Martin Cropp, Leiden/Boston, 183-192.

Mannsperger, B., (1971), ,Die Rhesis', in W. Jens (Hg.), Die Bauformen der griechischen Tragödie, München, 143-181.

Meibauer, J., (22001 [1999]), Pragmatik. Eine Einführung, Tübingen.

Miller, T., (1887), Euripides rhetoricus, Göttingen.

Mortara Garavelli, B., $\left({ }^{15} 2014\right.$ [1988]), Manuale di retorica, Mailand. 
Pelling, C., (2005), ,Tragedy, Rhetoric, and Performance Culture', in J. Gregory (Hg.), A Companion to Greek Tragedy, Malden/Oxford/Chicester, 83-102.

Perelman, C. und Olbrechts-Tyteca, L., (1958), Traité de l'argumentation: la nouvelle rhétorique, Paris.

Pfister, M., (11 2001 [1977]), Das Drama, München.

Piazza, F., (2011), ,L'arte retorica: antenata o sorella della pragmatica?', Esercizi Filosofici $6,116-132$.

Riedweg, C., (2000), ,Der Tragödiendichter als Rhetor? Redestrategien in Euripides' Hekabe und ihr Verhältnis zur zeitgenössischen Rhetoriktheorie', Rheinisches Museum für Philologie 143, 1-32.

Schegloff, E.A., (2007), Sequence Organization in Interaction, Cambridge.

Schuren, L., (2015), Shared Storytelling in Euripidean Stichomythia, Leiden/Boston.

Schwinge, E.-R., (1968), Die Verwendung der Stichomythie in den Dramen des Euripides, Heidelberg.

Seidensticker, B., (1971), ,Die Stichomythie', in W. Jens (Hg.), Die Bauformen der griechischen Tragödie, München, 183-220.

Sperber, D. und Wilson, D., (1980), ,Rhetoric and Relevance', in D. Wellbery und J. Bender (Hg.): The Ends of Rhetoric: History, Theory, Practice, Stanford, 140-155.

Tietze, F., (1933), Die Euripideischen Reden und ihre Bedeutung, Breslau.

Ungeheuer, G., (1980), ,Gesprächsanalyse an literarischen Texten: Lessing, Der Freigeist", in E.W.B. Hess-Lüttich (Hg.), Literatur und Konversation, Wiesbaden, 43-71.

Venier, F., (2008), Il potere del discorso: retorica e pragmatica linguistica, Rom.

West, M.L., (1987), Euripides, Orestes, Warminster.

Willink, C.W., (1986), Euripides, Orestes, Oxford.

Wright, M., (2008), Euripides, Orestes, London.

Zimmermann, B., (2011), ,Das Drama', in B. Zimmermann (Hg.), Handbuch der griechischen Literatur der Antike, Band 1: Die Literatur der archaischen und klassischen Zeit, München, 451-610. 
-978-90-04-44026-5

Downloaded from Brill. com $04 / 26 / 2023$ 11:30:38AM via free access 


\section{Index Rerum}

All terms listed in the index not only refer to the given word, but also cover nouns, adjectives, and verbs derived from the same root when relating to the same notion (e.g. 'deceit' also includes 'deception', 'deceptive', 'deceitful', 'deceive'). In addition, a German translation is recorded of those terms that occur in a paper composed in German (e.g. 'adjacency pair' / 'Paarsequenz').

address / Anrede 7, 70-75, 77-92, 168, 172,

$175,213,218,243,247,249-25$ o, 329,

$347-348$

see also vocative

adjacency pair / Paarsequenz 7, 7on1, 78,

9o, 107, 161, 163, 283, 289, 322n16, 455

expansion (of an adjacency pair) /

Sequenzerweiterung 107-112,151,

201, 216-217, 219

see also insertion sequence, pre-sequence advice / Rat(schlag) 3, 10, 77, 82, 164-165, 223, 240-241, 246-247, 250, 259, 264288, 328-329, 335n63, 435, 464

Agamemnon $36,64,160,162-163,165-170$, $172-174,176,193,323,330,359,423$

age $74-75,8 \circ, 84,92$

Ajax $\quad 8,25-30,32,39,53 n 18,55,65^{-66,104}$, $106,122,124,126-136$

alliteration see under figure of speech ambiguity (in communication) / Zweideu-

tigkeit $38,136,155,162 \mathrm{n} 4,188,2 \mathrm{O}$, 279n22, 327n42, 333, 383, 395-396, 399, 410

anaphora processing $\quad 20-21$

Andromache 404-408, 410-413, 418, 423436

aposiopesis see under figure of speech assertive (speech act) see under speech act

Athena 8, 26, 29, 123, 125-136, 259

Atreus 435-440

audience involvement 123,136

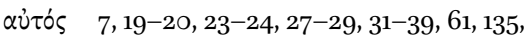
328

body / Körper $11,24,29-36,39,175,177$, $339-340,344,347,35^{\circ-} 35^{1}, 356$, 35936 o, 365, 373, 4o3n2, 426n2o, 458, 467

body language $\quad 344,365,382 \mathrm{n} 1$ see also gesture, non-verbal (communication) break (in contact) $\quad 320,323-324,327,329-$

$331,333,335$

Cassandra $36-37,225,320-324,326-327$, $336,405 n 6$

centre vs. periphery $24,28,33-34,37$

characterisation (of dramatic characters) /

Charakterisierung $\quad 7-9,84,91,96-97$, 10o, 106, 111, 116, 141n $5,146,160-161,164$, $168,172,192-193,197 \mathrm{n}_{5} \mathrm{O}, 2 \mathrm{O}, 214,22 \mathrm{O}$, 225, 237n3, 295-296, 451-452, 466, 468 chiasmus see under figure of speech clarity (of communication) / Klarheit 145, 153-154, 157-158, 170, 209

Clytaemestra / Klytaimestra 8, 64, 161-169, 172-174, 176-181, 320-324, 326-328, 330, 351, 359

commissive (speech act) see under speech act

common ground $4,7,43-63,67,121 n_{3}, 220$, 26on48, 278-279, 282, 311

conversational maxim / Konversations-

maxime 98-99, 114, 28o, 448

see also cooperative principle conversation analysis (CA) / Gesprächsana-

lyse $\quad 5,7-8,70,72-73,77-79,82,85^{-}$

$86,88,91-92,107-109,140,160,163$,

$187,190,201,265 \mathrm{n} 2,283,322,324,45^{2}$,

$455^{\mathrm{n}} 45$

cooperative principle / Kooperationsprinzip $188,189,448$

see also conversational maxim

courtesan $10,247,25$ o, 284n26, 291, 295, 303-311, 366, 368, 37o, 373-374, 378

deceit / Trug 12, 54, 88, 96, 16o, 162, 165, 167, 272n13, 374, 398, 406-410, 413-414, 421425, 429, 431, 435, 437, 440-441 see also fraus, simulatio declarative (speech act) see under speech act 
deixis / Deixis $\quad 7,19-20,22,24,29,31-32$, $36-37,39,52,68,99,342,348-35$ o, 355 , $367 \mathrm{n} 7$

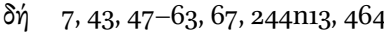
see also particle

Dionysus / Dionysos 8, 58, 67, 140, 142-143, $148,15^{6}-158,215 \mathrm{n} 8,257,259$

directive (speech act) see under speech act distance (D) see under politeness

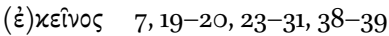

Electra / Elektra $31 n 22,37-38,61,96$, 168n26, 345, 349-359, 452-461, 463468

enjambement see under figure of speech expansion (of an adjacency pair) see under adjacency pair

expressive (speech act) see under speech act

face (in im/politeness theory) / Gesicht,

Selbstbild $\quad 9-10,165,188,193,196,198-$ 200, 202-203, 205, 208-209, 214-215, 221-222, 224, 230, 272n14, 274, 276-279, 281, 284, 286-287, 294-295, 3oon32, $302,310,312 n 59,455 \mathrm{n} 44,460,467$ see also im/politeness

face threatening act (FTA) / gesichtsbedro-

hend $\quad 8-10,70 n 1,74,83-84,89,165^{-167}$, 174n44, 200-201, 203, 205n68, 208209, 214-218, 220-221, 223, 264ni, 273275, 277, 281n25, 285, 287-288, 46in 8 see also indirect (language, speech act), mitigation, softener

failure (of persuasion, tricks) $\quad 11,319,326-$ 327, 329-331, 334-335, 407, 413, 425, 429, 435

fides 417, 424-425, 430-431, 436-438, 441 figure of speech / rhetorische Figur 447$448,45^{1}$

see also irony, rhetoric

alliteration / Alliteration $\quad 454-45^{6}, 45^{8-}$ 46o, 463, 466

aposiopesis / Aposiopese 6, 199, 319n4, $338 \mathrm{n} 4,347,358,449$

chiasmus / Chiasmus $155,175 \mathrm{n} 45,411$, 466

enjambement / Enjambement 453-454, $456,459-460,464,466$ hysteron proteron / Hysteron proteron $453,46 \circ, 466$

litotes / Litotes 448-449

metaphor / Metapher 29, 30n18, 3435, 99, 205, 293n11, 358, 448, 453n29, $456-457,460,464,466$

synaesthesia 416

fraus 12, 406, 421-427, 429-430, 432-434, 436-441

see also deceit, simulatio

gesture / Geste, Gebärde 2-5, 11-12, 169, 175, 33 on $52,338-361,364-368,370-378$, 382-384, 386-389, 394-399, 403-418, $426 \mathrm{n} 2 \mathrm{O}, 432$

see also body: body language, non-verbal (communication)

cultural value of gestures $12,339 n 7,384$, 388-389, 391, 396, 399, 412n21

gift 226, 228-229, 309, 311, 432-433, 435, 439

greeting / Gruß 12, 83, 107, 161n3, 167-169, 171-172, 178-180, 222-223, 226, 275, 300, 349n34, 367n6, 383, 388, 393-394, 408, 461,465

Gricean maxim see conversational maxim

Hippolytus $33-36,323-324,330-331,408-$ 409, 413-414

hysteron proteron see under figure of speech

illocution / Illokution 57n23, 176-178, 241, 266, 268, 270, 273, 28o-281, 288, 322$323,326,328,331-335,338,359,448$ see also speech act illocutionary act / illokutionärer Akt 321-322, 340n12, 355, 427, 439, 449 illocutionary force / illokutionäre Kraft 21, 23, 37, 39, 91, 163n8, 167, 175, 215, 242, 267n6, 272, 280, 324, 448

imperative / Imperativ $57,77,91,143,147$, 157, 164, 167n19, 178-179, 224, 235, 237, 239-246, 250-252, 254-255, 257, $259-26$ o, 277, 282, 285, 321-322, 348,

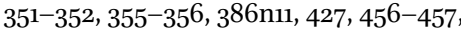
$459 n_{52}, 461,464$ see also speech act: directive 


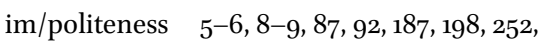
264, 277, 282, 292

see also face, mitigation, softener

impoliteness 4, 90, 73n1o, 187-188, 19o191, 199n $57,202,213,221,223-226,23$, 256-257, 291-292, 294, 298n3o, 3O1, $303 n 40$

politeness see politeness

indirect (language, speech act) / indirekt

(Sprache, Sprechakt) 91, 135, 151-152, 165-166, 200, 203, 205, 218, 271, 323n21, 454, 455n44, 457-459, 467

see also face threatening act, politeness: off-record (strategy), speech act insertion sequence / Einschubsequenz 163

see also adjacency pair: expansion (of an adjacency pair)

Iphigenia / Iphigenie 8, 16o-162, 164$165,167,169-181,323,330-331$, $46 \operatorname{n}_{5} 6$

irony / Ironie $\quad 5$ o, 9on32, 97n3, 148, 152n45, 188, 200, 209, 221n24, 226, 231, 256n35, 259n43, 448, 454n39, 467

Jocasta 103n28, 11on38, 191, 199, 347, 414415,417

kinesics see under non-verbal (communication)

kiss see under non-verbal (communication)

language use see use of language

left periphery (LP) 7O-74, 78-88, 91-92

litotes see under figure of speech

locution $\quad 213,215,322-323,331,334-335$,

340, 428-429, 431

see also speech act

manipulation / Manipulation 5, 192-193, 196, 214, 217, 291-295, 300, 310, 312, 425, 429, 431, 434, 439, 441, 448

meretrix see courtesan

metadirective (expression) see under speech act

metaphor see under figure of speech metapragmatic (comment) 217, 220, 293294, 300, 305

mind style $\quad 7,96-99,101,107,114 n 45$ misunderstanding / Missverständnis 8, 109, 142, 152, 218, 276n19, 394, 396

see also problem of communication

mitigation / Abmilderung 9, 163n8, 165, 167, 178-179, 200-201, 215, 221n23, 223-224, 239, 243-244, 272n14, 278-279, 281282, 285-287, 449, 454-459, 461, 464, $466-467$

see also face: face threatening act, $\mathrm{im} /$ politeness, softener

multiperspectivity $137 \mathrm{n} 34$

non-response $\quad 323-324,326,329-330,334-$ 335

see also non-verbal (communication): silence

non-verbal (communication) / nicht-verbal, nonverbal (Kommunikation) 1, 6, 11, 165n16, 169, 174-175, 179, 366, 382-383, 425-426, 431-433, 435, 439, 441, 46o, 468

see also body: body language, gesture kinesics 339, 426, 432, 435, 439

kiss / Kuss 12, 175, 309, 382-384, 386399, 410-412

proxemics $339 n 7,386-387,426,432,435$ silence / Schweigen 11, 144, 151, 178, 180, 19o, 194n37, 319-327, 329-331, 333-336, 356, 409, 432, 449, 454-455 see also non-response tears / Tränen $12,173,177-178,180,375^{-}$ 378, 383, 396n28, 4O3-412, 426n2o, 432, $46 \operatorname{non}_{5} 6,467$

vultus $403,405,407,412-414,416-418$

Odysseus, Ulysses $\quad 8,23,25^{-27}, 31 n 22,37$, $84,104,106,123,125^{-137}, 333,334$ n62, 406-408, 411, 413, 423, 426-435

Oedipus $\quad 8,9,30,96-97,99-116,137,187-$ 188, 190-209, 323, 327-329, 347, 414416

off-record (strategy) see under politeness on-record (strategy) see under politeness Orestes / Orest $31,36-38,104,106,164,176$, 179, 248, 259n43, 331n53, 345, 349-359, $45^{2-468}$

osculum see non-verbal (communication): kiss

over-politeness see under politeness 
parasite $10,267,291,295^{-296}, 298-302$, 310-312, 370

particle / Partikel 7, 23, 47-51, 56-58, 61-64, $66-67,72,122 n 4,130-131,142,147,149-$ 15o, 154, 156, 244n13, 248, 452n26, 457, 463-466

see also $\delta \dot{n}, \tau \circ$

Pentheus $8,58,65,67,140-158$

perlocution / Perlokution 76-77, 173, 175, 292, 312, 322, 324, 327n42, 330, 340n12, 427, 429, 432, 436, 441, 448 see also speech act

Phaedra 323n19, 330, 407-410, 413-414

Philoctetes 103-104, 106, 331-335 politeness / Höflichkeit 6, 9, 10, 71n3, 73n1o, 75n16, 92, 16o, 165-166, 174n44, 187-19o, 193, 195, 197-199, 203-205, 209, 213-226, 230-231, 234-243, 247, 249-261, 264, 273-274, 278-279, 281289, 291-295, 299, 301-303, 311-313, 386n11, 449, 452, 454-456, 458, 461, 467

see also face, im/politeness, mitigation, softener

distance (D) 10, 74, 90, 217n13, 218, 221, 247, 274, 288, 295, 307, 311

negative politeness / negative Höflichkeit 18on54, 188n6, 200-201, 214, 219-221, 225, 246-249, 251-255, 26o261, 271, 278-279, 282, 284, 294, 3О2, $457-45^{8}$

off-record (strategy) 165-166, 188, 199-200, 2O2, 205, 249n23, 279-28o, 282-283, 288, 455n44, 46o, 462, 466, 467 see also indirect (language, speech act) on-record (strategy) $74,83,85,87-88$, 188, 2OO, 2O2, 224, 277, 281-283, 285286, 288, 461

over-politeness $\quad 6,10,214 \mathrm{n}_{5}, 217-218$, 23o, 291, 294, 303, 310, 312-313 positive politeness / positive Höflichkeit 188n6, 200-2O2, 204, 214-216, 220-222, 225, 246-254, 26o-261, 278279, 281-282, 284-285, 291n3, 294, 296, 302, 306, 310-311, 454-458, 461, 466467

power (P) 10, 197-198, 217-218, 221-224, 23o, 243, 264, 274, 277, 288 pragmalinguistic vs. sociopragmatic politeness 221

ranking of imposition (R) 217n13, 218, 274, 288

possible-world theory see theory of possible worlds

power $(\mathrm{P})$ see under politeness

pragmatics of communication $1 \mathrm{n1}, 11,364$, 378, 382, 384n5, 396n27, 399

pre-sequence / Präsequenz 163n7

see also adjacency pair: expansion (of an adjacency pair)

problem of communication / Kommunika-

tionsproblem, -schwierigkeit 140-141

see also misunderstanding

proxemics see under non-verbal (communication)

Pylades $\quad 46 o-468$

quarrel 188-191, 298

ranking of imposition $(\mathrm{R})$ see under politeness

relevance theory $(\mathrm{RT})$ / Relevanztheorie 5 , 99n13, 113-115, 447

repair $85,89,92,108,109$

resonance (in the theory of dialogic syntax)

$8,121-123,13$ on 21

revenge / Rache $127,135,43^{2-433}, 436,439-$ 440,467

rhetoric / Rhetorik 3,6, 12, 63, 96, 11on38, 129, 173, 177, 227n41, 28o-282, 284, 319, 328, 33o, 338, 347, 382n1, 384n5, 434, $447-45^{2}, 455,46 \circ, 462,466-469$

see also figure of speech

right periphery $(\mathrm{RP}) \quad 7,7 \mathrm{O}-74,78-92$

silence see under non-verbal (communication)

simulatio $\quad 374,422,425,429,439,441$

see also deceit, fraus

softener $10,237,239,244,246,248,250-255$, 26o-261, 302

see also face: face threatening act, imperative, im/politeness, mitigation

speech act / Sprechakt $\quad 2,7-8,10-11,43$, $46,48,5$ o, $57,63,73^{-77}, 81-83,85^{-86}$, 88, 91, 144, 16o, 163-167, 169, 171-173, 175-179, 239, 241-242, 257-258, 264- 
269, 272-274, 277, 282, 288, 292, 300, $321-322,324,330,333,335,338-342$, $344,347-35$ o, 355, 359-36o, 364-367, 448-449, 452, 454, 457, 459-46o, 462, 466-468

see also illocution, indirect (language, speech act), locution, perlocution advisory act see advice

assertive / assertiv $\quad 76-77,163,172 n 35$, $266-267,282,288$

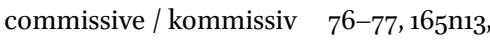
177,466

declarative $75^{\mathrm{n} 16}, 81$

directive / direktiv $10,57,76-77,81-$ $83,86,164-165,173,175,177-179,215$, 224, 236-241, 244-246, 250, 256, 258 , 264-268, 270, 273-274, 277, 279-280, $284-288,386,454,457,468$

expressive / expressiv $\quad 76,167,171-172$, 175, 177, 179n53, 453-454, 457, 459-46o, 467

metadirective (expression) $\quad 77,81,326$ statistics $101,105,237,244,245^{-246}, 250-$ 253, 281, 308

supplication / Flehen $\quad$ 164-165, 167n21, 174176, 202, 217, 219, 243, 342, 344, 351, 403n1

synaesthesia see under figure of speech

tears see under non-verbal (communication)

term of address (TAd) see address theory of mind (ToM) 4, 9, 11, 187, 189-19o, 193, 196-198, 207, 209, 327-329, 335 theory of possible worlds $\quad 9,187,189-190$, 193

Thyestes $\quad 435^{-440}$

Tiresias / Teiresias 9, 102-103, 105, 109-110, 114-115, 148, 157n59, 187-188, 190-209

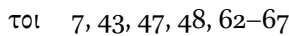
see also particle

topicalisation 109

turn / Redebeitrag $\quad 5-8,10,66,71-73,77-79$, 85-86, 88, 92, 103, 107, 109, 111, 121, 123, $125,135,142,147-148,162-167,169-170$, 178-180, 265, 267, 273, 279-281, 283$287,289,322-326,329-33$ o, 335,386 , $451,454,456-46$ o, 463

turn-taking / Sprecherwechsel $71 \mathrm{n}_{3}, 78$, 142, 144, 149

use of language / Sprachgebrauch 11, 19, 38, 46, 98-99, 116, 121n3, 140, 142, 145, 147, 149-151, 155, 157-158, 234, 251, 281n25, 345

verbal formula mismatch $\quad 223,226$ see also face: face threatening act, $\mathrm{im} /$ politeness: impoliteness

vocative / Vokativ 3on19, 32n24, 70-72, 75, 79, 82n22, 85n23-24, 91, 168n26, 172, 180, 215n7, 225, 242-244, 247, 249-25o, 253-255, 261, 292n1o, 304, 311, 427-429, $454-457,459 n 54,461,464,467-468$ see also address

vultus see under non-verbal (communication) 


\section{Index Locorum}

Abbreviations follow the Oxford Classical Dictionary, 4th edition: see https://oxfordre.com/ classics/page/abbreviation-list/

\begin{tabular}{|c|c|c|c|}
\hline \multirow{2}{*}{\multicolumn{2}{|c|}{$\begin{array}{l}\text { Accius } \\
\text { Neoptolemus }\end{array}$}} & 287 & 64 \\
\hline & & 331 & 61 \\
\hline \multirow[t]{2}{*}{184} & 426 & 706 & 64 \\
\hline & & 1071 & 53 \\
\hline Aeschylus & & Supp. & 73 \\
\hline \multirow[t]{2}{*}{$A g$} & $51,63,3^{20}-3^{22}, 3^{26}$ & 99-102 & 88 \\
\hline & $45^{2}$ & $811-816$ & 91 \\
\hline 539 & $5^{6}$ & 811 & 91 \\
\hline $55^{\circ}$ & $5^{6}$ & $814-815$ & 91 \\
\hline 887 & 53 & Fragments & \\
\hline 905 & 168 & Edonoi $\operatorname{TrGF} 61$ & 319,325 \\
\hline 907 & 168 & Edonoi TrGF 61.1 & \\
\hline 922 & 65 & & 319 \\
\hline 925 & 168 & Myrmidones & 319,336 \\
\hline 974 & 64 & & \\
\hline 1014 & 64 & Apollonius Dyscol & \\
\hline 1035 & $3^{20}, 3^{21}$ & De Constructione & \\
\hline 1039 & 320,321 & 3.104 .9 & 243 \\
\hline 1040 & 64 & $3.105 .2-5$ & 243 \\
\hline $1049-105^{\circ}$ & 324 & & \\
\hline 1049 & 225,321 & Aristophanes & \\
\hline $105^{0-105^{2}}$ & 320 & Ach. & $213,224,237$ \\
\hline $105^{0}-105^{1}$ & $3^{21}$ & 55 & 256 \\
\hline $105^{\circ}$ & 321 & $130-131$ & 257 \\
\hline $105^{2}$ & $321,326,327$ & $165^{-166}$ & 257 \\
\hline $1053^{-1055}$ & 324 & 169 & $25^{8}$ \\
\hline 1054 & 321 & 172 & 257 \\
\hline 1059 & 321 & 221 & $25^{8}$ \\
\hline $1059^{-1065}$ & 320 & 233 & $25^{8}$ \\
\hline 1064 & 321 & $253-254$ & 259 \\
\hline 1073 & 321 & 296 & 215 \\
\hline $1172-1330$ & 36 & 305 & 215 \\
\hline 1304 & 64 & 334 & 259 \\
\hline $1322-1323$ & 36 & 393 & $25^{8}$ \\
\hline 1323 & 36 & $404-405$ & 214 \\
\hline $1343^{-1345}$ & 454 & 404 & 220 \\
\hline Cho. & 345,359 & 405 & 219, 260 \\
\hline 157 & 168 & 410 & 257 \\
\hline $212-246$ & $35^{\circ}$ & $414-479$ & 218,221 \\
\hline 876 & 454 & $414-417$ & 218 \\
\hline 9०3-904 & 31 & 417 & 219 \\
\hline Pers. & $51,63,137,456$ & $430-431$ & 219 \\
\hline 159 & $6 o$ & $43^{1}$ & 260 \\
\hline
\end{tabular}




\begin{tabular}{|c|c|c|c|}
\hline $437-439$ & 219 & $1010-1011$ & 222 \\
\hline $43^{8}$ & 260 & $1016-1017$ & 222 \\
\hline 447 & 220 & $1025^{-1026}$ & 223 \\
\hline $45^{2}$ & 219 & 1031 & 224 \\
\hline 455 & 219 & 1214 & 225 \\
\hline $45^{6}$ & 220 & $1253^{-125^{6}}$ & 223 \\
\hline $45^{8}$ & 220 & 1259 & 224 \\
\hline 460 & 220 & $1368-1369$ & 261 \\
\hline $462-463$ & 220 & 1377 & 223 \\
\hline 467 & 220 & 1407 & 224 \\
\hline 472 & 220 & 1436 & 215 \\
\hline $475^{-478}$ & 220 & 1577 & 215 \\
\hline 475 & 220 & 1581 & 221 \\
\hline 477 & 220 & 1638 & 215 \\
\hline 478 & 261 & Eccl. & \\
\hline 479 & 220,223 & $46-47$ & 256 \\
\hline $483-484$ & $25^{6}$ & 118 & 260 \\
\hline $564-565$ & $25^{8}$ & 132 & 259 \\
\hline 568 & 261 & $162-163$ & 259 \\
\hline 618 & $25^{8}$ & 300 & 259 \\
\hline 627 & 256 & 437 & 259 \\
\hline $77^{2}$ & 260 & $493-494$ & $25^{8}$ \\
\hline 822 & 256,257 & 514 & $25^{8}$ \\
\hline 864 & 260 & 564 & 215 \\
\hline 926 & 224 & 695 & 224 \\
\hline 929 & 215 & 784 & 215 \\
\hline $948-949$ & $25^{\circ}$ & $1015^{-1017}$ & 229 \\
\hline $95^{6}$ & 455 & $877-1111$ & 229 \\
\hline 968 & 259 & 915 & 261 \\
\hline 1020 & 215 & 970 & 219 \\
\hline 1024 & 455 & 1005 & 224 \\
\hline $1028-1029$ & 261 & 1074 & 224 \\
\hline 1028 & 216 & 1145 & 256 \\
\hline 1081 & 224 & $E q$. & 237 \\
\hline $1085^{-1086}$ & 224 & 48 & 214 \\
\hline 1094 & 224 & $160-161$ & 218 \\
\hline 1107 & 224 & 240 & 215 \\
\hline 1112 & $25^{6}$ & $618-619$ & 259 \\
\hline $1115^{-1116}$ & 223 & $719-720$ & 214 \\
\hline 1117 & 223 & $725-727$ & 213 \\
\hline 1126 & 224 & $73^{2}$ & 213,214 \\
\hline & $221,223,224$ & 843 & 215 \\
\hline $12 \mathrm{O}-122$ & 217 & 860 & 215 \\
\hline 206 & 215 & 960 & 248 \\
\hline 207 & 219 & 1202 & 219 \\
\hline $640-642$ & 224 & Lys. & \\
\hline 846 & 215 & 95 & 215 \\
\hline 916 & 223 & $97-98$ & 220 \\
\hline 961 & 215 & 140 & 215 \\
\hline
\end{tabular}




\begin{tabular}{|c|c|c|c|}
\hline Lys. (cont.) & & 1325 & 88 \\
\hline $181-182$ & 257 & 1487 & 261 \\
\hline 309 & 259 & $\operatorname{Pax}$ & 224 \\
\hline $35^{6}$ & 256 & $1-2$ & 224 \\
\hline $411-412$ & 260 & 62 & 261 \\
\hline 656 & $25^{8}$ & 87 & 219 \\
\hline 762 & 215 & 118 & 261 \\
\hline 883 & 215 & $376-377$ & 219 \\
\hline 945 & 215 & 382 & 214,249 \\
\hline $1074-1075$ & 222 & $384-388$ & 219 \\
\hline 1086 & 225 & 400 & 219,261 \\
\hline 1188 & 260 & $416-418$ & 261 \\
\hline 1230 & 257 & 1119 & 224 \\
\hline Nub. & 73,85 & $1207-1208$ & 224 \\
\hline $3^{8}$ & 88,215 & 1228 & 223 \\
\hline $75^{-77}$ & 216,217 & 1229 & 223 \\
\hline 79 & 217 & 1238 & 215 \\
\hline $8 o-89$ & 215 & $1242-1244$ & 223 \\
\hline 80 & 87 & 1245 & 224 \\
\hline 86 & 216 & $1262-1263$ & 223 \\
\hline $86-93$ & 88 & 1264 & 224 \\
\hline 110 & 248 & Plut. & $213,224,226,230$ \\
\hline $121-123$ & 216 & 25 & 222 \\
\hline 155 & 219 & $61-62$ & 216 \\
\hline 189 & 224 & 103 & 219 \\
\hline 224 & 219 & $107-109$ & 227 \\
\hline 314 & 219 & $144-146$ & 228 \\
\hline 357 & 260 & $149^{-159}$ & 229 \\
\hline $35^{8}-363$ & 226 & 240 & 220 \\
\hline 367 & $25^{6}$ & $36 o$ & 215 \\
\hline $413-414$ & $25^{8}$ & 444 & 219 \\
\hline 429 & 220 & $567-570$ & 227 \\
\hline 510 & 261 & $576-577$ & $25^{8}$ \\
\hline $731-73^{6}$ & 88 & 824 & 225 \\
\hline 746 & 214 & 880 & 225 \\
\hline $77^{6}-784$ & 88 & 886 & 225 \\
\hline $789-790$ & 222 & 899 & 225 \\
\hline 790 & 87 & $926-934$ & 225 \\
\hline 816 & 215 & $928-943$ & 225 \\
\hline $854-85^{8}$ & 87 & $93^{2}$ & 224 \\
\hline 1009 & 259 & $944-95^{\circ}$ & 224,225 \\
\hline 1138 & 215 & $959-961$ & 225 \\
\hline 1145 & 221 & $962-963$ & 226 \\
\hline $1146-1147$ & 222 & 967 & 225 \\
\hline 1238 & 224 & $970-972$ & 226 \\
\hline 1267 & 224 & $975^{-979}$ & 227 \\
\hline 1297 & 224 & $975^{-978}$ & 228 \\
\hline 1298 & 223 & $977-978$ & 228 \\
\hline 1299 & 223 & 994 & 227 \\
\hline
\end{tabular}




$\begin{array}{ll}1003-1005 & 227 \\ 1018-1024 & 227 \\ 1023-1024 & 227 \\ 1025 & 225 \\ 1029 & 228 \\ 1034 & 225 \\ 1047-1048 & 227 \\ 1055 & 228 \\ 106 \circ & 225 \\ 1066 & 225 \\ 1071-1087 & 227 \\ 1071-1085 & 230 \\ 1171 & 225 \\ 1098-1101 & 229 \\ 1134 & 217 \\ 1171 & 225 \\ 1176 & 219 \\ 1201 & 227,230 \\ \end{array}$

Ran.

44

96

167

175

299

431-433

436

503

507

512

517

$5^{22}$

526

$635-636$

669

687-688

832

835

997

1227

Thesm.

$\begin{array}{ll}64 & 215 \\ 179-18 \text { o } & 217,219 \\ 183 & 217 \\ 368-371 & 259 \\ 748 & 167 \\ 763 & 261 \\ 982 & 261 \\ 1146-1147 & 259 \\ 1155 & 249\end{array}$

$\begin{array}{ll}\begin{array}{l}1229-1231 \\ \text { Vesp. } \\ 138\end{array} & 259 \\ 248 & 224 \\ 291-292 & 224 \\ 529 & 216 \\ 76 \circ & 224 \\ 829 & 219,222 \\ 962 & 224 \\ 967 & 215 \\ 1052 & 215 \\ 1145 & 215 \\ 1149 & 215 \\ 1152 & 215 \\ 1303 & 215 \\ 1319 & 223 \\ 1320 & 223 \\ 1388 & 224 \\ 1406-1408 & 219 \\ 1406 & 224 \\ 1417-1418 & 224 \\ 1436 & 224 \\ 1441 & 224 \\ 139 & 223\end{array}$

Fragments

Islands PCG 404214

Aristotle

Eth. Nic.

1113b21-26 194

Mag. Mor.

$1208 b 30 \quad 214$

Poet.

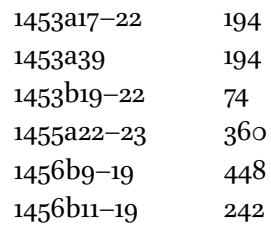

Rh.

135b25-34 447

$1356 \mathrm{a} 4 \quad 434$

1356a14-15 434

1356a2o-25 434

1358b13-14 $\quad 328$

\section{Athenaeus}

10.440e-f $\quad 389$ 


\section{Auctor ad Herennium}

$4 \cdot 3^{8.5}$

449

Carmina Popularia

fr. 8 PMG

214

Cicero (M. Tullius)

Amic.

$\begin{array}{cc}\begin{array}{c}44 \\ \text { Brut. } \\ 141 \\ \text { Clu. } \\ 72\end{array} & 276 \\ \text { De or. } & 407 \\ 1.17 & 374 \\ 1.178 & 251 \\ 2.115 & 434 \\ 3.216 & 434 \\ 3.222 & 434 \\ \text { Dat. } & 407\end{array}$

Nat. D.

\begin{tabular}{|c|c|}
\hline \multirow{2}{*}{\multicolumn{2}{|c|}{ Off. }} \\
\hline & \\
\hline 1.23 & 430 \\
\hline 1.41 & 433 \\
\hline 2.43 & 374 \\
\hline 3.61 & 374 \\
\hline 3.64 & 422 \\
\hline
\end{tabular}

Pis.

\begin{tabular}{rl}
\multicolumn{1}{c}{1} & 374 \\
Rep. & \\
4.6 & $39 \circ, 395$ \\
4.7 & 430
\end{tabular}

Rab. Post.

$$
35
$$

Red. sen.

15

Tusc.

5.61

Cicero (Q. Tullius)

Comment. pet.

$$
\text { 42-43 }
$$

Demetrius

Eloc.

7
369

313

374

374

243
Dionysius of Halicarnassus

Comp.

$14 \quad 455$

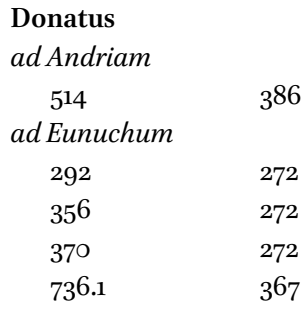

Eugraphius

ad Heautontimorumenum

$\begin{array}{ll}372 & 371 \\ 373 & 372\end{array}$

\section{Euripides}

Alc.

$\begin{array}{ll}30 & 92 \\ 93 & 325 \\ 476-477 & 71 \\ 510 & 72 \\ 516-517 & 88 \\ 517 & 89\end{array}$

$517 \quad 89,90$

$529 \quad 88,89,9 \circ$

536-539 $\quad 88,89$

$540 \quad 220$

$6 \circ 8 \quad 453$

$614 \quad 92$

$620 \quad 92$

$629 \quad 88$

82199

861-867 24

$866 \quad 24,25$

$867 \quad 24,25$

1007-1008 88

$1133 \quad 464$

Andr. 73

$170 \quad 92$

234-237 72, 92

$245 \quad 154$

3०9-313 92

416-417 412

$590 \quad 92$

$631 \quad 92$

1073-1074 88 


\begin{tabular}{|c|c|c|c|}
\hline Bacch. & $5^{1}, 63,140-158,35^{6}$ & 486 & 153 \\
\hline $53-54$ & 142 & 488 & 153 \\
\hline $5^{6}$ & 141 & $489-490$ & 67 \\
\hline $73-74$ & 157 & 489 & 153 \\
\hline 186 & 154 & 490 & 154 \\
\hline 196 & 155 & 491 & 154 \\
\hline 228 & 147 & 492 & 150 \\
\hline 232 & 147 & $493-499$ & 149 \\
\hline 233 & 143 & 493 & 147 \\
\hline 234 & $15^{2}$ & 495 & 147 \\
\hline 238 & 147 & 497 & 147 \\
\hline 239 & 147 & 499 & 149 \\
\hline 240 & 147 & 500 & 156 \\
\hline $242-243$ & 148 & $5^{\mathrm{O} 1}$ & $145,146,147,156$ \\
\hline 260 & 147 & 502 & 156 \\
\hline $267-269$ & 155 & 503 & 147 \\
\hline $286-297$ & 148 & 505 & 147 \\
\hline $290-291$ & 54 & 506 & 156 \\
\hline 332 & 155 & 507 & $15^{6}$ \\
\hline 346 & 147 & 508 & 157 \\
\hline $35^{\circ}$ & 147 & 509 & 147,157 \\
\hline $35^{1}$ & 147 & 511 & 147 \\
\hline $35^{2}$ & 147 & 512 & 147 \\
\hline 367 & 157 & 514 & 147 \\
\hline $453-459$ & 143 & $5^{15}-517$ & 67 \\
\hline $460-508$ & 143 & 642 & 155 \\
\hline 460 & $143,146,147,151,15^{6}$ & $645^{-656}$ & 143 \\
\hline 461 & $15^{2}$ & $645^{-646}$ & 144 \\
\hline $462-463$ & $15^{2}$ & 648 & 151 \\
\hline 464 & 151 & 649 & 151 \\
\hline 465 & 146,147 & $65^{\circ}$ & 155 \\
\hline $466-469$ & 148 & 654 & 150 \\
\hline 467 & 146 & $655^{-656}$ & 154 \\
\hline 468 & $15^{\circ}$ & 667 & 155 \\
\hline 469 & 146 & 672 & 147 \\
\hline 470 & 147,155 & 716 & 155 \\
\hline 471 & 146,147 & $778-786$ & 144 \\
\hline 473 & $146,15^{2}$ & 780 & 147 \\
\hline 474 & $15^{2,}, 153$ & 781 & 147 \\
\hline 475 & 153 & $787-846$ & 144 \\
\hline 476 & 147,156 & 787 & 144 \\
\hline 477 & $145,146,147,153,155$ & 792 & 147 \\
\hline 478 & 153 & 793 & 147 \\
\hline $479-480$ & 155 & 796 & 147,149 \\
\hline 479 & 153 & $8 \circ 9$ & 144,147 \\
\hline 480 & 156 & 810 & $145,15^{\circ}$ \\
\hline 481 & 146 & $816-818$ & 151 \\
\hline $483-484$ & 155 & 816 & 145,147 \\
\hline 485 & 146 & 818 & 145 \\
\hline
\end{tabular}


Bacch. (cont.)$$
820
$$

821-822

829

840

843

845

846

849

851

913

918-972

918-919

924

925

934

937-938

942

954

956

957-958

960

966-970

1034

1059-1062

1060

1062

1063

1118-1121

1118-1119

1123

1320-1322

El.

274

275

276

278-28o

282

345

487-595

550

576-599

578

$5^{81}$

584

596

753

1178

1224-1225
147

57

146

147

147

147

147

157

157

157

145

156

157

157

147

157

147

147

146

158

147

$15^{8}$

141

145

$15^{8}$

$15^{8}$

158

145

65

155

145

11, 16o, 345, 356, 452, 459

37,38

462

37

37

37,38

168

350

153

357

359

31

359

359

455

31

359
Hec.

423

$415^{-431}$

425

433-434

457

843

180

1035-1037

455

Hel.

266

$45^{2}$

625

636

Heracl.

574-596

646-647

648

1050-1051

HF

518

531

Hipp.

54

179-283

616

761

889

893

895

897

898

899

900-945

900

902-1101

909-912

910-911

948

1028-1031

1064

1084

1166

1169-1172

1171

1172

1187

1236

1265

IA

354
454

201

220

168

168

73

180

92

92

92

109

168

$33^{-} 36,237,323,331$

33,34

323

153

35

36

36

33,36

36

36

$33,36,37$

330

36

323

330

324

330

466

456

33, 34

33, 34

34

35

33, 34

33, 34

34

34

16o-181, 331

464 


\begin{tabular}{|c|c|c|c|}
\hline 414 & 177 & 867 & 165 \\
\hline $6 \circ 7-630$ & 164,172 & 872 & 165 \\
\hline $6 \circ 9$ & 167 & $900-916$ & 165 \\
\hline $631-63^{2}$ & 169,176 & $9 \circ 3-9 \circ 8$ & 167 \\
\hline $633-634$ & 168 & $9 \circ 4$ & 455 \\
\hline $640-685$ & 169 & $985-989$ & 165 \\
\hline $640-643$ & 169 & $992-996$ & 165,167 \\
\hline $640-642$ & 169 & 993 & 167 \\
\hline 640 & 171,172 & $995-996$ & 165 \\
\hline 642 & 171,172 & $1098-1105$ & 162 \\
\hline $644-65^{\circ}$ & 169 & $1106-1145$ & 162 \\
\hline 644 & $170,171,172$ & $1115^{-1116}$ & 162 \\
\hline $645^{-646}$ & 170 & $1117-1119$ & 164 \\
\hline $648-65^{\circ}$ & 170 & 1121 & 162 \\
\hline 648 & 172 & $1124-1131$ & 162 \\
\hline $65^{1-671}$ & 169 & 1129 & 165 \\
\hline 654 & 171,172 & 1131 & 163 \\
\hline 656 & 172 & $113^{2-1145}$ & 163 \\
\hline $65^{8-66 o}$ & 170 & 1133 & 165 \\
\hline 658 & 172 & 1135 & 165 \\
\hline 659 & 170 & $1141-1142$ & $33^{\circ}$ \\
\hline $66 o$ & 172 & 1143 & 165 \\
\hline $661-662$ & 170 & $1146-1208$ & 165,173 \\
\hline 662 & 172 & 1167 & 173 \\
\hline 664 & 171,172 & $1168-1169$ & 173 \\
\hline 666 & 171,172 & $1171-1178$ & 173 \\
\hline $668-670$ & 170 & $1177-1178$ & 173 \\
\hline 668 & 172 & $1183-1184$ & 173 \\
\hline 670 & 172 & 1185 & 173 \\
\hline 671 & 170 & 1186 & 173 \\
\hline 672 & 172 & 1187 & 173 \\
\hline $673-677$ & 169 & 1188 & 173 \\
\hline 674 & 171,172 & 1191 & 173 \\
\hline $675^{-676}$ & 170 & $1192-1193$ & 173 \\
\hline 676 & 172 & $1194-1195$ & 173 \\
\hline $677-685$ & 170 & $1197-1198$ & 173 \\
\hline $678-685$ & 169 & 1209 & $33^{\circ}$ \\
\hline $685-740$ & 161,169 & $1211-125^{2}$ & 173 \\
\hline $691-740$ & 172 & $1218-1219$ & 174 \\
\hline $691-692$ & 167 & $122 \mathrm{O}-123 \mathrm{O}$ & 174 \\
\hline $733-740$ & 165 & 1220 & 175 \\
\hline 734 & 166 & 1222 & 175 \\
\hline 736 & 166 & $1223^{-1225}$ & 175 \\
\hline 738 & 166 & $1228-1230$ & 175 \\
\hline 739 & 167 & $123^{6}-1237$ & 174 \\
\hline 740 & 165 & $123^{8-1257}$ & 323,33 o \\
\hline $831-832$ & 165 & $123^{8}-1240$ & 175 \\
\hline 844 & 167 & $1239-1240$ & 330 \\
\hline 847 & 167 & $1241-1248$ & 176 \\
\hline
\end{tabular}




\begin{tabular}{|c|c|c|c|}
\hline IA (cont. $)$ & & 309 & 88,92 \\
\hline 1245 & 325 & 333 & 92 \\
\hline $1249^{-125^{\circ}}$ & 174 & 339 & 92 \\
\hline $1276-1282$ & 176 & 372 & 92 \\
\hline $1279-1282$ & 176 & 379 & 92 \\
\hline $1343^{-1344}$ & 164,176 & $492-5 \circ 6$ & 72 \\
\hline $1345^{-1368}$ & 161 & 645 & 88 \\
\hline 1368-1401 & 176 & 999 & 88 \\
\hline $1368-1369$ & 177 & 1211 & 88 \\
\hline 1368 & 161,176 & 1261 & 464 \\
\hline $1369-1370$ & 177 & $I T$ & \\
\hline 1371-1373 & 177 & $674-686$ & 462 \\
\hline 1374 & 177 & 868 & 457 \\
\hline 1377 & 177 & $9 \circ 5$ & 464 \\
\hline 1383 & 177 & Med. & $51,63,237$ \\
\hline $1392-1393$ & 177 & 81 & 325 \\
\hline 1392 & 177 & 316 & 326 \\
\hline 1398 & 177 & $35^{8}$ & 457 \\
\hline $1433^{-1466}$ & 177,46 o & $446-447$ & 199 \\
\hline $1433-1436$ & 178 & $5^{16}$ & 153 \\
\hline 1433 & 180 & 615 & 199 \\
\hline 1436 & 180 & 1008-1009 & 454 \\
\hline $1437-143^{8}$ & 178 & $1107-1111$ & 59 \\
\hline 1439 & 180 & 1118 & $5^{2}$ \\
\hline 1440 & 179 & Or. & $45^{2-468}$ \\
\hline 1442 & 178 & $16 \circ$ & 457 \\
\hline 1444 & 178 & $255^{-257}$ & 459 \\
\hline 1445 & 180 & 786 & 457 \\
\hline 1446 & 179 & $1013^{-1245}$ & $45^{2}$ \\
\hline $1447^{-145^{2}}$ & 179 & $1018-1021$ & 453 \\
\hline 1448 & 178 & 1018-1019 & 453 \\
\hline 1449 & 179 & 1018 & 453,454 \\
\hline $145^{\circ}$ & 178 & 1019 & 453,454 \\
\hline $145^{2}$ & 179 & $1020-1021$ & 453 \\
\hline 1454 & 178,18 o & 1020 & 453,454 \\
\hline $145^{8-1466}$ & 178 & 1021 & 453,454 \\
\hline $1459-1461$ & 178 & $1022-1023$ & 454 \\
\hline 1459 & 178 & 1022 & 454 \\
\hline 1460 & 180 & 1023 & $45^{8}$ \\
\hline 1461 & 179 & 1024 & 454 \\
\hline $1464-1466$ & 178 & $1025^{-1026}$ & 455 \\
\hline 1464 & 180 & 1026 & $456,46 o$ \\
\hline 1466 & 178,18 o & $1027-1028$ & $45^{6}, 45^{8}$ \\
\hline $1487-1490$ & 180 & 1028 & $45^{6}, 46$ o \\
\hline Ion & 73,85 & $1029-1030$ & $45^{6}$ \\
\hline $237-240$ & 92 & 1029 & 457 \\
\hline 244 & 92 & $1031-103^{2}$ & 457,46 o \\
\hline 255 & 92 & $1033-1034$ & $45^{8}$ \\
\hline 289 & 92 & 1033 & $45^{8}$ \\
\hline
\end{tabular}




\begin{tabular}{|c|c|c|c|}
\hline 1034 & $45^{8,}, 467$ & Phoen. & $207-208$ \\
\hline 1035 & $45^{8}$ & 891-909 & 207 \\
\hline 1042 & $45^{8}$ & $891-895$ & 207 \\
\hline $1043^{-1044}$ & $45^{8}$ & $896-897$ & 207 \\
\hline 1043 & 459 & 898 & 207 \\
\hline $1045^{-1046}$ & 459 & 900 & 207 \\
\hline 1045 & 467 & $901-910$ & 207 \\
\hline 1046 & 459 & $9 \circ 3-9 \circ 4$ & 207 \\
\hline $1047-1051$ & 459 & 910 & 207 \\
\hline 1048 & 460 & $967-970$ & 323 \\
\hline $105^{0}-1051$ & 460 & $985^{-1012}$ & 208 \\
\hline 1051 & 460 & Supp. & \\
\hline $105^{2-1064}$ & 460 & 293 & 204 \\
\hline $1056-1057$ & 460 & 403 & 88 \\
\hline 1057 & 460 & 1058 & 453 \\
\hline $1060-1061$ & 460 & 1111 & 153 \\
\hline $1061-1062$ & 460 & Tro. & 137,423 \\
\hline $1065-1068$ & 460 & $48-5^{8}$ & 217 \\
\hline 1065 & 465 & $48-5^{\circ}$ & 222 \\
\hline 1067 & $461,463,467$ & $628-629$ & 454 \\
\hline 1068 & 461,464 & $709-779$ & 423 \\
\hline 1069-1070 & 461 & 721 & 427 \\
\hline 1069 & 461,465 & Fragments & \\
\hline 1070 & 462 & Andromeda $\mathrm{Tr}$ & $F_{12} 6 / 127 / 128$ \\
\hline 1071 & 462 & & 319,325 \\
\hline 1072 & 462 & Hypsipyle TrGI & $757.839-841$ \\
\hline 1073 & 463 & & 319 \\
\hline 1074 & 463 & Hypsipyle TrGI & 757.839 \\
\hline $1075^{-1083}$ & 463 & & 325,326 \\
\hline $1075^{-1077}$ & 466 & Telephus TrGF & $6.3-4$ \\
\hline $1076-1077$ & 464 & & 325 \\
\hline 1076 & 464 & $\operatorname{TrGF}$ fr. 1008 & $319,325,326$ \\
\hline $1078-1081$ & 464,466 & TrGF fr. 1037 & 325 \\
\hline 1080 & 464 & & \\
\hline 1081 & 464 & Eustathius & \\
\hline 1083 & 465 & Il. & \\
\hline $1085^{-1099}$ & 465 & $8 \circ 6.27$ & 73 \\
\hline $1086-1088$ & 466 & & \\
\hline $1086-1087$ & 466 & Evanthius & \\
\hline $1087-1088$ & 466 & De Comoedia & \\
\hline $1089-1091$ & 466 & 4.2 & 377 \\
\hline 1091 & 466 & & \\
\hline 1093 & 466 & Festus & \\
\hline 1095 & 466 & 214 & 388 \\
\hline 1097 & 466 & & \\
\hline 1098 & 467 & Gellius & \\
\hline 1099 & 467 & $N A$ & \\
\hline 1100 & 467 & 10.23 & 389 \\
\hline
\end{tabular}




\begin{tabular}{|c|c|}
\hline \multicolumn{2}{|l|}{ Herodas } \\
\hline Mimi & $23^{6-255}$ \\
\hline \multicolumn{2}{|l|}{ Herodotus } \\
\hline $1.35 \cdot 3$ & 91 \\
\hline 1.41 .1 & 91 \\
\hline 1.42 .1 & 91 \\
\hline 1.45 .2 & 91 \\
\hline $1.155 \cdot 3$ & 240 \\
\hline \multicolumn{2}{|l|}{ Hesiod } \\
\hline \multicolumn{2}{|l|}{$O p$} \\
\hline $1-2$ & 242 \\
\hline \multicolumn{2}{|l|}{ Homer } \\
\hline Il. & $84,125,244$ \\
\hline 1.4 & 31 \\
\hline $1.17-3^{2}$ & 198 \\
\hline $1.62-115$ & 198 \\
\hline $1.5^{87}$ & 453 \\
\hline $9 \cdot 5^{87}$ & 327 \\
\hline $10.278-279$ & 125 \\
\hline $14.190-192$ & 225 \\
\hline $15.201-204$ & 225 \\
\hline 18.190 & 453 \\
\hline 20.204 & 73 \\
\hline $20.3 \circ 3$ & 73 \\
\hline Od. & $23,37,244$ \\
\hline $1-4$ & 25,237 \\
\hline 1.1 & 23,242 \\
\hline 4.247 & 36 \\
\hline $24 \cdot 3^{21}$ & 31 \\
\hline $24.433-436$ & 466 \\
\hline
\end{tabular}

\section{Isidorus}

Etym.

$$
5.26 .7
$$

Lysias

$\begin{array}{ll}10 & 206 \\ 10.6 & 199\end{array}$

\section{Menander}

$$
\text { Aspis }
$$$$
\text { Dysc. }
$$$$
\text { 1-3 }
$$$$
41
$$$$
45^{-46}
$$

107

$\begin{array}{ll}171 & 213 \\ 299-300 & 249 \\ 375 & 240 \\ 630-632 & 248 \\ 632 & 247 \\ \text { Epit. } & 237 \\ \quad 862-863 & 247 \\ \text { Pk. } \\ \quad \text { 400 } \\ \quad 720-721 \\ \text { Sam. } \\ \text { 518 }\end{array}$

Mimus (anonymous)

P.Oxy. 413

Naevius

Tarentilla

$74-76 \quad 370$

Ovid

Am.

$\begin{array}{ll}1.4 \cdot 17^{-19} & 374 \\ 2.5 \cdot 15^{-20} & 375\end{array}$

Her.

$16.233 \quad 372$

17.79-92 375

Met.

4.142-144 414

\section{Philostratus}

VS

$1.78 .8 \quad 341$

Plato

Ap. $\quad 91$

Cra. $\quad 236-255$

Grg.

$\begin{array}{ll}453 a & 447 \\ 486 c & 222\end{array}$

Leg.

816а3-6 340

$844 a \quad 153$

944b-e $\quad 206$

Phd.

8ob-81c $\quad 91$

Phdr.

$\begin{array}{cc}279 \mathrm{c} & 463 \\ \text { Symp. } & 237\end{array}$




\begin{tabular}{ll} 
Plautus & \\
Amph. & 398 \\
$59-63$ & 398 \\
$676-860$ & 393 \\
688 & 393,397 \\
692 & 393,397 \\
$711-713$ & 393 \\
$714-716$ & 393 \\
716 & 393 \\
$799-801$ & 393 \\
$800-801$ & 393 \\
Asin. & 295 \\
$204-206$ & 304 \\
208 & 304 \\
$210-214$ & 304 \\
$215-223$ & 303 \\
$664-668$ & 304 \\
784 & 370 \\
$893-985$ & 396 \\
929 & 396 \\
\hline
\end{tabular}

Aul.

$$
113-117
$$$$
\text { 182-185 }
$$

293

Bacch.

$\begin{array}{ll}39-100 & 304 \\ 50 & 304 \\ 577-583 & 298 \\ 1178-1179 & 306\end{array}$

Capt.

69-9o

133-137

139-141

146-153

174-175

191

780

868-869

Cas.

$$
\text { 134-138 }
$$$$
585-586
$$

295

295

299

299

300

270

300

300

265

305

304

Cist.

$\begin{array}{ll}\begin{array}{l}\text { Colax } \\ \text { fr. } 2\end{array} & 310 \\ & \\ \text { Curc. } & 296\end{array}$

Curc.

$$
\text { 457-46o }
$$

Epid.

$112-113$
$255^{-25} 6$

$$
570-576
$$$$
574
$$$$
\text { 575-576 }
$$$$
\text { 581-582 }
$$

391, 393

392

393

393

Merc.

$574-576 \quad 396$

Men. $\quad 265$

96-103 295

$143^{-151} \quad 298$

$162 \quad 299$

182-186 305

190-193 305

207-212 306

207-209 306

213-215 306

344-345 270

361-374 $\quad 306$

568-569 $\quad 267$

$677 \quad 306$

$85^{\circ}-85^{1} \quad 287$

$946 \quad 287$

1021-1024 $\quad 285$

$1023 \quad 287$

Mil.

9-12 297

16-24 297

25-30 296

33-35 296

38-41 297

55-6o $\quad 296$

$354 \quad 270$

570-573 $\quad 267$

947-990 296

1034-1036 271

1037-1093 295

1161-1163 306

1239-1241 310

126o-1261 310

1272-1273 $\quad 310$

1330-1332 310

Mostell.

$181 \quad 293$

$500 \quad 436$

Persa

$\begin{array}{ll}53^{-6} \text { o } & 295 \\ 766 & 3 \circ 3\end{array}$

Poen.

$330-409 \quad 3 \circ 3$

$470-5 \circ 3 \quad 296$ 
Pseud.

$$
\text { 448-452 }
$$

Rud.

$$
\text { 435-438 }
$$$$
\text { 938-958 }
$$$$
\text { 96o-962 }
$$$$
\text { 962-963 }
$$

Stich.

1-6

69

70-74

75-87

79

82

89-96

89-92

90

91

92

93

94

95

99

99-101

126

155-195

465-469

471-482

483-496

577-578

742-744

750-753

Trin.

245-247

297-298

633-636

674

680

106o-1063

Truc.

22-73

162-163

190-192

352-353

$355^{-}-35^{6}$

$35^{8-}-363$

425-427

434-440

499-542
293

304

269

269

269

265, 383-399

398

384

384

394

387

397

385

383,384

386, 387

$386,387,388$

386, 395

386

386

386

398

396

397

295

300

301

302

273

308

308

265

310

278

275

276

276

286

309

303

304

312

309

309

309

309

309

309 86o-861

309

Pliny the Elder

$H N$

14.90

389

Pliny the Younger

Ep.

$\begin{array}{ll}7.27 .9 & 368\end{array}$

\section{Plutarch}

Comp. Ar. et Men. $853 \mathrm{~b} 5-8 \quad 236,237$

$853 \mathrm{~d} 10-853 \mathrm{e} 4 \quad 237$

Quaest.Rom.

6

389, 390

\section{Polybius}

6.11a. $\quad 389$

\section{Protagoras}

8о A 13-17 448

\section{Quintilian}

Inst.

$\begin{array}{ll}1.2 .30 & 434 \\ 1.6 .2 & 434 \\ 11.3 .66 & 407 \\ 11.3 .67 & 407\end{array}$

Sallust

Cat.

31.7

374

Sappho

fr. 31.1

31

Scholia (see also Donatus, Eugraphius)

Scholia Bembina in Terenti Heautontimoumenum

$\begin{array}{ll}372 & 371 \\ 373 & 373\end{array}$

Scholia in Sophoclem

Aj. 66a

128

Aj. 74

132

OT 1

100

Scholia Terentiana

ad Heaut.

372

371 


\begin{tabular}{|c|c|c|c|}
\hline \multirow[t]{2}{*}{373} & \multirow[t]{2}{*}{373} & 291 & 437 \\
\hline & & 293 & 437 \\
\hline \multicolumn{2}{|c|}{ Seneca (the Younger) } & 295 & 437 \\
\hline \multicolumn{2}{|c|}{ Ag. } & 316 & 440 \\
\hline $659-663$ & 405 & 318 & 440 \\
\hline \multicolumn{2}{|l|}{ Ben. } & 416 & 435,439 \\
\hline 2.13 .2 & 371 & $424-425$ & 437 \\
\hline \multicolumn{2}{|l|}{$E p$} & $472-473$ & 437 \\
\hline 52.12 & 407 & $482-484$ & 437 \\
\hline 114.22 & 407 & $5^{\circ} 4-5^{11}$ & 438 \\
\hline \multicolumn{2}{|r|}{$414-417$} & 505 & 435 \\
\hline 913 & 406 & $5^{\circ} 7$ & 438 \\
\hline 998-1003 & 414 & $5^{21-}-5^{24}$ & 439 \\
\hline 1003 & 414 & $5^{28}$ & 439 \\
\hline 1004-1009 & 415 & 536 & 439 \\
\hline 1009-1011 & 415 & 542 & 439 \\
\hline $1011-1012$ & 415 & 773 & 440 \\
\hline 1011 & 415 & 894 & 439 \\
\hline $1012-1014$ & 416 & $9 \circ 7$ & 440 \\
\hline Phaedr. & $408-410,422$ & 963 & 437 \\
\hline 363 & 407 & $983-984$ & 439 \\
\hline $372-373$ & 407 & 984 & 439 \\
\hline 374 & 407 & 1004-1005 & 440 \\
\hline $431-434$ & 408 & $105^{2}$ & 436 \\
\hline 583 & 413 & 1101 & 439 \\
\hline $5^{87}-5^{88}$ & 413 & Tro. & $404-408,410-412,418$ \\
\hline $5^{87}$ & 413,414 & & $422-435,440$ \\
\hline $85^{0}-85^{2}$ & 408 & $63-65$ & 404 \\
\hline 873 & 409 & $83-85$ & 404 \\
\hline 875 & 409 & $87-89$ & 404 \\
\hline 880 & 409 & $92-95$ & 404 \\
\hline 883 & 409 & 213 & 429,440 \\
\hline $886-887$ & 409 & $409-413$ & 404 \\
\hline $1275^{-1276}$ & 410 & $412-413$ & 405 \\
\hline Phoen. & & 417 & 405 \\
\hline $224-225$ & 416 & $448-45^{1}$ & 405 \\
\hline $471-474$ & 417 & $45^{2-453}$ & 424 \\
\hline $475^{-48 o}$ & 417 & 453 & 424 \\
\hline Thy. & $422,435^{-440}$ & $46 \circ$ & 412 \\
\hline 178 & 436,440 & 461 & 423 \\
\hline $199-200$ & 436 & 462 & 423 \\
\hline 224 & 436,440 & $464-466$ & 407 \\
\hline 235 & 436 & 471 & 423 \\
\hline 239 & 436 & $476-477$ & 423 \\
\hline $285^{-286}$ & 436 & 476 & 424 \\
\hline $286-295$ & 436 & 477 & 424 \\
\hline 286 & 440 & $481-482$ & 424 \\
\hline 289 & 437 & 482 & 424 \\
\hline 290 & 437 & $489-490$ & 424 \\
\hline
\end{tabular}




\begin{tabular}{|c|c|c|c|}
\hline Tro. (cont.) & & $962-963$ & 416 \\
\hline 492 & 424 & & \\
\hline 502 & 424 & Sophocles & \\
\hline $503-5 \circ 5$ & 435 & $A j$. & $25^{-} 3 \circ, 3^{2}, 51,63,121-137$, \\
\hline $5^{13}-5^{18}$ & 425 & & $45^{2}$ \\
\hline 514 & 426 & $1-133$ & 121 \\
\hline $5^{17}$ & 426 & $1-17$ & 124 \\
\hline $522-523$ & 408,426 & 6 & 26 \\
\hline $5^{22}$ & 427 & 14 & 125 \\
\hline $5^{24}$ & 427 & 20 & 26 \\
\hline $5^{25}-5^{27}$ & 427 & $21-24$ & 124 \\
\hline $5^{28}$ & 427 & 23 & 125,128 \\
\hline 531 & 427 & 24 & 125,129 \\
\hline $53^{2-533}$ & 427 & $25^{-31}$ & 27 \\
\hline 533 & 427 & 28 & 26,27 \\
\hline 545 & 435 & 29 & 27 \\
\hline $553-555$ & 427 & $31-35$ & 124 \\
\hline $55^{6}-55^{8}$ & 428 & $31-32$ & 125,129 \\
\hline $55^{6}$ & 428 & 33 & 125,126 \\
\hline $5^{61-562}$ & 431 & $34-40$ & 126 \\
\hline $5^{62-566}$ & 428 & $3^{8-65}$ & 127 \\
\hline $568-571$ & 428 & $66-77$ & 128 \\
\hline 569 & 440 & $66-70$ & 128 \\
\hline 588 & 431 & $66-67$ & 128 \\
\hline $594-597$ & 429 & 74 & 129 \\
\hline 594 & 429 & $75^{-88}$ & 129 \\
\hline 598 & 430 & 75 & 129 \\
\hline 599-6o4 & 430 & $76-78$ & 130 \\
\hline $6 \circ 3$ & 430 & 76 & 131 \\
\hline 6o7-6o9 & 430 & 77 & 130 \\
\hline $6 \circ 8$ & 431 & $78-80$ & 130 \\
\hline $611-612$ & 430 & 78 & 130,131 \\
\hline $613-618$ & $43^{1}$ & 79 & 131 \\
\hline 613 & 431,440 & $81-88$ & 131 \\
\hline 614 & 433 & 82 & 132 \\
\hline $615^{-618}$ & 406 & 84 & 132 \\
\hline 615 & 407,431 & 86 & 132 \\
\hline 618 & 408,432 & 88 & 132 \\
\hline $621-622$ & 433 & $89-117$ & 133 \\
\hline $623-631$ & 434 & 113 & 26 \\
\hline 625 & 408,434 & $118-126$ & 133 \\
\hline 626 & 434 & $125^{-133}$ & 134 \\
\hline 627 & 434,440 & $125^{-126}$ & 134 \\
\hline $75^{\circ}$ & 435 & $127-133$ & 136 \\
\hline $75^{2}$ & 435 & 127 & 135 \\
\hline 757 & 435 & 128 & 135 \\
\hline $799-801$ & 411 & $131-132$ & 135 \\
\hline 8о6-8o9 & 411 & $132-133$ & 135 \\
\hline $8 \circ 9-812$ & 412 & 201 & 29 \\
\hline
\end{tabular}




\begin{tabular}{|c|c|c|c|}
\hline 220 & 26 & 1045 & 55 \\
\hline $271-276$ & 27 & 1119 & 64 \\
\hline 271 & 26,28 & $1139-1141$ & 122,123 \\
\hline $272-273$ & 28 & 1140 & 122,123 \\
\hline $275^{-276}$ & 28 & $1159-1160$ & 190 \\
\hline 275 & 26 & 1195 & 26 \\
\hline $282-287$ & 28 & 1198 & 26 \\
\hline 285 & 26 & 1199 & 26 \\
\hline $35^{6}-36 \circ$ & 65 & 1271 & 53 \\
\hline 437 & 26 & $13 \circ 3$ & 26 \\
\hline 472 & 26 & $135^{\circ}$ & 64 \\
\hline 513 & 26 & Ant. & $51,63,96,237$ \\
\hline $5^{20}$ & 64 & $78-81$ & 55 \\
\hline $529-577$ & 32 & 91 & $6 o$ \\
\hline $5^{29-545}$ & $3^{2}$ & $155^{-15^{8}}$ & $5^{2}$ \\
\hline $530-545$ & $3^{2}$ & $162-163$ & 53 \\
\hline $530-531$ & 59 & $241-243$ & 64 \\
\hline 530 & 32 & $244-245$ & $5^{8}$ \\
\hline 531 & 32,33 & 245 & $5^{8}$ \\
\hline 533 & $3^{2}$ & 248 & 319 \\
\hline 538 & 32,33 & $280-331$ & 191 \\
\hline 541 & 32 & $441-442$ & $5^{2}$ \\
\hline 542 & 32,33 & 473 & 64 \\
\hline 544 & $5^{2}$ & $5^{22}$ & 64 \\
\hline 545 & 32,33 & $531-535$ & $5^{6}$ \\
\hline 567 & 26 & 580 & 64 \\
\hline $5^{80}$ & 64 & $613-617$ & 54 \\
\hline 734 & 66 & $834-835$ & 64 \\
\hline $735^{-736}$ & 66 & $937-939$ & 53 \\
\hline $743-744$ & 66 & 1028 & 64 \\
\hline $75^{2-762}$ & 29 & 1289 & 319 \\
\hline 754 & 29 & El. & $11,73,345$ \\
\hline 755 & 26,29 & 385 & 61 \\
\hline $762-777$ & 136 & $66 o-662$ & 226 \\
\hline 762 & 26 & $673-675$ & 88 \\
\hline 766 & 136 & 675 & 319 \\
\hline 783 & 26,28 & 855 & 319 \\
\hline 795 & 26 & $924-925$ & 88 \\
\hline 798 & 26 & $1098-1231$ & $35^{\circ}$ \\
\hline 877 & 53 & $1119-1120$ & $35^{1}$ \\
\hline 933 & 26 & 1178 & 31 \\
\hline 977 & 464 & $1179-1182$ & 88 \\
\hline 988 & 64 & $1205^{-1236}$ & $35^{1}$ \\
\hline 991 & $26,28,3^{\circ}$ & 1206 & 349 \\
\hline 1028-1039 & 26 & $12 \circ 8$ & $349,35^{1}$ \\
\hline 1032 & 26 & 1222 & 31 \\
\hline 1035 & 26 & 1236 & 356 \\
\hline 1039 & 26 & 1491 & 259 \\
\hline 1140 & 122,123 & & \\
\hline
\end{tabular}




\begin{tabular}{|c|c|c|c|}
\hline$O C$ & 323,331 & $330-331$ & 202 \\
\hline $118-137$ & 30 & 330 & 319 \\
\hline $137-140$ & 30 & $33^{2-333}$ & $191,192,202$ \\
\hline $1036-1037$ & 190 & $334-336$ & $107,191,202$ \\
\hline $1268-1269$ & 324 & 335 & 199,205 \\
\hline $1268-1272$ & 324 & $337-343$ & 202 \\
\hline $1271-1348$ & 323,327 & $337-33^{8}$ & 199,205 \\
\hline $1271-1274$ & 325 & $339-340$ & 107,205 \\
\hline $1271-1272$ & 327 & 339 & 199 \\
\hline 1271 & 319 & $342-349$ & 115 \\
\hline 1272 & 328 & $343-344$ & 192 \\
\hline $1275^{-1276}$ & 327 & $344-345$ & 202 \\
\hline $128 \mathrm{o}-1283$ & 328,335 & 344 & 116, 199 \\
\hline 1282 & $3^{27}, 3^{28}$ & $345^{-}-346$ & 203 \\
\hline $1346-1347$ & 329 & 345 & 199 \\
\hline $1348-1396$ & 329 & $346-349$ & 203 \\
\hline $1443^{-1446}$ & 190 & $35^{\mathrm{O}-353}$ & $109,192,200,203$ \\
\hline$O T$ & $96-116,187-209,347$ & 353 & 203 \\
\hline 89 & 110 & $35^{6}-362$ & 108 \\
\hline 99 & 110 & $35^{8}$ & 203 \\
\hline 102 & 110 & 359 & 110 \\
\hline $116-121$ & 110 & 361 & 203 \\
\hline 120 & 110 & 362 & 192,203 \\
\hline 128 & 110 & 363 & 203,204 \\
\hline 238 & 203 & $364-367$ & 204 \\
\hline $278-281$ & 194 & 364 & $188,200,204,2 \circ 5$ \\
\hline 282 & 201 & 365 & 204 \\
\hline $284-291$ & 111 & $366-367$ & 192,200 \\
\hline $284-286$ & 195,200 & 368 & 204 \\
\hline 291 & 110 & $370-371$ & 204 \\
\hline $297-462$ & 187 & $372-373$ & 200 \\
\hline $300-315$ & 200 & $374-375$ & 204 \\
\hline $300-301$ & 2OO, 201, 204 & $376-377$ & 196 \\
\hline 300 & 195 & 377 & 195 \\
\hline 303 & 200,201 & 379 & 200 \\
\hline 304 & 201, 204 & $380-403$ & 197,204 \\
\hline $305-314$ & 200,201 & $390-397$ & 205 \\
\hline $3 \circ 5-3 \circ 9$ & 195 & $390-394$ & 195,197 \\
\hline $310-315$ & 201 & $391-398$ & 195 \\
\hline $316-333$ & 187 & $403-404$ & 197 \\
\hline $316-318$ & 201 & $404-405$ & 205 \\
\hline $317-319$ & 200 & $408-428$ & 204 \\
\hline 318 & 204 & $408-411$ & 198 \\
\hline $322-333$ & 202 & 412 & 199, 204 \\
\hline $324-325$ & 202 & $413-428$ & 192,200 \\
\hline $326-327$ & 202 & 413 & 205 \\
\hline $3^{28-329}$ & 192,201 & $426-428$ & 205 \\
\hline 328 & $2 \mathrm{O} 2$ & 427 & 205 \\
\hline 329 & 202 & 428 & 205 \\
\hline
\end{tabular}




\begin{tabular}{|c|c|c|c|}
\hline $429-431$ & 107,205 & 1233 & 319 \\
\hline $43^{0}-43^{1}$ & 206 & 1288 & 199,206 \\
\hline $43^{2}-437$ & 112 & 1289 & 199 \\
\hline 432 & $188,200,205$ & $1329-1335$ & 137 \\
\hline $433-434$ & 205 & $1329-1333$ & 195 \\
\hline $435^{-436}$ & 188,200 & $1369-1415$ & 103 \\
\hline 436 & 205 & 1371 & 110 \\
\hline 437 & 110,206 & $1427-1428$ & 466 \\
\hline $43^{8-439}$ & 205 & $1446-1475$ & 103 \\
\hline 438 & 200 & $1489-1490$ & 107 \\
\hline 440 & $188,200,205$ & 1489 & 110 \\
\hline 442 & 200,206 & 1490 & 110 \\
\hline 444 & 206 & Phil. & 137,237 \\
\hline $445^{-446}$ & 206 & $79-8$ o & 334 \\
\hline $447-462$ & 193,206 & $87-88$ & 334 \\
\hline $447-448$ & 192,193 & $729-755$ & 333 \\
\hline 447 & 187 & $730-735$ & 325 \\
\hline $457-46$ o & 206 & $73^{\circ}-73^{1}$ & $319,324,3^{25}$ \\
\hline 559 & 110 & $73^{1-745}$ & 323,331 \\
\hline $5^{62-565}$ & 195 & $755^{-761}$ & 331 \\
\hline $568-569$ & 194 & $762-773$ & $33^{2}$ \\
\hline 571 & 110 & $799-8$ o6 & $33^{2}$ \\
\hline 654 & 319 & $804-8 \circ 5$ & 325 \\
\hline 700 & 168 & 805 & 319,333 \\
\hline $720-722$ & 195 & $8 \circ 6$ & 325,333 \\
\hline 747 & 195 & 813 & 333 \\
\hline $774-834$ & 103 & 915 & 333 \\
\hline 807 & 116 & $95^{\circ}-95^{1}$ & 333 \\
\hline $891-909$ & 207 & $95^{1-95^{2}}$ & 325 \\
\hline $891-895$ & 207 & $95^{1}$ & 319 \\
\hline $896-897$ & 207 & $961-962$ & 333,334 \\
\hline 898 & 207 & $965-966$ & 333 \\
\hline 900 & 207 & 965 & 334 \\
\hline $901-910$ & 207 & 991 & 190 \\
\hline $9 \circ 3-9 \circ 4$ & 207 & 1237 & 319 \\
\hline 910 & 207 & 1242 & 319 \\
\hline 935 & 110 & $1257-125^{8}$ & 190 \\
\hline 957 & 319 & Trach. & 73 \\
\hline $964-972$ & 103 & 349 & 319 \\
\hline 989 & 110 & 598 & 77 \\
\hline 1017 & 110 & $1071-1074$ & 457 \\
\hline 1041 & 110 & $1264-1278$ & 137 \\
\hline $1064-1065$ & 113 & 1278 & 195 \\
\hline $1076-1085$ & 103 & Fragments & \\
\hline 1124 & 110 & \multicolumn{2}{|c|}{ Ichneutai $\operatorname{Tr} G F$ 314.203-205 } \\
\hline 1129 & 110 & & $325,3^{26}$ \\
\hline 1164 & 110 & \multicolumn{2}{|c|}{ Ichneutai $\operatorname{Tr} G F 314.203$} \\
\hline $1173-1176$ & 112 & & 319 \\
\hline 1176 & 110 & & \\
\hline
\end{tabular}




\section{Suetonius}

Poet.

11.103

244

\section{Terence}

Ad.

170-171 $\quad 368$

$170 \quad 368$

173-174 $\quad 369$

948-955 278

An.

305-306 286

$318-320 \quad 275$

Eun.

$376-378 \quad 272$

735-737 $\quad 366$

Haut.

83-86 $\quad 375$

$167-168 \quad 376$

$371 \quad 374$

369-373 $\quad 369$

416-419 274

$562-564 \quad 373$

781-784 374

922-923 $\quad 276$

Hec.

715-719

731
Phorm.

$\begin{array}{ll}185^{-190} & 376 \\ 210 & 374 \\ 386 & 201 \\ 45^{2-459} & 271 \\ 540-542 & 280 \\ & \\ & \\ 3.42 .1 & 199 \\ 3.82 .4-6 & 463\end{array}$

\section{Ulpian}

Dig.

$\begin{array}{ll}2.14 .7 .9 & 422\end{array}$

Valerius Maximus

3.8.6 390

Vergil

Aen.

2.269-297 406

$2.271 \quad 406$

$2.279 \quad 406$

$6.469 \quad 415$

$7.291 \quad 406$

$7.292 \quad 406$

$12.894 \quad 406$ 